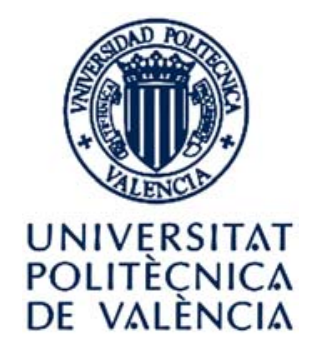

Departamento de Ingeniería Hidráulica y Medio Ambiente

\title{
Influencia de los costes del Agua y la Energía en la renovación de tuberías
}

\section{TESIS DOCTORAL}

Presentado por:

D. Miguel Ángel Pardo Picazo

Dirigida por:

D. Enrique Cabrera Marcet

D. Ricardo Cobacho Jordán 

"Si añades un poco a lo poco y lo haces así con frecuencia, pronto llegará a ser mucho".

Hesíodo

"Anyone who has never made a mistake has never tried anything new"

Albert Einstein 



\section{AGRADECIMIENTOS}

Son muchas las personas que me han ayudado en la realización de esta tesis doctoral. En primer lugar quería agradecer la ayuda prestada a mis dos directores, Enrique Cabrera Marcet y Ricardo Cobacho Jordán, quienes siempre me han orientado en este trabajo de investigación y han realizado innumerables aportaciones a la misma. Tanto Enrique como Ricardo han seguido con enorme interés el desarrollo de la tesis y sin duda, una parte de ésta les pertenece.

Asimismo, quisiera agradecer al resto de profesores del ITA (Jorge, Paco Arregui, Vicent y Quique) que prestaron su ayuda desinteresada a las cuestiones surgidas en este periodo de tiempo, y aportaron su punto de vista diferente a lo largo de los años de preparación de la misma. Tampoco quiero olvidarme del resto de compañeros de oficina, con los que he compartido esta época de mi vida, Javier, Paco Valero, José, Mario, Camilo y tantos otros con los que compartí conversaciones sobre los problemas hidráulicos que indirectamente influyeron en el desarrollo de este trabajo.

También me gustaría reconocer el apoyo de todos aquellos que respondieron mis consultas. Entre ellos cabe destacar a Balvant Rajani (que aportó sus conocimientos en los temas de renovación y de materiales), Gary Wolff (que me permitió utilizar su modelo water to air), Zoran Kapelan (que me enseñó a calibrar un modelo hidráulico y con el que trabajé en una aplicación práctica en una red real en Holanda) y Miguel Andrés (por sus aportaciones prácticas).

Por último, quiero acordarme de todos los amigos que estuvieron a mi lado durante este tiempo y agradecerles a mis padres y a mi hermana su apoyo incondicional. Con la alegría propia de haber hecho esta tesis una realidad, les digo nuevamente "sin vosotros, esto no sirve de nada". 



\section{RESUMEN}

En el siglo XX la política del agua en España se han caracterizado por el aumento de la oferta hídrica y por la construcción de nuevas infraestructuras tanto de regulación (presas) como de distribución (redes de tuberías). Sin embargo, en el siglo XXI, el paulatino aumento de la demanda ha originado que satisfacer estas necesidades sea cada vez más y más difícil. El agua es un recurso abundante pero no inagotable. Debido al cambio climático, las sequías son más frecuentes y la utilización del recurso exige mayores niveles de eficiencia. Todo esto ha motivado que, en la actualidad, las políticas del agua se centren en la minimización de los consumos y en la renovación de las infraestructuras existentes.

Numerosos estudios han abordado el problema de la renovación de las tuberías de una red de distribución urbana. Éstos se centran en la utilización de nuevos materiales, la determinación precisa del orden de sustitución de las tuberías, la obtención del periodo óptimo de renovación y la minimización de los costes.

Esta tesis comienza con una revisión bibliográfica de las necesidades de inversión económica en la renovación de las tuberías, facilita las principales características de los materiales más comúnmente empleados en las redes de distribución y muestra las principales ventajas e inconvenientes, así como el coste, de las nuevas técnicas de rehabilitación y renovación sin zanja. Asimismo, también presenta los últimos trabajos en la obtención de sistemas soporte a la decisión para elegir el orden de renovación de las tuberías.

A continuación, se analiza la influencia de los costes del agua y de la energía en la obtención del periodo óptimo de renovación. Para ello, se propone una revisión de la metodología tradicional que incluye por primera vez, además de los costes anteriores, los sociales originados por la ejecución de una renovación y los posibles ahorros que se pueden obtener si la obra se realiza entre varias empresas. Se pretende identificar los factores clave que condicionan el periodo óptimo de renovación, y de entre todos éstos, se subraya la influencia de los costes del agua y de la energía. 
Como la determinación del periodo óptimo de renovación considera los costes del agua y de la energía, conocer tanto la cantidad de agua como de energía que se consume en una red de distribución se torna esencial. De lo primero se encarga la auditoría hídrica y para obtener lo segundo se presenta una metodología que lo permite. Ambas auditorías también están relacionadas puesto que, para calcular la energética, se necesita haber resuelto la hídrica además de disponer de un modelo hidráulico del sector hidrométrico analizado. Esta herramienta, la auditoría energética, es la primera que permite cuantificar en qué se consume la energía en una red y a partir de ésta adoptar decisiones tanto en el ámbito de la renovación, operación y gestión de redes. Aunque su principal importancia radica en que por primera vez, se puede calcular la magnitud de la energía que se pierde por fugas en la red de distribución e incluso, si se consideran todas las etapas previas del ciclo urbano del agua, la energía total relacionada con las fugas.

La interacción entre el agua y la energía se acrecienta cuando se analizan sus implicaciones sobre el cambio climático. El consumo de agua supone un gasto energético, de tal forma que un aumento del primero implica el incremento del segundo. Además, un mayor consumo energético lleva a unas mayores emisiones de gases de efecto invernadero, que a su vez condicionará la disponibilidad futura de agua. Por tanto, se observa que estos tres conceptos están estrechamente ligados. A partir de los consumos energéticos obtenidos gracias a la auditoría y gracias al modelo water to air se pueden calcular los créditos equivalentes de carbono emitidos por la gestión de una red de abastecimiento, y mediante comparación entre dos escenarios obtener los ahorros energéticos y en emisiones. 


\section{ABSTRACT}

During the last century, Spanish water policy focused on increasing the hydraulic supply and on the construction of new infrastructures of regulation (dams) and distribution (water networks). However, in this century, continuously increasing water demand has become more and more difficult to satisfy. Water is an abundant but not inexhaustible resource. Due to climate change, droughts are more frequent and water use requires higher levels of efficiency. Consequently, water policy is now focused on minimising supply and renovating existing networks.

Several studies have looked at the question of the renovation of pipes in water distribution systems. These commonly deal with the use of new pipes, the determination of the order of renovation, the calculation of the optimum renovation period for mains systems and the minimisation of the economic cost of renewal.

This thesis begins with a review of economic investment in pipe renovation. It then goes on to present the main characteristics of the most commonly used pipe materials along with their respective pros and cons. The new trenchless technologies are also looked at and economically analysed. In addition, there is an overview of the latest studies on decision-support systems to prioritize renovation.

Thereafter, the influence of the cost of water and energy and how they help on the optimum renovation of pipes is analysed here. Thus, a review of the traditional methodology is presented. A complete cost model (i.e. one consisting of not only the usual costs) is shown. For the first time the social, variable and opportunity costs are considered. Social costs are those caused by disruptions arising from repair works, such as traffic problems, pavement damage, loss of productivity, etc. Variable costs are related to water lost through leakage and its effect on production and the environment, and the expenditure resulting from increased energy use when pressurizing leaked water. Lastly, opportunity costs represent the potential savings made by sharing the cost of renovation with another operator, which, in practice can be rendered as a profit or a negative cost. The key factors are identified and the influences of water and energy costs are highlighted. 
Consequently, the quantification of water and energy becomes essential to the optimisation of pipe renovation. The first is calculated with a water balance and the second with a new methodology. Both audits are linked, so as to calculate the energy audit of water networks which requires solving the water balance and the mathematical model of a system contained within a control volume defined at will. This is the first tool to allow the quantification of the energy consumed but also indicates how that energy is used. These results are useful when it comes to adopting the proper decisions as regards the renovation, operation and management of water distribution systems. The key objective of the audit is to determine the amount of energy lost through leaks and, if previous stages of the water cycle are considered, to calculate relation between energy and water loss.

Interaction between water and energy increases when climate change is taken into account. Water is an energy-consuming agent, the higher consumption of the first the higher that of the second. Moreover, energy consumption produces greenhouse gas emissions, which will condition the future availability of water. So, these three concepts are inextricably linked. Taking into account the results of the water audit and using the water to air model, the carbon credits earned by the management of a water distribution system may be evaluated, and comparing two cases, a leak-free network and a real one, the energy savings and emission reductions resulting from eliminating leaks may be calculated. 


\section{RESUM}

Al segle XX la política de I'aigua a Espanya s'ha caracteritzat pel augment de I'oferta hídrica i per la construcción d'infraestructures tant de regulació (preses) dels recursos com a de distribució (xarxes de canonades). Malgrat això, al segle $X X I$, el gradual augment de la demanda ha provocat que el satisfer aquestes necessitats siga cada vegada més i més difícil. L'aigua es un recurs abundant pero no inesgotable. Degut al canvi climàtic, les sequeres són cada vegada més freqüents i la utilització del recurs exigeix majors nivells d'eficiència. Tot açò ha motivat que, en l'actualitat, les polítiques de l'aigua se centren en la minimització dels consums i la renovació de les infraestructures existents.

Nombrosos estudis han tractat el problema de la renovació de les canonades d'una xarxa de distribució urbana. Aquests solen versar sobre la utilització de nous materials, la determinació precisa de l'ordre de renovació, el moment en el que una obra s'ha de mamprendre i la minimització del cost econòmic d'aquesta.

Aquesta tesi comença amb una revisió bibliogràfica de les necessitats d'inversió econòmica en la renovació de les canonades, facilita les principals característiques dels materials més comuns emprats en les xarxes de distribució i mostra els principals avantatges i inconvenients, així com els costs, les noves tècniques de rehabilitació i renovació sense rasa. Així mateix, també presenta els últims treballs en l'obtenció de sistemes suport a la decisió per triar l'ordre de renovació de les canonades.

A continuació, s'analitza la influencia dels costs de l'aigua i de l'energia en l'obtenció del període òptim de renovació. Per a això, es proposa una revisió de la metodologia tradicional que inclou per primera vegada, a més dels costs anteriors, els socials originats per l'execució d'una renovació i els possibles estalvis que es poden obtindre si l'obra es realitza entre diverses empreses. Es pretén identificar els factors clau que condicionen el període òptim de renovació, i d'entre tots aquests, es subratlla la influència dels costs de l'aigua i l'energia. 
Com la determinació del període òptim de renovació considera els costs de l'aigua i de l'energia, conèixer tant la quantitat d'aigua com d'energia que es consumeix en una xarxa de distribució es torna essencial. D'allò primer s'encarrega l'auditoria hídrica i per obtindre allò segon es presenta una metodologia que ho fa possible. Ambdues auditories també estan relacionades donat que, per calcular la energètica, es necessita haver resolt I'hídrica a més de disposar d'un model hidràulic del sector hidromètric analitzat. Aquesta ferramenta, I'auditoria energètica, es la primera que permet quantificar en que es consumeix I'energia d'una xarxa i a partir d'aquesta prendre decisions tant en l'àmbit de la renovació, operació i gestió de xarxes. Encara què a seua principal importància radica en què per primera vegada, es pot calcular la magnitud de l'energia que es perd per fuites en la xarxa de distribució i inclús, si es consideren totes les etapes prèvies del cicle urbà de I'aigua, I'energia total relacionada amb les fuites.

La interacció entre I'aigua i l'energia augmenta quan s'analitzen les seues implicacions sobre el canvi climàtic. El consum d'aigua suposa una despesa energètica, de forma que un augment del primer implica l'increment del segon. A més, un major consum energètic du a unes majors emissions de gasos efecte hivernacle, que, a la seua vegada condicionaran la disponibilitat futura d'aigua. Per tant, s'observa que aquests tres conceptes estan estretament relacionats. A partir dels consums energètics obtinguts gràcies a l'auditoria i gràcies al model water tor air es poden calcular els crèdits equivalents de carboni emesos per la gestió d'una xarxa d'abastiment, i mitjançant comparació entre dos escenaris obtindre estalvis energètics i en emissions. 


\section{CONTENIDOS}

CITAS I

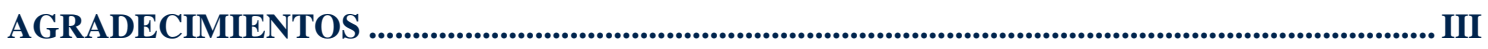

RESUMEN ...................................................................................................................................................

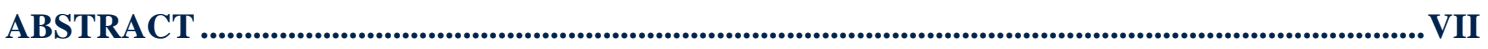

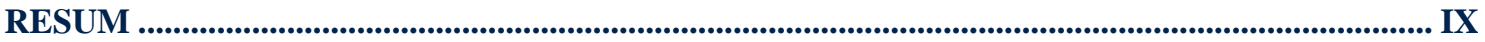

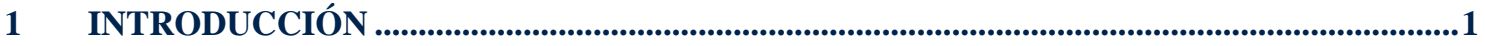

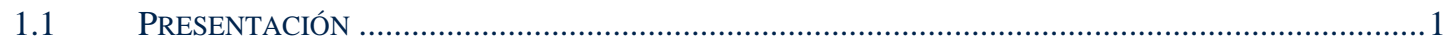

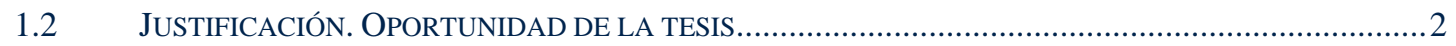

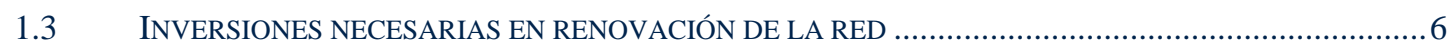

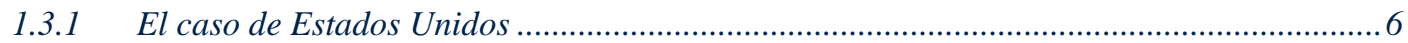

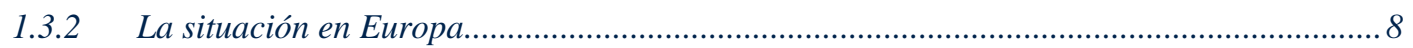

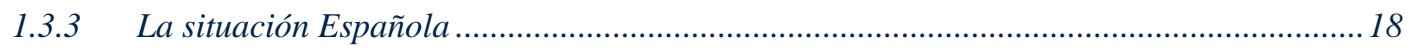

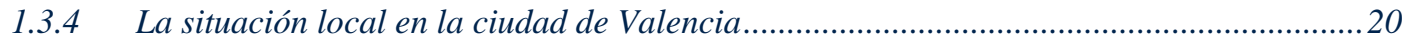

1.3.5 Resumen de las inversiones necesarias en la renovación de la red ....................................23

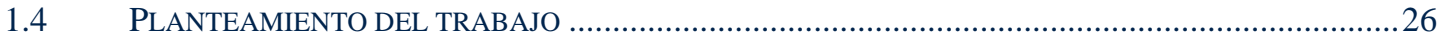

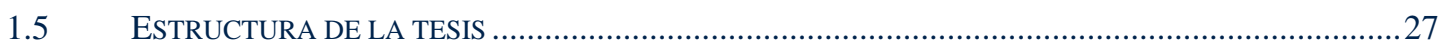


2 REHABILITACIÓN Y RENOVACIÓN DE TUBERÍAS. ESTADO DEL ARTE.

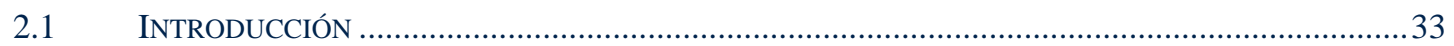

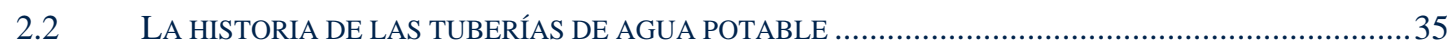

2.3 TIPOS DE MATERIALES UTILIZADOS EN LOS ABASTECIMIENTOS ...............................................42

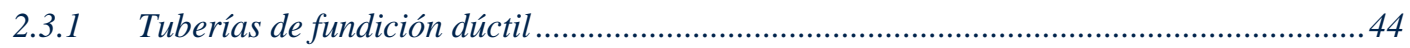

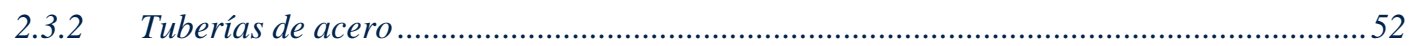

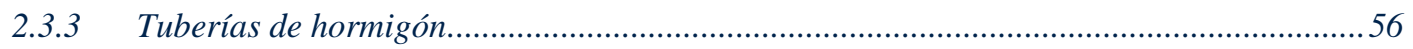

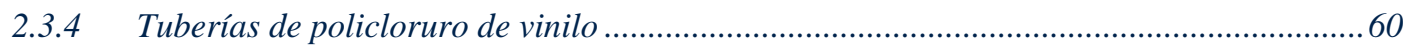

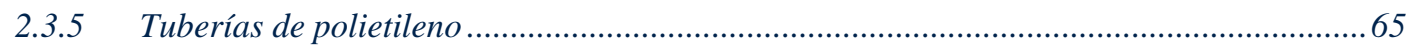

2.3.6 Tuberías de policloruro de vinilo con orientación molecular ...........................................69

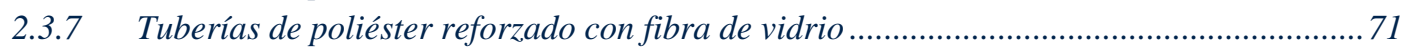

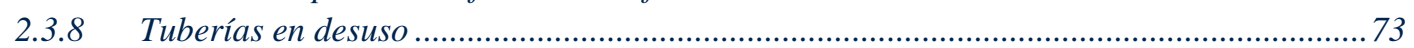

2.3.9 Tablas resumen de las características de las tuberías según los materiales........................80

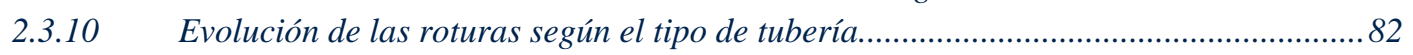

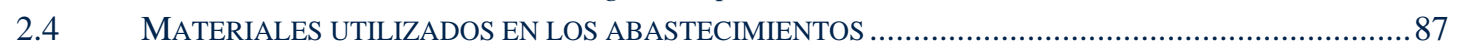

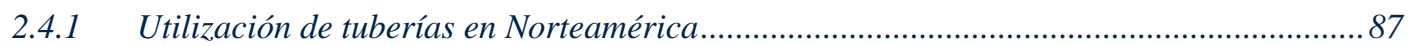

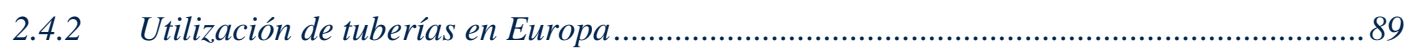

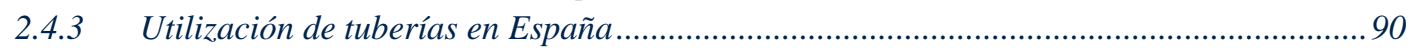

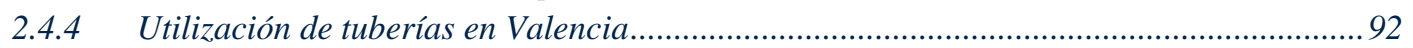

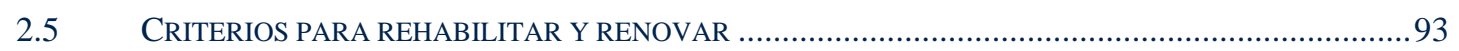

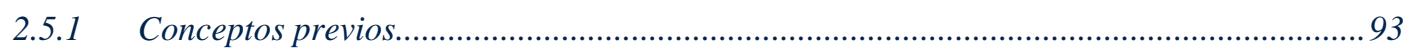

2.5.2 Razones que aconsejan la rehabilitación y/o renovación....................................................94

2.5.3 Criterios que se deben adoptar en la renovación..................................................................97

2.5.4 Los sistemas de soporte a la decisión...............................................................................99

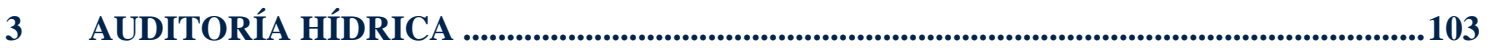

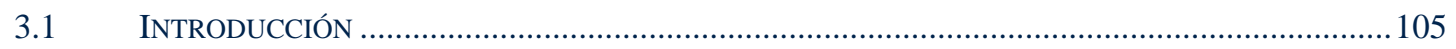

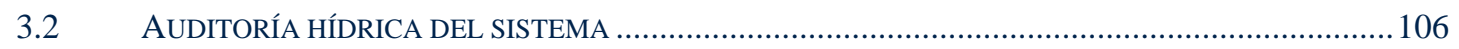

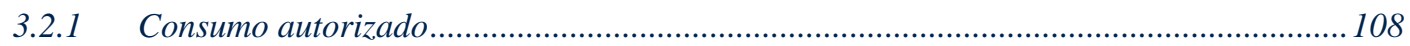

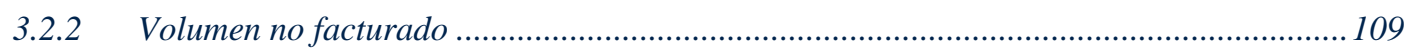

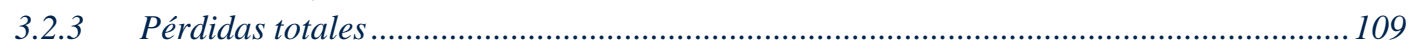

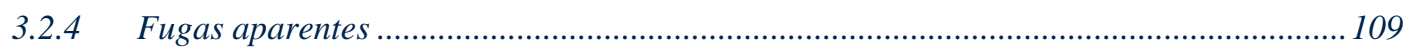

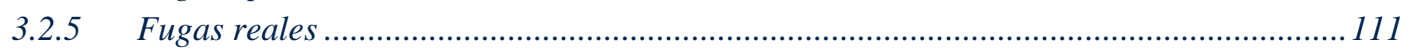

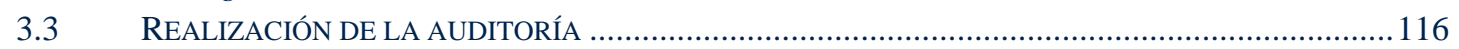

3.4 INDICADORES DE GESTIÓN MÁS FRECUENTEMENTE UTILIZADOS ...............................................118

3.4.1 Rendimiento volumétrico de una red de distribución ......................................................118

3.4.2 Indicadores de gestión relacionados con la auditoría hídrica ..........................................118

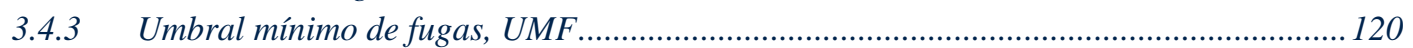

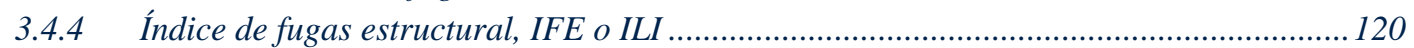

3.5 EJEMPLOS DE AUDITORÍA HÍDRICA EN REDES DE DISTRIBUCIÓN …………………….................123 


\section{POLÍTICAS DE GESTIÓN DE FUGAS EN EL ABASTECIMIENTO A LARGO PLAZO133}

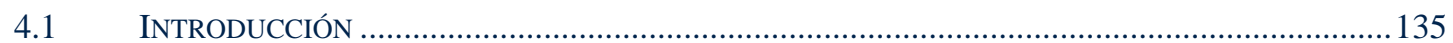

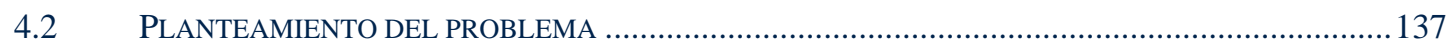

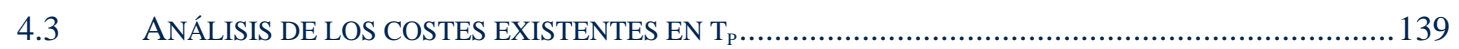

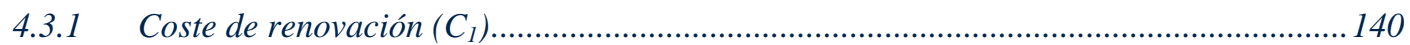

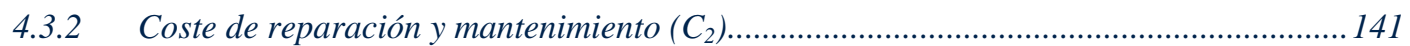

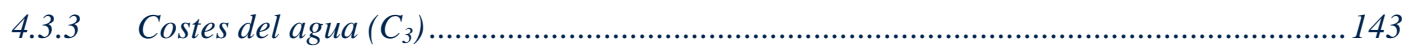

4.3.4 Coste social asociado a la perturbación por obras $\left(C_{41}\right)$..................................................145

4.4 OTROS COSTES IMPUTABLES DE APARICIÓN OCASIONAL ……….................................................146

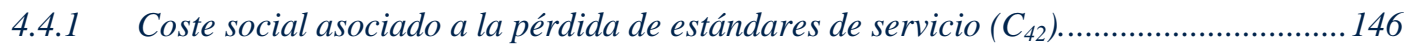

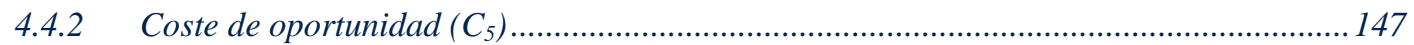

4.5 OBTENCIÓN DEL PERIODO ÓPTIMO DE RENOVACIÓN...............................................................148

4.5.1 Periodo óptimo de renovación para la primera renovación ...............................................148

4.5.2 Periodo óptimo de renovación para las infinitas sustituciones .........................................150

4.5.3 Periodo óptimo de renovación para un tiempo definido ..................................................153

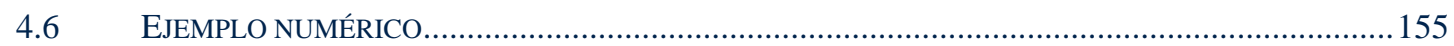

4.6.1 Desarrollo de los cálculos para una renovación............................................................156

4.6.2 Desarrollo de los cálculos para las infinitas renovaciones...............................................160

4.6.3 Desarrollo de los cálculos para la renovación en un periodo de tiempo definido............168

5 PARÁMETROS QUE INFLUYEN EN EL PERIODO ÓPTIMO DE RENOVACIÓN..........171

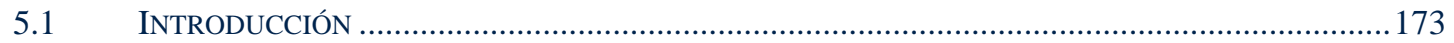

5.2 PARÁMETROS INFLUYENTES EN EL PERIODO ÓPTIMO DE RENOVACIÓN.....................................174

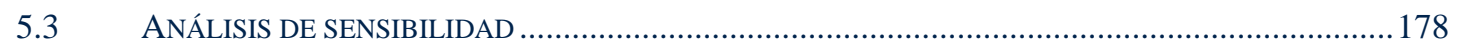

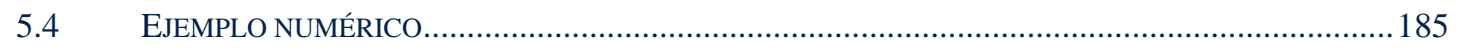

5.4.1 Desarrollo de los cálculos para una renovación................................................................188

5.4.2 Desarrollo de los cálculos para las infinitas renovaciones..............................................199

5.4.3 Influencia de las particularidades propias de una técnica sin zanja. El caso del entubado

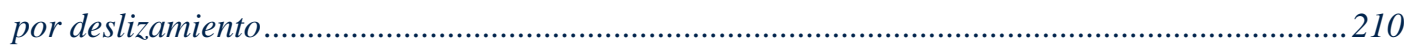




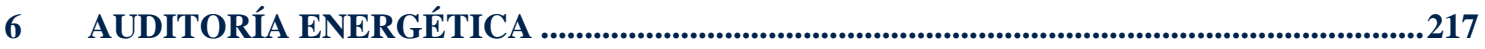

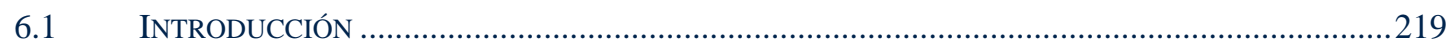

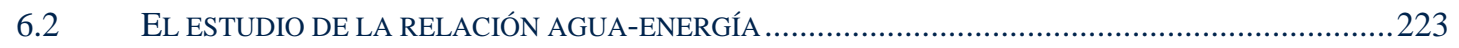

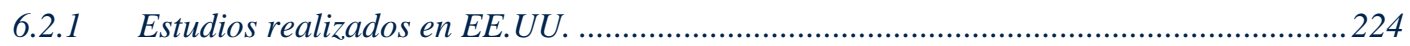

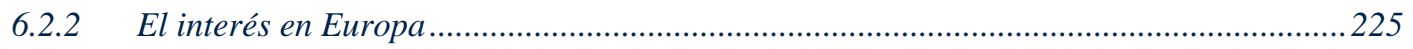

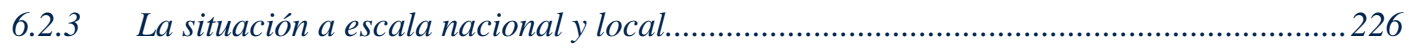

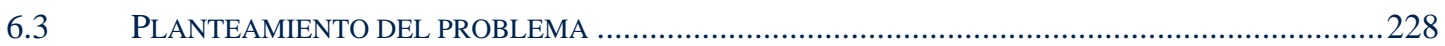

6.4 INTEGRACIÓN EN PERIODO EXTENDIDO DE LA ECUACIÓN DE LA ENERGÍA .................................2231

6.4.1 Energía entrante en la red, aportada por el embalse .....................................................2232

6.4.2 Energía entrante en la red, aportada por el equipo de bombeo (energía de eje)..............233

6.4.3 Energía entregada a los usuarios en los nudos de consumo ...........................................233

6.4.4 Energía saliente de la red, a través de las fugas existentes..............................................2.234

6.4.5 Energía disipada en la fricción del agua con las tuberías ................................................234

6.4.6 Término energético de compensación del depósito de cola .............................................235

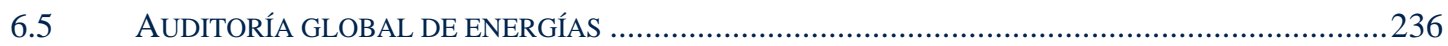

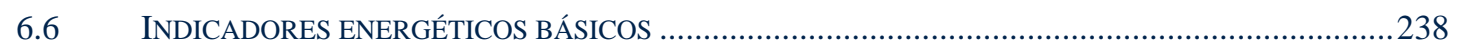

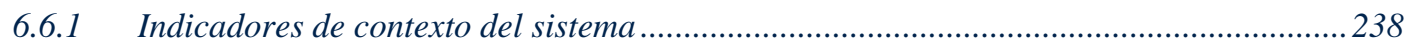

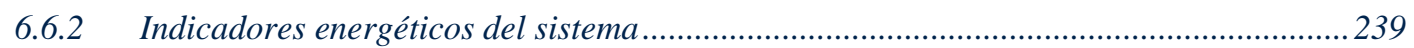

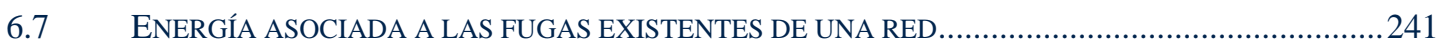

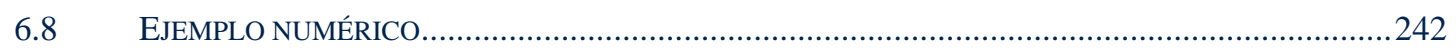

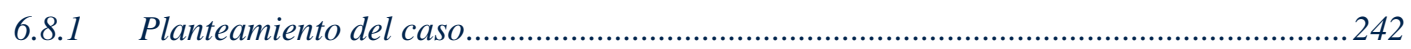

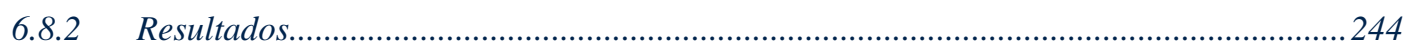

6.8.3 Valoración de la gestión energética de la red con los nuevos indicadores.......................246

6.9 EL CAMINO A SEGUIR EN ESPAÑA Y PRINCIPALES OBSTÁCULOS A VENCER...............................249

\section{UTILIZACIÓN DEL MODELO DE ANÁLISIS ENERGÉTICO. BÚSQUEDA DE UNA}

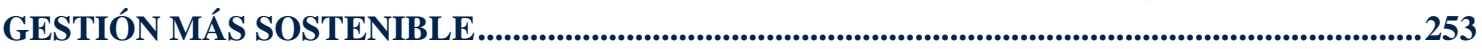

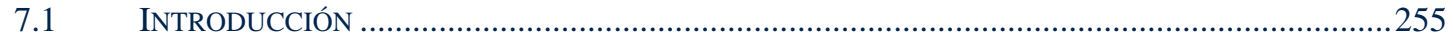

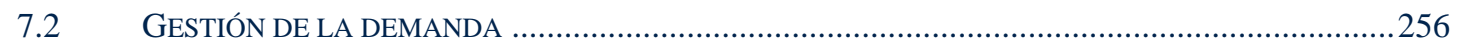

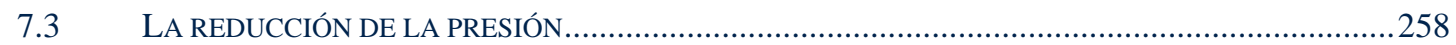

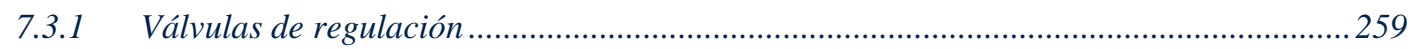

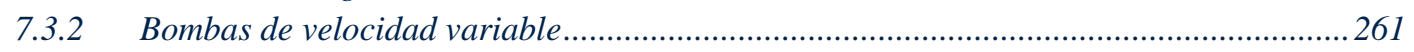

7.4 EFECTO ENERGÉTICO DE LAS POLÍTICAS ANALIZADAS ORIENTADAS HACIA UNA GESTIÓN

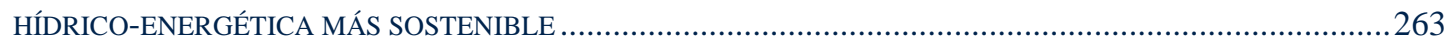

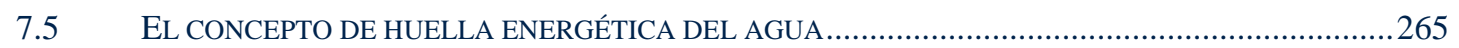

7.5.1 Etapa de captación bombeo y transporte del agua en alta..................................................26

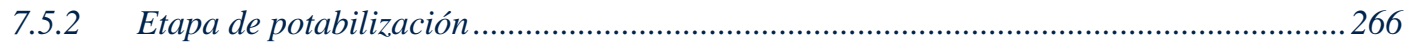

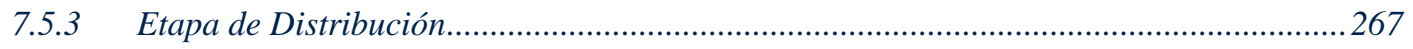

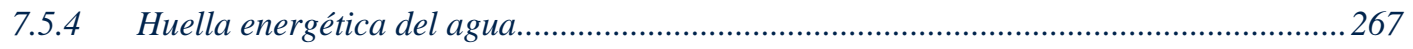

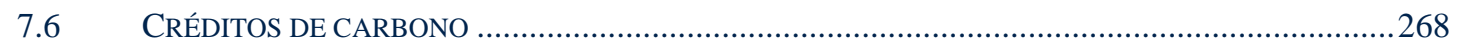

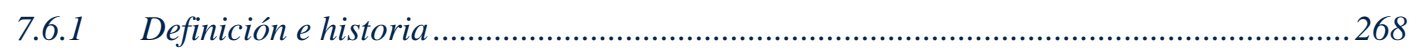

7.6.2 El modelo agua-aire desarrollado por el Pacific Institute ..................................................2.

7.6.3 Cálculo del ahorro en las emisiones a partir de la reducción de las fugas.......................276

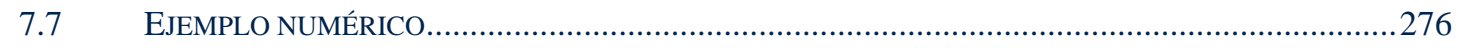

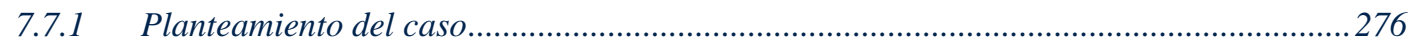

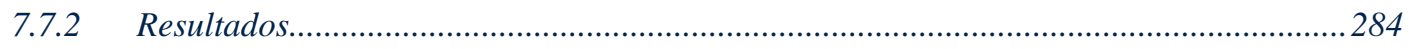

7.7.3 Valoración de la gestión energética de la red con los nuevos indicadores........................288

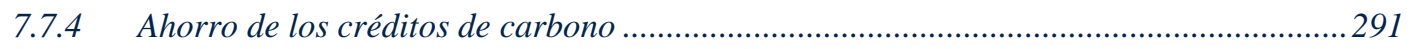

7.7.5 Combinación de todas las actuaciones descritas ............................................................294 


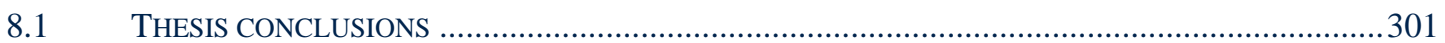

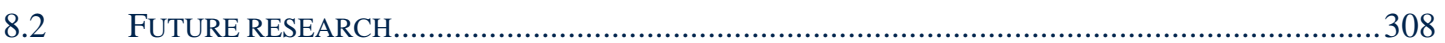

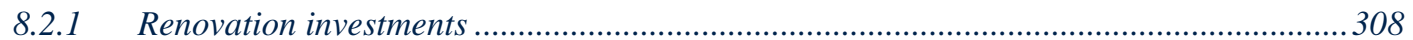

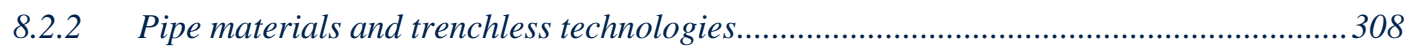

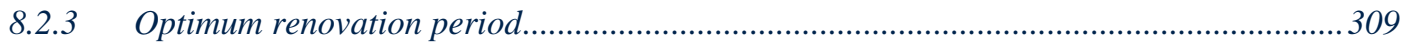

8.2.4 Relationship between short-term policies and long-term ones .........................................310

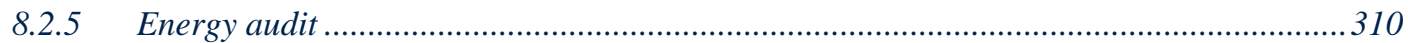

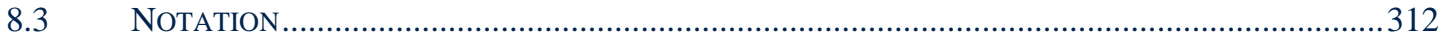

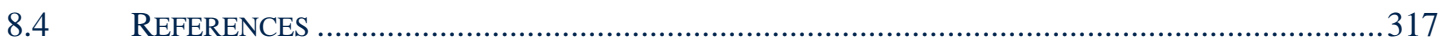

ANEXOS

\section{ANEXo A: TÉCNICAS DE REHABILITACIÓN SIN ZANJA}

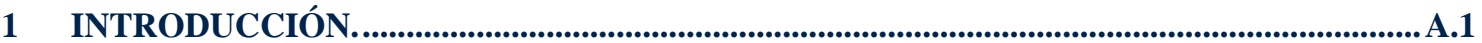

2 UN PASEO POR LA HISTORIA DE LAS TECNOLOGÍAS SIN ZANJA.............................A.4

3 DESCRIPCIÓN DE LAS TÉCNICAS DE RENOVACIÓN SIN ZANJA. ...............................A.14

3.1 MÉTODOS DE LIMPIEZA ................................................................................................14

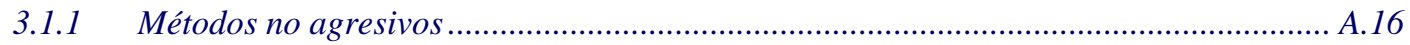

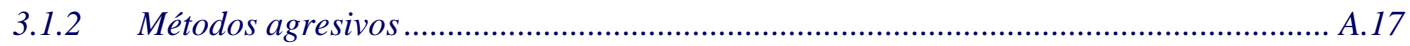

3.2 REVESTIMIENTOS NO ESTRUCTURALES ..........................................................................2.21

3.2.1 Revestimiento con mortero de cemento ..................................................................... A.21

3.2.2 Revestimiento con resinas de tipo polimérico .......................................................... A.23

3.3 REVESTIMIENTOS ESTRUCTURALES _............................................................................ A.24

3.3.1 Entubado por deslizamiento ........................................................................................ A.25

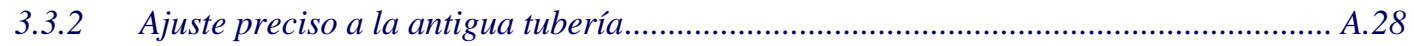

3.3.3 Encamisado térmico .............................................................................................. A.34

3.3.4 Entubado espiral ............................................................................................. A.38

3.4 MÉTODOS CON ROTURA DE TUBERÍA ..................................................................................39

3.4.1 Inserción mediante rotura de tubería por apertura y cierre de un cabezal accionado

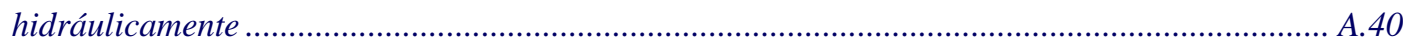

3.4.2 Inserción de tubería mediante rotura por percusión .................................................... A.42

3.4.3 Inserción mediante rotura de tubería con cuchilla....................................................... A.44

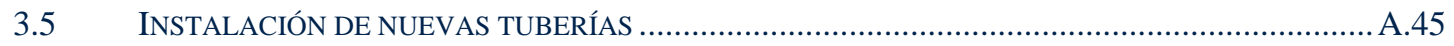

3.5.1 Perforación horizontal dirigida................................................................................... A.45

3.5.2 Perforación no dirigida sin extracción del terreno .......................................................... A.49

3.5.3 Perforación no dirigida con arrastre del terreno.......................................................... A.51

3.6 CARACTERÍSTICAS GENERALES DE LA RENOVACIÓN DE TUBERÍAS CON TÉCNICAS SIN ZANJA .......

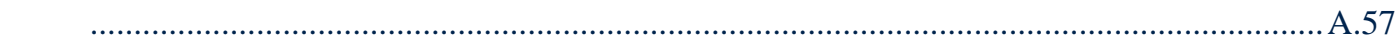

3.6.1 Resumen de la aplicabilidad de las técnicas según el diámetro nominal....................... A.59

3.6.2 Resumen de la aplicabilidad de las distintas técnicas según la longitud del tramo a rehabilitar.

3.6.3 Aplicabilidad de las técnicas sin zanja en redes de distribución.................................... A.61

3.6.4 Criterios de selección del tipo de renovación o rehabilitación de la tubería.................. A.63 
4 COSTES ASOCIADOS A LAS DIFERENTES TÉCNICAS

4.1 RELACIÓN DE COSTES DE LAS DIFERENTES TÉCNICAS DE REHABILITACIÓN Y RENOVACIÓN SIN APERTURA DE ZANJA EMPLEADAS EN REDES URBANAS.

ANEXO B: CONCEPTOS RELACIONADOS CON LOS NUEVOS COSTES CONSIDERADOS PARA LA OBTENCIÓN DEL PERIODO ÓPTIMO DE RENOVACIÓN

1. CONCEPTOS ECONÓMICOS BÁSICOS UTILIZADOS EN LA DETERMINACIÓN DEL PERIODO ÓPTIMO DE RENOVACIÓN

2. COSTE SOCIAL ASOCIDO A LA PÉRDIDA DE ESTÁNDARES DE SERVICIO .............. B.2

2.1. PÉRDIDAS DE ESTÁNDARES DE SERVICIO RELACIONADOS CON LA HIDRÁULICA. .................... B.2

2.2. PÉRDIDAS DE ESTÁNDARES DE SERVICIO RELACIONADOS CON LA CALIDAD ........................... B.4

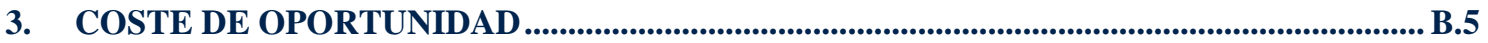

Anexo C: Políticas de gestión de fugas EN REDES de ABASTECiMiento EN EL CORTO Y LARGo PLAZO

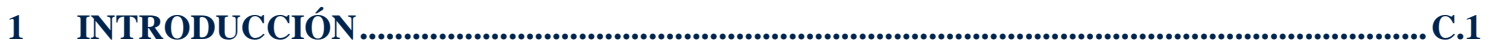

2 PUNTO ÓPTIMO DE COSTES DE MANTENIMIENTO ....................................................... C.2

2.1 CURVA DE GASTOS EN REPARACIONES Y MANTENIMIENTO ............................................... C.3

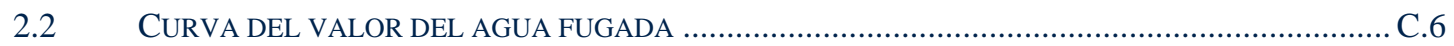

2.3 CURVA DE COSTES TOTALES RELACIONADOS CON EL MANTENIMIENTO ................................ C.7

3 OPTIMIZACIÓN A LARGO PLAZO: LA RENOVACIÓN....................................................... C.8

3.1 MODELACIÓN DEL DETERIORO DEBIDO A LA EDAD DEL SISTEMA ....................................... C.9

3.2 OPTIMIZACIÓN DEL CONTROL ACTIVO DE FUGAS CON ENVEJECIMIENTO DEL SISTEMA.......... C.11

4 RELACIÓN ENTRE LAS POLÍTICAS A CORTO Y LARGO PLAZO...............................C.13

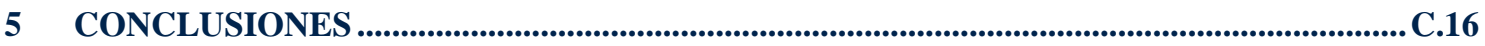




\section{ANEXo D: CUANTIFICACión DEL COSTE SOCIAL}

1 COSTES SOCIALES ASOCIADOS A LA RENOVACIÓN DE TUBERÍAS.............................1

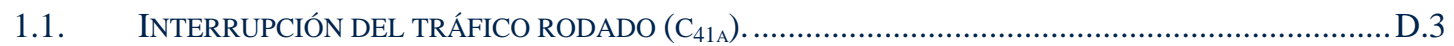

1.2. DAÑOS QUE SE REALIZAN EN EL PAVIMENTO DE CARRETERAS CERCANAS A LA OBRA (C41B $)$. D. 4

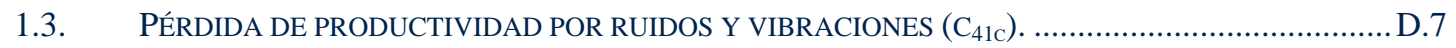

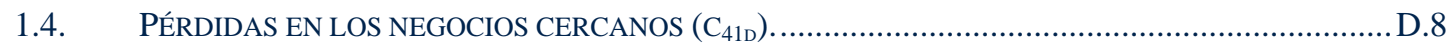

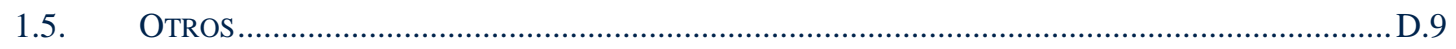

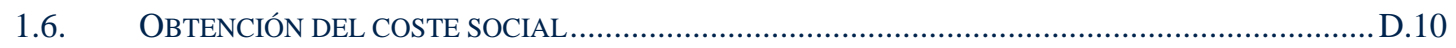

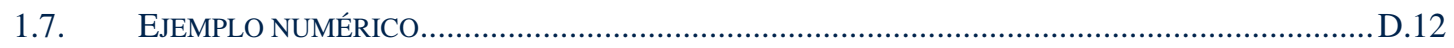

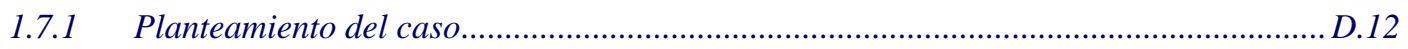

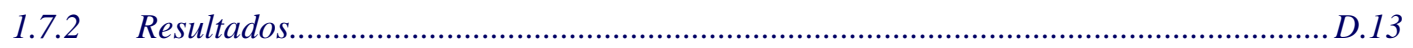

ANEXo E: EVALUACIÓN DEL CONSUMO ENERGÉTICO PARA UN SISTEMA CON Y SIN VÁLVULA

1. EVALUACIÓN DEL CONSUMO ENERGÉTICO PARA UN SISTEMA CON Y SIN

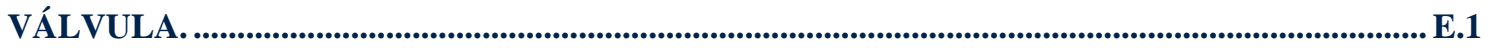

1.1 INCIDENCIA ENERGÉTICA DE LA INSTALACIÓN DE UNA VÁLVULA EN UNA RED SIN FUGAS. .... E.1

1.2 INCIDENCIA ENERGÉTICA DE LA INSTALACIÓN DE UNA VÁLVULA EN UNA RED CON FUGAS.... E.3

2. APLICACIÓN NUMÉRICA DEL PROBLEMA.............................................................................. E.7

\section{ANEXO F: CONCLUSIONES Y DESARROLLOS FUTUROS}

1 APORTACIONES DE LA TESIS................................................................................................... F.1

2 DESARROLLOS FUTUROS ....................................................................................................... F.9

2.1 INVERSIÓN EN RENOVACIÓN .............................................................................................10

2.2 TUBERÍAS DE DISTINTO MATERIAL Y TÉCNICAS DE RENOVACIÓN SIN ZANJA .............................10

2.3 DETERMINACIÓN DEL PERIODO ÓPTIMO DE RENOVACIÓN ………………………......................11

2.4 RELACIÓN ENTRE LAS POLÍTICAS A CORTO PLAZO (REHABILITACIÓN) Y A LARGO PLAZO

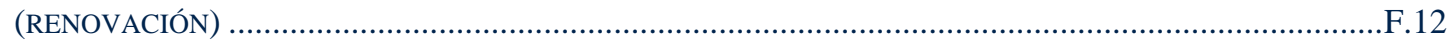

2.5 AUDITORÍA ENERGÉTICA.................................................................................................12

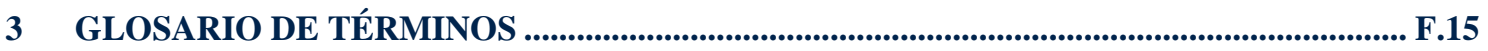

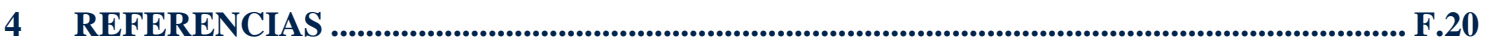




\section{ÍNDICE DE FIGURAS}

FIGURA 1. El BUCLE AGUA - ENERGÍA - CAMBIO CLIMÁTICO .4

FIGURA 2. COMPARACIÓN DE LAS INVERSIONES A REALIZAR EN LOS PRÓXIMOS 20 AÑOS (EPA, 2009)........8 FIGURA 3. COMPARACIÓN ENTRE LAS INVERSIONES Y DINERO FACTURADO REALES Y ESPERADAS (OFWAT, 2008)...... 10

FIGURA 4. HISTÓRICO DE GASTOS DE OPERACIÓN EN ESCOCIA (WICS, 2008A), ............................................11

FIGURA 5. INVERSIONES PREVISTAS, REALIZADAS Y FUTURAS EN LAS REDES ESCOCESAS (WICS, 2008B)...11 FigURA 6. HiSTÓRICO DE INVERSIONES EN REDES DE ABASTECIMIENTO EN ALEMANIA (BGW, 2008).........13 FIGURA 7. HISTÓRICO DE INVERSIONES EN REDES DE SANEAMIENTO DE ALEMANIA (BGW, 2008).............14 FIGURA 8. INVERSIONES DE LOS ABASTECIMIENTOS HOLANDESES (VEWIN, 2007).....................................17

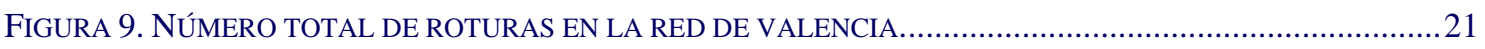
FIGURA 10. ROTURAS POR KM DE TUBERÍA EN LA RED DE ABASTECIMIENTO DE VALENCIA.........................22 FIGURA 11. TUBERÍA DE ARCILLA UTILIZADA EN EL AÑO 1800 EN CALIFORNIA

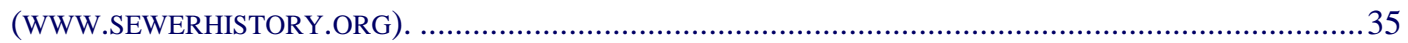

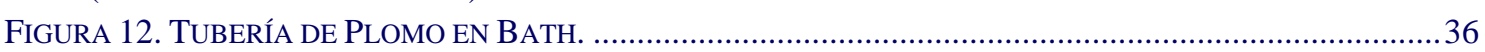

FigURA 13. TUBERÍA DE MADERA INSTALADA EN HAMILTON, ONTARIO (RAJANI, 2009A). ........................36

FIGURA 14. TUBERÍA DE FUNDICIÓN GRIS QUE SIRVE PARA TRAER AGUA HASTA LOS JARDINES DE VERSALLES. TODAVÍA EN SERVICIO EN EL AÑO 1914 (WWW.SEWERHISTORY.ORG).............................37

FIGURA 15. PRIMEROS PASOS EN LA FABRICACIÓN DE FUNDICIÓN GRIS, AÑO 1880 APROX. ..........................37

FIGURA 16. UNIÓN CAMPANA Y ENCHUFE CON SELLADO DE LA JUNTA DE PLOMO. .........................................38

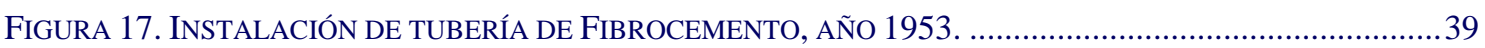

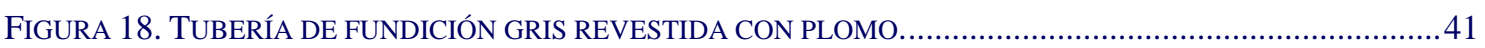

FIGURA 19. UTILIZACIÓN DE LOS DIVERSOS MATERIALES CON EL TIEMPO EN EE.UU.

(CROMWELL Y COL., 2007).

FIGURA 20. ASPECTO DE LAS TENSIONES EN TUBERÍAS DE FUNDICIÓN DÚCTIL (PARTE IZQDA, NÓDULO

ESFÉRICO) Y FUNDICIÓN GRIS (PARTE DCHA, UNA LÁMINA DE GRAFITO)..............................................45

FIGURA 21. INSTALACIÓN DE UN ÁNODO DE SACRIFICIO EN UNA TUBERÍA METÁLICA.....................................47

FIGURA 22. EJEMPLO DE CORROSIÓN EN TUBERÍA DE FUNDICIÓN DÚCTIL. .......................................................4

FigURA 23. PATRÓN DE ROTURAS DE LAS TUBERÍAS DE FUNDICIÓN DÚCTIL INSTALADAS EN SCARBOROUGH

(RAJANI, 2009B).

FIGURA 24. POSICIÓN DE LOS DISTINTOS COMPONENTES QUE SE UTILIZAN PARA EL HORMIGÓN EN CASO DE SER DE TIPO CILINDRO ALINEADO, (PARTE IZQDA) O CILINDRO ENCAMISADO (PARTE DERECHA)........57 
FIGURA 25. ROTURA FRÁGIL DE LOS ALAMBRES DE ACERO POR EXPOSICIÓN AL HIDRÓGENO. ....................59

FIGURA 26. DOS TIPOS DE ROTURAS DE UNA TUBERÍA DE HORMIGÓN ARMADO. ......................................59

FIGURA 27. ROTURA DE TUBERÍAS DE GRAN DIÁMETRO HORMIGÓN ARMADO Y PRETENSADO (RAJANI,

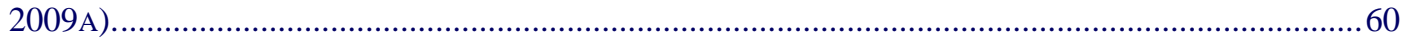

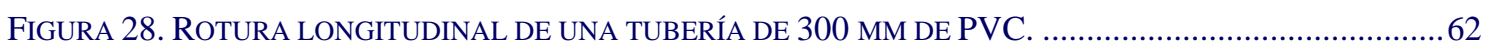

FIGURA 29. PATRÓN DE ROTURAS PARA TUBERÍAS DE PVC (RAJANI, 2009C) ..........................................63

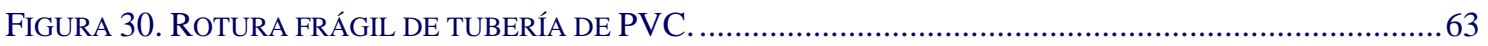

FIGURA 31. DECAPADO INTERNO DE LAS TUBERÍAS DE LDPE Y PROBLEMAS DE OBSTRUCCIÓN DE UN CONTADOR DOMICILIARIO (CORTESÍA DE AGUAS DE VALENCIA).............................................67

FigURA 32. DECAPADO EXTERIOR EN UNA TUBERÍA DE LDPE (CORTESÍA DE AGUAS DE VALENCIA)........68

FigurA 33. CURVAS DE REFERENCIA EN TUBOS DE PVC-U Y PVC-O (CEDEX, 2006).............................70

FIGURA 34. FUNDICIÓN GRIS CON TRAZAS DE GRAFITO (PARTE IZQDA) Y GRAFITO AGRUPADO CON FORMA

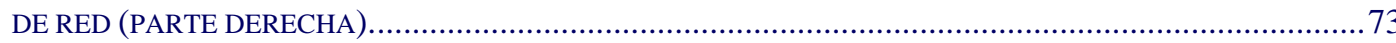

FigURA 35. PATRÓN DE ROTURAS DE LAS TUBERÍAS DE FUNDICIÓN GRIS DE OTTAWA (RAJANI, 2009D)....75

FIGURA 36. TIPOS DE ROTURA EN TUBERÍA DE FUNDICIÓN GRIS...........................................................75

Figura 37. PATRÓn DE ROTURAS DE LAS TUbERÍAS DE FIBROCEMENTO DE REGINA (Hu AND HubBLE, 2007) 79

FigURA 38. DiÁMETROS EN MM DE LOS DiSTINTOS TIPOS DE TUBOS (CEDEX, 2006). ................................81

FIGURA 39. LONGITUD (M) DE LOS DISTINTOS TUBOS (CEDEX, 2006). ..................................................82

FIGURA 40. INFLUENCIA DEL TERRENO EN EL ÍNDICE DE ROTURAS EN TUBERÍAS DE ACERO (NEWPORT,

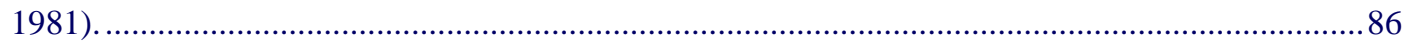

FIGURA 41. PORCENTAJE DE UTILIZACIÓN DE LOS DIFERENTES MATERIALES EN NORTEAMÉRICA (RAJANI, 2009A). ...88

Figura 42. PorCENTAJE DE UTILIZACIÓN DE LOS DIFERENTES MATERIALES EN EUROPA (RAJANI, 2009A). 89

FigURA 43. LONGITUDES DE TUBERÍA SEGÚN MATERIAL EN ABASTECIMIENTOS ESPAÑOLES (AEAS, 2006).

(n)

FIGURA 44. LONGITUDES DE TUBERÍA SEGÚN MATERIAL EN LA RED DE ALTA DE VALENCIA.....................992

FIGURA 45. LONGITUDES DE TUBERÍA SEGÚN MATERIAL EN LA RED DE BAJA DE VALENCIA.......................93 FiguRA 46. ESQUEMA DEL CICLO URBANO DEL AGUA EN LA CIUDAD DE VALENCIA (MURGUI Y COL., 2009)

FIGURA 47. ENUMERACIÓN DE LOS COSTES TOTALES CONSIDERADOS. .................................................137

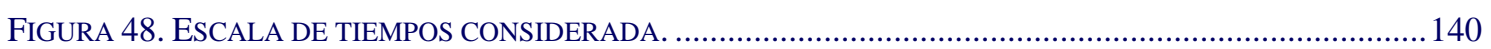

FIGURA 49. REPRESENTACIÓN CUALITATIVA DEL COSTE DE RENOVACIÓN DE LA TUBERÍA EN € DEL AÑO

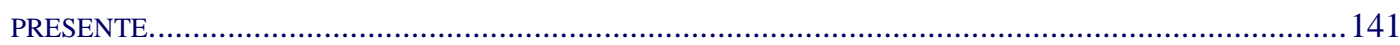

FIGURA 50. REPRESENTACIÓN CUALITATIVA DEL COSTE DE MANTENIMIENTO......................................142

FIGURA 51. REPRESENTACIÓN CUALITATIVA DE LOS COSTES DEL AGUA FUGADA...................................143

FIGURA 52. EVOLUCIÓN DE LOS COSTES DESDE EL AÑO PRESENTE HASTA EL INFINITO............................151

FIGURA 53. EVOLUCIÓN DE LOS COSTES DESDE EL AÑO PRESENTE HASTA EL INSTANTE $T^{*} \ldots . . . . . . . . . . . . . . . . .153$

FIGURA 54. REPRESENTACIÓN DE LOS COSTES TOTALES ASOCIADOS A LA RENOVACIÓN DE UNA TUBERÍA.

FIGURA 55. VARIACIÓN DEL COSTE TOTAL CUANDO SE INCUMPLEN LOS ESTÁNDARES DE SERVICIO A PARTIR

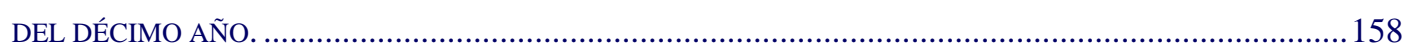

FIGURA 56. REPERCUSIÓN TEMPORAL DEL AHORRO CONSECUENCIA DE LA OPORTUNIDAD.......................159

FIGURA 57. COMPARACIÓN DEL MODELO DE HABITUALES (SHAMIR Y HOWARD, 1979) CON EL MODELO PROPUESTO QUE INCORPORA LOS COSTES DEL AGUA, DE LA ENERGÍA Y SOCIALES. ........................160

FIGURA 58. COSTES DE LAS INFINITAS RENOVACIONES DE UNA CONDUCCIÓN. APLICACIÓN NUMÉRICA

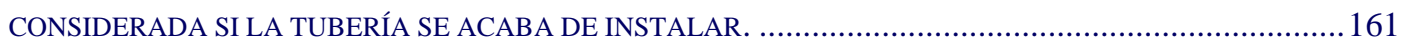

FIGURA 59. DISTRIBUCIÓN TEMPORAL DE COSTES DE RENOVACIÓN DE UNA TUBERÍA. ..............................161

FIGURA 60. DISTRIBUCIÓN TEMPORAL DE COSTES DE RENOVACIÓN DE UNA TUBERÍA. CASO HABITUAL EN EL CUAL SE COMIENZA CON UNA RED QUE SE ENCUENTRA EN UN ESTADO DETERMINADO. 
FiguRA 61. PERIODO ÓPTIMO DE RENOVACIÓN Y COSTES TOTALES (€/M) ASOCIADOS A LAS INFINITAS RENOVACIONES DE UNA TUBERÍA.

FIGURA 62. VARIACIÓN DEL COSTE TOTAL CUANDO SE INCUMPLEN LOS ESTÁNDARES DE SERVICIO EN EL CASO DE QUE SE CONSIDEREN LAS INFINITAS RENOVACIONES DE UNA TUBERÍA.

FIGURA 63. EFECTO DEL AHORRO CONSECUENCIA DE LA OPORTUNIDAD EN EL CASO EN QUE SE CONSIDEREN LAS INFINITAS RENOVACIONES DE UNA TUBERÍA. 165

FigURA 64. DISTRIBUCIÓN TEMPORAL DE COSTES DE RENOVACIÓN DE UNA TUBERÍA. 166

FIGURA 65. DISTRIBUCIÓN TEMPORAL DE COSTES DE RENOVACIÓN DE UNA TUBERÍA PARA EL PLANTEAMIENTO DE SHAMIR Y HOWARD EN EL CASO EN QUE SE CONSIDEREN LAS INFINITAS RENOVACIONES DE UNA TUBERÍA.

Figura 66. COMPARACIÓN DEL MODELO DE SHAMIR Y HOWARD, (COSTES HABITUALES) CON EL NUEVO QUE CONSIDERA LOS COSTES DEL AGUA FUGADA Y LOS COSTES SOCIALES.

FIGURA 67. DISTRIBUCIÓN TEMPORAL DE LAS INVERSIONES EN RENOVACIÓN DE LA TUBERÍA.................168

FIGURA 68. CLASIFICACIÓN DE LOS PARÁMETROS QUE INFLUYEN EN EL PERIODO ÓPTIMO DE RENOVACIÓN.

FIGURA 69. VARIACIÓN DEL PERIODO ÓPTIMO DE RENOVACIÓN SEGÚN DIFERENTES VALORES DEL PARÁMETRO A.

FIGURA 70. PERIODO ÓPTIMO DE RENOVACIÓN PARA DISTINTOS VALORES DE LOS PARÁMETROS MENOS SIGNIFICATIVOS.

FIGURA 71. CICLO DE VIDA DE UNA TUBERÍA ENTERRADA. CURVA DE BAÑERA. 186

FIGURA 72. REPRESENTACIÓN DE LOS COSTES TOTALES ASOCIADOS A LA RENOVACIÓN DE UNA TUBERÍA.

188

FIGURA 73. VARIACIÓN DEL COSTE TOTAL CUANDO SE INCUMPLEN LOS ESTÁNDARES DE SERVICIO A PARTIR DEL DÉCIMO AÑO. 189

FIGURA 74. REPERCUSIÓN TEMPORAL DEL AHORRO CONSECUENCIA DE LA OPORTUNIDAD.......................190

FIGURA 75. REPRESENTACIÓN DE LOS COSTES TOTALES ASOCIADOS A LA RENOVACIÓN DE UNA TUBERÍA PARA LAS DIFERENTES TÉCNICAS.

FIGURA 76. EVOLUCIÓN DE LA CURVA DE COSTES TOTALES SEGÚN EL PRECIO DE PRODUCCIÓN DEL AGUA

FIGURA 77. COSTE ASOCIADO A LAS PÉRDIDAS DE AGUA POR FUGAS SEGÚN VARIACIÓN DEL COSTE DEL AGUA......

IGURA 78. EVOLUCIÓN DE LA CURVA DE COSTES TOTALES SEGÚN EL COSTE ENERGÉTICO DE PRODUCCIÓN DEL AGUA

FigURA 79. EVOLUCIÓN DE LA CURVA DE COSTES TOTALES SEGÚN EL CAUDAL MEDIO UNITARIO POR FUGA.

FIGURA 80. EVOLUCIÓN DE LA CURVA DE COSTES TOTALES SEGÚN ELTIEMPO MEDIO DE ACTIVIDAD DE LA FUGA......

FIGURA 81. REPERCUSIÓN DE LA VARIACIÓN DE LA TASA CONTINUA DE ACTUALIZACIÓN EQUIVALENTE. 197

FIGURA 82. VARIACIÓN DEL COSTE MÍNIMO TOTAL EN FUNCIÓN DEL INDICE DE CRECIMIENTO DEL NÚMERO DE ROTURAS.

FIGURA 83. COSTES DE LAS INFINITAS RENOVACIONES EN UNA CONDUCCIÓN SEGÚN DISTINTOS TIPOS DE TÉCNICA.

FIGURA 84. DISTRIBUCIÓN TEMPORAL DE COSTES DE RENOVACIÓN SI SE PARTE DE UNA SITUACIÓN CON TUBERÍA NUEVA Y TÉCNICA TRADICIONAL CON APERTURA DE ZANJA.

FigURA 85. DiSTRIBUCIÓN TEMPORAL DE COSTES DE RENOVACIÓN CON LA TÉCNICA TRADICIONAL. CASO HABITUAL EN EL CUAL SE COMIENZA CON UNA RED QUE SE ENCUENTRA EN UN ESTADO DETERMINADO.

FIGURA 86. COSTES TOTALES (€/M) ASOCIADOS A LAS INFINITAS RENOVACIONES PARA LAS J TÉCNICAS. 202 FIGURA 87. VARIACIÓN DEL COSTE TOTAL CUANDO SE INCUMPLEN LOS ESTÁNDARES DE SERVICIO A PARTIR DEL DÉCIMO AÑO PARA EL CASO DE LAS INFINITAS RENOVACIONES.

FIGURA 88. REPERCUSIÓN TEMPORAL DEL AHORRO CONSECUENCIA DE LA OPORTUNIDAD PARA EL CASO DE LAS INFINITAS RENOVACIONES. 
FiguRA 89. EVOLUCiÓN DE LA CURVA DE COSTES TOTALES SEGÚN EL PRECIO DE PRODUCCIÓN DEL AGUA PARA EL CASO DE LAS INFINITAS RENOVACIONES.

FIGURA 90. EVOLUCIÓN DE LA CURVA DE COSTES TOTALES SEGÚN LA HUELLA ENERGÉTICA DEL AGUA EN EL CASO DE LAS INFINITAS RENOVACIONES.

FIGURA 91. EVOLUCIÓN DE LA CURVA DE COSTES TOTALES SEGÚN EL CAUDAL MEDIO UNITARIO POR FUGA EN EL CASO DE LAS INFINITAS RENOVACIONES.

FIGURA 92. EVOLUCIÓN DE LA CURVA DE COSTES TOTALES SEGÚN ELTIEMPO MEDIO DE ACTIVIDAD DE LA FUGA PARA EL CASO DE LAS INFINITAS RENOVACIONES. 208

FIGURA 93. REPERCUSIÓN DE LA VARIACIÓN DE LA TASA CONTINUA DE ACTUALIZACIÓN EQUIVALENTE PARA EL CASO DE LAS INFINITAS RENOVACIONES.

FIGURA 94. REPERCUSIÓN DE LA VARIACIÓN DE LA TASA CONTINUA DE ACTUALIZACIÓN EQUIVALENTE PARA EL CASO DE LAS INFINITAS RENOVACIONES.

FIGURA 95. DISTRIBUCIÓN DE LOS COSTES EN LA DETERMINACIÓN DE LAS INFINITAS RENOVACIONES DE UNA CONDUCCIÓN CON LA TÉCNICA DE ENTUBADO POR DELIZAMIENTO Y TÉCNICA TRADICIONAL. LA SEGUNDA RENOVACIÓN SE REALIZA CON EL MÉTODO DE ENTUBADO POR DESLIZAMIENTO. .............211

FIGURA 96. REPRESENTACIÓN DE LAS INVERSIONES A LO LARGO DEL TIEMPO........................................212

FIGURA 97. DISTRIBUCIÓN DE LOS COSTES EN LA DETERMINACIÓN DE LAS INFINITAS RENOVACIONES DE UNA CONDUCCIÓN CON LA TÉCNICA DE ENTUBADO POR DELIZAMIENTO Y TÉCNICA TRADICIONAL. LA SEGUNDA RENOVACIÓN SE REALIZA CON EL MÉTODO TÉCNICA TRADICIONAL. 213

FIGURA 98. DISTRIBUCIÓN DE LAS INVERSIONES EN EL TIEMPO EN EL CASO DE RENOVACIÓN MEDIANTE EL ENTUBADO POR DESLIZAMIENTO.

FIGURA 99. COSTES TOTALES (€/M) ASOCIADOS A LAS INFINITAS RENOVACIONES PARA LAS TÉCNICAS DE ENTUBADO POR DESLIZAMIENTO Y TÉCNICA TRADICIONAL ........................................................215

FIGURA 100. INVERSIONES EN I+D EN LOS PAÍSES IEA (IEA, 2008) ..................................................219

FIGURA 101. PRECIO DEL PETRÓLEO EN \$ 2007 (WWW.INFLATIONDATA.COM) ......................................220

FIGURA 102. ETAPAS DEL CICLO DEL AGUA Y ENERGIA NECESARIA PARA CADA UNA DE ELLAS EN KWH/M ${ }^{3}$ (CEC, 2005). 224

FIGURA 103. CONSUMO DE ENERGÍA DEL CICLO URBANO DEL AGUA EN LA CIUDAD DE VALENCIA. MURGUI Y COL (2009)

FIGURA 104. TÉRMINOS QUE INTERVIENEN EN LA AUDITORÍA ENERGÉTICA DE UNA RED ..........................228

FIGURA 105. NOTACIÓN UTILIZADA PARA LOS NUDOS Y LÍNEAS DE LA RED DE DISTRIBUCIÓN...................231

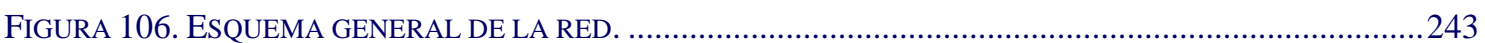

FIGURA 107. EL COMPLEJO PUZZLE AGUA - ENERGÍA - CAMBIO CLIMÁTICO (HIGHTOWER, 2005).............251

FIGURA 108. NUEVO ESCENARIO SOBRE EL QUE CALCULAR LA ENERGÍA INVERTIDA EN LA RED DE DISTRIBUCIÓN .260

FIGURA 109. CURVA CARACTERÍSTICA, CURVA DEL RENDIMIENTO Y COLINAS DE ISORRENDIMIENTO DE UN EQUIPO DE BOMBEO A DIFERENTES VELOCIDADES DE GIRO....................................................262

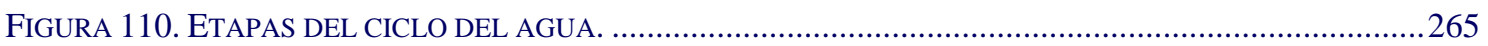

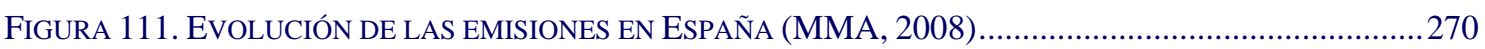

FIGURA 112. CAMPAÑA DE PUBLICIDAD DE LA ORGANIZACIÓN GREENPEACE PREVIA A LA REUNIÓN DEL COP 15 EN EL AEROPUERTO DE LUFTHAVNEN, COPENHAGUE. ....................................................2271

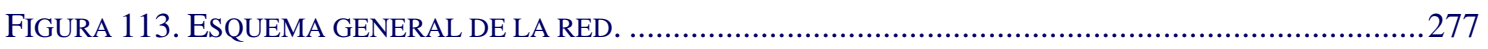

FIGURA 114. CURVA DE CONSIGNA Y CURVA DE FUNCIONAMIENTO DEL EQUIPO DE BOMBEO A DIFERENTES VELOCIDADES DE GIRO.

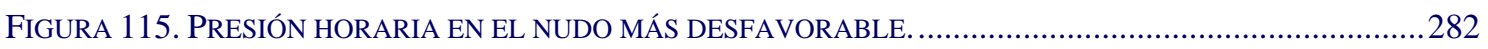

FIGURA 116. PRESIÓN HORARIA EN EL NUDO MÁS DESFAVORABLE EN EL ESCENARIO COMBINADO. ..........295 


\section{FIGURAS EN LOS ANEXOS}

FIGURA A.1. UTILIZACIÓN DE LAS TÉCNICAS DE REHABILITACIÓN SIN ZANJA EN REDES DE SANEAMIENTO DE EE.UU. (NAJAFI Y GOKHALE, 2004).

FIGURA A.2. BOCETO DE UN DISPOSITIVO DE LIMPIEZA DE UNA RED DE SANEAMIENTO EN LA CIUDAD DE PARÍS (WWW.SEWERHISTORY.ORG).

FIGURA A.3. CONJUNTO DE CARRETILLA Y BARCA QUE REALIZABAN LA PRIMERA LIMPIEZA EN PARIS (WWW.SEWERHISTORY.ORG).

FigurA A.4. PRIMEROS PROTOTIPOS DE RASCADORES AUTOMÁTICOS EN 1896 (WWW.SEWERHISTORY.ORG).

FIGURA A.5. TANQUE QUE PERMITÍA LA DESCARGA DE AGUA (TUCSON, ARIZONA, 1900-1925)...............A.7 FIGURA A.6. DISCO UTILIZADO PARA LA LIMPIEZA EN LA CIUDAD DE NUEVA YORK EN EL AÑO 1910........ A.7 FIGURA A.7. CÁMARAS CON TUBO DE VIDICON DE LOS AÑOS 50 FABRICADAS POR RCA CORPORATION.....A.8 FIGURA A.8. INSPECCIÓN DE TUBERÍAS CON CÁMARA DE VIDEO. A.9 FIGURA A.9. VISTA DE UN MODERNO SISTEMA DE SELLADO, FRESADO EN TUBERÍAS CON CONTROL DE EQUIPOS DE TELEVISIÓN....

FIGURA A.10. ENTUBADO POR DESLIZAMIENTO, SLIPLINING.

FIGURA A.11. MECANISMO DE INYECCIÓN DE RESINAS QUE SIRVEN COMO REVESTIMIENTO NO ESTRUCTURAL.

FIGURA A.12. PERFORACIÓN NO DIRIGIDA REALIZADA POR CHERRINGTON EN SACRAMENTO DURANTE LOS AÑOS SESENTA.

FIGURA A.13. CLASIFICACIÓN DE LAS PRINCIPALES TÉCNICAS DE REHABILITACIÓN O RENOVACIÓN SIN ZANJA.

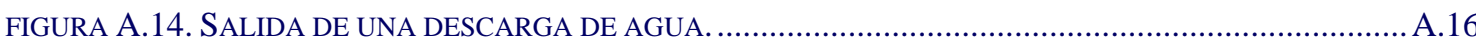

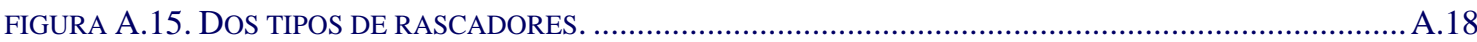

FIGURA A.16. INYECCIÓN DE AGUA A ALTA PRESIÓN. ....................................................................... A.19

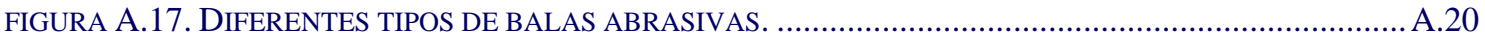

FIGURA A.18. DiSPOSITIVOS DE INYECCIÓN DE RESINAS SOBRE LA CONDUCCIÓN. ................................. A.24

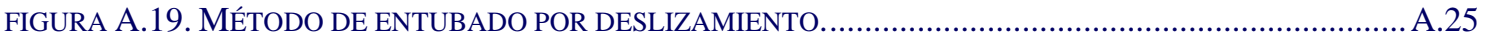

FIGURA A.20. UNIÓN POR SOLDADURA DE UNA TUBERÍA EN UNA CATA DE ENTRADA............................A.26

FIGURA A.21. CATA DE ENTRADA EN UNA RENOVACIÓN EN TUBERÍA DE 910 MM DE FUNDICIÓN GRIS MEDIANTE ENTUBADO POR DESLIZAMIENTO CON TUBERÍA DE POLIETILENO DE 840 MM, OTTAWA, CANADÁ.

FIGURA A.22. CLASIFICACIÓN DE LAS DISTINTAS TÉCNICAS DE AJUSTE PRECISO A LA ANTIGUA TUBERÍA.

FIGURA A.23. MECANISMO DE REDUCCIÓN DE LA TUBERÍA DE POLIETILENO. ........................................30

FIGURA A.24. RODILLOS QUE PRODUCEN LA DEFORMACIÓN EN LAS TÉCNICAS DE AJUSTE MEDIANTE

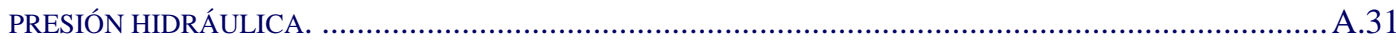

FIGURA A.25. VISTA DE LA DEFORMACIÓN REALIZADA SOBRE LA TUBERÍA DE POLIETILENO Y UN EJEMPLO

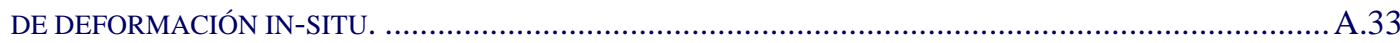

FIGURA A.26. INSTALACIÓN DE MANGA INVERTIDA PARA REHABILITACIÓN ............................................3.35 FIGURA A.27. PROCESO DE REVERSIÓN DE LA MANGA SOBRE LA ANTIGUA CONDUCCIÓN.......................A.36 FIGURA A.28. REHABILITACIÓN D EUNA TUBERÍA MEDIANTE ENCAMISADO TÉRMICO............................A.36 FIGURA A.29. UNIDAD CON LA QUE SE REALIZA EL FRAGUADO CON RAYOS UV ..................................A.37

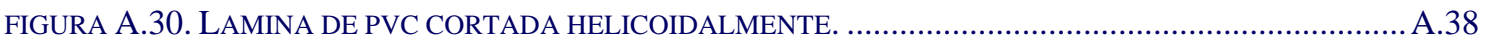
FIGURA A.31. CATA DESDE LA QUE SE REALIZAN DISTINTAS TÉCNICAS. .............................................40 FIGURA A.32. MOVIMIENTO DEL CABEZAL DE TIRO QUE PRODUCE LA ROTURA DE LA CONDUCCIÓN........A.41

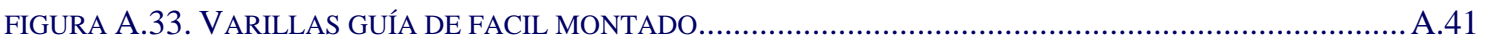
FIGURA A.34. UNIÓN DEL CABEZAL DE TIRO Y LA PIEZA UTILIZADA PARA EL ENSANCHAMIENTO...........A.41 FIGURA A.35. INSERCIÓN DE NUEVA TUBERÍA CON ROTURA DE LA ANTIGUA CONDUCCIÓN CON MOTOR ACCIONADO HIDRÁULICAMENTE. 
FIGURA A.36. INSERCIÓN DE NUEVA TUBERÍA CON ROTURA DE LA ANTIGUA CONDUCCIÓN CON MOTOR ACCIONADO NEUMÁTICAMENTE.

FIGURA A.37. CABEZAL DE TIRO QUE PRODUCE UNA ROTURA EN LA TUBERÍA MEDIANTE PERCUSIÓN NEUMÁTICA.

FIGURA A.38. EJEMPLO DEL CORTE DE TUBERÍAS MEDIANTE UNA CUCHILLA......

FIGURA A.39. ESQUEMA GENERAL DE LA TÉCNICA INSERCIÓN MEDIANTE ROTURA DE TUBERÍA CON CUCHILLA.

FIGURA A.40. EJEMPLO DEL ESTUDIO DEL TERRENO PREVIA A LA REALIZACIÓN DE LA PERFORACIÓN HORIZONTAL DIRIGIDA

FIGURA A.41. CABEZAL UTILIZADOS PARA LA EXCAVACIÓN EN ROCA.................................................47

FIGURA A.42. MÁQUINA UTILIZADA PARA PERFORACIÓN HORIZONTAL DIRIGIDA.................................A.48

FIGURA A.43. CILINDRO METÁLICO QUE SE INSERTA EN EL TERRENO..................................................49

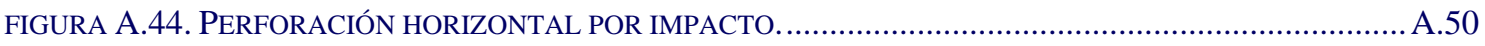

FIGURA A.45. EJEMPLO DE LA PERFORACIÓN POR EMPUJE. ................................................................ A.51

FIGURA A.46. ESQUEMA DE LA HINCA DE TUBERÍA DE ACERO.........................................................5.52

FIGURA A.47. HINCA DE TUBERÍA DE ACERO DE 1800 MM QUE CRUZA UNA AUTOPISTA EN PRAGA, DICIEMBRE DE 2006.

FIGURA A.48. VARILLAS EMPLEADAS EN LA TÉCNICA INSERCIÓN DE TUBERÍA MEDIANTE EL TALADRO CON TORNILLO SIN FIN

FIGURA A.49. ESQUEMA DE INSERCIÓN DE TUBERÍA MEDIANTE EL TALADRO CON TORNILLO SIN FIN. .....A.54 FIGURA A.50. DISPOSITIVOS HIDRÁULICOS DE PERFORACIÓN. .............................................................5

FIGURA A.51. TUBERÍAS MACHO Y HEMBRA UTILIZADAS EN LAS HINCAS. ............................................56

FIGURA A.52. APLICABILIDAD DE LAS TÉCNICAS SEGÚN DIÁMETRO. ...................................................59

FIGURA A.53. APLICABILIDAD DE LAS TÉCNICAS SEGÚN LONGITUD ..................................................60

FIGURA A.54. DIAGRAMA DE FLUJO DE LAS OPCIONES DE RENOVACIÓN. .............................................63

FIGURA A.55. SELECCIÓN DE LA TÉCNICA DE RENOVACIÓN (RAJANI, 2009)............................................64

FIGURA A.56. SELECCIÓN DE LA TÉCNICA DE RENOVACIÓN. (DEB Y COL., 2009).....................................65

FIGURA B.1. REPRESENTACIÓN GRÁFICA DE LA EVOLUCIÓN DEL COSTE DE OPORTUNIDAD ....................... B.7

FIGURA C.1. CURVA DE GASTOS EN REPARACIÓN Y MANTENIMIENTO, CGRM(VF).................................. C.3

FIGURA C.2. NIVEL PROMEDIO DE FUGAS PARA DOS POLÍTICAS DE MANTENIMIENTO DIFERENTES............ C.4

FIGURA C.3. CURVA DE COSTES TOTALES EN MANTENIMIENTO_........................................................... C.8

FIGURA C.4. AUMENTO DEL INAF A LARGO PLAZO. ............................................................................. 10

FIGURA C.5. TRES PERIODOS DE TIEMPO OPTIMIZADOS EN EL LARGO PLAZO........................................ C.11

FIGURA C.6. EJEMPLO DE LA EVOLUCIÓN TEMPORAL DE LA CURVA DE COSTES TOTALES CON EL PASO DEL

TIEMPO.

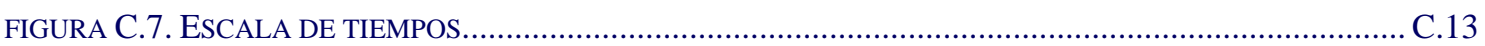

FIGURA C.8. PROCESO REALIZADO PARA CONJUGAR LOS PERIODOS A LARGO Y A CORTO PLAZO. ............ C.15

FIGURA D.1. COSTES SOCIALES ASOCIADOS A DISTINTAS TÉCNICAS DE RENOVACIÓN............................ D.14

FIGURA D.2. COSTES SOCIALES DE LA RENOVACIÓN DE UNA TUBERÍA CON LA TÉCNICA DE APERTURA DE

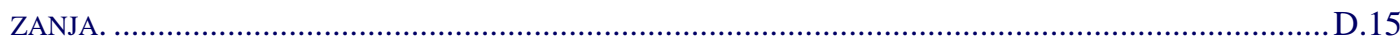

FIGURA E.1. PLANTEAMIENTO DEL PROBLEMA EN UNA RED IDEAL SIN FUGAS. ....................................... E.2

FIGURA E.2. PLANTEAMIENTO DEL PROBLEMA EN UNA RED REAL ........................................................ E.4

FIGURA E.3. RELACIÓN ENTRE LA ENERGÍA CONSUMIDA EN EL CASO A Y B PARA LAS COMBINACIONES MOSTRADAS. 


\section{ÍNDICE DE TABLAS}

TABLA 1. ESTIMACIÓN DE LAS INVERSIONES Y RETORNOS DE LA RENOVACIÓN EN REDES DE AGUA EN INGLATERRA Y GALES DEL AÑO 2003 AL 2008 (OFWAT, 2008).

TABLA 2. INDICADORES BÁSICOS DEL ESTADO DE LAS REDES EN FRANCIA SEGÚN EL TAMAÑO DE LA

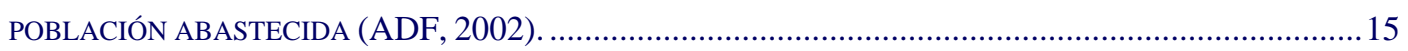

TABLA 3. INVERSIONES REALIZADAS Y PREVISTAS EN LAS REDES FRANCESAS (ADF, 2002).........................15

TABLA 4. LONGITUD DE TUBERÍAS POR HABITANTE EN ESPAÑA (AEAS, 2006).........................................18

TABLA 5. RELACIÓN ENTRE POBLACIÓN Y KILÓMETROS DE TUBERÍAS PARA ESPAÑA (AEAS, 2006). .........18

TABLA 6. INVERSIÓN EN RENOVACIÓN DE REDES DE DISTRIBUCIÓN (AEAS, 2006).......................................19

TABLA 7. INVERSIÓN EN RENOVACIÓN DE REDES DE DISTRIBUCIÓN POR COMUNIDAD AUTÓNOMA

(INE, 2006) 19

TABLA 8. LONGITUDES DE LAS TUBERÍAS SEGÚN DIÁMETRO EN LA RED DE ALTA Y DE BAJA DE VALENCIA.

20

TABLA 9. INDICADORES DE LOS EQUIPAMIENTOS DE LAS REDES DE VALENCIA...........................................21

TABLA 10. RESUMEN DE LAS INVERSIONES EN RENOVACIÓN DE TUBERÍAS LOS PRÓXIMOS AÑOS. ................24

TABLA 11. INDICADORES BÁSICOS DE LA INVERSIÓN EN RENOVACIÓN POR KM DE TUBERÍA Y POR

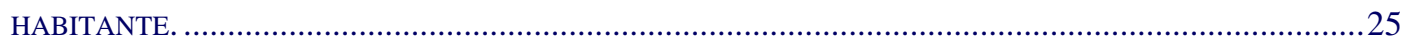

TABLA 12. TIPOS DE REVESTIMIENTOS QUE PROTEGEN LAS TUBERÍAS DE FUNDICIÓN DÚCTIL (RAJANI Y

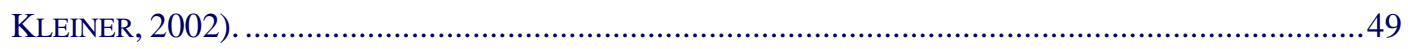

TABLA 13. TIPOS DE REVESTIMIENTOS EN TUBOS DE FUNDICIÓN DÚCTIL (CEDEX, 2006)............................50

TABLA 14. REVESTIMIENTOS HABITUALES EN LOS TUBOS Y PIEZAS DE FUNDICIÓN DUCTIL (UNE-EN 545:1995).

TABLA 15. RESISTENCIA A LA TRACCIÓN Y COMPRESIÓN SEGÚN LAS NORMAS UTILIZADAS EN LA

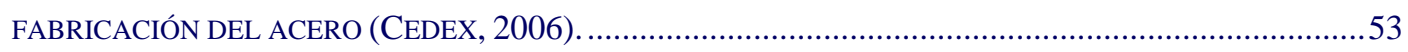

TABLA 16. REVESTIMIENTOS HABITUALES EN LOS TUBOS DE ACERO (CEDEX, 2006)....................................55

TABLA 17. ALAMBRES DE PRETENSADO. VALORES MÍNIMOS DE LA ESTRICCIÓN TRAS EL ENSAYO DE

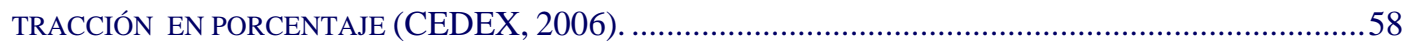

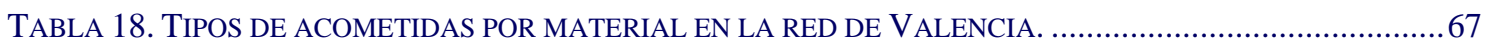

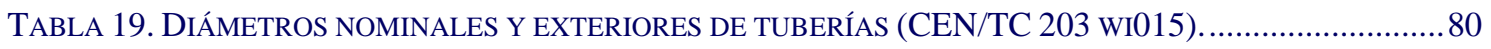

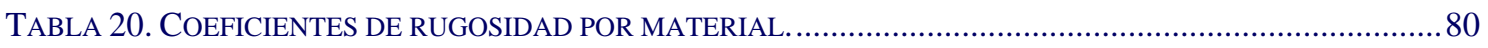

TABLA 21. ROTURAS POR UNIDAD DE LONGITUD Y AÑO EN TUBERÍAS DEL REINO UNIDO (MACKELLAR Y

PEARSON, 2003). 
TABLA 22. RotURAS OBSERVADAS EN 21 CIUDADES DE CANADÁ (NRC, 1993).....................................83

TABLA 23. DAÑOS REGISTRAdOS EN LAS TUBERÍAS DE ALEMENIA (HIRNER, 1997A)...............................84

TABla 24. PARÁMETROS CARACTERÍSTICOS DE LA RED DE DiSTRIBUCión DE Ho CHi Minh (LuONG Y

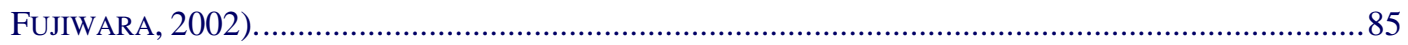

TABLA 25. COMPOSICIÓN DE LA RED DE DISTRIBUCIÓN (Di FEDERICO Y COL., 2002). ...............................85

TABLA 26. RotURAS PRODUCIDAS EN LOS AÑOS DE ESTUDIO (DI FEDERICO Y COL., 2002)........................86

TABLA 27. LONGITUD DE TUBERÍAS INSTALADAS EN EE.UU. (AWWA, 2004). .....................................8

TABLA 28. DiSTRIBUCIÓN DE MATERIALES EN LOS ABASTECIMIENTOS ESPAÑOLES (AEAS, 2000 Y 2006). 91

TABla 29. PROBlemas DE EPIDEMIAS POR CONTAMINACIÓN DE AGUAS (LiNDLEY Y BuCHBERGER, 2002).

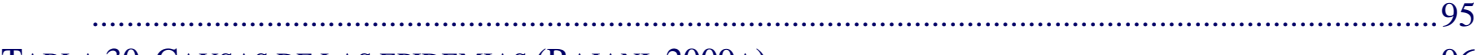

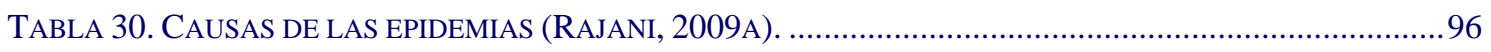

TABla 31. VALORES RECOMENDAdOS DE FUGAS DE AGUA ESPECÍfICAS EN ALEMANIA (HiRner, 1997B) .96

TABLA 32. VIDA ÚTIL DE ALGUNOS DISPOSITIVOS HIDRÁULICOS. .....................................................98

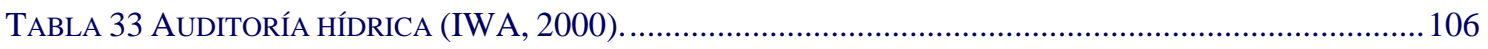

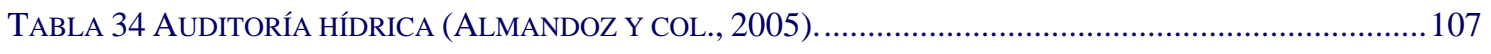

TABLA 35. COMPONENTES DEL CAUDAL MÍNIMO NOCTURNO.............................................................114

TABLA 36. VALORES DEL IFE EN PAÍSES DESARROLLADOS Y EN VÍAS DE DESARROLLO (LIEMBERGER,

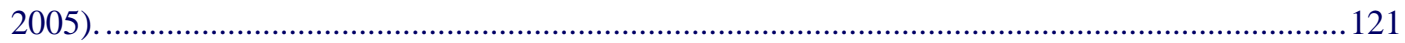

TABLA 37. VALORES DEL IFE (MCKENZIE Y COL., 2007) .....................................................................121

TABLA 38. VALORES DEL IFE COMO DESCRIPTORES Y COMO OBJETIVO (AWWA, 2003) .........................122

TABLA 39 AUDITORÍA HÍDRICA EN LARISSA EN EL AÑO 2001. (TSITSIFLI Y KANAKOUDIS, 2008).............124

TABLA 40 AUDITORÍA HÍDRICA EN LARISSA EN EL AÑO 2006. (TSITSIFLI Y KANAKOUDIS, 2008).............124

TABLA 41. VALORES ENCONTRADOS EN LOS ABASTECIMIENTOS DE LA REPÚBLICA CHECA. (TUHOVCAK Y

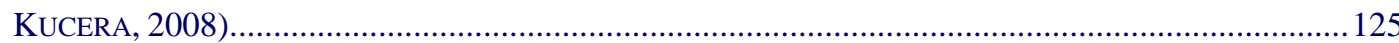

TABlA 42 AudiTORÍA HÍDRICA EN AUCKLAND, NuEVA ZELANDA. (FARLEY Y TROW, 2003). .................126

TABLA 43 AUDITORÍA HÍDRICA EN SARINA SHIRE COUNCIL (FARLEY Y TROW, 2003). ...........................126

TABLA 44. INDICADORES DE GESTIÓN INTERNACIONALES (FARLEY Y TROW (2003)...............................128

TABLA 45. VALORES ENCONTRADOS EN ABASTECIMIENTOS DE DIVERSAS CIUDADES (ALMANDOZ Y COL.,

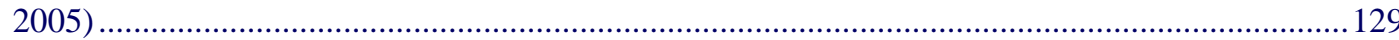

TABLA 46. BALANCE HÍDRICO EN LA RED DE DISTRIBUCIÓN DE VALENCIA EN HM ${ }^{3}$ /AÑO. .........................131

TABLA 47. CARACTERIZACIÓN DE LOS COSTES ANALIZADOS............................................................138

TABLA 48. VALORES ADOPTADOS PARA LOS PRINCIPALES TÉRMINOS QUE INFLUYEN EN EL PERIODO ÓPTIMO DE RENOVACIÓN.

TABLA 49. VALORES QUE PROPORCIONAN LOS ADOPTADOS PARA LOS TÉRMINOS QUE DETERMINAN LOS VALORES DE LOS TÉRMINOS DE INVERSIÓN Y MANTENIMIENTO.................................................. 180

TABLA 50. PRECIO DE LA TUBERÍA DE POLIETILENO ( $€$ DEL AÑO EN CURSO) ...........................................185

TABLA 51. COSTE SOCIAL ASOCIADO A LA S PERTURBACIONES POR EJECUCIÓN DE LAS OBRAS (€ DEL AÑO

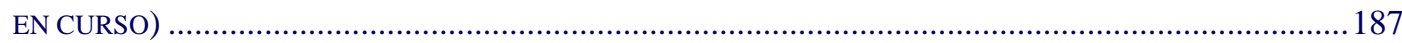

TABLA 52. PARÁMETRO DE INVERSIÓN SEGÚN LA TÉCNICA EMPLEADA (€ DEL AÑO EN CURSO) ................188

TABLA 53. PERIODO ÓPTIMO DE RENOVACIÓN SEGÚN LA TÉCNICA EMPLEADA (€ DEL AÑO EN CURSO).....190

TABLA 54. RELACIÓN ENTRE EL COSTE DEL AGUA Y EL PERIODO ÓPTIMO DE RENOVACIÓN. .......................192

TABLA 55. RELACIÓN ENTRE LA HUELLA ENERGÉTICA DEL AGUA Y EL PERIODO ÓPTIMO DE RENOVACIÓN.

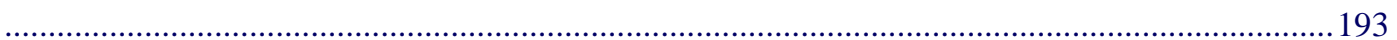

TABLA 56. RELACIÓN ENTRE EL CAUDAL MEDIO DE FUGAS Y EL PERIODO ÓPTIMO DE RENOVACIÓN. ........194

TABLA 57. RELACIÓN ENTRE EL CAUDAL MEDIO DE FUGAS Y EL PERIODO ÓPTIMO DE RENOVACIÓN. ........195

TABLA 58. RELACIÓN ENTRE LA TASA CONTINUA DE ACTUALIZACIÓN Y EL PERIODO ÓPTIMO DE RENOVACIÓN.

TABLA 59. RELACIÓN ENTRE EL COEFICIENTE DE CRECIMIENTO DE ROTURAS Y EL PERIODO ÓPTIMO DE RENOVACIÓN.

TABLA 60. PERIODO ÓPTIMO Y COSTE TOTAL ASOCIADO A LAS INFINITAS RENOVACIONES DE UNA TUBERÍA (EXCEPTO LA PRIMERA) Y SEGÚN LAS J TÉCNICAS CONSIDERADAS ( $€ / M$ DEL AÑO $T_{R}$ ) ....................200

TABLA 61. PERIODO ÓPTIMO Y COSTE TOTAL ASOCIADO AL CICLO DE RENOVACIONES DE UNA TUBERÍA SEGÚN LAS J TÉCNICAS EMPLEADAS ( $€ / M$ DEL AÑO $\left.T_{\mathrm{P}}\right)$ 
TABLA 62. RELACIÓN ENTRE EL COSTE DEL AGUA Y EL PERIODO ÓPTIMO DE RENOVACIÓN PARA EL CASO DE LAS INFINITAS RENOVACIONES.

TABLA 63. RELACIÓN ENTRE LA HUELLA ENERGÉTICA DEL AGUA Y EL PERIODO ÓPTIMO DE RENOVACIÓN PARA EL CASO DE LAS INFINITAS RENOVACIONES

TABLA 5.64. RELACIÓN ENTRE EL CAUDAL MEDIO DE FUGAS Y EL PERIODO ÓPTIMO DE RENOVACIÓN PARA EL CASO DE LAS INFINITAS RENOVACIONES. 206

TABLA 65. RELACIÓN ENTRE EL TIEMPO MEDIO DE ACTIVIDAD DE LA FUGA Y EL PERIODO ÓPTIMO DE RENOVACIÓN PARA EL CASO DE LAS INFINITAS RENOVACIONES.

TABLA 66. RELACIÓN ENTRE LA TASA CONTÍNUA DE ACTUALIZACIÓN Y EL PERIODO ÓPTIMO DE RENOVACIÓN PARA EL CASO DE LAS INFINITAS RENOVACIONES. 209

TABLA 67. RELACIÓN ENTRE EL COEFICIENTE DE CRECIMIENTO DE ROTURAS Y EL PERIODO ÓPTIMO DE RENOVACIÓN. PARA EL CASO DE LAS INFINITAS RENOVACIONES. .............................................209

TABLA 68. NOTACIÓN EMPLEADA EN LA DEFINICIÓN DE LAS ENERGÍAS ACTUANTES EN EL SISTEMA .........232

TABLA 69. ESQUEMA DE LA AUDITORÍA ENERGÉTICA EN EL LARGO PLAZO EN UNA RED..........................237

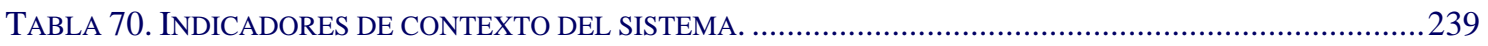

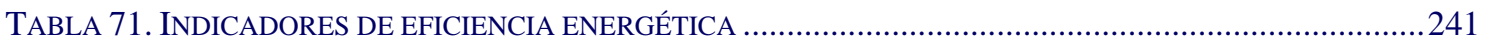

TABLA 72. CARACTERÍSTICAS PROPIAS DE LOS NUDOS Y LÍNEAS DE LA RED.........................................243

TABLA 73. COEFICIENTES DE MODULACIÓN HORARIA DEL CAUDAL ......................................................243

TABLA 74. AUDITORÍA ENERGÉTICA EN LA RED CON FUGAS Y SIN FUGAS. ...........................................245

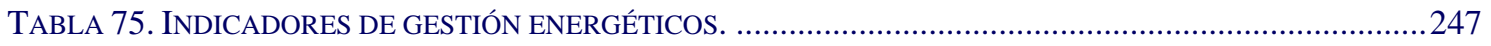

TABLA 76. DEMANDA ESTIMADA DE ENERGÍA ELÉCTRICA LIGADA AL USO DEL AGUA EN ESPAÑA (MIMAM,

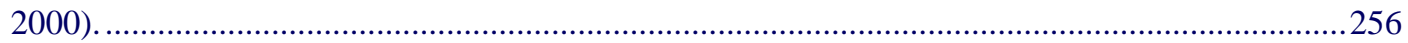

TABla 77. AHORRo dE ENERGÍA POR UN USO MÁS EFICIENTE DEL AGUA EN CALIFORNIA (CEC, 2005)...257

TABLA 78. ANÁLISIS CUALITATIVO DE LOS CONSUMOS ENERGÉTICOS ESPERADOS. ................................263

TABLA 79. VARIACIÓN DE LAS EMISIONES PERMITIDAS PARA PAÍSES DE LA UNIÓN EUROPEA CON RESPECTO A LAS EMISIONES DE 1990 .269

TABLA 80. VALORES TIPO DE LA HUELLA ENERGÉTICA DEL AGUA, DESDE EL ORIGEN HASTA LA FASE DE

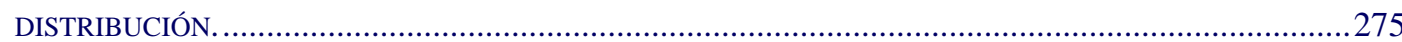

TABLA 81. CANTIDAD DE $\mathrm{CO}_{2}$ EMITIDA A LA ATMÓSFERA SEGÚN ORIGEN DE LA ENERGÍA. .......................275

TABLA 82. CARACTERÍSTICAS PROPIAS DE LOS NUDOS Y LÍNEAS. .........................................................277

TABLA 83. COEFICIENTES DE MODULACIÓN HORARIA DEL CAUDAL ......................................................278

TABLA 84. COEFICIENTES DE MODULACIÓN DE LA VELOCIDAD DE GIRO DEL EQUIPO DE BOMBEO. ............2281

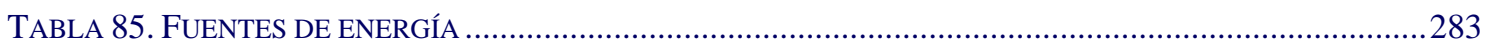

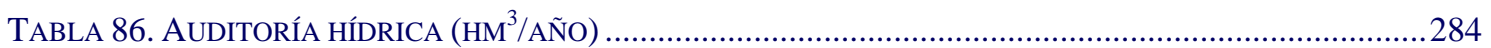

TABLA 87. AUDITORÍA ENERGÉTICA (MWH/AÑO) EN LOS DIFERENTES CASOS ESTUDIADOS, RED REAL....285

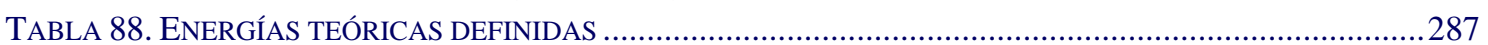

TABLA 89. AUdiTORÍA ENERGÉTICA (MWH/AÑO) EN UNA RED IDEAL SIN FUGAS..................................287

TABLA 90. VALORES DE LAS ENERGÍAS TOTALES (MWH/AÑO) ASOCIADAS A LAS FUGAS EN LA RED DE DISTRIBUCIÓN

TABLA 91. INDICADORES DE GESTIÓN ENERGÉTICOS PARA LOS CASOS ESTUDIADOS................................289

TABLA 92. TONELADAS DE CARBONO EMITIDAS PARA CADA UNO DE LOS CASOS REALES (CON FUGAS), IDEALES (SIN FUGAS) Y AHORROS ENTRE AMBOS CASOS.

TABLA 93. COEFICIENTES DE MODULACIÓN DE LA VELOCIDAD DE GIRO DEL EQUIPO DE BOMBEO EN EL ESCENARIO COMBINADO.

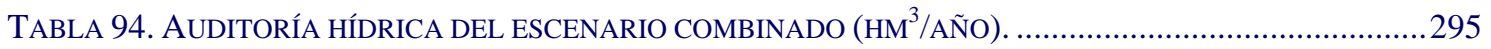

TABLA 95. AUdiTORÍA ENERGÉTICA (MWH/AÑO) ESCENARIO COMBINADO. ..........................................296

TABLA 96. INDICADORES DE GESTIÓN ENERGÉTICOS EN EL ESCENARIO COMBINADO...............................297

TABLA 97. TONELADAS DE CARBONO EMITIDAS EN EL ESCENARIO COMBINADO.....................................298 


\section{TABLAS EN LOS ANEXOS}

TABLA A.1. RELACIÓN ELACIÓN ENTRE POBLACIÓN Y KILÓMETROS DE TUBERÍAS PARA ALGUNOS PAÍSES.

TABLA A.2. VISIÓN GENERAL DE LAS CARACTERÍSITICAS DE LAS TÉCNICAS SIN ZANJA EN REDES DE ABASTECIMIENTO (EPA, 2009).

TABLA A.3. COSTE DEL CICLO DE LA VIDA LIFE-CYCLE-COST DE UN PROYECTO DE RENOVACIÓN. ........... A.66 TABLA A.4. COSTES ASOCIADOS A TÉCNICAS SIN ZANJA PARA SANEAMIENTO (ZHAO Y RAJANI, 2002)... A.68 TABLA A.5. COSTES ASOCIADOS A LAS INSPECCIONES DE LA TUBERÍA (ZHAO Y RAJANI, 2001 Y ALLOUCHE Y FREURE, 2002).

TABLA A.6. RANGO DE COSTES PARA REDES DE SANEAMIENTO (EPA, 1999) ………………………........69

TABLA A.7. COSTES ASOCIADOS A LAS TÉCNICAS SIN ZANJA (SELVAKUMAR Y COL., 2002)........................70

TABLA A.8. COSTES ASOCIADOS A TECNICAS SIN ZANJA. (PARDO Y CABRERA, 2006).................................71

TABLA D.1. COSTES SOCIALES EN REDES DE SANEAMIENTO (PETERS, 1984)........................................... 1

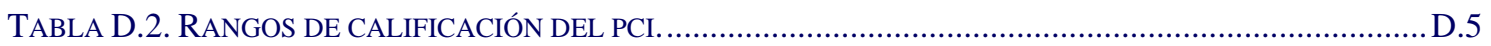

TABLA D.3. REDUCCIÓN DE LA VIDA UTIL DEL PAVIMENTO......................................................................

TABLA D.4. COEFICIENTE DE TECNOLOGÍA EMPLEADOS EN LA CUANTIFICACIÓN DE LAS PÉRDIDAS DE

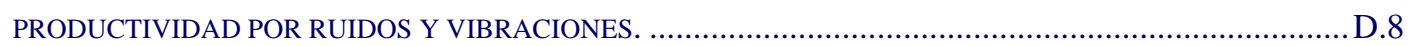

TABLA D.5. COEFICIENTES DE TECNOLOGÍA EMPLEADOS EN LA CUANTIFICACIÓN DE LOS COSTES SOCIALES. 

1

Introducción 



\subsection{Presentación}

La tesis que aquí se presenta se centra en la rehabilitación y renovación de tuberías de agua en redes de distribución urbana. Su objetivo fundamental es identificar y cuantificar los factores clave que condicionan la toma de decisiones del gestor del sistema (a la hora de renovar estas infraestructuras las necesidades son enormes y los recursos escasos, por lo que es esencial optimizarlos) en la rehabilitación o renovación de redes de agua, con especial atención a cómo influyen en el análisis los costes del agua y de la energía.

La gestión y manejo del agua y la energía, dos de los recursos que más condicionan el bienestar de la sociedad, presentan de manera intrínseca una serie de componentes sociológicos, históricos y políticos que frecuentemente no se valoran en su justa medida. Las cada vez más frecuentes sequías y el formidable reto del cambio climático exigen mayores niveles de eficiencia en su uso. Para alcanzarla, y dada la manifiesta interdependencia que existe entre ellos, es menester efectuar planteamientos globales e integradores.

La tesis busca dar respuesta a las preguntas que inevitablemente surgen cuando se aborda la renovación de las cada vez más viejas redes de agua urbanas. La necesidad de optimizar inversiones tan notables obliga a responder con certeza preguntas como ¿qué tubería conviene renovar en primer lugar?, ¿cuándo se debe realizar la renovación?, ¿conviene renovar o rehabilitar esta conducción?, ¿conviene utilizar alguna nueva técnica de renovación sin zanja?, ¿cuánta agua se fuga de la red de distribución? o ¿cuánta energía pierde?, ¿cuántos créditos de carbono se dejan de emitir tras reducir el volumen de fugas en la red en una determinada cantidad?, ¿qué ventajas energéticas obtengo con la puesta en práctica de estrategias concretas orientadas a reducir la demanda?

El trabajo desarrollado en esta tesis se ha intentado plantear desde el pragmatismo y alejada de criterios parciales de quienes al respecto pudieran tener algún conflicto de interés (por ejemplo los fabricantes de tuberías tienen una óptica muy diferente a los comercializadores de dispositivos de detección de fugas). Por el interés práctico del trabajo abordado, sus resultados se difundirán tanto cuanto sea posible. 


\subsection{Justificación. Oportunidad de la tesis}

A lo largo del siglo XX, se ha desarrollado en España una política hidráulica cuyo objetivo principal ha sido aumentar las disponibilidades y la capacidad de regulación de los recursos hídricos. Si bien dicho siglo se caracteriza por la ejecución de las grandes infraestructuras, el énfasis en el siglo XXI se pondrá en la renovación y la adecuada gestión de las mismas. Aunque esta idea es aplicable a todas las etapas del ciclo del agua, adquiere una importancia superlativa en la etapa de distribución por los posibles problemas sanitarios asociados.

Debido a la abundancia de los recursos en el pasado, a la otrora "juventud" de la infraestructura y a la falta de sensibilidad ambiental, el problema de la renovación se ha venido ignorando en los más de los abastecimientos españoles. Sin embargo, es evidente que el escenario actual ha cambiado porque muchas redes de distribución necesitan urgentemente la renovación de ciertos tubos, en algún caso centenarios, para proseguir con su funcionamiento de manera aceptable. Y no es sólo eso, la recuperación de costes que en 2010 hará obligatoria la Directiva Marco del Agua (EU, 2000), repercutirá directamente en las tarifas de los usuarios las malas inversiones. Por ello no solamente se ha de invertir en renovación, sino que cada vez más, se exige que se haga de manera más eficiente y certera.

A día de hoy, el gasto a realizar en la renovación y rehabilitación de tuberías representa un porcentaje significativo de las inversiones totales que requieren los abastecimientos de agua a las poblaciones. De acuerdo con la Environmental Protection Agency (EPA) en los Estados Unidos tal porcentaje representa dos terceras partes de la inversión total requerida (EPA, 2003), mientras que en otros países y dependiendo de la atención que previamente se le haya prestado al asunto, ese porcentaje es algo menor. En Holanda (Vewin, 2007), las inversiones en renovación y rehabilitación representan un $46 \%$ de la inversión total. En cualquier caso, los costes de renovación son significativos.

Situado el asunto en su actual contexto, se exponen las principales razones que aconsejan renovar las tuberías. Son:

- El envejecimiento de las más de las infraestructuras urbanas. Numerosas tuberías llevan instaladas mucho tiempo, con lo que presentan un elevado número de roturas y el consiguiente riesgo de intrusión patógena, insuficiencia de servicio, etc. 
- El aumento de la demanda. La demanda de agua crece paulatinamente, y ese aumento es cada vez mayor. Sin duda, el elevado consumo de agua en la actualidad supone un riesgo de sobreexplotación de recursos hídricos $y$, si no se controla, puede conducir a su agotamiento con consecuencias irreversibles. Por tanto, desarrollar políticas que potencien la eficiencia hídrica se torna imprescindible. La fuente del recurso es limitada, y aumentar la oferta es casi imposible. Frente a este aumento, se aboga en primer lugar por políticas de gestión de la demanda, que buscan la reducción del consumo por parte del usuario, y posteriormente por disminuir las pérdidas en todas las etapas del ciclo del agua previas al uso final del agua. Entre ellas, aquella en que este trabajo se centra, la distribución de agua potable. La reducción de las fugas en las redes contribuye no sólo a satisfacer adecuadamente la demanda, sino que evita muchos problemas de gestión del sistema, calidad, sobrepresión, etc.

- El coste del agua. Debido a la escasez del recurso y a su capital importancia, el agua viene progresivamente mostrando una subida de precio, tendencia que no sólo se mantendrá sino que será más acusada en un futuro inmediato. No en vano, según la Directiva Marco del Agua, se debe garantizar la recuperación íntegra de costes para el año 2010, y dicho precio debe reflejar todos los costes, incluidos los ambientales. El objetivo principal de esta directiva es implantar los principios de "quien usa paga" y "quien contamina paga".

- El coste de la energía. Tradicionalmente se ha considerado el agua como un recurso productor de energía. Sin embargo, la energía hidroeléctrica ha alcanzado su techo a día de hoy en los países desarrollados. Las grandes instalaciones están ya realizadas, y donde ello no es así, no escaseando las experiencias negativas en la materia, se es más sensible que hace unas décadas a las alteraciones medioambientales. En contraposición a la faceta del agua como generadora de energía, se estudia la relación inversa, es decir, la energía que se necesita tanto para mover el agua como para devolverle la calidad que tenía. El consumo de estas etapas no es una cuestión menor, tan es así que el 19\% de la energía consumida en California (CEC, 2005) se emplea en relación con el agua. La energía también es un recurso indispensable y limitado, que varía su precio con tendencia alcista y cuyo precio influye en decisiones como la renovación de las tuberías, implantación de políticas de reducción de la demanda, la reducción de la presión, etc. La última crisis energética, por mor del cambio climático, está teniendo un impacto social muy superior al de otras 
precedentes, y sitúa en primera página de las agendas política y científica al binomio agua y energía.

- Las emisiones. El binomio agua-energía interacciona con el cambio climático. De una parte, porque el gasto energético aumenta la emisión de gases de efecto invernadero (GEI) y de otra, porque de acuerdo con los pronósticos del Panel Intergubernamental para el estudio del Cambio Climático (IPCC) en muchas áreas geográficas de España, en especial la mediterránea, disminuirán las disponibilidades de recursos hídricos acentuándose el estrés que hoy ya sufren. Las cada vez más frecuentes sequías y el reto del cambio climático exigen mayores niveles de eficiencia en el uso de estos dos recursos, sobre todo porque su interdependencia amplifica el problema. El calentamiento global, la mayor evidencia del cambio climático, disminuye la disponibilidad de agua en las áreas de mayor estrés hídrico que además casi siempre coinciden con las de mayor demanda. Ello obliga a recurrir a fuentes alternativas energéticamente más consuntivas y a captar el agua subterránea desde profundidades mayores. Pero no acaba ahí la interdependencia. De una parte, menos agua supone menos producción de energía hidroeléctrica y de otra, más temperatura aumenta el consumo energético doméstico requerido por la climatización de las viviendas. Todo lleva a un mayor gasto de energía no renovable, favorece el cambio climático y alimenta, en fin, un ciclo vicioso de difícil control.

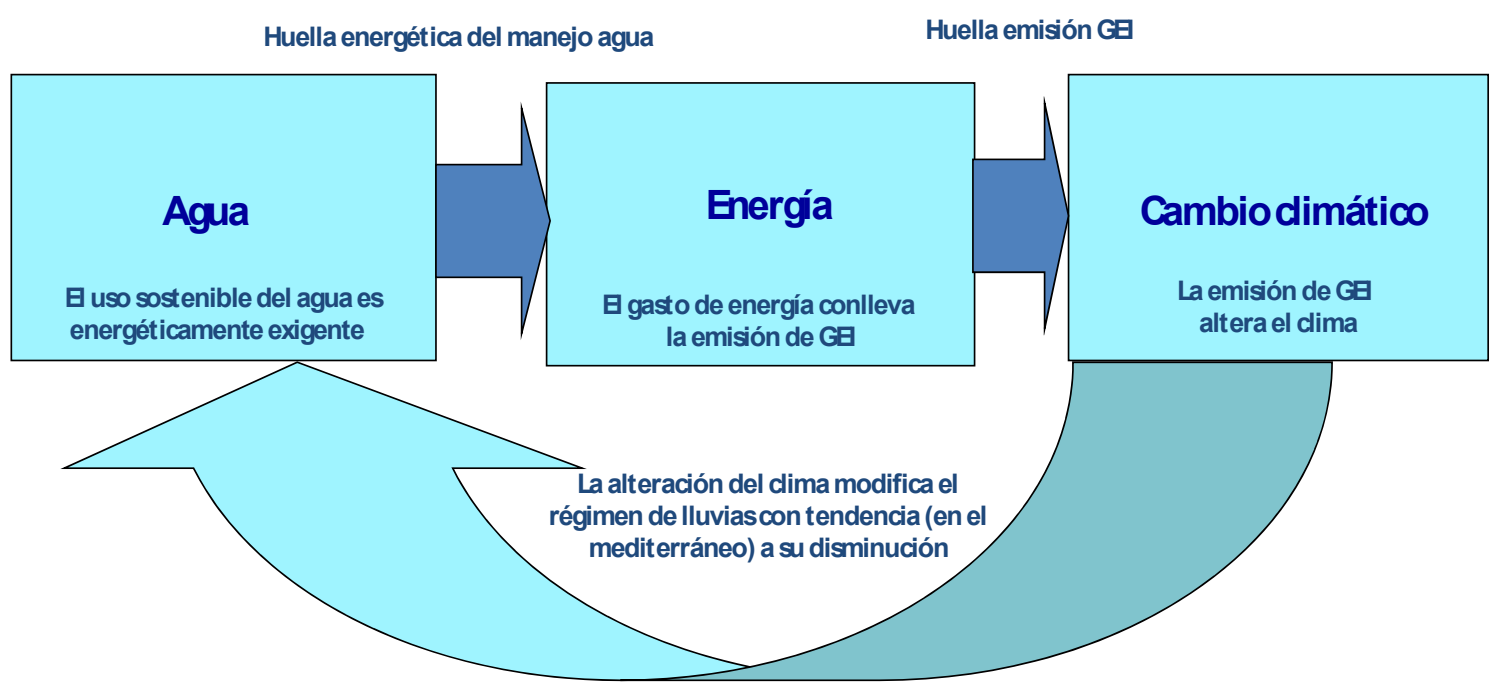

FIGURA 1. EL BUCLE AGUA - ENERGÍA - CAMBIO CLIMÁTICO 
Así pues el problema que se plantea, la racionalización conjunta del agua y de la energía y por ende, la renovación de las infraestructuras, está directamente relacionado con el cambio climático. La mayoría de los modelos desarrollados en el marco del trabajo del IPCC prevén para el área mediterránea una reducción de los recursos hídricos de hasta el 30\% (Milly y col., 2008) por lo que no es prudente aplazar en esta área geográfica la implantación de políticas de ahorro que mejoren la garantía de suministro. Máxime cuando la política del agua también debe poner todo cuanto esté de su parte para mitigar los efectos adversos del cambio climático. No en vano el ahorro de agua conlleva ahorro de energía y, en definitiva, minimiza la emisión de GEI.

Las emisiones de GEI se consideran como un coste ambiental más a la hora de tomar la decisión de renovación. Su inclusión como término influyente en la renovación es una muestra más de la preocupación creciente por los problemas medioambientales tanto de administración y compañías de distribución como del usuario final.

- El coste de renovación de la infraestructura. El montante económico necesario para mejorar el estado de las redes de distribución exige que los gestores conozcan los detalles pormenorizados de las posibilidades de renovación, de las características de las mismas, de los costes y de los ahorros hídricos y energéticos asociados.

No parece posible abordar un problema de renovación sin dedicar la máxima atención a los términos anteriores. Por ello, el desarrollo de los mismos, constituye el objetivo fundamental del trabajo que aquí se presenta. Se plantea la influencia de factores como los sociales, ambientales y económicos en la política de gestión de las fugas en abastecimientos a corto (reparación o rehabilitación) y a largo plazo (renovación). Asimismo, gracias a una metodología que posibilita la realización de una auditoría energética en redes de agua, también se incluye de manera expresa, y por primera vez, la influencia energética y medioambiental. 


\subsection{Inversiones necesarias en renovación de la red}

Tal y como se ha adelantado, la renovación de la red de abastecimiento representa la mayor parte de la inversión a realizar en las infraestructuras hídricas urbanas y, según aumenta la preocupación medioambiental, lo hace en consonancia la urgencia para acometer dichas inversiones. En los siguientes apartados se cuantifican las necesidades de inversión en renovación y rehabilitación de tuberías tanto a escala local, la ciudad de Valencia, como estatal y Europea. Por ser un país de referencia mundial, el estudio se extiende a los Estados Unidos (EPA, 2009). Asimismo, se muestran los valores numéricos de los indicadores típicos, unidades monetarias invertidas por habitante y por unidad de longitud.

\subsubsection{El caso de Estados Unidos}

Las necesidades económicas que deben afrontar los abastecimientos de Estados Unidos han sido objeto de periódicos informes de la Environmental Protection Agency (EPA). Los dos primeros, (EPA, 1995 y 1999) revelaron unas necesidades de 200.4 y 198.2 billones de dólares ${ }^{1}$, mientras que los dos siguientes (EPA, 2003 y 2009) diferían con respecto a los anteriores.

- En el informe del año 2003, se estimó que el gasto que debe realizarse en todos los abastecimientos alcanzará la cifra de 331.4 billones de dólares, 245.5 billones de euros ${ }^{2}$ en los próximos 20 años. De esa enorme cantidad de dinero, dos terceras partes se dedicarán a rehabilitación de los elementos que integran la infraestructura como, tuberías, hidrantes, válvulas, contadores, etc. Estas cifras supondrían la inversión de algo más de 11 billones de dólares anuales durante los próximos 20 años en rehabilitar las 53000 redes de abastecimiento urbano que proporcionan servicio a 260 millones de habitantes.

- El informe más actual, publicado en el año 2009 y con datos del año 2007, estimó el gasto total en 334.8 billones de dólares, y la parte correspondiente a renovación de tuberías es 200.8 billones de dólares (60\% de las necesidades económicas totales), desde Enero del 2007 hasta Diciembre del año 2026. Otras inversiones significativas serán las que se deberán realizar en el tratamiento del agua, 75.1 billones de dólares (22\%), o en depósitos de almacenamiento 36.9 billones de dólares (11\%).

\footnotetext{
${ }^{1}$ Todos los valores de los EE.UU. están expresados en billones anglosajones. Estos dos valores son en dólares del año 2007.

${ }^{2}$ Para la paridad $1 €=1.35$ USA \$.
} 
La Oficina de Presupuesto del Congreso en Estados Unidos, Congressional Budget Office (CBO, 2002), estimó que las necesidades económicas de la industria del agua en Estados Unidos varían entre 14.6 y 25.2 billones de dólares anuales, lo cual supondría en los próximos años unas necesidades de 292-504 billones de dólares ${ }^{3}$.

Otro estudio valoró el montante económico en los próximos 20 años en el rango de los 204-590 billones de dólares, siendo la estimación más probable de 363 billones de dólares ${ }^{4}$ (EPA, 2002). Por otra parte, la Water Infrastructure Network (WIN, 2000), estimó las necesidades en 25 billones de dólares anuales, es decir, unos 503 billones de dólares en los próximos 20 años.

En el último informe de la American Society of Civil Engineers (ASCE, 2009), las necesidades anuales en las redes de abastecimiento se estiman en 11 billones anuales de dólares, es decir unos 220 billones en 20 años. También hace hincapié en las fugas estimadas en 7 billones de galones diarios, $26.5 \mathrm{hm} /$ día. Finalmente la American Water Works Association (AWWA, 2004) cuantificó las necesidades económicas de los abastecimientos en 250 billones de dólares en los próximos 30 años. Para ajustar a la misma escala temporal, se consideró la inversión anual constante y por tanto, en los próximos 20 años, se necesitarán 166 billones de dólares.

Todos los trabajos citados muestran los mismos órdenes de magnitud de la inversión. Su notable número manifiesta el grado de actualidad que dichos estudios, Figura 2.

${ }^{3}$ Los resultados, inicialmente $\$$ del año 2001, fueron convertidos a \$ del año 2007 para su comparación.

${ }^{4}$ Datos convertidos a \$ del año 2007. 


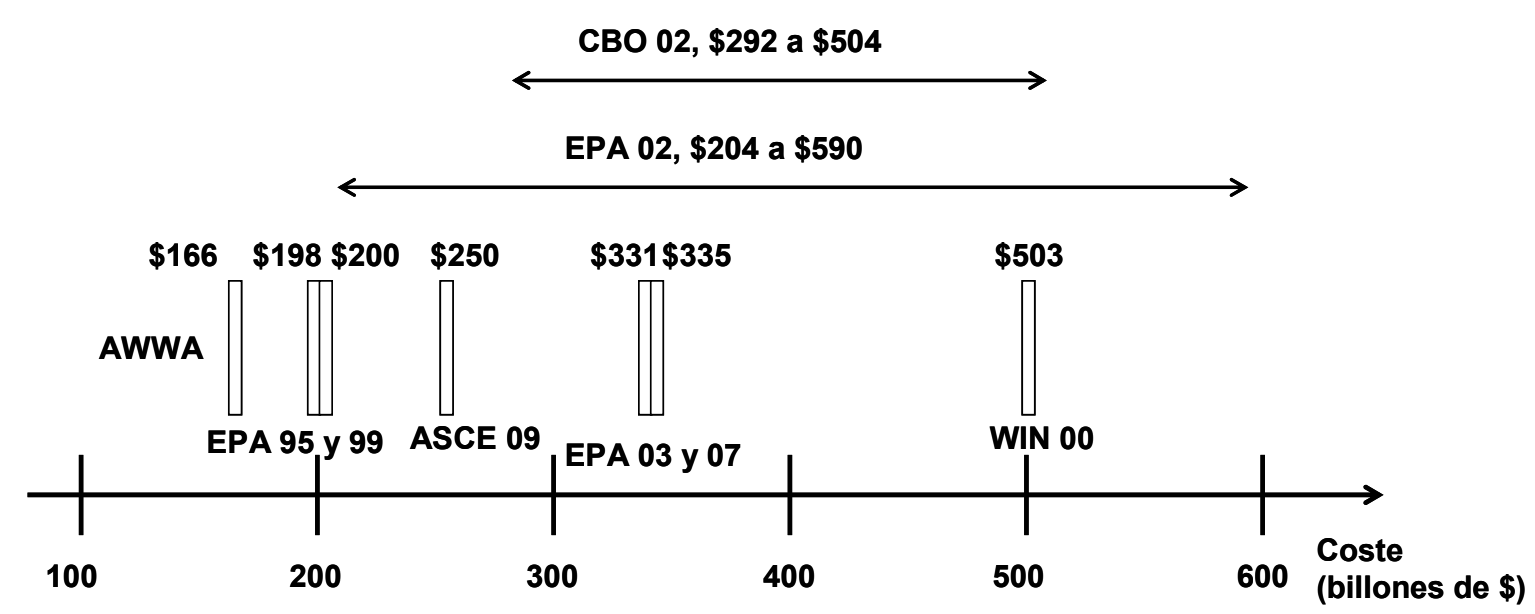

FIGURA 2. COMPARACIÓN DE LAS INVERSIONES A REALIZAR EN LOS PRÓXIMOS 20 AÑOS (EPA, 2009).

\subsubsection{La situación en Europa}

En el ámbito europeo, Portugal y Reino Unido han instaurado recientemente sendos organismos reguladores, entidades que se ocupan principalmente del estudio de las características propias de cada red y de establecer indicadores tanto para hacer un seguimiento de la gestión y operación de los sistemas, como para fomentar las buenas prácticas. Otros países, es el caso de Italia, disponen de reguladores con competencias centradas en los ATO (Ambito Territoriale Ottimale). Gracias a estos organismos, se dispone de un mayor número de datos que facilitan los estudios de las infraestructuras. Sin duda, el ejemplo de estos países es un referente a nivel europeo, ya que los organismos reguladores exigen una inversión mínima determinada, fijan las tarifas y velan por el correcto mantenimiento de las redes de distribución de agua urbanas. En otros países, como Holanda y Alemania, en los que los servicios son gestionados por empresas públicas, son los mismos abastecimientos los que han establecido unos mecanismos para su propia regulación.

El Reino Unido, es un caso que merece una explicación adicional. Como estado unitario integrado por cuatro países constituyentes, Inglaterra, Escocia, Gales e Irlanda del Norte, tiene tres organismos reguladores: la Office of Water Services (OFWAT) en Inglaterra y Gales, la Water Industry Comission for Scotland (WICS) en Escocia y la Northern Ireland Authority for Utility Regulation (NIAUR) en Irlanda del Norte. 
El OFWAT fijó en el 2004 los precios del agua para el periodo 2005-10 y dispuso para ello de información relativa a los costes de operación y de mantenimiento de las redes de abastecimiento y saneamiento. Cuantificó las inversiones de las empresas gestoras de las redes de abastecimiento y saneamiento en el año 20072008 en 3400 millones de libras $^{5}$, aproximadamente 3740 M€ (OFWAT, 2008). La estimación realizada en el año 2003 de las inversiones en renovación de todas las empresas de abastecimiento (transcripción literal de Infrastructure Renewals Expenditure, IRE) y del dinero que la empresa factura por efecto de las renovaciones (Infrastructure Renewals Charge, IRC) durante el periodo 2003-2008 los resume la Tabla 1.

TABLA 1. ESTIMACIÓN DE LAS INVERSIONES Y RETORNOS DE LA RENOVACIÓN EN REDES DE AGUA EN INGLATERRA Y GALES DEL AÑO 2003 AL 2008 (OFWAT, 2008).

\begin{tabular}{ccccccc}
\hline Precios del año 2007-08 & $\begin{array}{c}\mathbf{2 0 0 3 - 0 4} \\
\text { M€ }\end{array}$ & $\begin{array}{c}\mathbf{2 0 0 4 - 0 5} \\
\text { M€ }\end{array}$ & $\begin{array}{c}\text { 2005-06 } \\
\text { M€ }\end{array}$ & $\begin{array}{c}\text { 2006-07 } \\
\text { M€ }\end{array}$ & $\begin{array}{c}\text { 2007-08 } \\
\text { M€ }\end{array}$ & $\begin{array}{c}\text { Variación } \\
\text { en el } \\
\text { último año }\end{array}$ \\
\hline $\begin{array}{c}\text { Inversiones en renovación } \\
\text { de la red (IRE) }\end{array}$ & 376.2 & 375.1 & 405.9 & 562.1 & 613.8 & 9.3 \\
$\begin{array}{c}\text { Dinero facturado por } \\
\text { inversiones en renovación } \\
\text { de la red (IRC) } \\
\text { Diferencia }\end{array}$ & 438.9 & 414.7 & 501.6 & 502.7 & 555.5 & 10.4 \\
\hline
\end{tabular}

La Figura 3 muestra tanto las inversiones realizadas en la red de abastecimiento y la facturación tras esa renovación real en el periodo 2000-2008, como la estimada cuando se fijaron las tarifas en 1999 y 2004.

\footnotetext{
${ }^{5}$ Se convierten en $€$ del año 2008 con el cambio $1 £=1.1 €$. Esta cantidad monetaria cuantifica todas las inversiones de la red, no sólo la asociada a la renovación.
} 


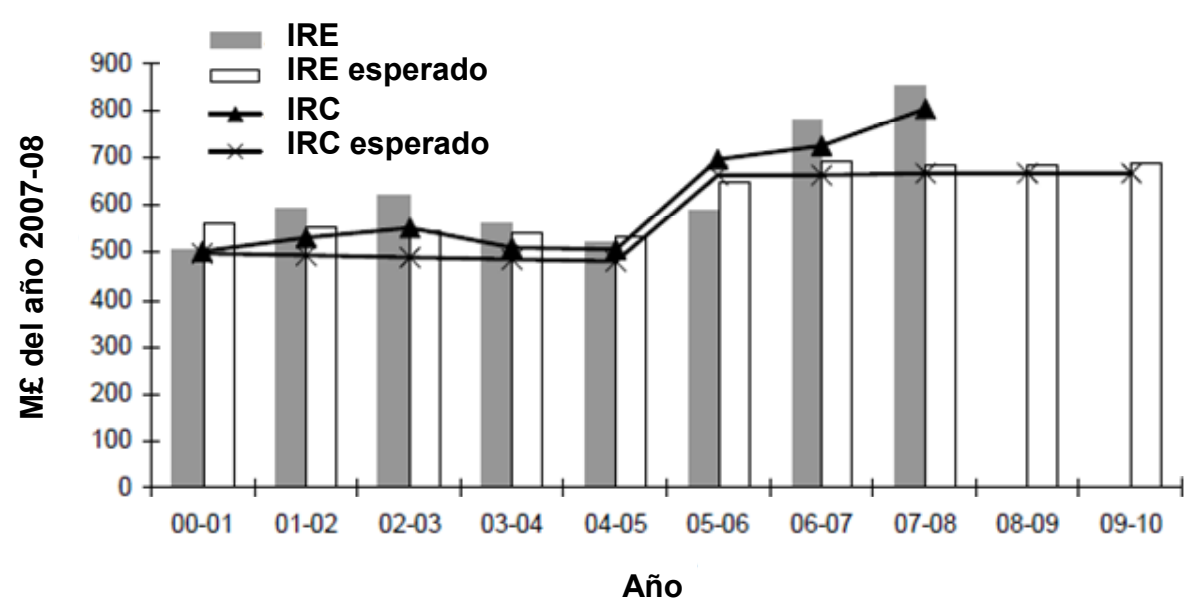

FIGURA 3. COMPARACIÓN ENTRE LAS INVERSIONES Y DINERO FACTURADO REALES Y ESPERADAS (OFWAT, 2008).

Cuando se fijaron las tarifas del agua en el periodo 2005-2010, se admitió que la inversión en la red aumentaría en el futuro, y así se reflejó en el aumento sostenido de la inversión en los tres primeros años de este periodo (Figura 3). La inversión en el año 2007-2008 fue de 856 M£, 64\% superior a las realizadas en el año 2004-2005. Análogamente, el dinero facturado en el año 2007-2008 es un $11 \%$ mayor que en el año anterior.

Tanto las inversiones en las redes del OFWAT como el dinero facturado por las compañías después de la inversión en renovación se espera se mantengan constantes en el futuro. Admitiendo una inversión media real (datos de la Figura 3) obtenida con los valores de estos últimos 5 años de 688.32 M€/año, y suponiéndola constante en los próximos 20 años (hipótesis conservadora según el OFWAT), se puede concluir que la inversión total en ese periodo de tiempo será de 13750 M€.

En Escocia, desde que en 2002 se creó la compañía Scottish Water, única que opera en territorio escocés, se han reducido los costes de operación hasta un $40 \%$ con respecto a los del 2002 y esto se traduce en un ahorros acumulado superior a los 800 M£ (WICS, 2008a). En el año 2007-2008, los costes de operación fueron $180 \mathrm{M} \pm$ inferiores a los del año 2001-2002 (Figura 4). 


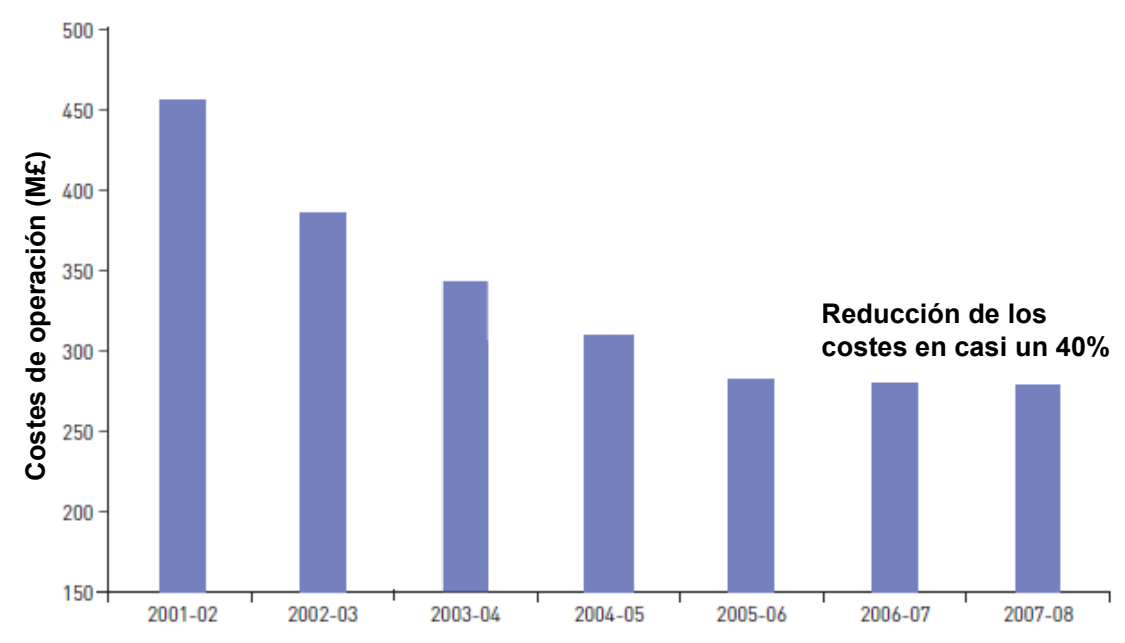

FIGURA 4. HISTÓRICO DE GASTOS DE OPERACIÓN EN ESCOCIA (WICS, 2008A).

Las inversiones a realizar en las redes de Escocia se refieren a nuevas infraestructuras o la remodelación de las ya existentes. Con la creación del organismo regulador, se ha trazado un plan de regulación con una fuerte inversión inicial (2450 M£) durante el periodo 2006-2010, con una inversión anual de 400-600M£/año (WICS, 2008b). La Scostish Water realizó las inversiones con mayor lentitud de la planeada (de hecho se invirtieron $127 \mathrm{M} \pm$ menos de los previstos en el año 2005, cuando se fijaron las tarifas). La inversión se incrementó en el año 2007-2008, Figura 5, y este aumento deberá de mantenerse en los próximos dos años.

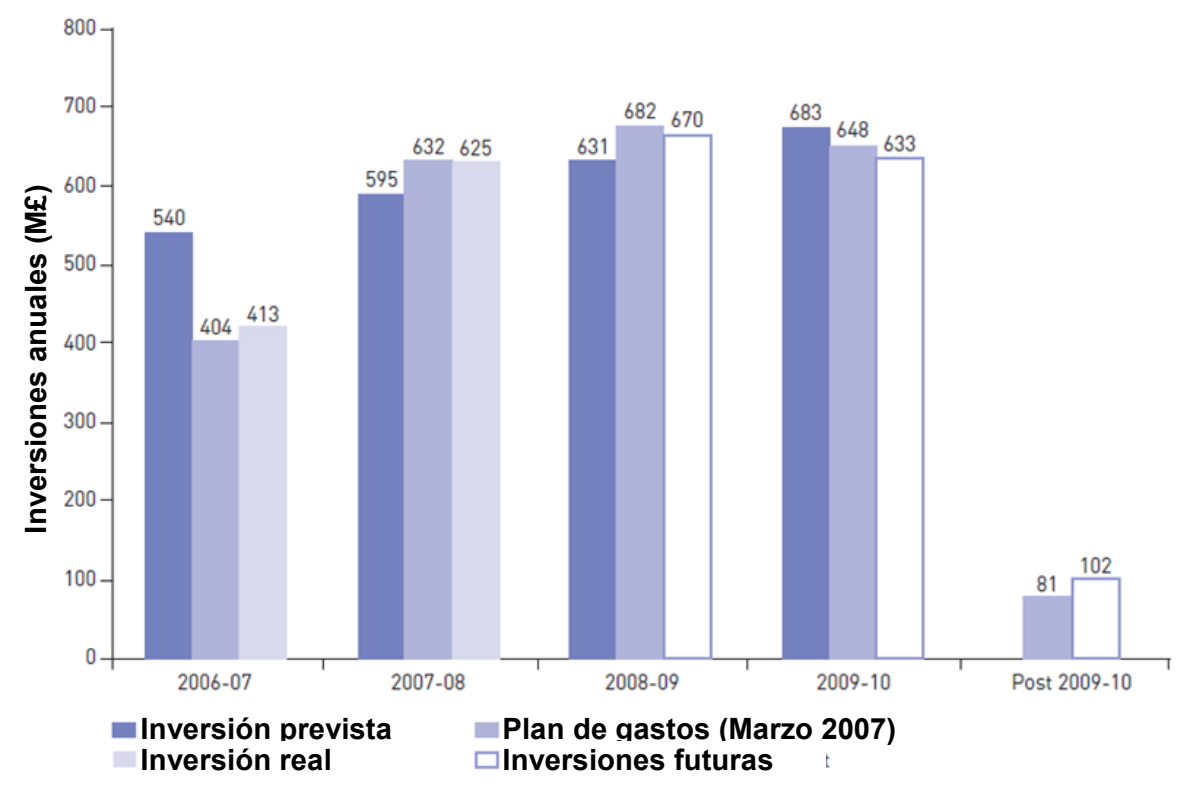

FIGURA 5. INVERSIONES PREVISTAS, REALIZADAS Y FUTURAS EN LAS REDES ESCOCESAS (WICS, 2008B). 
Una vez finalice el programa de inversión actual, en el año 2009-2010, la compañía gastará $102 \mathrm{M} £$ adicionales. Algunos de los resultados esperados (operacionales, reducción de fugas, económicos, etc.) se retrasarán hasta el final del periodo de inversión en Marzo del año 2010.

Los objetivos de la Scottish Water a partir del año 2010 en las redes escocesas no están todavía definidos. En el periodo 2010-2014 se centrarán en observar la influencia de las inversiones y en asegurar que las siguientes se realicen desde la sostenibilidad y la eficiencia. El informe concluye sugiriendo una inversión media a largo plazo que rondará los 400-450 M£ (440-495M€), si bien esta inversión se refiere a toda la red de abastecimiento y no únicamente a la renovación de las tuberías.

Por otra parte, la inversión en todo el Reino Unido durante el año 2006-2007 en planes de mejora de la calidad del suministro, que incluían la renovación en las fuentes origen del abastecimiento, fue de 830 M€ (Water UK, 2008) y entre el año 2002 y el 2007, esta inversión en Inglaterra y Gales fue de 3300 M€. Estas inversiones también se han traducido en mayores gastos de las compañías suministradoras en distribución. A partir de estos datos, el montante económico invertido en la red de abastecimiento en los próximos 20 años supondrá unos 13200 M€ para Inglaterra y Gales (si se estima la inversión anual del 2008 como promedio) y de $16600 \mathrm{M} €$ en el Reino Unido (con la inversión media de los últimos cinco años como constante).

En Portugal, la mayoría de las infraestructuras urbanas dedicadas al agua muestran una elevada tasa de roturas y requieren una notable inversión en renovación. Entre los años 2000 y 2006 se aprobó el plan PEAASAR I con el que se han invertido $900 \mathrm{M} €$ en las redes de abastecimiento y saneamiento. El plan PEAASAR II 20072013 estimó la inversión para ese periodo de tiempo en 2200 M€. Por lo que, finalmente, las inversiones realizadas desde el 2000 hasta el 2013 serán de 3100 M€ (en euros del 2005). Estas inversiones están relacionadas con la ampliación de la infraestructura, rehabilitación de las redes existentes y construcción de los colectores que contribuyan a aumentar la capacidad hidráulica del sistema. Las fuertes inversiones que se están realizando se corresponden con una fase de gran expansión y rehabilitación. Sin embargo, a partir del año 2013, las inversiones serán menores, y únicamente estarán relacionadas con mantenimiento y gestión eficiente de redes de distribución, no con la renovación. 
Los ratios de renovación existentes en Portugal registraron un valor medio del 3\% anual (RASARP, 2004), con valores extremos comprendidos en la horquilla 0-18\%. El intervalo de referencia se marca entre el 1-2\% anual, por lo que las compañías distribuidoras deben disponer de programas de gestión en los que la vida media de la red se encuentre entre los 50 y los 100 años.

Al igual que en Escocia, realizar una estimación de la inversión en los próximos 20 años es sumamente complejo. Por una parte, los datos están referidos a todas las inversiones en redes de abastecimiento, y por otra, a partir del año 2013, las inversiones únicamente serán en renovación de la infraestructura, precisamente el objetivo de este trabajo. Sin embargo, no se muestra una estimación de las inversiones cuando finalice el Plan PEAASAR II, lo cual imposibilita la estimación de la inversión en los próximos 20 años, pese a la extensa información disponible en el tema.

Otra situación se vive en Alemania. Las continuas inversiones en la renovación de la infraestructura son un factor decisivo para disponer de un servicio de calidad en el largo plazo. Según un informe realizado por las principales compañías que prestan este servicio dicho país (BGW, 2008), el sector de la gestión de agua potable y saneamiento invirtió más de 100 billones $^{6}$ de euros desde la reunificación alemana.

\section{Evolución de las inversiones desde 1990 hasta 2006} en el sector del agua.

\section{En billones de Euros}

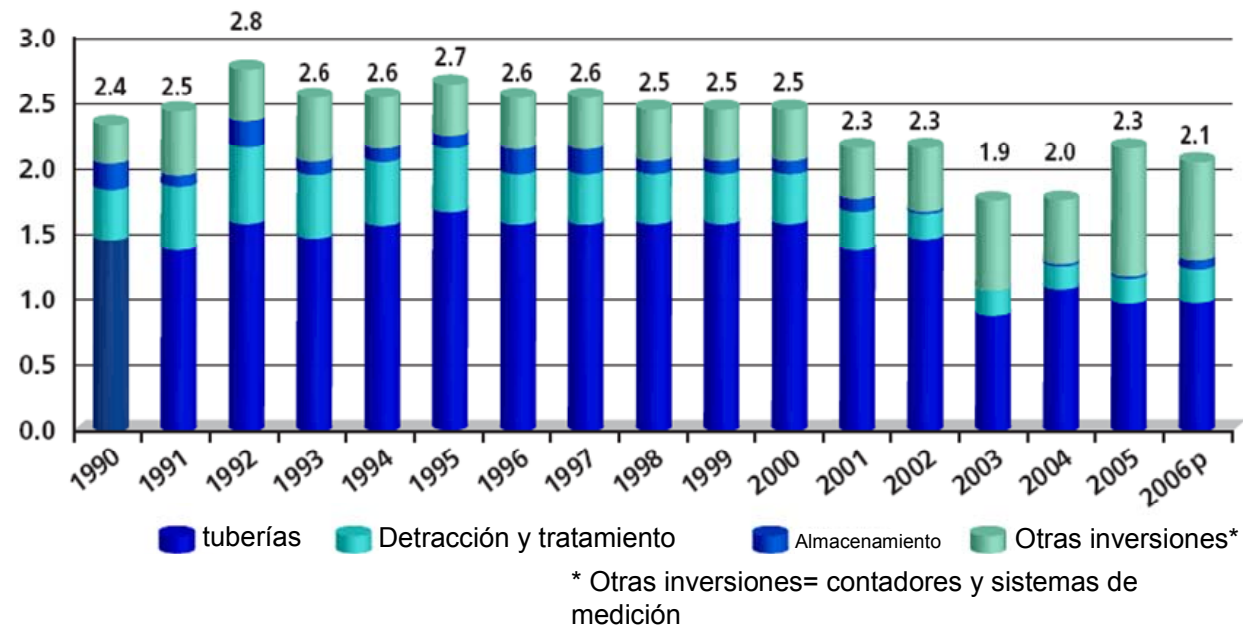

Figura 6. HISTÓRICO DE INVERSIONES EN REDES DE ABASTECIMIENTO EN ALEMANIA (BGW, 2008)

\footnotetext{
${ }^{6}$ Las inversiones están expresadas en billones anglosajones.
} 
En 2005 se invirtieron 2300 M€ en los abastecimientos urbanos. De éstos, $1000 \mathrm{M} €$ se han dedicado a renovar tuberías (Figura 6). Desde 1995 hasta el 2003, se invirtieron en la red $0.54 €$ por $\mathrm{m}^{3}$ consumido. Otros países como Inglaterra y Gales invirtieron en ese periodo de tiempo $0.53 € / \mathrm{m}^{3}$, mientras que en Francia o Italia la inversión fue de 0.33 y $0.15 € / \mathrm{m}^{3}$ respectivamente (BGW, 2008).

La inversión en las redes de saneamiento en Alemania en el año 2005 fue incluso mayor que la de abastecimiento, se gastaron 5.5 billones de euros (Figura 7). La inversión en redes de saneamiento desde 1995 hasta 2003 fue de $1.27 € / \mathrm{m}^{3}$ consumido, mientras que ese indicador muestra valores ligeramente inferiores en otros países como Inglaterra y Gales, Francia e Italia $\left(0.91,0.72\right.$ y $0.11 € / \mathrm{m}^{3}$ respectivamente). La diferencia estriba en que en Alemania todos los costes están incluidos en la tarifa del abonado satisfaciendo de este modo el principio de recuperación de costes, mientras que en otros países, por lo general las obras son financiadas, parcial o totalmente, por otras instituciones (generalmente canalizando fondos estructurales procedentes de Bruselas).

Evolución de las inversiones desde 1990 hasta 2006

en las redes de saneamiento

En billones de Euros

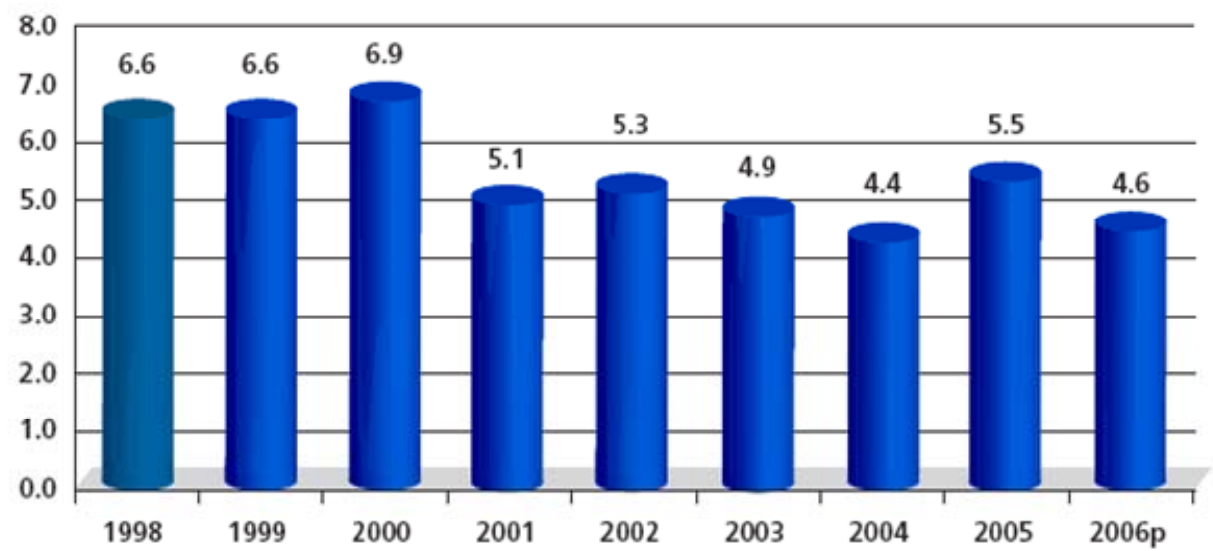

Fuente: BGW(2008). p=provisional

FIGURA 7. HISTÓRICO DE INVERSIONES EN REDES DE SANEAMIENTO DE ALEMANIA (BGW, 2008).

En síntesis, en Alemania, la inversión realizada en renovación de tuberías ha venido representando el $61 \%$ del total, mientras que el $18 \%$ se dedicó a plantas depuradoras y un $6 \%$ para depósitos de almacenamiento (BGW, 2008). La inversión media en los últimos 17 años fue de 1420 M€/año, por lo que si se sigue con esa media, en los próximos 20 años destinarán 28400 M€ del año 2009. 
En Francia existen $850000 \mathrm{Km}$ de tuberías en las redes de distribución según la Association des départements de France (ADF, 2002). Un 10\% de éstas tienen más de 50 años y un 44\% más de 30. Las tuberías que fueron instaladas antes de 1970 son mayoritariamente de fundición gris, mientras que para épocas posteriores son fundamentalmente plásticas (PVC, HDPE). La longitud de las canalizaciones es de media 40 m/abonado (Tabla 2).

TABLA 2. INDICADORES bÁSICOS DEL ESTADO DE LAS REDES EN FRANCIA SEGÚN EL TAMAÑO DE LA POBLACIÓN ABASTECIDA (ADF, 2002).

\begin{tabular}{ccc}
\hline $\begin{array}{c}\text { Número de } \\
\text { habitantes }\end{array}$ & $\begin{array}{c}\text { Longitud por } \\
\text { abonado }(\mathbf{m})\end{array}$ & $\begin{array}{c}\text { Rendimiento de la } \\
\text { red (\%) }\end{array}$ \\
\hline$<400$ hab. & 75 & 50 \\
400-1000 hab. & 65 & 62 \\
1 000-2500 hab. & 48 & 70 \\
3 500-10000 hab. & 28 & 71 \\
$>$ 10000 hab. & 20 & 75 \\
Media & 40 & 72 \\
\hline
\end{tabular}

En 2003, la ADF estimó que la renovación de las tuberías de abastecimiento requiere inversiones de $53000 \mathrm{M} €$ desde el año 2004 hasta el 2015 para renovar $535000 \mathrm{~km}$ de tuberías, un 65\% de la red. Esta estimación suponía una inversión de 4400 M€/año u 80 €/persona/año en renovación de tuberías (Tabla 3). Actualmente la tasa de renovación es del $0.6 \%$, un ritmo insuficiente para evitar el envejecimiento total de la red, ya que la red total se renovaría cada 166 años, situación claramente insostenible desde la óptica de la gestión eficiente. Se propone una renovación muy fuerte a corto plazo. El primer paso sería el cambio de las tuberías de fibrocemento y acero, que representan $100000 \mathrm{~km}$ en dos años, y acto seguido proseguir con las tuberías viejas más la que están experimentando una elevada tasa de roturas. Estas acciones, que representarían los $53000 \mathrm{M} €$ apuntados anteriormente, sólo se podrían realizar si se sube el precio medio del agua en $2 € / \mathrm{m}^{3}$.

TABLA 3. INVERSIONES REALIZADAS Y PREVISTAS EN LAS REDES FRANCESAS (ADF, 2002).

\begin{tabular}{ccccc}
\hline Años & $\begin{array}{c}\text { Longitud } \\
\text { renovada }(\mathbf{k m})\end{array}$ & Coste $(\mathbf{M} \boldsymbol{\epsilon})$ & $\begin{array}{c}\text { Coste anual } \\
(\mathbf{M} \in / \mathbf{a n ̃ o})\end{array}$ & $\begin{array}{c}\text { Coste por } \\
\text { habitante }(\boldsymbol{€} / \mathbf{h a b} .)\end{array}$ \\
\hline $2004-2005$ & 100000 & 9.3 & 4.65 & 80 \\
$2005-2010$ & 230000 & 23 & 4.65 & 80 \\
$2010-2015$ & 205000 & 21 & 4.2 & 80 \\
2015 & 9000 & 32 & 1 & 15.5 \\
\hline
\end{tabular}


La inversión en las redes de abastecimiento y saneamiento francesas se estimaron en 5600 M€ de euros del año 2007 (Tiret, 2008). Este valor es algo mayor que el obtenido en el estudio del ADF aunque muestra un mismo orden de magnitud. No en vano, éste se refiere a toda la red de abastecimiento y saneamiento, mientras que el trabajo de la ADF está referido únicamente a renovación de tuberías de distribución.

Las redes de abastecimiento de Holanda, aumentaron su longitud en más de $15000 \mathrm{~km}$ desde el año 1996 hasta el 2006. El principal material instalado en este tiempo fue el PVC, que incrementó su longitud en $14000 \mathrm{Km}$ y llegó hasta los $55000 \mathrm{Km}$ instalados $(48 \%$ del total), mientras que otros materiales como el fibrocemento y la fundición gris decrecieron en $3000 \mathrm{~km}$ aproximadamente. Pese a todo, existen 33500 y $10300 \mathrm{~km}$ de tuberías de fibrocemento y fundición gris respectivamente (29\% y 9\% del total). En el año 2006 se invirtieron 5300 M€ en el mantenimiento de la red (Vewin, 2007). De esa cantidad, 1200 M€ (23.7\%) fueron aportados por las propias compañías, 3500 M€ (65.3\%) provenían de prestamos y $600 \mathrm{M} €$ (el $11 \%$ restante) fueron aportados por otros inversores de capital como ayuntamientos y otro tipo de instituciones.

En Holanda, se aplicó en 1995 el cobro de una tasa por extracción de aguas subterráneas y en el 2000 se hizo extensiva al agua de boca. Éstos impuestos, Wet Belastingen op Milieugrondslag, son un ejemplo de costes medioambientales. En el año 2006, estas tasas ascendieron a $386 \mathrm{M} €$, equivalentes a $0.35 € / \mathrm{m}^{3}$ consumido. La tasa de extracción del agua subterránea representa $212 \mathrm{M} €$ $\left(0.19 € / \mathrm{m}^{3}\right), 169 \mathrm{M} €\left(0.15 € / \mathrm{m}^{3}\right)$ se relacionan con el consumo de agua potable, mientras que los $5 \mathrm{M} €$ restantes $\left(0.01 € / \mathrm{m}^{3}\right)$ son debidos a impuestos locales propios de cada región y provincia. El precio del agua en Holanda durante el año 2006 fue de $1.52 € / \mathrm{m}^{3}\left(1.17 € / \mathrm{m}^{3}\right.$ se destina a la entidad de abastecimiento y los $0.35 € / \mathrm{m}^{3}$ restantes, debido a tasas, se han de emplear nuevamente en la red de abastecimiento).

En la Figura 8 se muestra la evolución temporal de las inversiones de los abastecimientos holandeses (Vewin, 2007). Éstas decrecieron en los últimos 10 años (desde los 396 M€ del año 1996; hasta los 348 M€ del año 2006) y se estima que esta situación se mantenga hasta el año 2020. El descenso está relacionado con el empleo de materiales plásticos más baratos como el PVC. La inversión en renovación en Holanda se ha realizado en los últimos 10 años y en un futuro se centrarán en mejoras de la calidad del agua, por ejemplo en seguridad y en potabilización. La inversión media en la red de abastecimiento fue de $430 \mathrm{M} €$ y de éstos, un $46 \%$ fue empleado en renovación de tuberías, por lo que el montante anual dedicado a renovación de conducciones asciende a $198 \mathrm{M}$. En los 
próximos 20 años se habrá de invertir 3950 M€, obtenido como un promedio de los datos de los últimos 17 años.

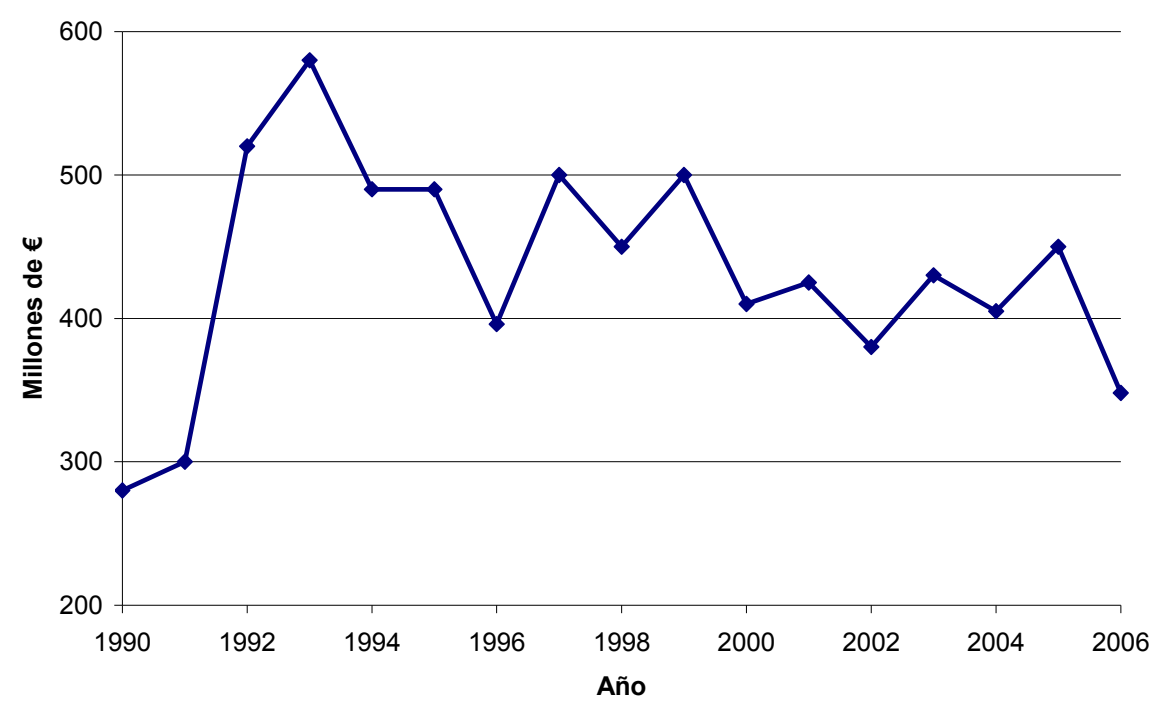

Figura 8. INVERSIONES DE LOS ABASTECIMIENTOS HOLANDESES (VEWIN, 2007).

A modo de conclusión, puede apuntarse que el estado de las redes de abastecimiento en Europa es muy diferente. Algunos países están realizando actualmente fuertes inversiones y en un futuro estas cantidades se reducirán notablemente (Escocia, Holanda y Francia), mientras que otros países (Alemania, Inglaterra y Gales) mantendrán el actual nivel de inversión económica actual en el futuro. Se pretende enfatizar que la importancia de los datos obtenidos no radica en el valor numérico presente sino en la evolución histórica de los mismos, y por tanto el análisis actual presenta una importancia menor.

Todo lo anterior justifica el elevado coste económico de la renovación de las redes de distribución en Europa y la situación desigual de los países analizados. El siguiente apartado se dedica a analizar las necesidades económicas de las redes de distribución españolas, sin duda diferentes a las europeas. 


\subsubsection{La situación Española}

Los datos más significativos acerca de las infraestructuras se encuentran en la X encuesta nacional sobre suministro de agua potable y saneamiento (AEAS, 2006). Dicha encuesta representaba 25.7 millones de personas $(57 \%$ del total) pertenecientes a 1023 municipios. Los resultados, por tanto, estaban sesgados por las anteriores premisas.

La longitud media de la red de distribución en España era de $2.86 \mathrm{~km} / \mathrm{mil}$ hab., si bien en grandes poblaciones este indicador es inferior $(2.11 \mathrm{~km} / \mathrm{mil}$ hab.) y en ciudades pequeñas puede ser hasta el doble $5.08 \mathrm{~km} / \mathrm{mil}$ hab. (como consecuencia de la menor densidad y altura de las edificaciones), Tabla 4.

TABLA 4. LONGITUd DE TUBERÍAS POR HABITANTE EN ESPAÑA (AEAS, 2006).

\begin{tabular}{cccccc}
\hline \multirow{2}{*}{ Tamaño Población } & $\begin{array}{c}\text { De } \mathbf{2 0 0 0 1} \\
\text { a } \mathbf{5 0 0 0 0}\end{array}$ & $\begin{array}{c}\text { De } \mathbf{5 0 0 0 1} \\
\mathbf{a ~} \mathbf{1 0 0 0 0 0}\end{array}$ & $\begin{array}{c}\text { De } \mathbf{1 0 0 0 0 1} \\
\mathbf{a ~ 5 0 0 0 0 0}\end{array}$ & $\begin{array}{c}\text { Mayor de } \\
\mathbf{5 0 0 0 0 1}\end{array}$ & Totales \\
\hline Población (miles) & 1675 & 1833 & 5409 & 11049 & 19966 \\
Municipios & 75 & 62 & 68 & 205 & 410 \\
\hline Km/mil habitantes & 5.08 & 4.33 & 3.20 & 2.11 & 2.86 \\
\hline
\end{tabular}

Las tuberías se agruparon según su edad, y se observó que el $37 \%{ }^{7}$ era menor de 15 años, el 34\% tenía entre 15 y 30 años y que un 30\% Ilevaba instalado más de 30 años. Por tanto, la antigüedad de la red se repartía en igual proporción entre los tres rangos de edad definidos.

En el año 2006 se renovó el 4.32\% de la red, Tabla 5, y el montante económico fue de 93.13 M€, Tabla 6.

TABLA 5. RELACIÓN ENTRE POBLACIÓN Y KILÓMETROS DE TUberíAS PARA ESPAÑa (AEAS, 2006).

\begin{tabular}{cccccc}
\hline Tamaño Población & $\begin{array}{c}\text { De } \mathbf{2 0 0 0 1} \\
\mathbf{a ~ 5 0 0 0 0}\end{array}$ & $\begin{array}{c}\text { De } \mathbf{5 0 0 0 1} \\
\mathbf{a ~ 1 0 0 0 0 0}\end{array}$ & $\begin{array}{c}\text { De } \mathbf{1 0 0 0 0 1} \\
\mathbf{a} \mathbf{5 0 0 0 0 0}\end{array}$ & $\begin{array}{c}\text { Mayor de } \\
\mathbf{5 0 0 0 0 1}\end{array}$ & Totales \\
\hline Km de red renovados & 95 & 90.2 & 933.8 & 145.5 & 1264.5 \\
Km de red distribución & 3869.7 & 3169.4 & 11032.5 & 22289.7 & 29261.3 \\
\% red renovada & 2.45 & 2.85 & 8.46 & 1.30 & $\mathbf{4 . 3 2}$ \\
No habitantes servidos $_{\text {\% habitantes servidos }}$ & 735278 & 904114 & 3452235 & 4533942 & 9625569 \\
\hline
\end{tabular}

${ }^{7}$ La agrupación de las tuberías según su edad se refiere a longitud instalada, no a número de tuberías. 
TABLA 6. INVERSIÓN EN RENOVACIÓN DE REDES DE DISTRIBUCIÓN (AEAS, 2006).

\begin{tabular}{cccccc}
\hline Tamaño Población & $\begin{array}{c}\text { De 20.001 } \\
\text { a 50.000 }\end{array}$ & $\begin{array}{c}\text { De 50.001 } \\
\text { a 100.000 }\end{array}$ & $\begin{array}{c}\text { De 100.001 } \\
\mathbf{a ~ 5 0 0 . 0 0 0}\end{array}$ & $\begin{array}{c}\text { Mayor de } \\
\mathbf{5 0 0 . 0 0 1}\end{array}$ & Totales \\
\hline $\begin{array}{c}\text { Número de } \\
\text { municipios }\end{array}$ & 57 & 25 & 97 & 4 & 217 \\
Población (miles) & 1135 & 1335 & 3624 & 5223 & 11317 \\
$\begin{array}{c}\text { Inversión en redes, } \\
\text { (miles de } € \text { ) }\end{array}$ & 14248 & 10060 & 29006 & 39812 & $\mathbf{9 3 1 2 6}$ \\
\hline
\end{tabular}

Si se extrapolan las inversiones mostradas en la Tabla 6 al total de la población española, la inversión en renovación de conducciones fue en el año 2006 de 163.4 M€ y si se supone esta cantidad como constante en los próximos 20 años, la inversión alcanzará los 3270 M€.

Por otra parte, el Instituto Nacional de Estadística mostró que la inversión en los servicios de suministro fue de 311.2 M€ (INE, 2006), un montante que contemplaba todas las inversiones realizadas en la red, y no únicamente en renovación, para cada comunidad autónoma.

TABLA 7. INVERSIÓN EN RENOVACIÓN DE REDES DE DISTRIBUCIÓN POR COMUNIDAD AUTÓNOMA (INE, 2006).

\begin{tabular}{|c|c|c|c|c|c|c|}
\hline & Andalucía & Aragón & Asturias & Baleares & Canarias & Cantabria \\
\hline \multirow[t]{2}{*}{$\begin{array}{l}\text { Importe total de } \\
\text { la inversión }(\mathrm{M} €)\end{array}$} & $\begin{array}{c}64.7 \\
(20.81 \%)\end{array}$ & $\begin{array}{c}3.3 \\
(1.06 \%)\end{array}$ & $\begin{array}{c}10.6 \\
(3.42 \%)\end{array}$ & $\begin{array}{c}34.2 \\
(10.98 \%)\end{array}$ & $\begin{array}{c}5.2 \\
(1.66 \%)\end{array}$ & $\begin{array}{c}1.1 \\
(0.34 \%)\end{array}$ \\
\hline & $\begin{array}{l}\text { Castilla y } \\
\text { León }\end{array}$ & $\begin{array}{l}\text { Castilla-La } \\
\text { Mancha }\end{array}$ & Cataluña & $\begin{array}{l}\text { Comunidad } \\
\text { Valenciana }\end{array}$ & Extremadura & Galicia \\
\hline \multirow[t]{2}{*}{$\begin{array}{l}\text { Importe total de } \\
\text { la inversión }(M €)\end{array}$} & $\begin{array}{c}22.1 \\
(7.11 \%)\end{array}$ & $\begin{array}{c}5.4 \\
(1.75 \%)\end{array}$ & $\begin{array}{c}61.2 \\
(19.67 \%)\end{array}$ & $\begin{array}{c}28.1 \\
(9.04 \%)\end{array}$ & $\begin{array}{c}4.1 \\
(1.32 \%)\end{array}$ & $\begin{array}{c}5.1 \\
(1.64 \%)\end{array}$ \\
\hline & Madrid & Murcia & Navarra & País Vasco & Rioja (La) & $\begin{array}{l}\text { Ceuta y } \\
\text { Melilla }\end{array}$ \\
\hline $\begin{array}{l}\text { Importe total de } \\
\text { la inversión }(\mathrm{M})\end{array}$ & $\begin{array}{c}40.0 \\
(12.84 \%)\end{array}$ & $\begin{array}{c}6.3 \\
(2.02 \%)\end{array}$ & $\begin{array}{c}13.3 \\
(4.26 \%)\end{array}$ & $\begin{array}{c}3.2 \\
(1.02 \%)\end{array}$ & $\begin{array}{c}3.0 \\
(0.95 \%)\end{array}$ & $\begin{array}{c}0.4 \\
(0.13 \%)\end{array}$ \\
\hline
\end{tabular}

Si se supone una inversión constante durante los próximos 20 años, en las redes de distribución de agua potable se ha de invertir $6224 \mathrm{M€}$. Esta cantidad de dinero es el doble que el mostrado por el trabajo de AEAS. La explicación es clara, la encuesta AEAS se refería exclusivamente a renovación de tuberías, y los datos del INE a todas las inversiones de la red. 


\subsubsection{La situación local en la ciudad de Valencia}

La red de abastecimiento urbano para la ciudad de Valencia consta de dos redes diferentes. La primera, de "alta", se emplea para el abastecimiento humano y tiene una longitud de $1080 \mathrm{Km}$. En cambio la segunda, de "baja", se utiliza en riego de parques y jardines, no cumple los requisitos de calidad para el consumo humano (agua de origen subterránea sin tratamiento) y tiene una longitud de $117 \mathrm{Km}$.

Las longitudes de las tuberías agrupadas según el diámetro para ambas redes se muestran en la Tabla 8. En la misma, se observa que la red de alta tiene un diámetro máximo de $400 \mathrm{~mm}$ mientras que en la de baja, existen tramos de diámetro superior.

\begin{tabular}{|c|c|}
\hline \multicolumn{2}{|l|}{ Red de Alta } \\
\hline Diámetro & Longitud $(\mathrm{Km})$ \\
\hline Menor o igual que 110 mm & 609.3 \\
\hline Mayor que 110 y menor o igual que 250 mm & 380.3 \\
\hline Mayor que 250 y menor o igual que 400 mm & 90.6 \\
\hline Total & 1080.2 \\
\hline \multicolumn{2}{|l|}{ Red de Baja } \\
\hline Diámetro & Longitud (Km) \\
\hline Menor o igual que 110 mm & 35.7 \\
\hline Mayor que 110 y menor o igual que 250mm & 50.3 \\
\hline Mayor que 250 y menor o igual que 400mm & 27.2 \\
\hline $500 \mathrm{~mm}$ & 0.6 \\
\hline $600 \mathrm{~mm}$ & 2.9 \\
\hline $630 \mathrm{~mm}$ & 0.04 \\
\hline $1000 \mathrm{~mm}$ & 0.3 \\
\hline $1200 \mathrm{~mm}$ & 0.03 \\
\hline Total & 117.1 \\
\hline
\end{tabular}


Las estadísticas de la compañía de distribución del año 2008, facilitaron una serie de indicadores que permitían conocer mejor el equipamiento existente en la red.

TABLA 9. INDICADORES DE LOS EQUIPAMIENTOS DE LAS REDES DE VALENCIA.

\begin{tabular}{|c|c|}
\hline Indicadores & Valores \\
\hline Válvulas/Km red & 15.3 \\
\hline Desagües/Km red & 1.2 \\
\hline Ventosas/Km red & 1.3 \\
\hline Acometidas/Km red & 39.5 \\
\hline Número abonados & 427912 \\
\hline Abonados $/ \mathrm{km}$ red & 396.2 \\
\hline Abonados/acometida & 10.0 \\
\hline Volumen facturación ( $\mathrm{Hm}^{3}$ /año) & 47.84 \\
\hline Facturación unitaria (m³/mes) & 9.3 \\
\hline
\end{tabular}

En el informe de la compañía distribuidora también se mostró la evolución temporal del número de roturas en la red de abastecimiento de Valencia (incluye las aducciones desde las plantas potabilizadoras de Picassent y Manises hasta el anillo de distribución, red arterial, de alta y de baja), Figura 9. Sin embargo, el aumento de la longitud de tuberías instaladas es mayor que el del número de roturas, por lo que el indicador de roturas por $\mathrm{Km}$ es decreciente en el tiempo, Figura 10.

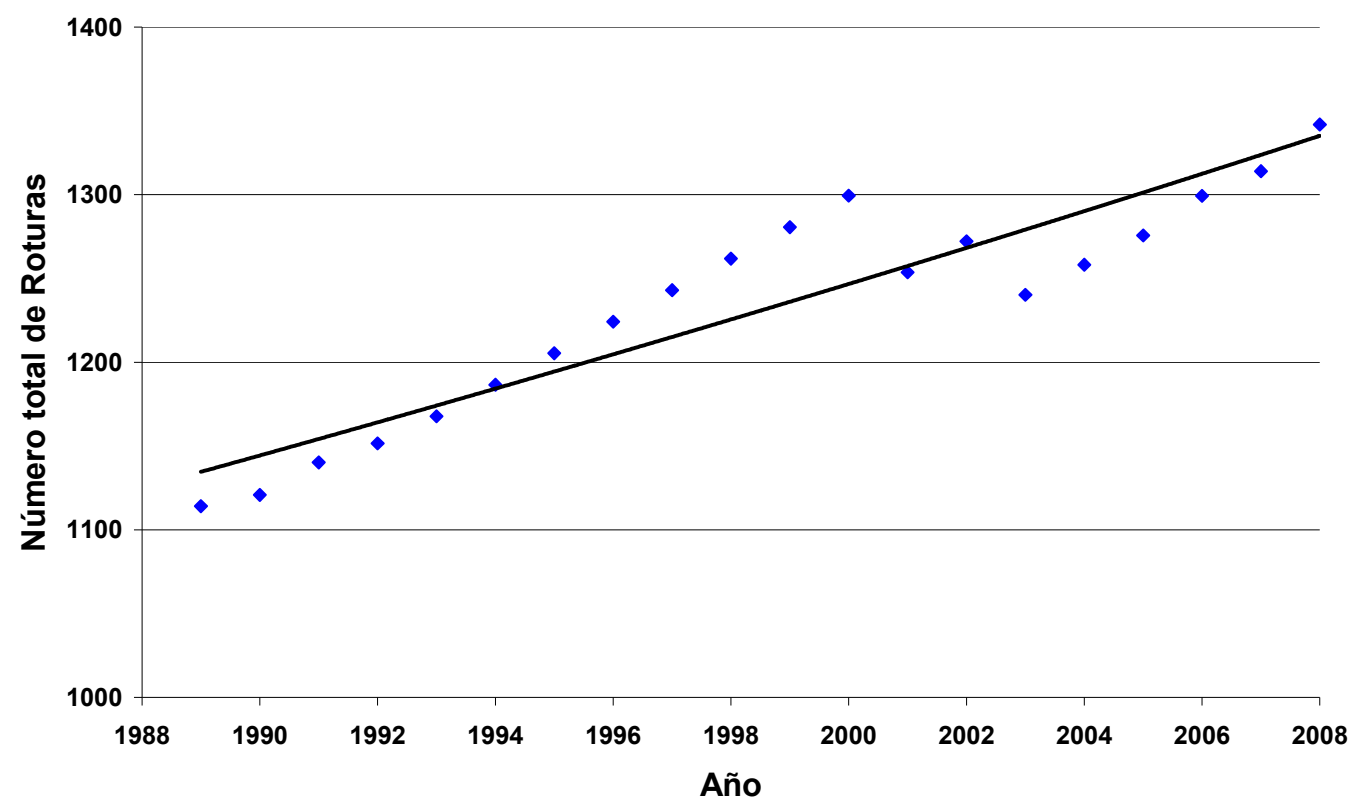




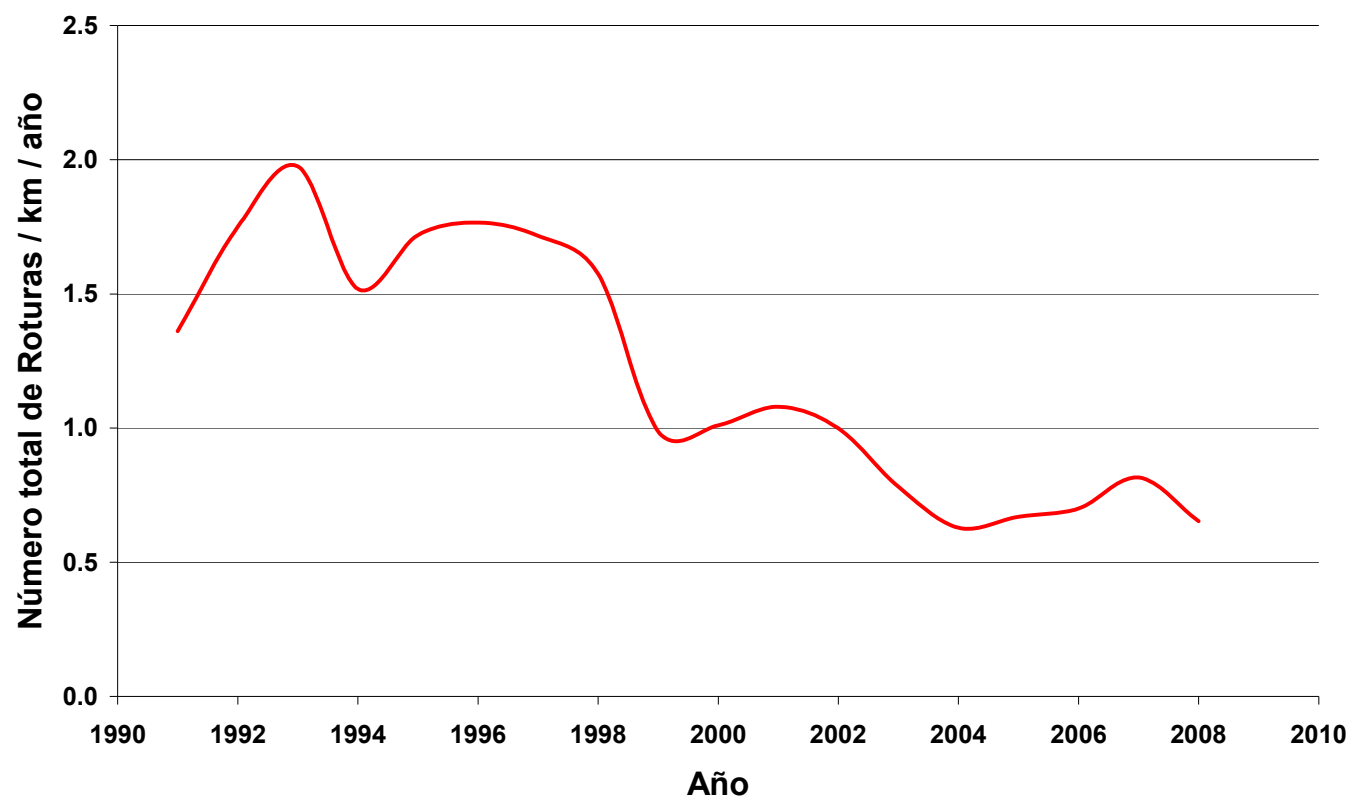

Figura 10. ROTURAS POR KM DE TUBERÍA EN LA RED DE ABASTECIMIENTO DE VALENCIA.

La inversión en renovación y rehabilitación que realizó el ayuntamiento de Valencia durante el año 2008 fue de 10.96 M€ (AICV, 2008). Sin embargo, el cálculo de la inversión a largo plazo se estima como la suma del montante en renovación y en rehabilitación. Para ello, se considera una evolución de las roturas durante los próximos 20 años similar a la existente en la actualidad, Figura 9 , y se asume un valor medio de reparación de la rotura igual al coste de la reparación de una tubería de diámetro $250 \mathrm{~mm}$ (coste de reparación medio de $1179 €\left(\right.$ rotura $\left.^{8}\right)$. Con estas suposiciones, el coste de rehabilitación en los próximos 20 años será de $29.86 \mathrm{M} €$ del año 2009, con una tasa de actualización continua deflactada del $2 \%$. Por otra parte, si se considera, que se renueva el $2 \%$ de la red cada año, y se admite que la evolución de las longitudes de las tuberías sigue la tendencia actual de crecimiento, se obtiene que con un coste medio de renovación de $317.24 € / \mathrm{m}$ (nuevamente el coste de una tubería de diámetro medio $250 \mathrm{~mm}$ ), el montante es de $158.4 \mathrm{M€}$ del año 2009 en los próximos 20 años. En definitiva, sumando los dos valores anteriores, la inversión será de 188.26 M€, si bien las restricciones propias del sistema, fundamentalmente el hecho de que las partidas presupuestarias sean limitadas, conducen a una inversión mayor o menor según la disponibilidad de capital.

\footnotetext{
${ }^{8}$ El coste de reparación medio para una tubería de diámetro $250 \mathrm{~mm}$ y el coste de renovación han sido facilitados por una compañía que trabaja en el abastecimiento de agua potable en una ciudad española.
} 


\subsubsection{Resumen de las inversiones necesarias en la renovación de la red}

Los datos mostrados en los apartados anteriores sirven para establecer un orden de magnitud de la inversión y no pretenden ser un valor absoluto de referencia. Sin duda, el valor numérico carece de importancia y la relevancia del mismo se fundamenta en su evolución temporal. Los datos son heterogéneos: los obtenidos para los EE.UU. se refieren exclusivamente a renovación de las redes de distribución, mientras que en la mayoría de las inversiones restantes se consideran tanto las propias de redes de abastecimiento como las inversiones en toda la red.

Únicamente los datos de la ciudad de Valencia, Holanda y los datos de AEAS (2006) muestran una inversión exclusiva en renovación. Por tanto, los datos pertenecientes a la ciudad de Valencia (mostrados en la Tabla 9 y en la Tabla 10) se han de tratar con sumo cuidado, ya que no son estimaciones exclusivas de renovación de agua potable, y por tanto no se pueden emplear para realizar benchmarking.

El indicador de longitud de tubería por mil habitantes muestra las particularidades de las redes de agua potable. En la ciudad de Valencia, presenta un bajo valor, ya que engloba una zona urbana con mucha densidad de población, y contrasta con valores como los de Francia, con elevadas longitudes de red por habitante, más propias de redes muy ramificadas. El número de habitantes se ha obtenido a partir del censo de cada país o ciudad, y no se corresponde exactamente con el número de habitantes abastecidos por las redes de abastecimiento. Así, los valores reales de la inversión por habitante, Tabla 11, serán ligeramente inferiores a los aquí mostrados.

Por tanto, aunque se haya mostrado un valor para cada país, se ha de comprender el estado actual del mismo. Existen países, quizá los ejemplos más claros son Escocia o Portugal, que en la actualidad disponen de unas notables inversiones y cuyos datos no pueden extrapolarse al futuro dado lo excepcional de esta circunstancia. En cualquier caso, los datos mostrados en la Tabla 10 y la Tabla 11, sí que justifican la relevancia de este estudio y su tremendo impacto a corto plazo. 
TABLA 10. RESUMEN DE LAS INVERSIONES EN RENOVACIÓN DE TUBERÍAS LOS PRÓXIMOS AÑOS.

\begin{tabular}{|c|c|c|c|c|c|}
\hline & $\begin{array}{c}\text { Inversión en } \\
\text { renovación }(\mathrm{M} €) \\
\text { del año }(x)\end{array}$ & Fuente & $\begin{array}{l}\text { Intervalo de } \\
\text { tiempo } \\
\text { (años) }\end{array}$ & Datos adicionales & $\begin{array}{c}\text { Inversiones } \\
\text { (M€ año } \\
2009)^{9}\end{array}$ \\
\hline \multirow{9}{*}{$\begin{array}{l}\text { Estados } \\
\text { Unidos }\end{array}$} & $122900(2007)$ & (AWWA, 2007) & 20 & - & 127900 \\
\hline & $146600(2007)$ & (EPA, 1995) & 20 & - & 152500 \\
\hline & $148200(2007)$ & (EPA, 1999) & 20 & - & 154200 \\
\hline & $185180(2007)$ & (ASCE, 2009) & 20 & - & 192700 \\
\hline & $245200(2007)$ & (EPA, 2003) & 20 & - & 255100 \\
\hline & 248150 (2007) & (EPA, 2009) & 20 & - & 258200 \\
\hline & $\begin{array}{c}216300-373000 \\
(2007)\end{array}$ & (CBO, 2002) & 20 & - & $\begin{array}{c}225000- \\
388100\end{array}$ \\
\hline & $\begin{array}{c}151100-437040 \\
(2007)\end{array}$ & (EPA, 2002) & 20 & - & $\begin{array}{l}157200- \\
454700\end{array}$ \\
\hline & $372600(2007)$ & $(\mathrm{WIN}, 2000)$ & 20 & - & 387700 \\
\hline \multirow{2}{*}{$\begin{array}{l}\text { Inglaterra } \\
\text { y Gales }\end{array}$} & 13750 (2008) & (OFWAT, 2008) & 20 & - & 14031 \\
\hline & 13200 (2008) & (Water UK, 2008) & 20 & $\begin{array}{l}\text { Incluye planes de } \\
\text { calidad }\end{array}$ & 13464 \\
\hline $\begin{array}{l}\text { Reino } \\
\text { Unido }\end{array}$ & 16600 (2008) & (Water UK, 2008) & 20 & $\begin{array}{l}\text { Incluye planes de } \\
\text { calidad del suministro }\end{array}$ & 16930 \\
\hline Alemania & 28400 (2008) & (BGW, 2008) & 20 & - & 28970 \\
\hline Francia & $53000(2002)$ & (ADF, 2002) & 10 & $\begin{array}{c}\text { Considera abastecimiento y } \\
\text { saneamiento }\end{array}$ & 60880 \\
\hline Holanda & $3950(2007)$ & (Vewin, 2007) & 20 & - & 4110 \\
\hline \multirow[b]{2}{*}{ España } & $3270(2006)$ & (AEAS, 2006) & 20 & - & 3470 \\
\hline & $6224(2006)$ & (INE, 2006) & 20 & $\begin{array}{l}\text { Inversión en todos los } \\
\text { servicios de suministro }\end{array}$ & 6605 \\
\hline Valencia & 188 (2009) & $\begin{array}{c}\text { Informes } \\
\text { municipales }\end{array}$ & 20 & & 188.3 \\
\hline
\end{tabular}

\footnotetext{
${ }^{9}$ Se supone una tasa de actualización continua deflactada del $2 \%$.
} 
TABLA 11. INDICADORES BÁSICOS DE LA INVERSIÓN EN RENOVACIÓN POR KM DE TUBERÍA Y POR HABITANTE.

\begin{tabular}{|c|c|c|c|c|c|c|}
\hline & $\begin{array}{c}\text { Inversiones } \\
\text { (M€ año 2009) }\end{array}$ & $\begin{array}{c}\text { Red } \\
\left(10^{3} \mathrm{Km}\right.\end{array}$ & $\begin{array}{l}\text { Habitantes } \\
\qquad\left(\begin{array}{c}\text { (10 } \\
-6\end{array}\right)\end{array}$ & $\begin{array}{c}\text { Km de } \\
\text { tubería por } \\
10^{3} \text { hab. }\end{array}$ & $\begin{array}{l}\text { Inversiones } \\
\text { (€/hab./año) }\end{array}$ & $\begin{array}{c}\text { Inversiones } \\
(€ / \text { km/año) }\end{array}$ \\
\hline \multirow{9}{*}{$\begin{array}{l}\text { Estados } \\
\text { Unidos }\end{array}$} & 127900 & 1390 & 306 & 4.54 & 20.90 & 4601 \\
\hline & 152500 & 1390 & 306 & 4.54 & 24.92 & 5486 \\
\hline & 154200 & 1390 & 306 & 4.54 & 25.20 & 5547 \\
\hline & 192700 & 1390 & 306 & 4.54 & 31.49 & 6932 \\
\hline & 255100 & 1390 & 306 & 4.54 & 41.68 & 9176 \\
\hline & 258200 & 1390 & 306 & 4.54 & 42.19 & 9288 \\
\hline & $225000-388100$ & 1390 & 306 & 4.54 & $36.76-63.42$ & $\begin{array}{l}8094- \\
12162\end{array}$ \\
\hline & $157200-454700$ & 1390 & 306 & 4.54 & $25.69-74.30$ & $\begin{array}{l}5655- \\
16356\end{array}$ \\
\hline & 387700 & 1390 & 306 & 4.54 & 63.35 & 13946 \\
\hline \multirow{2}{*}{$\begin{array}{l}\text { Inglaterra } \\
\text { y Gales }\end{array}$} & 14031 & 335 & 52.57 & 6.38 & 13.35 & 2091 \\
\hline & 13464 & 335 & 52.57 & 6.92 & 11.41 & 1650 \\
\hline $\begin{array}{l}\text { Reino } \\
\text { Unido }\end{array}$ & 16930 & 408 & 59 & 6.92 & 14.35 & 2075 \\
\hline Alemania & 28970 & 500 & 82.60 & 6.05 & 17.54 & 2897 \\
\hline Francia & 60880 & 850 & 65.1 & 13.06 & $93.52^{10}$ & 3581 \\
\hline Holanda & 4110 & 116 & 16.78 & 6.91 & 24.49 & 1772 \\
\hline \multirow{2}{*}{ España } & 3470 & 133 & 46.66 & 2.86 & 7.44 & 1305 \\
\hline & 6605 & 133 & 46.66 & 2.86 & 14.16 & 2483 \\
\hline Valencia & 188 & 1.12 & $1^{11}$ & 1.12 & 18.83 & 8406 \\
\hline
\end{tabular}

${ }^{10}$ Para la obtención de este indicador, se ha de recordar que la inversión mostrada se realizaba en un periodo de 10 años frente al resto de inversiones en 20 años.

${ }^{11}$ La red de Valencia abastece a Valencia ciudad, con 810.000 habitantes, y a otros municipios por lo que se supone una población de 1 millón de habitantes. 


\subsection{Planteamiento del trabajo}

El objetivo de la presente tesis es definir un planteamiento riguroso, desde la óptica ingenieril, para determinar las posibilidades, aplicación, evaluación y resultados de la renovación de tuberías. Es evidente que el escenario actual es muy diferente al que existía en el siglo XX, los recursos son escasos y la gestión de las infraestructuras desde una óptica global y no centrada en la mejora de procesos individuales, se convierte en la principal herramienta que posibilita la utilización racional de los recursos.

Además, el gestor ha de afrontar un problema de actualidad y completamente abierto, y éste es la relación entre agua, energía y cambio climático (Figura 1). La escasez hídrica y energética así como la preocupación medioambiental son claros condicionantes del escenario actual, por lo que su inclusión en los procesos de toma de decisiones se torna imprescindible. Su influencia está sobradamente justificada y es por ello que se incluyen en esta tesis doctoral. La situación actual es también muy cambiante ya que por ejemplo, las directrices medioambientales vigentes (establecidas hace más de 12 años en Kioto) han sido recientemente revisadas en Copenhague con ocasión de la Cumbre del Clima de la ONU. (Diciembre de 2009).

En cualquier caso, se pretende facilitar herramientas que permitan obtener una solución técnica a las cuestiones que habitualmente se plantea el gestor de una red de distribución de agua. Las herramientas definidas para adoptar la decisión de renovación o para auditar energéticamente una red de distribución son sencillas. No en vano, los resultados dependen mucho de la calidad de los datos de entrada. Por tanto, esta sencillez, alejada de complejos refinamientos matemáticos, confiere una mayor aplicabilidad a las herramientas definidas. Todas ellas, se detallan junto a la estructura de la tesis en el apartado siguiente. 


\subsection{Estructura de la tesis}

La tesis se estructura en cuatro partes diferenciadas. La primera comienza con la revisión de los parámetros y particularidades que condicionan el estado de las tuberías existentes en las redes de abastecimiento urbanas. Se analizan los datos recogidos en los abastecimientos de Estados Unidos, en casi toda Europa, en España y en Valencia. Se agrupan las conducciones según el material.

Además de las características de cada uno de los materiales que forman las tuberías, se muestran también las características de las técnicas de instalación sin zanja. Dichas técnicas representan una alternativa más a la hora de plantearse la renovación. Tienen ya una larga historia, si bien comenzaron a tomar fuerza a partir de 1986, cuando se creó la International Society of Trenchless Technology (ISTT). Se ofrece una visión general de estas técnicas y se obtienen los costes de ejecución de cada una. Los costes deben ser entendidos como un primer orden de magnitud y en cualquier caso, frente a una renovación, se ha de consultar los precios con el fabricante, ya que cada proyecto es único y depende de múltiples factores.

Los principales métodos utilizados para adoptar la decisión de renovar, salvo raras excepciones, conjugan tanto criterios heurísticos, como estadísticos y físicos. Asimismo, cada vez es más frecuente el planteamiento de sistemas de soporte a la decisión multicriterio, que utilizan idénticas pautas para todas las tuberías del sistema. Finalmente, se subrayan las aplicaciones de la matemática difusa, que permite al usuario conocer la bondad de las hipótesis de partida a la hora de plantearse la renovación.

En esta primera parte, también se repasan las metodologías empleadas más frecuentemente para realizar auditorías hídricas (IWA, 2000 y Almandoz y col. 2005). La auditoría hídrica en una red de distribución de agua cuantifica los componentes del caudal incontrolado, tanto las pérdidas reales, como las aparentes (que incluyen las relacionadas con los errores de medición del parque de contadores). El gestor del abastecimiento adquiere una idea general del estado de la red, y esto le permite adoptar decisiones de todo tipo, desde renovación de tuberías hasta reducción de la presión en sectores, etc. 
La auditoría hídrica es imprescindible para plantear la auditoría energética. Las únicas premisas para realizar la auditoría energética, aplicar el teorema de arrastre de Reynolds a la propiedad energía, son conocer las entradas y salida hídricas a lo largo de la superficie de control y disponer de su modelo matemático para evaluar el comportamiento de los elementos que lo integran. En otras palabras, es necesario previamente haber resuelto el problema hidráulico. Porque cuando el fluido es incompresible, y el agua lo es, las ecuaciones mecánicas y las térmicas se desacoplan y el problema energético puede resolverse a continuación del mecánico, (White, 1974). La auditoría energética se trata en la tercera parte de la Tesis, y su estrecha relación con la hídrica justifica la presencia de ésta última en el presente trabajo.

La segunda parte, profundiza en las políticas de gestión de fugas a largo plazo desarrollando una revisión de la metodología clásica de obtención del periodo óptimo de renovación de tuberías (Shamir y Howard, 1979), con una visión más global de los parámetros que influyen a la hora de decidir cuando renovar la red. Para ello, se añaden los costes variables del agua (coste del agua en sí y coste de la energía), costes sociales y de oportunidad. En lo cuantitativo, las expresiones propuestas permiten calcular con aceptable precisión la influencia de toda una serie de costes que, aún existiendo, no acostumbran a considerarse. Por tanto, el periodo óptimo de reposición se anticipa, tanto más cuanto mayores sean éstos. De otra parte, los costes asociados a la renovación de la tubería, sociales, al aumentar la inversión, alargan el periodo óptimo de renovación.

Algunos de los nuevos costes considerados merecen especial atención. El coste social evalúa los perjuicios y molestias que una obra genera a la población y al entorno. Es difícil de cuantificar, y no suele repercutir sobre la compañía encargada de la realización de la obra, sino en los ciudadanos afectados. Quizá por esto último suele ser ignorado. El coste de oportunidad representa un coste negativo, un ahorro en la ejecución de la obra que puede ser realizada por otras compañías encargadas de las infraestructuras urbanas (gas, teléfono). Este coste, difícilmente aprovechable, se debe entender como un aviso que permita, a los gestores de la red de abastecimiento, advertir los posibles ahorros. Esta propuesta permite considerar la conveniencia de recurrir a técnicas no convencionales sin apertura de zanja. 
Asimismo, se aborda la renovación desde la óptica económica con un planteamiento que permite considerar estrategias de renovación para distintos periodos de tiempo (25, 50 ó 100 años) e incluso cómo proceder cuando se consideran de modo integrado sucesivas renovaciones de nuestro sistema, siguiendo un planteamiento similar al de Kleiner y col. (2001). En este punto se analiza la influencia en el periodo de renovación de ciertos parámetros (caudal medio del agua fugada por rotura, tasa de crecimiento del número de roturas, presión del sistema, etc.), y se desea obtener cuál de éstos es el más influyente en el periodo óptimo de renovación.

Otros parámetros que influyen en el periodo óptimo de manera significativa son el precio del agua y de la energía. El primero puede incluir los costes medioambientales, en España todavía no considerados, aunque sí en otros países Europeos con una superior sensibilidad ambiental. El segundo ha despertado una creciente preocupación en el campo de la gestión del agua, especialmente desde que se utilizan las desaladoras como origen del agua, ya que el consumo energético es elevado, $3.5 \mathrm{kWh} / \mathrm{m}^{3}$ (NRC, 2008). Todas las etapas anteriores a la de distribución en el ciclo integral del agua son consumidoras de energía, lo cual reafirma la inclusión del precio de la energía como factor de influencia en el cálculo del periodo óptimo de renovación.

Tras este paso, se delinean las políticas de gestión de fugas en el corto plazo. Partiendo del principio de recuperación de costes, se presenta una metodología que determina el punto óptimo de funcionamiento del sistema en el corto plazo, valor que se determina minimizando la curva del gasto total que requiere el mantenimiento del sistema. Una curva que al incluir también el coste energético del agua permite relacionar las políticas a corto y largo plazo.

La tercera parte presenta una metodología para auditar, desde la óptica energética, una red de distribución. La auditoría energética identifica por primera vez los usos finales de la energía entrante en la red. Esta metodología es la primera que permite discriminar tales usos energéticos y, a partir de ellos, cuantificar la influencia del coste de la energía en las políticas de renovación de redes. También permite identificar la energía que escapa en las propias fugas, así como la energía total disipada por efecto de las mismas en la red de distribución. Finalmente se definen indicadores energéticos básicos que completan la sucinta información facilitada por el indicador tradicional, consumo energético por unidad de volumen en $\mathrm{kWh} / \mathrm{m}^{3}$. Se presentan los resultados de la cuantificación de la energía consumida por cada etapa del ciclo del agua en California, (CEC, 2005) y un primer acercamiento en la ciudad de Valencia (Murgui y col., 2009). 
La energía que se pierde con las fugas en la etapa de distribución se puede calcular como la suma de la que se escapa con el agua fugada y de la fricción adicional existente (Colombo y Karney, 2002). La existencia de fugas provoca que circule un mayor caudal (ya que circula el caudal consumido por el usuario y el caudal que se fuga), y por consiguiente, exista una mayor fricción en el sistema. La auditoría energética permite este cálculo a partir de la comparación de dos estados del sistema (el real y el renovado). El sistema renovado que se simula puede incluir sólo una parte de las tuberías y, de este modo, valorar mejoras parciales.

La utilización del modelo energético permite cuantificar su influencia en las distintas estrategias de operación de las redes, tales como la gestión de la presión con válvula de regulación o la regulación con bombas de velocidad variable. Asimismo permite el cálculo de las emisiones (por ejemplo los créditos equivalentes de carbono) asociados a cualquier estrategia que disminuya el consumo energético. Las emisiones son proporcionales a la energía, aunque existen otros factores que influencian esta relación. Entre ellos, los más significativos son la huella energética del agua (cantidad de energía invertida para la obtención del agua, $\mathrm{kWh} / \mathrm{m}^{3}$ ), así como la fuente de origen de la energía (nuclear, térmica de carbón, solar, etc.).

Por último, la cuarta parte resume los principales resultados de la investigación realizada y delinea los desarrollos futuros. En cualquier caso, y con independencia de tales desarrollos, el trabajo realizado ya permite abordar proyectos concretos de notable utilidad. Como por ejemplo, la auditoría energética en tres redes de distribución ATO de Pisa (Ponsacco, Altopascio y Castelfiorentino) y la cuantificación de la energía consumida para cada etapa del ciclo urbano del agua en Valencia, un estudio similar al realizado en California (CEC, 2005). Asimismo, una parte de esta Tesis doctoral, bajo el título "Auditoría energética en redes de agua", ha sido galardonado por la concejalía de juventud del ayuntamiento de Valencia con el premio "Valencia IDEA 2009" en la categoría de Energía y Medio Ambiente. Esto implica la realización de un módulo de cálculo que se pueda implementar en el software hidráulico EPAnet 2.0 y permita la evaluación de todos los términos de la auditoría energética. Debido a estos proyectos, el futuro de los trabajos de investigación desarrollados parece, a priori, alentador por el carácter aplicado de los mismos y por la creciente preocupación por la gestión eficiente y sostenible de dos recursos tan preciados como el agua y la energía. 
2

Rehabilitación y renovación de tuberías. Estado del arte 



\subsection{Introducción}

Buena parte de los $133000 \mathrm{~km}$ de tuberías enterradas en las ciudades españolas (INE, 2006) han cumplido ya 50 años (vida útil razonable de la mayoría de materiales), por lo que en muchas ocasiones se ha de plantear una estrategia de choque para renovar estas infraestructuras envejecidas. La cuantificación de la inversión, realizada en el capítulo 1 de la presente Tesis, justifica los estudios realizados en renovación y rehabilitación de tuberías y el capítulo 2 pretende abordar el principal factor para ello: el funcionamiento de los distintos materiales instalados en las redes de distribución urbana.

El presente capítulo comienza con un paseo por la historia de las tuberías, y muestra la evolución de los materiales empleados desde la era de los romanos, con tuberías cerámicas, hasta la era actual con las innovaciones realizadas por la industria en materiales plásticos. Tras esto se detallan las características particulares de cada uno de los materiales más frecuentemente utilizados en el suministro de agua potable (fundición dúctil, acero, etc.). Asimismo, se analizan los detalles de las tuberías en desuso (fundición gris y fibrocemento) por su extensa presencia en las redes de agua. En España (MMA, 1998) el 47.9\% y el $37.6 \%$ de las tuberías son de fundición ${ }^{12}$ y fibrocemento respectivamente. De igual modo, se cuantifica la proporción de tuberías según el material en abastecimientos de Estados Unidos, algunos países europeos, España y la ciudad de Valencia.

Por último, se describen los criterios que se adoptan para abordar la decisión de renovar y/o rehabilitar las conducciones de la red. La comprensión de estos criterios es básica para la construcción de una herramienta propia que permita la toma de decisiones para la renovación. Esta herramienta debe considerar múltiples factores y se construye tanto a partir de las propiedades físicas del sistema como del análisis de los datos estadísticos disponibles.

La obtención de un modelo que permita al gestor decidir qué tubería renovar es un problema que, aunque se ha intentado universalizar, se ha mostrado muy dependiente tanto de las particularidades propias de la red (deterioro de las tuberías, etc.) como de los datos disponibles en cada abastecimiento. Así, la estructura de dicho modelo debe ser flexible y capaz de incorporar las particularidades de la red de estudio.

\footnotetext{
${ }^{12}$ No se precisa la proporción de fundición dúctil y gris. A lo largo del capítulo se observará que el término "fundición" se refiere generalmente al conjunto dúctil y gris, aunque en otras ocasiones únicamente se refiere únicamente a la primera.
} 
Es evidente que la simple implantación en un abastecimiento de un modelo de decisión ya es importante, puesto que representa el primer paso hacia una gestión eficiente y una política predictiva. Muchos abastecimientos se encuentran en este punto. La implantación de estos modelos de decisión conlleva un esfuerzo notable (recolección de información, análisis de los mismos, etc.), y la utilización de numerosos recursos materiales, humanos y económicos. Quizá esto provoca que la toma de decisiones de renovación, con mucha frecuencia, sea política. Las presiones que sufre el gestor de la red a la hora de levantar una determinada calle, la existencia de dinero de un lote presupuestario que se ha de invertir en un determinado instante de tiempo (antes de la pérdida del mismo), o el retraso de una obra por la existencia de un acto de relevancia en la ciudad que no debe verse afectado por una zanja, suelen ser situaciones comunes que se anteponen a la decisión puramente técnica. Sin embargo y aceptando que con frecuencia las decisiones de renovación están impuestas por diversas causas de fuerza mayor, nunca se deben soslayar los criterios técnicos, ya que éstos sirven para adoptar y justificar las decisiones desde una óptica no política.

Finalmente, se incluye un anexo dedicado a las nuevas técnicas de renovación, caracterizadas por la inexistencia de la zanja, un menor tiempo de ejecución de las obras y en definitiva, menores molestias a los ciudadanos. Estas técnicas, se han desarrollado fundamentalmente en el ámbito de las redes de saneamiento, aunque algunas de ellas ya se emplean en redes de abastecimiento. Sin duda, representan una alternativa cada vez más interesante frente a las técnicas tradicionales y su impacto en el ámbito de la renovación de tuberías de abastecimiento irá en aumento conforme se desarrollen las técnicas correspondientes. 


\subsection{La historia de las tuberías de agua potable}

Las tuberías son una de las mayores contribuciones para garantizar la salubridad (especialmente las empleadas en redes de saneamiento) y el confort (las de agua limpia) de las poblaciones a lo largo de la historia. Desde la tubería de arcilla o cerámica de los tempranos días de Babilonia (4000 A.C.) ha existido un considerable esfuerzo para llegar al estado actual, una tubería que pudiera fabricarse económicamente y que mantuviese sus características estructurales bajo tierra durante un periodo de tiempo elevado.

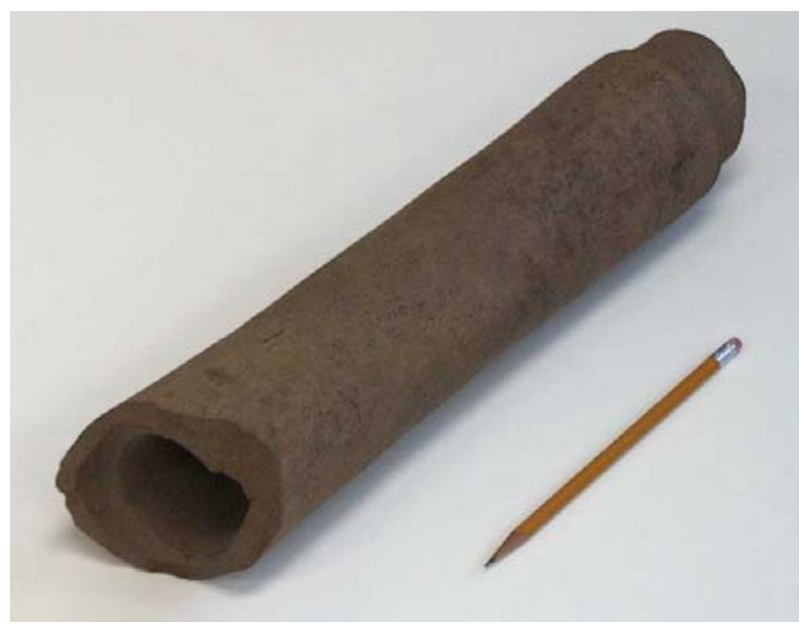

FIGURA 11. TUBERÍA DE ARCILLA UTILIZADA EN EL AÑO 1800 EN CALIFORNIA (WWW.SEWERHISTORY.ORG).

Ya en el año 1500 A.C. se construyó un acueducto en la ciudad cretense de Cnosos que utilizaba conductos tubulares para el transporte del agua. Sin embargo, del siguiente acueducto del que se tiene constancia data del año 700 A.C. en Jerusalén. En esa misma época, 600 A.C. los antiguos griegos construyeron acueductos en Atenas, Samos y Siracusa (todavía en uso).

En el 144 A.C. Ios romanos construyeron el primer acueducto aqua marcia de $90 \mathrm{~km}$ de longitud y que abastecía a la propia Roma. En esa época se construyeron principalmente de piedra y cemento natural, eran sencillos pero funcionales. 
Aunque los técnicos romanos usaban también conducciones bajo presión por tubos de plomo o de cerámica, rara vez escogían estas conducciones. Las tuberías cerámicas eran baratas y fáciles de fabricar a pie de obra, pero resultaban demasiado frágiles mientras que las de plomo, además del elevado coste del material, exigían un transporte muy laborioso, dado su peso. Los romanos consiguieron refinar las conducciones de arcillas o madera para el transporte en el año 50 A.C. en la ciudad de Bath, Reino Unido, utilizando plomo. En Bath, se canalizaba agua caliente provinente de un manantial natural y se empleó este material para evitar el deterioro de las tuberías de madera o de arcilla que eran las frecuentemente empleadas. Los romanos ya imaginaban que el plomo podría causar serios problemas de salud. Ellos achacaban a este material la locura y la muerte. Sin embargo, estaban tan confiados en los diversos usos que presentaba que infravaloraron los riesgos asociados al mismo. En el año 14 A.C. el arquitecto romano Vitrubio ya percibe la complexión pálida y las enfermedades contraídas por los operarios que trabajan con plomo (www.cleanwaterpipecouncil.org). En su libro De architectura sugirió que el agua que circulaba por las tuberías de plomo contaminaba la sangre humana.

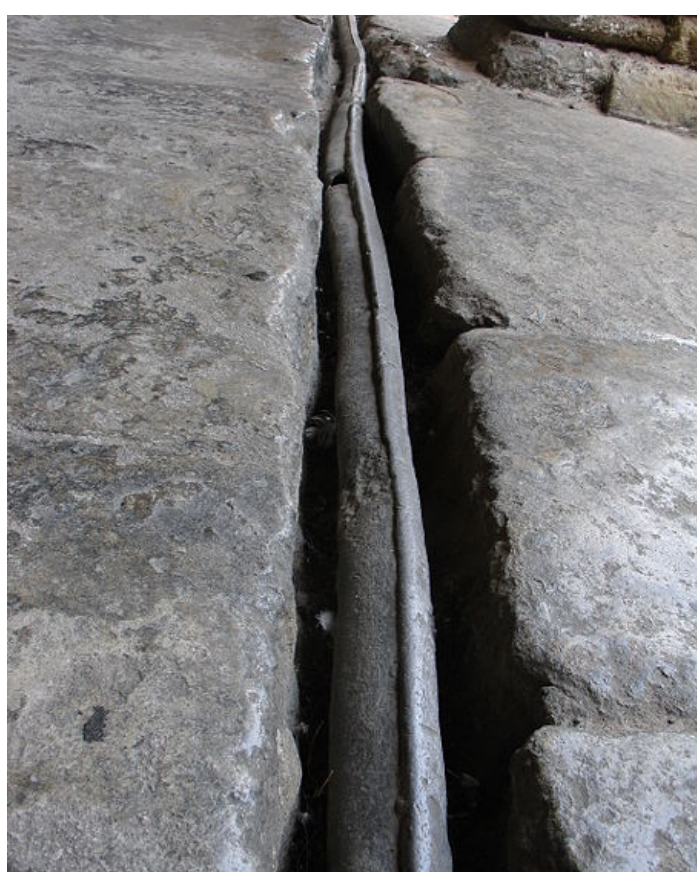

Figura 12. Tubería de Plomo en Bath.

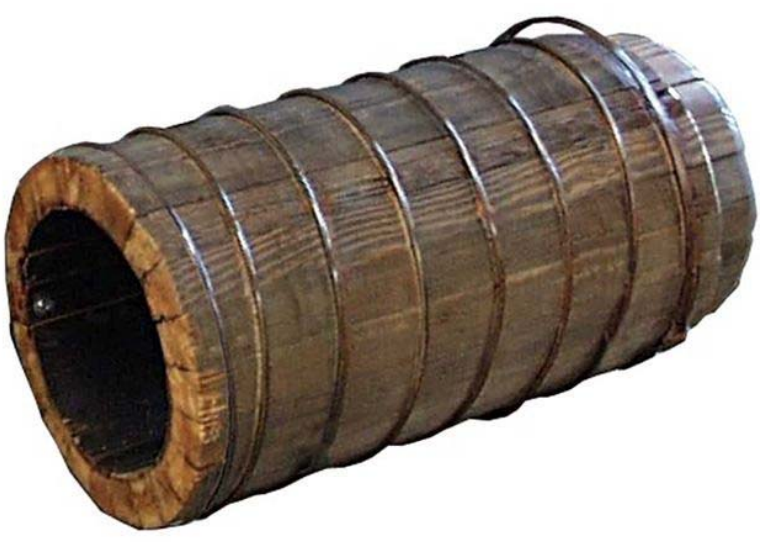

FIGURA 13. TUBERÍA DE MADERA INSTALADA EN HAMILTON, ONTARIO (RAJANI, 2009A). 
Por otra parte, el hierro se conocía desde las épocas prehistóricas, aunque la fecha más temprana de su empleo a gran escala se remonta a 1313 (manufactura de cañones de hierro fundido en Gante, Bélgica). La primera aplicación del hierro en relación con la distribución de agua se realizó el año 1455, en el que se instaló una tubería de fundición en el castillo Dillenberg, Alemania (Tyco, 2000). En 1664, se emplearon tuberías de fundición gris (diámetro de $400 \mathrm{~mm}$ y 8 km de longitud) en Versalles (Rajani, 2009a). Todavía en la actualidad existen algunos tramos de la misma que se mantienen en servicio.

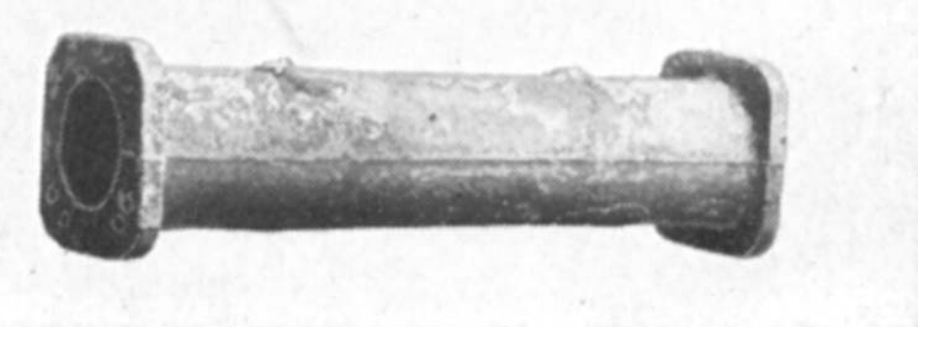

FIGURA 14. TUBERÍA DE FUNDICIÓN GRIS QUE SIRVE PARA TRAER AGUA HASTA LOS JARDINES DE VERSALLES.

TODAVÍA EN SERVICIO EN EL AÑO 1914 (WWW.SEWERHISTORY.ORG).

En 1692, se instaló en Boston una tubería de madera para el abastecimiento de agua (Rajani, 2009a). Más de un siglo después, en 1746, se tuvo constancia de la instalación de una tubería de fundición en Londres, mientras que en el nuevo continente, fue en Filadelfia donde se instaló la primera tubería de fundición gris, año 1804, ya que anteriormente todas eran de madera. Dicha tubería, procedente de Inglaterra, fue servida en tramos de $3 \mathrm{~m}$ y se instaló con juntas campana y enchufe (bell and spigot).

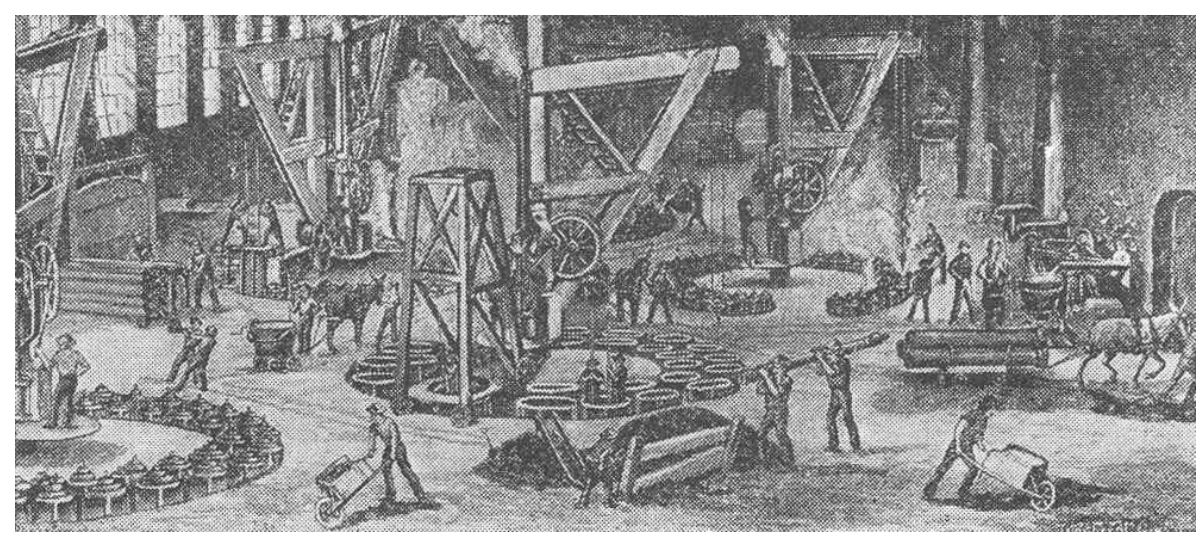

FIGURA 15. PRIMEROS PASOS EN LA FABRICACIÓN DE FUNDICIÓN GRIS, AÑo 1880 APROX. 
Durante el siglo XVII, las tuberías de fundición se utilizaron en casos aislados para llevar agua hacia propiedades de la aristocracia como mansiones, casas de campo, jardines y otros. En 1785, la Chelsea Water Company en Londres comenzó a utilizar la junta de campana y enchufe con un sellado de plomo. Este tipo de junta, inventado por Sir Thomas Simpson, consistía en añadir cáñamo en el ensanchamiento de la campana (que realizaba la función de la junta) y posteriormente se añadía plomo fundido sobre esta junta. Cuando el plomo solidificaba se movía y ajustaba a tope con martillo y cincel por parte del operario.

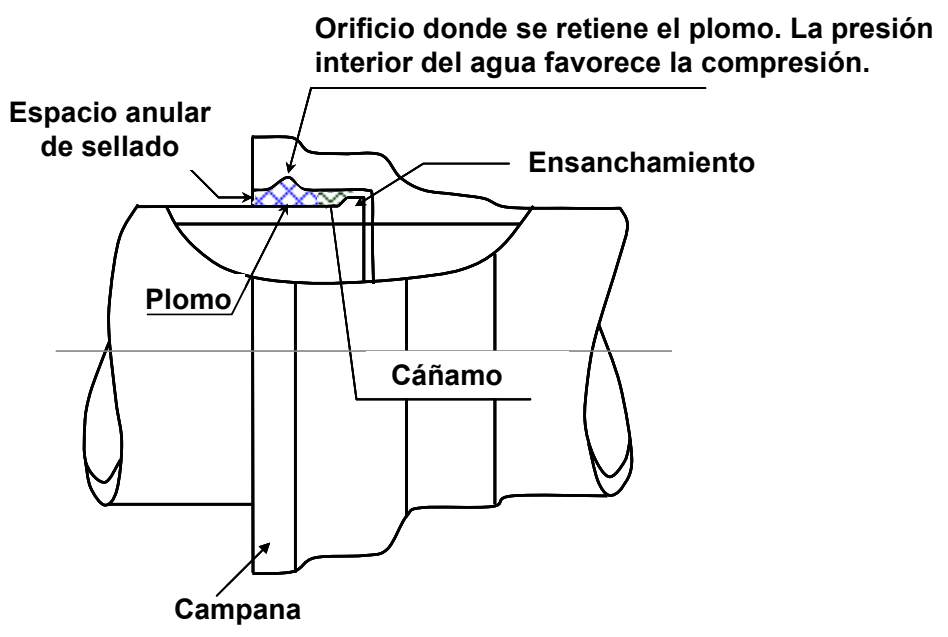

FIGURA 16. UNIÓN CAMPANA Y ENCHUFE CON SELLADO DE LA JUNTA DE PLOMO.

En el siglo XIX con la llegada de la revolución industrial, pueblos, ciudades e industria empezaron a desarrollarse. El crecimiento y la concentración demográfica motivaron la ampliación de las infraestructuras de agua potable, gas y recogida de aguas residuales. Por ejemplo, en 1842 finalizó la construcción del acueducto de Croton, que abasteció de agua a la ciudad de Nueva York. En 1915, se construyó otro acueducto de $150 \mathrm{~km}$ de longitud que unía el antiguo acueducto de Croton con el sistema de distribución de Manhattan. El agua circulaba con una velocidad de $1.2 \mathrm{~m} / \mathrm{s}$ y con un caudal de $1.9 \mathrm{hm}^{3} / \mathrm{día}$.

Ya en España, en 1848 se aprobó un anteproyecto para la traída de agua a Madrid. En 1851 concluyó el proyecto gracias al cual se abastecía de agua a la capital y se creó la empresa pública Canal de Isabel II. EI anteproyecto de la red de distribución se realizó en el año 1855 y en 1859, los ciudadanos comenzaron a tener agua potable en sus casas, que originalmente provenía del río Guadalix (www.cyii.es). 
A finales de siglo XIX, se produjo la expansión de la industria de los tubos de hormigón. En 1886, P. H. Jackson, un ingeniero de San Francisco, California, obtuvo las patentes para atar varillas de acero en piedras artificiales y en arcos de hormigón que servían como losas de pisos. En 1907 se creó la interstate cement tile manufactures association, que en 1914 pasa a ser la american concrete pipe association (ACPA). En ese mismo año, se empezaban a escribir las primeras especificaciones sobre tubos de hormigón. La contribución más importante en la industria del hormigón se atribuye al ingeniero francés Eugène Freyssinet, quien en 1928, inició el desarrollo moderno del hormigón pretensado usando alambres de acero. Pretensar un elemento estructural consiste en crear en él esfuerzos de tal magnitud que al combinarse con las fuerzas externas, anulen o disminuyan las tensiones y las mantenga por debajo de las admisibles por el material.

Las primeras tuberías de fibrocemento se fabricaron en Italia en los años 1906 1913 aproximadamente. Sin duda, su pequeño peso, fácil transportabilidad y bajos costes de instalación provocaron que se convirtiera en una tubería muy utilizada en la distribución urbana de agua a lo largo del siglo XX. Ya en el año 1930, el inspector médico Edward Merewether encontró la relación entre la exposición al amianto y la aparición de asbestosis, lo que llevó a la adopción de las primeras regulaciones industriales que fijaban valores máximos de exposición.

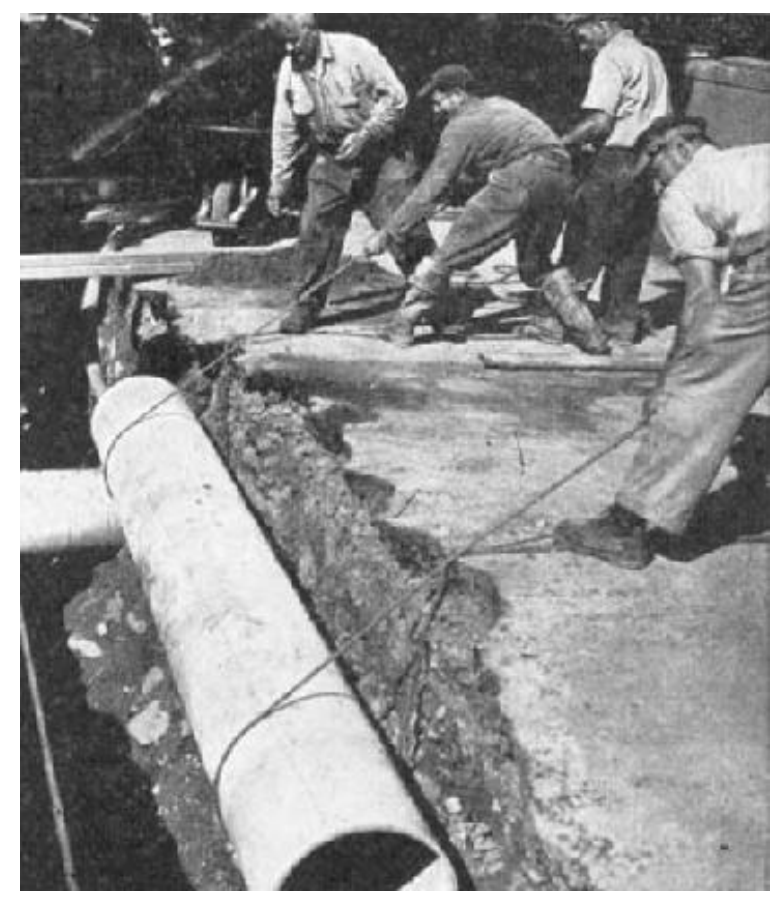

FIGURA 17. INSTALACIÓN DE TUBERÍA DE FIBROCEMENTO, AÑO 1953. 
En 1920 se empezó a revestir con mortero de cemento las tuberías de agua para minimizar corrosión y crecimiento bacteriano. Los procedimientos para la limpieza y el revestimiento estructural de las tuberías se desarrollaron en los años 30.

Los materiales plásticos fueron desarrollados en los años 30. Las primeras tuberías de policloruro de vinilo (PVC) se construyeron en Alemania en 1932, y se empezaron a instalar en redes a presión y saneamiento en 1936 en ese mismo país. En Estados Unidos, se utilizó el PVC en tuberías de abastecimiento en el año 1955, y las primeras normas específicas para dicha tuberías (ASTM D1785) fueron publicadas en el año 1960.

Durante la segunda guerra mundial se desarrolló el poliéster reforzado con fibra de vidrio en el Reino Unido. Si bien, su primer uso fue militar (remplazo de piezas de madera contrachapada en aviones), pasó al uso civil en los años 50 como material de construcción de botes, y posteriormente se utilizó en tuberías de agua potable y saneamiento.

En 1959, los fabricantes de polietileno (PE) encontraron en la fabricación de tuberías de agua potable un mercado para dicho material. El polietileno de alta densidad (HDPE) se dedicó a la distribución de agua a presión, mientras que el de baja densidad (LDPE) se empleó en redes de riego y en acometidas de viviendas, aunque su aplicación fundamental es en fabricación de juguetes, bolsas plásticas, etc.

Otra vez en tubería metálica, el desarrollo de la fundición dúctil surgió en 1948. En un período relativamente corto, esta tubería desplazó casi totalmente a la de fundición gris. Las especificaciones para el uso de fundición dúctil han provocado que todas las tuberías de hierro que se han instalado en los últimos años hayan sido de tipo dúctil, y que la tubería de fundición gris ya no se fabrique por la fragilidad de la misma. 
En cambio, el plomo, que se había utilizado ampliamente para la fabricación de tuberías (desde los romanos en Bath) se deja de instalar cuando se comprueba sus efectos prejudiciales para la salud humana, que especialmente afectan al cerebro, riñón y sistema nervioso. Un informe de la environmental protection agency (EPA, 1973) confirmó el, hasta entonces supuesto, efecto prejudicial del plomo en la salud pública. Aunque el informe se centró en el efecto del plomo añadido como catalizador a las gasolinas, se hizo extensible a sus aplicaciones habituales como material con el que se fabricaban tuberías, pinturas, etc. Sin embargo, hasta 1988 no se publicó una norma para establecer los requerimientos mínimos para el control de las aguas que están en contacto con el plomo (NSF/ANSI Standard 61).

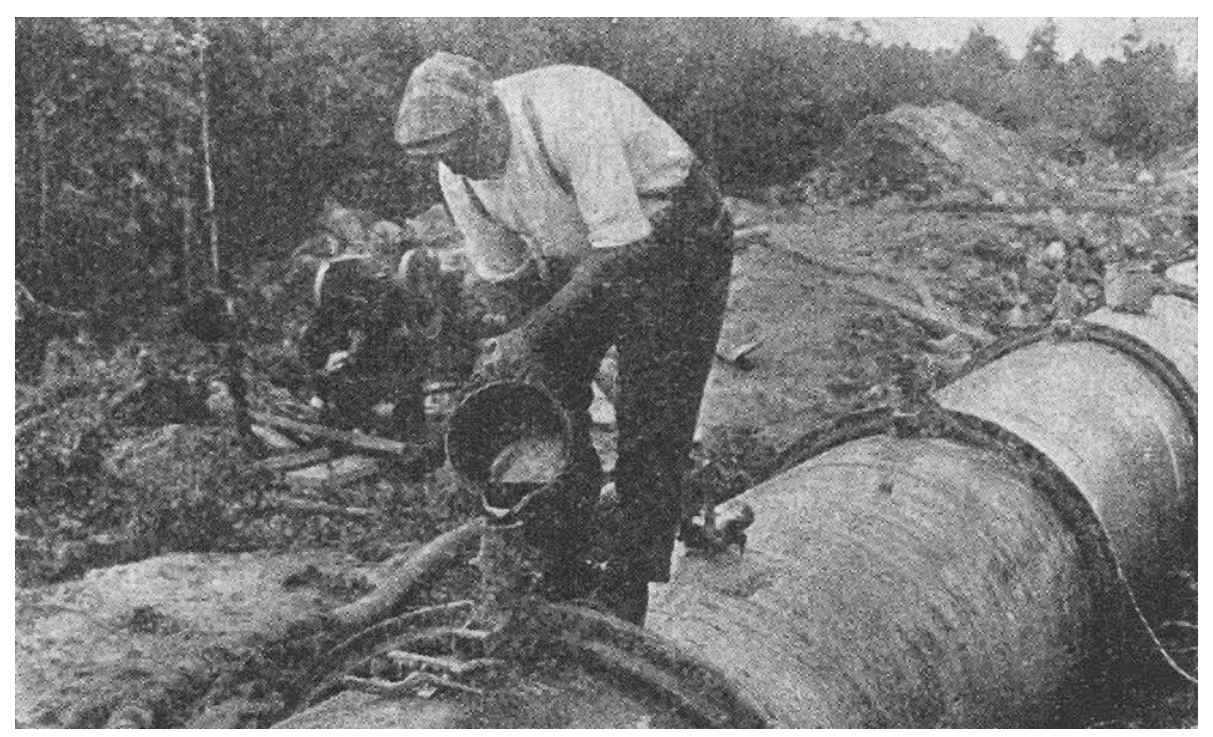

FIGURA 18. TUBERÍA DE FUNDICIÓN GRIS REVESTIDA CON PLOMO. 
Otro problema de salud asociado al empleo de tuberías se encontró en la liberación de fibras de amianto en tuberías de fibrocemento. Se demostró que las tuberías de fibrocemento incrementaban las concentraciones de amianto en agua (Chatfield y Dillon, 1979; Webber y col., 1989; Millette y col., 1983). En 1993, la organización mundial de la Salud (OMS) subrayó las escasas evidencias de los efectos cancerígenos de la ingesta de fibras de amianto, y que en estudios de laboratorio no se comprobó el aumento de la probabilidad de tumores en el tracto gastrointestinal. Las tuberías de fibrocemento son un peligro para la salud en el manejo de las mismas, aunque no bebiendo agua que haya circulado por ellas. El desuso de dichas tuberías es provocado sobre todo por la aparición de nuevos materiales así como por la alarma producida por los posibles problemas de calidad asociados a las fibras de amianto. A través de la Orden de 7 de diciembre de 2001, España transpuso la Directiva Comunitaria 1999/77/CE, por la que se prohibió el uso y comercialización de todo tipo de amianto y de los productos que lo contengan. La prohibición se hizo efectiva para la fabricación el 15 de junio de 2002 y para la instalación a finales de ese mismo año.

\subsection{Tipos de Materiales utilizados en los abastecimientos}

Numerosos materiales se han utilizado en la construcción de las redes de abastecimiento. En cada época, existe un material predominante, no sólo en la nueva instalación sino también en la renovación. Prueba de ello es la inversión anual para cada material, tal y como lo muestran Cromwell y col. (2007), (Figura 19). En el eje horizontal se representa el año y en el vertical las inversiones realizadas (en $\mathrm{M} \$$ ) en cada tipo de tubería. Por tanto, se puede observar que en la actualidad la inversión (o sea los materiales que se instalan) se centra en tuberías de fundición dúctil y PVC. En España, la situación es similar a la mostrada en este estudio aunque retrasada unos 10 ó 20 años. Por ejemplo, el fibrocemento se instaló en las redes españolas fundamentalmente en los años 40, no en los años 30, (Figura 19) y su instalación se mantuvo hasta mediados de los años 80. 


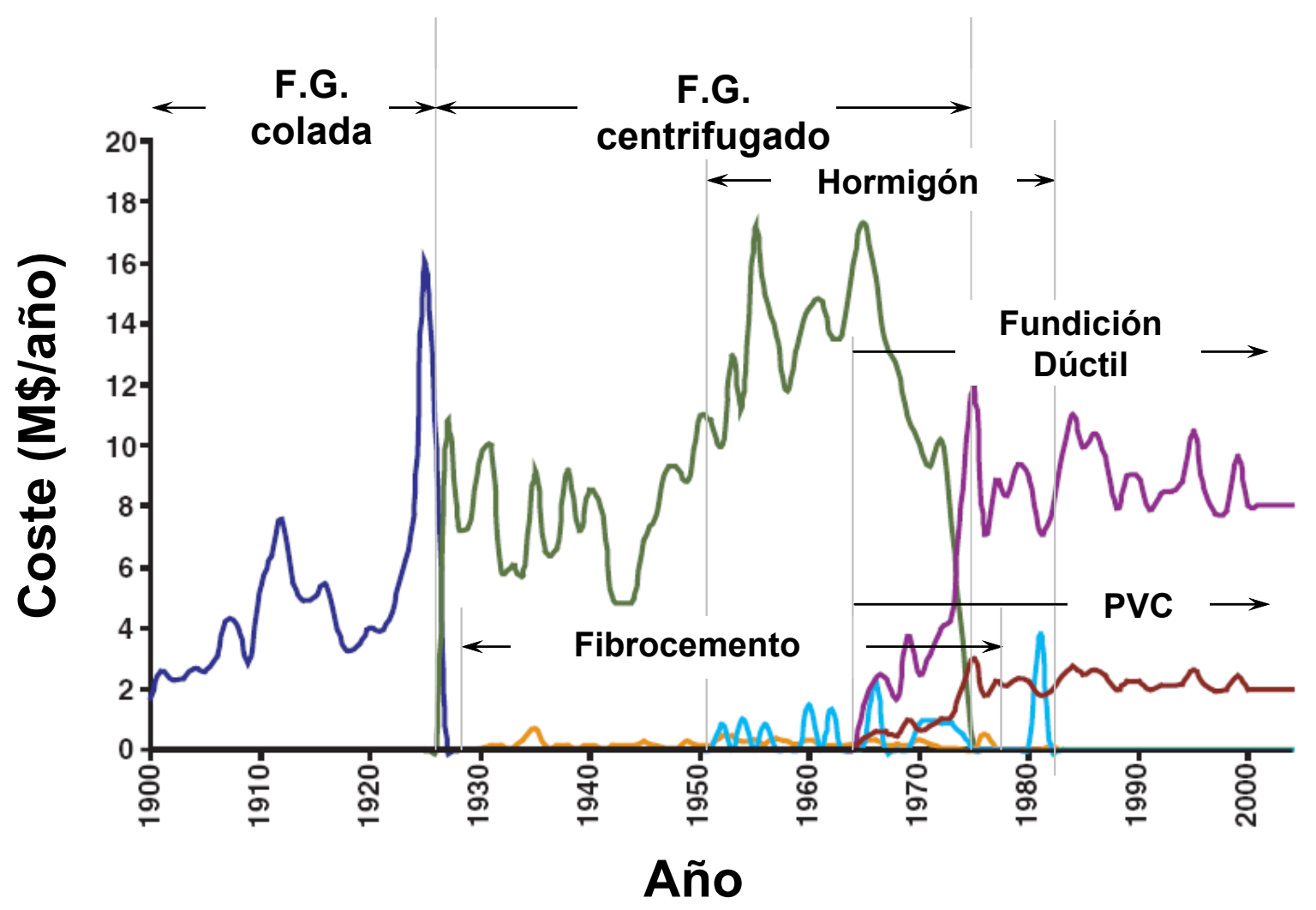

Figura 19. UtilizaCión de los diversos materiales CON el tiempo en EE.UU. (CROMWELl y COL., 2007).

Seguidamente se muestran las principales características de las tuberías empleadas en redes de distribución de agua. Algunas como la fundición gris y el fibrocemento están en desuso, pero su estudio se justifica porque representan una parte importante de las tuberías instaladas en la actualidad. 


\subsubsection{Tuberías de fundición dúctil}

Los tubos de fundición dúctil son utilizados en Europa desde el año 1948. Tal y como se ha comentado. Este material ha desplazado completamente a la antigua fundición gris (de menor resistencia y susceptible de sufrir roturas frágiles), que venía siendo empleada desde mucho antes (siglo XVIII).

\section{Características físicas fundamentales}

El hierro fundido en forma de arrabio $^{13}$ se obtiene con la aleación de carbón de coque en un alto horno con el mineral de hierro en un proceso denominado como fundición. En este proceso, parte del carbono se disuelve en el hierro líquido, disminuyendo el punto de fusión desde los 1540 hasta los $1150^{\circ} \mathrm{C}$. Éste es el requisito más importante para el procesamiento industrial, ya que permite la reducción del gasto de energía, de material refractario y de material fundido. Otra ventaja sucede cuando el hierro fundido solidifica: la contracción del volumen del hierro cuando pasa a sólido es contrarrestada por el volumen del carbono disuelto que cristaliza. En consecuencia, los productos hechos de hierro fundido suelen tener una microestructura densa y libre de cavidades.

La forma de cristalización del carbono se modifica mediante un tratamiento metalúrgico de la fusión por medio de metales con alta afinidad al oxígeno, por ejemplo cerio o magnesio. En un caldo de hierro fundido, el carbono ya no cristaliza en forma laminar como en el caso de la fundición gris (si se impide la grafitización de la cementita eutectoide, la matriz será totalmente perlítica y el producto será fundición dúctil) sino en forma esferoidal gracias a los aditivos. La mayoría de las fundiciones dúctiles son aleaciones que contienen un $3.5 \%$ de carbono, $2.5 \%$ de silicio, $0.4 \%$ de manganeso, $0.005 \%$ de azufre, $0.06 \%$ de fósforo y $0.04 \%$ de magnesio.

Mientras que en fundición gris el grafito rompe la estructura cristalina (CEDEX, 2006) y ello conlleva la tradicional rotura frágil de ésta, el grafito en forma esferoidal reduce la concentración de tensiones internas en el metal base. En la Figura 20 se comparan las tensiones existentes en una muestra de fundición dúctil (con el grafito cristalizado en forma de esfera) y otra de fundición gris (con el grafito en forma de una lámina). La resistencia de la fundición que contiene grafito esferoidal es considerablemente mayor que la que contiene grafito en forma de lámina, y es capaz de deformarse plásticamente bajo la acción de cargas externas.

\footnotetext{
${ }^{13}$ Arrabio. Fundición de hierro que se obtiene en el alto horno y que constituye la materia prima de la industria del hierro y del acero.
} 


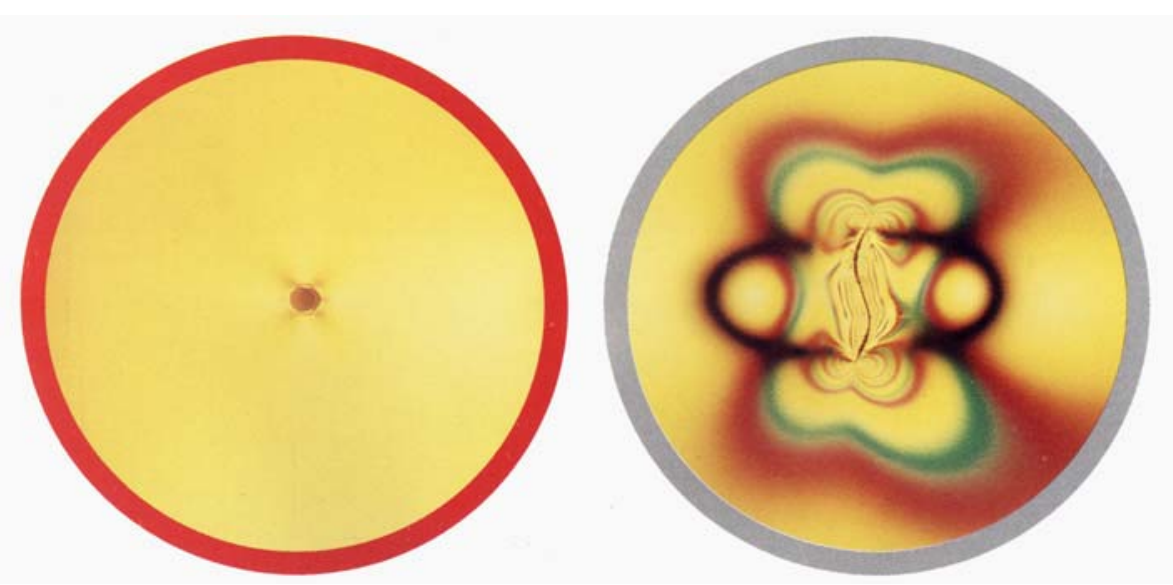

FIGURA 20. ASPECTO DE LAS TENSIONES EN TUBERÍAS DE FUNDICIÓN DÚCTIL (PARTE IZQDA, NÓDULO ESFÉRICO) Y FUNDICIÓN GRIS (PARTE DCHA, UNA LÁMINA DE GRAFITO).

\section{Dimensiones}

Las tuberías de fundición dúctil están normalizadas por UNE-EN hasta el diámetro $2000 \mathrm{~mm}$, si bien se pueden fabricar hasta $2600 \mathrm{~mm}$ (no empleados habitualmente). Asimismo, las longitudes en las que se fabrica no son superiores a los 5-6 m (CEDEX, 2006).

\section{Propiedades}

Entre las ventajas de los tubos de fundición dúctil debe destacarse, en primer lugar, el excelente comportamiento de los mismos ante la presión hidráulica interior y la acción de las cargas externas, lo que hace que su campo de aplicación abarque un amplio rango de diámetros. Las características físicas más destacables son las siguientes:

1. Resistencia a la tracción: $420 \mathrm{MPa}$.

2. Resistencia a la compresión: 420 MPa (mismo valor que la tracción).

3. Alargamiento: entre el 10 y el $25 \%$.

4. Dureza: entre 165 a 230 Brinell $^{14}\left(\mathrm{Kg} / \mathrm{mm}^{2}\right)$.

5. Módulo Elástico: 165-180 GPa.

6. Otros: la instalación de tubos de fundición dúctil se ve facilitada porque éstos son fácilmente mecanizables en obra (se pueden cortar, taladrar, roscar, etc.) y también porque el tipo de unión habitual (flexible, de enchufe y campana) es de fácil colocación.

\footnotetext{
${ }^{14}$ Se denomina dureza Brinell a la medición de la dureza de un material mediante el método de indentación, midiendo la penetración de un objeto en el mismo.
} 
Mecanismos de deterioro

La tubería de fundición dúctil se deteriora únicamente por corrosión, la destrucción de los cuerpos metálicos por un ataque electroquímico de agentes externos (oxidación). La velocidad de la misma depende de diversos factores como la temperatura, la salinidad del fluido y el tipo de material en cuestión.

La corrosión sucede bien por la unión de metales diferentes (acometidas de cobre o plomo, nuevas tuberías conectadas a viejas, etc.), o bien por la existencia de distinto tipos de terreno, o distinta compactación de los mismos en presencia de oxígeno). Las condiciones de la superficie de la tubería (arañazos causados en el transporte o instalación de la tubería) es uno de los factores que facilita la corrosión.

Los posibles sistemas de protección de la tubería frente a la corrosión son, básicamente la protección catódica o el recubrimiento mediante revestimientos (aislamiento de la tubería). La elección entre un método de protección u otro es básicamente una cuestión económica que depende de las circunstancias particulares de cada instalación.

La protección catódica se caracteriza por impedir que la tubería metálica sea el ánodo en las reacciones de oxidación-reducción. Existen dos maneras de asegurar esto:

- Instalación de un material que interfiera en la corrosión (ánodos de sacrificio): El ánodo de sacrificio tiene menor electronegatividad que la tubería a proteger, de manera, que la corrosión sucede en este material y no en la tubería que protege (Figura 21). Como ánodos o electrodos de sacrificio se emplean algunas aleaciones de magnesio, cinc o aluminio. Estos ánodos van enterrados y se rodean de una mezcla activadora que evita la pasivación del ánodo y disminuye su resistencia a tierra. La mezcla activadora suele estar compuesta por yeso, bentonita y sulfato sódico. 


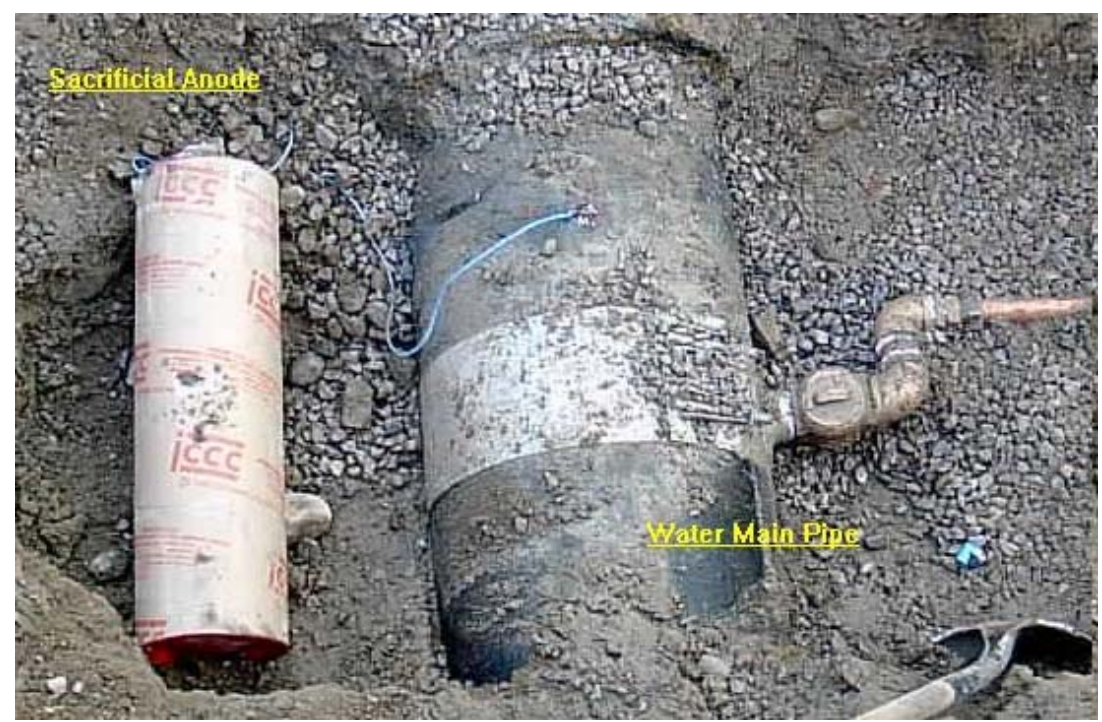

FIGURA 21. INSTALACIÓN DE UN ÁNODO DE SACRIFICIO EN UNA TUBERÍA METÁLICA.

- Por fuentes de corriente impresa, rectificadores manuales o regulados: Los sistemas de corriente impresa con rectificador manual se caracterizan por forzar la salida de corriente continua hacia el suelo a través de un lecho de ánodos, actuando la tubería como cátodo y recibiendo corriente continua del suelo que la rodea. Los ánodos son, en general, de grafito, ferrosilicio, titanio activado con platino o mezcla de óxidos metálicos. Ocasionalmente, incluso se utiliza acero. El contacto de los ánodos con el suelo suele mejorarse utilizando rellenos de grafito, coque de hulla y coque de petróleo calcinado. Los sistemas de "corriente impresa con rectificador automático" trabajan igual que el caso de rectificación manual, pero con un sistema de regulación de la corriente de protección en función del potencial de la tubería.

La protección frente a corrosión con protección catódica requiere que la tubería sea eléctricamente continua. La instalación de uniones flexibles rompe la continuidad eléctrica y, como se deben evitar discontinuidades, es frecuente la instalación de puentes, elementos mecánicos u otros accesorios que garanticen la misma. 
En general, la protección catódica no suele emplearse en España (CEDEX, 2006), y la protección frente a la corrosión se realiza casi exclusivamente mediante revestimientos o mangas de polietileno. Ésta no requiere continuidad eléctrica y por tanto, el tipo de unión entre los tubos es irrelevante. Los tubos de fundición dúctil van provistos de revestimientos tanto exteriores como interiores, el material empleado para realizar este revestimiento depende de las características del agua a transportar y del medio en el que se instalen (aunque generalmente el revestimiento suele ser mortero de cemento). En la instalación de los mismos, al ser un tubo flexible en diámetros grandes (y por tanto resistir las solicitaciones deformándose y contando con la ayuda del empuje pasivo del relleno), las características y grado de compactación de los materiales a colocar alrededor de la tubería adquieren gran importancia, lo que obliga a una cuidadosa ejecución en obra.

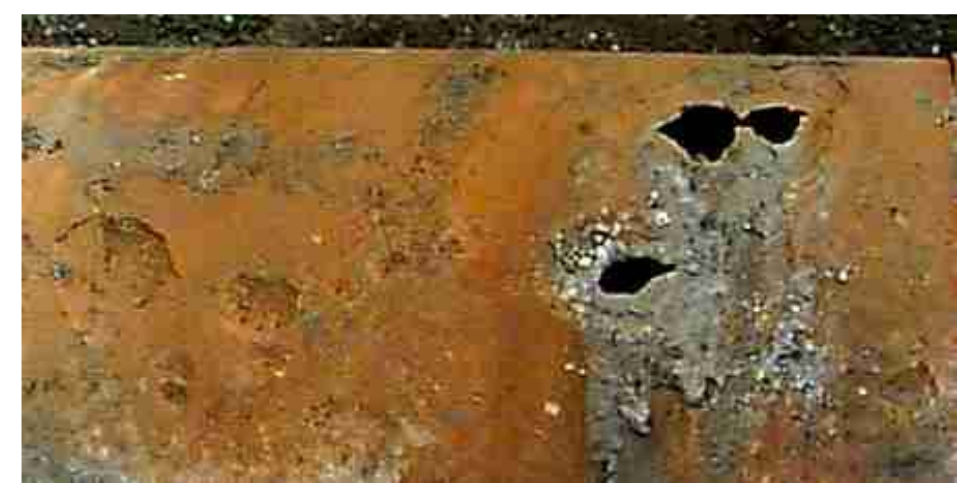

FIGURA 22. EJEMPLO DE CORROSIÓN EN TUBERÍA DE FUNDICIÓN DÚCTIL.

Rajani y Kleiner (2002) estudiaron los tipos de revestimientos orgánicos e inorgánicos, y obtuvieron los resultados siguientes (Tabla 12). 
TABLA 12. TIPOS DE REVESTIMIENTOS QUE PROTEGEN LAS TUBERÍAS DE FUNDICIÓN DÚCTIL (RAJANI Y KLEINER, 2002).

\begin{tabular}{|c|c|c|}
\hline Revestimientos inorgánicos & $\begin{array}{l}\text { Mínimo espesor del } \\
\text { revestimiento }\end{array}$ & Calidad de la protección \\
\hline Mortero de cemento & $5 \mathrm{~mm}$ & $\begin{array}{c}\text { Durabilidad a largo plazo (para pH } \\
\text { no bajos) }\end{array}$ \\
\hline $\begin{array}{c}\text { Zinc }+ \text { capa semi-impermeable } \\
\text { en la superficie }\end{array}$ & $130 \mathrm{~g} / \mathrm{m}^{2}+50 \mu \mathrm{m}$ & $\begin{array}{c}\text { Durabilidad a largo plazo (para pH } \\
\text { no bajos) }\end{array}$ \\
\hline $\begin{array}{c}\text { Zinc }+ \text { entubado con PE } \\
\text { (envuelto) }\end{array}$ & $130 \mathrm{~g} / \mathrm{m}^{2}+200 \mu \mathrm{m}$ & $\begin{array}{c}\text { Temporal a largo plazo en casos con } \\
\text { baja corrosión }\end{array}$ \\
\hline Revestimientos orgánicos & $\begin{array}{l}\text { Mínimo espesor del } \\
\text { revestimiento }\end{array}$ & Calidad de la protección \\
\hline \multirow{2}{*}{ Fino } & $50 \mathrm{~mm}$ & Mala \\
\hline & $50 \mathrm{~mm}+200 \mathrm{~mm}$ & Parcial, reduce la corrosión \\
\hline Polietileno & $1.8 \mathrm{~mm}$ & Completa \\
\hline Epoxi & $250 \mathrm{~mm}$ & Completa \\
\hline Grueso & & \\
\hline Alquitrán y epoxi & $250 \mathrm{~mm}$ & Completa \\
\hline Poliuretano & $250 \mathrm{~mm}$ & Completa \\
\hline
\end{tabular}

El estudio anterior muestra las características fundamentales de los revestimientos existentes para la fundición dúctil. Sin embargo, es el siguiente el que muestra la situación española, Tabla 13. 
TABLA 13. TIPOS DE REVESTIMIENTOS EN TUBOS DE FUNDICIÓN DÚCTIL (CEDEX, 2006),

\begin{tabular}{|c|c|c|c|c|}
\hline $\begin{array}{l}\text { Revestimientos } \\
\text { inorgánicos }\end{array}$ & $\begin{array}{l}\text { Aplicaciones } \\
\text { posibles }\end{array}$ & $\begin{array}{c}\text { Normativa } \\
\text { complementaria } \\
\text { UNE-EN }\end{array}$ & Espesor mínimo & $\begin{array}{c}\text { Otras } \\
\text { características }\end{array}$ \\
\hline $\begin{array}{c}\text { Cinc con capa } \\
\text { bituminosa }\end{array}$ & $\begin{array}{l}\text { Exterior de los } \\
\text { tubos }\end{array}$ & ISO 8179:1995 & $70 \mu \mathrm{m}$ & $\begin{array}{c}\text { Riqueza Cinc: } \\
130 \mathrm{~g} / \mathrm{m}^{2}\end{array}$ \\
\hline $\begin{array}{c}\text { Pintura rica en cinc con } \\
\text { capa de acabado }\end{array}$ & $\begin{array}{l}\text { Exterior de tubos } \\
\text { y piezas } \\
\text { especiales }\end{array}$ & & & $\begin{array}{l}\text { Riqueza Cinc: } \\
150 \mathrm{~g} / \mathrm{m}^{2}\end{array}$ \\
\hline $\begin{array}{l}\text { Cinc reforzado con } \\
\text { chapa de acabado }\end{array}$ & $\begin{array}{c}\text { Exterior de los } \\
\text { tubos }\end{array}$ & & & $\begin{array}{c}\text { Riqueza Cinc: } \\
200 \mathrm{~g} / \mathrm{m}^{2}\end{array}$ \\
\hline $\begin{array}{l}\text { Cinc-Aluminio (85/15) } \\
\text { con chapa de acabado }\end{array}$ & $\begin{array}{l}\text { Exterior de los } \\
\text { tubos }\end{array}$ & & & $\begin{array}{c}\text { Riqueza Cinc: } \\
400 \mathrm{~g} / \mathrm{m}^{2}\end{array}$ \\
\hline Polietileno extrudido & $\begin{array}{l}\text { Exterior de los } \\
\text { tubos }\end{array}$ & $\begin{array}{c}\text { DIN 30674- } \\
1: 1992\end{array}$ & 1.8 y 3 mm & \\
\hline Manga de polietileno & $\begin{array}{l}\text { Exterior de tubos } \\
\qquad \text { y piezas } \\
\text { especiales }\end{array}$ & $\begin{array}{l}\text { ISO 8180:1995 } \\
\text { AWWAC105-99 } \\
\text { ASTM A74-98 }\end{array}$ & $\begin{array}{c}200 \mathrm{~mm} \\
(\mathrm{DN}<1200) \\
400 \mathrm{~mm} \\
\mathrm{DN}<1200)\end{array}$ & $\begin{array}{c}\text { Res. A la } \\
\text { tracción: } 8.3 \\
\text { N/mm }{ }^{2}\end{array}$ \\
\hline $\begin{array}{l}\text { Mortero de cemento } \\
\text { reforzad con fibras }\end{array}$ & $\begin{array}{l}\text { Exterior de los } \\
\text { tubos }\end{array}$ & & $5 \mathrm{~mm}$ & \\
\hline Bandas asfálticas & $\begin{array}{l}\text { Exterior de tubos } \\
\text { y piezas } \\
\text { especiales }\end{array}$ & & $\begin{array}{c}1.6 \mathrm{~mm} \text { (solape del } \\
50 \%)\end{array}$ & \\
\hline Poliuretano & $\begin{array}{c}\text { Exterior/interior } \\
\text { de tubos, } \\
\text { enchufes y piezas } \\
\text { especiales }\end{array}$ & NF A48-851:1995 & $\begin{array}{l}700 \mu \text { m (mínimo) } \\
900 \mu \mathrm{m} \text { (medio) }\end{array}$ & \\
\hline Mortero de cemento & $\begin{array}{l}\text { Interior de tubos, } \\
\text { enchufes y piezas } \\
\text { especiales }\end{array}$ & $\begin{array}{c}\text { ISO 4179:1995 } \\
\text { AWWA C104-95 } \\
\text { DIN 30674-2/92 } \\
\text { BS 7892:2000 }\end{array}$ & $\begin{array}{c}3.5 \mathrm{~mm}(\mathrm{DN}<300) \\
5 \mathrm{~mm}(300<\mathrm{DN}<600) \\
6 \mathrm{~mm}(600<\mathrm{DN}<1200) \\
9 \mathrm{~mm}(\mathrm{DN}>1200)\end{array}$ & $\begin{array}{c}\text { Res. a } \\
\text { compresión } \\
40-50 \mathrm{~N} / \mathrm{mm}^{2} \\
\text { Densidad } \\
2200 \mathrm{~kg} / \mathrm{m}^{2}\end{array}$ \\
\hline Pintura bituminosa & Interior tubos & & & \\
\hline Pintura & Ext/int piezas esp. & & & \\
\hline Pintura epoxi & $\begin{array}{c}\text { Ext/int enchufes y } \\
\text { piezas esp. }\end{array}$ & AWWA C116-98 & $70 \mu \mathrm{m}$ & \\
\hline Esmaltado & Int. Piezas esp. & & & \\
\hline Electodepositado & Ext/Int. Piezas esp. & & $50 \mu \mathrm{m}$ & \\
\hline
\end{tabular}


Para finalizar con los tipos de revestimiento, se muestran aquéllos normalizados según la norma UNE-EN 545:1995.

TABLA 14. REVESTIMIENTOS HABITUALES EN LOS TUBOS Y PIEZAS DE FUNDICIÓN DUCTIL (UNE-EN 545:1995).

\begin{tabular}{ccc} 
& Revestimiento exterior & Revestimiento interior \\
\hline Tubos & $\begin{array}{c}\text { Cinc metálico con capa } \\
\text { de acabado }\end{array}$ & $\begin{array}{c}\text { Mortero de cemento } \\
\text { Cinc/Aluminio }(85 / 15)\end{array}$ \\
Enchufes & Pintura & Pintura \\
& Cinc metálico con capa \\
de acabado & Pintura \\
Bridas & Cinc/Aluminio (85/15) & \\
\hline
\end{tabular}

Patrón de rotura

La obtención del patrón de rotura en cualquier tipo de material es un arduo trabajo que exige, sobre todo, una notable disciplina por parte del personal de mantenimiento de la compañía o institución encargada de la red de abastecimiento. Debido a que son múltiples los factores que influyen en la ocurrencia de las roturas (condiciones de instalación, entorno, etc.), no se puede, ni tampoco se pretende, generalizar un patrón de roturas para cada tipo de tubería. Sin embargo, sí que se puede particularizar un patrón de roturas por material para cada red específica.

Un ejemplo se obtuvo en Scarborough, Canadá, donde se encontraron 247 roturas en $124 \mathrm{Km}$ de tuberías de $150 \mathrm{~mm}$ de fundición dúctil no revestidas e instaladas entre 1960 y 1994. La evolución temporal de las roturas (trazada con puntos) define un patrón de roturas (línea de trazos discontinuos, Figura 23). Las primeras roturas se produjeron sólo 7 años más tarde de la instalación de las tuberías. A partir de 1984, se comenzó un programa de protección catódica de tipo hot spot, es decir, instalando ánodos de sacrifico y conectando eléctricamente las tuberías aprovechando la ocasión de una apertura de zanja para rehabilitación de un tramo de tubería. Esta protección catódica permitió controlar las roturas, de modo que, tras unos años, las mismas decrecieron.

En trazos discontinuos (Figura 23) se puede observar la evolución exponencial calculada del número de roturas, y que el crecimiento del éste no sigue tal exponencial a partir de la protección catódica. 


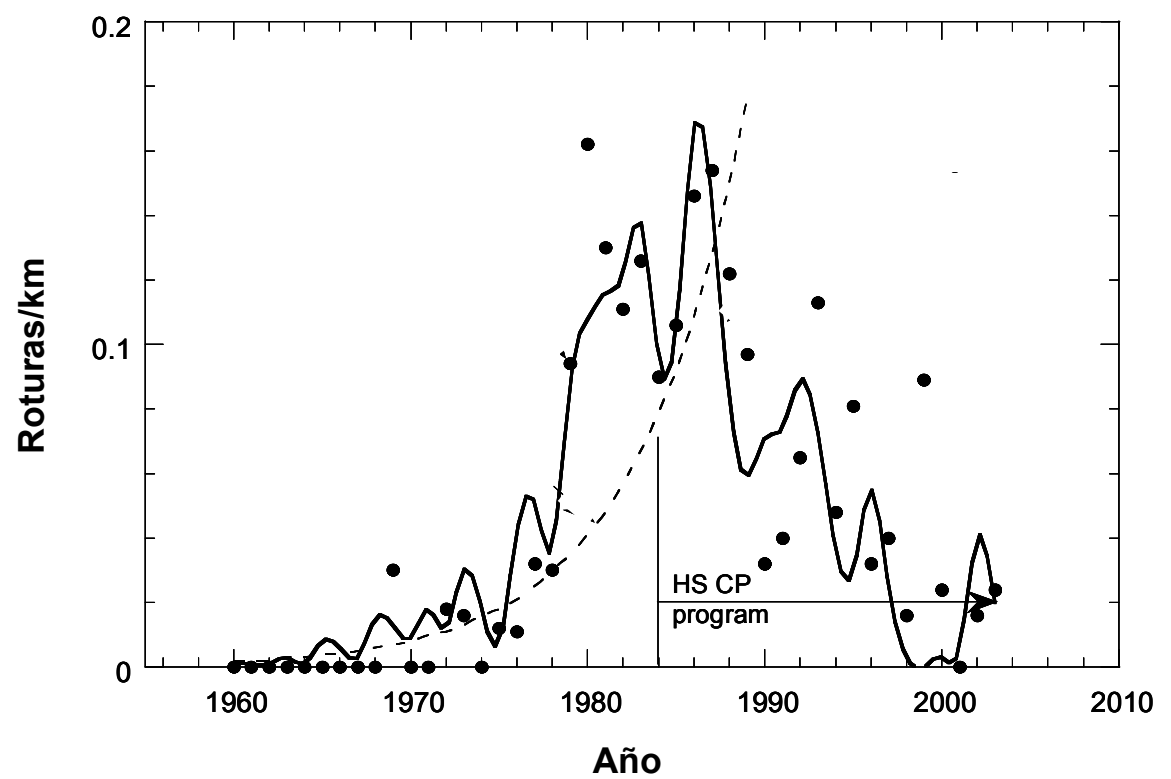

FIGURA 23. PATRÓN DE ROTURAS DE LAS TUBERÍAS DE FUNDICIÓN DÚCTIL INSTALADAS EN SCARBOROUGH (RAJANI, 2009B).

\subsubsection{Tuberías de acero}

Los tubos de acero se han utilizado desde el siglo XIX. Por ejemplo, en EE.UU. existen referencias de su empleo a mediados de dicho siglo, mientras que en España se empezaron a fabricar en el año 1926. Las tuberías de acero pertenecen a las de tipo metálico y se emplean especialmente en casos de altas presiones. Las características de estas tuberías se detallan a continuación.

\section{Características físicas fundamentales}

El acero es una aleación de hierro y carbono, donde el carbono no supera el $2.1 \%$ en peso de la composición de la aleación, alcanzando normalmente porcentajes entre el $0.2 \%$ y el $0.3 \%$. Porcentajes mayores que el $2.0 \%$ de carbono dan lugar a las fundiciones, que no se pueden forjar y que en cambio, a diferencia de los aceros, se moldean.

Los tubos de acero pueden ser sin y con soldadura. Los primeros se obtienen por extrusión y un posterior laminado o estirado, tanto en caliente como en frío. También pueden obtenerse por colada centrifugada. En general, el diámetro de estos tubos es inferior a $200 \mathrm{~mm}$. Los segundos se obtienen por conformación de un producto plano laminado, en caliente o frío, hasta conseguir una sección circular. Los tipos de soldadura son a tope por presión, por inducción o por arco sumergido. Generalmente, los tubos de acero para el transporte de agua a presión son soldados helicoidalmente (soldadura por inducción o por arco sumergido). Las piezas especiales se obtienen por soldadura a partir de trozos de tubo o de chapas de acero iguales a las utilizadas en los tubos. 
Actualmente no existe ninguna normativa UNE relativa a tubos de acero para transporte de agua a presión. En cambio, en la UE existe un proyecto de norma (prEN 10224:1998), que cuando sea aprobada, será traspuesta como UNE.

\section{Dimensiones}

Las tuberías de acero se fabrican en un amplio rango de diámetros, desde 150 a 3600 mm, e incluso superiores. Su máxima utilización, en países con una amplia tradición (Estados Unidos) se corresponde con el rango de diámetros 400$1500 \mathrm{~mm}$. Se suele fabricar en longitudes de $5 \mathrm{~m}$. Por ejemplo, el transvase JúcarVinalopó se ha construido con acero helicosoldado y en algunos tramos tiene diámetros de $1900 \mathrm{~mm}$.

\section{Propiedades}

Determinar las propiedades físicas y mecánicas del acero es complejo ya que éstas varían según la composición y los tratamientos térmicos, químicos o mecánicos, con los que se adecua el acero a la aplicación final. Pese a todo, se citan algunas propiedades genéricas:

\section{Densidad: $7.85 \mathrm{~g} / \mathrm{cm}^{3}$.}

2. Punto de fusión: en general el acero presenta frecuentemente temperaturas de fusión alrededor de $1375^{\circ} \mathrm{C}$.

3. Resistencia a la tracción y a la compresión: según la norma de referencia (prEN 10224:1998), las resistencias del acero L 235 varía entre 360 y $500 \mathrm{MPa}$, para el acero L 275 entre 430 a $570 \mathrm{MPa}$ y finalmente para el acero L 355 entre 500 y 600 MPa. En cambio, la norma de UNE 63080 o la UNE EN 10025, definen otras características de los aceros (CEDEX, 2006).

TABLA 15. RESISTENCIA A LA TRACCIÓN Y COMPRESIÓN SEGÚN LAS NORMAS UTILIZADAS EN LA FABRICACIÓN DEL ACERO (CEDEX, 2006).

\begin{tabular}{|c|c|c|c|}
\hline \multicolumn{2}{|c|}{ Tipo de Acero } & \multicolumn{2}{|c|}{ Resistencia mínima a la tracción $\left(\mathrm{N} / \mathrm{mm}^{2}\right)$} \\
\hline UNE 36080 & UNE EN 10025 & $\mathrm{e} \leq 3$ & $3<\mathrm{e}<40$ \\
\hline A 310 & S 185 & 310 a 540 & 290 a 510 \\
\hline AE 235 & S 235 & 360 a 510 & 340 a 470 \\
\hline AE 275 & S 275 & 430 a 580 & 410 a 560 \\
\hline AE 355 & S 355 & 510 a 680 & 490 a 630 \\
\hline A 490 & E 295 & 490 a 660 & 470 a 610 \\
\hline A 590 & E 335 & 590 a 770 & 570 a 610 \\
\hline A 690 & E 360 & 690 a 900 & 670 a 830 \\
\hline
\end{tabular}

En definitiva, la resistencia a la tracción/compresión depende del acero considerado y del espesor de la tubería, pero los valores oscilan entre 300 y $900 \mathrm{MPa}$. 
4. Alargamiento: el acero L 235 presenta un alargamiento mínimo en la rotura longitudinal del $25 \%$ y $23 \%$ en la rotura transversal. Otros aceros como los L 275 y L 355 muestran valores menores, 21\% y 19\% respectivamente.

5. Dureza: el acero tiene dureza de 175-300 Brinell.

6. Coeficiente de dilatación: $1.210^{-5} \mathrm{~m}^{-1}$.

7. Módulo Elástico: $\mathrm{E}=2.110^{6} \mathrm{~kg} / \mathrm{cm}^{2}$.

8. Otros: el acero es fácilmente soldable, presenta baja fragilidad y un amplio rango de tipos de juntas y diámetros disponibles. Asimismo, es muy resistente a condiciones externas de operación, e incluso puede soportar presiones internas de 400 m.c.a. Los tubos de acero se pueden adaptar a las exigencias de funcionamiento concreto sin necesidad de un sobredimensionamiento excesivo por mor de los numerosos aceros existentes y del amplio escalonamiento posible de los espesores. Como tubos flexibles que son, exigen una cuidadosa compactación de los rellenos de las zanjas.

Mecanismos de deterioro

La corrosión es la mayor desventaja de los aceros ya que el hierro se oxida con suma facilidad incrementando su volumen y provocando grietas superficiales que posibilitan el progreso de la oxidación hasta que se consume la pieza por completo. Tradicionalmente los aceros se han venido protegiendo mediante tratamientos superficiales diversos, si bien existen aleaciones con resistencia a la corrosión mejorada como los aceros inoxidables.

Todos los tubos y piezas especiales deben protegerse con revestimientos exteriores e interiores, que recubran uniformemente la totalidad de sus contornos y que constituyan superficies lisas y regulares, exentas de defectos tales como cavidades o burbujas. El revestimiento, preferiblemente de secado rápido, se debe adherir adecuadamente al acero, sin exfoliación ni descascarillado. Para todo tipo de revestimientos empleado, las condiciones exigibles son las siguientes:

1. Protección del acero contra el medio corrosivo en que esté situado.

2. Impermeabilidad al medio corrosivo.

3. Buena adherencia a la superficie de la tubería a proteger.

4. Resistencia a la abrasión, choques, variaciones de temperatura, etc.

5. Baja rugosidad, en el caso de protecciones interiores.

Los revestimientos de tipo metálico, epoxi y con mortero de cemento se emplean tanto en las superficies exteriores e interiores de los tubos de acero. En cambio, los de tipo plástico únicamente se utilizan en la superficie exterior de los mismos (Tabla 16). 
TAbla 16. ReVestimientos habituales en los tubos de ACERO (CedeX, 2006).

\begin{tabular}{|c|c|c|c|c|c|}
\hline \multicolumn{2}{|c|}{ Tipo de revestimiento } & \multirow{2}{*}{$\begin{array}{c}\begin{array}{c}\text { Normativa de } \\
\text { aplicación }\end{array} \\
\text { UNE-EN } \\
\text { 22063:1994 }\end{array}$} & \multirow{2}{*}{$\begin{array}{c}\text { Aplicabilidad } \\
\text { Interior o } \\
\text { Exterior }\end{array}$} & \multirow{2}{*}{$\begin{array}{c}\text { Espesor mínimo } \\
\text { erv } \\
120 \mu \mathrm{m}\end{array}$} & \multirow{2}{*}{$\begin{array}{c}\text { Otras } \\
\text { Riqueza en Zinc } \\
1200 \mathrm{~g} / \mathrm{m}^{2}\end{array}$} \\
\hline$\stackrel{\text { ? }}{\stackrel{0}{2}}$ ? & $\begin{array}{l}\text { Metalización } \\
\text { (cincado) }\end{array}$ & & & & \\
\hline 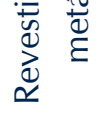 & Galvanizado & $\begin{array}{l}\text { UNE 37501:1988 } \\
\text { UNE 37508:1988 }\end{array}$ & $\begin{array}{l}\text { Interior o } \\
\text { Exterior }\end{array}$ & & \\
\hline \multirow{4}{*}{ 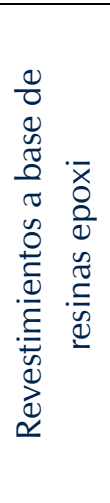 } & Epoxi líquido & $\begin{array}{l}\text { AWWA C210-97 } \\
\text { prEN 10289:2001 }\end{array}$ & $\begin{array}{l}\text { Interior o } \\
\text { Exterior }\end{array}$ & $200 \mu \mathrm{m}$ & $\begin{array}{l}\text { Res. Tracción } \\
2.7 \mathrm{~N} / \mathrm{mm}^{2}\end{array}$ \\
\hline & Epoxi en polvo & $\begin{array}{l}\text { AWWA C213-96 } \\
\text { prEN 10310:2001 }\end{array}$ & $\begin{array}{l}\text { Interior o } \\
\text { Exterior }\end{array}$ & $\begin{array}{l}380 \mu \mathrm{m} \text { (int) } \\
300 \mu \mathrm{m} \text { (ext) }\end{array}$ & $\begin{array}{l}\text { Res. Tracción } \\
20.6 \mathrm{~N} / \mathrm{mm}^{2}\end{array}$ \\
\hline & $\begin{array}{l}\text { Epoxi reforzado } \\
\text { con fibra de } \\
\text { vidrio }\end{array}$ & & $\begin{array}{c}\text { Interior o } \\
\text { Exterior } \\
\text { No apta para } \\
\text { agua potable }\end{array}$ & $300 \mu \mathrm{m}$ & $\begin{array}{l}\text { Res. Tracción } \\
3.7 \mathrm{~N} / \mathrm{mm}^{2}\end{array}$ \\
\hline & $\begin{array}{l}\text { Epoxi sin } \\
\text { disolvente }\end{array}$ & & $\begin{array}{l}\text { Interior o } \\
\text { Exterior }\end{array}$ & $200 \mu \mathrm{m}$ & $\begin{array}{l}\text { Res. Tracción } \\
2.5-3 \mathrm{~N} / \mathrm{mm}^{2}\end{array}$ \\
\hline \multirow{4}{*}{ 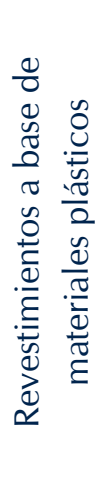 } & Polietileno & DIN 30670:1991 & Exterior & 1.8 a $5 \mathrm{~mm}$ & \\
\hline & Poliuretano & $\begin{array}{l}\text { DIN 30671:1992 } \\
\text { prEN 10290:2001 }\end{array}$ & Exterior & $800 \mu \mathrm{m}$ & \\
\hline & Cintas plásticas & $\begin{array}{l}\text { AWWA C203-91 } \\
\text { AWWA C209-91 } \\
\text { AWWA C214-00 }\end{array}$ & Exterior & $1150 \mu \mathrm{m}$ & $\begin{array}{l}\text { Res. Tracción } \\
3.7 \mathrm{~N} / \mathrm{m} \text { ancho }\end{array}$ \\
\hline & Poliolefinas & $\begin{array}{l}\text { AWWA C215-88 } \\
\text { AWWA C217-90 } \\
\text { MR0274: } 1995 \\
\text { RP0185:1996 }\end{array}$ & Exterior & & \\
\hline \multicolumn{2}{|c|}{$\begin{array}{l}\text { Revestimientos de } \\
\text { mortero de cemento }\end{array}$} & AWWA C205-00 & $\begin{array}{l}\text { Interior o } \\
\text { Exterior }\end{array}$ & $\begin{array}{c}6 \mathrm{~mm}(\mathrm{DN} \leq 250) \\
8 \mathrm{~mm}(250<\mathrm{DN} \leq 600) \\
10 \mathrm{~mm}(600<\mathrm{DN} \leq 900) \\
13 \mathrm{~mm}(\mathrm{DN}>900)\end{array}$ & \\
\hline
\end{tabular}

La protección catódica es el otro mecanismo para evitar la corrosión en tuberías de acero. En este caso, se deben seguir las mismas especificaciones definidas en la protección catódica de tuberías de fundición dúctil. 


\subsubsection{Tuberías de hormigón}

Los tubos de hormigón se emplean para grandes diámetros (normalizados en UNEEN) y para presiones medias y elevadas. Se emplean, por tanto en redes arteriales y en aducciones.

Pueden ser, en general, de los siguientes tipos:

- Tubos de hormigón armado sin camisa de chapa.

- Tubos de hormigón con armadura difusa, sin camisa de chapa.

- Tubos de hormigón armado con camisa de chapa.

- Tubos de hormigón pretensado sin camisa de chapa.

- Tubos de hormigón pretensado con camisa de chapa.

Debido a la escasa resistencia a la tracción del hormigón, no se pueden utilizar tubos de hormigón en masa para transporte de agua a presión, y es necesario recurrir al hormigón armado (bien con armaduras activas o pasivas) para poder resistir adecuadamente los esfuerzos de tracción. Además, en los tubos sin camisa de chapa, puede producirse entrada de agua externa y contaminación en el caso de niveles freáticos altos y/o terrenos contaminados por vertidos, por lo que son inadmisibles en el caso de agua potable (CEDEX, 2006). Los tubos de hormigón con armadura difusa sin camisa de chapa, por su parte, son de muy rara utilización en España y los pretensados sin camisa de chapa están en desuso.

\section{Características físicas fundamentales}

Se denomina hormigón pretensado a aquél que dispone de unos elementos estructurales (fundamentalmente cables de acero) sometidos intencionadamente a esfuerzos de compresión previos a su puesta en servicio. Esta tensión se aplica a los cables de acero que son tensados y anclados al hormigón. De este modo, se supera la debilidad natural del hormigón a los esfuerzos de tracción.

El hormigón pretensado con camisa de chapa se compone de los siguientes componentes:

- Núcleo de hormigón. Aprovecha la resistencia a compresión del hormigón.

- Cilindro de acero (chapa). Actúa como membrana impermeable.

- Barras pretensadas. Mantienen el núcleo de hormigón a compresión.

- Revestimiento de mortero. Protege las barras frente a la corrosión. 
Existen dos tipos de hormigón pretensado con camisa de chapa, según la disposición de sus elementos (Figura 24):

a) Cilindro alineado (hormigón añadido por la cara interna del cilindro). El rango de diámetros es amplio, desde 400 hasta $1500 \mathrm{~mm}$. El cilindro de acero se encuentra entre el núcleo de hormigón y el revestimiento de mortero, y las barras de acero son envolventes sobre el cilindro.

b) Cilindro encamisado (hormigón añadido a ambas caras del cilindro). El rango de diámetros es todavía superior al anterior tipo, con un valor mínimo de 750 y máximo de $6000 \mathrm{~mm}$. El cilindro de acero se sitúa dentro del núcleo de hormigón y las barras de acero son envolventes sobre el mismo núcleo.

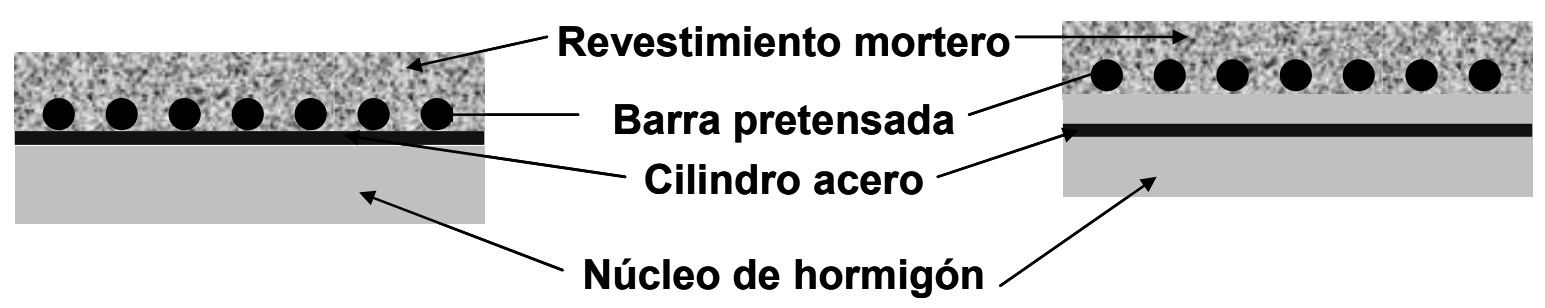

FIGURA 24. POSICIÓN DE LOS DISTINTOS COMPONENTES QUE SE UTILIZAN PARA EL HORMIGÓN EN CASO DE SER DE TIPO CILINDRO ALINEADO, (PARTE IZQDA) O CILINDRO ENCAMISADO (PARTE DERECHA).

\section{Dimensiones}

Se fabrica para una alta gamma de diámetros, entre 200 y $5000 \mathrm{~mm}$, e incluso valores superiores, si bien el rango de mayor utilización se sitúa entre los 600 y los 2000 mm. Son tuberías normalizadas hasta diámetros de 4000 mm.

\section{Propiedades}

Los materiales a emplear en los tubos de hormigón armado y pretensado, deben cumplir con lo especificado en la vigente instrucción de hormigón estructural, EHE. Otras características fundamentales se subrayan a continuación.

1. Resistencia a la tracción: Las cargas de tracción son soportadas por los alambres pretensados y por tanto, la sección de éstos determinarán la resistencia a la tracción de los mismos y no se proporciona un valor guía o referencia. El diámetro de los alambres de pretensado suelen oscilar entre los 5 y $8 \mathrm{~mm}$. Cuando se seleccionan los alambres que pueden ser empleados como armaduras activas se exige que la estricción ${ }^{15}$ de las mismas tras el ensayo de tracción no sea inferior a los valores mostrados en la Tabla 17.

\footnotetext{
${ }^{15}$ La estricción es la reducción de la sección que se produce en la zona de la rotura.
} 
TABLA 17. ALAMBRES DE PRETENSADO. VALORES MÍNIMOS DE LA ESTRICCIÓN TRAS EL ENSAYO DE TRACCIÓN EN PORCENTAJE (CEDEX, 2006).

\begin{tabular}{ccccc}
\hline $\begin{array}{c}\text { Diámetro } \\
\text { alambre }(\mathbf{m m})\end{array}$ & \multicolumn{5}{c}{ Carga unitaria máxima a tracción del acero, $\mathrm{f}_{\max }\left(\mathbf{N} / \mathbf{m m}^{2}\right)$} \\
\hline 5 & $\mathbf{1 5 0 0}$ & $\mathbf{1 6 0 0}$ & $\mathbf{1 7 0 0}$ & $\mathbf{1 8 0 0}$ \\
\hline 6 & 35 & 34 & 32 & 31 \\
7 & 34 & 33 & 31 & 30 \\
8 & 33 & 32 & 30 & - \\
\hline
\end{tabular}

2. Resistencia a la compresión: como el hormigón es el encargado de soportar las cargas a tracción, la resistencia a compresión de la tubería es la propia de éste. No se facilita un valor por depender de la composición del mismo para adoptar un valor numérico.

3. Alargamiento: $1.5 \%$

4. Módulo elástico: $150 \mathrm{GPa}$.

5. Otros: la instalación conlleva altos costes de transporte por el elevado peso de la tubería. La manipulación in situ y la dificultad para cortar los tubos para adaptarlos a las condiciones propias de cada montaje suponen una limitación notable.

Mecanismos de deterioro

La protección de los alambres de pretensado es imprescindible para proteger de la corrosión que se produce por el alto índice de alcalinidad del cemento. Las armaduras activas transversales deben estar protegidas por un revestimiento exterior de hormigón (espesor mínimo $20 \mathrm{~mm}$ ) o mortero de cemento (espesor mínimo $15 \mathrm{~mm}$ ). El tipo y espesor del revestimiento vendrá impuesto por las características del medio en el que se instale el tubo.

El revestimiento exterior de hormigón se debe compactar de forma que se consiga un bajo índice de porosidad y permeabilidad. Por tanto, se requiere que la cantidad mínima de cemento sea de $400 \mathrm{~kg} / \mathrm{m}^{3}$, y que la relación máxima de agua y cemento 0.45 (UNE-EN 642:1995). En caso de que el revestimiento exterior fuera de mortero de cemento, los requerimientos son que tenga una relación de agua y cemento menor que 0.35 y de cemento y arena menor que 0.33 .

La corrosión de los cables de acero, incrustados dentro del núcleo de hormigón, se inhibe si existe una capa de óxido que recubra los mismos. Por tanto, se pretende crear esta capa mediante agentes químicos (cloruros y sulfatos). La corrosión de los cables depende de la disponibilidad de oxígeno, lo que está regulado por la porosidad del mortero de cemento externo. 
Un tipo de corrosión muy común es la fragilización por hidrógeno, hydrogen embrittlement, un proceso en el que el acero se vuelve frágil y se rompe por su exposición al hidrógeno. Debido a la rotura de cables, se reduce la resistencia a la tracción a un valor menor que el de las condiciones iniciales de diseño. El fallo sucede en cualquier tipo de cable (Figura 25) aunque es más susceptible cuando soporta mayores tensiones.

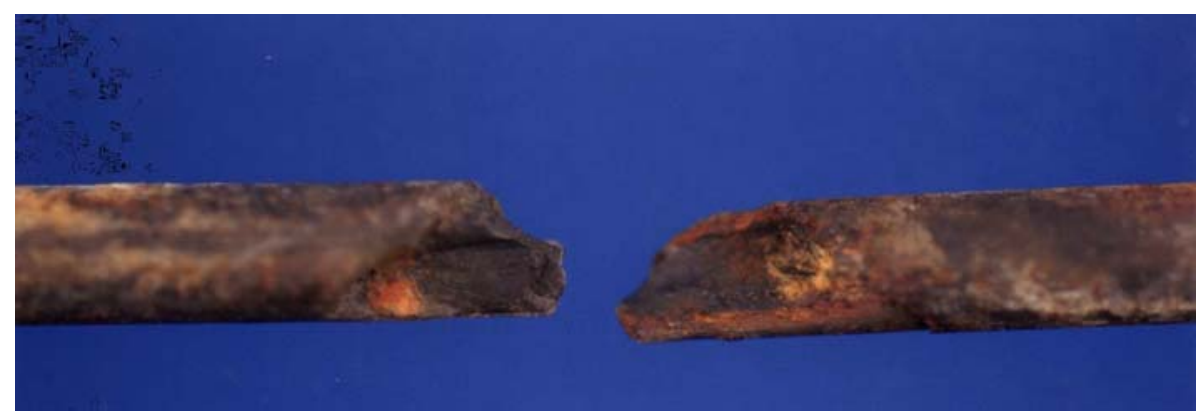

FIGURA 25. ROTURA FRÁGIL DE LOS ALAMBRES DE ACERO POR EXPOSICIÓN AL HIDRÓGENO.

El principal problema de estas tuberías consiste en que el fallo es repentino y catastrófico (Figura 26, Figura 27). Asimismo, debido a que las tuberías de hormigón tienen un elevado diámetro, pertenecientes a la red arterial de la ciudad y generalmente no redundantes. Por tanto, la inspección de las mismas, aunque es costosa en términos económicos ya que se debe realizar en su pared interna, debe ser planificada para reducir el riesgo. Generalmente, se buscan marcas de corrosión y decapado, o desprendimiento de capa de mortero de cemento como indicativo de una próxima rotura.

En contrapartida, éste es el material que mejor se comporta frente a roturas, ya que rara vez presenta fugas en el tubo, si bien su punto débil son las juntas (tanto elásticas como soldadas).
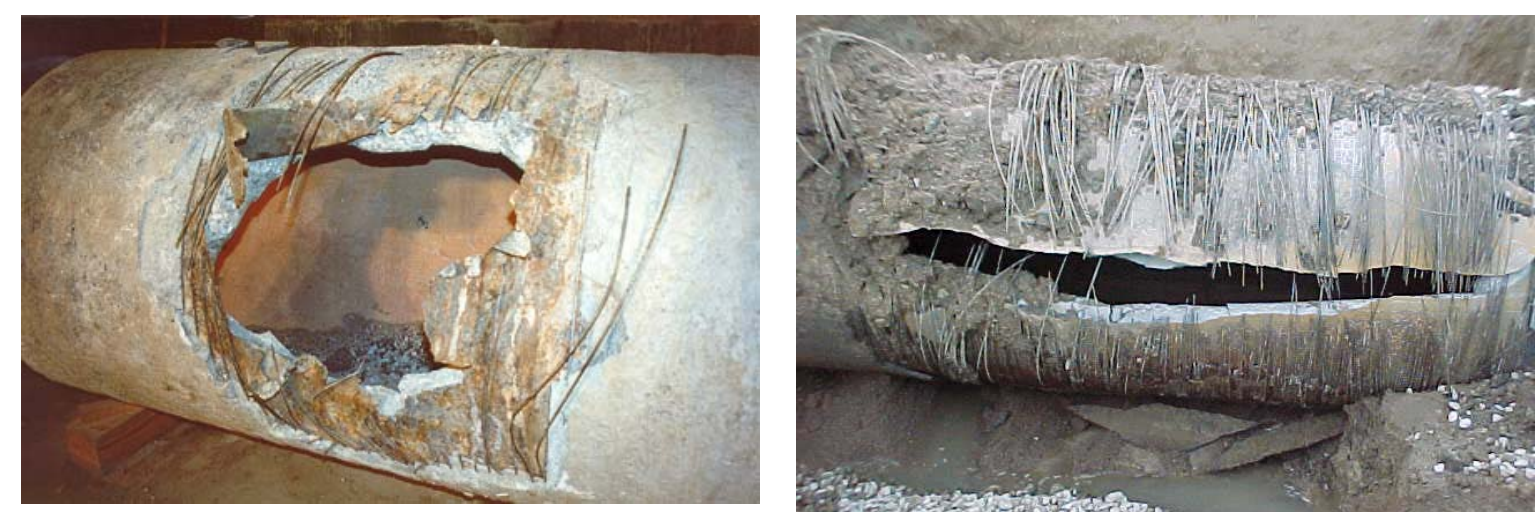


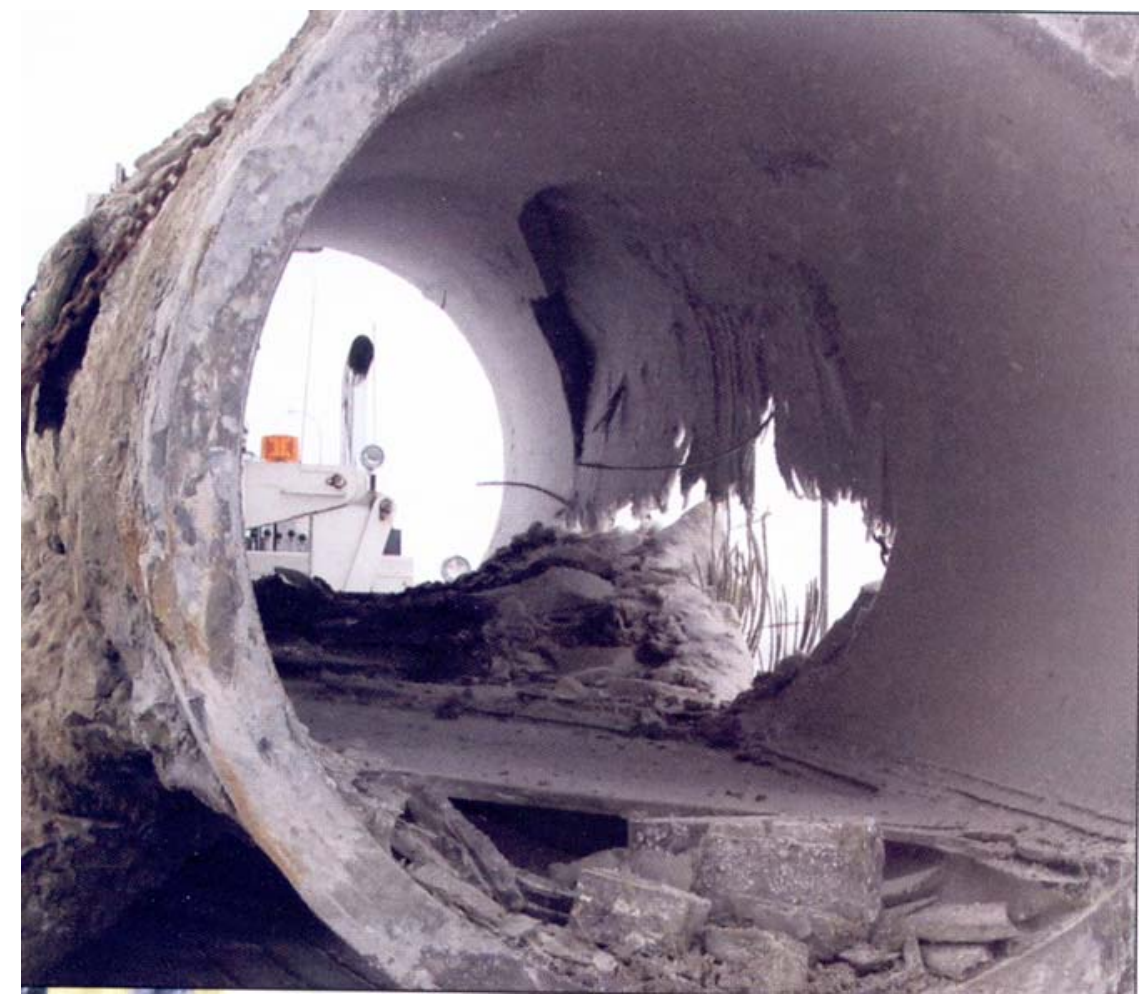

FIGURA 27. ROTURA DE TUBERÍAS DE GRAN DIÁMETRO HORMIGÓN ARMADO Y PRETENSADO (RAJANI, 2009A).

\subsubsection{Tuberías de policloruro de vinilo}

Las tuberías de policloruro de vinilo (PVC) tienen la condición de termoplásticos. Pueden ser de tres tipos, PVC-U (no plastificado), PVC-P (plastificado) y PVC-M (modificado). De estos tres, es el primero el que se emplea para la fabricación de tuberías. EI PVC-U, comúnmente designado PVC, es una resina que resulta de la polimerización del cloruro de vinilo. El procedimiento de fabricación usual de los tubos es la extrusión, mientras que las piezas especiales generalmente se fabrican por inyección en moldes o bien mediante manipulación a partir del tubo. La fabricación por unión mediante soldadura o pegamento, se realiza en fábrica y no se considera una solución adecuada para pequeños diámetros.

Los tubos y piezas especiales de PVC deben cumplir la norma europea EN 1452, que se transpone como norma UNE-EN 1452:2000 y sustituye a la antigua norma UNE 53112:1988.

\section{Dimensiones}

Las tuberías de PVC se pueden fabricar para diámetros de hasta $1000 \mathrm{~mm}$, presentando su máxima aplicabilidad hasta el diámetro $700 \mathrm{~mm}$. Se suele fabricar en longitudes de $6 \mathrm{~m}$. 
Propiedades

1. Densidad: $1.35-1.46 \mathrm{~g} / \mathrm{cm}^{3}$.

2. Módulo de elasticidad a corto plazo: $3000-3600 \mathrm{~N} / \mathrm{mm}^{2}$.

3. Módulo de elasticidad a largo plazo: $1750 \mathrm{~N} / \mathrm{mm}^{2}$.

4. Dureza: a $20^{\circ} \mathrm{C}, 70-85$ Shore $^{16}, 3.3-4.3 \mathrm{MPa} \mathrm{m}^{1 / 2}$.

5. Coeficiente de Poisson: 0.35.

6. Resistencia al impacto: $<10 \%$.

7. Resistencia a la tracción: 34-62 MPa.

8. Resistencia a la compresión: 55-90 MPa.

9. Resistencia a la flexión: 69-110 MPa.

10. Modulo elástico: 24-41 MPa.

11. Módulo elástico: 165-180 GPa.

12. Otros: la ligereza del PVC implica mayor simplicidad en la instalación de los tubos en obra. Presenta baja rugosidad, por lo que dispone de una mayor capacidad hidráulica frente a otros materiales, y una elevada resistencia al ataque químico. Otras características son un elevado coeficiente de dilatación térmica y una disminución de la resistencia y módulo de elasticidad con el tiempo. El PVC es mecanizable en obra (se puede cortar, taladrar, roscar, etc.) y el tipo de unión habitualmente empleado (flexible, de enchufe y campana) es de fácil colocación.

Mecanismos de deterioro

El envejecimiento puede ser debido a:

- Factores ambientales. Así se designan la temperatura ambiente, oxígeno atmosférico, radiaciones solares, medios agresivos, etc. a los que está sometido el PVC por efecto del entorno. De los anteriores, el más perjudicial para las tuberías plásticas es la acción de los rayos UV. EI PVC presenta un menor deterioro por esta causa que otros materiales plásticos como el polietileno. Para impedir dicha degradación, se utilizan materiales estabilizadores como el estaño (en Norteamérica), o como el calcio y el zinc (en Europa). También se empleó el plomo aunque actualmente se encuentra en desuso.

\footnotetext{
${ }^{16}$ La dureza Shore se obtiene con el ensayo Barcol. Se basa en la reacción elástica del material cuando se deja caer sobre él otro material más duro. No produce ninguna huella y es de tipo no destructivo.
} 
- Factores funcionales. Por este nombre se conocen las características propias en su operación habitual (presión interna del agua, fatiga del material, esfuerzos mecánicos de tracción, compresión, flexión, agresión química irreversible del agua, esfuerzos térmicos, esfuerzos eléctricos, etc.).

Las roturas suelen tener forma de fisura o raja longitudinal, y aparecen por lo general cuando la tubería ya tiene ciertos años. Posiblemente, esto se debe al tipo de estructura molecular que se rigidiza longitudinalmente. La mayoría de los fallos de estas tuberías son longitudinales (Figura 28) y se producen en juntas. La proporción de roturas circulares es menor.

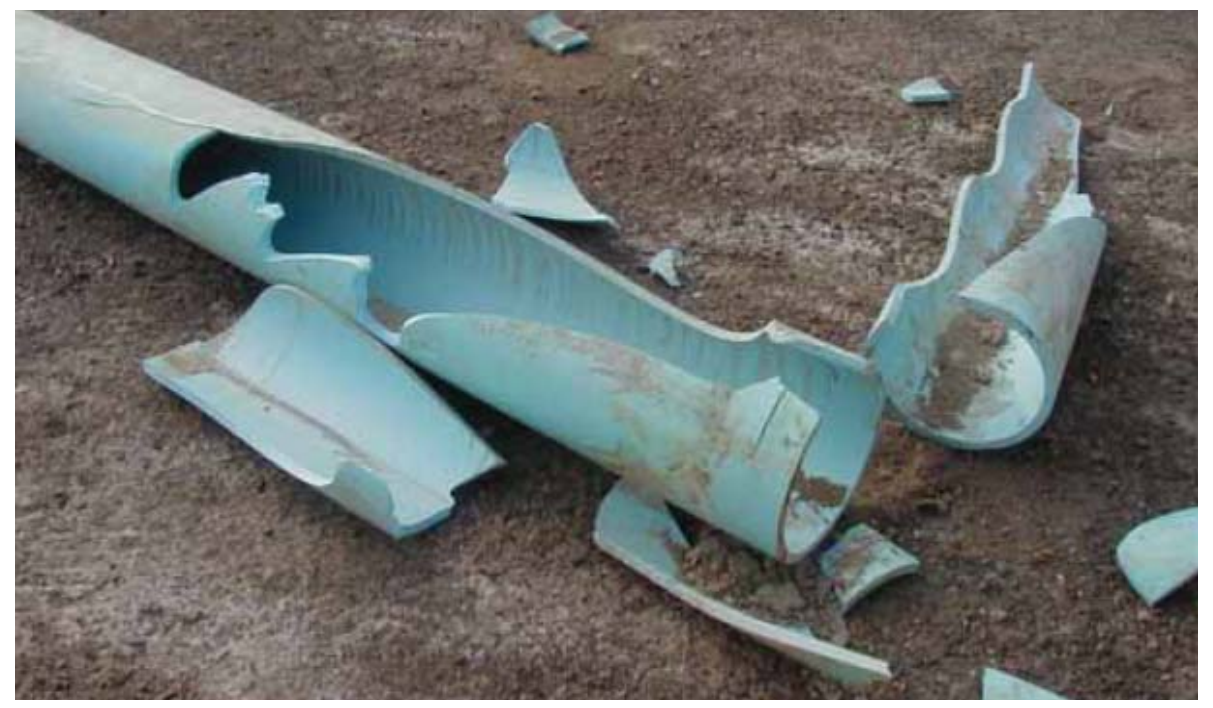

FIGURA 28. ROTURA LONGITUDINAL DE UNA TUBERÍA DE 300 MM DE PVC.

Como prácticas recomendables en todas las tuberías plásticas, no únicamente en el PVC, cabe resaltar que una cama de buena calidad y el relleno adecuado de la zanja son vitales para alargar la vida de la tubería. También es importante prestar especial atención durante las fases de transporte y de instalación, ya que la mayoría de los fallos de las tuberías plásticas son debidos a daños previos en la tubería. Asimismo, los arañazos y picaduras de tubería reducen sensiblemente su vida útil.

La vida útil requerida para una tubería destinada a la distribución de agua a presión es de 50 años. El valor inicial del coeficiente de seguridad es 5.5, y como éste es decreciente con el tiempo el valor estimado a los 50 años será de 1.5. Asimismo, el PVC suele verse muy afectado por la temperatura. En laboratorios, la rotura es dúctil y dependiente del tiempo debido a la fluencia y a la flexión. El tipo de rotura cambia de dúctil a frágil por efecto de las bajas temperaturas. 
Patrón de rotura

En un estudio realizado en el Reino Unido para tuberías de PVC con diámetros entre 50 y $500 \mathrm{~mm}$, se ha podido obtener la evolución de las roturas con la edad de la tubería (Rajani, 2009c).

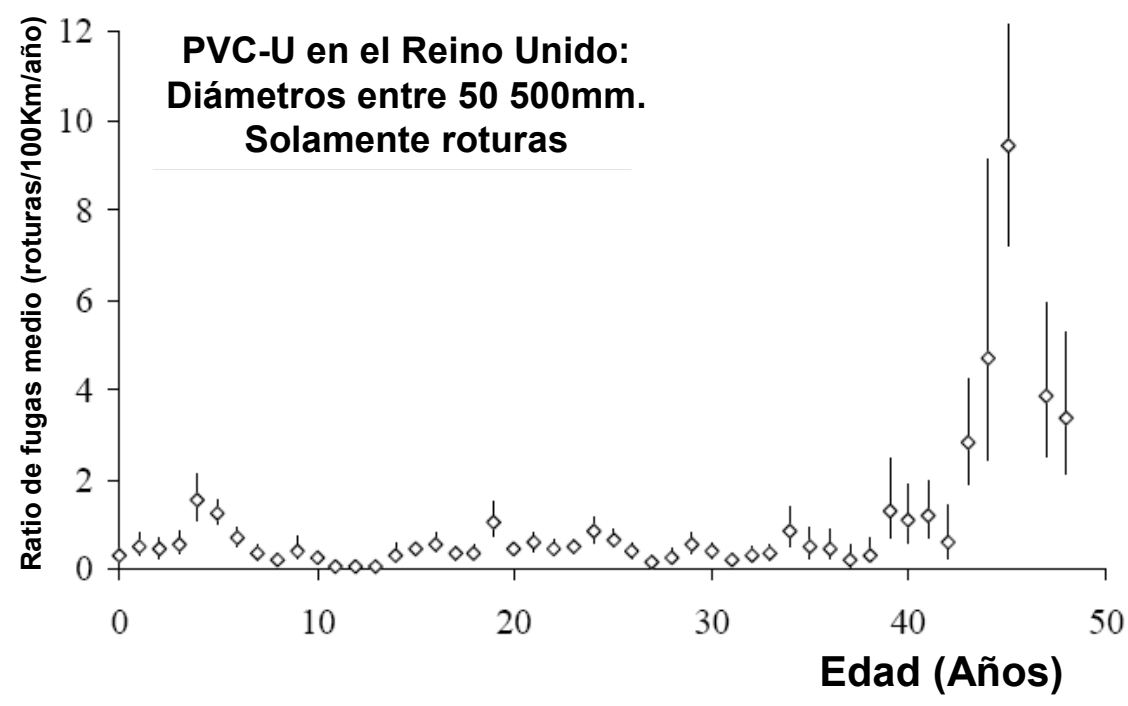

Figura 29. PATRÓN DE ROTURAS PARA tUberías DE PVC (RAJANI, 2009C)

El PVC, como el resto de tuberías termoplásticas, se degrada con el tiempo. Asimismo, es un material sensible a la exposición a productos químicos, a las juntas de plástico-metal y a los elevados coeficientes de expansión térmica. Quizá el mayor problema de este grupo de materiales es el conocimiento incompleto del mecanismo de degradación, y por ahora, no existe el procedimiento de conocer su comportamiento a largo plazo.
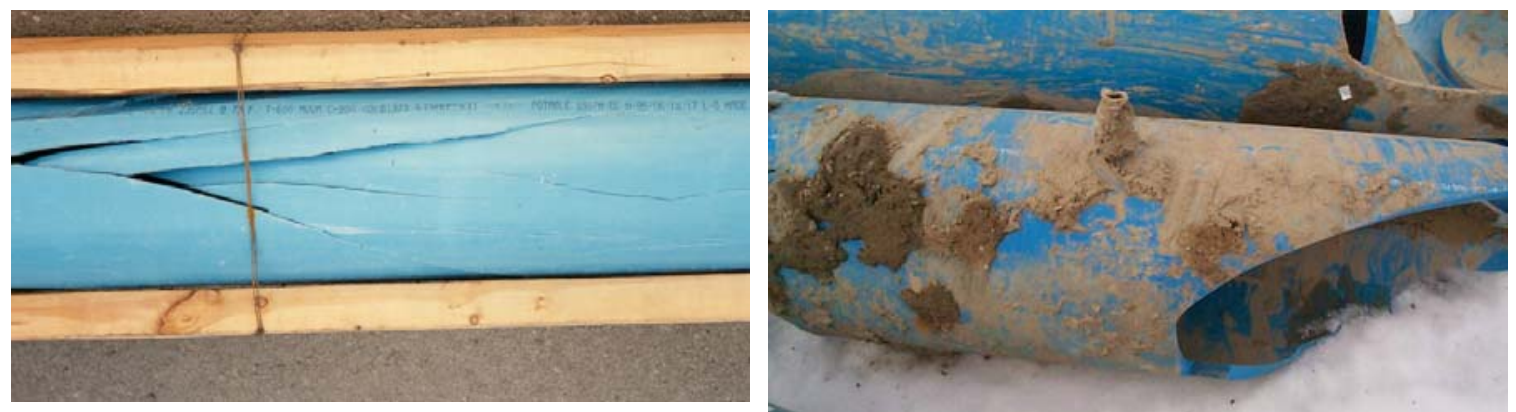

Figura 30. ROTURA FRÁGIL DE TUBERÍA DE PVC. 
Problemas medioambientales del PVC

Tanto a escala nacional como internacional, la asociación Greenpeace mantiene una postura abiertamente contraria al uso del PVC (Greenpeace, 2001). Según esta asociación "el PVC es un veneno medioambiental y los productos de PVC son tóxicos".

El 30\% de la producción mundial de cloro se emplea en la fabricación de PVC. Éste es un gas tóxico que al combinarse con sustancias orgánicas forma compuestos órgano clorados muy estables y con efectos perjudiciales para el medio ambiente y los seres vivos (especialmente en los sistemas inmunitario, reproductor, endocrino y nervioso). Por otra parte, el PVC necesita estabilizantes, plastificadores, biocidas, pirorretardantes ${ }^{17}$ y otros que contienen metales pesados (bario, estaño, plomo, cadmio, zinc) ftalatos o compuestos orgánicos extremadamente tóxicos. Estos aditivos se liberan de los productos de PVC durante su uso, contaminando el medio circundante.

Por estos motivos, Dinamarca adoptó en 1996 la decisión de eliminar progresivamente el uso del PVC e implantó la ley correspondiente (vigente para todos los usos de dicho material excepto en tuberías) en Septiembre del año 1999. Con anterioridad (1991) Luxemburgo ya había recomendado a las compañías que no instalasen tuberías de PVC en la ciudad de Luxemburgo, aunque sin una prohibición expresa. En Austria, está prohibido envasar todo tipo de bebidas y alimentos en PVC. Dos de los nueve estados austriacos no autorizan el uso de PVC en sus edificios públicos, y en tres de las capitales regionales está absolutamente prohibido. En Viena, varios centros hospitalarios están reemplazando los productos de PVC por otros de materiales alternativos.

En Lake in the Hills, Illinois, se produjo la primera prohibición expresa de utilización de este material ya en 1996. Algo similar sucedió en el estado de Kansas donde la prohibición se debió a la aparición de cloruro de vinilo en el agua de boca por la migración del material en tuberías mayores de 20 años. Por último, en Shiga city, Japón, también se prohibió la instalación de PVC a partir del año 2000. En esta ciudad, el 48\% de la longitud total de tuberías (680 Km) están compuestas de PVC.

\footnotetext{
17 Sustancia química que se añade a los materiales durante su fabricación con el doble fin de reducir la probabilidad de que el producto final se incendie y ralentizar su combustión.
} 
Éstos son algunos ejemplos que ilustran la problemática que se cierne sobre el uso del PVC en tuberías. Por el momento, aunque existen 62 ciudades que se han declarado "libres de PVC" (las más importantes de ese grupo son Barcelona, Bilbao, Córdoba y Sevilla) no existe en España una prohibición en la utilización de PVC en tuberías de agua potable. La situación actual es todavía compleja, y no se sabe como evolucionará, si hacia la prohibición expresa como en los casos anteriores, o hacia simples recomendaciones de no instalación como en el caso de Austria y Dinamarca.

\subsubsection{Tuberías de polietileno}

El polietileno PE se obtiene por polimerización del etileno. Por su alta producción mundial (60 millones de toneladas/año) es también el más barato, siendo uno de los plásticos más comunes. Existen dos procedimientos distintos que dan lugar al polietileno de baja densidad (LDPE) y al polietileno de alta densidad (HDPE).

\section{Características físicas fundamentales}

Este polímero puede ser producido por diferentes reacciones de polimerización: polimerización aniónica, por coordinación de iones, catiónica o por radicales libres (producción LDPE y HPDE si se realiza a bajas presiones y empleando catalizadores tipo Ziegler-Natta). Las cadenas de polietileno se agrupan bajo la temperatura de reblandecimiento en regiones amorfas y semicristalinas. La estructura es irregular y cuanto peor está agrupado es de menor densidad. El peso molecular del LDPE oscila entre $210^{4}$ y $610^{4} \mathrm{~g} / \mathrm{mol}$, en cambio, el HDPE presenta una mejor alineación de las cadenas $\mathrm{y}$, por tanto, un peso molecular entre $2 \cdot 10^{5} \mathrm{y}$ $4 \cdot 10^{5} \mathrm{~g} / \mathrm{mol}$.

Al igual que el PVC, el PE es un excelente dieléctrico que, en frío, resiste muy bien las acciones químicas. En cambio en caliente su resistencia es mucho menor.

La situación de la normativa aplicable en el diseño de los tubos de PE es compleja. En uno o dos años se publicará la norma europea EN 12201 que tratará sobre tubos de PE para conducción de agua a presión para consumo humano, y éstas deberán considerarse en el dimensionamiento de estos tubos.

\section{Dimensiones}

Las tuberías de PE se pueden fabricar para diámetros de hasta $1600 \mathrm{~mm}$, presentando su máxima aplicabilidad hasta el diámetro $1200 \mathrm{~mm}$. Se suele fabricar en longitudes de $12 \mathrm{~m}$. 
Propiedades

1. Densidad: LDPE tiene una densidad que oscila entre los valores 0.91-0.97 g/ $\mathrm{cm}^{3}$, mientras que para el HDPE ese rango es $0.94-0.97 \mathrm{~g} / \mathrm{cm}^{3}$.

2. Resistencia a la tracción: El rango de valores para LDPE es 7-16 MPa, y para el HDPE es 21-41 MPa.

3. Resistencia a la compresión: La resistencia a la compresión del LDPE es 11$17 \mathrm{MPa}$, y para HDPE es 17-22 MPa.

4. Resistencia a la flexión: Para el HDPE es 14-21 MPa, y en el caso del LDPE no existe la fractura por flexión (Rajani, 2009c).

5. Modulo elástico: El LDPE tiene un módulo elástico con valores comprendidos entre los 1-2.5 MPa, mientras que el HDPE tiene valores entre los 5.5-10.5 MPa.

6. Alargamiento: El alargamiento del LPDE, oscila entre el 90 y el $650 \%$, mientras que ese rango tiene los valores límites de 15 - 1000\% para el HDPE.

7. Uniones: Los tipos de uniones habituales son la soldada térmicamente a tope (calentar los extremos hasta una temperatura de $210^{\circ} \mathrm{C}$ y comunicar una determinada presión), la unión mediante accesorios mecánico (la estanqueidad se consigue al comprimir una junta sobre el tubo, a la vez que un elemento de agarre se clava ligeramente sobre el mismo para evitar el arrancamiento) y la electrofusión (rodear el tubo a unir por unos accesorios con espiras metálicas por la que circula corriente que por el calor desprendido por efecto Joule suelda el tubo con el accesorio).

8. Otros: El PE es un material ligero, lo cual simplifica notablemente las tareas de instalación de los tubos en obra. Presenta una baja rugosidad, y ello implica una mayor capacidad hidráulica frente a otros materiales, así como una elevada resistencia al ataque químico.

Mecanismos de deterioro

Los mecanismos de deterioro son los mismos que los de la tubería de PVC (en el apartado 2.3.4 se ha detallado el deterioro de los materiales plásticos de manera más extensa). Un mecanismo de protección contra el envejecimiento, causado por las radiaciones ultravioleta el calor y el oxigeno del aire, muy común en tuberías de PE consiste en añadir negro de humo (un absorbente y reflector de la radiación infrarroja) de partículas muy finas y disperso en la masa y material antioxidante (en proporción menor del $0.3 \%$ ). La vida de estas tuberías se espera esté entre los 5075 años. 
Problema del polietileno

En la actualidad, el principal problema del LDPE es el desprendimiento de una capa de polietileno tras el funcionamiento de la tubería durante cierto tiempo (aproximadamente 10-15 años). El deterioro de la tubería se debe a un decapado de la parte interna de la tubería y el posterior desprendimiento de una parte de la tubería que visualmente parece una serpiente (Figura 31). Se generan, por tanto, dos problemas, el primero es el descenso de la capacidad estructural de la tubería, mientras que el segundo es de tipo operacional, ya que el polietileno desprendido obstruye los contadores de agua y las válvulas de corte situados aguas abajo.
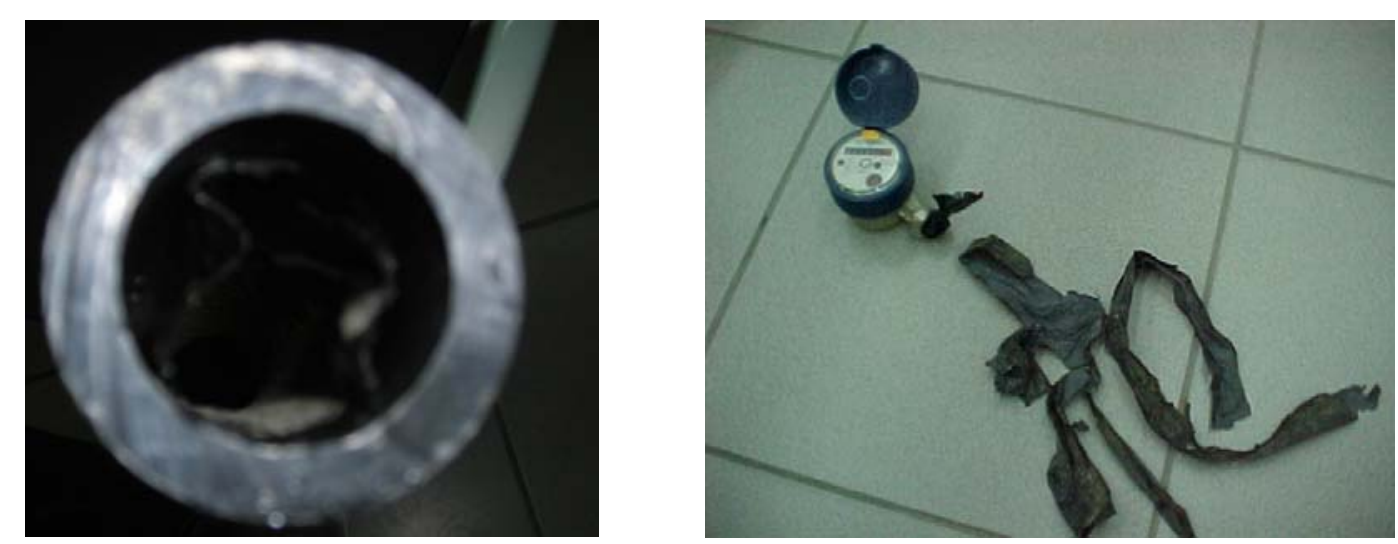

FIGURA 31. DECAPADO INTERNO DE LAS TUBERÍAS DE LDPE Y PROBLEMAS DE OBSTRUCCIÓN DE UN CONTADOR DOMICILIARIO (CORTESía de Aguas de VAlenCia).

Generalmente el LDPE se utiliza en el entronque con acometidas y ha sido empleado extensamente por las ventajas que comporta, fácil manejo y rápida conexión. En la Tabla 18, se muestran los materiales que componen las acometidas existentes en la red de alta presión para la ciudad de Valencia, y se puede observar que casi el $60 \%$ de las mismas están fabricadas en LDPE, por lo que existe un gran interés por conocer el deterioro de este tipo de material.

TABLA 18. TIPOS DE ACOMETIDAS POR MATERIAL EN LA RED DE VALENCIA.

\begin{tabular}{ccc}
\hline Acometidas por Materiales & Número & Porcentaje \\
Plomo & 6188 & $14.5 \%$ \\
Polietileno baja densidad & 24398 & $57.2 \%$ \\
Fundición & 9940 & $23.3 \%$ \\
Hierro galvanizado & 11 & $0.0 \%$ \\
Sin determinar & 2103 & $4.9 \%$ \\
\hline Total & $\mathbf{4 2 6 4 0}$ & \\
\hline
\end{tabular}


Aunque por el momento la causa de este problema es desconocido, los fabricantes creen que puede ser debido al efecto del cloro sobre las tuberías. No en vano, en el abastecimiento de la ciudad de Valencia se realizó una prueba que puede confirmar la afirmación anterior. En una tubería ciega se dejó una tubería de LDPE en contacto con el agua de la red durante un periodo de tiempo y se comprobó que se había producido la exfoliación en la parte exterior de la misma (ya que dicha tubería estaba Ilena de burbujas, Figura 32). Tras esto, aún sin una evidencia científica probada, casi se puede afirmar que la causa de dicho desprendimiento es el cloro, ya que fue el único elemento químico que estuvo en contacto con el tubo.

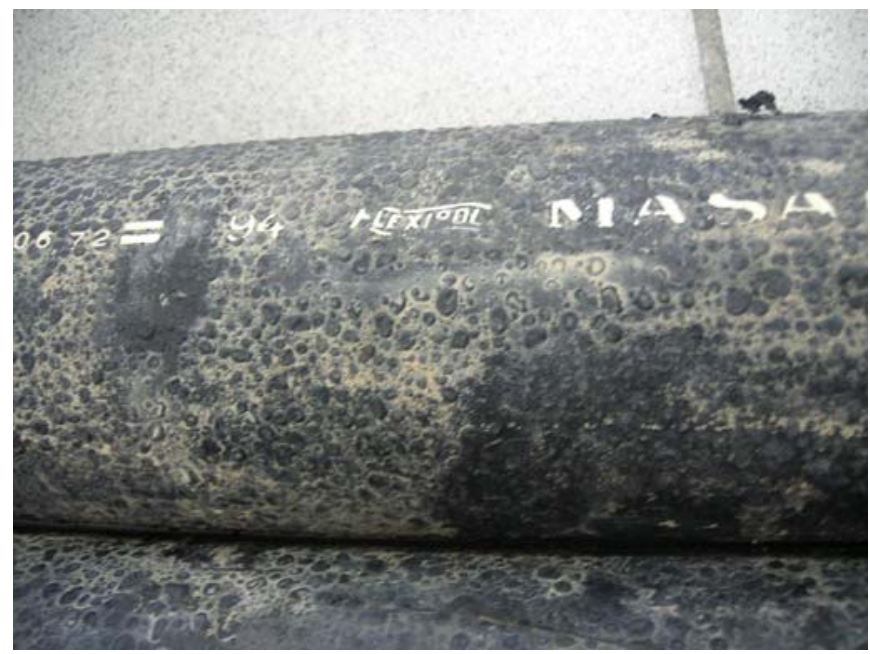

Figura 32. DeCapado exterior en una tubería de LDPE (Cortesía de Aguas de ValenCia).

Por tanto, el futuro de la tubería de baja densidad es incierto por el clima de preocupación surgido recientemente. Por el momento, ningún fabricante ha sabido justificar este problema, y la solución adoptada consiste en instalar HDPE, que aparentemente no se ve afectado por este problema. Esta problemática fue expuesta en el curso de Renovación y rehabilitación de redes de agua potable que se desarrolló en la universidad Politécnica de Valencia en junio de 2009 por el personal encargado del abastecimiento en la ciudad de Valencia. Ningún fabricante respondió a estas cuestiones. 


\subsubsection{Tuberías de policloruro de vinilo con orientación molecular}

En los últimos años, los materiales plásticos están sufriendo un proceso de continua evolución, apareciendo nuevos materiales que complementan o sustituyen a los tradicionales tubos de PVC o PE, tanto en el ámbito del abastecimiento y el regadío como en el de la edificación. Estos son los más representativos:

1. PVC con orientación molecular (PVC-O).

2. Polietileno reticulado (PE-X), que presenta mejor resistencia a la corrosión, abrasión.

3. PVC clorado (PVC-C), con mejores características mecánicas, resistencia química y alta resistencia al fuego.

4. Polipropileno (PP), que presenta una alta resistencia a las temperaturas extremas, al impacto y al aplastamiento.

De todos ellos, el más importante y común (lo que justifica este detalle) es el PVC-O. Se empezó a fabricar, hace más de 20 años, en el Reino Unido y su empleo se extendió a EEUU y Australia, mientras que su utilización en Francia o España comenzó aproximadamente en el año 1997. La fabricación de estos tubos se caracteriza por una reorientación circunferencial de las moléculas de una tubería de PVC. La estructura pasa de ser amorfa a laminar en la pared del tubo y mejoran notablemente sus características físicas y mecánicas. Se fabrican en continuo (a la salida de la línea extrusora del tubo de PVC-U convencional) o bien tubo a tubo de forma independiente.

Uno de los principales inconvenientes que hay para su uso es su escasa normalización. En la actualidad se está elaborando el proyecto de norma prISO 16422-4:2000 Pipes and joints made of oriented unplasticized poly(vinyl chloride) (PVC-O) for water transport. Specifications que a corto plazo se convertirá en norma europea EN y se asimilará a escala nacional como UNE-EN.

\section{Dimensiones}

Los tubos de PVC-O tienen la condición de termoplásticos y son utilizados habitualmente en el rango de diámetros pequeños (menores de $400 \mathrm{~mm}$ ) y presiones de hasta 20 bar. 


\section{Propiedades}

- Densidad: $1.42 \mathrm{~g} / \mathrm{cm}^{3}$.

- Módulo de elasticidad tangencial: $3500 \mathrm{~N} / \mathrm{mm}^{2}$.

- Módulo de elasticidad axial: $3000 \mathrm{~N} / \mathrm{mm}^{2}$.

- Límite elástico: $48 \mathrm{~N} / \mathrm{mm}^{2}$.

- Temperatura de reblandecimiento: $84^{\circ} \mathrm{C}$.

- Coeficiente de dilatación lineal: $0.510^{-4} \mathrm{~m} / \mathrm{m}^{\circ} \mathrm{C}^{-1}$.

- Número de Poisson: 0.41.

- Constante dieléctrica: 3.0 (a $60 \mathrm{~Hz}$ ).

- Otros: Las uniones entre los tubos deben ser flexibles, con embocadura y junta de anillo elastomérico, admitiéndose distintas tipologías. No deben admitirse nunca en este tipo de tubos uniones encoladas.

La principal característica de este material es su elevada resistencia, lo cual permite utilizar tubos de menor espesor para lograr las mismas prestaciones. A título orientativo, se ha dibujado una curva de referencia tipo de este material (Figura 33). Ésta, es más plana que en el resto de materiales termoplásticos, ya que la pérdida de resistencia mecánica con el paso del tiempo es menor, similar a otros materiales (los metálicos, por ejemplo).

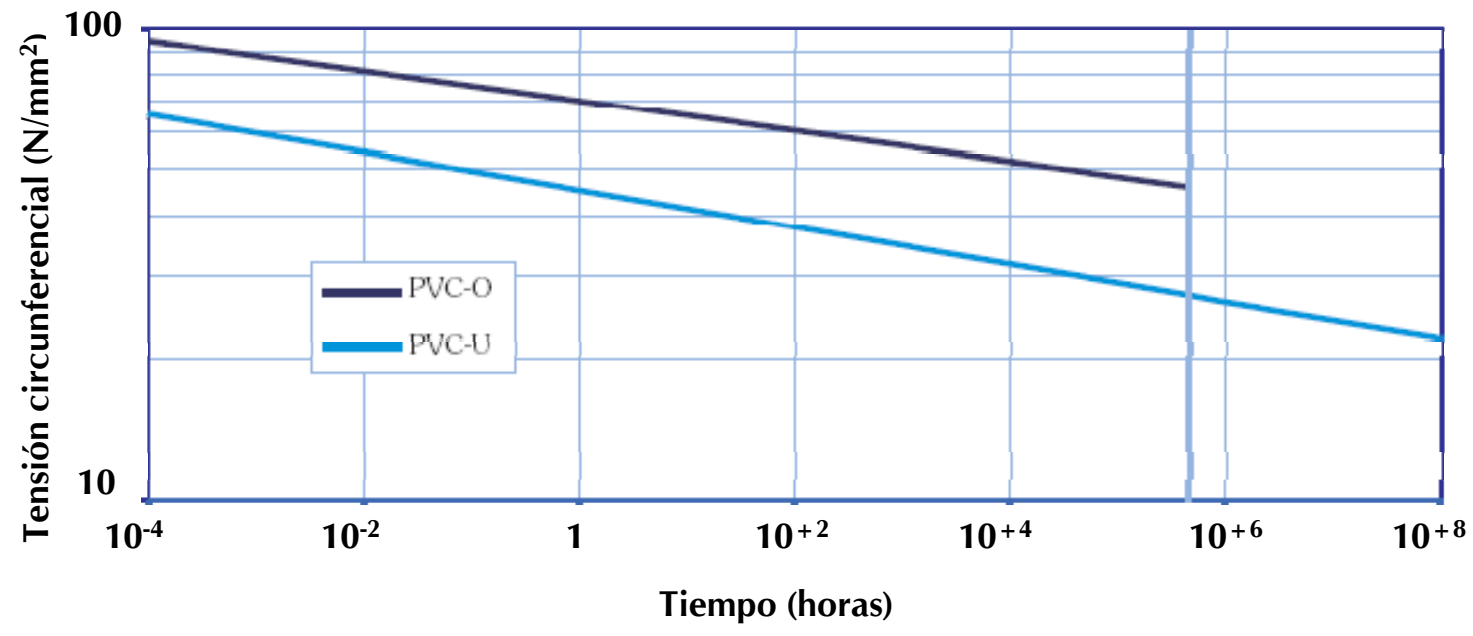

Figura 33. CuRVAS DE REFERENCIA EN TUbos DE PVC-U y PVC-O (CEDEX, 2006).

Mecanismos de deterioro

Los fabricantes aseguran una vida útil de las tuberías de PVC-O muy superior a los 50 años y justifican esa afirmación por la pendiente plana de la curva de regresión (Figura 33) y la inalterabilidad química de este material. La estructura laminar de la tubería reduce la evolución de daños como arañazos, grietas, impactos y erosiones. 
Es un material muy resistente a agentes químicos, por lo que se puede utilizar en instalaciones en las que existen límites de $\mathrm{pH}$ inferiores o superiores a los habituales en redes a presión.

\subsubsection{Tuberías de poliéster reforzado con fibra de vidrio}

Los tubos de PRFV tuvieron sus orígenes en los años 50 y fueron inicialmente concebidos para las industrias petrolífera y química. Para el transporte de agua (saneamientos o abastecimientos) comenzaron a utilizarse en los años 60. La primera obra realizada con tubería de PRFV se hizo en Suiza en el año 1963. Desde entonces se han instalado en todo el mundo más de 60000 kilómetros de tubería de PRFV en más de 50 países de los cinco continentes.

\section{Características físicas fundamentales}

Los materiales empleados en la fabricación del PRFV son una resina de poliéster no saturado, fibra de vidrio (que forma la estructura del tubo) y materiales que aporten resistencia estructural a la mezcla (si se emplean áridos, por ejemplo, éstos deberán tener un tamaño máximo de 1/5 del espesor de la pared del tubo ó como máximo $2.5 \mathrm{~mm}$ ).

Asimismo, se puede añadir ciertos aditivos que mejoran la calidad del producto. La adición de estos se realizará en cantidades tales que no se produzcan elementos tóxicos, ni provoquen crecimientos microbianos. Tampoco deben perjudicar el proceso de fabricación ni afectar a las propiedades físicas, químicas o mecánicas del material, especialmente en lo que se refiere a la resistencia a largo plazo y al impacto.

Los procedimientos habituales de fabricación son los siguientes:

- Material enrollado mecánicamente sobre mandril. El proceso de fabricación consta de la aplicación de los diferentes componentes encima de un mandril metálico fijo que realiza la función de molde interior. El mandril metálico realiza un movimiento de rotación sobre su eje, en el cual se van aplicando las resinas primeras mediante un cabezal inyector. Éste se desplaza en sentido longitudinal, y realiza un movimiento de ida y vuelta a una velocidad específica y proporciona el ángulo de aplicación de la fibra de vidrio deseado. El espesor de la pared de la tubería depende del número de avances que el cabezal realiza. Una vez conseguido el espesor y curada la resina, la tubería se extrae del mandril metálico. 
- Centrifugación. Se introduce en un molde cilíndrico una mezcla, en una proporción fijada, de resina, la fibra de vidrio y el material estructural. El curado de la resina y la compactación se producen por un aumento de la temperatura y una centrifugación a alta velocidad lo que hace que se desaloje el aire que pudiera haberse introducido en la pared del tubo durante la dosificación de los distintos componentes. Posteriormente, se enfría el molde y se retira el tubo.

\section{Dimensiones}

El rango habitual de los diámetros de las tuberías de PRFV es desde los 100 hasta los $2400 \mathrm{~mm}$, aunque se podrían incluso fabricar tuberías especiales de diámetro $3600 \mathrm{~mm}$. La longitud habitual de fabricación es 6 ó $12 \mathrm{~m}$.

\section{Propiedades}

- Resistencia a la tracción: los valores de la resistencia a la tracción y de la rigidez a largo plazo no están recomendados ni normalizados, sino que quedan pendientes de ser declarados por cada fabricante. Esto se debe a los distintos procesos de fabricación y su influencia sobre las características mecánicas del producto resultante. A título orientativo, la rigidez a largo plazo (50 años) suele ser del orden del $40 \%$ de la inicial y la resistencia a tracción suele oscilar entre 50 y 150 MPa. Sometido a tracción, se deforma proporcionalmente a ésta (por tanto, cumple la ley de Hooke), y la rotura se produce sin presentar fluencia previa.

- Densidad: el valor es superior a los $1.80 \mathrm{~g} / \mathrm{cm}^{3}$.

- Contenido en fibra de vidrio: mayor que el10\% en peso.

- Dureza Shore: es superior al $80 \%$ del valor correspondiente a la resina empleada. El incremento de la dureza debe ser inferior al $15 \%$ del valor inicial (CEDEX, 2006).

- Otros: El bajo peso del tubo facilita el transporte y la instalación. Tiene menores necesidades de mantenimiento. Las uniones más habituales son las rígidas (bridas y encoladas) y las flexibles (enchufe y extremo liso con anillo elastomérico, con manguitos y elemento de estanquidad).

\section{Mecanismos de deterioro}

Entre las ventajas de estos tubos debe destacarse la excelente resistencia que presentan a la abrasión y al ataque químico. Su ligereza y el que se fabriquen habitualmente en tramos de 12 metros de longitud, con la consecuente reducción del número de uniones, facilitan su instalación. 
Es necesario, al igual que el resto de tuberías plásticas, realizar ensayos a largo plazo que aseguren una vida útil superior a 50 años. Los ensayos a los que se somete la tubería son:

- $\quad$ Resistencia a largo plazo a la presión interna (UNE-EN 1447)

- Deflexión circunferencial a largo plazo en entorno acuoso (UNE-EN 1227)

- $\quad$ Rigidez circunferencial específica a largo plazo (UNE-EN 1225)

\subsubsection{Tuberías en desuso}

Las principales tuberías en desuso, la fundición gris y el fibrocemento, representan una elevada proporción en los abastecimientos de todo el mundo, lo cual justifica su estudio. Las causas de su actual desuso ya han sido expuestas, en el caso de la fundición gris la fragilidad y en el caso del fibrocemento, los efectos cancerígenos (asbestosis) de la inhalación de las fibras de amianto.

\subsubsection{Tuberías de fundición gris}

Características físicas fundamentales

La mayoría de las fundiciones grises son aleaciones hipoeutécticas que contienen entre 2.5 y $4 \%$ de carbono, así como pequeños porcentajes de fósforo y silicio. La colada se funde entre los 1200 y $1300{ }^{\circ} \mathrm{C}$ y se caracteriza porque parte del carbono se separa en forma de grafito al solidificarse, en un proceso denominado grafitización (Figura 20 y Figura 34) que se produce más fácilmente por altas temperaturas y en coladas con elevada concentración de carbono y silicio.

Si la composición y la velocidad de enfriamiento son tales que la cementita eutectoide también se grafitiza y la estructura resultante es totalmente ferrítica, fundición gris. La fundición gris constituida por mezcla de grafito y ferrita es la más blanda y la que menor resistencia mecánica presenta. La resistencia a la tracción y la dureza aumentan con la cantidad de carbono combinada que exista, y alcanza su valor máximo en la fundición perlítica, dúctil.
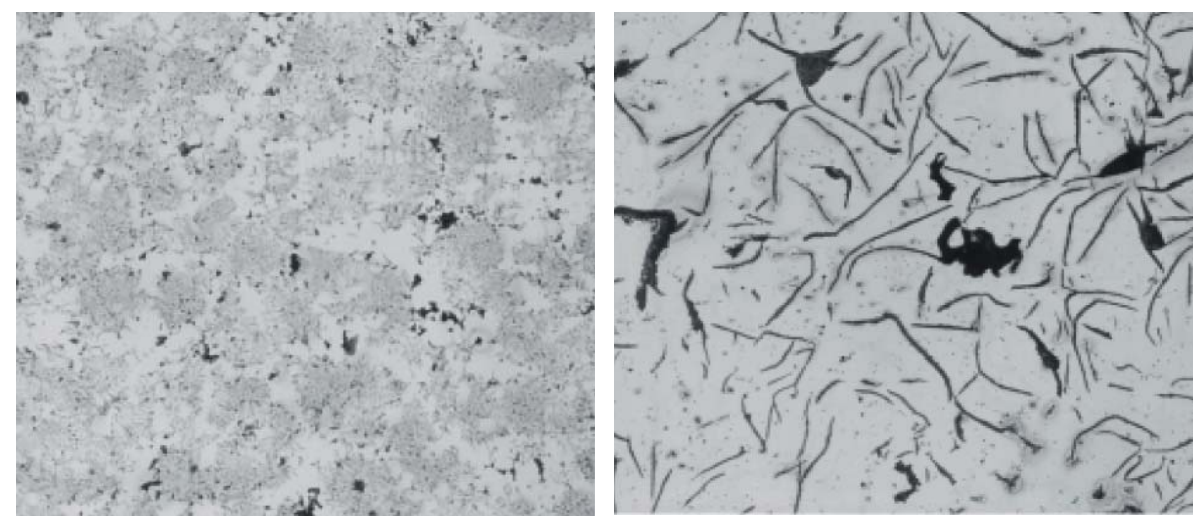

FIGURA 34. FUNDICIÓN GRIS CON TRAZAS DE GRAFITO (PARTE IZQDA) Y GRAFITO AGRUPADO CON FORMA DE RED (PARTE DERECHA). 


\section{Dimensiones}

Las tuberías de fundición gris se fabrican desde diámetros pequeños hasta grandes (1600 mm). Los diámetros comerciales Ilegan hasta los $600 \mathrm{~mm}$ según la norma (CEN/TC 203 wi015). La longitud habitual de fabricación es 3 m.

\section{Propiedades}

- Resistencia a la tracción: 100-160 MPa.

- Resistencia a la compresión: 180-400 MPa.

- Resistencia a la flexión: puesto que en la flexión las fibras del elemento quedan tensas en la parte convexa, y comprimidas en la cóncava, la resistencia a la flexión varia según la orientación de la sección.

- Resistencia al choque: el choque y la resiliencia son solicitaciones dinámicas y en ellas, la fundición gris se comporta de un modo particular, ya que resisten muy mal los choques y son frágiles porque no sufren deformaciones plásticas.

- Dureza: la dureza de la fundición gris es relativamente elevada, 140 a 250 Brinell según la composición de la colada.

- Resistencia química: la fundición tiene poca resistencia química, y se deteriora con los ácidos, los álcalis y las oxidaciones.

- Alargamiento: entre el 1 y el $2 \%$.

- Otras: la fundición gris no es dúctil ni maleable y se puede soldar al latón con soldadura oxiacetilénica y con soldadura eléctrica de arco. La fundición puede recibir baños galvánicos (ser niquelada, por ejemplo), ser galvanizada en caliente, estañada y esmaltada al fuego (piezas de uso doméstico y para la industria química)

\section{Mecanismos de deterioro}

La tubería de fundición gris se ve afectada fundamentalmente por corrosión galvánica. Los sistemas de protección de tuberías metálicas (tanto fundición gris como dúctil) contra la corrosión son, básicamente, el recubrimiento mediante revestimientos o la protección catódica. La información acerca del deterioro y la protección de la fundición gris es similar a la mostrada para la fundición dúctil (apartado 2.3.1).

Patrón de rotura

Un ejemplo de obtención del patrón de roturas en tuberías de fundición gris se muestra en trazos discontinuos en la Figura 35. En este caso de estudiaron las roturas en un grupo de tuberías de dicho material (de $150 \mathrm{~mm}$ y longitud total de 207 km) en Ottawa, Canadá. De acuerdo con estos datos (1107 roturas) y su disposición temporal, se consiguió trazar el patrón de roturas. 


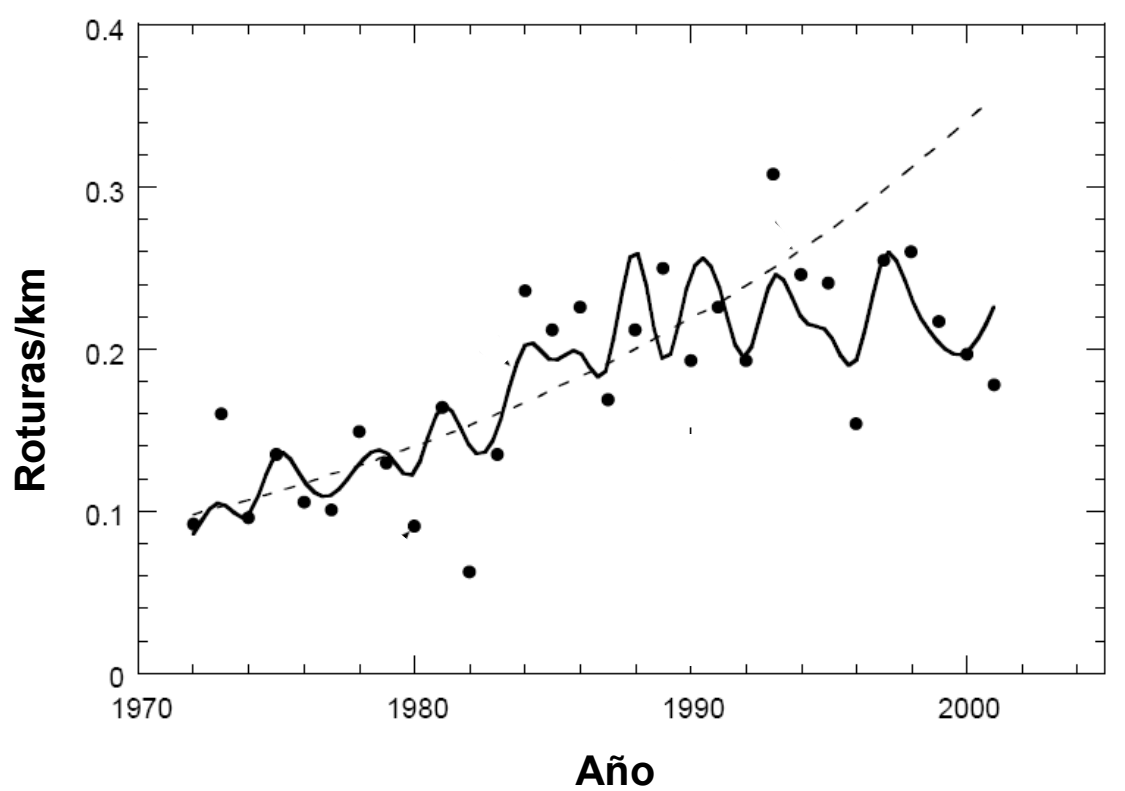

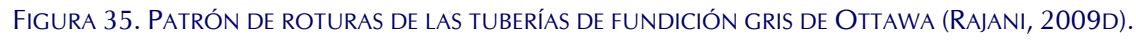

Los tipos de roturas más habituales de la tubería de fundición gris (construction innovation, 1999) son:

- Rotura circunferencial (parte derecha de la Figura 36), 80\% de las roturas aunque este porcentaje varía según los abastecimientos.

- Roturas en la campana (parte izquierda de la Figura 36). Éstas se deben a diferentes dilataciones térmicas de la tubería y de la junta.

- Roturas longitudinales, que se pueden prolongar a lo largo de la tubería.
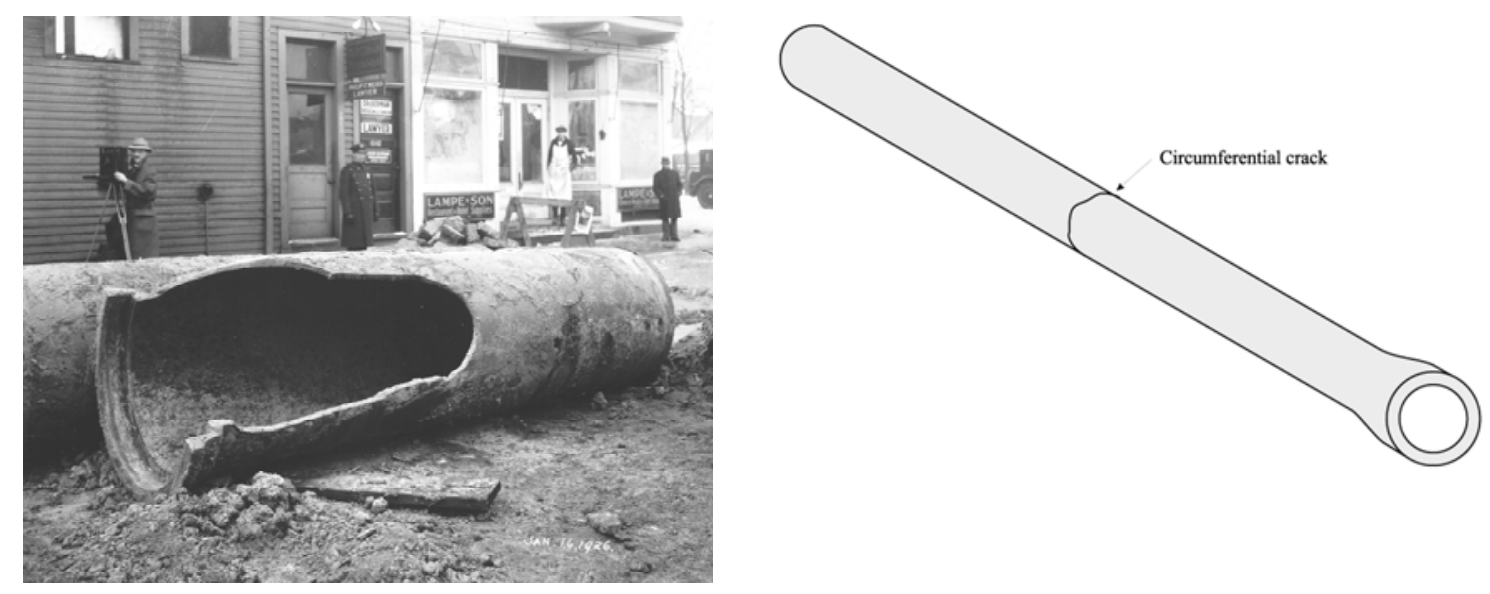

FIGURA 36. TIPOS DE ROTURA EN TUBERÍA DE FUNDICIÓN GRIS. 
La inspección regular es fundamental para evitar los fallos. Las tuberías de fundición gris suelen pertenecer a la red arterial y, por tanto, son de grandes dimensiones y generalmente no redundantes. La inspección de estas tuberías se debe centrar en las juntas, y se debe comprobar que los giros de las juntas están dentro de los límites permitidos. Asimismo, se debe buscar grietas en la campana (generalmente se encontrarán en la parte interna de la misma) aunque esto imposibilite la inspección con el sistema en funcionamiento. Las fugas en las juntas pueden ser las precursoras de una rotura, por lo que no se debe reparar la fuga únicamente, sino que cada caso exige un análisis en profundidad.

\subsubsection{Tuberías de fibrocemento}

El interés en la actualidad que todavía despierta el fibrocemento radica en que el $37.6 \%$ de las tuberías que se utilizan en los abastecimientos españoles están fabricadas en este material (MMA, 1998), aunque en poblaciones comprendidas entre los 50000 y 100000 habitantes, esa proporción puede llegar al 70\% de la longitud. Con ese elevado porcentaje son frecuentes las averías, nuevas conexiones o renovación en tuberías de fibrocemento.

\section{Características físicas fundamentales}

Las tuberías de fibrocemento se fabrican a partir de una mezcla de cemento portland, fibras de amianto y agua. Una capa delgada de la mezcla (de 0.1 a $0.2 \mathrm{~mm}$ ) se enrolla de una forma continua sobre una barra de acero, cuya longitud coincide con la del tubo que se desea fabricar. Las sucesivas capas, fuertemente comprimidas, originan el crecimiento progresivo del espesor de pared de la tubería hasta alcanzar la medida prevista.

A continuación, los tubos se sumergen en agua durante varios días y, posteriormente, se almacenan al aire libre. Durante este proceso han adquirido el endurecimiento necesario para soportar una presión de prueba equivalente al doble de la presión de servicio.

Una de las ventajas de la utilización del fibrocemento es que es muy económico en relación a otros materiales, tanto en inversión como en mantenimiento, además es también muy ligero. Para la fabricación de este material se utilizaba el amianto como fibra de refuerzo, pero cuando se hicieron patentes los problemas de salud que originaba, se fue abandonando paulatinamente su uso en los distintos países. Hasta ahora, los intentos de sustitución del amianto ó asbesto por otros tipos de fibras, como celulosa, fibra de vidrio o vinílicas han tenido poco éxito. 
El problema de la abstestosis se genera por inhalación del amianto, no por migración de las fibras en contacto con el agua. Por tanto, no hay que cambiar las tuberías instaladas urgentemente sino de manera gradual, ya que el coste de la renovación de todas las tuberías de fibrocemento en España sería prohibitivo. La seguridad en la operación de corte de las tuberías se garantiza por a la utilización de dispositivos de corte equipados con un sistema de inyección de agua (corte húmedo) o bien con la utilización de trajes de protección integral de polietileno. Ésta última posibilidad no evita la expansión del polvo producido por el corte, y aunque el técnico esté protegido, no lo está la zona circundante.

\section{Dimensiones}

Las tuberías de fibrocemento se podían fabricar para diámetros comprendidos entre los 50 y los $900 \mathrm{~mm}$, presentando su máxima aplicabilidad entre los 100 y $500 \mathrm{~mm}$.

\section{Propiedades}

1. Peso específico: $2 \mathrm{~g} / \mathrm{cm}^{3}$.

2. Coeficiente de dilatación lineal: $1.2 \times 10^{-5} \mathrm{~m}^{-1}$.

3. La curva de tensión-deformación: incluso en estados con poca tensión no es lineal. El proceso químico de fraguado de la mezcla de cemento portland, amianto y agua causa un incremento de la resistencia mecánica con el tiempo.

4. Resistencia química: Debido a su composición inorgánica, el fibrocemento resiste todo tipo de ataques biológicos. Los fenómenos electrolíticos no producen ningún tipo de corrosión en estos tubos, tampoco se oxidan ni se pudren por efecto de la humedad, son resistentes a los rayos ultravioleta y pueden permanecer al sol por largos períodos sin afectar a sus propiedades físicas y químicas.

5. Propiedades aislantes: El fibrocemento tiene una alta capacidad como aislante térmico y no es un conductor eléctrico. Por tal motivo, la corrosión electrolítica no puede ocurrir aun con corrientes inducidas.

\section{Mecanismos de deterioro}

La tubería de fibrocemento tiene buena resistencia a los ataques químicos del entorno, salvo de aquellos que sean ácidos ( $\mathrm{pH}$ menor que 6), contengan sulfatos (en concentración superior al $0.3 \%$ ) o tengan una alta alcalinidad. Los principales problemas de deterioro en tuberías de fibrocemento surgen con aguas blandas (dureza inferior a 3 grados hidrométricos franceses ${ }^{18}$ ).

\footnotetext{
${ }^{18}$ El grado francés es un indicativo de la dureza del agua, $1^{\circ} \mathrm{f}=10 \mathrm{mg} / \mathrm{l}$ de $\mathrm{CaCO}_{3}$
} 
Para evitar el desgaste de la tubería de este material, se emplean revestimientos internos de los siguientes tipos:

- Bituminoso: Elaborado a base de compuestos derivados de carbón y resistente a la acción de sales neutras, ácidos y álcalis diluidos. No resiste la acción de aceites grasos e hidrocarburos aromáticos.

- Epóxico: Revestimientos elaborado a partir de resinas epoxi, alquitrán de hulla y catalizador de amina. Resistente a la acción de álcalis, ácidos, abrasión y gasolina. La acción de la intemperie prolongada puede deteriorar el recubrimiento.

Finalmente, cuando se presenta la degradación química en estos tubos, ésta se manifiesta por un ablandamiento de la superficie de la tubería. Las fibras de amianto quedan al desnudo por la deposición de calcio, que se entrelazan formando un tejido semejante a un filtro, y establece una autoprotección del material contra el avance gradual del deterioro.

Debido a todas estas características, en condiciones normales, puede considerarse que la vida útil de los tubos de fibrocemento es prácticamente indefinida, ya que están constituidos por componentes inorgánicos y no metálicos.

\section{Patrón de rotura}

Un ejemplo de obtención del patrón de roturas en tuberías de fibrocemento se muestra en trazos discontinuos en la Figura 37. En este caso de estudiaron las roturas en $530 \mathrm{~km}$ de tuberías de fibrocemento con diámetros 100-400 mm en Regina, Canadá. El número de roturas registrado fue de 2282 y por su disposición temporal, se consiguió trazar el patrón de roturas. 


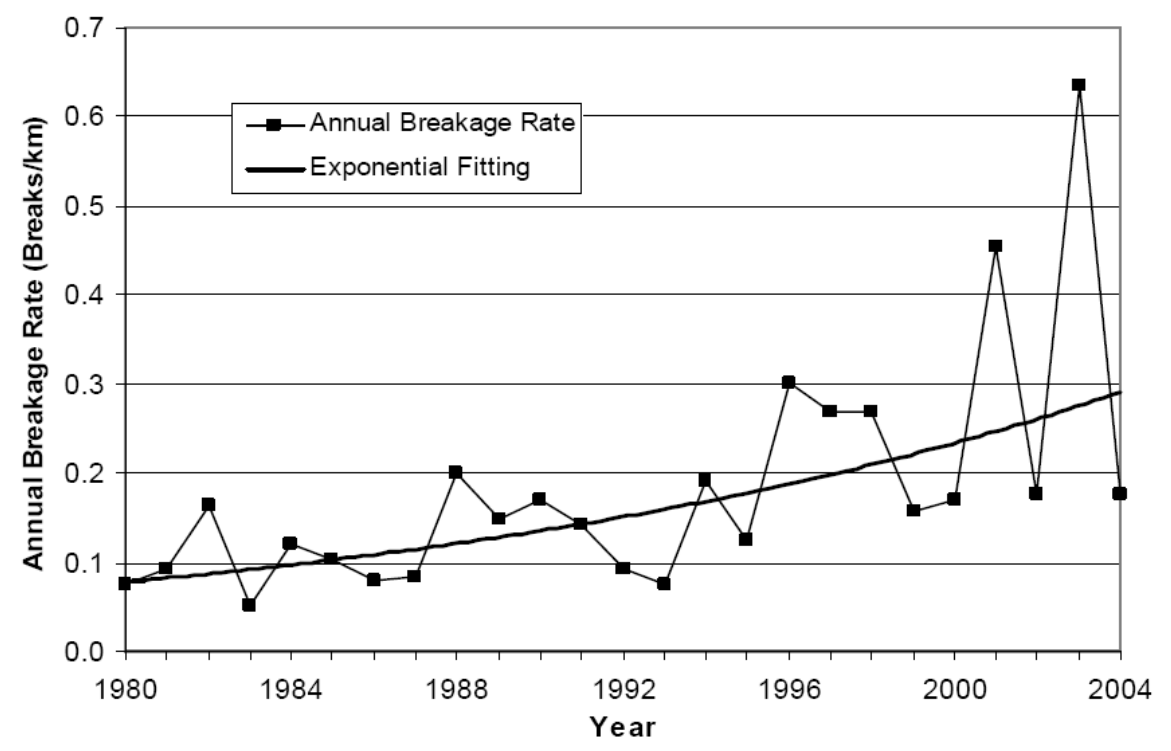

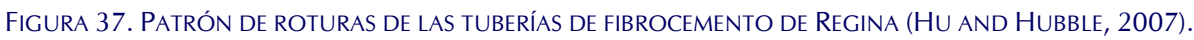

Las causas fundamentales de las roturas en el abastecimiento estudiado son el clima y el tipo de suelo. El movimiento del suelo adyacente a la tubería es la primera causa de las roturas circunferenciales. Otros factores, de menor relevancia tras el estudio, son la edad de la tubería, el diámetro de la conducción y los métodos de reparación y construcción. 


\subsubsection{Tablas resumen de las características de las tuberías según los materiales}

En este apartado se muestran resumidas las características de los materiales descritos. En principio, se muestran los diámetros normalizados de las tuberías.

TABLA 19. DIÁMETROS NOMINALES Y EXTERIORES DE TUBERÍAS (CEN/TC 203 WI015).

\begin{tabular}{|c|c|c|c|c|c|c|c|}
\hline \multirow{2}{*}{\multicolumn{2}{|c|}{$\begin{array}{c}\text { Fundición } \\
\text { gris }\end{array}$}} & \multirow{2}{*}{\multicolumn{2}{|c|}{$\begin{array}{l}\text { Fundición dúctil } \\
\text { UNE-EN 545:1995 } \\
\text { ISO 2531:1998 }\end{array}$}} & \multicolumn{2}{|c|}{ Acero } & \multirow{3}{*}{$\begin{array}{c}\text { PVC-U } \\
\text { UNE-EN } \\
1452: 2000 \\
\text { DN = DE }\end{array}$} & \multirow{3}{*}{$\begin{array}{c}\text { PE } \\
\text { prEN 12201:2000 } \\
\text { prEN 13224:1998 } \\
\text { DN = DE }\end{array}$} \\
\hline & & & & \multirow{2}{*}{$\begin{array}{l}\text { DIN 2448:1981 } \\
\text { DN = DE }\end{array}$} & \multirow{2}{*}{$\begin{array}{c}\text { DIN 2458:1981 } \\
\text { ISO 559:1991 } \\
\text { prEN 10224:1998 } \\
\text { DN = DE }\end{array}$} & & \\
\hline DN & $\mathrm{DE}^{19}$ & DN & $\mathrm{DE}$ & & & & \\
\hline 40 & 56 & 40 & 56 & 44.5 & 48.3 & 50 & 50 \\
\hline 50 & 66 & 50 & 66 & 57 & 60.3 & 63 & 63 \\
\hline 60 & 79 & 60 & 77 & & & 75 & 75 \\
\hline 65 & 82 & 65 & 82 & 76.1 & 76.1 & & \\
\hline 70 & 86 & & & & & & \\
\hline 80 & 98 & 80 & 98 & 88.9 & 88.9 & 90 & 90 \\
\hline 90 & 107 & & & & & & \\
\hline \multirow[t]{2}{*}{100} & 118 & 100 & 118 & 108 & 114.3 & 110 & 110 \\
\hline & & & & & 125 & 125 & 125 \\
\hline 125 & 144 & 125 & 144 & 133 & 139.7 & 140 & 140 \\
\hline 150 & 170 & 150 & 170 & 159 & 168.3 & 160 & 160 \\
\hline 175 & 197 & & & & & 180 & 180 \\
\hline 200 & 222 & 200 & 222 & 216 & 219.1 & 200 & 200 \\
\hline 225 & 245 & & & & & 225 & 225 \\
\hline 250 & 274 & 250 & 274 & 267 & 273 & 250 & 250 \\
\hline 275 & 296 & & & & & 280 & 280 \\
\hline 300 & 326 & 300 & 326 & 318 & 323.9 & 315 & 315 \\
\hline 350 & 378 & 350 & 378 & 368 & 355.6 & 355 & 355 \\
\hline 400 & 429 & 400 & 429 & 419 & 406.4 & 400 & 400 \\
\hline 450 & 480 & 450 & 480 & & & 450 & 450 \\
\hline \multirow[t]{2}{*}{500} & 532 & 500 & 532 & 521 & 508 & 500 & 500 \\
\hline & & & & & & 560 & 560 \\
\hline 600 & 635 & 600 & 635 & 610 & 610 & 630 & 630 \\
\hline
\end{tabular}

Los coeficientes de rugosidad para cada uno de los materiales son los mostrados por la Tabla 20.

TABLA 20. COEFICIENTES DE RUGOSIDAD POR MATERIAL.

\begin{tabular}{cccc}
\hline Material & $\begin{array}{c}\text { C Hazen Williams } \\
\text { (adimensional) }\end{array}$ & $\begin{array}{c}\boldsymbol{\varepsilon} \text { Darcy-Weisbach } \\
(\mathbf{m m})\end{array}$ & $\begin{array}{c}\mathbf{n} \text { Manning } \\
\text { (adimensional) }\end{array}$ \\
\hline Plástico (PE, PVC) & $140-150$ & 0.0015 & $0.006-0.01$ \\
Fundición & $130-140$ & 0.25 & $0.012-0.015$ \\
Hormigón & $120-140$ & $0.3-3$ & $0.012-0.017$ \\
Acero & $140-145$ & 0.05 & $0.010-0.017$ \\
PRFV & 140 & 0.01 & 0.009 \\
\hline
\end{tabular}

${ }^{19} \mathrm{DE}$ hace referencia al diámetro exterior, mientras que $\mathrm{DN}$ es el diámetro nominal. 
En la Figura 38 se muestran los diámetros habituales de cada tipo de material.
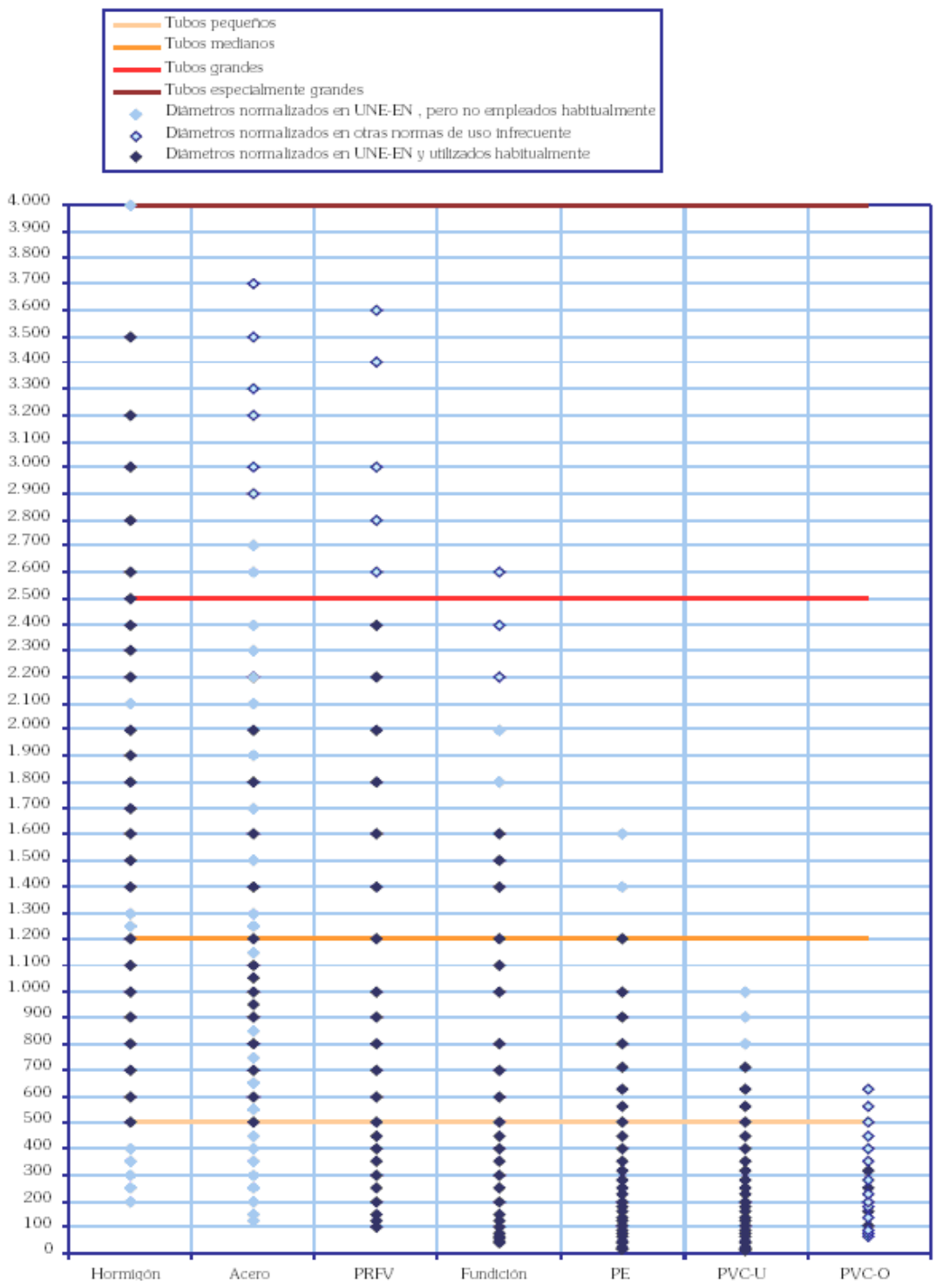

FIGURA 38. DiÁMETROS EN MM DE LOS DistinTOS TIPOS DE TUBOS (CEDEX, 2006). 
Y por último, la Figura 39 muestra las longitudes en las que se suele suministrar los tubos.

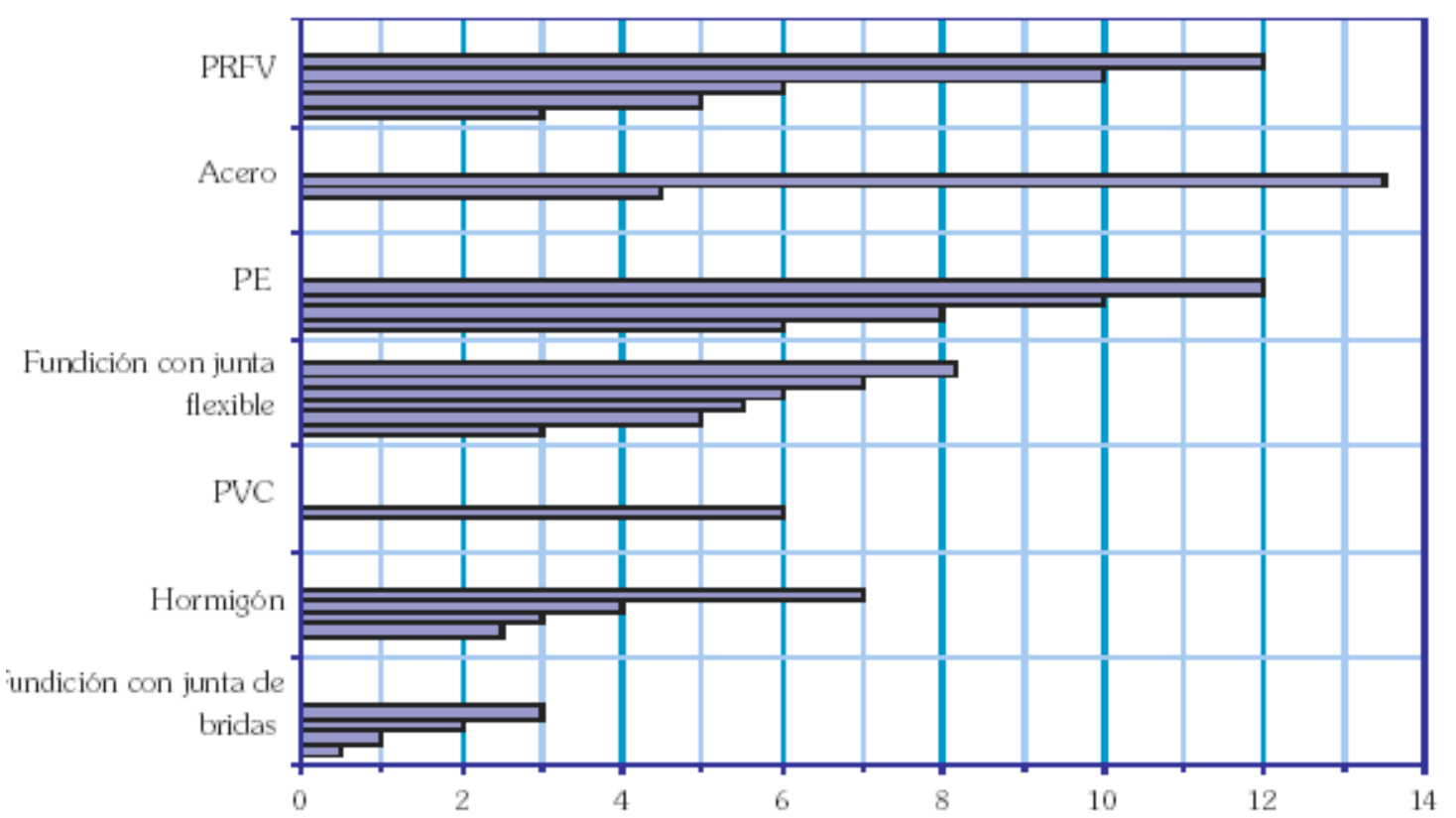

Figura 39. LONGITUd (M) DE LOS DistinTOS TUBOS (CEDEX, 2006).

\subsubsection{Evolución de las roturas según el tipo de tubería}

Es evidente que la tasa de roturas depende del tipo de material aunque no es el único factor influyente. Otros factores serían el diámetro, el tipo de instalación, la profundidad de la zanja, la humedad del terreno, etc. Por tanto, aunque siempre es interesante conocer los valores de la tasa de rotura de los materiales, éstos no se pueden extrapolar de un abastecimiento a otro y representan un orden de magnitud más que un valor de referencia.

En lo que sigue se presentan algunos datos extraídos de la literatura, en los que se analiza primeramente el factor más influyente, el material instalado. MacKellar y Pearson (2003), realizaron un estudio del ratio de roturas medio en 17 abastecimientos en el Reino Unido. Se analizó la influencia de la edad sobre el número de roturas y se agruparon los datos disponibles por cada uno de los materiales instalados (Tabla 21). 
TABLA 21. ROTURAS POR UNIDAD DE LONGITUD Y AÑO EN TUBERÍAS DEL REINO UNIDO (MACKELLAR Y PEARSON, 2003).

\begin{tabular}{l|cccccc}
\hline Ratios de rotura (roturas/100km/año) & \multicolumn{7}{|c}{ Año } \\
Tipo de Material & $\mathbf{1 9 9 8}$ & $\mathbf{1 9 9 9}$ & $\mathbf{2 0 0 0}$ & $\mathbf{2 0 0 1}$ & $\mathbf{2 0 0 2}$ & Total \\
\hline Fibrocemento & 16.4 & 17.1 & 15.1 & 15.8 & 15.6 & 16.0 \\
Fundición dúctil & 5.0 & 5.3 & 4.8 & 4.8 & 6.5 & 5.3 \\
Fundición gris & 23.7 & 23.7 & 19.1 & 21.7 & 12.3 & 20.1 \\
Polietileno & 3.5 & 2.9 & 3.3 & 3.1 & 3.0 & 3.2 \\
PVC & 9.6 & 9.1 & 7.2 & 7.4 & 3.3 & 7.3 \\
Acero & 5.0 & 6.1 & 5.8 & 5.7 & 33.1 & 11.1 \\
Desconocido & 0.1 & 0.0 & 0.0 & 0.1 & 15.9 & 3.2 \\
\hline Total & 9.0 & 9.2 & 7.9 & 8.4 & 12.8 & 9.5 \\
\hline
\end{tabular}

Los resultados obtenidos no deparan sorpresas, las mayores tasas de roturas se encontraron en los materiales en desuso (de mayor edad), mientras que las tasas bajas correspondían a materiales como fundición dúctil y plásticas.

Otro estudio (NRC, 1993) recopiló los datos de roturas durante los años 1992 y 93 en 21 ciudades canadienses y obtuvo los ratios de rotura medios según el material instalado.

TABla 22. Roturas ObSERVADAS EN 21 CIUDADES DE CANAdÁ (NRC, 1993).

\begin{tabular}{lccccc}
\hline \multirow{1}{*}{ Material } & \multicolumn{2}{c}{ Longitud de tubería } & \multicolumn{3}{c}{ Ratios de rotura } \\
& Km & $\mathbf{( \% )}$ & $\mathbf{1 9 9 2}$ & $\mathbf{1 9 9 3}$ & Media \\
\hline Fundición gris & 8769.9 & 50 & 35.1 & 36.7 & 35.9 \\
Fundición dúctil & 4237.5 & 24 & 9.3 & 9.8 & 9.5 \\
Fibrocemento & 2105.4 & 12 & 5.4 & 6.1 & 5.8 \\
PVC & 1818.0 & 10 & 0.9 & 0.5 & 0.7 \\
Hormigón & 623.4 & 4 & 0.5 & 0.8 & 0.6 \\
\hline
\end{tabular}

En 1992 y 93 el número total de roturas fue 3601 y 3773 respectivamente. El estudio asumió un coste de reparación de 2500 dólares canadienses ${ }^{20}$ por rotura, con lo que el coste total de las reparaciones fue de 9.2 millones de CAN\$. Las 21 ciudades satisfacían la demanda del $11 \%$ de los habitantes de Canadá (3.14 millones de personas), por lo que el informe estimó que el coste en roturas extrapolado para toda la nación sería de 82 millones de dólares canadienses.

${ }^{20}$ Para la paridad $1 \mathrm{CAN} \$=0.633 €$ 
El ratio de roturas del fibrocemento es muy alto, casi el doble que el mostrado en el estudio del Reino Unido (Tabla 21), y dado que la mitad de la red esta construida utilizando ese material, la conclusión es inmediata, las primeras tuberías que deben ser renovadas son las de este material y además su empleo se ve desplazado por la fundición dúctil. Sin embargo, en el estudio de Canadá no se consideraron otros factores que influyen en la aparición de las roturas, edad, material de relleno de la cama, condiciones medioambientales, clima y tipo de instalación.

En Alemania, Hirner (1997a) muestra un orden de magnitud de roturas por kilómetro y año en varias redes de distribución. Se analizaron 36546 km y los resultados los resume la Tabla 23.

TABLA 23. Daños Registrados en las tuberías de alemenia (HiRner, 1997A).

\begin{tabular}{lcccc}
\hline \multirow{2}{*}{ Material } & $\begin{array}{c}\text { Longitud de } \\
\text { tubería }(\mathbf{k m})\end{array}$ & $\begin{array}{c}\text { Número de } \\
\text { roturas }\end{array}$ & \multicolumn{2}{c}{$\begin{array}{c}\text { Ratios de rotura } \\
\text { (roturas/100 km/año) }\end{array}$} \\
\cline { 4 - 5 } & 15922 & 3462 & $10-40$ & 22 \\
\hline Fundición gris & 8593 & 2483 & $10-50$ & 29 \\
DN < 100 & 5770 & 907 & $10-40$ & 16 \\
$100<$ DN $<300$ & 1599 & 72 & $3-15$ & 5 \\
DN $>300$ & 11560 & 321 & $1-10$ & 3 \\
Fundición dúctil & 3990 & 1020 & $4-90$ & 26 \\
Acero & 790 & 81 & $3-30$ & 10 \\
Polietileno & 2976 & 99 & $2-10$ & 3 \\
PVC & 1302 & 179 & $10-50$ & 14 \\
Fibrocemento & 36546 & 5162 & $5-20$ & 14 \\
Total & & & & \\
\hline
\end{tabular}

En otros estudios no se agrupan los ratios de roturas según el material instalado sino según diámetro de la tubería. Luong y Fujiwara (2002) estudiaron el ratio de roturas en tres grupos diferenciados (diámetros de 150, 200 y $250 \mathrm{~mm}$ ) en la ciudad de Ho Chi Minh en Vietnam. La red de abastecimiento satisface la demanda de gran parte de los 6.5 millones de habitantes de dicha ciudad. Para ello consideran que los grupos presentan similares edades, tipo de funcionamiento y condiciones de instalación. Los resultados se muestran en la Tabla 24. 
Tabla 24. Parámetros Característicos de la Red de distribución de Ho CHI MinH (LUONG y FujIWARA, 2002).

\begin{tabular}{lccc}
\hline Parámetros & Grupo 1 & Grupo 2 & Grupo 3 \\
\hline Diámetro $(\mathrm{mm})$ & 150 & 200 & 250 \\
Longitud $(\mathrm{km})$ & 173.63 & 80.12 & 105.96 \\
Ratio de roturas anual (roturas/100 km/año) & 116.5 & 78.8 & 44.1 \\
Tamaño de fuga media (l/s) & 1.40 & 1.47 & 1.53 \\
\hline
\end{tabular}

La primera conclusión tras este estudio es clara, el ratio de roturas es muy elevado, especialmente para el diámetro 150 . Por otra parte el volumen fugado medio en cada rotura también es alto ${ }^{21}$, superior a los $120 \mathrm{~m}^{3} /$ día, lo que sugiere que la red está bastante presurizada.

Valores inferiores muestra un estudio realizado en un área de $1312.6 \mathrm{Km}^{2}$ en la costa de la región Emilia-Romagna en Italia (Di Federico y col., 2002). Las redes de abastecimiento elegidas suministran agua a varias poblaciones con 110000 habitantes que en verano aumentan hasta 200000. Para comprender mejor el estudio, se muestra la proporción de los materiales instalados en los $1863.5^{22} \mathrm{Km}$ de la red de distribución.

TABLA 25. COMPOSICIÓN DE LA RED DE DISTRIBUCIÓN (DI FEDERICO Y COL., 2002).

\begin{tabular}{lcc}
\hline \multicolumn{1}{c}{ Tipo de material } & Longitud total $(\mathbf{k m})$ & Porcentaje \\
\hline Acero & 69.26 & 3.72 \\
Hormigón & 32.13 & 1.72 \\
Fibrocemento & 1263.56 & 67.81 \\
Hierro & 4.21 & 0.23 \\
Fundición gris & 3.51 & 0.19 \\
Fundición dúctil & 87.35 & 4.69 \\
PE & 48.08 & 2.58 \\
PVC & 315.38 & 16.92 \\
Otros & 40.01 & 2.15 \\
\hline Total & $\mathbf{1 8 6 3 . 4 9}$ & $\mathbf{1 0 0}$ \\
\hline
\end{tabular}

\footnotetext{
${ }^{21}$ Un umbral habitual entre fuga comunicada y no comunicada sería un caudal unitario de fuga de $500 \mathrm{l} / \mathrm{h}$, lo cual proporciona un volumen fugado diario de $12 \mathrm{~m} /$ día (10 veces inferior al encontrado en Ho Chi Minh).

${ }^{22}$ La longitud de tubería por habitante es muy elevada (16.94 $\mathrm{m} / \mathrm{habitante)}$ por lo que dicha red es muy ramificada. Los valores esperados para este indicador son entre 1-5 m/hab. (Valencia 1.2 m/hab. ó como se emplea con mayor frecuencia Km/1000hab).
} 
Se registraron 2844 roturas en el periodo 1995 - 2000. A partir de éstos, se obtienen los correspondientes ratios de roturas (Tabla 26).

TABLA 26. RotURAS PRODUCIDAS EN LOS AÑOS DE ESTUDIO (DI FEDERICO Y COL., 2002).

\begin{tabular}{ccc}
\hline Año & Roturas & Ratio de roturas (roturas/100 km/año) \\
\hline Desconocido & 2 & - \\
1995 & 278 & 14.9 \\
1996 & 405 & 21.7 \\
1997 & 560 & 30.1 \\
1998 & 515 & 27.6 \\
1999 & 541 & 29 \\
2000 & 543 & 29.1 \\
\hline Total/media & $\mathbf{2 8 4 4}$ & $\mathbf{0 . 2 5 4}$
\end{tabular}

Para concluir, hay que destacar la importancia que tienen los suelos y las facilidades de montaje. La Figura 40 muestra el índice relativo de roturas en tuberías de acero en Inglaterra de acuerdo con un estudio de la compañía severn trent (Newport, 1981). En ésta se observa como el tipo de suelo puede multiplicar hasta por tres el número de roturas.

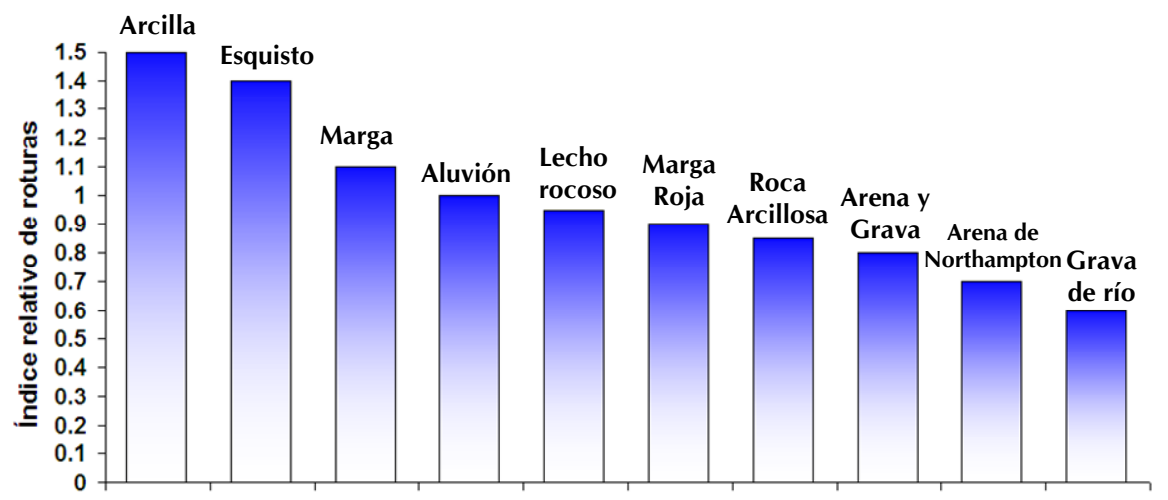

Figura 40. INFLUENCIA DEL TERRENO EN EL ÍNDICE DE ROTURAS EN TUBERÍAS DE ACERO (NEWPORT, 1981).

La importancia de tener un historial de los daños de las tuberías se torna casi en imprescindible para delinear las estrategias de mantenimiento y renovación de las mismas. De hecho, todos los análisis económicos parten de la estimación del número de roturas por año y su evolución en el tiempo (capítulo 4). 


\subsection{Materiales utilizados en los abastecimientos}

Es evidente que no existe el material universal. Cada uno de los descritos anteriormente tiene sus ventajas e inconvenientes que justifican que cada tramo de la red se construya con uno u otro.

A continuación, se muestra la distribución por materiales de los principales abastecimientos de Norteamérica y algunos países Europeos, para finalmente concentrarse en la situación española y la local de la ciudad de Valencia.

\subsubsection{Utilización de tuberías en Norteamérica}

Para el contexto norteamericano ${ }^{23}$ se han agrupado las redes según las diferentes compañías de abastecimiento urbano. Por eso, se disponen datos relativos al Noreste, Oeste, etc. Sin duda, la amplia superficie abarcada por los Estados Unidos valida y aporta significado al estudio de los materiales en dichas redes agrupadas por zonas. La Figura 41 muestra como datos fundamentales que:

1. En la actualidad, la fundición gris es el material preponderante en Estados Unidos y Canadá.

2. La fundición dúctil representa cerca del $20 \%$ en Canadá y del $15 \%$ en Estados Unidos.

3. El fibrocemento se utilizó sobre todo en abastecimientos de la zona Oeste, alcanzando valores del $50 \%$ de la totalidad de la red.

4. La presencia de tuberías de hormigón es testimonial en prácticamente todas las regiones de estudio.

5. EI PVC se está empezando a utilizar, y en algunos abastecimientos ya Ilega al $10 \%$.

\footnotetext{
${ }^{23}$ Se considera únicamente los datos referentes a Estados Unidos y Canadá.
} 


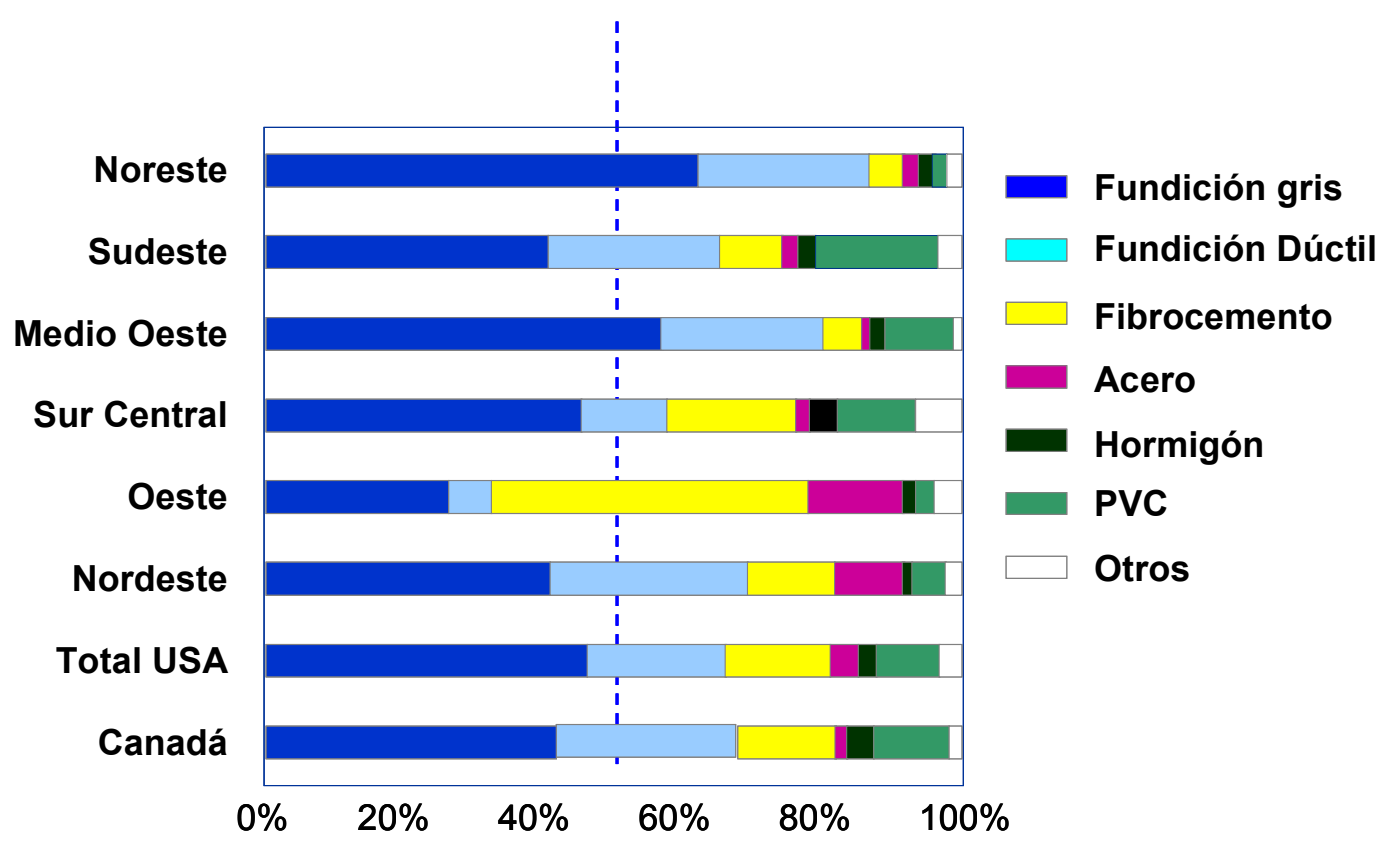

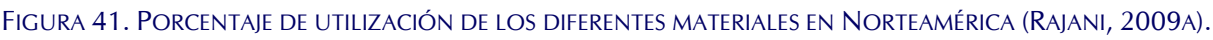

AWWA (2004) clasifica las tuberías entre las de distribución (diámetros iguales o menores que $250 \mathrm{~mm}$ ) y las arteriales (diámetros mayores que $250 \mathrm{~mm}$ ), donde aproximadamente el $73 \%$ de la longitud de las tuberías son de pequeño diámetro.

TABLA 27. LONGITUD DE TUBERÍAS INSTALADAS EN EE.UU. (AWWA, 2004).

\begin{tabular}{ccc}
\hline Composición de la red & Km instalados & \% del total \\
Fibrocemento & 219186.2 & 15.8 \\
Fundición gris no revestido & 246897.5 & 17.8 \\
$\begin{array}{c}\text { Fundición gris con revestimiento de } \\
\text { mortero de cemento }\end{array}$ & 257211.8 & 18.5 \\
Fundición gris & 45827.7 & 3.3 \\
Hormigón pretensado & 37954.8 & 2.7 \\
Fundición dúctil no revestido & 57801.2 & 4.2 \\
Fundición dúctil con revestimiento & 242536.2 & 17.5 \\
de mortero de cemento & & 0.3 \\
Fundición dúctil con otro o sin & 4013.7 & 0.08 \\
revestimiento & 1070.2 & 0.4 \\
PRFV & 5389.7 & 13.2 \\
Polietileno & 183709.8 & 3.9 \\
PVC & 54793.3 & 2.3 \\
Acero & 32458.9 &
\end{tabular}


En la Tabla 27 se muestran valores similares a los de otros estudios, con cerca de un $40 \%$ de la red compuesto por fundición gris y casi una sexta parte de fibrocemento. Destaca la implantación de la fundición dúctil y del PVC que sobrepasan el 20 y el $13 \%$ de la longitud total de la red respectivamente.

\subsubsection{Utilización de tuberías en Europa}

En Europa, las tuberías se distribuyen según su material tal y como se muestra en la Figura 42. Las conclusiones que se pueden obtener son:

- Un elevado porcentaje de la red del Reino Unido y Suiza está instalada con tuberías fundición.

- España es el país junto con Holanda en los que existe una mayor proporción de tuberías de fibrocemento, cercana al 40\%

- En Finlandia predominan las tuberías plásticas.

- Luxemburgo, y en menor medida Bélgica, son los países donde se ha instalado una mayor cantidad de acero, Ilegando casi al $25 \%$ y al $15 \%$ del total, respectivamente.

- La utilización del hormigón en redes es meramente testimonial, y únicamente en Suecia y Bélgica ronda el 5\%.

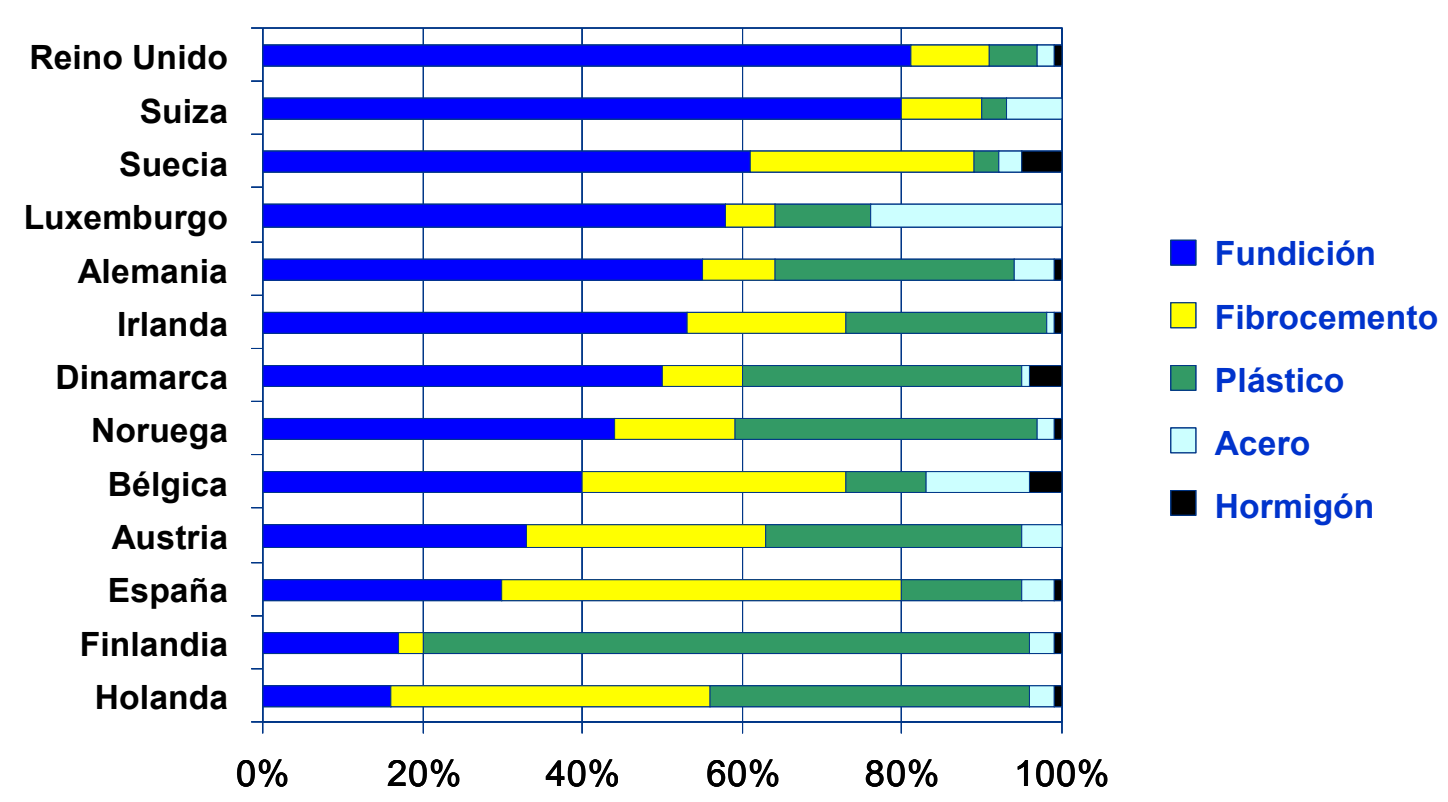

Figura 42. Porcentaje de utilizaCión DE LOS DifERENTES MATERIALES EN EUROPA (RAJANI, 2009A). 
El estudio no distingue entre fundición dúctil y gris sino que los agrupa en un término denominado fundición. Asimismo, se puede observar la situación española, que al fin y al cabo es en la que se centra la presente tesis, aunque un trabajo a escala nacional más detallado se muestra en el siguiente apartado.

\subsubsection{Utilización de tuberías en España}

La distribución de las tuberías en España según el número de habitantes de la población abastecida (AEAS, 2006) se muestra en la Tabla 28. La observación de la misma muestra como datos fundamentales que:

- El fibrocemento, la fundición gris y el PE son los materiales más utilizados en las redes de distribución españolas.

- Cuando se analizan los materiales utilizados para determinar la composición de la red, la presencia de unos u otros varía significativamente en los distintos segmentos en los que se divide la muestra. Así, en la edición anterior del informe (AEAS, 2000) la fundición y el fibrocemento eran los preponderantes en longitud, $80 \%$ del total, mientras que en ésta los porcentajes de ambos se han reducido hasta el 60\%. Destaca el aumento de longitud instalada del polietileno, que aumenta desde el $12 \%$ al $26 \%$. No obstante, estas variaciones, obedecen no tanto a una evolución real en espacios de tiempo cortos sino a las características de la muestra de cada encuesta y al diferente peso de cada uno de los segmentos de población. En el capítulo 1 se detalla más información acerca de la fiabilidad de dicha encuesta, que muestra los valores de las redes que abastecen al $57 \%$ de la población total española. Por tanto, los datos no son representativos de todos los abastecimientos españoles, aunque si resultan una buena estimación de dichas características. 
TABLA 28. DistribuCIÓN DE MATERIALES EN lOS ABASTECIMIENTOS ESPAÑOLES (AEAS, 2000 Y 2006).

\begin{tabular}{|c|c|c|c|c|c|c|}
\hline \multirow{2}{*}{$\begin{array}{c}\text { Composición de } \\
\text { la red }\end{array}$} & \multicolumn{5}{|c|}{ AEAS (2006) } & \multirow{2}{*}{$\begin{array}{c}\text { AEAS } \\
(2000) \\
\text { Totales }\end{array}$} \\
\hline & $\begin{array}{c}\text { De } 20001 \\
\text { a } 50000\end{array}$ & $\begin{array}{l}\text { De } 50001 \\
\text { a } 100000\end{array}$ & $\begin{array}{c}\text { De } 100001 \text { a } \\
500000\end{array}$ & $\begin{array}{c}\text { Mayor de } \\
500001\end{array}$ & Totales & \\
\hline Fibrocemento & $48 \%$ & $39 \%$ & $36 \%$ & $17 \%$ & $30 \%$ & $40 \%$ \\
\hline Fundición ${ }^{24}$ & $12 \%$ & $27 \%$ & $38 \%$ & $21 \%$ & $26 \%$ & \multirow{2}{*}{$40 \%$} \\
\hline Fundición Gris & $0 \%$ & $2 \%$ & $2 \%$ & $4 \%$ & $3 \%$ & \\
\hline Hormigón & $0 \%$ & $4 \%$ & $1 \%$ & $3 \%$ & $2 \%$ & $2 \%$ \\
\hline Polietileno & $21 \%$ & $16 \%$ & $19 \%$ & $37 \%$ & $26 \%$ & $12 \%$ \\
\hline PVC & $10 \%$ & $6 \%$ & $2 \%$ & $1 \%$ & $3 \%$ & $3 \%$ \\
\hline Otros & $8 \%$ & $6 \%$ & $2 \%$ & $17 \%$ & $10 \%$ & $3 \%$ \\
\hline
\end{tabular}

Los porcentajes de la Figura 43 se refieren a los datos facilitados por AEAS (2006). En ella se muestra la longitud de los tramos de tuberías para cada material y el porcentaje respecto a la longitud total.

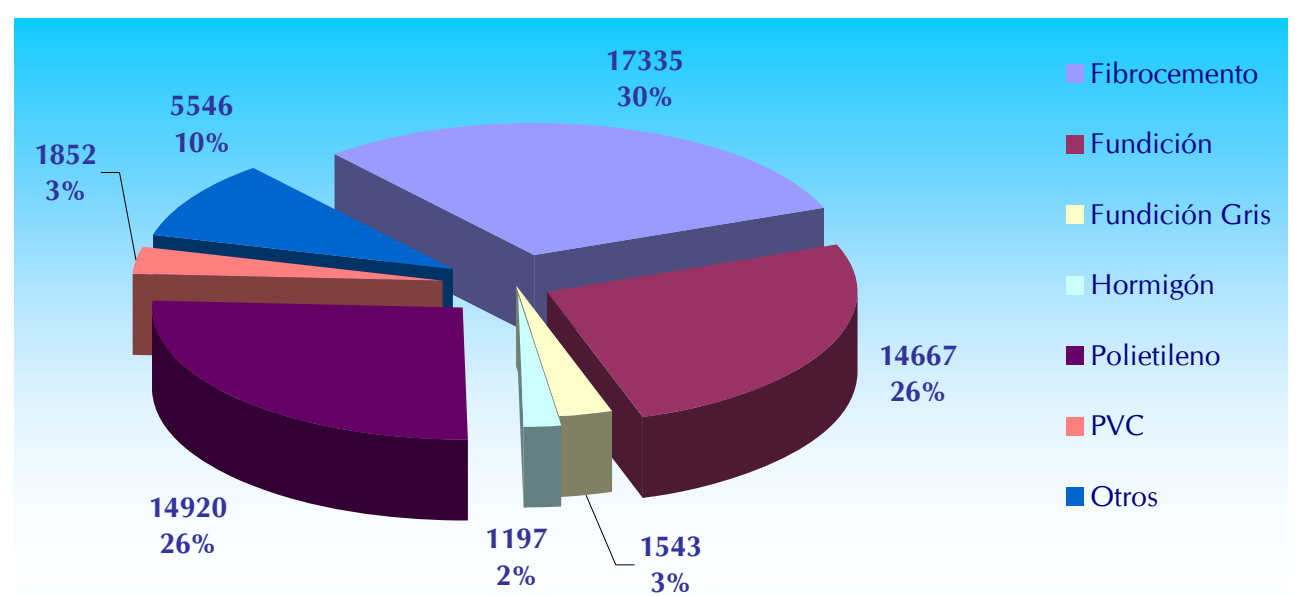

Figura 43. LONGITUDES DE TUBERÍA SEGÚN MATERIAL EN ABASTECIMIENTOS ESPAÑOLES (AEAS, 2006).

${ }^{24}$ El informe del año 2006 designa la fundición dúctil como fundición a secas. Por eso se mantiene esta denominación en la tabla anterior. En cambio, en el informe del año 2000, la denominación fundición se refiere tanto a la dúctil como a la gris. 


\subsubsection{Utilización de tuberías en Valencia}

En el capítulo 1 de la presente tesis se describen las dos redes de distribución existentes en la ciudad de Valencia. La primera o de "alta" está compuesta en su mayoría por tuberías de fundición ${ }^{25}(42 \%)$, fibrocemento (33.3\%) y polietileno $(23.7 \%)$. El porcentaje de red con respecto al total de cada material resulta muy similar al existente en el contexto nacional y europeo (Figura 44). En Valencia, destaca la notable presencia de tuberías de polietileno y la todavía relevancia de un material como el fibrocemento, del que se pretende su desaparición.

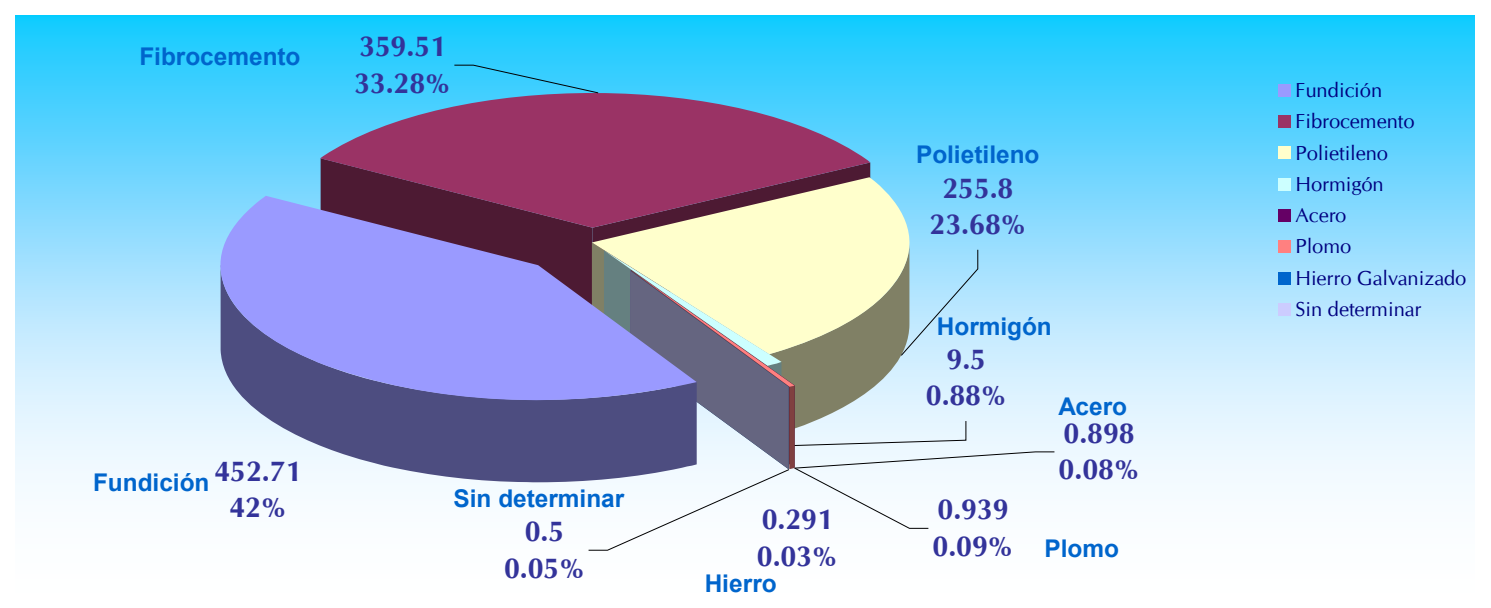

FIGURA 44. LONGITUDES DE TUBERÍA SEGÚN MATERIAL EN LA RED DE ALTA DE VALENCIA.

La segunda red existente en Valencia, de "baja", se compone de los mismos materiales aunque en distinta proporción: fundición $(42 \%)$, fibrocemento $(25 \%)$ y polietileno (34\%). Destaca la mayor proporción de material plástico que en la red de alta.

\footnotetext{
${ }^{25}$ Nuevamente, el término fundición se refiere tanto a fundición dúctil como a la fundición gris.
} 


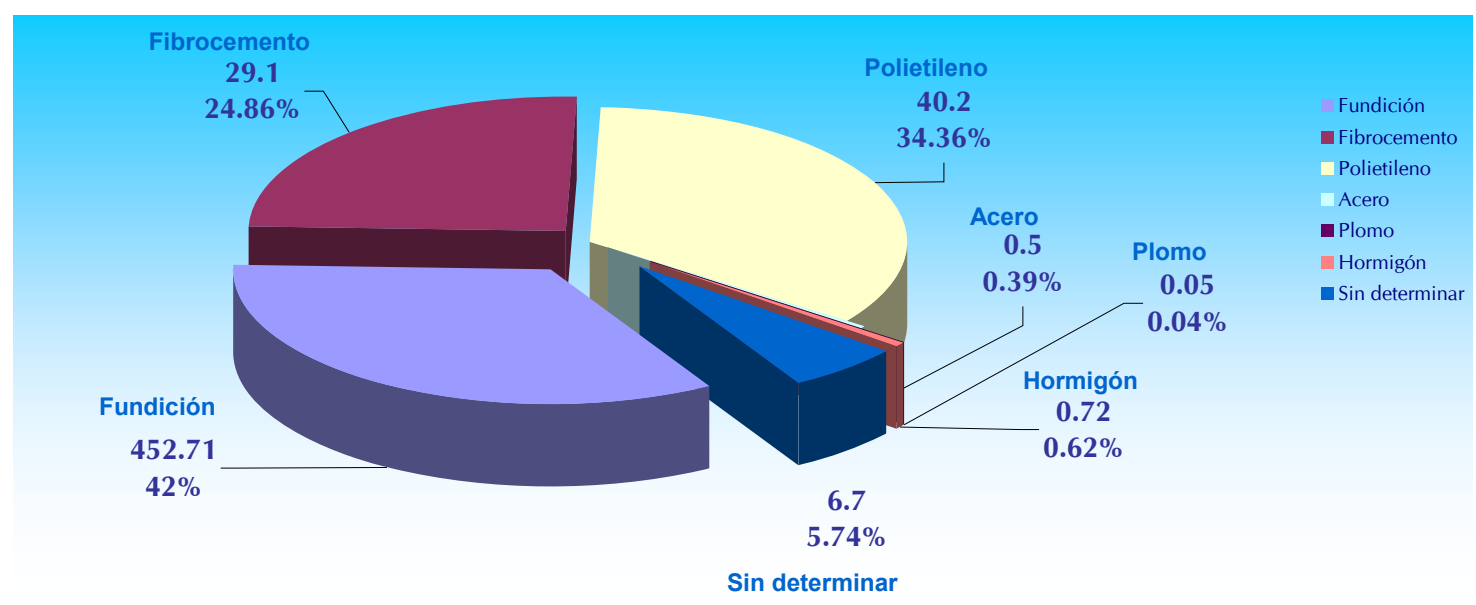

FIGURA 45. LONGITUDES DE TUBERÍA SEGÚN MATERIAL EN LA RED DE BAJA DE VALENCIA.

\subsection{Criterios para rehabilitar y renovar}

El gestor de la red afronta la problemática de adoptar la decisión de renovar o rehabilitar, así como de decidir por qué tubería empezar. Por el efecto del tiempo, la infraestructura va envejeciendo, aumentan las roturas y consecuentemente las fugas. Por tanto, problemas de intrusión patógena, pérdida del recurso, insuficiencia hidráulica, etc. son cada vez más una amenaza para la red de distribución. Los valores habituales de roturas o averías en redes pueden oscilar entre las 10 y 100 roturas por cada $100 \mathrm{~km}$ y año. En España, por ejemplo, se considera aceptable valores de éste indicador de hasta 40 roturas $/ 100 \mathrm{~km} / \mathrm{año}$ (MIMAM, 2000).

\subsubsection{Conceptos previos}

\subsubsection{El concepto de la rehabilitación y de la renovación}

Aunque los conceptos de rehabilitación y de renovación son fácilmente comprensibles, surge con frecuencia confusión entre el significado de los mismos.

Por renovación se entiende, en general, la acción de sustituir una cosa vieja, o que ya ha servido, por otra nueva de la misma clase. Mientras que por rehabilitar se entiende habilitar de nuevo o restituir a su antiguo estado. Por eso, términos como reparar, restituir, arreglar, etc. se refieren al concepto de rehabilitación, mientras que otros términos como cambiar, sustituir, reponer se refieren al concepto de renovación. 


\subsubsection{Políticas reactivas y activas de renovación de tuberías}

En el contexto de la renovación de tuberías, una política reactiva es aquélla en la que la actuación se produce tras el fallo (en este caso, la rotura). En cambio, una política activa es aquella en la que se adoptan las directrices de actuación previas al fallo de la conducción y por tanto, se centran en consideraciones técnicas.

La asignación de recursos y la operación de los mismos para el primer caso (política reactiva) atienden generalmente a criterios económicos, y la elección de las tuberías o sectores a afectar se realiza acorde a estadísticas aisladas u otros datos, predicción de trabajos de construcción de vías o restauración del pavimento. En estas situaciones, el abastecimiento suele no considerar a fondo el estado actual de la red. En el segundo caso (política activa), el modo de actuación se determina solo después de considerar la situación de las tuberías en el presente y su grado de afectación con el paso del tiempo.

Si bien, resulta evidente que es esta última la manera de actuación la deseable, su aplicación requiere de un amplio estudio de la red, así como de una base de datos importante tanto en su magnitud como en la calidad de la información que contiene. Evidentemente, la política de renovación activa es fundamental para la gestión eficiente de una red de abastecimiento. Además es la única de interés, y aceptable, desde la óptica del ingeniero. Pero además, y sobretodo, urge de la disponibilidad de estructuras teóricas aplicadas a la práctica, que faciliten, una vez conocido el estado de forma del sistema, la toma de decisiones para una eficiente intervención encaminada a renovar sus tuberías.

\subsubsection{Razones que aconsejan la rehabilitación y/o renovación}

Son tres, las causas fundamentales que pueden aconsejar la rehabilitación o renovación de una serie de tuberías en una red de distribución de agua. La insuficiencia sanitaria, insuficiencia de suministro e insuficiencia hidráulica.

- Insuficiencia sanitaria, que fundamentalmente se manifiesta a través de un aumento de la turbiedad, población bacteriana, hierro, manganeso, etc. 
En el año 1993, se observó que en una zona de Washington D.C. 1993 el agua no cumplía los estándares de calidad exigidos por la normativa (Safe drinking Water Act). Se previno a los ciudadanos y se indicó la necesidad de utilizar agua hervida para el consumo humano. Según una estimación conservadora, el coste adicional fue de 24 millones de dólares, y posteriormente se renovó la red por completo. Los problemas de las epidemias por contaminación de agua en Estados Unidos durante la etapa 1971-1998 fueron recopilados y tras su análisis se obtuvieron los siguientes resultados (Lindley y Buchberger, 2002; Tabla 29).

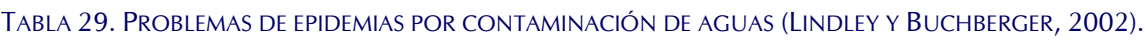

\begin{tabular}{|c|c|c|c|c|c|}
\hline Tipos de error & $\begin{array}{l}\text { Número de } \\
\text { sucesos }\end{array}$ & $\begin{array}{l}\text { \% del total } \\
\text { de errores }\end{array}$ & $\begin{array}{l}\text { Presiones } \\
\text { negativas }\end{array}$ & $\begin{array}{l}\text { Intrusión } \\
\text { patógena }\end{array}$ & $\begin{array}{c}\text { Contaminación } \\
\text { de la fuente }\end{array}$ \\
\hline $\begin{array}{c}\text { Errores en las conexiones } \\
\text { de acometidas con la red } \\
\text { de saneamiento y flujo } \\
\text { inverso }\end{array}$ & 60 & 53.1 & $X$ & $X$ & $X$ \\
\hline $\begin{array}{c}\text { Separación incorrecta de } \\
\text { potables y saneamiento }\end{array}$ & 1 & 0.9 & $X$ & $X$ & $X$ \\
\hline Roturas y fugas en tuberías & 10 & 8.8 & $X$ & $X$ & $X$ \\
\hline $\begin{array}{l}\text { Contaminación en } \\
\text { almacenamiento }\end{array}$ & 15 & 13.3 & & $X$ & $X$ \\
\hline $\begin{array}{l}\text { Contaminación en fase de } \\
\text { reparación/construcción }\end{array}$ & 6 & 5.3 & & $X$ & $X$ \\
\hline $\begin{array}{c}\text { Contaminación de } \\
\text { instalaciones interiores en } \\
\text { viviendas }\end{array}$ & 8 & 7.1 & & & $X$ \\
\hline $\begin{array}{c}\text { Corrosión y arranque de } \\
\text { material en la tubería }\end{array}$ & 13 & 11.5 & & & $X$ \\
\hline TOTAL & 113 & 100 & & & \\
\hline
\end{tabular}

En éste trabajo, se observan las causas fundamentales de los problemas de contaminación de aguas son errores en las conexiones, contaminación de aguas en depósitos de almacenamiento y corrosión y migración de materiales provinentes de una tubería. Por tanto, el esfuerzo para evitar la mayor parte de las epidemias se ha de realizar en estos factores que son los de más probabilidad de ocurrencia. Asimismo, por roturas y fugas en la conducción se producen, afortunadamente, menos problemas de epidemias en los consumidores finales. 
Rajani (2009a) también determina las causas fundamentales que provocan las epidemias en redes de abastecimiento públicas en el periodo 19711998. Los resultados se muestran en la Tabla 30.

TABLA 30. CAusas de LAS EPIDEMIAS (RAJANI, 2009A).

\begin{tabular}{cccccc}
\hline Red de abastecimiento & $\begin{array}{c}\text { Fuente sin } \\
\text { tratamiento }\end{array}$ & $\begin{array}{c}\text { Tratamiento } \\
\text { inadecuado }\end{array}$ & $\begin{array}{c}\text { Fallos en } \\
\text { distribución }\end{array}$ & $\begin{array}{c}\text { Fallos } \\
\text { desconocidos } \\
\text { u otros }\end{array}$ & Total \\
\hline $\begin{array}{c}\text { Instalaciones interiores } \\
\text { Red urbana }\end{array}$ & 149 & 146 & 89 & 20 & 294 \\
$\begin{array}{c}\text { Red de abastecimiento } \\
\text { completa, suma de las } \\
\text { anteriores }\end{array}$ & 184 & 127 & 24 & 29 & 325 \\
\hline
\end{tabular}

En el estudio se muestra que los problemas de calidad son mayoritariamente debidos al tratamiento inadecuado o inexistente del agua, y que una quinta parte de los problemas de calidad son debidos a fallos en la etapa de distribución. Aún así, no se deben obviar los problemas de calidad originados en la red de distribución, tanto relacionados con las roturas de las tuberías y con los fallos en las conexiones.

- Insuficiencia de suministro. Al objeto de poder establecer comparaciones, su magnitud se expresa mediante indicadores de gestión. Aún siendo el rendimiento de la red el parámetro más empleado (calculado como el cociente entre volumen de agua fugado y volumen agua inyectada) resulta más adecuado para comparar el estado de una determinada conducción utilizar el indicador $\mathrm{m}^{3} / \mathrm{km} / \mathrm{h}$. Hirner (1997b) proporciona los siguientes valores guía en función del tipo de suelo, ver Tabla 31.

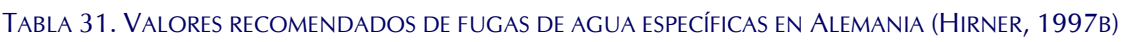

\begin{tabular}{ccc}
\hline Tipo de suelo & $\begin{array}{c}\text { Indicador específico de pérdidas en } \\
\mathbf{~ m}^{\mathbf{3}} / \mathbf{k m} / \mathbf{h}\end{array}$ \\
\hline Marga & 0.1 & 0.3 \\
Arena & 0.05 & 0.15 \\
Roca & 0.02 & 0.60 \\
\hline
\end{tabular}

Como orden de magnitud, un nivel de fugas de $0.2 \mathrm{~m}^{3} / \mathrm{km} / \mathrm{h}$ se considera aceptable, mientras que el nivel se considera elevado si adopta el valor $2 \mathrm{~m}^{3} / \mathrm{km} / \mathrm{h}$. Resulta evidente que con la edad de las tuberías, el índice de roturas aumenta. Como prueba de este hecho, únicamente se deben observar los patrones de roturas mostrados en las distintas tuberías, y por tanto, se debe reparar la tubería con mayor frecuencia. 
- Insuficiencia hidráulica. Con el paso del tiempo, los abastecimientos deben satisfacer mayores demandas bien debido al aumento del número de abonados, bien debido al aumento de la dotación, bien por el aumento de las fugas, bien a la superposición de todos los anteriores factores. Por lo tanto, una tubería antaño suficiente, únicamente con el paso del tiempo, puede quedar ahora obsoleta. Hirner (1997b) proporciona un criterio para considerar la suficiencia de la tubería basada en la presión de suministro en la red de distribución. El abastecimiento debe garantizar en la acometida del abonado, un valor mínimo de presión dependiente del número de plantas del edificio a abastecer en horas punta. En España este criterio supondría renovar, de manera automática, muchos miles de kilómetros de tuberías toda vez que las redes están plagadas de aljibes, no ya porque no se cumplen estos mínimos de presión, sino porque incluso las conducciones llegan a ser insuficientes para que el agua llegue a los lugares más alejados.

De las tres razones apuntadas, es la primera la más importante y la que provoca la más rápida respuesta por parte de la compañía suministradora. Las dos restantes, representan un problema operacional del gestor y aunque también son muy importantes, no suponen un caso tan grave, con tanta repercusión como los problemas de calidad de las aguas.

Recientemente se realizó una encuesta realizada para conocer los principales problemas que deben afrontar las compañías distribuidoras de los Estados Unidos (Runge y Mann, 2008). De los catorce problemas planteados en la encuesta, tres son referentes a la calidad del agua. Concretamente, el tratamiento del agua, la seguridad del sistema y la calidad del agua de boca ocupaban el sexto, octavo y undécimo lugar para los 1800 profesionales que respondieron la encuesta.

\subsubsection{Criterios que se deben adoptar en la renovación}

Los gestores encargados de estructurar los planes de renovación de redes de agua potable acuden tradicionalmente a la experiencia (métodos heurísticos). Éstos se basan en los conocimientos adquiridos por métodos no rigurosos, tanto por experiencia, tanteos, reglas empíricas, etc. Sin duda, dichos métodos suelen representar el primer paso que se adopta cuando se afronta la cuestión de la renovación de la red. 
Las decisiones se basan fundamentalmente en:

1. La experiencia. Suelen estar basadas en un indicador del número de roturas (roturas/km/año) y se fija un umbral máximo las mismas. Por ejemplo, si una tubería llega al umbral de 3 roturas/km/año, se decide renovar la misma.

En teoría, los elementos que conforman la red deben ser remplazados cuando alcanzan su vida útil teórica (Tabla 32) aunque la aplicación práctica es bien diferente y generalmente se produce la renovación cuando lo permite la partida presupuestaria o cuando se ha producido la rotura, política reactiva, laissez faire.

TABLA 32. VIDA ÚTIL DE ALGUNOS DISPOSITIVOS HIDRÁULICOS.

\begin{tabular}{lc}
\multicolumn{1}{c}{ Dispositivo } & Vida útil \\
\begin{tabular}{lc}
\hline Tuberías de fibrocemento, plomo, polietileno, acero y hormigón \\
armado sin camisa de chapa
\end{tabular} & 35 \\
Tuberías de fundición y hormigón armado con camisa de chapa & 70 \\
Válvulas, hidrantes y desagües & 50 \\
Ventosas & 35 \\
\hline
\end{tabular}

2. Reglas básicas. Consiste en adoptar decisiones basándose en un único criterio y con él, elegir la mejor solución. Posteriormente, se procede a buscar entre las posibles soluciones aquella que obtenga un mejor valor del criterio seleccionado, la cual debe cumplir con las restricciones del problema planteado. Por ejemplo: edad de la conducción ó aumento de la pendiente unitaria.

Resulta claro que dadas las habituales limitaciones en el presupuesto, con frecuencia se renuevan ciertas conducciones gracias a la disponibilidad de partidas presupuestarias en un periodo de tiempo determinado. Por ejemplo, debido al plan E (año 2009) se han destinado grandes lotes presupuestarios a los ayuntamientos (generalmente propietarios de la red de abastecimiento) por lo que se puede preveer un aumento en la longitud de tubería renovada. Otro ejemplo podría ser la canalización de los fondos europeos de ayuda al desarrollo que la Unión Europea ha venido invirtiendo en los diversos países pertenecientes a la UE. 
En principio, se debe identificar aquellos criterios fundamentales a la hora de escoger la tubería de puede ser afectada en primera instancia. La edad es, sin lugar a dudas, el primer criterio a incluir en la lista, aunque no el único. Además es preciso tener en cuenta otros factores como el historial y la predicción de los fallos o roturas ocurridos y futuribles, los problemas de insuficiencia o de incapacidad hidráulica originados que afectan a la fiabilidad hidráulica de la red, el posible deterioro de la calidad del agua, el incremento de los costes tanto de mantenimiento de las propias tuberías como de las consecuencias que un reventón puede originar en el entorno urbano, etc., porque cada vez más los sistemas de agua, además de tener que cumplir los objetivos hidráulicos para los que nacieron, deben garantizar otros de tipo social, sanitario, económico y medioambiental (Almandoz y col., (2004); Parra, 2006).

Asimismo, se proponen herramientas aplicadas a la práctica que faciliten, una vez conocido el estado de forma del sistema, la toma de decisiones para una eficiente intervención encaminada a renovar sus tuberías. Así se abordará el campo de la renovación de redes con conocimiento de causa, atendiendo así a la necesidad de solventar problemas típicos como el establecimiento de un orden de renovación de tuberías.

\subsubsection{Los sistemas de soporte a la decisión}

La comprensión de los mecanismos de deterioro de la tubería y su relación con los fallos estructurales son un paso previo para plantear la renovación. La decisión se debe apoyar en un sistema de soporte a la misma. En caso de plantear la rehabilitación o renovación de una tubería en una red de distribución, tan importante puede ser el agua perdida por fugas, como el riesgo de una rotura que ocasione importantes desperfectos en vía pública, o que se mantenga los parámetros de calidad del sistema en unos límites aceptables. En el proceso de toma de decisiones reales se debe encontrar la mejor alternativa sobre la base de múltiples criterios. Por tanto, se plantean sistemas de soporte a la decisión para priorizar la renovación de tuberías atendiendo a razones técnicas, económicas, hidráulicas y heurísticas.

La toma de decisiones con un enfoque monocriterio todavía genera importantes resultados gracias a la experiencia de las personas que en ella participan. Aunque, la solución lógica a esta problemática es el planteamiento multicriterio, dado que cada vez se afrontan problemas más complejos y con un mayor número de variables a considerar que requieren el desarrollo de herramientas que permitan analizar la complejidad inherente a cualquier decisión sujeta a múltiples criterios, objetivos y condiciones. 
Muchos estudios han versado sobre la caracterización y comprensión de los métodos de soporte a la decisión multicriterio. Aunque se centran tanto en la importancia de los pesos asignados a los criterios, como en los procesos matemáticos utilizados para resolver los problemas (mediante sumas ponderadas, como otros más complejos, jerarquías analíticas).

Almandoz y col. (2004) plantean la renovación de tuberías en la ciudad de San Sebastián mediante el método de las sumas ponderadas aplicado sobre varios criterios con un peso asignado fijo. Así, se consideraron los siguientes criterios:

1. Edad

2. Historial de roturas

3. Capacidad de transporte

4. Fugas no comunicadas

5. Incendio

6. Periodo óptimo de renovación

7. Corte de suministro

8. Impacto en el entorno

Asimismo, se incidía en la importancia de la asignación de pesos a cada uno de los criterios, y se expuso que la asignación de estos valores se debe realizar tras un análisis profundo y haciendo valer la experiencia acumulada durante los años de gestión del abastecimiento. Los criterios se agruparon en fundamentales (los dos primeros), hidráulicos (3, 4 y 5) y criterios especiales (los tres últimos).

Parra (2006) realiza una comparación entre los métodos de las sumas ponderadas, el método de la programación por compromiso y la jerarquía analítica difusa. En ese trabajo, plantea nuevamente el problema de la renovación en la ciudad de San Sebastián, obteniendo resultados similares a los obtenidos por Almandoz y col. (2004). Las teorías de números difusos permiten conocer la consistencia demostrada en la asignación de pesos para cada criterio considerado a partir de la inclusión de un índice $\lambda$. De esta manera, se consigue tener información de cuan consistentes son los resultados parciales a los cuales se asocian con las preferencias que, a este nivel, indica el gestor.

Sin duda, el aporte más importante de los sistemas soporte a la decisión multicriterio se manifiesta en la adopción de medidas de evaluación iguales para diversas alternativas. Asimismo, la manera de realizar la calificación es discutible, ya que requiere la manifestación de las preferencias y por tanto, adquiere cierta subjetividad. 
Finalmente, todas estas metodologías proporcionan como resultado el orden en el que las tuberías deben ser renovadas y la ejecución de las mismas se acometerá según el presupuesto disponible. La implantación de estas técnicas aumentará en consonancia con las políticas de eficiencia en la gestión de los recursos disponibles, y con la constante preocupación medioambiental. 

3

Auditoría hídrica 



\subsection{Introducción}

Que la auditoría hídrica ha sido un tema candente en los programas de gestión del agua se prueba con los numerosos trabajos realizados en los últimos 20 años. No en vano, representa el punto de partida para cualquier programa de gestión de una red de abastecimiento. Aunque en redes que abastecen poblaciones pequeñas (menores de 100000 habitantes) con frecuencia no se realizan análisis tan exhaustivos como el balance hídrico, los gestores siempre tienen un orden de magnitud del estado del sistema, del porcentaje de volumen fugado con respecto al inyectado. Este orden de magnitud, si bien útil, no puede considerarse como una auditoría del sistema propiamente dicha.

La auditoría aporta información acerca cómo se reparte el volumen inyectado en la red. Para ello, se distingue entre el volumen consumido por el usuario así como el agua perdida en fugas, pérdidas aparentes, etc. Se puede plantear en la red completa (obtiene información global del sistema) o en partes de la misma, sectores (información particularizada para esa zona).

Una de las aplicaciones fundamentales de la auditoría consiste en determinar el nivel de fugas existente en la red de abastecimiento. Para ello, las pérdidas de agua se separan en dos términos, las pérdidas reales o fugas y las pérdidas aparentes (agua consumida aunque no medida). Otra utilización de la auditoría hídrica sería la realización de un modelo calibrado de la red, esto es, que represente lo más fidedignamente posible el funcionamiento real del sistema con el que realizar simulaciones en período extendido.

Una vez determinado cada uno de los términos de la auditoría, las preguntas siguientes son inmediatas: el nivel de fugas en el abastecimiento, ¿Es alto o bajo?, ¿dónde se pierde el agua?, ¿por qué se pierde el agua?, ¿cuánto se ha de invertir para reducir las fugas? La auditoría facilita una respuesta a las anteriores preguntas y mediante la gestión del sistema se pueden delinear las directrices pertinentes para reducir las pérdidas (reales o aparentes). Por ejemplo, si se muestra una elevada tasa de fugas, se invertirá en renovación o en regular la presión a determinadas horas del día, mientras que si se detecta un elevado volumen no medido por los contadores, se hará hincapié en medidas relacionadas con la gestión del parque de contadores, etc. 
El presente capítulo se estructura en cuatro bloques bien diferenciados. El primero muestra los modelos de auditorías de referencia y define cada uno de los términos que la componen. El segundo facilita las directrices para la realización de la auditoría hídrica en una red de abastecimiento cualquiera. Para ello, se centra en el orden de obtención de cada uno de los términos. El tercero muestra los principales indicadores de gestión que se pueden calcular tras la realización de la auditoría. Estos indicadores permiten la comparación entre abastecimientos y son ampliamente utilizados Asimismo, se facilita un orden de magnitud de los mismos que permite conocer el estado de la red. El último bloque muestra algunos ejemplos de auditorías hídricas realizadas en todo el mundo, así como un ejemplo en la propia ciudad de Valencia.

\subsection{Auditoría hídrica del sistema}

A finales de los años 90, se propusieron numerosas metodologías para realizar la auditoría hídrica. Entre ellas, la International Water Association (IWA) y la American Waterworks Association (AWWA) realizaron las propuestas más conocidas: IWA (2000) y AWWA (1999), respectivamente. Estos dos enfoques finalmente convergen cuando AWWA en 2003, acepta la propuesta de IWA (2000), y ésta se considera la referencia a escala mundial. Tabla $33^{26}$.

TABLA 33 AUDITORÍA HÍDRICA (IWA, 2000).

\begin{tabular}{|c|c|c|c|c|}
\hline \multirow{8}{*}{$\begin{array}{c}\text { Volumen } \\
\text { entrante en el } \\
\text { sistema } \\
1\end{array}$} & \multirow{3}{*}{$\begin{array}{c}\text { Consumo } \\
\text { autorizado } \\
5\end{array}$} & $\begin{array}{c}\text { Consumo } \\
\text { facturado } \\
2\end{array}$ & $\begin{array}{l}\text { Consumo facturado y } \\
\text { medido } 2 \\
\text { Consumo facturado no } \\
\text { medido } 2 \\
\end{array}$ & $\begin{array}{c}\text { Volumen } \\
\text { facturado } \\
2\end{array}$ \\
\hline & & \multirow{2}{*}{$\begin{array}{c}\text { Consumo no } \\
\text { facturado } \\
4\end{array}$} & $\begin{array}{l}\text { Consumo no facturado } \\
\text { aunque medido } 4\end{array}$ & \multirow{7}{*}{$\begin{array}{c}\text { Volumen no } \\
\text { facturado } \\
3\end{array}$} \\
\hline & & & $\begin{array}{l}\text { Consumo facturado y no } \\
\text { medido } 4\end{array}$ & \\
\hline & \multirow{5}{*}{$\begin{array}{c}\text { Pérdidas } \\
\text { totales } \\
6\end{array}$} & \multirow{2}{*}{$\begin{array}{c}\text { Pérdidas } \\
\text { aparentes } \\
7\end{array}$} & Consumos no autorizados 7 & \\
\hline & & & $\begin{array}{l}\text { Consumos no medidos por } \\
\text { errores de los contadores } 7\end{array}$ & \\
\hline & & \multirow{3}{*}{$\begin{array}{c}\text { Pérdidas } \\
\text { reales } \\
8\end{array}$} & Fugas en tuberías 9 & \\
\hline & & & $\begin{array}{l}\text { Fugas en tanques de } \\
\text { almacenamiento } 9\end{array}$ & \\
\hline & & & Fugas en acometidas 9 & \\
\hline
\end{tabular}

\footnotetext{
${ }^{26}$ Los números mostrados en la presente tabla hacen referencia a los pasos a seguir para resolver la auditoría, y han sido definidos por la propia IWA. El procedimiento se detalla en el apartado 3.3 del presente capítulo.
} 
La propuesta de IWA está orientada hacia la determinación del volumen facturado y no facturado, mientras que otras se definen desde la óptica técnica (Almandoz y col., 2005) y resuelven la auditoría análogamente a la ecuación de continuidad (Tabla 34). El objetivo fundamental del trabajo de Almandoz y col (2005) es determinar las fugas de agua, a partir de la discriminación de dos componentes, las pérdidas reales y el caudal consumido pero no medido por los contadores. Los abonados que son facturados mediante estimación o cuota fija se consideran parte de las pérdidas aparentes. Asimismo, considera todo el consumo no medido (las pérdidas aparentes y reales) como incontrolado.

La principal limitación de la propuesta de Almandoz y col. (2005) estriba en la necesidad del modelo matemático de la red. Por tanto, la auditoría se utiliza para refinar el modelo y que, de este modo, se ajuste a las mediciones realizadas en campo. De este trabajo, destaca el original planteamiento en la obtención de las pérdidas reales y aparentes. Esta auditoría se emplea en numerosos abastecimientos del mundo, especialmente en Sudamérica, siendo una propuesta complementaria a la auditoría más universal, la definida por IWA.

TABLA 34 AUDITORÍA HÍDRICA (ALMANDOZ Y COL., 2005).

\begin{tabular}{|c|c|c|c|}
\hline \multirow{7}{*}{$\begin{array}{l}\text { Caudal entrante en el } \\
\text { sistema, Q }\end{array}$} & \multirow{3}{*}{\multicolumn{2}{|c|}{$\begin{array}{l}\text { Caudal medido por los contadores de los } \\
\text { abonados, } \mathrm{Q}_{\mathrm{m}}\end{array}$}} & Consumo doméstico \\
\hline & & & Consumo comercial \\
\hline & & & Consumo industrial \\
\hline & \multirow{4}{*}{$\begin{array}{c}\text { Caudal incontrolado } \\
\qquad \mathrm{Qu}^{\mathrm{u}}\end{array}$} & \multirow{3}{*}{$\begin{array}{c}\text { Caudal consumido no } \\
\text { medido, pérdidas } \\
\text { aparentes, Quc }\end{array}$} & $\begin{array}{l}\text { Consumo no medido } \\
\text { en contadores, errores } \\
\text { de medida, Quce }\end{array}$ \\
\hline & & & $\begin{array}{l}\text { Consumo facturado } \\
\text { mediante cuota fija, } \\
\text { (agua no medida) }\end{array}$ \\
\hline & & & $\begin{array}{l}\text { Consumo de hidrantes } \\
\text { de incendios, } \\
\text { descargas de la red, } \\
\text { tomas ilegales (agua } \\
\text { no medida) }\end{array}$ \\
\hline & & $\begin{array}{l}\text { Caudal fugado, } \\
\text { pérdidas reales, Qul }\end{array}$ & $\begin{array}{l}\text { Fugas físicas en } \\
\text { tuberías de } \\
\text { distribución y } \\
\text { acometidas }\end{array}$ \\
\hline
\end{tabular}


Los términos definidos en este último trabajo (Tabla 34) son análogos a los definidos en el anterior, aunque existen ciertas discrepancias que aquí se explican. Las pérdidas reales (Tabla 33) se relacionan con el caudal fugado Quı. El caudal consumido no medido, Quc se corresponde con las pérdidas aparentes de la auditoría de IWA junto con los consumos no medidos (tanto facturado como no facturado, ambos pertenecientes al consumo autorizado Tabla 33). Otra diferencia es el consumo en los hidrantes, que Almandoz y col. (2005) la considera pérdidas aparentes mientras que IWA (2000) la considera consumo autorizado no facturado y no medido. Aparte de esas salvedades, el resto de términos es similar.

La mayoría de los términos definidos en la auditoría de IWA son fácilmente comprensibles, mientras que algunos merecen una aclaración especial, tal y como se expresa en los siguientes apartados.

\subsubsection{Consumo autorizado}

Se entiende por consumo autorizado aquél volumen consumido (por abonados, la propia compañía u otros) tras una conformidad implícita o explícita para ello. Esto es, que es un uso legal. El consumo autorizado puede incluir $^{27}$ consumos en hidrantes en la protección contra incendios, limpiezas de calles y de tuberías, riego de parques y jardines, fuentes públicas, entre otros.

El consumo autorizado se disgrega en cuatro grupos según sea facturado o no facturado y medido o no medido (Tabla 33). La identificación del tipo de consumo dentro de los cuatro grupos anteriores es bastante simple. Por ejemplo, en un abonado doméstico, si existe contador sería un consumo medido y facturado (ya que el usuario paga por el volumen consumido), mientras que si no existe contador sería consumo facturado no medido ya que la compañía realizaría el cobro mediante una cuota fija o variable, etc. Un ejemplo de consumo no facturado podría ser el de una institución como el ayuntamiento, policía u hospital. En este último caso, los consumos serían autorizados y medidos o no, según se haya instalado un contador para estos abonados especiales. El consumo autorizado no facturado suele ser un bajo porcentaje de la auditoría, menor que el $1 \%$ del volumen de entrada (Farley y Trow, 2003).

27 Estos consumos se consideran autorizados según las ordenanzas municipales de cada abastecimiento. Por tanto serán no medidos y no facturados o pérdidas aparentes según cada caso particular. 


\subsubsection{Volumen no facturado}

El volumen no facturado o non-revenue water (NRW) se define como la diferencia entre el volumen total entrante en el sistema y el volumen facturado. Se prefiere esta acepción a unaccounted for water (UFW), ya que éste estaba sujeto a otras interpretaciones (si bien la más común consistía en el cálculo de manera similar al volumen no facturado o NRW).

Es importante reseñar que parte del volumen no facturado es consumo autorizado (Tabla 33) por lo que no se ha de confundir éste concepto con el de pérdidas totales. Esto es, no todo el volumen no facturado son pérdidas totales.

\subsubsection{Pérdidas totales}

Comúnmente designado como water losses, cuya traducción literal sería "fugas de agua" este término se compone de las fugas aparentes y reales, que se definen a continuación.

\subsubsection{Fugas aparentes}

Son consumos no autorizados, robos o usos ilegales y subcontajes. Las fugas aparentes suelen estar comprendidas en la horquilla 0-10\% del volumen entrante, (Farley y Trow, 2003) aunque en numerosos abastecimientos, el porcentaje es mucho mayor. En Valencia las fugas aparentes alcanzan un valor superior al $15 \%$ (Murgui y col., 2009) lo que justifica un aumento de los esfuerzos por evaluar y gestionar adecuadamente esta cantidad de agua en la red.

\subsubsection{Consumos no medidos por errores de los contadores}

Los errores de medición son debidos a varios factores. Por una parte, existen ciertos contadores que están sobredimensionados y funcionan a caudales bajos con un mayor error en la medida; por otra, el efecto de envejecimiento de los contadores provoca que éstos no registren adecuadamente el volumen circulante y sea necesario un ajuste de los mismos. Este ajuste se ha de realizar con cierta periodicidad para verificar la curva de error de los contadores.

Los errores de medida son debidos a:

1. Errores sistemáticos de los contadores. Son los que se producen de igual modo en todas las mediciones, con lo que se puede corregir una vez conocidos. Por su propia definición, el error sistemático se contrapone conceptualmente al error aleatorio. 
2. Errores aleatorios. Son los inevitablemente suceden por eventos únicos imposibles de controlar durante la medición. Bien por errores en la lectura, estimaciones de consumo erróneas en contadores parados, etc.

Para realizar la auditoría es indispensable la utilización de contadores de agua. Sin duda, los esfuerzos de calibración de los mismos se han de dirigir hacia los contadores que totalizan el volumen entrante en el sistema, ya que debido a su escaso número, es fácil reducir el error en este término de la auditoría. La calibración de estos contadores y caudalímetros es sumamente compleja (estos caudalímetros pueden tener un calibre de $2000 \mathrm{~mm}$ ) y muchas veces basta con asegurar que las condiciones de instalación son las requeridas por el fabricante. Comúnmente, se realiza una dry verification, un proceso con el que corregir los posibles errores de la parte electrónica.

Por el contrario, los contadores particulares de los abonados (de pequeño calibre, 15-25 mm) sí que permiten una fácil calibración tanto en campo como en laboratorio, aunque su elevado número hace prohibitivo la calibración de todos los medidores. La solución adoptada consiste en seleccionar una muestra representativa de los equipos de medición instalados y a partir del ensayo de éstos estimar el error del parque. Las estrategias para asegurar un adecuado mantenimiento y renovación del parque de contadores se definen en el primer libro específico dedicado a la gestión integral de contadores de agua, el escrito por Arregui y col. (2007).

\subsubsection{Consumos no autorizados}

Las pérdidas aparentes incluyen un término designado como consumos no autorizados, unauthorised consumption. Éste incluye el volumen detraído de la red mediante robos o hurtos. Aunque se mantiene la nomenclatura definida por IWA, si que parece razonable incidir en que a simple vista este término no es complementario al consumo autorizado definido en el apartado 3.2.1. Esto es, el volumen total entrante en el sistema se compone de consumo autorizado y no autorizado aunque también de las pérdidas reales y de los consumos no medidos por el contador.

Finalmente, estos robos, hurtos o consumos en hidrantes se han estimado en el $0.36 \%$ del volumen inyectado en las redes de Inglaterra y Gales (OFWAT, 2001) y se recomienda no excedan del 1\% (Farley y Trow, 2003). 


\subsubsection{Fugas reales}

Representan el volumen de agua que se pierde a través de defectos en la red de distribución, bien sea en las tuberías, depósitos de almacenamiento y en acometidas. Su cuantificación es uno de los motivos fundamentales para plantear la auditoría hídrica, aunque ésta no debe ser utilizada únicamente como único método para determinar las fugas reales ya que surgen los siguientes problemas:

- Los errores en la obtención de los otros términos de la auditoría se arrastran hasta la estimación de las fugas reales.

- La auditoría se plantea en un periodo de tiempo anual, por lo que las perdidas reales sólo pueden considerarse como una advertencia que permita identificar roturas comunicadas y no comunicadas (descritas en el apartado 3.2.5.1), y justificar el comienzo de un control activo de fugas para limitar la duración de las mismas.

- El balance ${ }^{28}$ hídrico no indica los componentes individuales de las pérdidas reales y la influencia de las políticas adoptadas. Simplemente refleja el estado puntual del sistema de forma estática. El planteamiento en periodo extendido se conseguiría con la realización del balance en diferentes instantes de tiempo.

Por estos motivos, las fugas reales deben ser evaluadas con métodos adicionales como las metodologías específicas de análisis de los componentes de las fugas reales o el análisis de los flujos nocturnos. A ello se dedican los siguientes apartados.

${ }^{28}$ El concepto auditoría hídrica es el mismo que balance hídrico y se usa indistintamente. 


\subsubsection{Análisis de los componentes de las fugas reales}

El principio fundamental para evaluar los componentes de las fugas reales consiste en clasificar la fuga. La metodología burst and background estimate (BABE) tiene por objetivo evaluar los componentes individuales de las fugas en una zona del abastecimiento, en contraste con la metodología habitual que englobaba todos los términos de fugas bajo el concepto de consumo no facturado. Asimismo, también permite comparar el valor estimado con el nivel de fugas obtenido a partir de un balance de agua anual o el análisis del flujo nocturno. Para ello, disgrega el amplio concepto de fugas según sus características fundamentales (Lambert, 1994):

- Fugas latentes o background leakage. Se componen de numerosas fugas individualmente pequeñas y que se encuentran activas durante un largo periodo de tiempo. Fundamentalmente son aquéllas que aparecen en juntas y uniones de tuberías, codos, válvulas, etc. En sistemas bien gestionados, en los que las fugas son rápidamente controladas, las fugas latentes representan casi la totalidad de las fugas existentes.

El tipo de material es un factor que influye en el nivel de fugas latentes. Los materiales que permiten uniones soldadas (polietileno) estarán menos predispuestos a las fugas latentes que otros con mayor número de acoples mecánicos (metálicos).

- Roturas comunicadas o reported bursts. Son las conocidas por el gestor de la red sin necesidad de una búsqueda específica. Suelen ser aquellas que resultan visibles para el viandante y aunque tienen una magnitud superior a las fugas latentes, se reparan relativamente pronto y generalmente el volumen fugado es inferior a las primeras.

Si la compañía encargada del abastecimiento no practica un control activo de fugas y únicamente repara las roturas comunicadas, sigue una estrategia frente a las fugas pasiva o reactiva. Ésta es inadmisible desde la óptica técnica que nos atañe, aunque es frecuente en abastecimientos en los que el coste del agua es bajo y en ausencia de un organismo regulador (que asegure las inversiones para mejorar la eficiencia y en general vele por la realización de buenas prácticas).

- Roturas no comunicadas o unreported bursts. Representan una situación intermedia entre los dos anteriores, son roturas que se manifiestan tras un control activo de fugas, por lo que su tiempo de actividad depende de la frecuencia con la que se inspeccione la red. 
En cualquier sistema particular, el número y la importancia relativa de estos tres tipos de fugas varía y no existe una situación normal o de referencia. Asimismo tampoco se pueden extrapolar datos o indicadores obtenidos de esta clasificación de una red particular a otra, ya que factores como las condiciones y tipo de suelo, el material y la presión, entre otros, afectarán a la proporción entre los tres tipos anteriores.

Los modelos BABE se utilizan para estimar el nivel actual de fugas y comprender sus componentes, así como para evaluar el impacto de diferentes decisiones (gestión de la presión, aumento del control activo de fugas, renovación, etc.). Asimismo, se puede estimar el nivel óptimo de fugas en el corto y largo plazo y el nivel de fugas debido a las fugas latentes. Aunque los modelos BABE para gestión de la presión distribuidos en el Reino Unido están disponibles para las compañías y consultores de todo el mundo, su precio ha limitado su utilización en beneficio de otros modelos gratuitos como PRESMAC (McKenzie, 2001) que analiza los flujos nocturnos.

\subsubsection{Análisis de los flujos nocturnos}

El análisis de los flujos nocturnos se realiza en situaciones en la que no se dispone de datos suficientes de la red. Es una técnica bastante sencilla y no necesita un modelo matemático.

El consumo en los periodos nocturnos está limitado a usos esporádicos en viviendas e industrias. Los primeros son consumos de pequeña magnitud que pueden ser cuantificados estadísticamente, mientras que los segundos se pueden conocer con una adecuada medición. En definitiva, en ciertas horas de la noche, se puede conocer con exactitud el volumen fugado a partir de la diferencia entre el volumen inyectado y el consumido. La variación del caudal nocturno puede ser un indicador fiable de que se ha producido una anomalía en el sistema (una rotura, consumos en hidrantes contra incendios, etc.).

El caudal mínimo nocturno se disgrega en el entregado a los consumidores y las pérdidas en la red de distribución, Tabla 35. Del mismo modo, el caudal entregado a los consumidores, a su vez, se compone de fugas en instalaciones interiores (de gran duración y magnitud constante) y el consumo intencionado (de corta duración y magnitud variable). La existencia de aljibes distorsiona el consumo nocturno y aunque es propia de redes insuficientes, representa un problema habitual en numerosos abastecimientos españoles. 
Dentro de las pérdidas en la red de distribución se pueden distinguir las fugas producidas tanto en roturas comunicadas como no comunicadas y las fugas latentes. Un criterio para discernir si el volumen que escapa de la red es fuga o pérdida latente es el siguiente: un defecto determinado se considera fuga si su caudal es mayor que $500 \mathrm{l} / \mathrm{h}$ a una presión de 50 m.c.a., mientras que si el caudal es menor que los $500 \mathrm{l} / \mathrm{h}$ a la misma presión se considera latente (Lambert y col., 1998).

TABLA 35. COMPONENTES DEL CAUDAL MÍNIMO NOCTURNO.

\begin{tabular}{|c|c|c|c|}
\hline \multirow{4}{*}{$\begin{array}{c}\text { Caudal mínimo } \\
\text { nocturno }\end{array}$} & $\begin{array}{c}\text { Caudal entregado a } \\
\text { los consumidores }\end{array}$ & Uso consumidores & Uso doméstico \\
\cline { 2 - 3 } & \multirow{2}{*}{$\begin{array}{c}\text { Pérdidas en la red } \\
\text { de distribución }\end{array}$} & Fugas consumidores & Uso no doméstico \\
\cline { 2 - 3 } & & Caudal de fuga & noturas comunicadas y \\
& & Fugas latentes & \\
\end{tabular}

La estimación de los caudales nocturnos es un proceso largo, no en vano se recomienda que se realice durante un año. Una vez finalizado, se puede extender este análisis a las restantes horas del día, y se obtiene la evolución horaria del caudal fugado.

OFWAT (2001) extrapola el caudal fugado utilizando un factor horario que se obtiene a partir de las variaciones de presión lo largo del día. Otra manera de calcular el caudal de fugas en las restantes horas del día sería la ecuación simplificada siguiente (May, 1994).

$Q_{L}(t)=Q_{L}\left(t_{M N F}\right) \cdot\left(\frac{P_{A Z P}(t)}{P_{A Z P}\left(t_{M N F}\right)}\right)^{\alpha}=Q_{L}\left(t_{M N F}\right) \cdot K(t)$ 
Donde $Q_{L}(t)$ es el caudal de fugas a una hora distinta de la que se obtiene el mínimo nocturno de fugas, $t_{M N F}$ es la hora a la que se mide el caudal mínimo nocturno de fugas, $P_{A Z P}(t)$ es la presión en el nudo AZP (que se ha escogido como promedio de la red) en una hora $t \neq t_{M N F}, P_{A Z P}\left(t_{M N F}\right)$ es la presión en el nudo AZP en la hora $t_{M N F}$ y finalmente $\alpha$ que es el exponente de emisor ${ }^{29}$. La ecuación anterior se fundamenta en la teoría de descargas a través de áreas fijas o variables, fixed and variable area discharge (FAVAD).

El método PRESMAC, desarrollado por la South African Water Research Comission, determina precisamente el nudo representativo de las presiones en la red y por tanto, permite obtener el caudal de fugas a lo largo de todo el día y en consecuencia, dicho término de la auditoría hídrica de la red.

Además de la ecuación anterior, PRESMAC también emplea la ecuación para obtener la relación entre las pérdidas de carga y el caudal:

$$
H_{L}=K \cdot Q^{2}
$$

Con $H_{L}$ es la pérdida de carga en (m.c.a.), $Q$ el caudal en $\mathrm{m}^{3} / \mathrm{h}$ y $k\left(\mathrm{~m}^{-5} . \mathrm{h}^{2}\right)$ el coeficiente de pérdidas de carga.

En definitiva, cuando se han determinado las fugas reales en periodos nocturnos, se consigue extender al periodo extendido (ecuación 3.1) o con el empleo de un modelo como PRESMAC. A continuación se muestran los pasos a realizar para obtener la auditoría.

29 El exponente de emisor representa el comportamiento del material tras la rotura. Adoptará valores de $\alpha=0.5$ si la tubería es metálica y hasta $\alpha=1.5$ si plástica. Como una red nunca está compuesta todas las tuberías del mismo material, un valor habitual sería $\alpha=1-1.2$. 


\subsection{Realización de la auditoría}

La auditoría es el primer paso hacia una gestión eficiente de la red. Su realización exige un consumo de recursos tanto humanos como económicos considerable. El modelo de auditoría más común (IWA, 2000) define los pasos a seguir para resolver la auditoría (la numeración está relacionada con los términos de la auditoría de la Tabla 33), estos son:

1. Cálculo del volumen entrante al sistema. Este primer paso es sencillo, ya que únicamente consiste en registrar el volumen que ha circulado a través de los contadores o caudalímetros situados en la entrada de agua a la red de distribución. El error obtenido en la determinación de este volumen es el error de los contadores a la entrada al sistema.

2. Definición del consumo facturado medido y no medido, y con la adición de ambos términos obtener el consumo facturado. El cálculo del volumen facturado y no medido es algo laborioso porque exige recopilar las lecturas de todos los contadores instalados en los puntos de consumo, pero se puede resolver rápidamente si se dispone de un registro de lecturas automatizado, esto es, en un soporte informático. Asimismo, el consumo no medido es fácilmente cuantificable ya que simplemente consiste en recabar todas las estimaciones realizadas. El error que se comete en el volumen facturado y medido es el relativo al parque de contadores y los errores propios de la estimación del volumen facturado y no medido.

3. Por diferencia entre el volumen entrante al sistema y el volumen facturado se obtiene el volumen no facturado.

4. Se definen los consumos no facturados medidos y no medidos. La suma de ambos es el consumo no facturado. La determinación del consumo no facturado y medido es también sencilla, simplemente se determina el volumen consumido por instituciones a las que no se le factura el agua. En el caso de consumo no facturado y no medido, el gestor realiza una estimación directa del mismo. Los errores de estos dos términos son los relativos a los medidores correspondientes y los propios de la estimación respectivamente.

5. El consumo autorizado se obtiene sumando los consumos facturados y no facturados.

6. Las pérdidas se obtienen como diferencia entre el volumen total entrante y el consumo autorizado. 
7. De acuerdo con una metodología determinada, se identifican los consumos no autorizados y los consumos no medidos por los medidores. La suma de ambos términos cuantifican las fugas aparentes. Este proceso es complicado porque identificar los consumos no autorizados (robos, etc.) es un proceso laborioso y requiere sucesivos peinados de la red. El objetivo siempre será disminuir estos consumos al máximo.

8. Las fugas reales se obtienen por diferencia entre el volumen incontrolado y las fugas aparentes. Como se observa, las fugas reales se determinan a partir de todos los términos anteriores, por lo que aglutinan todos los errores de medición de los pasos previos. Esto motiva la determinación de las fugas reales por otros procedimientos alternativos (ya mostrados) como el análisis de los flujos nocturnos o de los componentes de la fuga.

9. Finalmente, se obtiene cómo se distribuyen las fugas en el sistema de distribución de la mejor manera posible, identificando las pérdidas en tuberías, acometidas y depósitos de almacenamiento.

En este apartado se ha realizado una propuesta del orden de realización de la auditoría. Aunque cada abastecimiento delineará su propia hoja de ruta para acometer la misma, y todas las propuestas son igualmente válidas. A continuación, se definen los principales indicadores de gestión que permiten transformar esta ingente cantidad de información, la auditoría, en datos que ayuden a conocer el estado de la red. 


\subsection{Indicadores de gestión más frecuentemente utilizados}

El manual de buenas prácticas del IWA (Alegre y col., 2006) muestra 170 indicadores de gestión para redes de abastecimiento. Éstos se engloban en recursos de agua, de personal, físicos, operacionales, calidad de servicio y financieros. Cada uno de ellos, por si solo, merece una explicación detallada, aunque se concretan los indicadores más significativos que están relacionados con la auditoría hídrica y que se muestran una información más precisa y, con posterioridad se definen los más comunes, el UMF y el IFE.

\subsubsection{Rendimiento volumétrico de una red de distribución}

El indicador más común es el rendimiento volumétrico. Se define como el cociente entre las pérdidas reales $\left(v_{f}\right)$ por el volumen entrante en el sistema $v_{\text {iny }}$.

$\eta=\left(1-\frac{V_{f}}{V_{\text {iny }}}\right) \cdot 100$

Sin duda este indicador ha sido el más utilizado aunque en la actualidad ha caído en desuso ya que no representa adecuadamente el nivel de fugas. El rendimiento volumétrico minusvalora el efecto de las fugas en caso de sistemas con fuerte consumo. Por ejemplo, si una red que consume $800 \mathrm{~m}^{3} /$ día y tiene unas fugas de $200 \mathrm{~m}^{3} /$ día, el rendimiento volumétrico será del 75\%, mientras que en el mismo sistema con un consumo de $1000 \mathrm{~m}^{3} /$ día, el rendimiento será del $80 \%$. Por tanto, queda claro que con un mismo nivel de fugas se obtiene diferentes valores del mismo indicador y no se puede utilizar para comparar la gestión hídrica de abastecimientos.

\subsubsection{Indicadores de gestión relacionados con la auditoría hídrica}

Los indicadores relacionados con la auditoria y definidos por el manual de buenas prácticas ${ }^{30}$ son:

- Op 23, Pérdidas totales por acometida ( $\mathrm{m}^{3} /$ acometida/día). Se calcula como:

$$
\text { Op23 }=\frac{V_{\text {perd }}\left(m^{3}\right)}{N_{\text {acometidas }} \cdot T(\text { dias })}
$$

\footnotetext{
${ }^{30}$ Se definen siguiendo la nomenclatura de IWA (Alegre y col., 2006).
} 
Donde $v_{\text {perd }}$ el volumen total de pérdidas $\left(\mathrm{m}^{3}\right), N_{\text {acometidas }}$ es el número de acometidas y $T$ el periodo de tiempo en el que se calculan los anteriores parámetros y expresado en días (habitualmente un año).

- Op 24, Pérdidas totales por longitud de tubería $\left(\mathrm{m}^{3} / \mathrm{km} /\right.$ día). Se puede usar como alternativa al anterior Op 23. Op 24 se utiliza si la densidad de acometidas es menor de 20 por km de tubería. Se calcula como:

Op $24=\frac{V_{\text {perd }}\left(m^{3}\right)}{L_{\text {tub }} \cdot T(\text { dias })}$

Donde $L_{\text {tub }}$ la longitud de las tuberías de la red en $\mathrm{km}$.

- Op 26, Pérdidas aparentes por volumen entrante en el sistema (\%). Se calcula como el cociente entre las fugas aparentes $v_{a p}$ y el volumen de entrada en el sistema.

$$
\text { Op } 26=\frac{V_{a p}}{V_{\text {iny }}} \cdot 100
$$

- Op 27, Fugas reales por acometida (I/acometida/día).

Op27 $=\frac{V_{f}(I)}{N_{\text {acometidas }} \cdot T(\text { dias })}$

Dónde $v_{f}$ representa las pérdidas reales.

- Op 28, Fugas reales por longitud de tubería (l/km/día).

Op $28=\frac{V_{f}(I)}{L_{\text {tub }} \cdot T(\text { dias })}$

Tanto el indicador Op 27 como el Op 28 se pueden utilizar indistintamente, aunque se recomienda el empleo del último si la densidad de acometidas es menor de 20 por km de tubería.

Todos los indicadores, se pueden calcular fácilmente una vez se ha resuelto la auditoría hídrica y existe información acerca del número de acometidas y la longitud de tuberías existentes en la red. Asimismo, deben ser cuidadosamente evaluados si la auditoría se realiza en periodos de tiempo menores de un año, ya que pueden inducir a conclusiones erróneas. 


\subsubsection{Umbral mínimo de fugas, UMF}

El umbral mínimo de fugas (UMF) representa el valor mínimo de agua fugada existente en la red, que por mucho que se invierta en rehabilitación y renovación es imposible de rebajar. Éste umbral es debido a las fugas latentes principalmente. Se calcula como:

$$
U M F=\frac{p \cdot\left(18 \cdot L_{\text {tub }}+0.8 \cdot N_{\text {acomentidas }}+25 \cdot L_{\text {acometidas }}\right)}{N_{\text {acometidas }}}
$$

Donde $L_{\text {acometidas }}(\mathrm{km})$ es la longitud total de todas las acometidas y $p$ (m.c.a.) es la presión media de operación. UMF se expresa en (I/acometida/día).

\subsection{4 Índice de fugas estructural, IFE o ILI}

El infrastructure leakage index (ILI) o índice de fugas estructural (IFE) fue propuesto como indicador en el manual de buenas prácticas bajo la denominación Op 29. Se obtiene como el cociente entre las perdidas totales (Tabla 33) y el umbral mínimo de fugas. La expresión analítica es:

$I F E=\frac{V_{f}}{U M F}$

Se esperan valores cercanos a 1 para sistemas bien gestionados y valores superiores conforme la gestión sea menos eficiente.

El IFE, que probablemente sea el indicador más utilizado para la comparación de redes de abastecimiento, se ha utilizado para evaluar el estado de los abastecimientos. Los valores aceptables según se analicen redes de países desarrollados o en vías de desarrollo se muestran en la Tabla 36 (Liemberger, 2005). La propuesta pretende clasificar los niveles de fugas en 4 categorías según los valores del IFE tal y como sigue:

- $\mathrm{A}=$ Excelente. No requiere ningún tipo específico de intervención.

- $\mathrm{B}=$ Buena. No requiere ninguna acción urgente, aunque debe ser monitorizado cuidadosamente.

- $\quad \mathrm{C}=$ Pobre. Requiere especial atención.

- $\mathrm{D}=$ Malo. Requiere intervenciones inmediatas para la reducción del nivel de fugas. 
TABLA 36. VALORES DEL IFE EN PAÍSES DESARROLLADOS Y EN VÍAS DE DESARROLLO (LIEMBERGER, 2005).

\begin{tabular}{|c|c|c|c|c|c|c|c|}
\hline & & \multirow[t]{2}{*}{ IFE } & \multicolumn{5}{|c|}{ Litros/Conexión/día } \\
\hline & & & $10 \mathrm{~m}$ & $20 \mathrm{~m}$ & $30 \mathrm{~m}$ & $40 \mathrm{~m}$ & $50 \mathrm{~m}$ \\
\hline \multirow{4}{*}{ 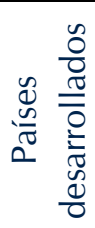 } & A & $1-2$ & & $<50$ & $<75$ & $<100$ & $<125$ \\
\hline & $\mathrm{B}$ & $2-4$ & & $50-100$ & $75-150$ & $100-200$ & $125-500$ \\
\hline & $\mathrm{C}$ & $4-8$ & & $100-200$ & $150-300$ & $200-400$ & $250-500$ \\
\hline & $\mathrm{D}$ & $>8$ & & $>200$ & $>300$ & $>400$ & $>500$ \\
\hline \multirow{4}{*}{ 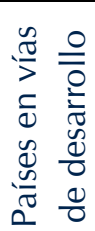 } & A & $1-4$ & $<50$ & $<100$ & $<150$ & $<200$ & $<250$ \\
\hline & $\mathrm{B}$ & $4-8$ & $50-100$ & $100-200$ & $150-300$ & $200-400$ & $250-500$ \\
\hline & $\mathrm{C}$ & 8-16 & $100-200$ & $200-400$ & $300-600$ & $400-800$ & $500-1000$ \\
\hline & $\mathrm{D}$ & $>16$ & $>200$ & $>400$ & $>600$ & $>800$ & $>1000$ \\
\hline
\end{tabular}

McKenzie y col. (2007) muestran el IFE de 25 países obtenidos a partir de un estudio del grupo de trabajo de fugas de la IWA. Para ello, recibieron 269 series de datos y 197 fueron finalmente empleadas para mostrar los siguientes resultados (Tabla 37).

TABLA 37. VALORES DEL IFE (MCKENZIE Y COL., 2007)

\begin{tabular}{|c|c|c|c|}
\hline \multirow{2}{*}{ País } & \multirow{2}{*}{ Número de datos } & \multicolumn{2}{|c|}{ Valores del ILI } \\
\hline & & Mínimo & Max \\
\hline Australia & 2 & 0.5 & 1.7 \\
\hline Austria & 27 & 0.3 & 6.6 \\
\hline Burkina Faso & 1 & 8 & - \\
\hline Canadá & 17 & 1.1 & 9 \\
\hline $\begin{array}{c}\text { Croacia y Bosnia } \\
\text { Herzegovina }\end{array}$ & 13 & 1.5 & 17 \\
\hline Chipre & 1 & 2.0 & - \\
\hline Etiopía & 1 & 20 & - \\
\hline Finlandia & 1 & 3.0 & - \\
\hline Reino de Bahrein & 1 & 60 & - \\
\hline Kosovo & 7 & 3.3 & 23 \\
\hline Malawi & 2 & 12 & 26 \\
\hline Namibia & 1 & 10 & - \\
\hline Holanda & 4 & 0.3 & 0.6 \\
\hline Nueva Zelanda & 8 & 0.6 & 47 \\
\hline Sudáfrica & 54 & 0.4 & 16.9 \\
\hline Zona sureste asiático & 15 & 19 & 598 \\
\hline España & 1 & 12 & - \\
\hline Tanzania & 2 & 16 & 32 \\
\hline Tailandia & 14 & 46 & 543 \\
\hline Reino Unido & 2 & 1.7 & 1.8 \\
\hline \multirow{2}{*}{ Estados Unidos y Canadá } & 3 & 2.8 & 4.6 \\
\hline & 20 & 1.0 & 6.7 \\
\hline Total & 197 & & \\
\hline
\end{tabular}


Por último, la propia experiencia en la utilización del IFE también ha permitido utilizar este indicador no sólo como descriptor de la situación en que se encuentra un sistema sino como objetivo a alcanzar en el futuro (AWWA, 2003).

TABLA 38. VALORES DEL IFE COMO DESCRIPTORES Y COMO OBJETIVO (AWWA, 2003)

\begin{tabular}{|c|c|c|c|}
\hline $\begin{array}{l}\text { Rangos } \\
\text { del ILI }\end{array}$ & $\begin{array}{l}\text { Consideraciones acerca } \\
\text { del origen del agua }\end{array}$ & $\begin{array}{l}\text { Condiciones de } \\
\text { operación }\end{array}$ & Consideraciones económicas \\
\hline $1-3$ & $\begin{array}{l}\text { Disponibilidad de los } \\
\text { recursos muy limitada }\end{array}$ & $\begin{array}{l}\text { Requiere aumento de } \\
\text { la oferta y aumentar } \\
\text { los diámetros de la } \\
\text { red. }\end{array}$ & $\begin{array}{l}\text { - El agua es difícil de obtener y es } \\
\text { cara. } \\
\text { - Los ingresos por la venta de agua } \\
\text { no puede aumentar, bien por la } \\
\text { existencia un organismo regulador } \\
\text { o por un bajo beneficio por } \\
\text { volumen consumido }\end{array}$ \\
\hline $3-5$ & $\begin{array}{l}\text { Los recursos permiten } \\
\text { cubrir las necesidades a } \\
\text { largo plazo. Requiere } \\
\text { una reducción del nivel } \\
\text { de fugas }\end{array}$ & $\begin{array}{l}\text { Requiere aumento de } \\
\text { la oferta y se exige un } \\
\text { control de las fugas }\end{array}$ & $\begin{array}{l}\text { - El agua se puede obtener con un } \\
\text { gasto razonable } \\
\text { - Se puede incrementar el precio } \\
\text { del agua y ésta será tolerada por } \\
\text { los consumidores }\end{array}$ \\
\hline $5-8$ & $\begin{array}{lrr}\text { El agua } & \text { se } & \text { obtiene } \\
\text { fácilmente } & y & \text { es de } \\
\text { calidad } & & \end{array}$ & $\begin{array}{l}\text { Las redes son inmunes } \\
\text { a cortes en el } \\
\text { abastecimiento }\end{array}$ & $\begin{array}{l}\text { - El agua se puede obtener } \\
\text { fácilmente } \\
\text { - El coste del agua es bajo }\end{array}$ \\
\hline $\begin{array}{l}\text { Mayores } \\
\text { que } 8\end{array}$ & \multicolumn{3}{|c|}{$\begin{array}{l}\text { Aunque las consideraciones operacionales y económicas pueden permitir un indicador } \\
\text { mayor que } 8 \text {, un elevado nivel de fugas no representa una utilización adecuada del } \\
\text { agua como recurso. Por tanto, representa una situación desalentadora, y se ha de } \\
\text { intentar reducir las fugas a corto plazo. }\end{array}$} \\
\hline
\end{tabular}




\subsection{Ejemplos de auditoría hídrica en redes de distribución}

A continuación se muestran algunos ejemplos de auditorías realizadas en varias ciudades o países. Las primeras publicaciones en esta materia comienzan hace más de 10 años y el planteamiento de la auditoría hídrica en redes de distribución se sigue realizando en la actualidad. Los casos estudiados pertenecen tanto de ciudades europeas como de Australia y EE.UU. Asimismo, se muestran ejemplos de la auditoría propuesta por IWA (2000) y otras con la propuesta por Almandoz y col. (2005). Finalmente, se muestra un primer estudio de elaboración propia realizado en Valencia.

En el primer estudio Tsitsifli y Kanakoudis (2008) resolvieron la auditoría hídrica en la ciudad de Larissa, situada en la zona este de Grecia. Con una población de 192000 habitantes y una red de distribución de 627 km $(3.27$ km /1000 habitantes), compuesta por fundición gris (12\% en longitud), fibrocemento (30\%), acero $(10 \%)$ y PVC (48\%), el estudio se centró en la evolución de la auditoría entre los años 2001 y 2006. Entre esos años, se realizó un esfuerzo para medir el consumo no medido y no facturado empleado contra incendios, riego de parques, edificios municipales, etc. y resultó que éste era casi nulo. El consumo no autorizado (conexiones ilegales) representaba el $1 \%$ del volumen entrante en el sistema y el volumen no medido por errores de los contadores, cerca del $8 \%$ del total inyectado. Aunque en estos 5 años el consumo facturado aumentó un $6.4 \%$, las pérdidas reales (fugas) disminuyeron en más de $1 \mathrm{hm}^{3}$ (más del $20 \%$ de las pérdidas reales), lo que se tradujo en la reducción del volumen entrante en la red pese al aumento de la demanda. 
TABLA 39 AUDITORÍA HÍDRICA EN LARISSA EN EL AÑO 2001. (TSITSIFLI Y KANAKOUDIS, 2008).

\begin{tabular}{|c|c|c|c|c|}
\hline \multirow{5}{*}{$\begin{array}{c}\text { Volumen } \\
\text { entrante en el } \\
\text { sistema } \\
18.06 \mathrm{hm}^{3}\end{array}$} & \multirow{2}{*}{$\begin{array}{c}\text { Consumo } \\
\text { Autorizado } \\
11.71 \mathrm{hm}^{3}\end{array}$} & $\begin{array}{l}\text { Consumo } \\
\text { facturado } \\
10.98 \mathrm{hm}^{3}\end{array}$ & $\begin{array}{l}\text { Consumo facturado y } \\
\text { medido } 8.80 \mathrm{hm}^{3} \\
\text { Consumo facturado no } \\
\text { medido } 2.18 \mathrm{hm}^{3}\end{array}$ & $\begin{array}{l}\text { Volumen } \\
\text { Facturado } \\
10.98 \mathrm{hm}^{3}\end{array}$ \\
\hline & & $\begin{array}{c}\text { Consumo no } \\
\text { facturado } \\
0.73 \mathrm{hm}^{3}\end{array}$ & $\begin{array}{l}\text { Consumo no facturado } \\
\text { aunque medido } 0.73 \mathrm{hm}^{3} \\
\text { Consumo facturado y no } \\
\text { medido } 0 \mathrm{hm}^{3}\end{array}$ & \multirow{4}{*}{$\begin{array}{c}\text { Volumen no } \\
\text { Facturado } \\
7.08 \mathrm{hm}^{3}\end{array}$} \\
\hline & \multirow{3}{*}{$\begin{array}{l}\text { Pérdidas } \\
\text { totales } \\
6.35 \mathrm{hm}^{3}\end{array}$} & \multirow{2}{*}{$\begin{array}{c}\text { Pérdidas } \\
\text { aparentes } \\
1.60 \mathrm{hm}^{3}\end{array}$} & $\begin{array}{l}\text { Consumos no autorizados } \\
0.17 \mathrm{hm}^{3}\end{array}$ & \\
\hline & & & $\begin{array}{l}\text { Consumos no medidos por } \\
\text { incertidumbres de los } \\
\text { contadores } 1.43 \mathrm{hm}^{3}\end{array}$ & \\
\hline & & \multicolumn{2}{|r|}{$\begin{array}{c}\text { Pérdidas Reales } \\
4.75 \mathrm{hm}^{3}\end{array}$} & \\
\hline
\end{tabular}

TABLA 40 AUDITORÍA HÍDRICA EN LARISSA EN EL AÑO 2006. (TSITSIFLI Y KANAKOUDIS, 2008).

\begin{tabular}{|c|c|c|c|c|}
\hline \multirow{6}{*}{$\begin{array}{c}\text { Volumen } \\
\text { entrante en el } \\
\text { sistema } \\
17.77 \mathrm{hm}^{3}\end{array}$} & \multirow{3}{*}{$\begin{array}{c}\text { Consumo } \\
\text { Autorizado } \\
12.46 \mathrm{hm}^{3}\end{array}$} & $\begin{array}{l}\text { Consumo } \\
\text { facturado } \\
11.69 \mathrm{hm}^{3}\end{array}$ & $\begin{array}{l}\text { Consumo facturado y } \\
\text { medido } 9.10 \mathrm{hm}^{3} \\
\text { Consumo facturado no } \\
\text { medido } 2.59 \mathrm{hm}^{3}\end{array}$ & $\begin{array}{l}\text { Volumen } \\
\text { Facturado } \\
11.69 \mathrm{hm}^{3}\end{array}$ \\
\hline & & \multirow{2}{*}{$\begin{array}{c}\text { Consumo no } \\
\text { facturado } \\
0.77 \mathrm{hm}^{3}\end{array}$} & $\begin{array}{l}\text { Consumo no facturado } \\
\text { aunque medido } 0.77 \mathrm{hm}^{3}\end{array}$ & \multirow{5}{*}{$\begin{array}{c}\text { Volumen no } \\
\text { Facturado } \\
6.08 \mathrm{hm}^{3}\end{array}$} \\
\hline & & & $\begin{array}{l}\text { Consumo facturado y no } \\
\text { medido } 0 \mathrm{hm}^{3}\end{array}$ & \\
\hline & \multirow{3}{*}{$\begin{array}{l}\text { Pérdidas } \\
\text { totales } \\
5.31 \mathrm{Hm}^{3}\end{array}$} & \multirow{2}{*}{$\begin{array}{c}\text { Pérdidas } \\
\text { aparentes } \\
1.66 \mathrm{hm}^{3}\end{array}$} & $\begin{array}{l}\text { Consumos no autorizados } \\
0.18 \mathrm{hm}^{3}\end{array}$ & \\
\hline & & & $\begin{array}{l}\text { Consumos no medidos por } \\
\text { incertidumbres de los } \\
\text { contadores } 1.48 \mathrm{hm}^{3}\end{array}$ & \\
\hline & & & $\begin{array}{l}\text { érdidas Reales } \\
3.65 \mathrm{hm}^{3}\end{array}$ & \\
\hline
\end{tabular}


En la Republica Checa Tuhovcak y Kucera (2008) identificaron la evolución temporal de algunos términos de la auditoría hídrica para ese país, Tabla 41.

TABLA 41. VALORES ENCONTRAdOS EN lOS ABASTECIMIENTOS DE LA REPÚBLICA CHECA. (TUHOVCAK Y KUCERA, 2008)

\begin{tabular}{|c|c|c|c|c|c|}
\hline Indicadores y términos de la auditoría & Unidades & 2002 & 2003 & 2004 & 2005 \\
\hline $\begin{array}{l}\text { Volumen no facturado } \\
\text { con respecto al inyectado }\end{array}$ & $(\%)$ & 15.5 & 17.9 & 17.2 & 16.4 \\
\hline $\begin{array}{l}\text { Volumen no facturado } \\
\text { por longitud y día }\end{array}$ & $\left(\mathrm{m}^{3} / \mathrm{km} / \mathrm{dí} a\right)$ & 6.5 & 6.8 & 6 & 5.4 \\
\hline Pérdidas totales por longitud y día & $\left(\mathrm{m}^{3} / \mathrm{km} / \mathrm{dí} a\right)$ & 5.5 & 4.9 & 4.6 & 4.1 \\
\hline
\end{tabular}

Otro ejemplo de auditoría (aunque menos elaborada que en los casos anteriores) mostraron los resultados en el abastecimiento de Austin (Texas, EE.UU.). En los años 2004/05, se inyectaron $181.7 \mathrm{hm}^{3}$, siendo facturados $155.2 \mathrm{hm}^{3}$. Un $14.6 \%$ del volumen fue no facturado, en contraste con los $14.3 \%$ y $15 \%$ que habían obtenido en los años 2003/04 y 2002/03 respectivamente (Gregg y Dewees, 2007).

Farley y Trow (2003) publicaron un ejemplo de cálculo de la auditoría hídrica de una zona del noroeste de Auckland, Nueva Zelanda. Los límites de confianza del cálculo, con una probabilidad del 95\%, valoraron el consumo autorizado con una incertidumbre menor del $2 \%$. Para bajos niveles de fuga, como se tenía en esta zona, la incertidumbre en otros términos de la auditoría fue mayor (como las fugas reales $( \pm 28 \%)$, aparentes $( \pm 50 \%)$ y agua no facturada $( \pm 23 \%)$ ) Tabla 42 . 
Tabla 42 Auditoría hídrica en AuckLand, Nueva Zelanda. (Farley y Trow, 2003).

\begin{tabular}{|c|c|c|c|c|}
\hline \multirow{6}{*}{$\begin{array}{c}\text { Volumen } \\
\text { entrante en el } \\
\text { sistema } \\
14.321 \mathrm{hm}^{3} \\
\pm 2.0 \%\end{array}$} & \multirow{3}{*}{$\begin{array}{c}\text { Consumo } \\
\text { Autorizado } \\
12.791 \mathrm{hm}^{3} \\
\pm 1.6 \%\end{array}$} & $\begin{array}{c}\text { Consumo } \\
\text { facturado } \\
12.747 \mathrm{hm}^{3} \\
\pm 1.6 \%\end{array}$ & $\begin{array}{l}\text { Consumo facturado } \mathrm{y} \\
\text { medido } 12.747 \mathrm{hm}^{3} \pm 1.6 \% \\
\text { Consumo facturado no } \\
\text { medido } 0 \mathrm{hm}^{3}\end{array}$ & $\begin{array}{c}\text { Volumen } \\
\text { Facturado } \\
12.747 \mathrm{hm}^{3} \\
\pm 1.6 \%\end{array}$ \\
\hline & & \multirow{2}{*}{$\begin{array}{c}\text { Consumo no } \\
\text { facturado } \\
0.044 \mathrm{hm}^{3} \\
\pm 29.4 \%\end{array}$} & $\begin{array}{l}\text { Consumo no facturado } \\
\text { aunque medido } 0 \mathrm{hm}^{3}\end{array}$ & \multirow{5}{*}{$\begin{array}{c}\text { Volumen no } \\
\text { Facturado } \\
1.574 \mathrm{hm}^{3} \\
\pm 22.6 \%\end{array}$} \\
\hline & & & $\begin{array}{l}\text { Consumo facturado y no } \\
\text { medido } 0.044 \mathrm{hm}^{3} \pm 29.4 \%\end{array}$ & \\
\hline & \multirow{3}{*}{$\begin{array}{l}\text { Pérdidas } \\
\text { totales } \\
0.153 \mathrm{hm}^{3} \\
\pm 23.2 \%\end{array}$} & \multirow{2}{*}{$\begin{array}{l}\text { Pérdidas } \\
\text { aparentes } \\
0.232 \mathrm{hm}^{3} \\
\pm 52.2 \%\end{array}$} & $\begin{array}{l}\text { Consumos no autorizados } \\
0.003 \mathrm{hm}^{3} \pm 80 \%\end{array}$ & \\
\hline & & & $\begin{array}{l}\text { Consumos no medidos por } \\
\text { incertidumbres de los } \\
\text { contadores } 0.229 \mathrm{hm}^{3} \\
\pm 52.7 \%\end{array}$ & \\
\hline & & \multicolumn{2}{|c|}{$\begin{array}{c}\text { Pérdidas Reales } \\
1.298 \mathrm{hm}^{3} \pm 28.9 \%\end{array}$} & \\
\hline
\end{tabular}

En este trabajo, Farley y Trow (2003) mostraron un análisis de los datos de consumo y de presiones existentes en la red de abastecimiento de Sarina Shire Council (Australia). Éste se centró en determinar las fugas en la red y los posibles ahorros potenciales que podían obtenerse tras la implementación de un programa de control de fugas, sectorización y gestión de la presión. Los resultados obtenidos para una auditoría realizada en medio año, concretamente entre el 1 de Julio y el 30 de diciembre de 2001, se detallan en la Tabla 43 separados en tres bloques, la de la propia ciudad y las que abastecen a dos playas cercanas.

TAbla 43 Auditoría hídrica en SARina Shire CounCil (FARley y TroW, 2003).

\begin{tabular}{cccc}
\hline & Sarina Township & Northern Beaches & Armstrong Beach \\
\hline $\begin{array}{c}\text { Volumen entrante en el } \\
\text { sistema }\left(\mathrm{hm}^{3}\right)\end{array}$ & 0.3132 & 0.2882 & 0.0511 \\
\hline Consumo autorizado $\left(\mathrm{hm}^{3}\right)$ & 0.2705 & 0.2804 & 0.047 \\
\hline Agua no facturada $\left(\mathrm{hm}^{3}\right)$ & 0.0427 & 0.0078 & 0.0041 \\
\hline $\begin{array}{c}\text { Fugas reales }\left(\mathrm{hm}^{3}\right)^{31} \\
(\% \text { sobre el volumen entrante) }\end{array}$ & $0.0421(13.4 \%)$ & $0.0077(2.7 \%)$ & $0.0041(8.0 \%)$ \\
\hline
\end{tabular}

${ }^{31}$ En este estudio, las fugas reales son parte del agua no facturada. Se puede observar que el volumen entrante en el sistema es igual a la suma del consumo autorizado y del agua no facturada. 
Del estudio anterior se desprendió que con un precio medio de venta del agua de 1100 AUS $\$ / \mathrm{Ml}\left(0.642 € / \mathrm{m}^{3}\right)^{32}$, y con los $0.0546 \mathrm{hm}^{3}$ no facturados en la totalidad de la red, los ahorros potenciales obtenidos podían ser de 60060 AUS \$/medio año, $70200 € /$ año.

Farley y Trow (2003) mostraron un ejemplo de determinación de las fugas reales en 27 abastecimientos en Brasil, Dinamarca, Francia, Finlandia, Alemania, Gibraltar, Grecia, Islandia, Japón, Malta, Holanda, Nueva Zelanda, Singapur, España, suiza, Suecia, Reino Unido, Estados Unidos y Palestina para un periodo anual. Todos los datos eran anónimos, excepto el de Malta (Gozo) que tiene la referencia número 3 (Tabla 44).

\footnotetext{
${ }^{32}$ Para la paridad $1 \mathrm{AUS} \$=0.5843 €$
} 
TABLA 44. INDICADORES DE GESTIÓN INTERNACIONALES (FARLEY Y TROW (2003).

\begin{tabular}{|c|c|c|c|c|c|c|c|c|c|}
\hline \multirow{2}{*}{$\begin{array}{c}\text { Referencia } \\
1\end{array}$} & \multirow{2}{*}{$\begin{array}{c}\text { Presión } \\
\text { media } \\
\text { (m.c.a.) } \\
35\end{array}$} & \multirow{2}{*}{$\begin{array}{c}\begin{array}{c}\text { Densidad } \\
\text { acometidas }\end{array} \\
\text { (acometida/km) } \\
55\end{array}$} & \multirow{2}{*}{$\begin{array}{c}\text { Long. } \\
\text { media (m) } \\
\text { de } \\
\text { acometidas } \\
3\end{array}$} & \multirow{2}{*}{$\begin{array}{l}\text { IFE } \\
0.45\end{array}$} & \multicolumn{2}{|c|}{$\begin{array}{l}\text { Pérdidas } \\
\text { reales } \\
\begin{array}{r}\text { (I/acom/día) } \\
\text { rank }\end{array}\end{array}$} & \multirow{2}{*}{$\begin{array}{c}\text { Consumo } \\
\text { (I/acom/día) }\end{array}$} & \multicolumn{2}{|c|}{$\begin{array}{r}\text { Pérdidas } \\
\text { reales (\%) } \\
\text { rank }\end{array}$} \\
\hline & & & & & 19 & 1 & & 3.5 & 3 \\
\hline 2 & 50 & 53 & 3 & 0.53 & 32 & 2 & 525 & 6.1 & 6 \\
\hline 3 & 45 & 103 & 0 & 0.97 & 42 & 3 & 266 & 15.8 & 16 \\
\hline 4 & 40 & 38 & 10 & 1.21 & 74 & 5 & 7824 & 0.9 & 1 \\
\hline 5 & 57 & 47 & 30 & 1.31 & 146 & 12 & 496 & 29.4 & 23 \\
\hline 6 & 106 & 28 & 0 & 1.32 & 202 & 14 & 1023 & 19.7 & 19 \\
\hline 7 & 35 & 39 & 6 & 1.55 & 76 & 6 & 1734 & 4.4 & 4 \\
\hline 8 & 46 & 72 & 14 & 1.62 & 104 & 7 & 533 & 19.5 & 18 \\
\hline 9 & 60 & 55 & 0 & 1.66 & 114 & 8 & 1199 & 9.5 & 8 \\
\hline 10 & 46 & 71 & 23 & 1.72 & 130 & 9 & 543 & 23.9 & 21 \\
\hline 11 & 39 & 86 & 0 & 1.77 & 70 & 4 & 1280 & 5.5 & 5 \\
\hline 12 & 57 & 45 & 0 & 1.94 & 132 & 10 & 1142 & 11.6 & 12 \\
\hline 13 & 54 & 48 & 20 & 2.91 & 263 & 16 & 511 & 51.5 & 25 \\
\hline 14 & 30 & 35 & 10 & 2.94 & 138 & 11 & 5633 & 2.4 & 2 \\
\hline 15 & 70 & 31 & 5 & 3.25 & 342 & 18 & 4230 & 8.1 & 7 \\
\hline 16 & 30 & 65 & 5 & 4.99 & 180 & 13 & 567 & 31.7 & 24 \\
\hline 17 & 46 & 37 & 0 & 5.42 & 320 & 17 & 2208 & 14.5 & 14 \\
\hline 18 & 50 & 58 & 5 & 5.94 & 367 & 19 & 2552 & 14.4 & 13 \\
\hline 19 & 36 & 29 & 15 & 6.21 & 401 & 21 & 719 & 55.8 & 26 \\
\hline 20 & 39 & 26 & 10 & 6.44 & 436 & 22 & 3004 & 14.5 & 15 \\
\hline 21 & 35 & 29 & 20 & 7.06 & 477 & 23 & 2652 & 18 & 17 \\
\hline 22 & 31 & 79 & 0 & 8.02 & 256 & 15 & 2481 & 10.3 & 9 \\
\hline 23 & 48 & 114 & 0 & 8.04 & 370 & 20 & 1742 & 21.2 & 20 \\
\hline 24 & 71 & 21 & 0 & 8.15 & 956 & 27 & 1669 & 57.3 & 27 \\
\hline 25 & 45 & 24 & 10 & 9.39 & 759 & 25 & 6921 & 11 & 10 \\
\hline 26 & 37 & 27 & 10 & 9.48 & 600 & 24 & 5214 & 11.5 & 11 \\
\hline 27 & 45 & 24 & 10 & 10.25 & 832 & 26 & 3230 & 25.8 & 22 \\
\hline
\end{tabular}


Almandoz y col. (2005) mostraron la distribución del caudal incontrolado en 4 casos correspondientes a diferentes ciudades o países.

TABLA 45. VALORES ENCONTRADOS EN ABASTECIMIENTOS DE DIVERSAS CIUDADES (ALMANDOZ Y COL., 2005)

\begin{tabular}{|c|c|c|}
\hline \multirow[b]{2}{*}{$\begin{array}{l}\text { Zurich, Suiza } \\
\text { (Skarda, 1997) }\end{array}$} & \multicolumn{2}{|c|}{$Q_{m} / Q=0.907$} \\
\hline & $Q_{u} / Q=0.093$ & $\begin{array}{c}Q_{u c} / Q=0.04 \\
Q_{u l} / Q=0.053\end{array}$ \\
\hline \multicolumn{3}{|c|}{$Q_{m} / Q=0.739$} \\
\hline $\begin{array}{l}\text { San Sebastián, España } \\
\text { (Almandoz y col, 2003) }\end{array}$ & $Q_{u} / Q=0.261$ & $\begin{array}{l}Q_{u c} / Q=0.055 \\
Q_{u l} / Q=0.206\end{array}$ \\
\hline $\begin{array}{l}\text { Inglaterra y Gales } \\
\text { (Ofwat, 2001) }\end{array}$ & $Q_{u} / Q=0.675$ & $\begin{array}{l}Q_{u c} / Q=0.517 \\
Q_{u l} / Q=0.158\end{array}$ \\
\hline $\begin{array}{c}\text { Chetumal, México } \\
\text { (Ochoa y Bourguett, 1998) }\end{array}$ & $Q_{u} / Q=0.676$ & $\begin{array}{l}Q_{u c} / Q=0.112 \\
Q_{u l} / Q=0.564\end{array}$ \\
\hline
\end{tabular}

Donde los términos son los siguientes:

- $Q$ es el caudal entrante en el sistema.

- $Q_{m}$ es el caudal medido por los contadores de los abonados, equivale al consumo autorizado.

- $Q_{u}$ es el caudal incontrolado, es similar a las pérdidas totales.

- $Q_{u c}$ es el caudal incontrolado no medido, pérdidas aparentes.

- $Q_{u l}$ es el caudal fugado, pérdidas reales.

Los casos anteriores reflejan el estado de algunas redes, aunque sin duda, el ejemplo más interesante es el que se presenta a continuación por ser el perteneciente a Valencia. Murgui y col. (2009) resuelven la auditoría hídrica como paso previo a su objetivo final, estimar la energía consumida por el ciclo del agua en la ciudad de Valencia. Por ello, la auditoría realizada no es tan detallada y precisa como se recomienda en otros trabajos. 
Para evaluar la relación agua-energía en la ciudad de Valencia, es necesario conocer las particularidades del ciclo urbano del agua. La red del área metropolitana de Valencia (que incluye la capital), abastece aproximadamente a 1.5 millones de habitantes de los que un 54\% (810000) residen en Valencia y pedanías, mientras el resto del consumo corresponde a municipios del área metropolitana. Todos los datos que siguen corresponden al año 2008. El esquema del ciclo urbano del agua de la ciudad de Valencia, lo muestra la Figura 46.

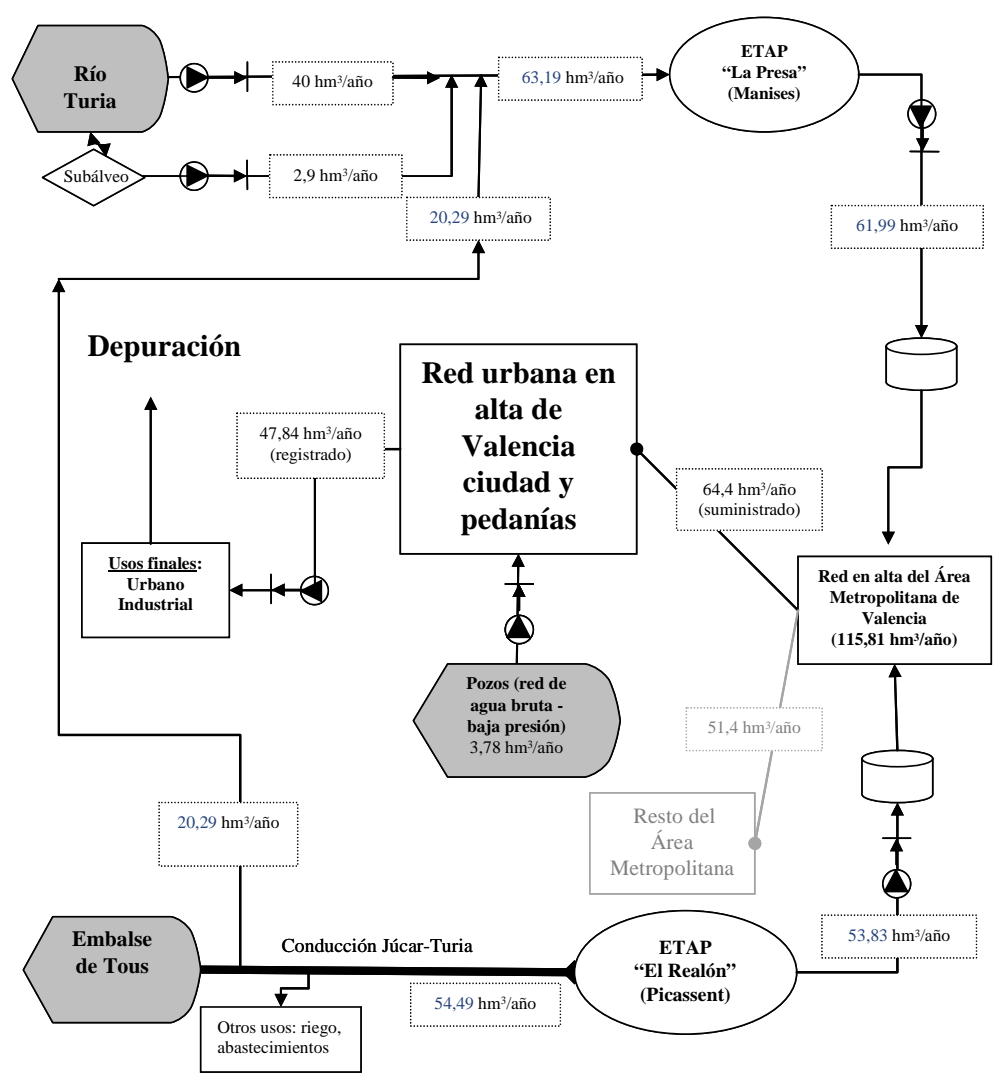

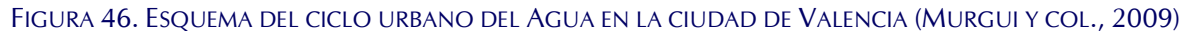

Las fuentes de suministro de la ciudad de Valencia y de sus pedanías son, principalmente, superficiales. El agua bruta procede del Turia y del canal JúcarTuria y es tratada en las Estaciones de Tratamiento de Agua Potable (ETAPs) de Picassent $\left(53.83 \mathrm{hm}^{3} / \mathrm{año}, 46.3 \%\right.$ del volumen potabilizado) y Manises $(61.98$ $\mathrm{hm}^{3} /$ año y $\left.53.70 \%\right)$. 
Del volumen anual potabilizado en las (ETAPs) es $115.81 \mathrm{hm}^{3} / \mathrm{año}$, de los cuales $64.4 \mathrm{hm}^{3} /$ año (el $55.61 \%$ ) es distribuido a Valencia y pedanías (Figura 46). Sin embargo, éste no es el único aporte de agua, pues se extraen $3.78 \mathrm{hm}^{3} / a n ̃ o ~ d e$ pozos que se distribuyen por una red de baja presión para el riego de parques y jardines. Éste último es un volumen no medido (esta red no dispone de contadores), por lo que se contabiliza en el apartado de las pérdidas aparentes. El volumen suministrado total en Valencia, suma de los volúmenes aportados a la

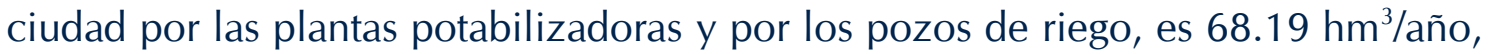
de los cuales, el $94.4 \%$ tiene como origen las plantas potabilizadoras, mientras que el resto es de origen subterráneo.

TABLA 46. BALANCE HÍDRICO EN LA RED DE DISTRIBUCIÓN DE VALENCIA EN HM³/AÑO.

\begin{tabular}{|c|c|c|}
\hline \multirow{5}{*}{$\begin{array}{c}\text { Volumen } \\
\text { suministrado } \\
68.19\end{array}$} & \multirow{3}{*}{$\begin{array}{c}\text { Volumen Registrado } \\
47.84(70.15 \%)\end{array}$} & $\begin{array}{l}\text { Uso doméstico } \\
34.04(49.92 \%)\end{array}$ \\
\hline & & $\begin{array}{l}\text { Uso industrial } \\
11.15(16.35 \%)\end{array}$ \\
\hline & & $\begin{array}{l}\text { Uso municipal } \\
2.65(3.88 \%)\end{array}$ \\
\hline & \multirow[b]{2}{*}{$\begin{array}{l}\text { Pérdidas aparentes y/o reales } \\
20.35(29.84 \%)\end{array}$} & $\begin{array}{c}\text { Perdidas reales }^{33} \\
9.95(14.58 \%)\end{array}$ \\
\hline & & $\begin{array}{c}\text { Pérdidas aparentes } \\
10.40(15.26 \%)\end{array}$ \\
\hline
\end{tabular}

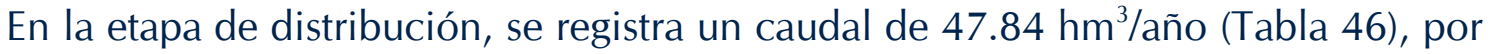
lo que las pérdidas aparentes y fugas de la red suponen $20.35 \mathrm{hm}$ /año (16.57 en la red de alta presión y $3.78 \mathrm{hm}^{3} /$ año en la red de baja). La red de distribución de alta tiene un rendimiento volumétrico del $74.28 \%$ (con respecto al volumen suministrado por las ETAPs) y unas fugas de $1.75 \mathrm{~m}^{3} / \mathrm{km} / \mathrm{h}$ (longitud de la red: $1080 \mathrm{~km}$ ). La misma tabla indica que el $49.92 \%$ del volumen total suministrado es consumo doméstico (que a su vez es el $71.2 \%$ del registrado), mientras que el uso industrial y el municipal representan el 16.35 y el $3.88 \%$ del volumen total suministrado (equivalentes al 23,3 y el 5,5\% del volumen registrado).

\footnotetext{
${ }^{33}$ Estimado
} 
Las pérdidas aparentes y reales son $20.35 \mathrm{hm}^{3} / \mathrm{año}, 29.84 \%$ del volumen total. Si se descuentan los $3.78 \mathrm{hm}^{3} /$ año de la red de baja, un caso singular en Valencia, y se cuantifican como pérdidas aparentes por no ser registrados; se obtiene un valor de $16.57 \mathrm{hm}^{3} /$ año. Se estima que un $60 \%$ de este volumen son fugas reales y el $40 \%$ restante aparentes. Un desglose más preciso requeriría un análisis más detallado como los anteriores. 


\section{4 \\ Políticas de gestión de fugas en el abastecimiento a largo plazo}





\subsection{Introducción}

La obtención del periodo óptimo de sustitución de las tuberías ha sido un problema abordado por numerosos investigadores. Por su posterior impacto, destaca el trabajo de Shamir y Howard (1979), quienes admitiendo un aumento exponencial de roturas en el tiempo, obtuvieron el periodo óptimo calculando el valor mínimo de la suma de los costes de renovación y de reparación para toda la vida útil de una tubería. Walski y col. (1982) plantearon la idea del umbral de roturas en el que se ha de renovar, mientras que Male y col. (1990) fijaron un valor para este umbral e identificaron el valor de la tasa de actualización como clave para la obtención del periodo óptimo de renovación.

Otros autores (Loganathan y col., 2002; Hong y col., 2006) también realizaron un planteamiento análogo a los anteriores aún cuando admiten que el número de roturas sigue una distribución de Poisson no homogénea. Kleiner y col. (2001) incluyeron otros criterios de renovación como el coste social derivado de la pérdida de estándares de servicio, mientras que Deb y col. (2009) consideran por primera vez unos costes que designan como indirectos y que, a su vez, engloban tanto los costes sociales (retrasos en el tráfico, pérdidas en los negocios) como los medioambientales. Sin embargo, únicamente cuantifican estos últimos como un porcentaje sobre los costes directos (reparación y mantenimiento).

Todos estos trabajos, así como el aquí mostrado, se definen para un sector de la red, por lo que las características de las tuberías son homogéneas (o se pueden considerar como tal), y por tanto, el comportamiento de las mismas es similar (mismo patrón de roturas, edad, rango de diámetros, etc.). La metodología propuesta por Shamir y Howard, que es la más extendida, considera dos costes bien diferenciados:

- Coste de renovación por metro de tubería $\left(C_{1}\right)$. Éste decrece en el tiempo, ya que el coste de renovación es constante y a mayor tiempo transcurrido representa un menor valor en unidades monetarias del año actual.

- Coste de reparación y mantenimiento $\left(\mathrm{C}_{2}\right)$. Éste muestra dos tendencias contrapuestas, por una parte el coste unitario de reparación es constante $y$, por efecto de la actualización de los costes, decrece en el tiempo y por otra, el número de roturas aumenta en el tiempo. La tendencia predominante es la segunda (aumentan más la roturas que desciende la actualización de la reparación unitaria) y el coste de mantenimiento presenta tendencia alcista. 
Dicho planteamiento general ignora factores (entre ellos destacan el coste del agua fugada y el coste de la energía) que cobran relevancia con el paso del tiempo. Por tanto, parece necesaria la inclusión de éstos en el cálculo del periodo óptimo de renovación, y ello requiere incluir los costes del agua fugada $\left(\mathrm{C}_{3}\right)$, los sociales $\left(\mathrm{C}_{4}\right)$ y por último, los de oportunidad ( $\left.\mathrm{C}_{5}\right)$.

Cada uno de los anteriores se compone, a su vez, de más de un sumando: por ejemplo, el coste del agua es la suma del coste de su producción y ambiental $\left(\mathrm{C}_{31}\right)$ y de su gasto energético $\left(\mathrm{C}_{32}\right)$. El coste social $\left(\mathrm{C}_{4}\right)$ incluye dos términos. El primero asociado al impacto que genera en el entorno la obra (como la interrupción del tráfico), mientras el segundo contempla penalizaciones derivadas del incumplimiento de algún estándar de servicio, incapacidad de la tubería para mantener la presión y calidad mínima de servicio.

El último coste, el de oportunidad ${ }^{34} \mathrm{C}_{5}$, se asocia al ahorro derivado de la renovación de la conducción si se aprovecha la ejecución de obras por parte de otras empresas. De este modo se pueden compartir gastos no despreciables, como los de desplazamiento de maquinaria, personal, herramientas, etc. Un ahorro que en el mejor de los casos (cuando la obra aprovecha las zanjas y la reposición del pavimento de otras infraestructuras) puede alcanzar el coste de la instalación de la conducción.

El interés de incluir en el análisis todos los costes es evidente desde el momento en que el resultado obtenido es sensible a ellos, particularmente cuando el coste del agua, $\mathrm{C}_{31}$, es elevado (como en el caso del agua desalada).

El presente capítulo expone las directrices a seguir para calcular el periodo óptimo de renovación de tuberías considerando estos nuevos costes que, desde la óptica que nos ocupa, no acostumbran a contemplarse. Sin duda, esta nueva formulación del planteamiento clásico se integra mejor en el actual escenario de mayor sensibilización medioambiental y persiguiendo el objetivo claro de propiciar el uso eficiente de dos recursos fundamentales, agua y energía (Figura 47).

\footnotetext{
${ }^{34}$ En este caso se designa coste de oportunidad al ahorro obtenido de aprovechar la realización de las obras por parte de otra compañía. No se debe confundir con el concepto económico, que designa el coste de la inversión de los recursos disponibles, en una oportunidad económica, a costa de las inversiones alternativas disponibles, o también el valor de la mejor opción no realizada.
} 
Una vez presentados los nuevos costes a analizar, se procede a la revisión o proposición de ciertas expresiones que, referidas al año del estudio e incluyendo la totalidad de los costes, permiten cuantificar el coste total de renovación de la tubería, y al tiempo responder a unas cuestiones concretas relacionadas con la identificación del efecto de estos nuevos costes sobre el periodo optimo de renovación y en especial, el efecto de un coste de oportunidad negativo.

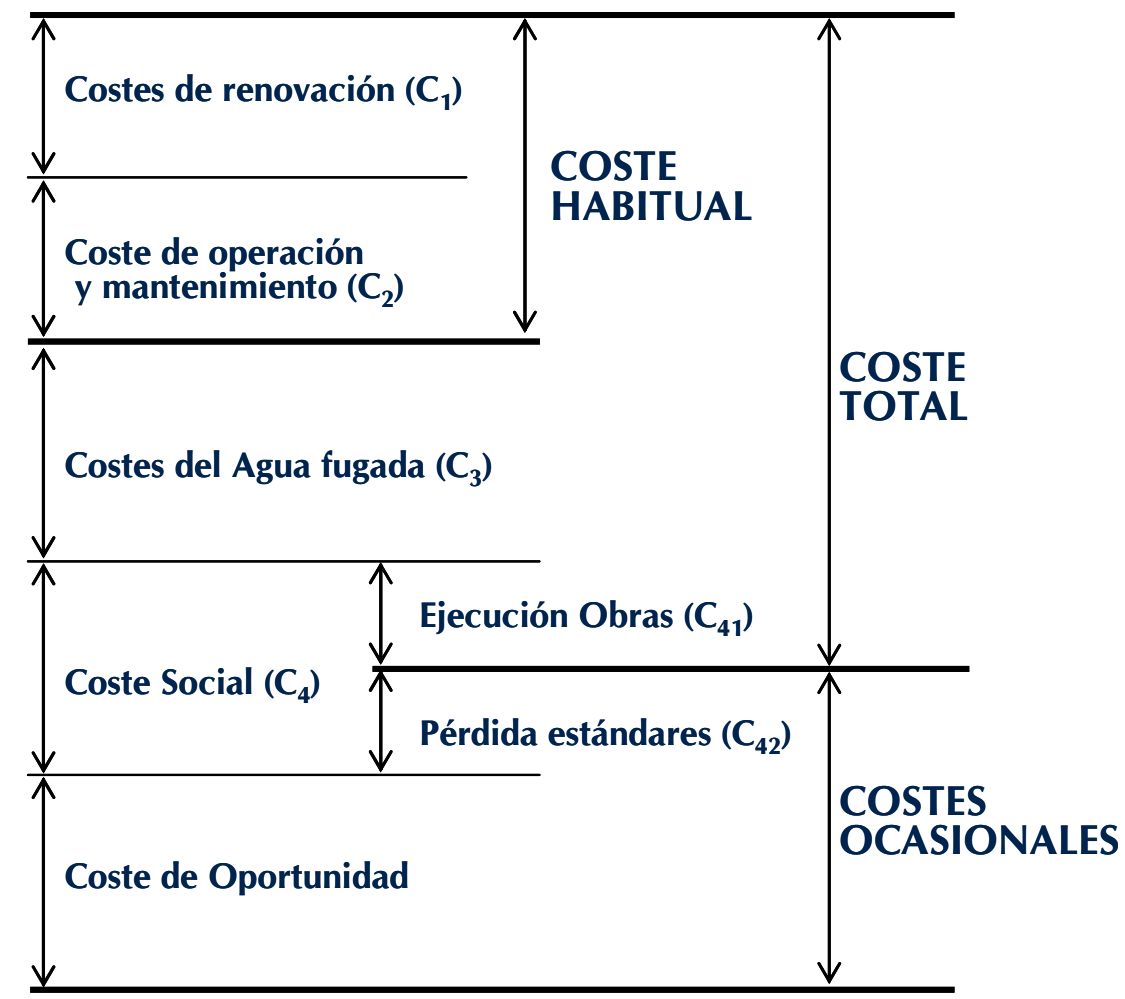

FIGURA 47. ENUMERACIÓN DE LOS COSTES TOTALES CONSIDERADOS.

\subsection{Planteamiento del problema}

Como se ha indicado ya, los dos costes habitualmente incluidos en el análisis (Shamir y Howard, 1979) se comportan de modo diferente: la renovación de la tubería es una inversión cuyo valor decrece en el tiempo mientras la reparación, acumulada año a año, es creciente. Los nuevos costes (excepto el de oportunidad) muestran un comportamiento similar a éstos dos. Por otra parte, los costes sociales y de oportunidad dependen del tipo de técnica empleada en la instalación de la tubería que también influye, y de manera notable, en el coste de renovación. Las posibilidades son muchas y crecen con el tiempo por lo que parece obvio el interés de cuantificar su incidencia. La Tabla 47 resume la notación empleada y caracteriza tanto el tipo de coste como la potencial incidencia en el mismo de la técnica de instalación utilizada. 
TABLA 47. CARACTERIZACIÓN DE LOS COSTES ANALIZADOS.

\begin{tabular}{|c|c|c|c|c|c|c|c|c|}
\hline $\begin{array}{l}\frac{0}{0} \\
\text { o. } \\
\frac{0}{2} \\
\frac{\bar{z}}{0} \\
\frac{0}{2}\end{array}$ & 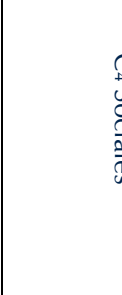 & & 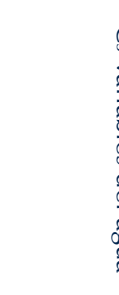 & & 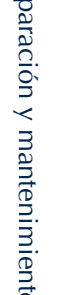 & & & 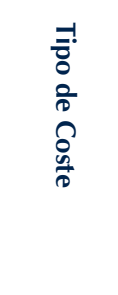 \\
\hline$\vec{n}$ & $\vec{v}_{\omega_{\omega}}$ & $\vec{r}$ & $\begin{array}{l}\vec{\circ} \\
\text { Oे. }\end{array}$ & $\begin{array}{l}\overrightarrow{0} \\
\overrightarrow{0}\end{array}$ & $\begin{array}{l}\overrightarrow{0} \\
\stackrel{\partial}{\circ}\end{array}$ & 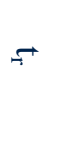 & $\vec{r}$ & 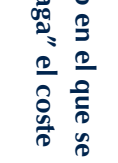 \\
\hline 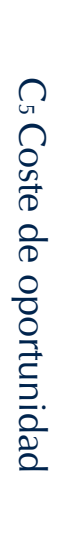 & 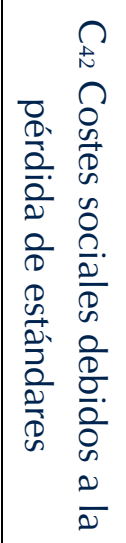 & 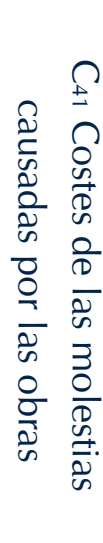 & 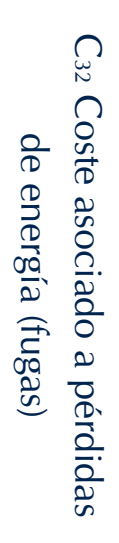 & 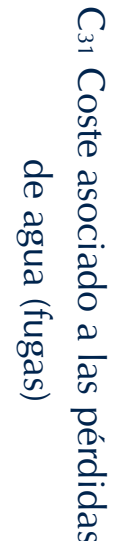 & 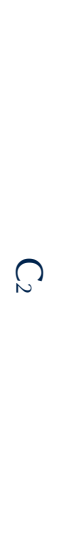 & 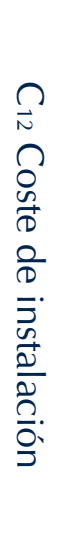 & 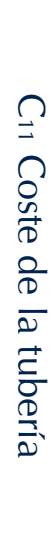 & 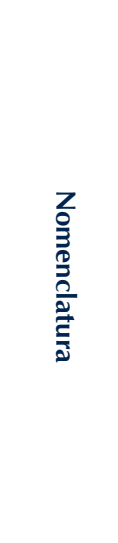 \\
\hline$\underline{\sim}$ & Z & $\underline{\sim}$ & Z & Ż & Z & $\underline{\sim}$ & Z & 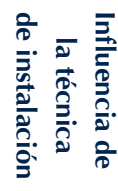 \\
\hline 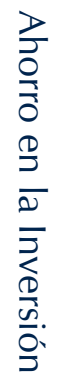 & $\begin{array}{l}\frac{3}{0} \\
\frac{1}{\vec{D}} \\
\frac{D}{D} \\
\frac{3}{3} . \\
\frac{3}{D} . \\
\frac{\vec{D}}{0}\end{array}$ & $\begin{array}{l}\overline{\bar{z}} \\
\frac{0}{1} \\
\frac{n}{0} \\
\frac{0}{2}\end{array}$ & 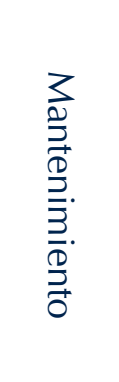 & 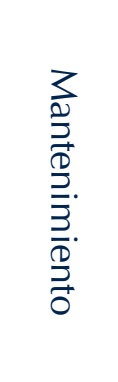 & 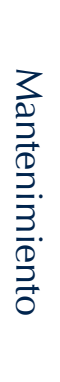 & 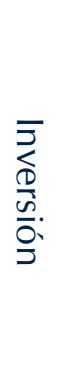 & $\frac{\overline{\bar{J}}}{\frac{0}{D}}$ & 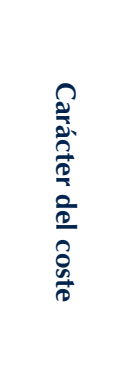 \\
\hline
\end{tabular}

${ }^{35}$ El tiempo ts es aquél en el que se deja de cumplir los estándares de servicio, mientras que tc es aquél en que sucede la oportunidad. Una explicación más detallada se muestra en el apartado 4.3 
En general, en relación con todos estos costes puede apuntarse lo siguiente: El coste de renovación de la tubería $C_{1}$ consta de dos sumandos $C_{11}$ y $C_{12}$. El valor de la tubería depende del material empleado, y el coste de instalación es función de la técnica utilizada. El coste de reparación y mantenimiento, $\mathrm{C}_{2}$, es sensible al aumento del número de roturas y por ende, a la edad de la tubería. El coste del agua fugada $C_{31}$ y el incremento del consumo energético $C_{32}$ no dependen de la técnica de renovación, sino del número de roturas de la tubería, creciente con el paso del tiempo. El coste social $\mathrm{C}_{41}$ que, en síntesis, valora las molestias derivadas de la sustitución, es sensible a la técnica de instalación, al contrario que la penalización por incumplimiento de estándares de servicio, $\mathrm{C}_{42}$. Finalmente, el coste de oportunidad también depende de la técnica empleada.

\subsection{Análisis de los costes existentes en $t_{p}$}

El cálculo del periodo óptimo de renovación exige cuantificar la evolución temporal de todos los costes. A ello se dedica este apartado. En el análisis que sigue todos los costes están expresados en unidades monetarias del año actual y están referidos a la unidad de longitud de la conducción. Por ello, el conjunto de tuberías que se considera debe ser homogéneo en diámetro, material y montaje.

En la Figura 48, se puede observar la escala temporal del análisis de costes. En ella se definen los instantes de tiempo siguientes:

- to, año a partir del cual se dispone de datos de las roturas en conducciones.

- $t_{p}$, año actual.

- $t r$, año en el que se realiza la primera renovación.

Éstos son los habitualmente considerados (Shamir y Howard, 1979), aunque para el presente estudio, pueden suceder dos situaciones ocasionales en los años:

- $\quad t_{c}$, año en que se tiene la oportunidad de abaratar costes de instalación (es el año en el que $C_{5}$ es distinto de cero)

- $t_{s}$, año a partir del cual se incumplen estándares de servicio

El problema se resuelve considerando los costes totales descritos en la Figura 47 (en otras palabras, ignorando los costes ocasionales), según la propuesta que se define a continuación. De este modo se obtiene el año en el que se produce la periodo óptimo de renovación ( $t$ r, Figura 48) y se analiza cuando acontecen (si lo hacen) tanto la oportunidad como el incumplimiento de servicio (tc $y t_{s}$ respectivamente). En caso de que éstos sucedan antes de la renovación se modifican la hipótesis de partida (considerando el/los nuevo/s coste/s) y se rehacen los cálculos cual corresponde (esto es, se añadirían los costes sociales por pérdida de estándares a partir de $t_{s}$ o bien se analizaría si el coste en $t_{c}$ es menor que el mínimo en tr. 
Por otra parte, se define $T_{t}$ como el tiempo fijo que transcurren entre renovaciones sucesivas y $T_{f}$ como el tiempo transcurrido entre el año presente y el año en el que se realiza la primera renovación, cumpliéndose $T_{f}=t_{r}-t_{p}{ }^{36}$

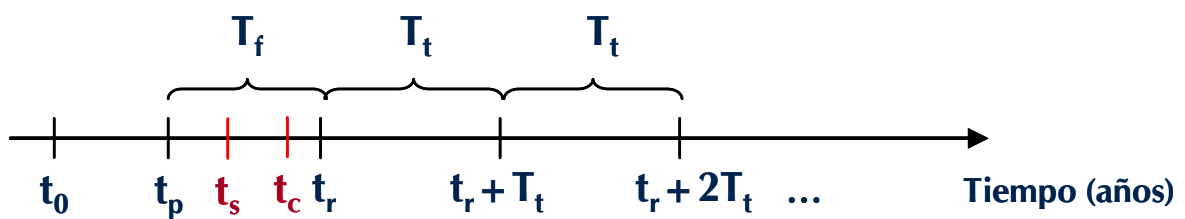

FIGURA 48. ESCALA DE TIEMPOS CONSIDERADA.

\subsubsection{Coste de renovación $\left(C_{1}\right)$}

Se puede expresar como:

$C_{1}\left(t_{r}\right)=C_{r_{j}} \cdot e^{-r T_{f_{j}}}$

Donde $c_{r_{j}}$ es el coste de renovación de una tubería con la técnica j expresado en $€ / m$ en el año actual y $r$ la tasa continua de actualización equivalente del coste en tanto por uno $^{37}$. La consideración de la técnica de montaje exige (Tabla 47) desglosar de $C_{1}\left(t_{r}\right)$ en coste de la tubería $C_{11}$ y coste de instalación $C_{12}$. De tal manera que:

$C_{1}\left(t_{r}\right)=C_{11}\left(t_{r}\right)+C_{12}\left(t_{r}\right)=C_{r_{1 j}} \cdot e^{-r T_{f j}}+C_{r_{2 j}} \cdot e^{-r T_{f j}}$

El coste de instalación de la tubería $C_{12}\left(t_{r}\right)$ depende de la técnica empleada. Si la renovación de la conducción se ha realizado siguiendo el método tradicional, $c_{12}\left(t_{r}\right)$ se cuantifica a partir de los costes de excavación, movilización de maquinaria, volumen de la excavación, introducción del lecho de arena, introducción de la tubería, horas de operarios, etc. En cambio, si se realiza la renovación empleando técnicas sin zanja se deben computar otra serie de costes como los derivados del desplazamiento de la maquinaria específica, realización de

${ }^{36}$ En la formulación del problema, se refiere a este término como $T_{f_{j}}$ (las mayúsculas indican intervalo de tiempo) y el subíndice j muestra el tipo de técnica empleado para renovar la conducción.

${ }^{37}$ La tasa continua de actualización equivalente se utiliza para expresar la equivalencia de los costes en distintos años. Una explicación detallada de este término se puede encontrar en el anexo $B$ de la presente tesis. 
catas de entrada y salida, equipos que sirven para realizar los procesos de limpieza y control con circuito cerrado de televisión.

Por otra parte, el término definido como $c_{11}\left(t_{r}\right)$, es el coste de la tubería. Este coste es fácilmente cuantificable y se obtiene simplemente del catálogo del fabricante.

El coste de renovación depende del tipo de técnica empleada y tiene carácter de inversión (Tabla 47). Ésta se realiza en un instante puntual y debido a la actualización de los costes con respecto al tiempo, decrece con éste (la Figura 49 da una imagen cualitativa).

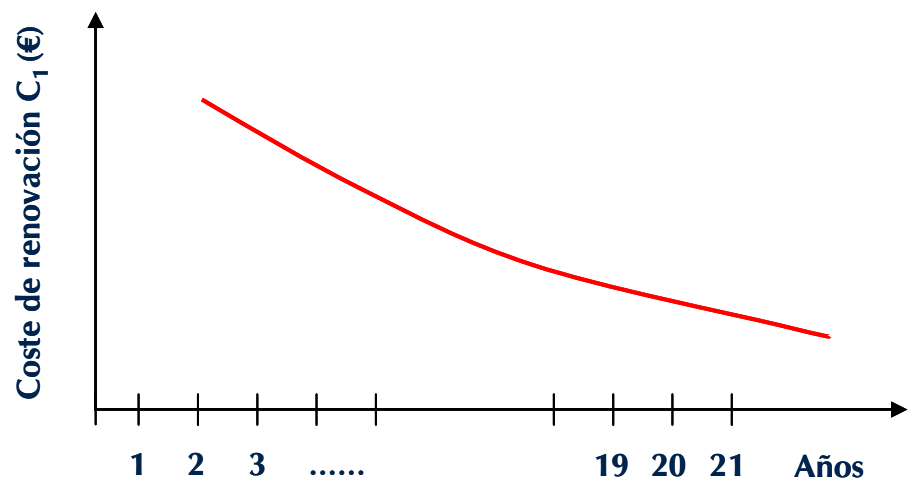

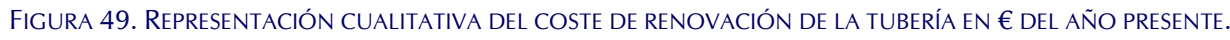

Particularmente, no todas las técnicas sin zanja son aplicables en cualquier proceso de renovación. Cada situación es diferente, y cualquier circunstancia podría provocar que el coste de una técnica se disparase en comparación con el de otra. (En el anexo A, se facilita más información sobre las técnicas de rehabilitación sin zanja, y en el capítulo 5 se analiza la influencia de algunas de estas técnicas sobre el óptimo de renovación).

\subsubsection{Coste de reparación y mantenimiento $\left(C_{2}\right)$}

El coste de las reparaciones se contabiliza desde el año actual hasta el de la renovación (por ello se engloba en los costes de tipo mantenimiento, Tabla 47) como la suma de las reparaciones puntuales realizadas en este periodo de tiempo (en contraposición con el coste de renovación que solamente se producía en un instante puntual). De este modo, este coste es proporcional al número de roturas y depende del año en que se realice la renovación. Para conocer la evolución de las roturas con el tiempo se adopta un modelo exponencial (Shamir y Howard, 1979). De esta manera, las roturas para un año genérico t se expresan como:

$N(t)=N\left(t_{0}\right) \cdot \exp \left(A \cdot\left(t-t_{0}\right)\right)$ 
Con $N(t)$ el número de roturas de una conducción en el año $\mathrm{t}$ y unidad de longitud, $N\left(t_{0}\right)$ el número de roturas en el año to y unidad de longitud (año a partir

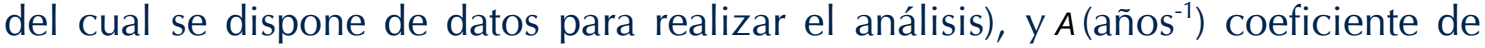
crecimiento del número de roturas.

Si se considera el coste unitario de una reparación puntual como una constante $\left(C_{b}\right)$, a partir del número de roturas se puede obtener el coste de reparación de éstas (siempre por unidad de longitud) $c_{m}(t)$ a partir de la expresión:

$C_{m}(t)=C_{b} \cdot N(t)=C_{b} \cdot N\left(t_{0}\right) \cdot \exp \left(A \cdot\left(t-t_{0}\right)\right)$

El coste total de la reparación de la conducción desde el año en curso hasta el año en el que procede la reposición de la tubería, expresado en euros del año en curso, $t_{p}$, es:

$C_{2}\left(t_{r}\right)=\int_{0}^{T_{t_{j}}} C_{m}(t) \cdot e^{-r \cdot t} \cdot d t=\int_{0}^{T_{t_{j}}} C_{b} \cdot N\left(t_{0}\right) \cdot \exp \left(A \cdot\left(t-t_{0}\right)\right) \cdot e^{-r \cdot t} \cdot d t{ }^{38}$

En esta ecuación, el límite superior de la integral se define como $T_{f_{j}}=t_{r}-t_{p}$, con $t_{p}$ el año actual y $t_{r}$ el año en el que la tubería será remplazada. Como $t_{r}$ es la variable que se quiere conocer, el coste de mantenimiento engloba los costes de las reparaciones que se realizan a lo largo de todos los años comprendidos entre $t_{p}$ y $t_{r}$, acumulados mediante la integral.

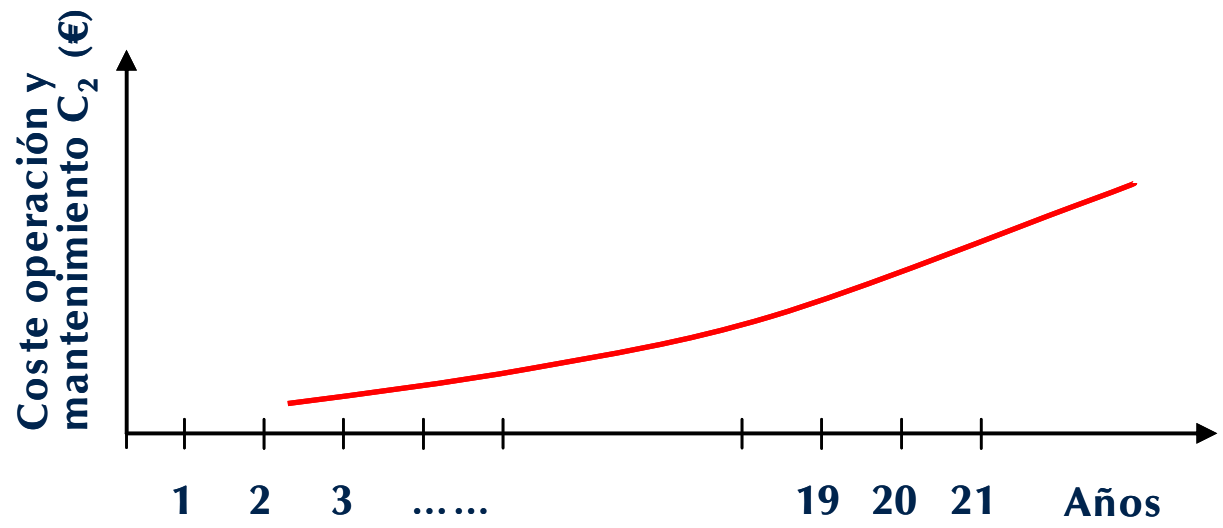

FIGURA 50. REPRESENTACIÓN CUALITATIVA DEL COSTE DE MANTENIMIENTO.

\footnotetext{
${ }^{38}$ En lo que sigue y por facilitar la identificación de los términos, se expresa la evolución temporal del número de roturas con la expresión exp y la actualización del dinero como $\mathrm{e}^{-\mathrm{rx}}$, aunque matemáticamente sean lo mismo.
} 


\subsubsection{Costes del agua $\left(C_{3}\right)$}

El término definido como coste del agua engloba:

- Los costes intrínsecos de producción y transporte del agua. Éstos se calculan según el Principio de Recuperación de Costes (PRC) tal y como lo define el artículo 9 de la Directiva Marco del Agua, de obligado cumplimiento a partir del año 2010. Por tanto, admitido el cumplimiento del PRC, estos costes dependen de las características propias del abastecimiento.

- Los costes medioambientales del agua, entendidos como los que se pagan por la detracción del recurso del medio natural. Es un coste fijado por el organismo responsable (ayuntamientos, confederaciones hidrográficas o un regulador como el OFWAT en Inglaterra o el IRAR en Portugal). Estos costes, por ejemplo en Alemania, pueden superar los $0.30 € / \mathrm{m}^{3}$.

- Los costes de la energía asociada al agua fugada. La energía que requiere el sistema de distribución también está influenciada por el nivel de fugas de la red. A la energía perdida directamente en la fuga se le ha de añadir la que requiere el extra de caudal circulante que genera una pérdida de carga adicional. Este término se puede calcular a partir de la auditoría energética (Cabrera y col., 2009 y capítulo 6 de la presente tesis) en dos escenarios, con y sin fugas. La comparación entre ambos permite evaluar las pérdidas energéticas totales asociadas al volumen fugado.

El coste del agua depende de las fugas existentes en la red de distribución. Éstas, a su vez, son proporcionales a las roturas por lo que su evolución temporal es similar. Por otra parte, este coste no depende de la técnica empleada para la rehabilitación y renovación de la red de distribución de agua.

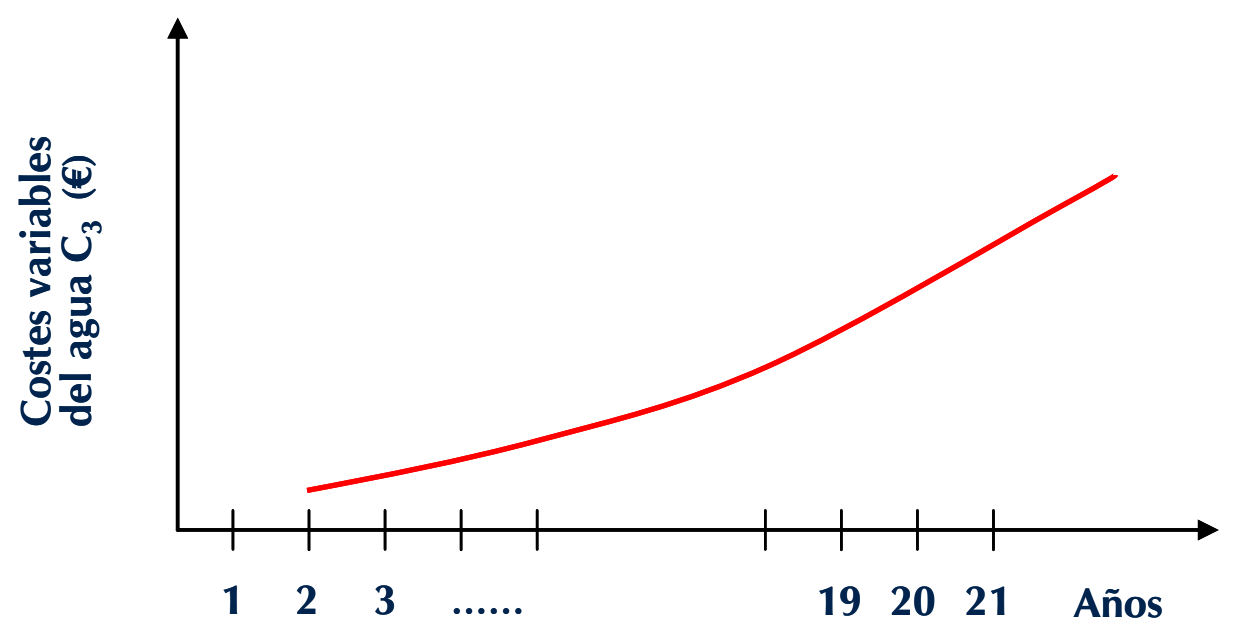




\subsubsection{Costes variables relacionados con las pérdidas de agua}

La evolución en el tiempo del volumen de agua fugada depende inevitablemente de las roturas, ya que se considera un caudal medio unitario por fuga $\left(q_{f}\right)$. Pese a las políticas de control de las fugas, con inspecciones periódicas y las consiguientes reparaciones, el volumen de fugas aumenta con el tiempo siguiendo una evolución exponencial idéntica a la rige en el caso de las roturas. Éste se cuantifica considerando un tiempo medio de actividad de la fuga $\left(\Delta t_{a}\right)$ igual al semiperiodo de inspección (se considera $\Delta t_{a}=$ medio año). De este modo se obtiene:

$V_{f}(t)=\Delta t_{a} \cdot q_{f} \cdot N\left(t_{0}\right) \cdot \exp \left(A \cdot\left(t-t_{0}\right)\right)$

En consecuencia, el coste total asociado a la pérdida de agua fugada $C_{31}\left(t_{r}\right)$ :

$C_{31}\left(t_{r}\right)=\int_{0}^{T_{t_{j}}} C_{W} \cdot q_{f} \cdot N\left(t_{0}\right) \cdot \exp \left(A \cdot\left(t-t_{0}\right)\right) \cdot \Delta t_{a} \cdot e^{-r \cdot t} d t$

Donde $C_{31}\left(t_{r}\right)$ es el coste asociado al agua fugada (en $€$ del año $t_{p}$ ) acumulado desde el año presente hasta el año $t_{r}$ y $c_{w}$ es el coste del agua en $€ / \mathrm{m}^{3}$ (incluye los términos de producción y ambiental) a excepción de la parte energética de este coste que se emplea en el término siguiente.

\subsubsection{Coste asociado a las pérdidas de energía}

El peaje energético de las fugas en una red de distribución se compone de dos términos, la energía directamente ligada a las fugas $\left(C_{32 a}\left(t_{r}\right)\right)$ y las pérdidas por fricción extra debido al exceso de caudal circulante que debido a las fugas $\left(C_{32 b}\left(t_{r}\right)\right)$.

El primer término se obtiene de manera análoga al coste total asociado a las fugas $\left(C_{31}\left(t_{r}\right)\right)$ :

$C_{32 a}\left(t_{r}\right)=\int_{0}^{T_{t_{j}}} C_{W E} \cdot q_{f} \cdot N\left(t_{0}\right) \cdot \exp \left(A \cdot\left(t-t_{0}\right)\right) \cdot \Delta t_{a} \cdot e^{-r \cdot t} d t$

Donde $C_{W E}$ es el coste energético del agua o la huella energética del agua, en $€ / \mathrm{m}^{3}$. El concepto de huella energética se refiere a la energía que se ha invertido desde su detracción del medio natural hasta su distribución. Se define más ampliamente en el capítulo 7 y en Cabrera y col., (2009). 
Por otro lado, el segundo término se refiere a la energía pérdida en fricción por efecto de las fugas. Esto es, debido a un mayor volumen fugado, el caudal circulante y las pérdidas de carga serán mayores. Por tanto, la energía necesaria en cabecera de la red será mayor para cumplir con los estándares de servicio.

El término asociado a las pérdidas por fricción extra debido al exceso de caudal circulante se cuantifica como:

$C_{32 b}\left(t_{r}\right)=\int_{0}^{T_{t_{j}}} C_{E} \cdot k \cdot \frac{\gamma \cdot\left(q_{f} \cdot N\left(t_{0}\right) \cdot \exp \left(A \cdot\left(t-t_{0}\right)\right) \cdot\left(p_{s} / \gamma\right) \cdot \Delta t_{a}\right.}{\eta} \cdot e^{-r \cdot t} \cdot d t$

Donde $\frac{p_{s}}{\gamma}$ es la presión media a la que se produce la fuga (asimismo, representa la presión media para todo el sector), $C_{E}$ es el coste de la energía consumida $(€ / \mathrm{kWh}), \eta$ el rendimiento en tanto por uno de los grupos de bombeo y $\mathrm{k}$ un coeficiente que cuantifica el aumento de la presión de cabecera derivado de la existencia de las fugas $(k>1)$. Este coeficiente se obtiene a partir de la auditoría energética, capítulo 6 de la presente tesis.

El coste de la energía consumida es:

$$
\begin{aligned}
C_{32}\left(t_{r}\right)=C_{32 a}\left(t_{r}\right)+C_{32 b}\left(t_{r}\right) & =\int_{0}^{T_{f_{j}}} C_{W E} \cdot q_{f} \cdot N\left(t_{0}\right) \cdot \exp \left(A \cdot\left(t-t_{0}\right)\right) \cdot \Delta t_{a} \cdot e^{-r \cdot t} d t+ \\
& +\int_{0}^{T_{f_{j}}} C_{E} \cdot k \cdot \frac{\gamma \cdot\left(q_{f} \cdot N\left(t_{0}\right) \cdot \exp \left(A \cdot\left(t-t_{0}\right)\right) \cdot\left(p_{s} / \gamma\right) \cdot \Delta t_{a}\right.}{\eta} \cdot e^{-r \cdot t} \cdot d t
\end{aligned}
$$

\subsubsection{Coste social asociado a la perturbación por obras $\left(C_{41}\right)$}

El coste social evalúa los perjuicios y molestias que una obra genera en su entorno. Su cuantificación es compleja y, además, no suele repercutir sobre la compañía que gestiona el abastecimiento (en definitiva, la que ejecuta la renovación), sino en los ciudadanos afectados. Un ejemplo de coste social sería la pérdida de ingresos que supone para un restaurante la imposibilidad de instalar la terraza.

El coste social sí que depende de la técnica empleada en la renovación de la red. Las técnicas sin zanja se han desarrollado, entre otras razones, para evitar las molestias a los viandantes, conductores, etc. Por ello, no es una sorpresa que el coste social máximo sea el obtenido en caso de que se realice una renovación mediante la técnica habitual, con apertura de zanja. 
Es evidente que si se considera el coste social se está primando la utilización de las técnicas sin zanja. El coste social de las molestias y perturbaciones originadas en la ejecución de la obra $\left(c_{s_{j}}\right)$ es de tipo puntual (sólo existe cuando se renueva) semejante al coste de renovación $C_{1}$, por lo que se expresa en $€$ del año presente como:

$C_{41}\left(t_{r}\right)=C_{S_{j}} \cdot e^{-r T_{t_{j}}}$

$c_{s_{j}}$ es el coste social de la renovación de una tubería con la técnica j. Este término se puede calcular siguiendo las directrices definidas en el Anexo C.

\subsection{Otros costes imputables de aparición ocasional}

En este punto se muestra como incluir algunos costes que no siempre existen. Como ya se ha dicho, estos son el coste de oportunidad y el de las pérdidas de estándares de servicio. En algunas ocasiones la conducción se renueva pese a que cumple con dichos estándares, no en vano se siguen políticas predictivas de renovación (capitulo 2 de la presente tesis). Con todo, cuando los siguientes costes se producen, se incluirán según se expone.

\subsubsection{Coste social asociado a la pérdida de estándares de servicio $\left(C_{42}\right)$.}

Las redes de abastecimiento urbano deben cumplir una serie de estándares de servicio, esto es, deben proporcionar al usuario el agua con una presión y caudal adecuados a cualquier hora del día, con una concentración adecuada de cloro, sales, nitratos, etc. Estos valores máximos y mínimos se regulan según la legislación vigente correspondiente (indicaciones definidas por la EPA o la OMS). Para asegurar los niveles de calidad fijados se han definido indicadores de gestión relativos al abastecimiento que proporcionan información acerca del estado actual de la red que será muy útil para adoptar decisiones relativas a la operación y mantenimiento del sistema.

Los costes sociales asociados a la pérdida de algún estándar de servicio (por ejemplo baja presión en la red o agua que no se entrega en condiciones de calidad aceptables) intervienen a partir de un año $t \geq t_{s}$. A partir de ese instante se admite que la compañía debe pagar una penalización monetaria constante $\left(c_{p}\right)$ al propietario de la red (generalmente el ayuntamiento u otra entidad similar), por lo que el coste social debido a la pérdida de estándares de servicio se cuantifica como: 
$C_{42}\left(t_{r}\right)=e^{-r \cdot\left(t_{s}-t_{p}\right)} \cdot \int_{t_{s}}^{t_{r}} C_{p} \cdot e^{-r t} \cdot d t$

Con $C_{42}\left(t_{r}\right)$ expresado en $€$ del año actual, y $C_{P}$ es la penalización en unidades monetarias constantes $(€ / \mathrm{m})$ por la pérdida de estándares de servicio. La penalización tiene un valor determinado entre el gestor del abastecimiento y el representante legal del consumidor. La pérdida de estándares de servicio puede deberse a problemas de tipo hidráulico (falta de presión en las acometidas abastecidas por la conducción) y de calidad (agua con concentraciones de cloro por debajo de los umbrales mínimos aceptables), por lo que el cálculo de la penalización total que se impone se calcula como $C_{p}=C_{p h}+C_{p c}$, siendo $C_{p h}$ y $C_{p c}$ las penalizaciones impuestas al abastecimiento por problemas de tipo hidráulico y calidad respectivamente.

\subsubsection{Coste de oportunidad $\left(C_{5}\right)$}

El coste de oportunidad es, de algún modo, un beneficio ya que como coste es negativo por los ahorros que se producen si el coste de la realización de la obra es Ilevado a cabo por varias empresas. Se puede presentar en un determinado momento ( $\mathrm{t}_{\mathrm{c}}$ ) y por tanto debe tratarse como una función de tipo escalón.

El coste de oportunidad representa una reducción del coste de renovación de la tubería. Con anterioridad se definió el coste de renovación como suma de dos componentes, el coste de la tubería en sí $\left(c_{11}\left(t_{r}\right)\right)$ y su coste de instalación $\left(C_{12}\left(t_{r}\right)\right)$. La oportunidad reduce el segundo, no en vano el coste de instalación sería el ahorro máximo (el primero, por su propia definición nunca disminuye). Tan es así que el coste de oportunidad varía entre los valores $-C_{12}\left(t_{r}\right)<C_{5}\left(t_{r}\right) \leq 0$. El coste de oportunidad también depende de la técnica empleada, y con la técnica tradicional con apertura de zanja mostrará un mayor ahorro. En cambio, las técnicas de renovación sin zanja dejan de ser aplicables ya que la oportunidad implica que se pierdan los beneficios en la reducción del coste social de estas técnicas ya que no se ha evitado la apertura de una zanja. 


\subsection{Obtención del periodo óptimo de renovación}

En este apartado se describe el cálculo del periodo óptimo de renovación. Como se verá, dicho periodo será distinto según el planteamiento particular de la problemática. En nuestro caso, el problema se resuelve según las siguientes hipótesis de partida:

- Se analiza el periodo óptimo de renovación para una única sustitución. Este planteamiento es el más común (similar a Shamir y Howard (1979)) y representa la solución más intuitiva y sencilla al problema.

- Se pretende obtener el óptimo para las infinitas renovaciones. Éste sería el caso más adecuado desde la óptica económica. Es similar al adoptado por Kleiner y col. (2001) y representa la situación de un abastecimiento gestionado por un organismo público que no tiene como objetivo obtener un beneficio económico a corto plazo. Por ello, puesto que analiza el problema de manera global, siempre obtiene un mejor aprovechamiento del capital invertido, por renovar siempre en el instante adecuado, aquél que proporciona un menor valor económico.

- Se calcula el periodo óptimo de renovación en un periodo determinado de tiempo. En numerosas ocasiones, la explotación de la concesión de un abastecimiento por una entidad determinada se realiza durante un periodo de tiempo fijo (25, 50 ó 100 años). Por ello, el interés de la entidad no se extiende más allá de ese periodo de tiempo. Este planteamiento sería propio de redes con gestión de un organismo privado o mixto, como ocurre en la mayoría de las ciudades españolas.

En lo que sigue se expone la obtención del óptimo de renovación con los costes previamente definidos y para cada una de las tres hipótesis previas.

\subsubsection{Periodo óptimo de renovación para la primera renovación}

La suma de los costes (a excepción de $C_{42}$ y $C_{5}$ que no siempre son imputables), es:

$C_{T} \equiv C_{11}\left(t_{r}\right)+C_{12}\left(t_{r}\right)+C_{2}\left(t_{r}\right)+C_{31}\left(t_{r}\right)+C_{32 a}\left(t_{r}\right)+C_{32 b}\left(t_{r}\right)+C_{41}\left(t_{r}\right)$

Con lo que el coste total se obtiene sustituyendo los valores de cada uno de los costes en la ecuación (4.13), obteniendo: 


$$
\begin{aligned}
& C_{T}\left(t_{r}\right)=C_{r_{j}} \cdot e^{-r T_{f_{j}}}+\int_{0}^{T_{t_{j}}} C_{b} \cdot N\left(t_{0}\right) \cdot \exp \left(A \cdot\left(t-t_{0}\right)\right) \cdot e^{-r \cdot t} \cdot d t+ \\
& +\int_{0}^{T_{t_{j}}} C_{W} \cdot q_{f} \cdot N\left(t_{0}\right) \cdot \exp \left(A \cdot\left(t-t_{0}\right)\right) \cdot \Delta t_{a} \cdot e^{-r \cdot t} d t+\int_{0}^{T_{f_{j}}} C_{W E} \cdot q_{f} \cdot N\left(t_{0}\right) \cdot \exp \left(A \cdot\left(t-t_{0}\right)\right) \cdot \Delta t_{a} \cdot e^{-r \cdot t} d t+ \\
& +\int_{0}^{T_{t_{j}}} C_{E} \cdot k \cdot \frac{\gamma \cdot\left(q_{f} \cdot N\left(t_{0}\right) \cdot \exp \left(A \cdot\left(t-t_{0}\right)\right) \cdot\left(\frac{p_{S} / \gamma}{\gamma}\right) \cdot \Delta t_{a}\right.}{\eta} \cdot e^{-r \cdot t} \cdot d t+C_{S_{j}} \cdot e^{-r T_{t_{j}}}
\end{aligned}
$$

Agrupando los costes puntuales, $C_{11}, c_{12}$ y $C_{41}$, de comportamiento análogo en el tiempo, en un término denominado inversión $\iota_{j}$ (expresado en $€ / \mathrm{m}$ y en el que se emplea la técnica de renovación j), que se define como:

$$
C_{11}\left(t_{r}\right)+C_{12}\left(t_{r}\right)+C_{41}\left(t_{r}\right)=\left(C_{r_{j}}+C_{s_{j}}\right) \cdot e^{-r T_{t_{j}}}=I_{j} \cdot e^{-r T_{t_{j}}}
$$

Mientras que los costes de carácter acumulativo $\left(c_{2}, C_{31}, c_{32 a}\right.$ y $\left.C_{32 b}\right)$, también se agrupan según:

$$
\begin{gathered}
C_{2}\left(t_{r}\right)+C_{31}\left(t_{r}\right)+C_{32 a}\left(t_{r}\right)+C_{32 b}\left(t_{r}\right)=\int_{0}^{T_{t_{j}}} C_{b} \cdot N\left(t_{0}\right) \cdot \exp \left(A \cdot\left(t-t_{0}\right)\right) \cdot e^{-r \cdot t} \cdot d t+ \\
+\int_{0}^{T_{t_{j}}} C_{W} \cdot q_{f} \cdot N\left(t_{0}\right) \cdot \exp \left(A \cdot\left(t-t_{0}\right)\right) \cdot \Delta t_{a} \cdot e^{-r \cdot t} d t+\int_{0}^{T_{t_{j}}} C_{W E} \cdot q_{f} \cdot N\left(t_{0}\right) \cdot \exp \left(A \cdot\left(t-t_{0}\right)\right) \cdot \Delta t_{a} \cdot e^{-r \cdot t} d t+ \\
\quad+\int_{0}^{T_{f_{j}}} C_{E} \cdot k \cdot \frac{\gamma \cdot\left(q_{f} \cdot N\left(t_{0}\right) \cdot \exp \left(A \cdot\left(t-t_{0}\right)\right) \cdot\left(p_{\mathrm{s}} / \gamma\right) \cdot \Delta t_{a}\right.}{\eta} \cdot e^{-r \cdot t} \cdot d t
\end{gathered}
$$

Obteniendo finalmente la expresión:

$$
C_{2}\left(t_{r}\right)+C_{31}\left(t_{r}\right)+C_{32 a}\left(t_{r}\right)+C_{32 b}\left(t_{r}\right)=M \cdot \int_{0}^{T_{t_{j}}} N\left(t_{0}\right) \cdot \exp \left(A \cdot\left(t-t_{0}\right)\right) \cdot e^{-r \cdot t} \cdot d t
$$

Donde:

$$
M=C_{b}+\left(q_{f} \cdot \Delta t_{a} \cdot\left(C_{W}+C_{W E}+\frac{k \cdot p_{S}}{\eta} \cdot C_{E}\right)\right)
$$

Siendo $M$ el coste de mantenimiento, con unidades de euros por rotura y por unidad de longitud consecuencia del envejecimiento de una tubería cualquiera del sector. Este término es independiente de la técnica empleada para la renovación, y por tanto presenta siempre el mismo valor para cada técnica j. 
Por último, el coste total asociado a una renovación de una tubería con el método j es:

$C_{T}\left(t_{r}\right)=I_{j} \cdot e^{-r T_{f_{j}}}+\int_{0}^{T_{f_{j}}} M \cdot N\left(t_{0}\right) \cdot \exp \left(A \cdot\left(t-t_{0}\right)\right) \cdot e^{-r \cdot t} \cdot d t$

Se puede obtener el valor de $T_{f_{j}}$ que minimiza el coste total derivando la ecuación anterior e igualando a cero. La expresión resultante es:

$t_{r_{j}}^{*}=t_{0}+\frac{1}{A} \ln \left(\frac{r \cdot l_{j}}{M \cdot N\left(t_{0}\right)}\right)$

Donde $t_{r_{j}}^{*}$ es el periodo óptimo de renovación de tuberías desde la óptica que nos ocupa y por su propia definición está relacionado con el valor mínimo de los costes totales. La expresión anterior recuerda el resultado de Shamir y Howard (1979) y Kleiner y col. (2001) pero con un significado mucho más general en los nuevos parámetros mantenimiento $M$ e inversión $l_{j}$. El tipo de técnica de renovación empleada interviene en (4.20) a través del término de inversión $l_{j}$. Por otra parte, el término $M$ engloba los costes de reparación y los costes variables del agua, siendo independiente de la técnica empleada.

\subsubsection{Periodo óptimo de renovación para las infinitas sustituciones}

Cuando se renueva una tubería en un instante determinado ( $\mathrm{t}_{\mathrm{r}}$ ) la nueva tubería tendrá un número de roturas igual a las existentes cuando se instaló por primera vez. Las roturas evolucionarán siguiendo el mismo patrón definido y aumentarán en número hasta el instante en que se produzca una nueva renovación. Este proceso sucederá cíclicamente con una duración fija e igual a $T_{t}$ (Figura 52). 


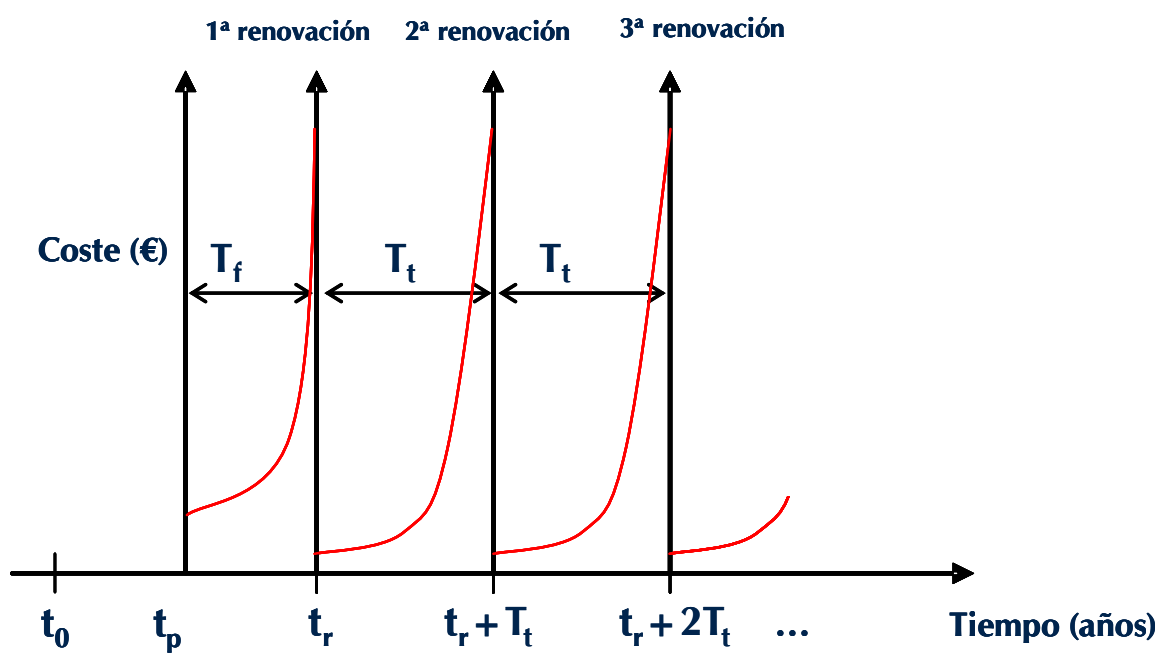

FIGURA 52. EVOLUCIÓN DE LOS COSTES DESDE EL AÑO PRESENTE HASTA EL INFINITO.

El coste total de todos los ciclos de renovación (excepto la primera) de la tubería hasta el infinito se calcula con la expresión:

$C_{\text {inf }}\left(t_{r}\right)=\frac{l_{j} \cdot e^{-r \cdot T_{t j}}+\int_{0}^{T_{t j}} M \cdot N\left(t_{0}\right) \cdot \exp \left(A \cdot\left(t-t_{0}\right)\right) \cdot e^{-r \cdot t} \cdot d t}{1-e^{-r T_{t j}}}$

Donde $c_{\text {inf }}\left(t_{r}\right)$ representa el coste (en $€ / m$ del año $t_{r}$ ) asociado a las infinitas renovaciones exceptuando la primera y con la utilización de la técnica j.

El plazo de tiempo que minimiza el coste total de todas las renovaciones excepto la primera $\left(C_{\text {inf }}\left(t_{r}\right)\right)$ desde el año $t_{r}$ hasta el infinito se designa $T_{t j}^{* *}$ y representa la duración óptima entre cada una de las infinitas renovaciones. Se calcula derivando la ecuación (4.21) e igualando a 0 . El proceso de obtención de este valor exige que $r \neq 0$ y $r \neq A_{i j}$ (Kleiner y col., 2001).

Una vez se ha obtenido ese valor $T_{t j}^{* *}$ (éste valor se obtiene resolviendo numéricamente la ecuación anterior), se puede expresar el coste total de todas las renovaciones de las tuberías en el año presente tp como la suma de los costes de la primera renovación y del resto de renovaciones: 


$$
\begin{aligned}
C_{T_{\text {inf }}}\left(t_{r}\right) & =C_{T}\left(t_{r}\right)+C_{\text {inf }}\left(T_{t_{j}}^{* *}\right) \cdot e^{-r \cdot T_{f_{j}}}= \\
& =I_{j} \cdot e^{-r \cdot T_{f_{j}}}+\int_{0}^{T_{f_{j}}} M \cdot N\left(t_{0}\right) \cdot \exp \left(A \cdot\left(t-t_{0}\right)\right) \cdot e^{-r \cdot t} \cdot d t+C_{\text {inf }}\left(T_{t_{j}}^{* *}\right) \cdot e^{-r \cdot T_{f_{j}}}
\end{aligned}
$$

En esta ecuación, el coste de mantenimiento (el que está incluido en la integral) se calcula con las roturas del año actual $\left(N\left(t_{p}\right)=N\left(t_{0}\right) \cdot \exp \left(A \cdot\left(t_{p}-t_{0}\right)\right)\right)$. Esto se debe a que en la primera renovación, el análisis comienza con unas roturas propias del año existente. Por el contrario, para las sucesivas sustituciones (englobadas en la ecuación 4.21) se emplea el valor $\left(N\left(t_{0}\right)\right)$ porque la tubería es nueva.

Y en este punto, sólo queda encontrar el valor de $T_{f_{j}}$ que minimice el coste total de la primera renovación. Este valor se obtiene derivando la ecuación anterior e igualando a cero.

$$
t_{r_{j}}^{\star}=t_{0}+\frac{1}{A} \ln \left(r \cdot \frac{l_{j}+C_{\text {inf }}\left(T_{t_{i}}^{* *}\right)}{M \cdot N\left(t_{p}\right)}\right)
$$

Esta expresión, es similar a la definida por Kleiner y col. (2001) aunque, al igual que la anterior (4.20), muestra un significado mucho más general por los nuevos parámetros mantenimiento $M$ e inversión $\iota_{j}$. 


\subsubsection{Periodo óptimo de renovación para un tiempo definido}

Con frecuencia, el gestor únicamente se encarga de la explotación de la concesión durante un número determinado de años y por ello, se plantea la renovación en este periodo de tiempo. La solución que busca será la óptima desde un enfoque económico para un periodo de tiempo determinado. El estudio de este caso tan particular se justifica porque representa un caso real y habitual a escala nacional, ya que España es un país carente de organismo regulador y con gran mayor parte de las redes urbana gestionadas por entidades privadas.

En este caso, las directrices a seguir sería la obtención del periodo óptimo de renovación con las hipótesis definidas en el apartado 4.5.2. Un vez se obtiene $c_{\text {inf }}\left(t_{r}\right)$ (Ecuación 4.21), $T_{t j}^{* *}$ (numéricamente), y $t_{r_{j}}^{*}$ ecuación (4.23), se conocen los instantes de tiempo en los que se producen las renovaciones en el periodo de tiempo de interés (hasta el año $T^{*}$, Figura 53).

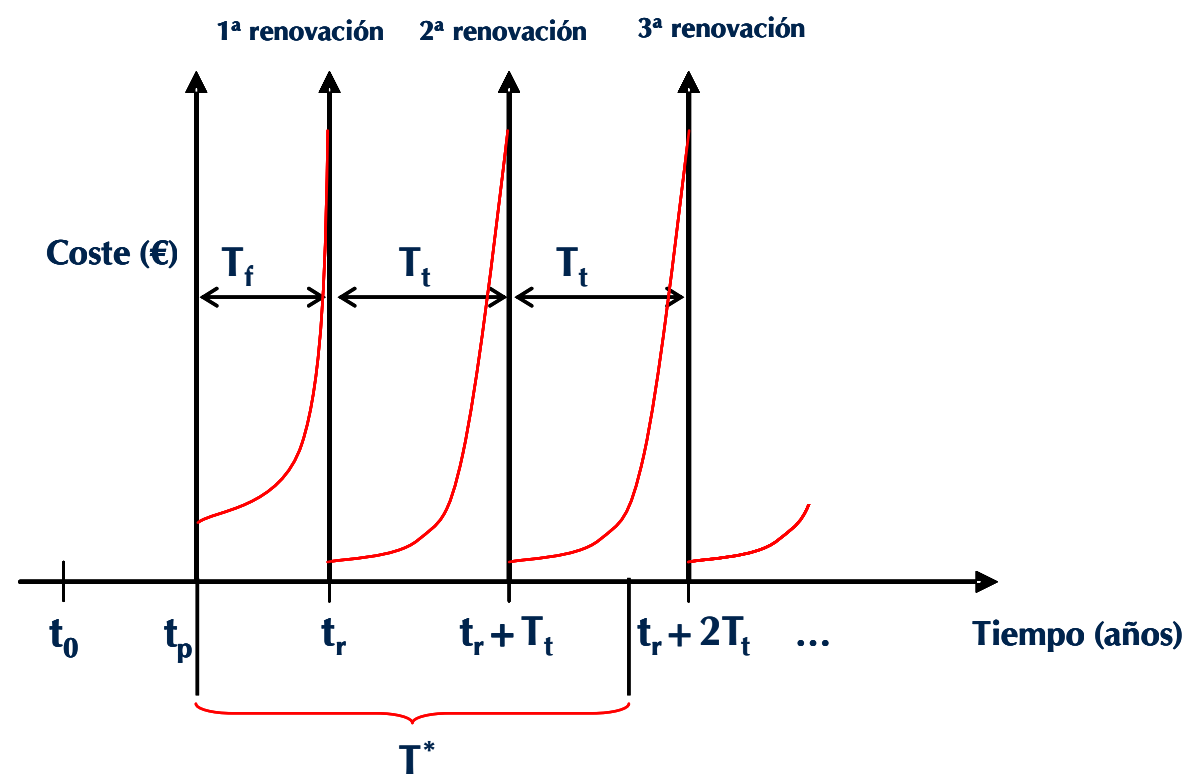

Figura 53. EVOluCión dE LOS COSTES DESDE El AÑO PRESENTE HASTA EL INSTANTE $T^{*}$.

Tras la comparación del periodo de tiempo $T^{*}$ con los instantes en los que se va a realizar las renovaciones (Figura 53), se valora si es conveniente o no la enésima renovación (en el instante de tiempo $\left(t_{r_{j}}^{*}+n \cdot T_{t j}^{* *}\right)$ ). La decisión es puramente económica, esto es, se analizan las dos alternativas (se realiza la última sustitución o no) y se decide la más eficiente. Estas dos alternativas son las mostradas a continuación. 
Alternativa 1: Las renovaciones se realizan en los instantes de tiempo $t_{r_{j}}^{*}, t_{r_{j}}^{*}+T_{t_{j}}^{* *}$, $\ldots$ y $t_{r_{j}}^{\star}+n \cdot T_{t_{j}}^{\star *}$ y el coste asociado a la vida total de la tubería se calcula como:

$C_{T^{*}}\left(t_{r}\right)=C_{T 1}\left(t_{r}\right)+\ldots .+C_{T n}\left(t_{r}\right)+\int_{t_{r_{j}}^{*}+n \cdot T_{t_{j}}^{* *}}^{T^{*}} M \cdot N\left(t_{0}\right) \cdot \exp \left(A \cdot\left(t-t_{0}\right) \cdot \exp \left(-r \cdot\left(t_{r_{j}}^{*}+n \cdot T_{t_{j}}^{* *}\right)\right) \cdot d t\right.$

Donde $c_{T^{*}}\left(t_{r}\right)$ representa el coste total a invertir, expresado en unidades monetarias del año actual $t_{p}$, en el periodo de tiempo definido $T^{*}, C_{T 1}\left(t_{r}\right), C_{T 2}\left(t_{r}\right)$ y $c_{T n}\left(t_{r}\right)$ representan el coste de la primera, segunda y enésima renovación de la tubería y el último término representa los costes de mantenimiento (reparaciones, agua y energía pérdidas) desde la enésima renovación hasta el año final de estudio, $T^{*}$.

Alternativa 2: Si no se realiza la última renovación, éstas se producen en los años $t_{r_{j}}^{*}, t_{r_{j}}^{*}+T_{t_{j}}^{* *}, \ldots$ y $t_{r_{j}}^{*}+(n-1) \cdot T_{t_{j}}^{* *}$. El coste asociado a la vida de la tubería se calcula como:

$C_{T^{*}}\left(t_{r}\right)=C_{T 1}\left(t_{r}\right)+. .+C_{T(n-1)}\left(t_{r}\right)+\int_{t_{r_{j}}^{*}+(n-1) \cdot T_{t_{j}}^{* *}}^{T^{*}} M \cdot N\left(t_{0}\right) \cdot \exp \left(A \cdot\left(t-t_{0}\right) \cdot \exp \left(-r \cdot\left(t_{r_{j}}^{*}+(n-1) \cdot T_{t_{j}}^{* *}\right)\right) \cdot d t\right.$

Donde el último término de la ecuación anterior, tendría un valor numérico elevado ya que la tubería llevaría muchos años en funcionamiento y la tasa de roturas (dependiente del tiempo) también lo sería.

Una vez se han calculado las dos alternativas, se elige la que tiene un menor valor numérico. Sin duda, en este planteamiento del problema influyen mucho los condicionantes políticos y su aplicabilidad práctica está limitada por variables de tipo externas y no técnicas. Por ejemplo, unos años antes del fin de la concesión, la compañía deja de renovar porque obtiene mayores beneficios manteniendo las tuberías existentes. Asimismo, si un tiempo antes de la finalice una concesión de explotación de un abastecimiento se decide prolongar la misma, se modifican las hipótesis de partida ya que el tiempo $T^{*}$ se amplía y se ha de replantear este problema. 


\subsection{Ejemplo numérico}

La aplicación numérica que sigue permite cuantificar la influencia de los nuevos costes. Los datos han sido facilitados por un abastecimiento de aguas español y son:

Coste $\mathrm{C}_{1}$

El sector estudiado esta compuesto por tuberías de diámetro nominal $300 \mathrm{~mm}$. El coste de renovación de éstas es de $329.1(€ / \mathrm{m})$. Este coste se obtiene como suma del coste de la tubería $C_{r_{1 j}}=70.5 € / \mathrm{m}$ y del coste de instalación de la misma, $C_{r_{2 j}}=258.6 € / \mathrm{m}$. Para valorar las inversiones en distintos tiempos, se emplea una tasa continua de actualización equivalente del coste de $r=1.98 \%$ (que se corresponde con un valor de la tasa de actualización real o deflactada $R=2 \%$ ).

Coste $\mathrm{C}_{2}$

La política que sigue la entidad de abastecimiento consiste en reparar todas las roturas que suceden en la red. El coste de reparación de una rotura es $C_{b}=1680 € /$ rotura. En el instante actual se las roturas en las tuberías del sector evolucionan según una exponencial definida por la ecuación (4.3). El número de roturas en el año presente es $N\left(t_{p}\right)=55$ (roturas/año/100 km), y cuando la tubería es nueva, las roturas son $N\left(t_{0}\right)=40$ (roturas/año/100 km). La evolución del número de roturas queda perfectamente descrita con el coeficiente de crecimiento roturas expresado en $\left(\right.$ años $\left.^{-1}\right) A=0.1$.

Coste $\mathrm{C}_{3}$

El cálculo de los costes del agua fugada requiere la cuantificación de varios parámetros. Los dos primeros son propios de los orígenes de los recursos e independientes de la gestión del sistema. Estos son el coste de producción y ambiental del agua $\left(c_{w}=0.2 € / \mathrm{m}^{3}\right)$ y el coste energético del agua es $\left(c_{w E}=0.1\right.$ $\left.€ / \mathrm{m}^{3}\right)$. 
Por otra parte, en cada rotura en la red de distribución, se supone que la fuga se produce a una presión media en la tubería i igual a $\frac{p_{s}}{\gamma}=25$ m.c.a., se encuentra activa durante $\Delta t_{a}=160$ días (valor que depende de las inspecciones realizadas en la conducción) y que el caudal fugado medio por rotura y día es $q_{f}=20$ ( $\mathrm{m}^{3} / \mathrm{d}$ ía). El coste de la energía empleada en el bombeo en la red de distribución es $C_{E}=0.1(€ / \mathrm{kWh})$ y dichos equipos tienen un rendimiento igual a $\eta=0.8$. Por último, se define el coeficiente $k$, que sirve para considerar el efecto del bombeo extra realizado en cabecera de la red para satisfacer la demanda pese a las fugas, $\mathrm{k}=1.4$. También se define el peso específico del agua como $\gamma=9810 \mathrm{~N} / \mathrm{m}^{3}$.

Coste $\mathrm{C}_{4}$.

El coste social asociado a las molestias y perturbaciones por la ejecución de obras es igual a $C_{S_{j}}=115(€ / \mathrm{m})$ y se podría calcular con la metodología propuesta en el Anexo D. El coste social (penalización por incumplimiento de estándares) del abastecimiento adopta un valor de $c_{P}=2 € / m$ año y se considera que aparecen en el año $t_{s}=10$.

Coste $\mathrm{C}_{5}$

La función escalón del coste de oportunidad tiene una amplitud de $C_{5}=15(€ / \mathrm{m})$.

\subsubsection{Desarrollo de los cálculos para una renovación}

El primer caso considerado, es similar al propuesto por Shamir y Howard (1979). Únicamente se plantea la primera renovación, y presenta como principal característica que por primera vez considera el coste del agua, la energía y el coste social.

\subsubsection{Cálculo del periodo óptimo de renovación}

En principio, se calculan los términos de inversión y mantenimiento con las expresiones definidas anteriormente (4.15) y (4.18). Obteniendo los valores de $\iota_{j}=444.1 € / \mathrm{m}$ y de $M=2679.4$ (€/rotura $\left.\mathrm{m}\right)$.

Con la expresión analítica definida en la ecuación (4.20), se obtiene el periodo óptimo de renovación:

$t_{r_{j}}^{*}=t_{0}+\frac{1}{A} \ln \left(\frac{r \cdot l_{j}}{M \cdot N\left(t_{p}\right)}\right)=0+\frac{1}{0.1} \ln \left(\frac{0.0198 \cdot 444.1}{2679.43 \cdot 0.00055}\right)=17.9$ años 
Y el coste mínimo se obtiene con la ecuación (4.19):

$C_{T}\left(t_{r}\right)=I_{j} \cdot e^{-r T_{t_{j}}}+\int_{0}^{T_{t_{i}}} M \cdot N\left(t_{0}\right) \cdot \exp \left(A \cdot\left(t-t_{0}\right)\right) \cdot e^{-r \cdot t} \cdot d t=370.4 € / \mathrm{m}$.

Si se representan todos los costes que generan el coste total asociado a la renovación a lo largo del tiempo, se obtiene:

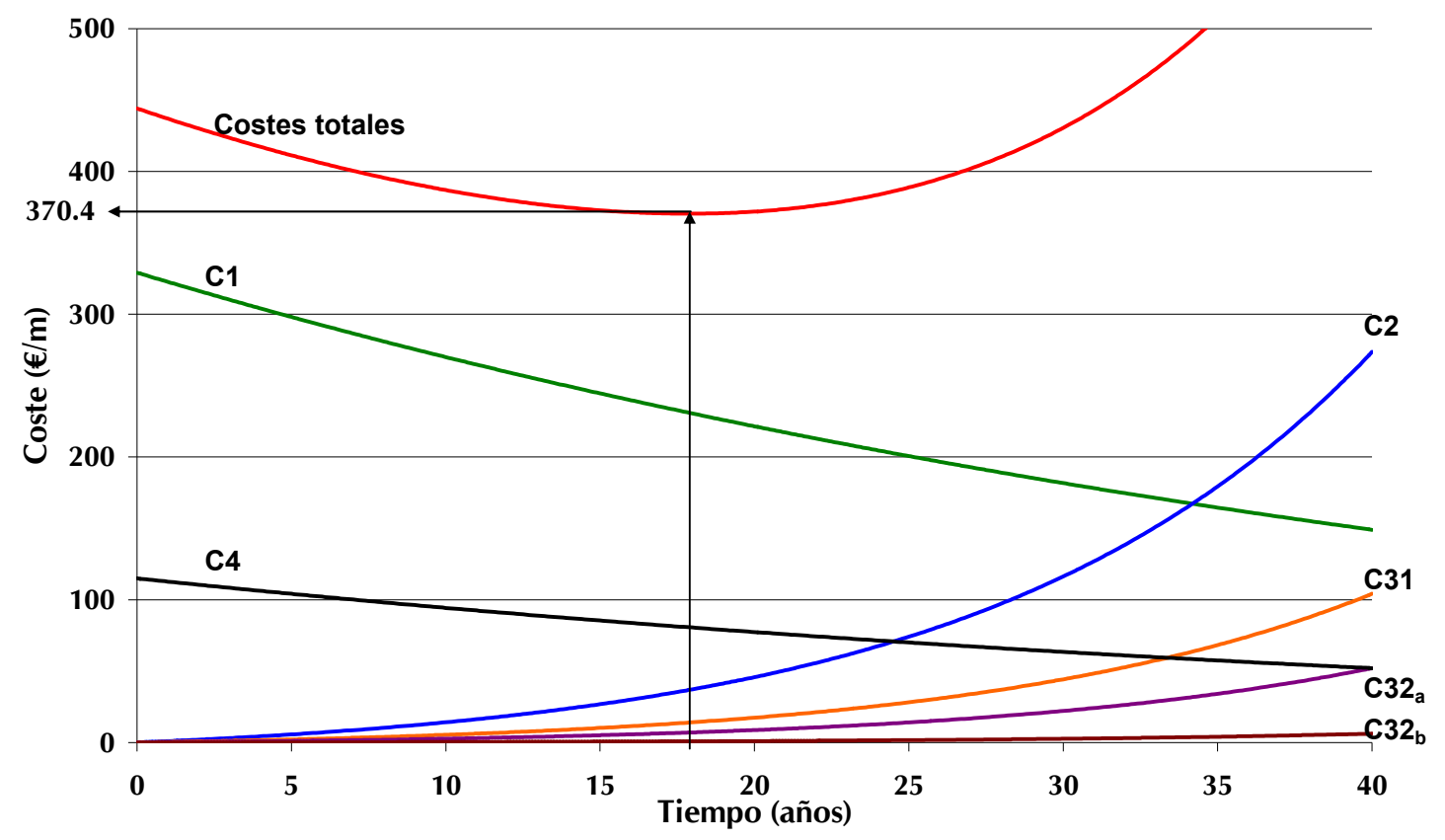

FIGURA 54. REPRESENTACIÓN DE LOS COSTES TOTALES ASOCIADOS A LA RENOVACIÓN DE UNA TUBERÍA.

\subsubsection{Tratamiento de los costes de aparición ocasional}

Los costes sociales generados por la pérdida de estándares o el coste de oportunidad son de tipo ocasional, esto es, no siempre han de tenerse en cuenta. El primero se integra en la estructura de costes a partir del año $t_{s}$ (con $t_{s}<t_{r}$ ) mientras que el segundo (coste de oportunidad negativo) interviene sólo si la obra se ejecuta el año $t_{c}$. En el primer supuesto, incumplimiento de los estándares de servicio, los costes sociales aumentan a partir de $t_{s}=10$ años y el periodo de renovación disminuye tal y como se refleja en la Figura 55. La penalización supuesta provoca una disminución del año óptimo de renovación que queda en $t_{r}=14.6$ años. Asimismo, el coste mínimo aumenta y adopta el nuevo valor de $382.5 € / \mathrm{m}$. 


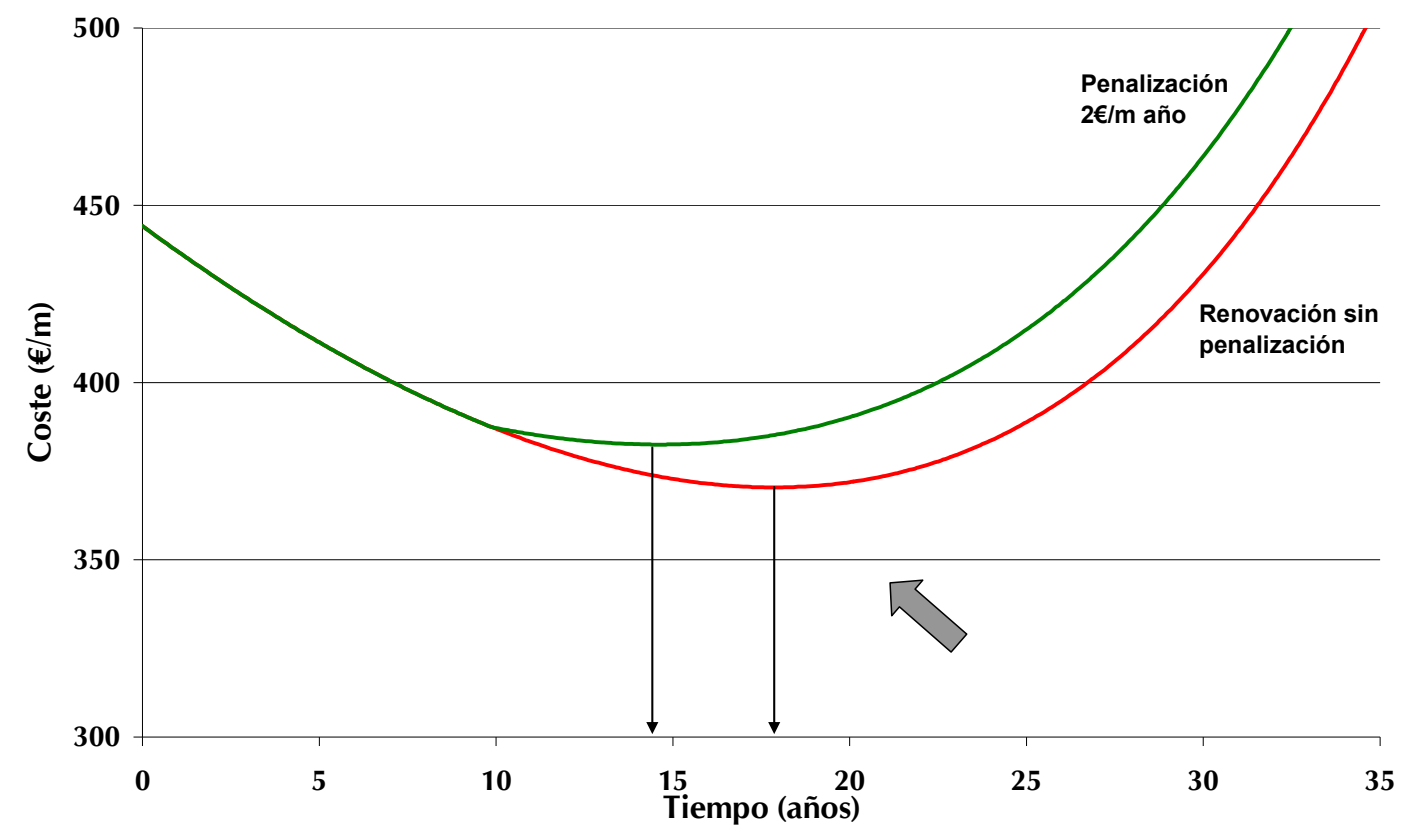

FIGURA 55. VARIACIÓN DEL COSTE TOTAL CUANDO SE INCUMPLEN LOS ESTÁNDARES DE SERVICIO A PARTIR DEL DÉCIMO AÑO.

Cuando se presente la oportunidad de beneficiarse de la ejecución simultánea de varias obras de infraestructura en el año $t_{c}$ (siempre con $t_{c}<t_{r}$ ) la curva de costes (Figura 56) se desplaza verticalmente y en sentido descendente un valor igual al coste de oportunidad negativo $C_{5}$. En realidad las curvas obtenidas a partir de la del coste total serían las obtenidas si la oportunidad se presentase durante todos los años del estudio, situación que claramente no se ajusta a la realidad. Por tanto, estas curvas, aunque no reales, sirven para identificar el año a partir del cual la renovación aprovechando la oportunidad se realiza con un coste menor que el existente en el óptimo. Y así, para un ahorro de $C_{5}=5 € / m$, convendría anticipar la obra si la oportunidad sucede entre los 13.6 y los 17.9 años. Valores mayores $\left(C_{5}=10\right.$ ó $15 € / m$,) aumentan el periodo de tiempo en el cual resulta conveniente anticipar la renovación (desde los 11.8 ó 10.4 respectivamente hasta los 17.9 años). 


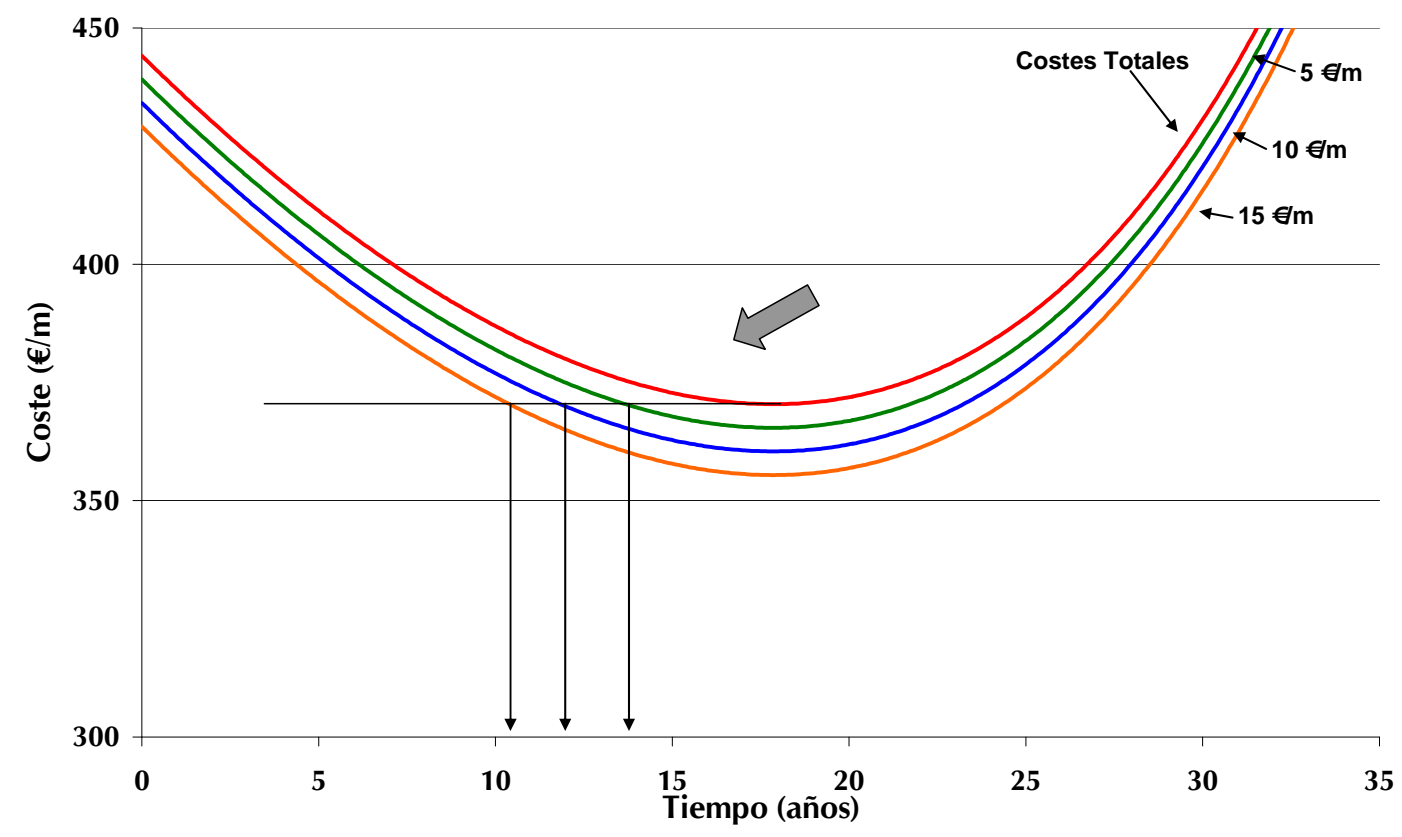

FIGURA 56. REPERCUSIÓN TEMPORAL DEL AHORRO CONSECUENCIA DE LA OPORTUNIDAD.

\subsubsection{Resultados obtenidos con el planteamiento clásico}

El periodo óptimo de renovación según el planteamiento habitual de Shamir y Howard (1979), se calcula con la ecuación (4.26) que es similar a la (4.20), aunque con la sustitución del término de inversión $\left(I_{j}\right)$ por el coste de renovación de una tubería $\left(C_{r_{j}}\right)$, y el término de mantenimiento $(M)$ por el coste de reparación de una rotura $C_{b}$.

$t_{r_{j}}^{*}=t_{0}+\frac{1}{A} \ln \left(\frac{r \cdot C_{r_{j}}}{C_{b} \cdot N\left(t_{p}\right)}\right)$

Para el ejemplo numérico, el periodo óptimo de renovación es:

$t_{r_{j}}^{*}=t_{0}+\frac{1}{A} \ln \left(\frac{r \cdot C_{r_{j}}}{C_{b} \cdot N\left(t_{p}\right)}\right)=0+\frac{1}{0.1} \ln \left(\frac{0.0198 \cdot 329.1}{1680 \cdot 0.00055}\right)=19.5$ años

Y el coste mínimo se obtiene con la ecuación siguiente:

$C_{T}\left(t_{r}\right)=C_{r_{j}} \cdot e^{-r \cdot t_{r_{j}}^{*}}+\int_{0}^{t_{r_{j}}^{*}} C_{b} \cdot N\left(t_{0}\right) \cdot \exp \left(A \cdot\left(t-t_{0}\right)\right) \cdot e^{-r \cdot t} \cdot d t=267.2 € / \mathrm{m}$ 


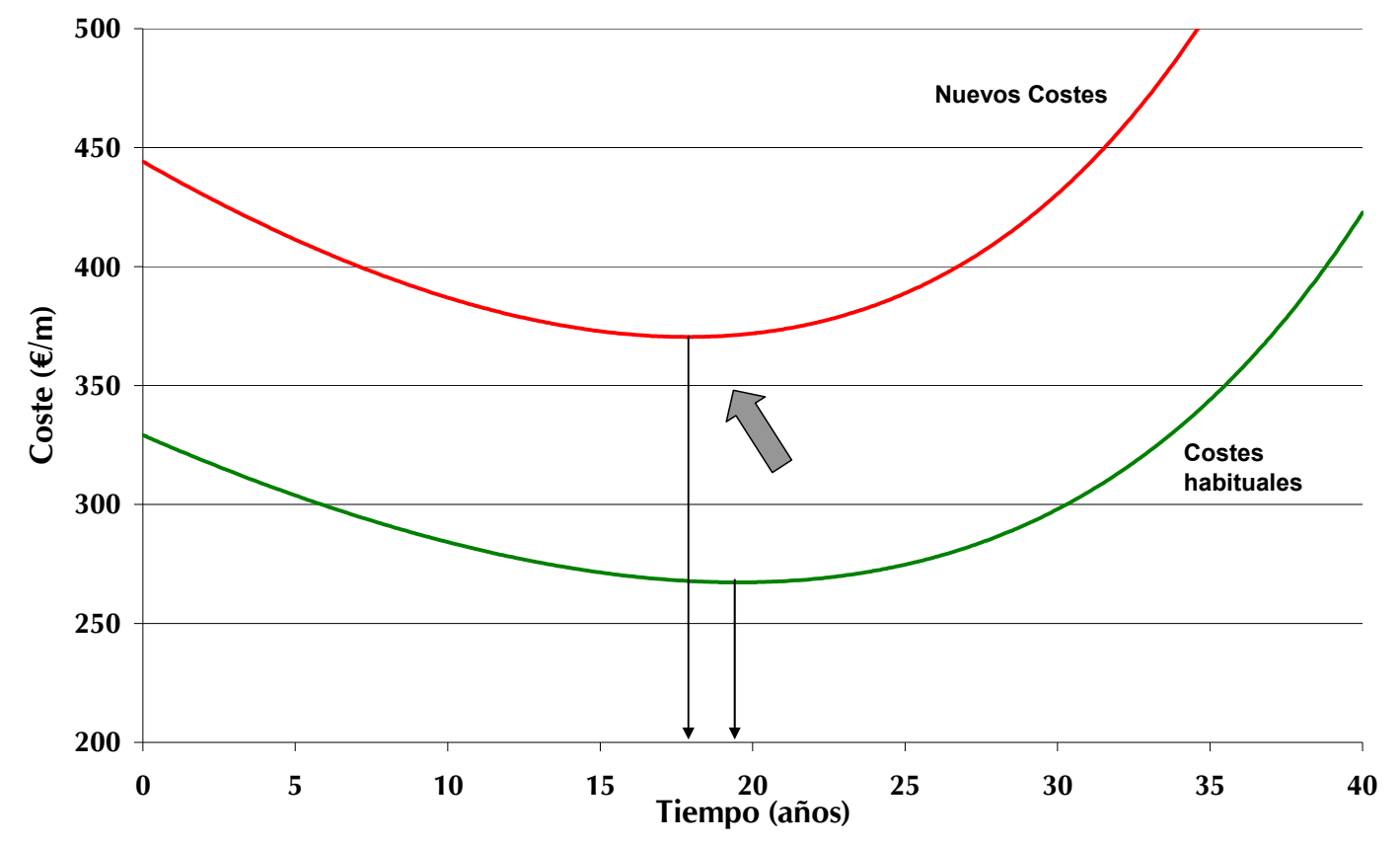

Figura 57. COMPARACIÓN DEL MODELO DE HABITUALES (SHAMIR Y HOWARD, 1979) CON EL MODELO PROPUESTO QUE INCORPORA LOS COSTES DEL AGUA, DE LA ENERGÍA Y SOCIALES.

En la Figura 57, se puede observar que la consideración del coste del agua, de la energía y los costes sociales anticipan el periodo óptimo de renovación y encarecen la sustitución.

\subsubsection{Desarrollo de los cálculos para las infinitas renovaciones}

En este segundo caso, se plantean las infinitas renovaciones siguiendo un procedimiento análogo al descrito por Kleiner y col. (2001) sólo que con los parámetros de inversión y mantenimiento, que muestran una visión más general que sus homólogos coste de renovación y coste del mantenimiento.

\subsubsection{Cálculo del periodo óptimo de renovación}

En principio se calculan los términos de inversión y mantenimiento del mismo modo que en el apartado 4.6.1 $\left(l_{j}=444.1 € / \mathrm{m}\right.$ y $M=2679.4 € /$ rotura $\left.\mathrm{m}\right)$. Con éstos se puede calcular el coste de las infinitas renovaciones de la tubería excepto de la primera (ecuación 4.21). Este coste depende del tiempo que trascurra entre dichas sustituciones (Figura 58). Por ejemplo, si las renovaciones suceden cada 15 años, el coste total de todas ellas en euros del año $t_{r}$ es de $1405.3(€ / m)$, si se renueva cada 25 años, $913.2(€ / \mathrm{m})$ y cada 40 años, $947.2(€ / \mathrm{m})$. 


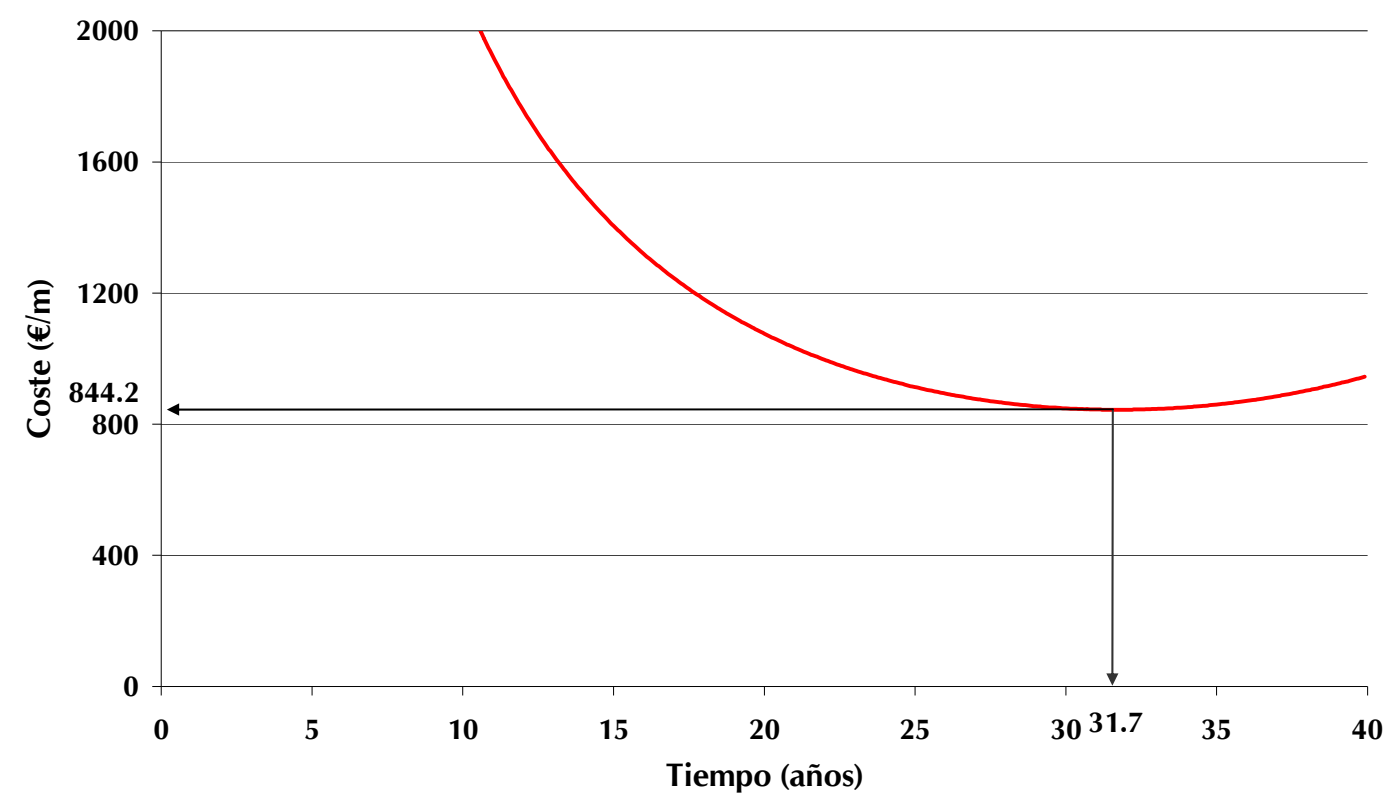

FIGURA 58. COSTES DE LAS INFINITAS RENOVACIONES DE UNA CONDUCCIÓN. APLICACIÓN NUMÉRICA CONSIDERADA SI LA TUBERÍA SE ACABA DE INSTALAR.

Estos costes presentan un valor mínimo en $T_{t_{j}}^{* *}=31.7$ años (obtenido numéricamente), y un coste de las infinitas renovaciones es de $C_{\text {inf }}\left(T_{t_{j}}^{* *}\right)=844.2 € / \mathrm{m}$ (Figura 58). Cada renovación individual tiene un coste de $393.5 €^{39} / \mathrm{m}$ (Figura 59 ).

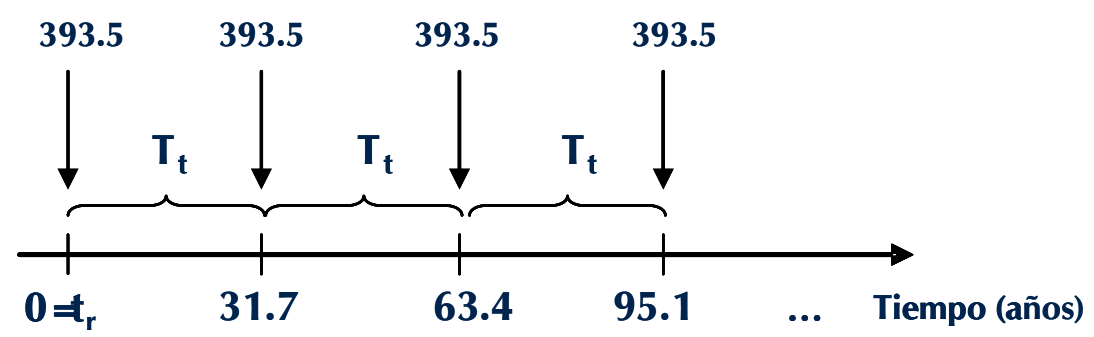

FIGURA 59. DISTRIBUCIÓN TEMPORAL DE COSTES DE RENOVACIÓN DE UNA TUBERÍA.

En caso de que se analice una situación en la que se acaba de renovar la conducción (esto es, es nueva y las roturas son iguales a $N\left(t_{p}\right)$ ), el análisis económico completo sería el definido los valores anteriores y el estudio se puede considerar como finalizado. La distribución temporal de los costes la mostraría la Figura 59.

\footnotetext{
${ }^{39}$ Cada una de las renovaciones se expresa en $€ / m$ del año en que ésta se produce.
} 
En este caso, la vida útil óptima de la conducción es de 31.7 años. Se puede observar como cuando se trasladan los costes de las infinitas renovaciones al año presente, se obtiene el valor ya conocido de las infinitas renovaciones.

$C_{\text {inf }}\left(T_{t_{j}}^{* *}\right)=393.5+393.5 \cdot e^{-31.7 \cdot r}+393.5 \cdot e^{-2 \cdot(31.7 \cdot r)}+\ldots \ldots . .=844.2 € / \mathrm{m}$.

Sin embargo, esta es una solución particular (los análisis no siempre se realizan en una tubería, zona o sector donde se acaba de realizar una renovación). Para generalizar el estudio en el presente ejemplo numérico se ha de considerar el caso común de una red de abastecimiento que se encuentra en un año concreto $\left(t_{p}\right)$ y con un número de roturas $\left(N\left(t_{p}\right)\right)$ que determinan el estado actual de la red. Por tanto, el instante en el que se producirá la primera renovación, así como el coste total, se calcula como:

$C_{T}\left(t_{r}\right)=I_{j} \cdot e^{-r T_{f_{j}}}+\int_{0}^{T_{t_{j}}} M \cdot N\left(t_{0}\right) \cdot \exp \left(A \cdot\left(t-t_{0}\right)\right) \cdot e^{-r \cdot t} \cdot d t+C_{\text {inf }}\left(T_{t_{j}}^{* *}\right) \cdot e^{-r \cdot T_{f_{j}}}$

Y el valor de $t_{r_{j}}^{*}$ que minimiza el coste total de todas las renovaciones derivando la ecuación anterior e igualando a cero (Ecuación 4.23).

$t_{r_{j}}^{*}=t_{0}+\frac{1}{A} \ln \left(r \cdot \frac{l_{j}+C_{\text {inf }}\left(T_{t_{j}}^{* *}\right)}{M \cdot N\left(t_{p}\right)}\right)=0+\frac{1}{0.1} \ln \left(0.0198 \cdot \frac{444.1+844.2}{2679.43 \cdot 0.00055}\right)=28.5$ años

La distribución temporal de los costes asociados a las infinitas renovaciones de una tubería considerando el estado actual de la red se puede ver en la Figura 60. En ella se observa que el coste de la primera renovación presenta un valor en el año presente de $414.9 €$ (que es el coste asociado a la renovación de la tubería dentro de 28.5 años) y a ese coste se debe añadir el coste de las infinitas renovaciones posteriores cada 31.7 años que tenían un valor de $844.2 €$ del año tr. Se observa que como se está calculando el año en el que se produce la primera renovación, el año $t_{r}$ es una variable más, y por tanto influye el coste total asociado a las infinitas renovaciones posteriores en el cálculo de la primera renovación. 


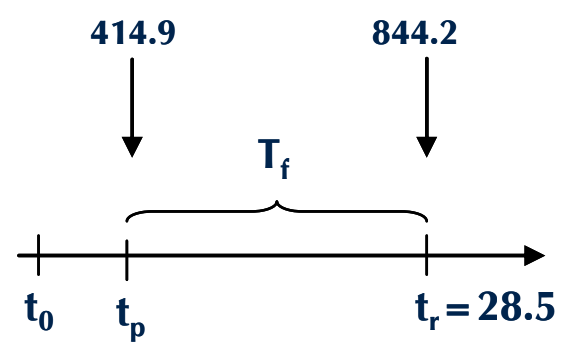

Figura 60. DistribuCión TEMPORAL DE COSTES DE RENOVACIÓN DE UNA TUBERÍA. CASO HABITUAL EN EL CUAL SE COMIENZA CON UNA RED QUE SE ENCUENTRA EN UN ESTADO DETERMINADO.

Cuando se trasladan todos los costes al año presente, se obtiene:

$C_{\text {inf }}\left(t_{r}\right)=414.9+844.2 \cdot e^{-28.5 \cdot r}=894.9 € / m$

La evolución temporal de los costes totales asociados a las infinitas renovaciones de una tubería considerando que el año cero es el año presente se muestra en la Figura 61.

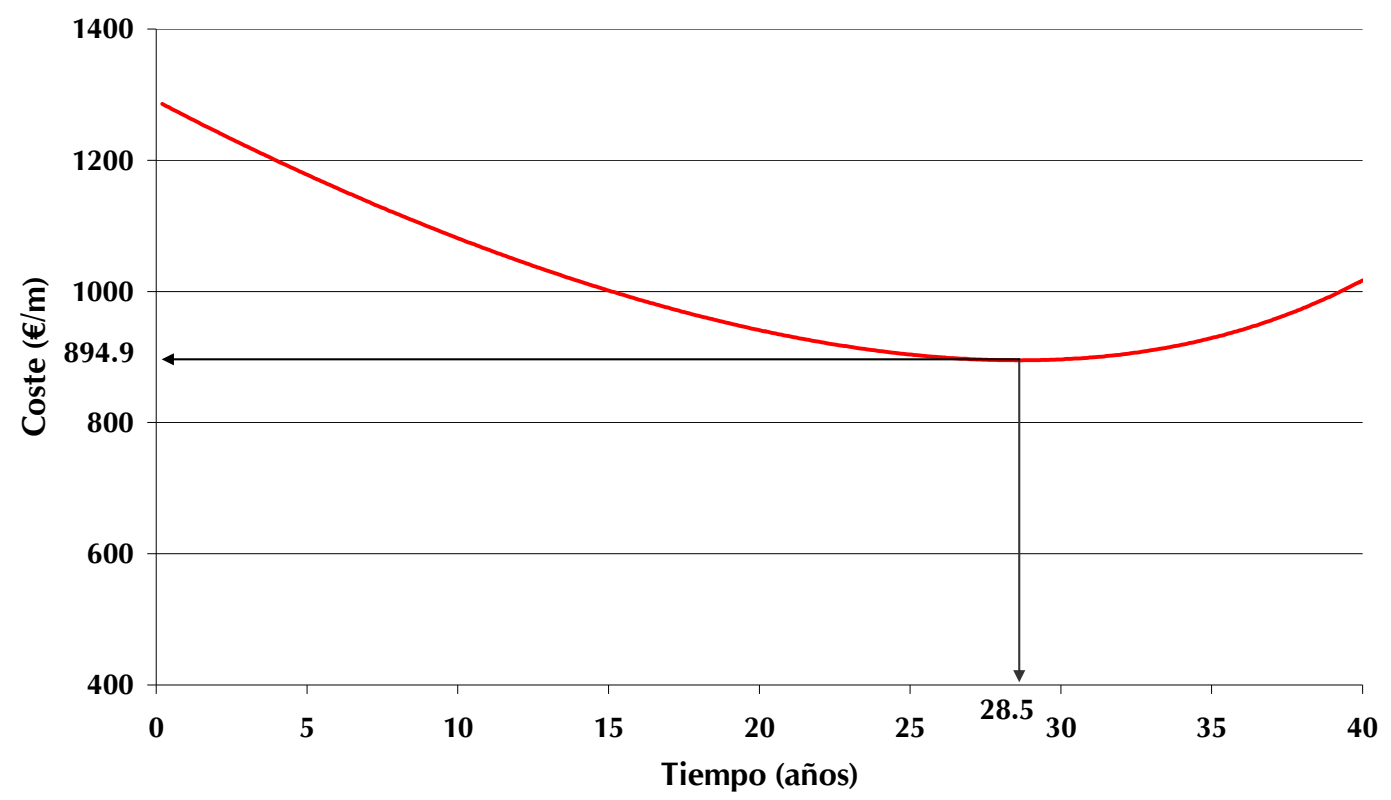

FIGURA 61. PERIODO ÓPTIMO DE RENOVACIÓN Y COSTES TOTALES (€/M) ASOCIADOS A LAS INFINITAS RENOVACIONES DE UNA TUBERÍA. 


\subsubsection{Tratamiento de los costes de aparición ocasional}

Los costes sociales generados por la pérdida de estándares se integran en la estructura de costes a partir del año $t_{s}\left(\operatorname{con} t_{s}<t_{r}\right)$ y el periodo de renovación disminuye tal y como se refleja en la Figura 62. En esta, se muestran los costes asociados a la instalación de una tubería y se supone que los estándares de servicio se incumplen a partir del año 10. La penalización supuesta provoca una disminución del año óptimo de renovación que queda en $t_{r}=27.5$ años, y el coste asociado es de $925.4 € / \mathrm{m}$.

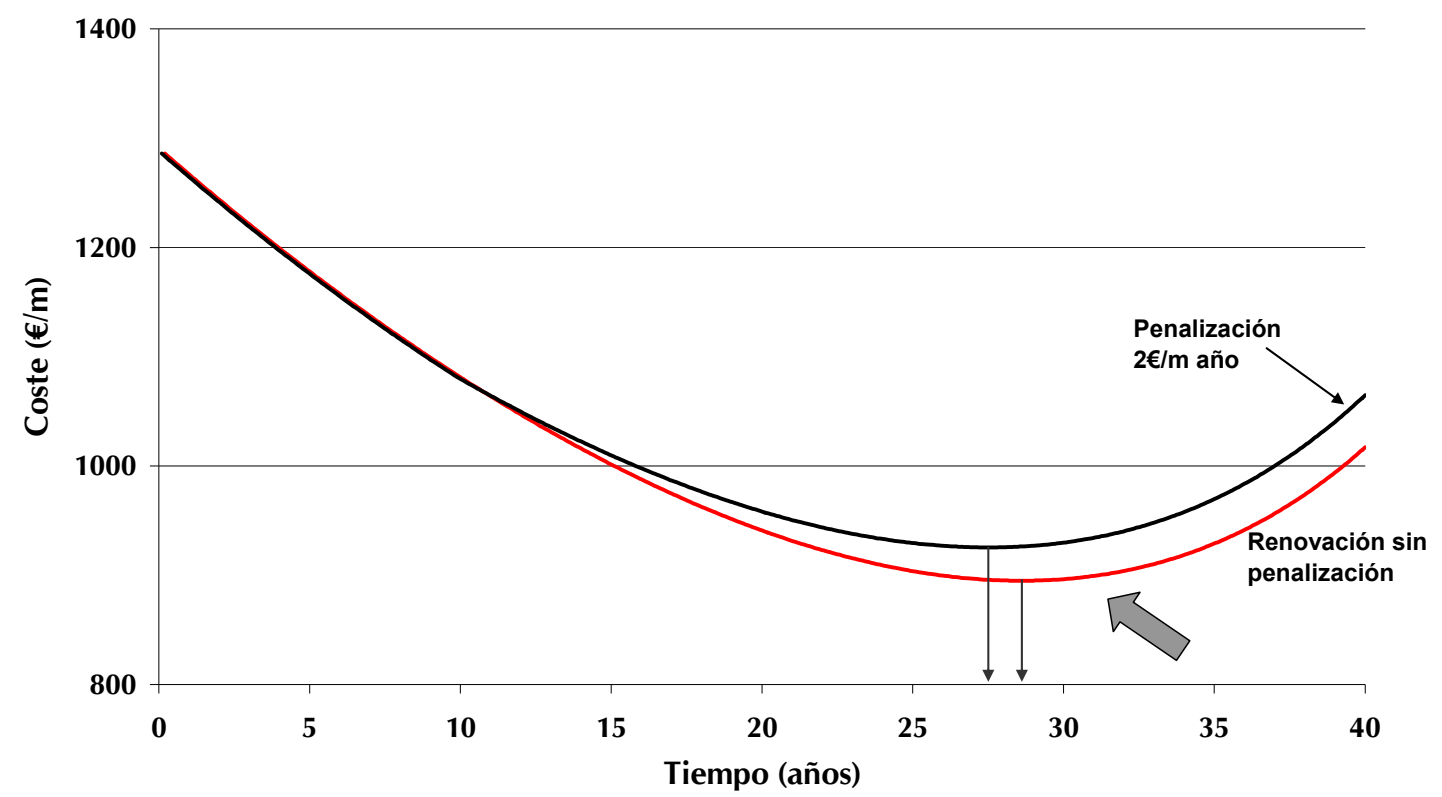

FIGURA 62. VARIACIÓN DEL COSTE TOTAL CUANDO SE INCUMPLEN LOS ESTÁNDARES DE SERVICIO EN EL CASO DE QUE SE CONSIDEREN LAS INFINITAS RENOVACIONES DE UNA TUBERÍA.

Cuando se presente la oportunidad de beneficiarse de la ejecución simultánea de varias obras de infraestructura en el año $t_{c}$ (siempre con $t_{c}<t_{r}$ ) la curva de costes (Figura 63) se desplaza verticalmente y en sentido descendente un valor igual al coste de oportunidad negativo $C_{5}$. La comparación entre las curvas desplazadas (para distintos valores de $C_{5}$ ) y la original indica a partir de cuántos años es razonable anticipar la obra. Y así, para un ahorro de $5 € / m$, convendría anticipar la obra si la oportunidad sucede entre los 25.9 y los 28.5 años. Valores mayores del coste de oportunidad (10 ó $15 € / \mathrm{m}$ ) aumentan el periodo de tiempo en el cual resulta conveniente anticipar la renovación (desde los 24.8 ó 23.8 hasta los 28.5 años respectivamente). 


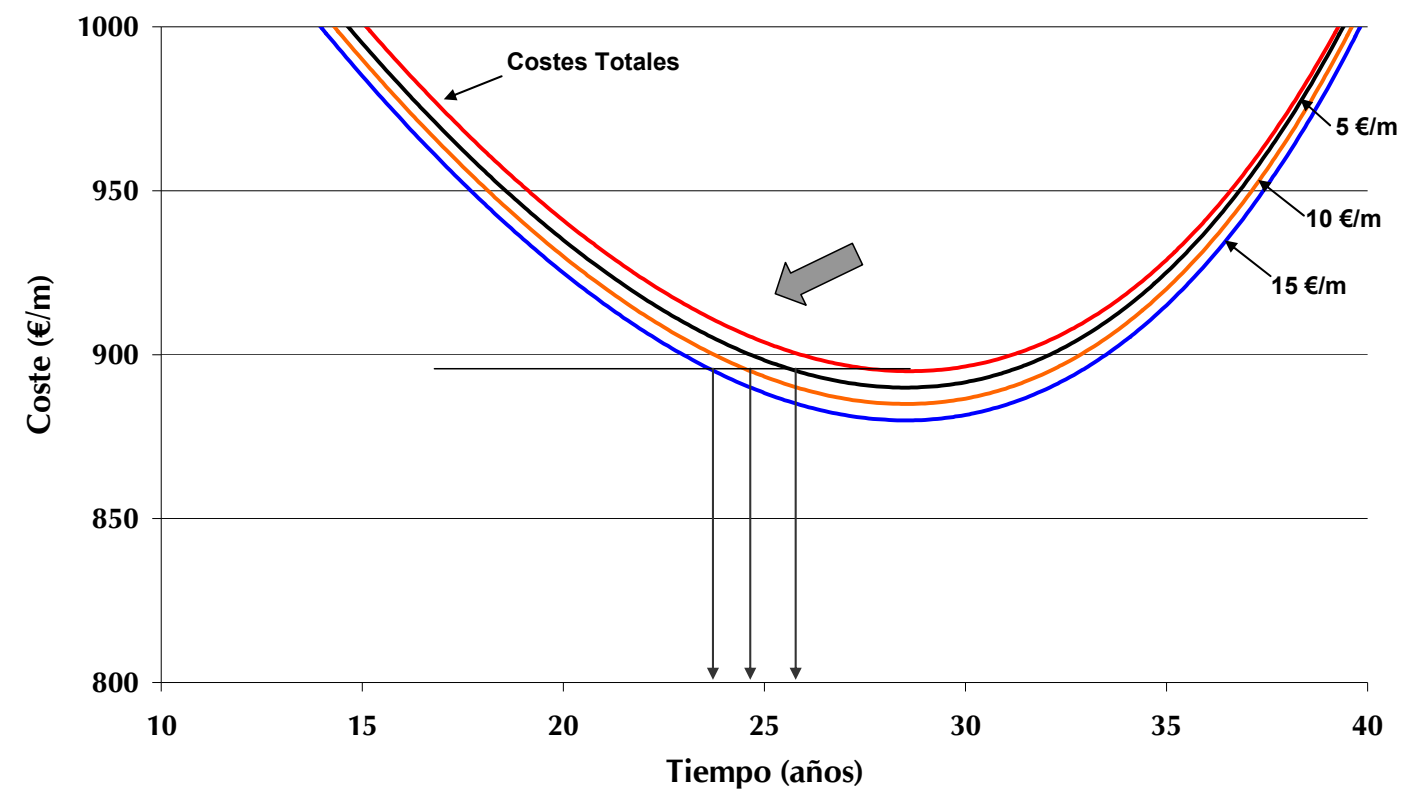

FIGURA 63. EFECTO DEL AHORRO CONSECUENCIA DE LA OPORTUNIDAD EN EL CASO EN QUE SE CONSIDEREN LAS INFINITAS RENOVACIONES DE UNA TUBERÍA.

El coste de oportunidad no siempre se ha de aprovechar. Por ejemplo, si la oportunidad se presenta en el año 20, es mejor dejar pasar el tiempo hasta el mínimo a los 28.5 años. Mientras que si la oportunidad sucede en el año 25, puede intentar aprovecharse en función de la cuantía de la misma.

\subsubsection{Resultados obtenidos con el planteamiento clásico}

Si se pretende calcular el periodo óptimo de renovación según el planteamiento habitual (Shamir y Howard, 1979), únicamente se ha de sustituir el término de inversión $l_{j}$ por el coste de renovación de una tubería $c_{r_{j}}$ y el de mantenimiento $M$ por el coste de reparación de una rotura $C_{b}$.

Con estos parámetros, el periodo óptimo de todas las renovaciones es $t_{t_{j}}^{* *}=32.9$ años y el valor de cada renovación $280.5 € / \mathrm{m}$ en unidades monetarias del año en el que se produce la renovación (Figura 64) y el coste de las infinitas renovaciones expresado en $€$ del año en el que se realiza la primera renovación tr es $C_{\text {inf }}\left(T_{t_{j}}^{* *}\right)=585.9 € / \mathrm{m}$. 


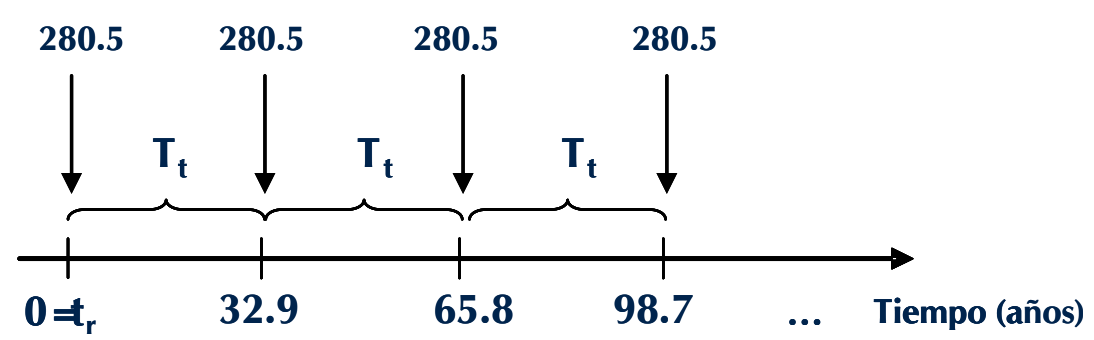

FIGURA 64. DISTRIBUCIÓN TEMPORAL DE COSTES DE RENOVACIÓN DE UNA TUBERÍA.

En caso de que se analice una situación en la que se acaba de renovar la conducción (esto es, es nueva y las roturas son iguales a $N\left(t_{0}\right)$ ), el análisis económico completo sería el definido los valores anteriores y el estudio se puede considerar como finalizado. Sin embargo, en el presente caso, se parte de una red de abastecimiento que se encuentra en un año y con unas roturas determinadas. Por tanto, se calcula el valor de $t_{r_{j}}^{*}$ que minimiza el coste total de todas las renovaciones es:

$t_{r_{j}}^{*}=t_{0}+\frac{1}{A} \ln \left(r \cdot \frac{C_{1}+C_{\text {inf }}\left(T_{t_{j}}^{* *}\right)}{C_{b} \cdot N\left(t_{p}\right)}\right)=0+\frac{1}{0.1} \ln \left(0.0198 \cdot \frac{329.1+585.9}{1680 \cdot 0.00055}\right)=29.7$ años

La distribución temporal de los costes asociados a las infinitas renovaciones de una tubería de polietileno considerando el estado actual de la red se puede ver en la Figura 65. El coste de la primera renovación (si se realiza en el año 29.7) presenta un valor en el año presente de $296.7 €$ y a ese coste se debe añadir el coste de las infinitas renovaciones posteriores, $585.9 €$ del año tr (en el año 29.7).

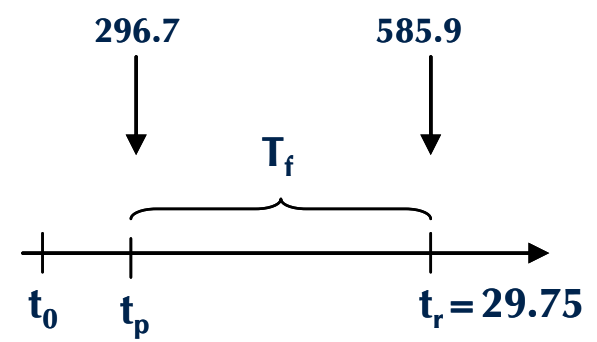

FIGURA 65. DISTRIBUCIÓN TEMPORAL DE COSTES DE RENOVACIÓN DE UNA TUBERÍA PARA EL PLANTEAMIENTO DE SHAMIR Y HOWARD EN EL CASO EN QUE SE CONSIDEREN LAS INFINITAS RENOVACIONES DE UNA TUBERÍA. 
Si se expresan todos los costes en unidades monetarias del año presente, se obtiene que el coste de todas las renovaciones es $621.8 € / \mathrm{m}$. La Figura 66 compara la evolución temporal de los costes totales asociados a las infinitas renovaciones de una tubería con los costes habituales (Shamir y Howard, 1979) y con los costes totales considerados en este trabajo. Donde se observa que, como era lógico esperar, los nuevos costes considerados anticipan la renovación y generan un mayor coste de la misma.

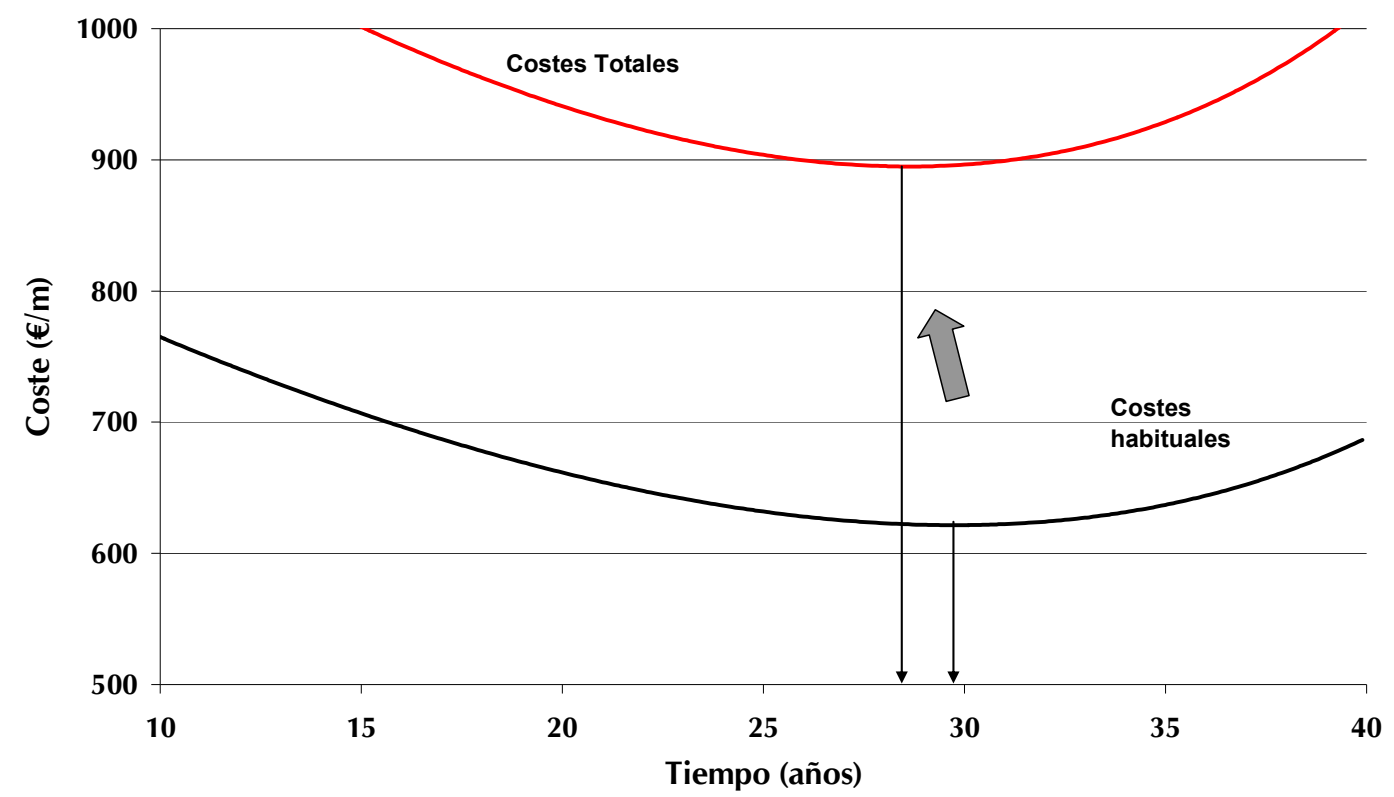

FIGURA 66. COMPARACIÓN DEL MODELO DE SHAMIR Y HOWARD, (COSTES HABITUALES) CON EL NUEVO QUE CONSIDERA LOS COSTES DEL AGUA FUGADA Y LOS COSTES SOCIALES. 


\subsubsection{Desarrollo de los cálculos para la renovación en un periodo de tiempo definido}

Se desea analizar la situación en la que se debe observar la solución más adecuada económica planteada en un periodo de tiempo determinado, 50 ó 100 años. Para ello, se parte del análisis anterior (apartado 4.6.2) según el que se conocen los instantes en los que se renueva una conducción y su coste (Figura $67)$.

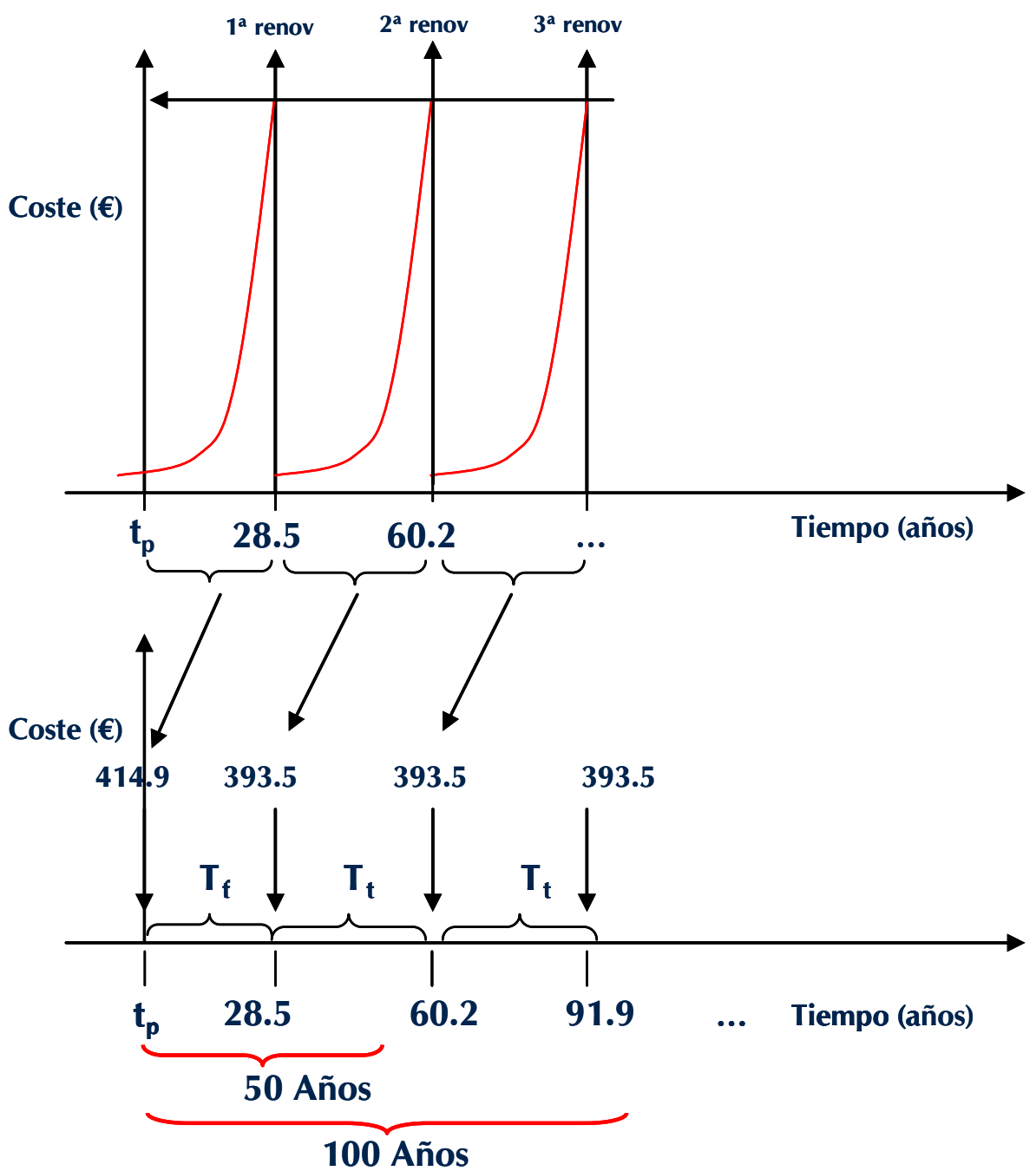

FIGURA 67. DISTRIBUCIÓN TEMPORAL DE LAS INVERSIONES EN RENOVACIÓN DE LA TUBERÍA.

La Figura 67 muestra que la primera renovación de la tubería se realiza en el año 28.5 y que su coste en el año actual es de $414.9 € / \mathrm{m}$. Por tanto, si se prepara un análisis a 50 años, únicamente hay que valorar la conveniencia económica de la sustitución de la tubería en el año 28.5. Las dos alternativas a estudiar serían: 
1. Alternativa 1-50: Se renueva a los 28.5 años.

2. Alternativa 2-50: No se produce ninguna sustitución en la tubería en los 50 años de estudio.

La primera (Alternativa 1-50) debe cuantificar el coste de la renovación y el coste de mantenimiento de la tubería desde el año 28.5 hasta el año final de nuestro estudio, año 50.

$$
\begin{aligned}
& C_{T^{*}}\left(t_{r}\right)=C_{T 1}\left(t_{r}\right)+\int_{t_{r_{j}}^{*}}^{T^{*}} M \cdot N\left(t_{0}\right) \cdot \exp \left(A \cdot\left(t-t_{0}\right) \cdot \exp \left(-r \cdot\left(t_{r_{j}}^{*}\right)\right) \cdot d t=\right. \\
& \quad=414.9+\int_{28.5}^{50} 2679.4 \cdot 0.0004 \cdot \exp (0.1 \cdot(t)) \cdot \exp (-0.0198 \cdot 28.5) \cdot d t=414.9+35.0=449.9 € / \mathrm{m}
\end{aligned}
$$

El término del mantenimiento en la época final de la etapa considerada interviene muy poco en el coste total de la renovación de la tubería debido a que la tubería tiene pocas roturas (se acaba de instalar nueva) y además el término de actualización (exp(-0.0198-28.5) provoca un menor valor del agua, energía y reparaciones en ese instante de tiempo.

La segunda (Alternativa 2-50) cuantifica únicamente los costes de mantenimiento a lo largo de los 50 años de estudio.

$$
C_{T^{*}}\left(t_{r}\right)=\int_{0}^{T^{*}} M \cdot N\left(t_{0}\right) \cdot \exp \left(A \cdot\left(t-t_{0}\right) \cdot d t=\int_{0}^{50} 2679.4 \cdot 0.004 \cdot \exp (0.1 \cdot(t)) \cdot d t=723.5 € / \mathrm{m}\right.
$$

En este caso, el elevado número de roturas provoca que el coste de mantenimiento se dispare en los últimos años de estudio. De este modo, conforme la tubería envejece, la renovación se torna en la opción más económica.

En caso de que se desee encontrar la alternativa más económica para los próximos 100 años, éstas son las que se deben valorar:

1. Alternativa 1-100: Considera que se renueva la tubería a los 28.5, 60.2 y 91.9 años.

2. Alternativa 2-100: Se renueva en los años 28.5 y 60.2 . 
La primera (Alternativa 1-100) considera los costes de renovación de la tubería a los 28.5, 60.2 y 91.9 años y los costes de mantenimiento desde el año 91.9 hasta el año final de nuestro estudio.

$$
\begin{aligned}
C_{T^{*}}\left(t_{r}\right)= & C_{T 1}\left(t_{r}\right)+C_{T 2}\left(t_{r}\right)+C_{T 3}\left(t_{r}\right)+\int_{t_{r_{j}}^{*}+2 \cdot T_{t j}^{* *}}^{T^{*}} M \cdot N\left(t_{0}\right) \cdot \exp \left(A \cdot\left(t-t_{0}\right) \cdot \exp \left(-r \cdot\left(t_{r_{j}}^{*}+t_{t_{j}}^{* *}\right)\right) \cdot d t=\right. \\
= & 414.9+393.5 \cdot e^{-28.5 \cdot r}+393.5 \cdot e^{-60.2 \cdot r}+\int_{91.9}^{100} 2679.4 \cdot 0.0004 \cdot \exp (0.1 \cdot(t)) \cdot \exp (-0.0198 \cdot 91.9) \cdot d t= \\
= & 414.9+223.8+119.5+2.0=760.2 € / \mathrm{m}
\end{aligned}
$$

Al igual que en el caso anterior, el término del mantenimiento en la época final de la etapa considerada interviene muy poco en el coste total de la renovación de la tubería debido a que la tubería tiene pocas roturas (se acaba de instalar nueva) y además el término de actualización $(\exp (-0.0198 \cdot 91.9)$ ) provoca un menor valor del agua, energía y reparaciones en ese instante de tiempo.

La segunda (Alternativa 2-100) considera que se producen dos sustituciones de tuberías, en el año 28.5 y 60.2. Por ello, se calculan los coses de mantenimiento desde el año 60.2 hasta el año 100, obteniendo:

$$
\begin{aligned}
C_{T^{*}}\left(t_{r}\right)= & C_{T 1}\left(t_{r}\right)+C_{T 2}\left(t_{r}\right)+\int_{t_{r_{j}+T_{t_{j}}^{*}}^{*}}^{T^{*}} M \cdot N\left(t_{0}\right) \cdot \exp \left(A \cdot\left(t-t_{0}\right) \cdot \exp \left(-r \cdot\left(t_{r_{j}}^{*}\right)\right) \cdot d t=\right. \\
=414.9+ & 393.5 \cdot e^{-28.5 \cdot r}+\int_{60.2} 100 \\
= & 414.9+4.4223 .8+94.7=733.4 € / \mathrm{m}
\end{aligned}
$$

En este caso, sería más económico no realizar la última renovación en el año 91.9, y la alternativa escogida será la Alternativa 2-100. 
5

Parámetros que influyen en el periodo óptimo de renovación 



\subsection{Introducción}

En este capítulo se propone determinar el efecto de cada uno de los parámetros que definen (a partir de las directrices expuestas en el capítulo 4) la obtención del periodo óptimo de renovación de tuberías. A la influencia del coste del agua y de la energía se presta especial atención, ambos son imprescindibles y por su escasez, cada vez su coste es mayor. Asimismo, también se muestra el efecto del empleo de las técnicas de renovación sin zanja sobre el periodo óptimo de renovación, ya que a la pregunta de ¿cuándo renovar? y ¿qué tubería renovar en primer lugar?, surge una nueva, que es ¿conviene utilizar alguna técnica de renovación sin zanja?

Muchos de los parámetros que influyen en la obtención del periodo óptimo de renovación son intrínsecos al problema y por tanto, no modificables por la compañía que gestiona el abastecimiento. Por ejemplo, el coste energético del agua depende del origen de la misma. El presente capítulo tiene como objetivo clasificar estos términos en independientes de la gestión o en modificables por el gestor, ya que estos últimos son los únicos sobre los que actuar para alargar la renovación.

Por último, se realiza un ejemplo sintético en el que se observa gráfica y numéricamente el efecto que sobre el periodo óptimo de renovación ejercen los términos anteriores. Para ello, se resuelve el problema según dos hipótesis diferentes de las definidas en el capítulo 4, si únicamente se considera una única sustitución o para las infinitas renovaciones. Por último, se analiza un caso particular que surge si la técnica empleada es el entubado por deslizamiento. Ésta, por ser una técnica que no se puede aplicar sucesivamente ${ }^{40}$ presenta unas particularidades que la hacen singular.

\footnotetext{
${ }^{40}$ El entubado por deslizamiento produce una reducción del 5-10\% de la sección útil de paso, por lo que no se puede utilizar de manera consecutiva porque el descenso de la capacidad hidráulica lo imposibilita.
} 


\subsection{Parámetros influyentes en el periodo óptimo de renovación}

De acuerdo con la propuesta del capítulo anterior, el periodo óptimo de renovación se calcula según la expresión:

$t_{r_{j}}^{\star}=t_{0}+\frac{1}{A} \ln \left(\frac{r \cdot I_{j}}{M \cdot N\left(t_{p}\right)}\right)$

A simple vista, la expresión muestra una dependencia de cinco parámetros, $(A$, $\left.N\left(t_{p}\right), r, l_{j}, M\right)$, ya que el parámetro to, no es una variable del sistema y está relacionado con el número de roturas de la manera siguiente, cuando to adopta el valor 0 , el número de roturas para el año cero es $N\left(t_{0}\right)=N\left(t_{p}\right)$. De los cinco parámetros anteriores, dos se calculan a partir de otros como:

$I_{j}=C_{r_{j}}+C_{S_{j}}$

$M=C_{b}+\left(q_{f} \cdot \Delta t_{a} \cdot\left(C_{W}+C_{W E}+\frac{k \cdot \gamma \cdot \frac{p_{s}}{\gamma}}{\eta} \cdot C_{E}\right)\right)$

Por lo que el periodo óptimo de renovación es función de catorce términos ( $\gamma$ es el peso específico del agua $=9810 \mathrm{~N} / \mathrm{m}^{3}$ y no es, por tanto, una variable). Éstos son:

$t_{r_{j}}^{*}=f\left(A, N\left(t_{p}\right), \mathrm{r}, C_{r_{j}}, C_{s_{j}}, C_{b}, C_{w}, C_{w E}, q_{f}, \Delta t_{a}, \frac{p_{s}}{\gamma}, C_{E}, \eta, \mathrm{k}\right)$

Donde:

- $A$, coeficiente de crecimiento del número de roturas (años $\left.{ }^{-1}\right)$.

- $\quad N\left(t_{p}\right)$, el número de roturas de la conducción i para el año tp (año actual).

- $\quad r$, la tasa continua de actualización equivalente del coste en tanto por uno.

- $\quad C_{r_{j}}$, coste de renovación de la tubería $(€ / m)$.

- $c_{s_{j}}$, coste social $(€ / m)$.

- $c_{b}$, coste unitario de una reparación puntual (€/m).

- $c_{w}$, coste total del agua a excepción de la parte energética $\left(€ / \mathrm{m}^{3}\right)$.

- $C_{W E}$, coste energético del agua, o huella energética del agua $\left(€ / \mathrm{m}^{3}\right)$.

- $q_{f}$, caudal medio unitario por fuga ( $\mathrm{m}^{3} /$ día).

- $\Delta t_{a}$, tiempo medio de actividad de la fuga (días).

- $\frac{p_{s}}{\gamma}$, presión media a la que se produce la fuga en la conducción (m.c.a.). 
- $C_{E}$ coste de la energía consumida por los equipos de bombeo pertenecientes a la etapa de distribución (€/kWh).

- $\quad \eta$ rendimiento en tanto por uno de los grupos de bombeo.

- $\mathrm{k}$ coeficiente adimensional que cuantifica el aumento de la presión de cabecera derivado de la existencia de las fugas $(k>1)$.

Dentro de este grupo, se identifican aquéllos que pueden ser modificados por el gestor de un abastecimiento, que son en definitiva los que se han de pretender controlar para minimizar costes y alargar la vida útil de las tuberías así como los parámetros independientes de la gestión del sistema (Figura 68).

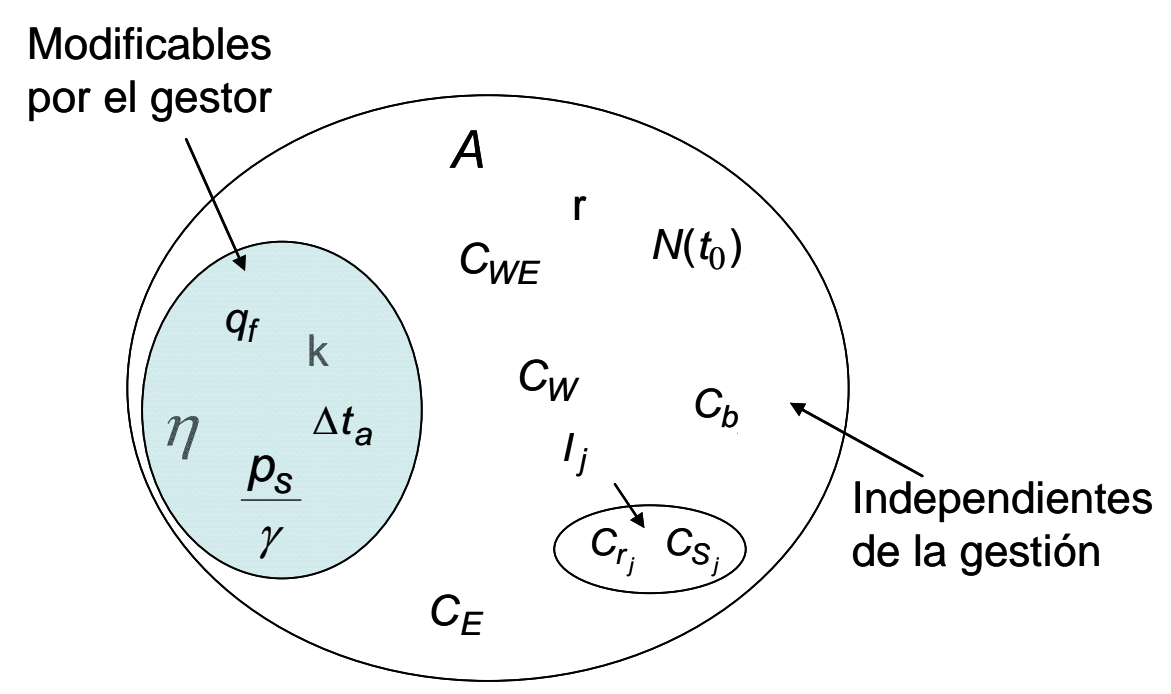

FIGURA 68. CLASIFICACIÓN DE LOS PARÁMETROS QUE INFLUYEN EN EL PERIODO ÓPTIMO DE RENOVACIÓN.

La clasificación merece una explicación detallada. Por una parte, los costes de reparación $\left(c_{r_{j}}\right)$, de mantenimiento $\left(c_{b}\right)$ y los sociales $\left(c_{s_{j}}\right)$, se consideran independientes de la gestión del sistema. Por otra, es evidente que con la negociación con los diferentes proveedores se pueden obtener precios reducidos para la rehabilitación y renovación de una conducción, pero aparte de la pericia negociadora del responsable, estos precios son los que son y no pueden ser modificados con una operación eficiente del sistema. 
Algo similar sucede con la tasa de actualización continua equivalente ( $r$ ), cuyo valor se obtiene a partir de la tasa de interés real y de la inflación (Anexo B). La primera expresa el valor temporal del dinero y se emplea para comparar los pagos en diferentes periodos de tiempo. De este modo, la tasa de interés real realmente es un parámetro que se toma como referencia según se valore el dinero en años futuros. El valor que adopta esta tasa suele ser los bonos del estado a 10 años (si el análisis se realiza en ese instante de tiempo) o un interés generado por un activo libre de riesgo. Aunque para valorar adecuadamente un coste en diferente periodo de tiempo también hay que considerar la inflación, que es un aumento sostenido y generalizado del nivel de precios de bienes y servicios (el coste de un bien aumenta sin modificar su valor). A partir de éstos dos se obtiene la tasa continua de actualización equivalente. En definitiva, para todos los análisis económicos realizados, se determina una tasa de actualización equivalente y a partir de ese instante ya no es un parámetro modificable por el gestor del sistema, no depende de la operación de la red.

El término a coeficiente de crecimiento del número de roturas en la tubería, aparentemente tampoco puede ser modificado por el gestor. Al menos, no puede variar de forma inmediata con la operación del sistema, ya que las roturas en las tuberías aumentan según un patrón definido. Sin embargo, existe una influencia indirecta de ciertos factores sobre el número de roturas, por ejemplo, la presión del sistema, la instalación de revestimientos internos o la instalación de sistemas de protección catódica pueden influir sobre el patrón de roturas aunque esta influencia indirecta escapa a los objetivos de este análisis.

El número inicial de roturas de la tubería $\left(N\left(t_{p}\right)\right)$ es el parámetro que muestra más claramente su invariabilidad con la gestión y operación del sistema. Éste, al igual que el anterior, se ha obtenido tras un análisis estadístico de las roturas de las tuberías según el material instalado, el diámetro, etc. 
Los costes variables del agua $\left(C_{W}\right.$ y $\left.C_{W E}\right)$ así como el coste de la energía $\left(C_{E}\right)$ tampoco son términos susceptibles de modificación por parte del gestor del abastecimiento. Si existe un organismo regulador, el coste del agua está impuesto por el mismo para todos los abastecimientos. En caso de que este organismo no exista, los precios del agua dependen de las autoridades locales. Asimismo, el coste de la energía ha sido impuesto a nivel estatal hasta que recientemente se ha liberalizado dicho mercado y el precio se puede pactar con la compañía distribuidora. En cualquier caso, el análisis de la influencia de estos dos parámetros sobre el periodo óptimo de renovación no carece de importancia pese a no ser modificables por el gestor, ya que reflejan los casos en los que cambia la fuente de origen del agua (que cambie el coste energético del agua, $C_{W E}$ ), o en los que se imponga un coste ambiental, etc.

El resto de parámetros son los modificables por el gestor. Es evidente que la presión media a la que se produce la fuga $\left(\frac{p_{s}}{\gamma}\right)$, el caudal unitario fugado $\left(q_{f}\right)$, el rendimiento de los equipos de bombeo $(\eta)$ y el tiempo medio de actividad de la fuga $\left(\Delta t_{a}\right)$ son claramente dependientes de las decisiones adoptadas en la operación del sistema. Algunas medidas que podría adoptar el gestor de la red para la modificación de los parámetros anteriores podrían ser la instalación de un equipo de bombeo más eficiente, el aumento del número de inspecciones o la disminución de la presión en periodos nocturnos.

Por último, el coeficiente adimensional k, cuantifica el aumento de la presión en cabecera de red derivado de la existencia de las fugas. Representa la energía que se debe aportar para satisfacer la demanda en un sistema real de abastecimiento en el que existen fugas frente a la aportada en el mismo sistema sin fugas (un estado ideal tras la renovación completa de la red). Por su propia definición, el coeficiente depende del volumen fugado, por lo que cualquier política de actuación frente a fugas repercute en la variación del mismo. Este parámetro se puede calcular con la auditoría energética (capítulo 6 de la presente tesis). 


\subsection{Análisis de sensibilidad}

Se pretende saber cual es el término más significativo de los requeridos por el modelo y, a priori, la conclusión es inmediata y sencilla, ya que el índice de crecimiento del número de roturas $(A)$ es el único que muestra una relación lineal con el periodo óptimo de renovación, mientras que el resto de parámetros están influenciados por el logaritmo (ecuación 5.1).

Por otra parte y atendiendo a la expresión analítica, la influencia del parámetro

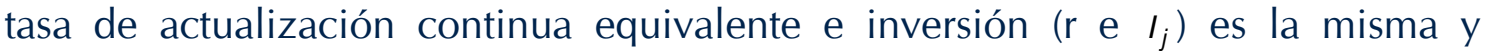
opuesta a la que producen los parámetros de mantenimiento y por el número de roturas inicial $\left(M\right.$ y $\left.N\left(t_{p}\right)\right)$.

Para subrayar la influencia de cada uno de los 5 parámetros anteriores en el periodo óptimo de renovación, se dan valores a todos ellos (Tabla 48) y se analizan las combinaciones de éstos, obteniendo 11550 soluciones de la ecuación (5.1).

TABLA 48. VALORES ADOPTADOS PARA LOS PRINCIPALES TÉRMINOS QUE INFLUYEN EN EL PERIODO ÓPTIMO DE RENOVACIÓN.

\begin{tabular}{ccccc}
\hline$A$ & $\mathbf{r}$ & $N\left(t_{p}\right)$ & $I_{j}$ & $M$ \\
\hline 0.05 & 0.02 & 0.0001 & 344 & 1530 \\
0.06 & 0.025 & 0.00015 & 450 & 2500 \\
0.07 & 0.03 & 0.0002 & 550 & 3500 \\
0.08 & 0.035 & 0.00025 & 650 & 4500 \\
0.09 & 0.04 & 0.0003 & 793 & 5500 \\
0.1 & & 0.00035 & & 6041 \\
0.11 & & 0.0004 & & \\
0.12 & & & & \\
0.13 & & & & \\
0.14 & & & & \\
0.15 & & & & \\
\hline
\end{tabular}

Los valores numéricos de los términos de inversión y mantenimiento $\left(\begin{array}{lll}l_{j} & \text { y } & M\end{array}\right)$ se calculan a partir de su definición (ecuaciones 5.2 y 5.3). La combinación de los parámetros utilizados en dichas ecuaciones $\left(c_{r_{j}}, c_{b}, c_{W}\right.$, etc. y todos los mostrados en la Tabla 49) proporciona unos valores de inversión y mantenimiento comprendidos entre los valores extremos de dichos parámetros tal y como se muestra en la Tabla 48. 
El valor de los costes de de renovación $\left(c_{r_{j}}\right)$ y rehabilitación $\left(C_{b}\right)$ de la tubería, expresado en unidades monetarias del año actual, han sido facilitados por varios abastecimientos españoles. Los costes de renovación dependen de la técnica empleada, y para ello se hizo un estudio de los presupuestos facilitados por distintos fabricantes (valores recogidos en el anexo A).

El coste social $\left(c_{S_{j}}\right)$ se obtuvo como suma de las molestias de las obras, interrupción del tráfico rodado, daños que se realizan en el pavimento de carreteras cercanas a la obra, pérdidas de productividad por ruidos y vibraciones, etc. tal y como se muestran en el anexo D. El coste total del agua a excepción de la parte energética $\left(c_{w}\right)$ varía entre $0.1 € / \mathrm{m}^{3}$, valor habitual del agua en la distribución en alta (agua que se compra por la entidad de abastecimiento antes de la potabilización y distribución) y $0.4 € / \mathrm{m}^{3}$, propio en abastecimientos en los que se añade un coste medioambiental por el daño que se hace al medio ambiente en la detracción del recurso de su medio natural. La huella energética del agua $\left(C_{W E}\right)$ varía entre $0.05 € / \mathrm{m}^{3}$, valor asociado a un origen del agua superficial, y $0.3 € / \mathrm{m}^{3}$, valor característico de agua provinente de una desaladora. Este valor es incluso bajo, ya que si se tienen en cuenta otros factores económicos no incluidos como por ejemplo la amortización, este precio puede alcanzar los $0.6 € / \mathrm{m}^{3}$ (desaladora del Prat, puesta en funcionamiento en Julio de 2009).

El caudal medio que se pierde en una fuga $\left(q_{f}\right)$ oscila entre 10 y $30 \mathrm{~m}^{3} /$ día. Según Lambert y col., (1998), las fugas se pueden clasificar como rotura o burst si el caudal es mayor de $12 \mathrm{~m}^{3} /$ día a una presión de 50 m.c.a. y como fuga latente o background losses si el caudal de fugas es menor. Por tanto, los valores considerados (Tabla 49) se pueden considerar dentro de la horquilla de caudales fugados, ya que el caudal de fugas depende del tamaño del agujero, de la presión, del tipo de rotura, etc.

El tiempo medio de actividad de la fuga en días $\left(\Delta t_{a}\right)$ depende del número de inspecciones que se realizan en un periodo de tiempo. Se supone que si se realizan dos inspecciones al año, la vida media de la fuga será la mitad del tiempo transcurrido entre inspecciones, 90 días (valor inferior del rango, Tabla 49), mientras que si se realiza una inspección al año, la vida media de la fuga es de la mitad del año, y en el cálculo se ha supuesto 200 días, (valor superior). 
La presión media a la que se produce la fuga en la conducción $\left(\frac{p_{s}}{\gamma}\right)$, se ha supuesto con valores entre 30 m.c.a. (valor garantizado por la compañía distribuidora en el abastecimiento en Valencia), mientras que el valor de 10 m.c.a. sería el valor en una red insuficiente que no es capaz de garantizar una presión mínima adecuada y que con frecuencia se debe apoyar en la instalación de aljibes domiciliarios para ser capaz de satisfacer la demanda. Dicho valor inferior también es un caso real en varios abastecimientos de ciudades españolas.

El coste de la energía consumida $\left(C_{E}\right)$ se considera variable entre 0.05 y 0.2 (€/kWh), valores habituales según los precios de la energía en España. El rendimiento en tanto por uno de los grupos de bombeo $(\eta)$ se considera entre los valores de 0.75 y 0.85 . Estos valores son elevados, pero se corresponden con equipos de bombeo que se mueven en un punto fijo y que habitualmente trabajan en su punto de rendimiento óptimo. La elevada energía consumida por los mismos, justifica la minuciosa elección del grupo adecuado.

Por último, el coeficiente adimensional que cuantifica el aumento de la presión de cabecera derivado de la existencia de las fugas, se define entre los valores 1 que se corresponde con el caso ideal en el cual no existan fugas en el sistema, y un valor 1.4 adoptado tras los análisis energéticos que se realizarán en el capítulo 6 de la presente tesis. Si bien, 1.4 se corresponde con un sistema en el que existe una elevada tasa de fugas (se suele obtener para una red con fugas del orden de $1 \mathrm{~m}^{3} / \mathrm{kmh}$, si bien la relación entre ambas no es directa sino que depende de las características particulares de la red).

TABLA 49. VALORES QUE PROPORCIONAN LOS ADOPTADOS PARA LOS TÉRMINOS QUE DETERMINAN LOS VALORES DE LOS TÉRMINOS DE INVERSIÓN Y MANTENIMIENTO.

\begin{tabular}{ccccccc}
\hline & $C_{r_{j}}(€ / \mathbf{m})$ & $C_{b}(€ / \mathbf{m})$ & $C_{S_{j}}(€ / \mathbf{m})$ & $C_{W}\left(€ / \mathbf{m}^{3}\right)$ & $C_{W E}\left(€ / \mathbf{m}^{3}\right)$ & $q_{f}\left(\mathbf{m}^{3} / \mathbf{d i ́ a}\right)$ \\
\hline $\min$. & 329.13 & 1391.74 & 15 & 0.1 & 0.05 & 10 \\
max. & 678 & 1680 & 115 & 0.4 & 0.3 & 30 \\
\hline & $\Delta t_{a}$ (días) & $\frac{p_{s}}{\gamma}$ (m.c.a.) & $C_{E}(€ / \mathbf{k W h})$ & $\eta$ & $\mathbf{k}$ & \\
\hline $\min$. & 90 & 20 & 0.05 & 0.75 & 1 & \\
$\max$. & 200 & 30 & 0.2 & 0.85 & 1.4 & \\
\hline
\end{tabular}


A partir de la ecuación definida para la obtención del periodo óptimo de renovación, se plantean todas las combinaciones posibles definidas por los valores numéricos expresados en la Tabla 48, con lo que se calcula el periodo óptimo de renovación para las 11550 combinaciones. Con estas simulaciones se pretende determinar cuál es el parámetro más influyente en la obtención del periodo óptimo de renovación.

Cuando se pretende comparar la influencia de un parámetro con respecto a otro se representan los valores normalizados. Una manera de hacerlo es presentar su variación entre los valores 0 y 1 . Para esto a cada valor se resta el valor mínimo y se divide por la anchura del rango de variación de dicho parámetro. En la siguiente ecuación se muestra cómo se ha normalizado un parámetro genérico, x.

$x_{N}=\frac{x_{i}-x_{\min }}{x_{\max }-x_{\min }}$

Se realizan los cálculos y se muestra la influencia de un parámetro con respecto al periodo óptimo de renovación. El único parámetro que resulta significativo en dicha relación es el índice de crecimiento de rotura ( $A$ ). En la Figura 69 se puede observar que valores de éste elevados reducen la importancia del resto de parámetros. El rango de variabilidad de los puntos de la misma (cada punto representa el periodo óptimo de renovación en una condición determinada) es menor que para valores de A bajos, tal como se observa en las curvas que definen las envolventes de los valores máximos y mínimos obtenidos. La línea recta en la muestra los valores medios de las distintas simulaciones y presenta una idea clara, mayor índice $A$, menor periodo óptimo de renovación. Tal conclusión se podría haber obtenido directamente a partir de la ecuación, pero las simulaciones muestran la fuerte dependencia del periodo óptimo de renovación a los valores de dicho parámetro. 


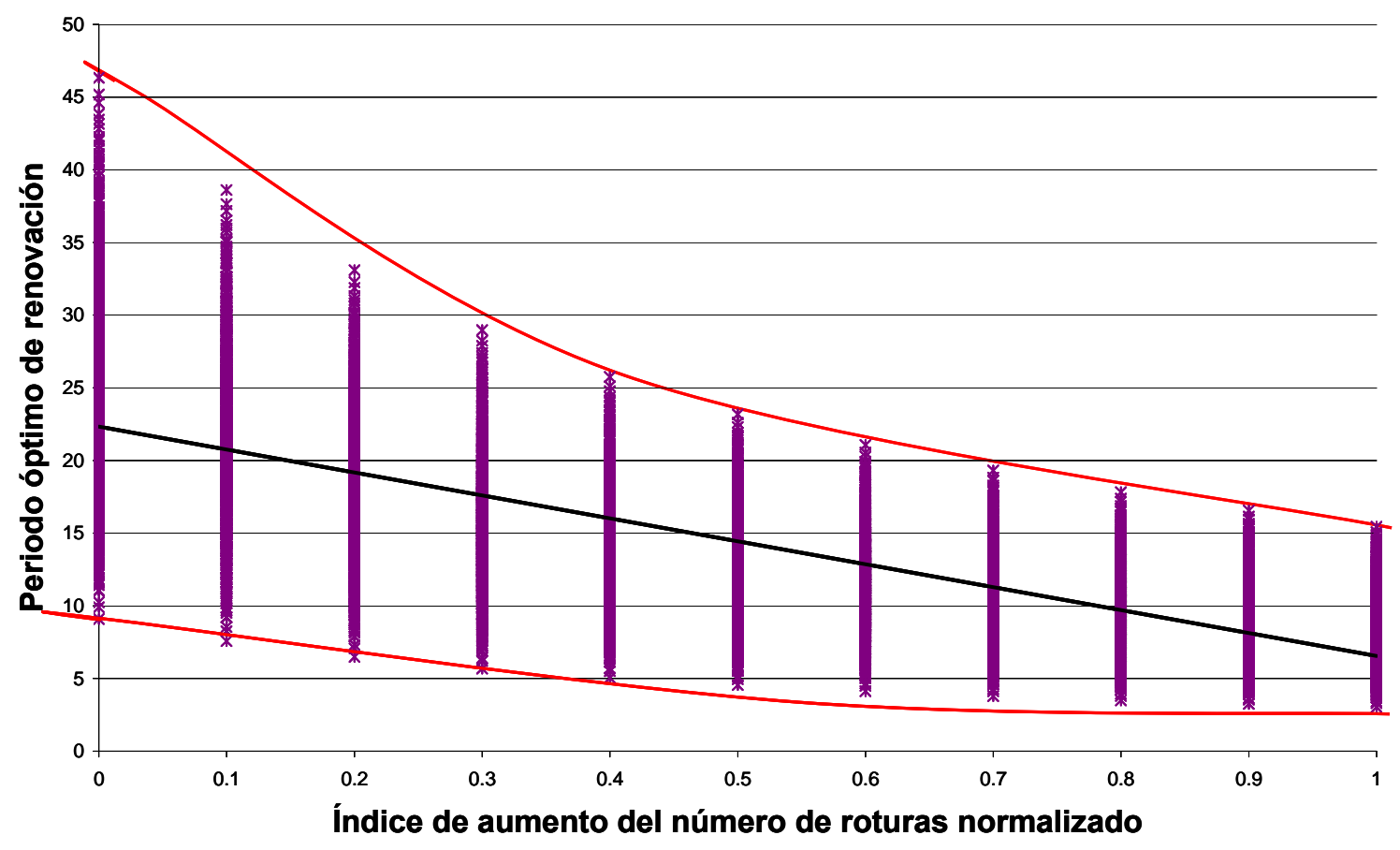

FIGURA 69. VARIACIÓN DEL PERIODO ÓPTIMO DE RENOVACIÓN SEGÚN DIFERENTES VALORES DEL PARÁMETRO A.

El resto de gráficos para los otros parámetros no muestran especial información (por eso no se incluyen en el presente capítulo), y ratifican las ideas iniciales:

- El aumento en el parámetro $r$ y en $\iota_{j}$, provocan un retraso en la sustitución. Esta afirmación coincide con la lógica, ya que si el coste de renovación es elevado o si se valora poco el dinero futuro, se decide prolongar al máximo adoptar la decisión de renovar. Asimismo, su influencia es la misma en magnitud. Esto es, una variación del 10\% del término de inversión tiene el mismo efecto sobre el periodo óptimo de renovación que es misma variación en el término de actualización equivalente.

- En cambio, el aumento en $N\left(t_{p}\right)$ y $M$ anticipa la renovación. Al igual que anteriormente, el resultado coincide con lo previsto, si el número de roturas o si los costes de mantenimiento son elevados, la decisión de renovación se adoptará antes. Al igual que anteriormente, la misma variación en estos dos parámetros tiene el mismo efecto en el óptimo de renovación. 
Si se desea cuantificar la influencia de los otros parámetros (los 9 definidos en la Tabla 49), simplemente se ha de considerar la variación que éstos producen en los términos $l_{j}$ y $M$. Por la propia definición de éstos (ecuaciones 5.2 y 5.3) es evidente la fuerte influencia de los parámetros $\left(c_{r_{j}}, C_{S_{j}}, C_{b}, c_{W}, C_{W E}, q_{f}\right.$ y $\left.\Delta t_{a}\right)$, mientras que los términos de menor influencia en el óptimo de renovación son los que provienen del término $c_{32 b}$, que cuantificaba las pérdidas por fricción extra producida por el exceso de caudal circulante por la red de abastecimiento. Con el siguiente cálculo se certifica que si bien es importante (desde una óptica conceptual) cuantificar el término $\left(C_{32 b}\right)$, no modifica los resultados sustancialmente.

Para ilustrar la influencia sobre el periodo óptimo de renovación de los términos $\left(\frac{p_{S}}{\gamma}, C_{E}, \eta \mathrm{y} \mathrm{k}\right)$ se ha realizado una simulación con el resto de parámetros con un valor fijo y éstos con valores pertenecientes al rango definido para los mismos en la Tabla 49. La Figura 70 muestra los resultados de estas simulaciones. En ella, se observa que la variación entre el valor máximo y mínimo de éstos únicamente produce una modificación del periodo óptimo de renovación de 3 meses (1/4 de año).

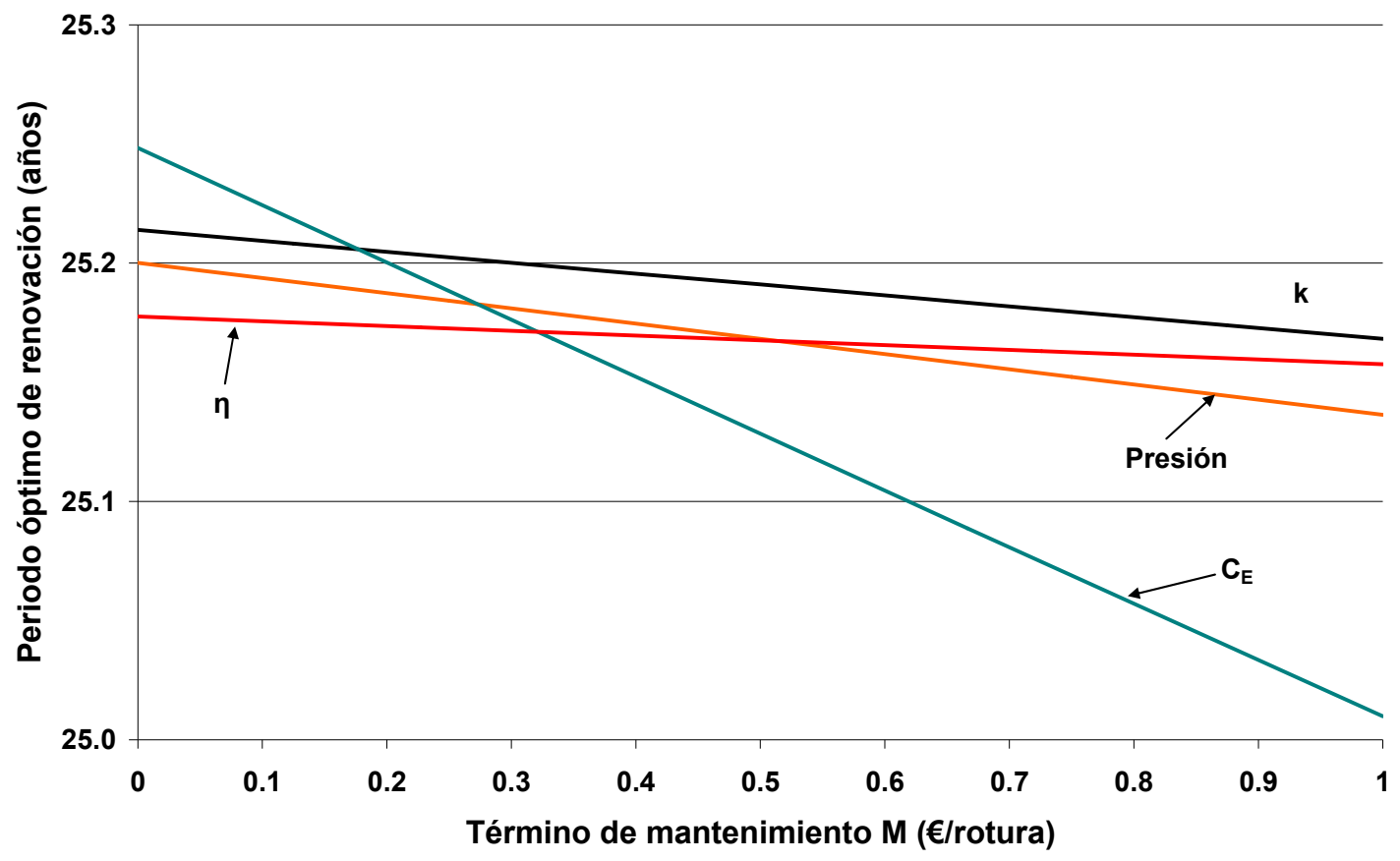

FIGURA 70. PERIODO ÓPTIMO DE RENOVACIÓN PARA DISTINTOS VALORES DE LOS PARÁMETROS MENOS SIGNIFICATIVOS. 
Se puede afirmar que el primer término $\left(\frac{p_{s}}{\gamma}\right)$ no es relevante para la obtención del periodo óptimo de renovación, aunque es indudable que el caudal fugado (que sí que lo es) depende de la presión. Por tanto, si se desprecia la variación de la presión como término significativo en la obtención del periodo óptimo de renovación, se hace conociendo que esta es una hipótesis de partida y que no sería completamente válida en la realidad.

Algo similar sucede con el coste de la energía $\left(C_{E}\right)$, ya que de él depende la huella energética del agua $\left(C_{W E}\right)$. Por tanto, aunque el primer término se considera despreciable a efectos numéricos, es evidente que valores elevados de éste repercuten en valores elevados del segundo $y$, en consecuencia, menores valores del óptimo de renovación.

Por último, el rendimiento del equipo de bombeo $(\eta)$ y el parámetro $k$, aumento de la presión de cabecera por existencia de fugas son los menos influyentes en el periodo óptimo de renovación. El segundo, concretamente, sólo depende de las fugas en la red, y por tanto, de los parámetros anteriores, $\frac{p_{s}}{\gamma}, q_{f}$, etc.

Así, el periodo óptimo de renovación es una función de los 10 términos siguientes:

$t_{r_{j}}^{*}=f\left(A, N\left(t_{p}\right), r, C_{r_{j}}, C_{S_{j}}, C_{b}, C_{w}, C_{w E}, q_{f}, \Delta t_{a}\right)$

En lo que sigue, se muestra un ejemplo numérico que detalla, uno a uno, los efectos que estos parámetros causan sobre el óptimo de renovación. También se subraya la influencia de las técnicas sin zanja. 


\subsection{Ejemplo numérico}

La aplicación numérica que sigue permite cuantificar la influencia de los nuevos costes. Los datos han sido facilitados por un abastecimiento de aguas español, y en su mayor parte coinciden con el ejemplo numérico del capítulo 4, lo cual facilita la relación entre ambos.

Asimismo, se analiza la problemática con las distintas hipótesis iniciales. Por una parte se resolverá el caso si se considera una única sustitución y, por otra, si se consideran las infinitas renovaciones. Por último, se resolverá el caso particular de una renovación mediante una técnica de revestimiento estructural que no se puede aplicar sucesivamente.

Los datos iniciales del problema se presentan a continuación:

Coste $\mathrm{C}_{1}$

La tubería que se desea renovar tiene un diámetro nominal de $300 \mathrm{~mm}$. Para ello se proponen diversas alternativas para ejecutar la renovación, cuyos costes de se muestran en la Tabla 50. Para valorar las inversiones se deben referir todas ellas al mismo tiempo, sólo así se podrán comparar. Por esto, se utiliza una tasa continua de actualización equivalente del coste $r=1.98 \%$ (que se corresponde con un valor de la tasa de actualización real o deflactada $R=2 \%$, Anexo B).

TABLA 50. PRECIO DE LA tUberíA DE POLIETILENO (€ DEL AÑO EN CURSO)

\begin{tabular}{cccc}
\hline Técnica & $C_{r_{1 j}}(\boldsymbol{€} / \mathbf{m})$ & $C_{r_{2 j}}(\boldsymbol{€} / \mathbf{m})$ & Coste total $(\boldsymbol{€} / \mathbf{m})$ \\
\hline Tradicional & 70.5 & 234.8 & 305.3 \\
Rotura por percusión & 70.5 & 190.5 & 261 \\
Rotura con sistema hidráulico & 70.5 & 238.5 & 309 \\
Entubado por deslizamiento & 70.5 & 254.5 & 325 \\
Perforación horizontal dirigida & 70.5 & 607.5 & 678 \\
\hline
\end{tabular}


Coste $\mathrm{C}_{2}$

Al igual que el ejemplo numérico del capítulo 4 de la Tesis, la política que sigue la entidad de abastecimiento consiste en reparar todas las roturas que suceden en la red. El coste de reparación de una rotura es $C_{b}=1680 € /$ rotura. En el instante actual se las roturas en las tuberías del sector evolucionan según una exponencial y el número de roturas en el año presente es $N\left(t_{p}\right)=55$ (roturas/año/100 Km), y cuando la tubería es nueva, las roturas son $N\left(t_{0}\right)=20$ (roturas/año/100 Km). Shamir y Howard (1979) sugieren este valor para una tubería como 40 roturas/año/100km, aunque éste valor es significativamente mayor que el encontrado en otros estudios 16-20 roturas/año/100Km (Deb y col., 2009).

La evolución del número de roturas queda perfectamente descrita con el coeficiente de crecimiento roturas expresado en $\left(\operatorname{años}^{-1}\right), A=0.1$. Este valor muestra un aumento considerable del número de roturas, por lo la tubería se encuentra en la parte final de la vida útil de la tubería (fase de deterioro, parte derecha de la Figura 71). Otros estudios obtienen un valor menor de $A=0.000272\left(\right.$ años $\left.^{-1}\right)$ (Deb y col., 2009), aunque, la importancia del ejemplo numérico versa más en obtener una idea de la influencia de cada uno de los parámetros estudiados que en obtener un valor concreto, ya que para la aplicación práctica de la metodología, se deben recoger los datos de la propia instalación.

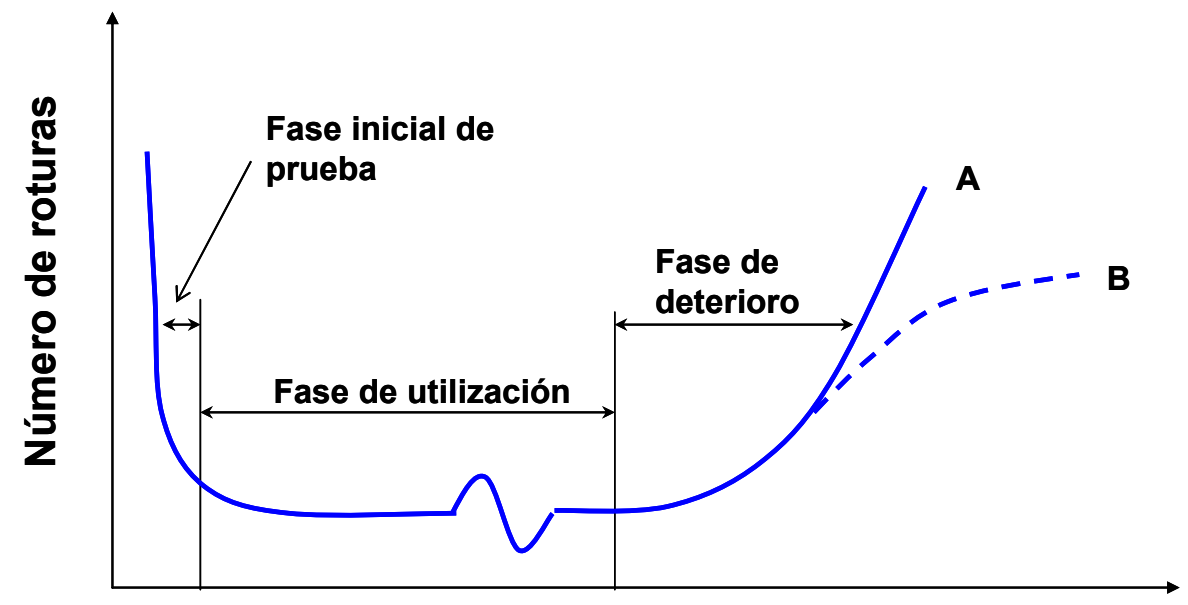

Tiempo (Años)

FIGURA 71. CICLO DE VIDA DE UNA TUBERÍA ENTERRADA. CURVA DE baÑERA. 
Coste $\mathrm{C}_{3}$

El coste del agua fugada se calcula a partir de varios parámetros, los dos primeros son el coste total (producción y ambiental) del agua $\left(c_{w}=0.2 € / \mathrm{m}^{3}\right)$ y el coste energético del agua $\left(c_{w E}=0.1\left(€ / \mathrm{m}^{3}\right)\right.$.

Las fugas se producen a una presión media igual a $\frac{p_{s}}{\gamma}=25$ m.c.a., se encuentra activa durante $\Delta t_{a}=160$ días (valor que depende de las inspecciones realizadas en la conducción) y el caudal fugado medio por rotura y día es $q_{f}=20$ ( $\mathrm{m}^{3} / \mathrm{dí}$ ). El coste de la energía empleada en el bombeo en la red de distribución es $C_{E}=0.1$ $(€ / \mathrm{kWh})$ y dichos equipos tienen un rendimiento igual a $\eta=0.8$. Por último, se define el coeficiente $k$, que sirve para considerar el efecto del bombeo extra realizado en cabecera de la red para satisfacer la demanda pese a las fugas, $\mathrm{k}=$ 1.4. También se define el peso específico del agua como $\gamma=9810 \mathrm{~N} / \mathrm{m}^{3}$.

Coste $\mathrm{C}_{4}$.

El coste social asociado a las molestias y perturbaciones por la ejecución de obras depende del tipo de técnica empleada. Tal y como se comentó cuando se definía el coste de renovación, existen distintas alternativas para la ejecución de la obra y como tales, cada uno tiene un coste social distinto (Tabla 51). Éstos se pueden calcular con la metodología propuesta en el Anexo D.

TABLA 51. COSTE SOCIAL ASOCIADO A LA S PERTURBACIONES POR EJECUCIÓN DE LAS OBRAS (€ DEL AÑO EN CURSO)
\begin{tabular}{cc} 
Técnica & $\boldsymbol{C}_{\boldsymbol{S}_{j}}(\boldsymbol{€} / \mathbf{m})$ \\
\hline Tradicional & 115 \\
Rotura por percusión & 49 \\
Rotura con sistema hidráulico & 27 \\
Entubado por deslizamiento & 15 \\
Perforación horizontal dirigida & 64 \\
\hline
\end{tabular}

El coste social (penalización por incumplimiento de estándares) del abastecimiento adopta un valor de $C_{42}=2 € / m$ año y se considera que aparecen en el año $t_{s}=10$.

Coste $C_{5}$

$C_{5}=15(€ / \mathrm{m})$ Amplitud de la función escalón del coste de oportunidad. 


\subsubsection{Desarrollo de los cálculos para una renovación}

Primeramente, se calculan los términos de inversión y mantenimiento con las expresiones definidas anteriormente (ecuaciones 5.2 y 5.3), obteniendo los resultados expresados en la Tabla 52.

TABLA 52. PARÁmetro de INVERSIÓN SEGÚN LA TÉCNICA EMPLEADA (€ DEL AÑo EN CURSO)

\begin{tabular}{cc}
\hline Técnica & $I_{j} \mathbf{l}_{\mathbf{i j}}(\boldsymbol{€} / \mathbf{m})$ \\
\hline Tradicional & 420.3 \\
Rotura por percusión & 310 \\
Rotura con sistema hidráulico & 336 \\
Entubado por deslizamiento & 340 \\
Perforación horizontal dirigida & 742 \\
\hline
\end{tabular}

El término de mantenimiento $M$ es independiente del tipo de técnica y para los valores numéricos definidos presenta un valor de $M=2679.4$ (€/rotura $\mathrm{m}$ ).

Con la expresión analítica definida en la ecuación (20), se obtiene que el periodo óptimo de renovación para la técnica tradicional es:

$t_{r_{j}}^{*}=t_{0}+\frac{1}{A} \ln \left(\frac{r \cdot l_{j}}{M \cdot N\left(t_{0}\right)}\right)=0+\frac{1}{0.1} \ln \left(\frac{0.0198 \cdot 420.3}{2679.4 \cdot 0.00055}\right)=17.3$ años

Y el coste mínimo se obtiene con la ecuación (19):

$C_{T}\left(t_{r}\right)=I_{j} \cdot e^{-r \cdot t_{r_{j}}^{*}}+\int_{0}^{t_{r_{j}}^{*}} M \cdot N\left(t_{0}\right) \cdot \exp \left(A \cdot\left(t-t_{0}\right)\right) \cdot e^{-r \cdot t} \cdot d t=353.6 € / \mathrm{m}$.

Si se representan todos los costes que generan el coste total asociado a la renovación a lo largo del tiempo, se obtiene:

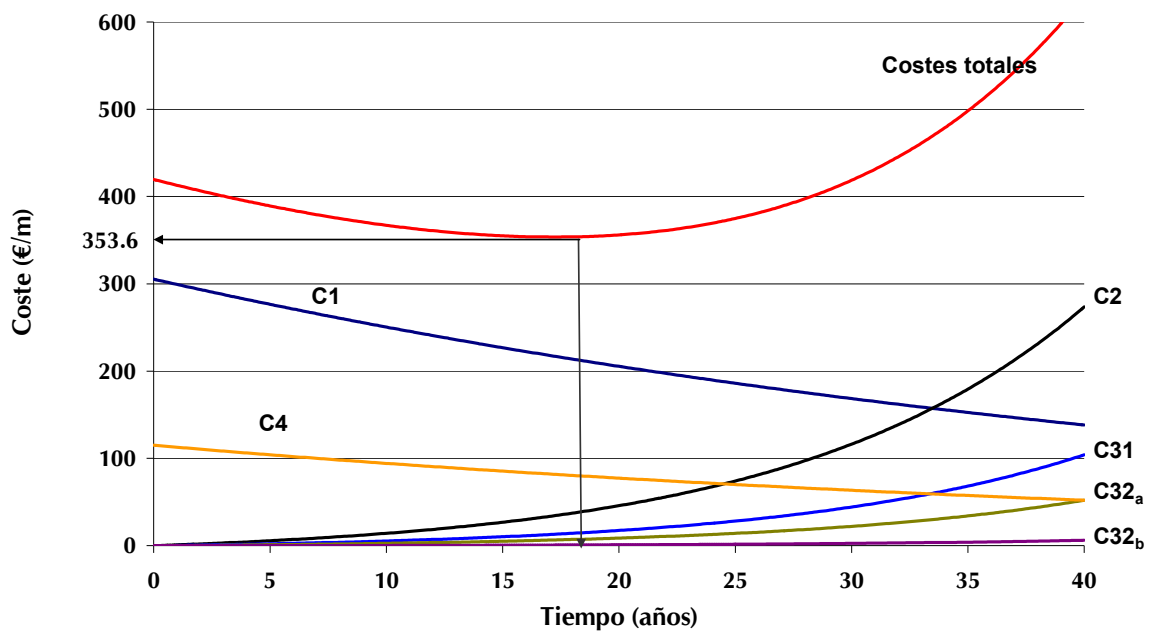

FIGURA 72. REPRESENTACIÓN DE LOS COSTES TOTALES ASOCIADOS A LA RENOVACIÓN DE UNA TUBERÍA. 


\subsubsection{Tratamiento de los costes de aparición ocasional}

La existencia de los costes ocasionales ya fue analizada en el capítulo 4 de la Tesis. Para mantener una estructura similar a la anterior se vuelve a tratar a continuación en otra aplicación numérica.

Los costes sociales generados por la pérdida de estándares se integran en la estructura de costes a partir del año $t_{s}\left(\operatorname{con} t_{s}<t_{r}\right)$ mientras que el coste de oportunidad (coste negativo) interviene sólo si la obra se ejecuta el año $t_{c}$. En el primer supuesto, incumplimiento de los estándares de servicio, los costes sociales aumentan a partir de $t_{s}=10$ años y el periodo de renovación disminuye tal y como se refleja en la Figura 73. La penalización supuesta provoca una disminución del año óptimo de renovación que queda en $t_{r}=13.9$ años. Asimismo, el coste mínimo aumenta y adopta el nuevo valor de $364.5 € / \mathrm{m}$.

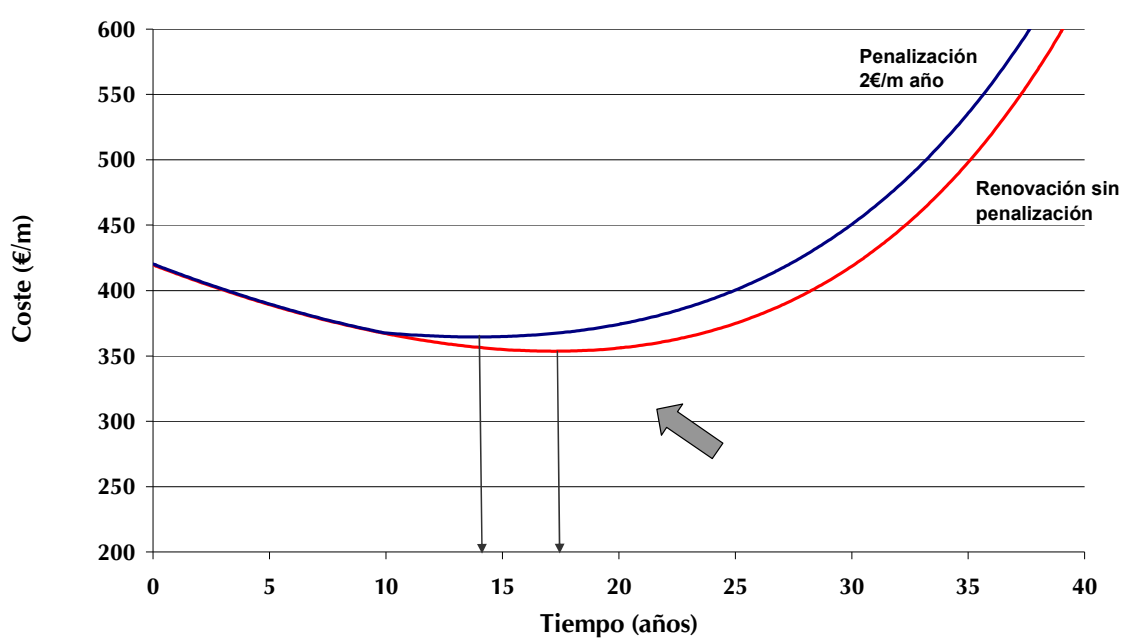

FIGURA 73. VARIACIÓN DEL COSTE TOTAL CUANDO SE INCUMPLEN LOS ESTÁNDARES DE SERVICIO A PARTIR DEL DÉCIMO AÑO.

Cuando se presente la oportunidad de beneficiarse de la ejecución simultánea de varias obras de infraestructura en el año $t_{c}$ (siempre con $t_{c}<t_{r}$ ) la curva de costes (Figura 74) se desplaza verticalmente y en sentido descendente un valor igual al coste de oportunidad negativo $C_{5}$. La comparación entre las curvas desplazadas (para distintos valores de $C_{5}$ ) y la original, indica a partir de cuántos años es razonable anticipar la obra. Y así, para un ahorro de $5 € / m$, convendría anticipar la obra si la oportunidad sucede entre los 13 y los 17.3 años. Valores mayores $\left(C_{5}=\right.$ 10 ó 15) aumentan el periodo de tiempo en el cual resulta conveniente anticipar la renovación (desde los 11.2 ó 9.7 respectivamente hasta los 17.3 años). 


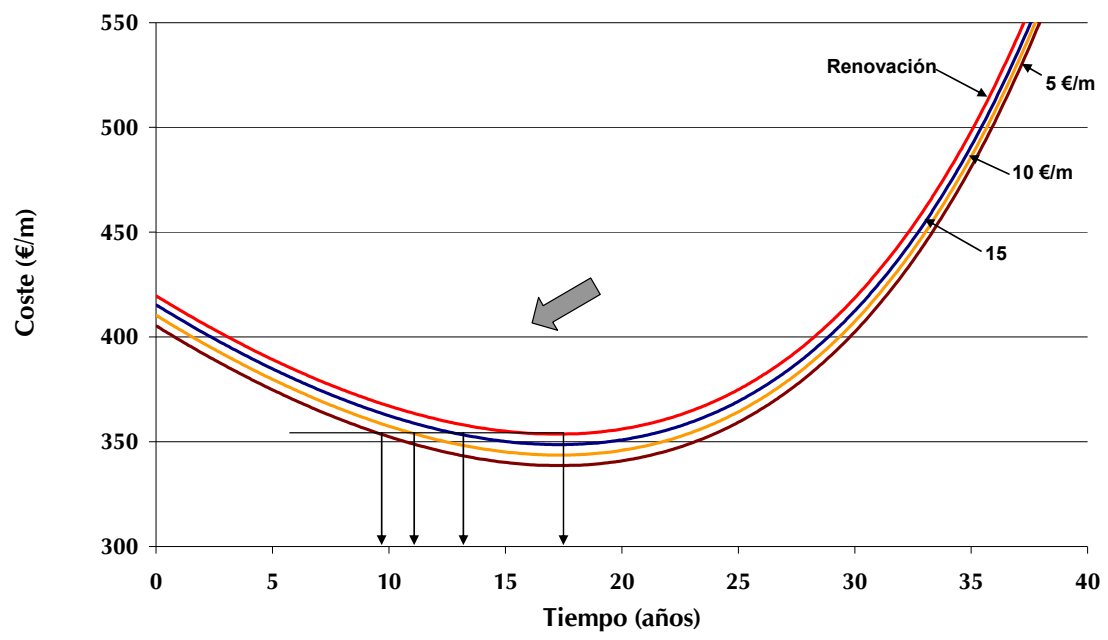

FIGURA 74. REPERCUSIÓN TEMPORAL DEL AHORRO CONSECUENCIA DE LA OPORTUNIDAD.

\subsubsection{Influencia de la técnica empleada para realizar la renovación}

Para cuantificar la influencia del tipo de técnica utilizado sobre el periodo óptimo de renovación, se utilizan los términos de inversión y mantenimiento calculados anteriormente, se emplea la ecuación (5.1), con los siguientes resultados.

TABLA 53. PeRIODO ÓPTIMO DE RENOVACIÓN SEGÚN LA TÉCNICA EMPLEADA (€ DEL AÑO EN CURSO)

\begin{tabular}{ccc}
\hline Técnica & $t_{r_{j}}^{*}($ años$)$ & $\boldsymbol{C}_{T}\left(t_{r_{j}}^{*}\right)(\boldsymbol{€} / \mathbf{m})$ \\
\hline Tradicional & 17.3 & 353.6 \\
Rotura por percusión & 14.3 & 273.0 \\
Rotura con sistema hidráulico & 15.1 & 292.5 \\
Entubado por deslizamiento & 15.2 & 295.4 \\
Perforación horizontal dirigida & 23.0 & 568.4 \\
\hline
\end{tabular}

Y la representación gráfica de la evolución de los costes de renovación para cada año a partir del actual se muestra en la Figura 75. 


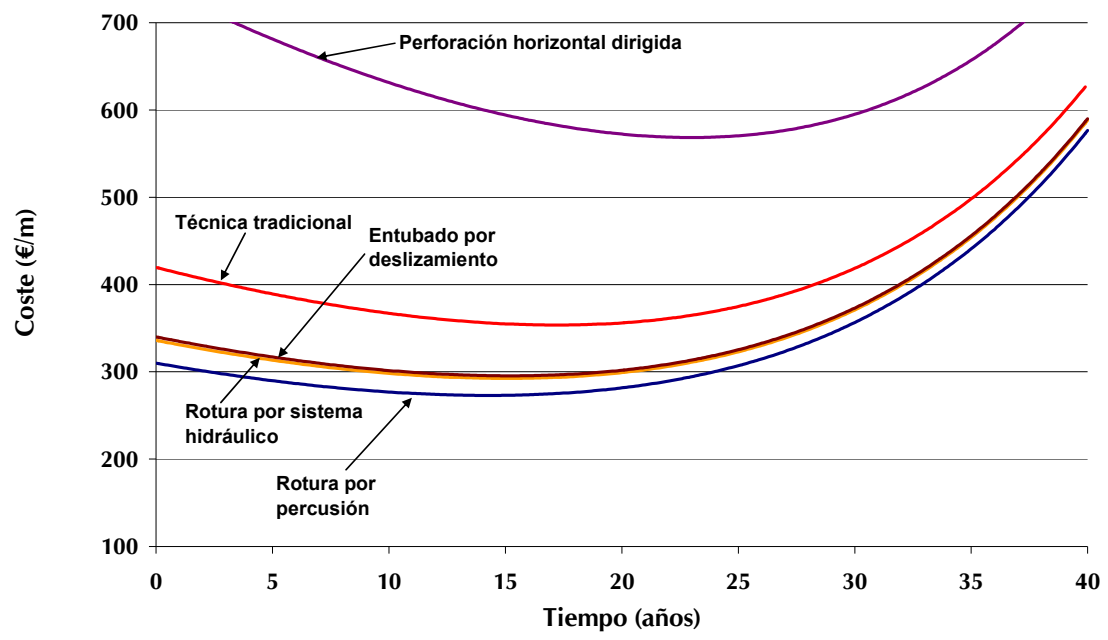

FIGURA 75. REPRESENTACIÓN DE LOS COSTES TOTALES ASOCIADOS A LA RENOVACIÓN DE UNA TUBERÍA PARA LAS DIFERENTES TÉCNICAS.

En la Figura 75 se observa que las técnicas que tienen una menor inversión, muestran un periodo óptimo de renovación menor. Obviamente, si el coste de sustitución es menor, la misma se anticipará. Por el contrario, las técnicas que requieren una mayor inversión alargarán la decisión de la renovación.

Éste análisis del efecto de la técnica realmente considera el efecto de la variación de los costes $C_{r_{j}}$ y $C_{s_{j}}$ ya que en definitiva, si se utiliza una nueva técnica, los costes de realización de la obra y los costes sociales asociados a la misma son los únicos que varían en el proceso de obtención del periodo óptimo de renovación. Para reforzar esta idea, el término de mantenimiento $(M)$ es exactamente el mismo para todas las técnicas seleccionadas y en la parte derecha de la Figura 75 (aquél en propio de valores elevados de tiempo), las curvas muestran un comportamiento similar, ya que en esa zona los costes de mantenimiento predominan sobre los de inversión. 


\subsubsection{Influencia del coste del agua}

La variación del coste del agua influye de manera muy significativa en el periodo óptimo de renovación, tal y como se muestra en la Figura 76. El periodo óptimo de renovación puede ser de 18.6 años si el coste de producción del agua es de $0.1 € / \mathrm{m}^{3}$ y reducirse a 15.2 años si el valor del agua es de $0.4 € / \mathrm{m}^{3}$.

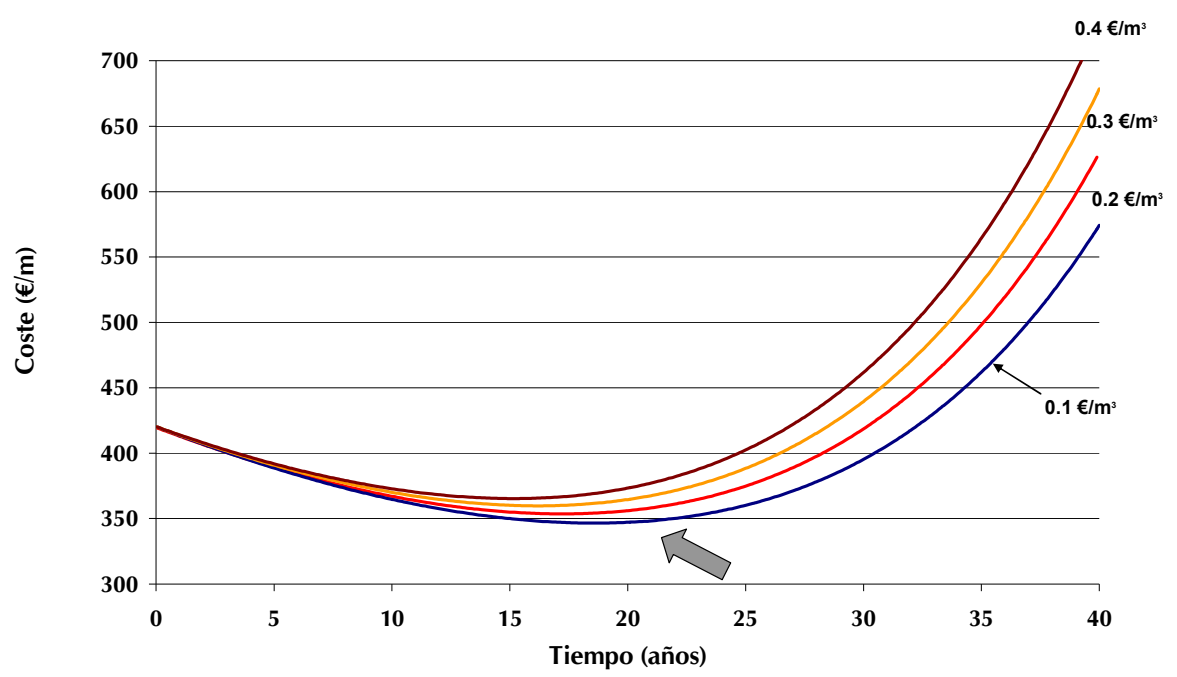

FIGURA 76. EVOLUCIÓN DE LA CURVA DE COSTES TOTALES SEGÚN EL PRECIO DE PRODUCCIÓN DEL AGUA

El aumento de este coste modifica los valores del término de mantenimiento y en consecuencia el periodo óptimo de renovación (Tabla 54).

TABLA 54. RELACIÓN ENTRE EL COSTE DEL AGUA Y EL PERIODO ÓPTIMO DE RENOVACIÓN.

\begin{tabular}{cccc}
\hline Coste del agua $(€ / \mathbf{m})$ & $M$ & $t_{r_{j}}^{*}$ & $C_{T}\left(t_{r_{j}}^{*}\right)$ \\
\hline 0.1 & 2359.4 & 18.6 & 346.5 \\
0.2 & 2679.4 & 17.3 & 353.6 \\
0.3 & 2999.4 & 16.2 & 359.8 \\
0.4 & 3319.4 & 15.2 & 365.3 \\
\hline
\end{tabular}

El término $C_{31}$ se ve afectado por la variación del coste unitario variable de producción del agua. Este término es creciente con el tiempo tal y como se observa en la Figura 77. 


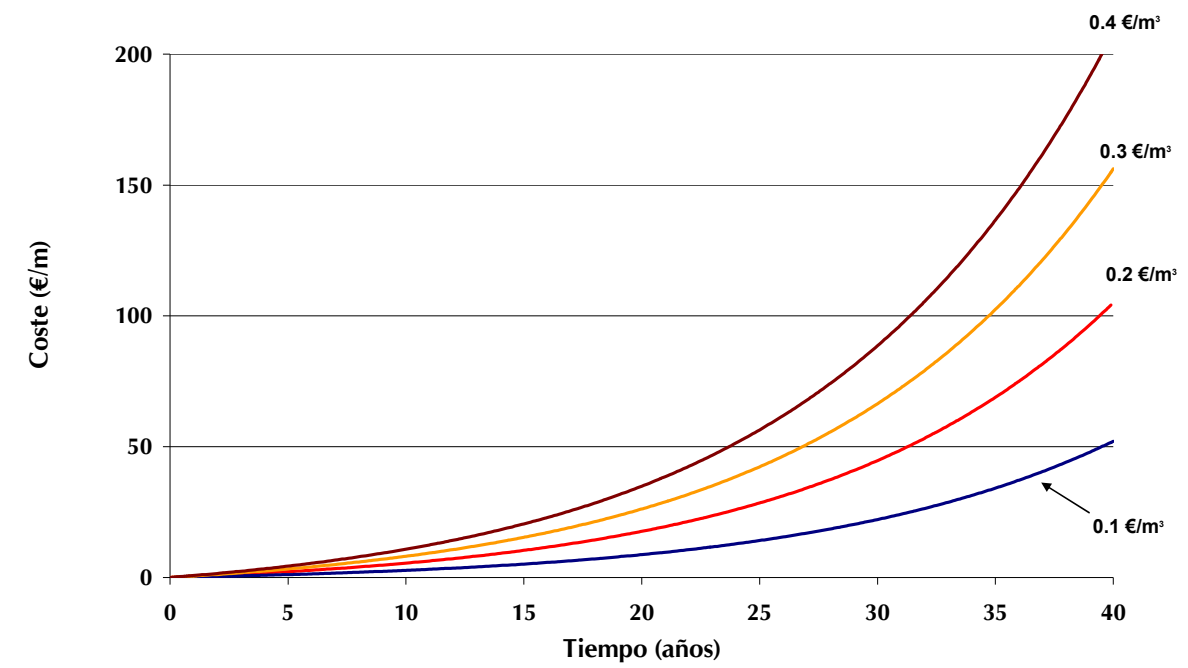

FIGURA 77. COSTE ASOCIADO A LAS PÉRDIDAS DE AGUA POR FUGAS SEGÚN VARIACIÓN DEL COSTE DEL AGUA.

\subsubsection{Influencia de la huella energética del agua}

Para comprobar esta influencia, se modifica el coste energético del agua para los valores de 0.05 y $0.3 € / \mathrm{m}^{3}$ (Figura 78). El efecto de dicha variación se traduce en nuevos valores del término de mantenimiento y del coste total de la renovación (Tabla 55).

TABLA 55. RELACIÓN ENTRE LA HUELLA ENERGÉTICA DEL AGUA Y EL PERIODO ÓPTIMO DE RENOVACIÓN.

\begin{tabular}{cccc}
\hline $\begin{array}{c}\text { Coste energético del agua } \\
(\boldsymbol{(} / \mathbf{m})\end{array}$ & $M$ & $t_{r_{j}}^{*}$ & $C_{T}\left(t_{r_{j}}^{*}\right)$ \\
\hline 0.05 & 2519.4 & 17.9 & 350.2 \\
0.1 & 2679.4 & 17.3 & 353.6 \\
0.2 & 2999.4 & 16.2 & 359.8 \\
0.3 & 3319.4 & 15.2 & 365.3 \\
\hline
\end{tabular}

La variación del coste energético del agua $\left(C_{W E}\right)$ produce el mismo efecto en el periodo óptimo de renovación que el aumento de los costes del agua $\left(c_{w}\right)$, ya que ambos afectan del mismo modo al término de mantenimiento $(M)$ (ecuación 5.3; Tabla 54 y Tabla 55). 


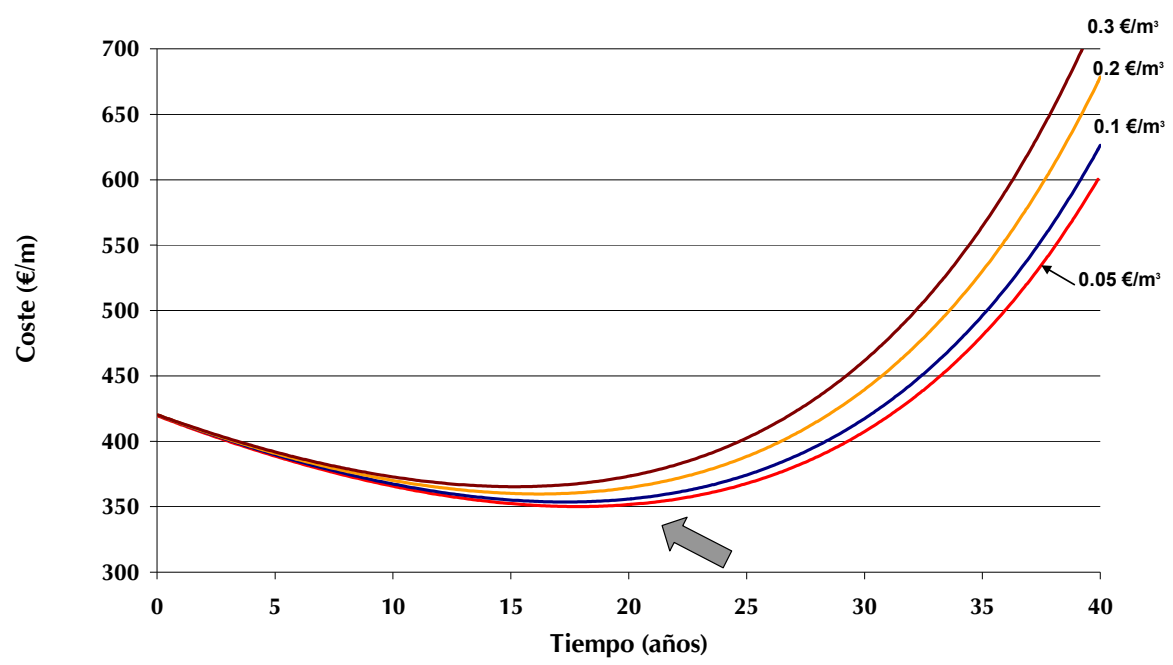

FIGURA 78. EVOLUCIÓN DE LA CURVA DE COSTES TOTALES SEGÚN EL COSTE ENERGÉTICO DE PRODUCCIÓN DEL AGUA

En cambio, el término relativo a la energía extra consumida en la red de distribución $\left(C_{32 b}\right)$ no produce un efecto significativo en la modificación del periodo óptimo de renovación, tal y como se justificó anteriormente. Los parámetros que fueron desechados tras el análisis son los pertenecientes exclusivamente a éste.

\subsubsection{Influencia del caudal medio unitario por fuga}

El caudal medio fugado por una rotura es directamente proporcional tanto a la cantidad de agua como la de energía perdida en una fuga. Por tanto, la variación de este término produce mayores variaciones del término de mantenimiento (que, por ejemplo, los costes del agua y de la energía analizados anteriormente) y en consecuencia, del periodo óptimo de renovación (Tabla 56 y Figura 79).

TABLA 56. RELACIÓN ENTRE EL CAUDAL MEDIO DE FUGAS Y EL PERIODO ÓPTIMO DE RENOVACIÓN.

\begin{tabular}{|c|c|c|c|}
\hline $\begin{array}{l}\text { Caudal medio fugado } \\
\qquad\left(\mathrm{m}^{3} / \mathrm{d} i ́ a\right)\end{array}$ & $M$ & $t_{r_{j}}^{*}$ & $C_{T}\left(t_{r_{j}}^{*}\right)$ \\
\hline 10 & 2180.3 & 19.4 & 342.1 \\
\hline 20 & 2679.4 & 17.3 & 353.6 \\
\hline 30 & 3178.5 & 15.6 & 363.0 \\
\hline
\end{tabular}




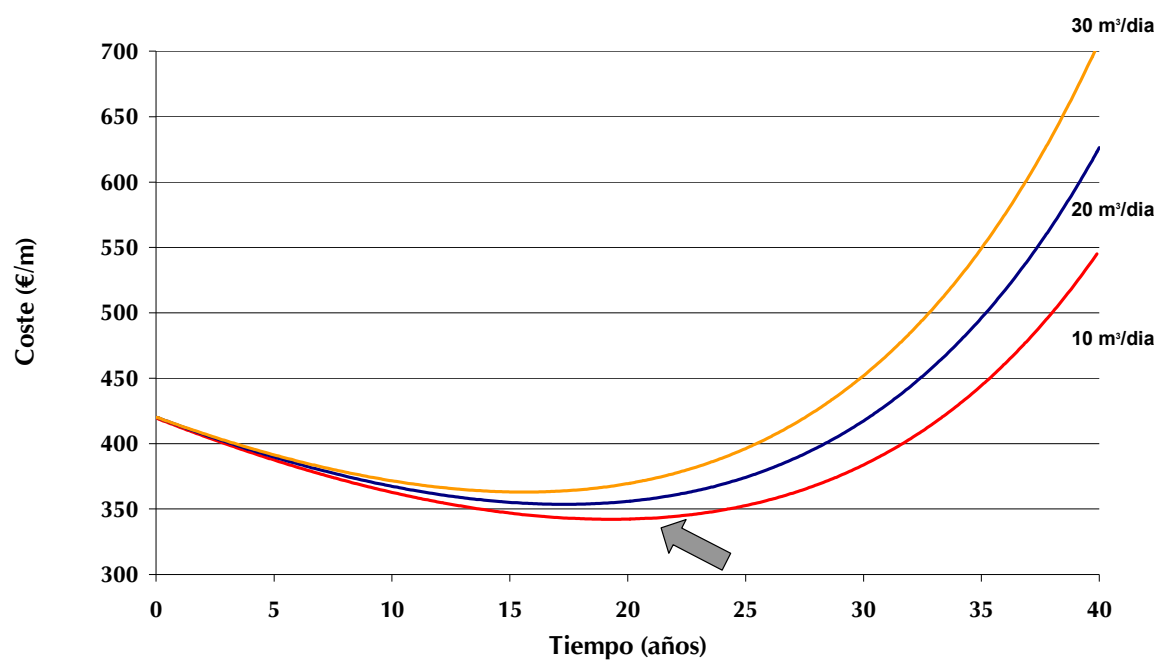

FIGURA 79. EVOLUCIÓN DE LA CURVA DE COSTES TOTALES SEGÚN EL CAUDAL MEDIO UNITARIO POR FUGA.

\subsubsection{Influencia del tiempo medio de actividad de la fuga}

Al igual que el término anterior, el tiempo medio de actividad de la fuga influye sobre la cantidad de agua y energía que se pierde en una fuga. Este término adquiere especial relevancia por ser uno de los que puede ser modificado por la gestión y operación del sistema, ya que depende directamente de cuán frecuentes son las inspecciones de la red (a mayor número de inspecciones, el tiempo medio de vida de la fuga será menor). Los valores del término de mantenimiento y del periodo óptimo de renovación se muestran a continuación (Tabla 57 y Figura 80).

TABLA 57. RELACIÓN ENTRE EL CAUDAL MEDIO DE FUGAS Y EL PERIODO ÓPTIMO DE RENOVACIÓN.

\begin{tabular}{cccc}
\hline $\begin{array}{c}\text { tiempo medio de actividad } \\
\text { de la fuga (días) }\end{array}$ & $M$ & $t_{r_{j}}^{*}$ & $C_{T}\left(t_{r_{j}}^{*}\right)$ \\
\hline 90 & 2242.7 & 19.1 & 343.7 \\
120 & 2429.9 & 18.3 & 348.2 \\
160 & 2679.4 & 17.3 & 353.6 \\
200 & 2929 & 16.4 & 358.5 \\
\hline
\end{tabular}




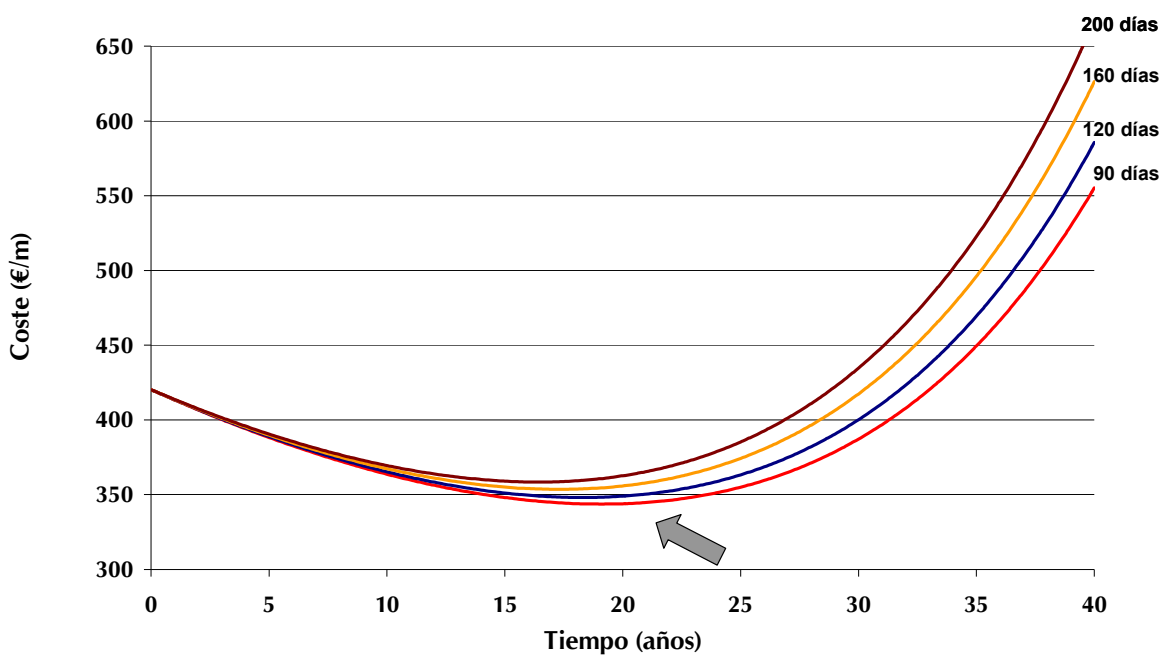

Figura 80. EVOLUCIÓN DE LA CURVA DE COSTES TOTALES SEGÚN ELTIEMPO MEDIO DE ACTIVIDAD DE LA FUGA.

El resultado no depara sorpresas. Si el tiempo que la fuga está activa es mayor, el coste del agua y la energía fugada también lo será (y consecuentemente mayor valor del término de mantenimiento) por lo que se anticipa la sustitución de la tubería.

\subsubsection{Influencia de la tasa continua de actualización equivalente}

La tasa continua de actualización equivalente, como ya se comentó con anterioridad, permite representar una unidad monetaria en distinta escala temporal. De tal forma, que mayores valores de ésta se relacionen con una menor importancia del dinero futuro y por tanto, menos se valora en comparación con el actual. Para tasas continuas de actualización equivalentes bajas, los términos de mantenimiento reflejan una mayor magnitud (ya que todos dependen del número de roturas que evoluciona con el tiempo) ya que en los instantes iniciales del cálculo representan valores bajos.

Este parámetro no modifica el valor del término de inversión ni de mantenimiento, aunque sí que afecta directamente al periodo óptimo de renovación y al coste mínimo. Estos valores se obtienen analíticamente y muestran los valores mostrados por la Tabla 58, que se traducen en los valores mostrados en la Figura 82. 
TABLA 58. RELACIÓN ENTRE LA TASA CONTINUA DE ACTUALIZACIÓN Y EL PERIODO ÓPTIMO DE RENOVACIÓN.

\begin{tabular}{ccc}
\hline $\boldsymbol{r}(\%)$ & $t_{r_{j}}^{*}$ & $C_{T}\left(t_{r_{j}}^{*}\right)$ \\
\hline 2 & 17.3 & 353.6 \\
2.5 & 19.5 & 325.1 \\
3 & 21.3 & 296.8 \\
3.5 & 22.8 & 285.8 \\
4 & 24.1 & 275.1 \\
\hline
\end{tabular}

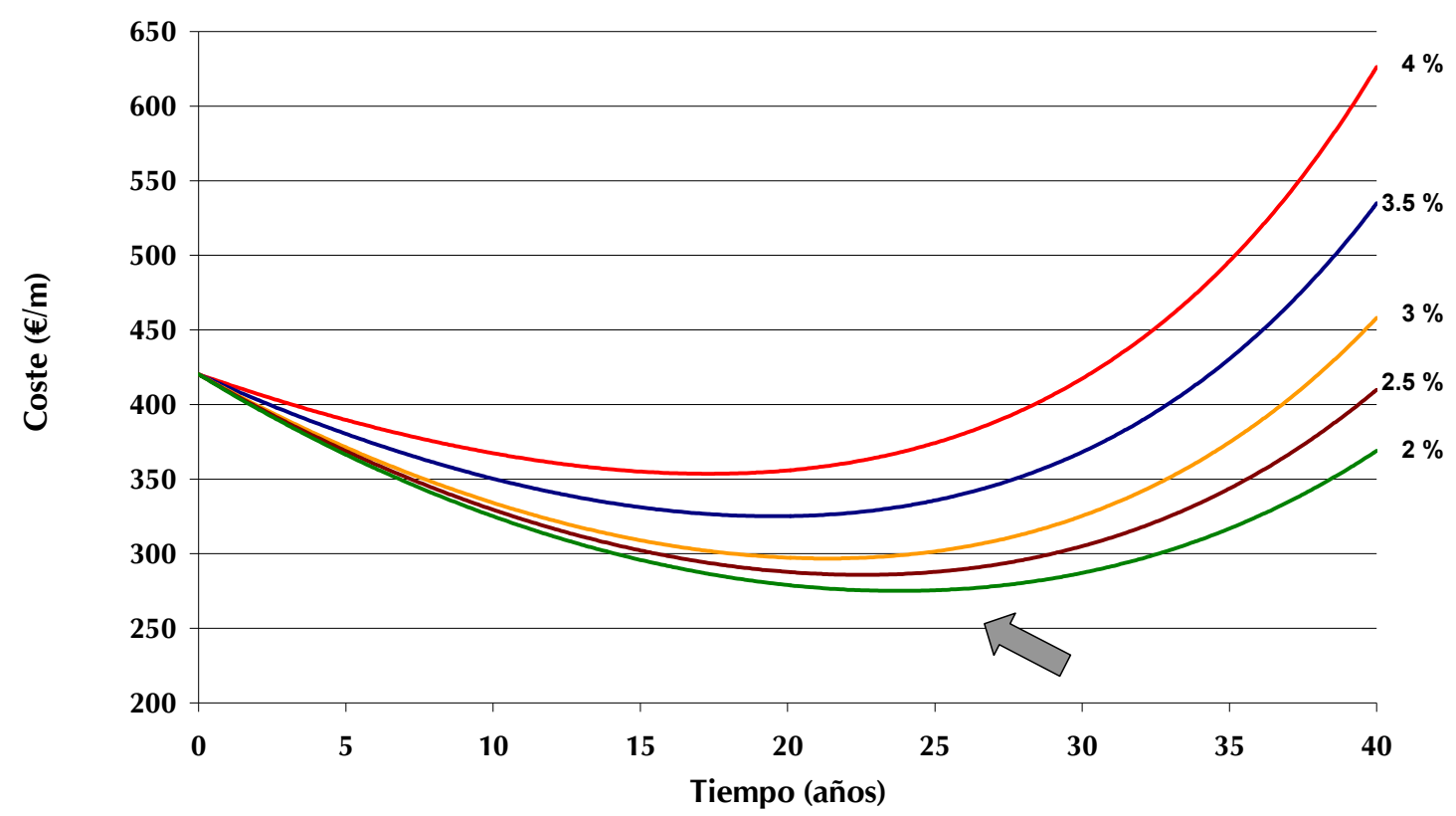

FIGURA 81. REPERCUSIÓN DE LA VARIACIÓN DE LA TASA CONTINUA DE ACTUALIZACIÓN EQUIVALENTE. 


\subsubsection{Influencia del coeficiente de crecimiento de roturas}

Finalmente se analiza la influencia del índice de crecimiento de roturas. Al no ser modificable, su estudio se entiende como la valoración de las características de la instalación a estudiar. Según la preponderancia de unos materiales u otros, o por las características de la instalación, se obtiene un patrón de roturas que interviene de manera muy importante en la determinación del periodo óptimo de renovación. La Figura 82, representa tres situaciones en las que se observa la influencia del parámetro del crecimiento de roturas.

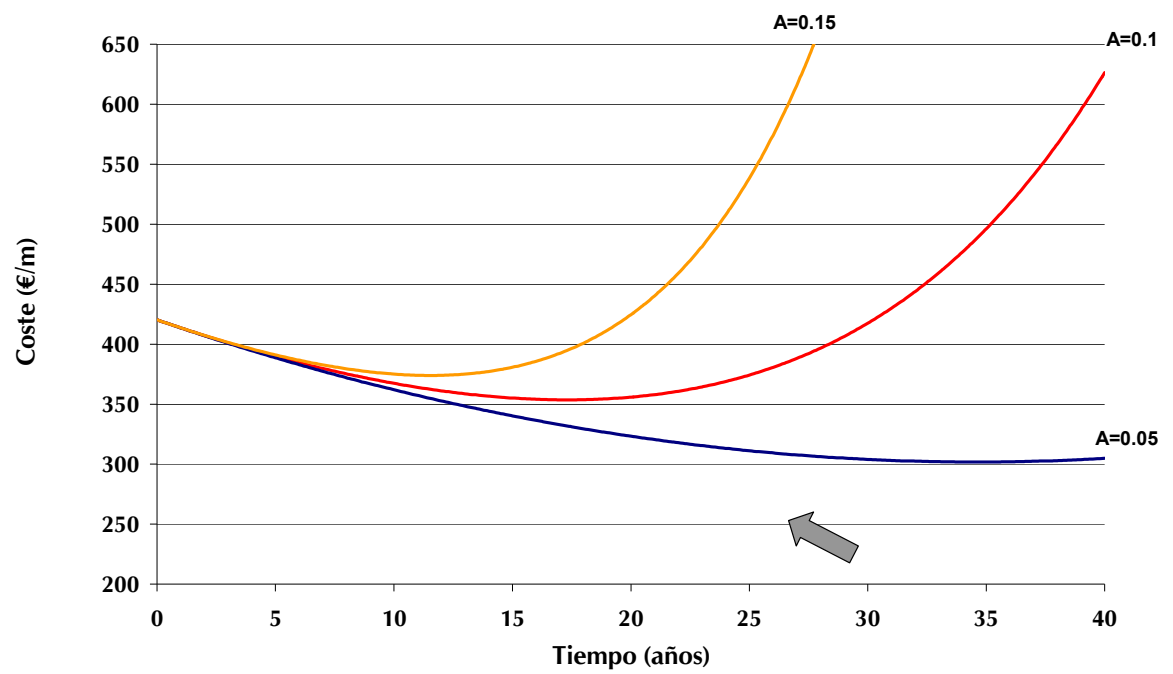

FIGURA 82. VARIACIÓN DEL COSTE MÍNIMO TOTAL EN FUNCIÓN DEL INDICE DE CRECIMIENTO DEL NÚMERO DE ROTURAS.

La Figura 82 subraya que este término es el más significativo ya que produce una mayor variación del periodo óptimo de renovación (con la flecha se indica gráficamente la variación del coste mínimo para los casos considerados). No en vano, afecta a todos los términos de mantenimiento (reparaciones, agua y energía perdida en fugas). Los valores de los óptimos de renovación se muestran a continuación (Tabla 59).

TABLA 59. RELACIÓN ENTRE EL COEFICIENTE DE CRECIMIENTO DE ROTURAS Y EL PERIODO ÓPTIMO DE RENOVACIÓN.

\begin{tabular}{ccc}
\hline $\mathbf{A}\left(\mathbf{a n ̃ o s}^{-1}\right)$ & $t_{r_{j}}^{*}$ & $C_{T}\left(t_{r_{j}}^{*}\right)$ \\
\hline 0.05 & 34.6 & 301.8 \\
0.10 & 17.3 & 353.6 \\
0.15 & 11.5 & 374.0 \\
\hline
\end{tabular}




\subsubsection{Desarrollo de los cálculos para las infinitas renovaciones}

El punto de partida para este cálculo son los términos de inversión y mantenimiento expresados en la Tabla 52. Con éstos se puede calcular el coste asociado a las infinitas renovaciones con la técnica j variando el tiempo que transcurre entre renovaciones. Este cálculo considera la hipótesis de que la tubería está recién instalada en el año actual y la primera renovación que se debe realizar se hará en el año tr, (objetivo de estos cálculos).

$C_{\text {inf }}\left(t_{r}\right)=\frac{l_{j} \cdot e^{-r \cdot T_{t j}}+\int_{0}^{T_{t_{j}}} M \cdot N\left(t_{0}\right) \cdot \exp \left(A \cdot\left(t-t_{0}\right)\right) \cdot e^{-r \cdot t} \cdot d t}{1-e^{-r T_{t j}}}$

En la Figura 83 se pueden observar los instantes de tiempo en los que se obtiene un coste mínimo para cada una de las técnicas.

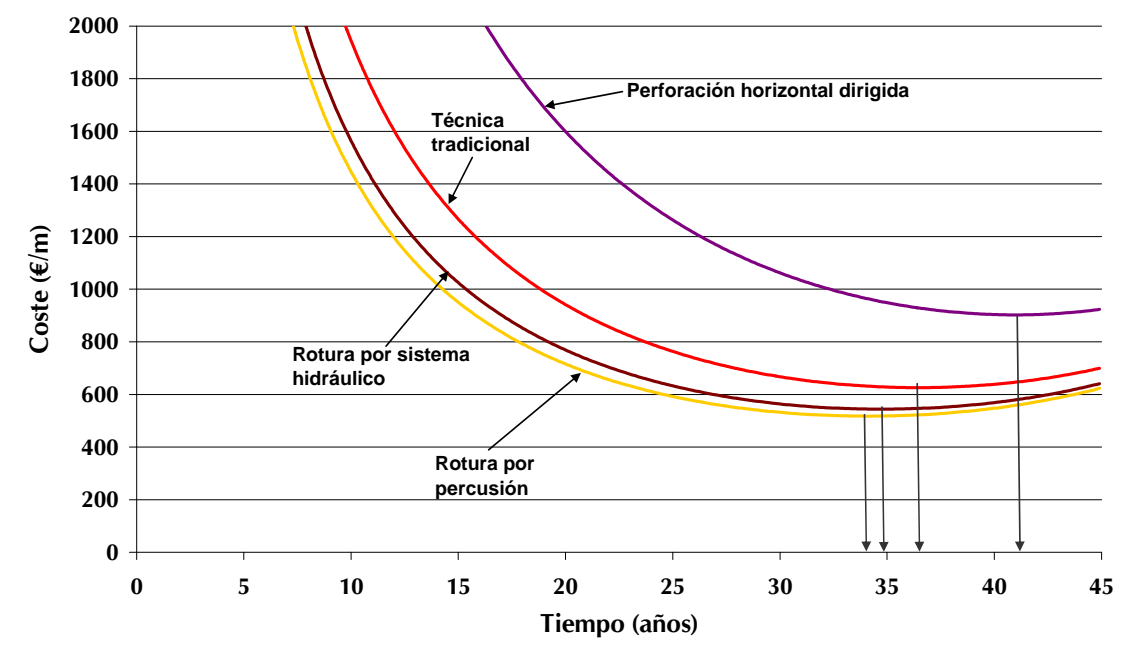

FIGURA 83. COSTES DE LAS INFINITAS RENOVACIONES EN UNA CONDUCCIÓN SEGÚN DISTINTOS TIPOS DE TÉCNICA.

A partir del coste total mínimo asociado al ciclo de renovaciones de las tuberías expresado en $€$ del año en el que se realiza la primera renovación $t_{r}$, se obtiene la duración óptima $T_{t_{j}}^{* *}$ que se muestra en la Tabla 60. 
TABLA 60. PERIODO ÓPTIMO Y COSTE TOTAL ASOCIADO A LAS INFINITAS RENOVACIONES DE UNA TUBERÍA (EXCEPTO LA PRIMERA) Y SEGÚN LAS J TÉCNICAS CONSIDERADAS (€/M DEL AÑO TR)

\begin{tabular}{ccc}
\hline Técnica & $T_{t_{j}}^{* *}$ & $C_{\text {inf }}\left(T_{t_{j}}^{* *}\right)$ \\
\hline Tradicional & 36.5 & 625.9 \\
Rotura por percusión & 34.2 & 517.4 \\
Rotura con sistema hidráulico & 34.8 & 543.9 \\
Entubado por deslizamiento & 34.9 & 548.0 \\
Perforación horizontal dirigida & 41.1 & 902.5 \\
\hline
\end{tabular}

En caso de que se parta de una situación en la que se acaba de renovar la conducción, el análisis económico completo sería el anterior (Tabla 60). Si se renueva empleando el método clásico cada renovación individual tendría un coste de $322.1 €^{41} / \mathrm{m}$ y la distribución temporal de los costes asociados a las infinitas renovaciones de una tubería de polietileno sería la mostrada en la Figura 84.

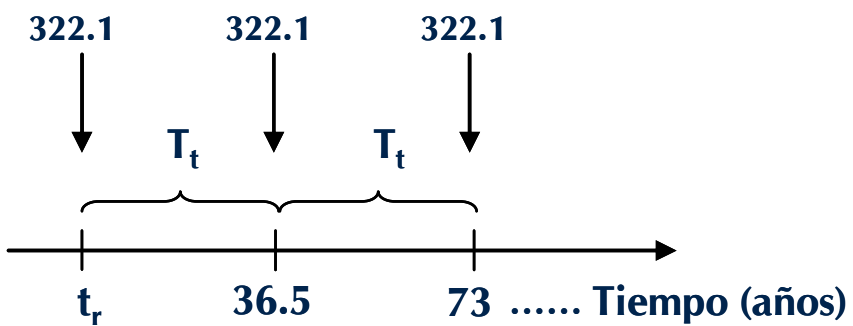

FIGURA 84. DISTRIBUCIÓN TEMPORAL DE COSTES DE RENOVACIÓN SI SE PARTE DE UNA SITUACIÓN CON TUBERÍA NUEVA Y TÉCNICA TRADICIONAL CON APERTURA DE ZANJA.

En este caso, la vida de la tubería entre renovaciones sería de 36.5 años. Si se trasladan los costes de las infinitas renovaciones al año $t_{r}$, se obtiene, como no puede ser de otro modo, el valor mostrado en la Tabla 60 para dicha técnica.

$C_{\text {inf }}\left(T_{t_{j}}^{* \star}\right)=322.1+322.1 \cdot e^{-36.5 \cdot r}+322.1 \cdot e^{-2 \cdot(36.11 \cdot r)}+\ldots \ldots . .=625.9 € / \mathrm{m}$

Sin embargo, en esta aplicación numérica, se parte de una red de abastecimiento que se encuentra en un año determinado, con un número de roturas distinto del existente en el año to. Por tanto, el coste y el instante en el que se produce la primera renovación son diferentes que en las restantes. El coste de todas se calcula como:

\footnotetext{
${ }^{41}$ En euros del año en que se produce la renovación.
} 
$C_{T}\left(t_{r}\right)=I_{j} \cdot e^{-r \cdot T_{f j}}+\int_{0}^{T_{t_{j}}} M \cdot N\left(t_{0}\right) \cdot \exp \left(A \cdot\left(t-t_{0}\right)\right) \cdot e^{-r \cdot t} \cdot d t+C_{\text {inf }}\left(T_{t_{j}}^{* *}\right) \cdot e^{-r \cdot T_{f j}}$

Y en este punto, sólo queda encontrar el valor de $t_{r_{j}}^{*}$ que minimiza el coste total de todas las renovaciones derivando la ecuación anterior e igualando a cero (Tabla $61)$.

Tabla 61. Periodo óptimo y COSte total asociado al CiClo de RENOVACIONES DE UNA tUbería SEGÚN LAS J TÉCNICAS EMPLEADAS (€/M DEL AÑO TP)

\begin{tabular}{ccc}
\hline Técnica $^{42}$ & $t_{r_{j}}^{*}$ & $C_{T}\left(t_{r_{j}}^{*}\right)$ \\
\hline Tradicional & 26.4 & 754.2 \\
Rotura por percusión & 24.1 & 622.1 \\
Rotura con sistema hidráulico & 24.7 & 654.4 \\
Perforación horizontal dirigida & 31.0 & 1093.3 \\
\hline
\end{tabular}

La distribución temporal de los costes asociados a las infinitas renovaciones de una tubería mediante la técnica tradicional considerando el estado actual de la red se puede ver en la Figura 85. En ella se observa que el coste de la primera renovación presenta un valor en el año presente de $383.3 € / \mathrm{m}$ (que es el coste asociado a la renovación de la tubería dentro de 26.4 años en $€$ del año presente) y a ese coste se debe añadir el coste de las infinitas renovaciones posteriores (todas excepto la primera) que tenían un valor de $625.9 € / \mathrm{m}$ del año tr. Se observa que como se está calculando el año en el que se produce la primera renovación, el año tr es una variable más.

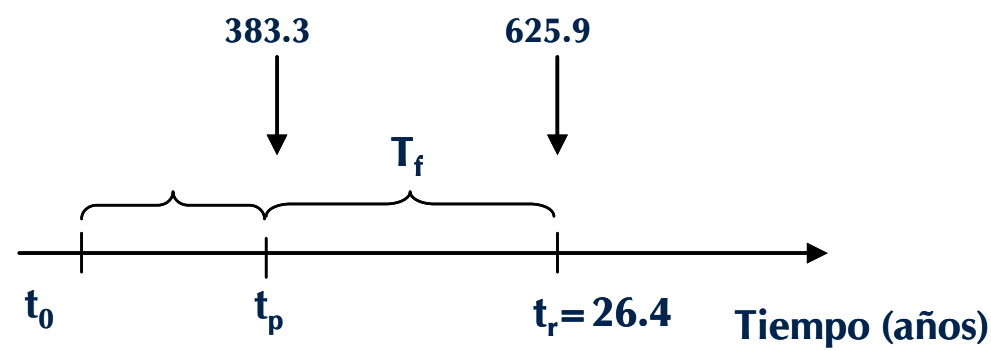

FIGURA 85. DISTRIBUCIÓN TEMPORAL DE COSTES DE RENOVACIÓN CON LA TÉCNICA TRADICIONAL. CASO HABITUAL EN EL CUAL SE COMIENZA CON UNA RED QUE SE ENCUENTRA EN UN ESTADO DETERMINADO.

\footnotetext{
${ }^{42}$ La técnica de entubado por deslizamiento no se puede utilizar sucesivamente y la obtención del periodo óptimo de renovación se calcula de modo diferente. Éste se detalla en el apartado 4.3.
} 
Cuando se trasladan todos los costes al año presente, se obtiene el coste de las infinitas renovaciones con la técnica tradicional con apertura de zanja de una tubería en una red de abastecimiento (con un valor idéntico al mostrado en la Tabla 61):

$C_{T}\left(t_{r_{j}}^{\star}\right)=383.3+625.9 \cdot e^{-26.4 \cdot r}=754.2 € / \mathrm{m}$

Si se representa la evolución temporal de los costes totales de las infinitas renovaciones de una tubería, se obtiene:

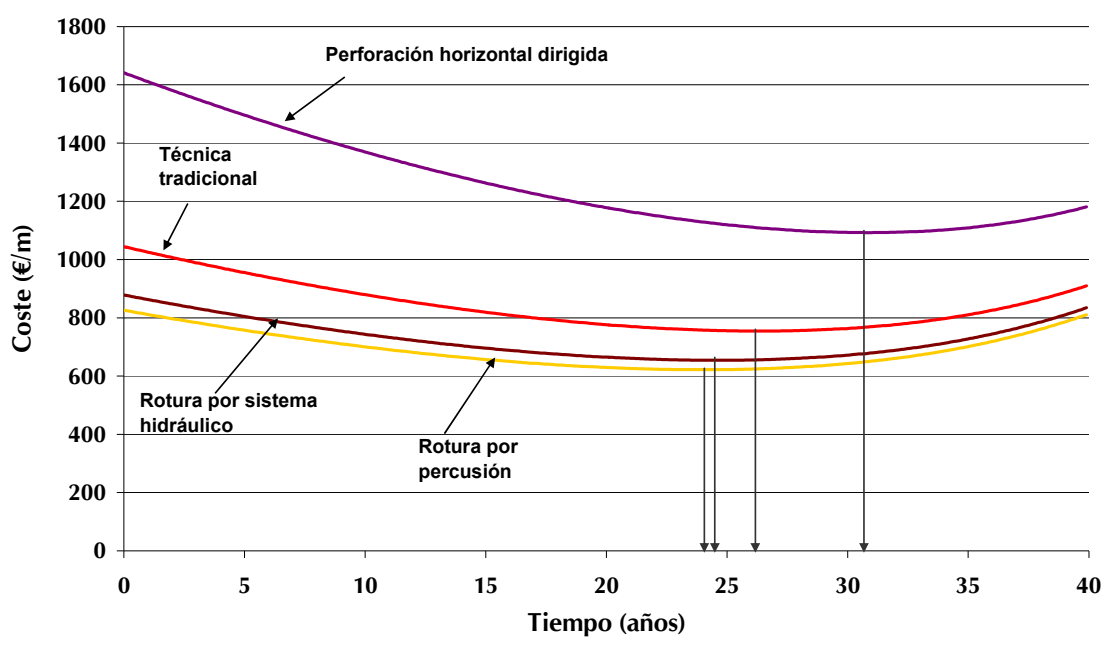

FIGURA 86. COSTES TOTALES (€/M) ASOCIADOS A LAS INFINITAS RENOVACIONES PARA LAS J TÉCNICAS. 


\subsubsection{Tratamiento de los costes de aparición ocasional}

Los costes sociales generados por la pérdida de estándares se integran en la estructura de costes a partir del año $t_{s}=10$ años $\left(t_{s}<t_{r}\right)$. El periodo de renovación disminuye tal y como se refleja en la Figura 55 (particularizado para el caso de la instalación de una tubería mediante la técnica tradicional con apertura de zanja). La penalización supuesta provoca una disminución del año óptimo de renovación que queda en $t_{r}=25.2$ años y con un coste asociado sensiblemente mayor, 781.9 $€ / m$.

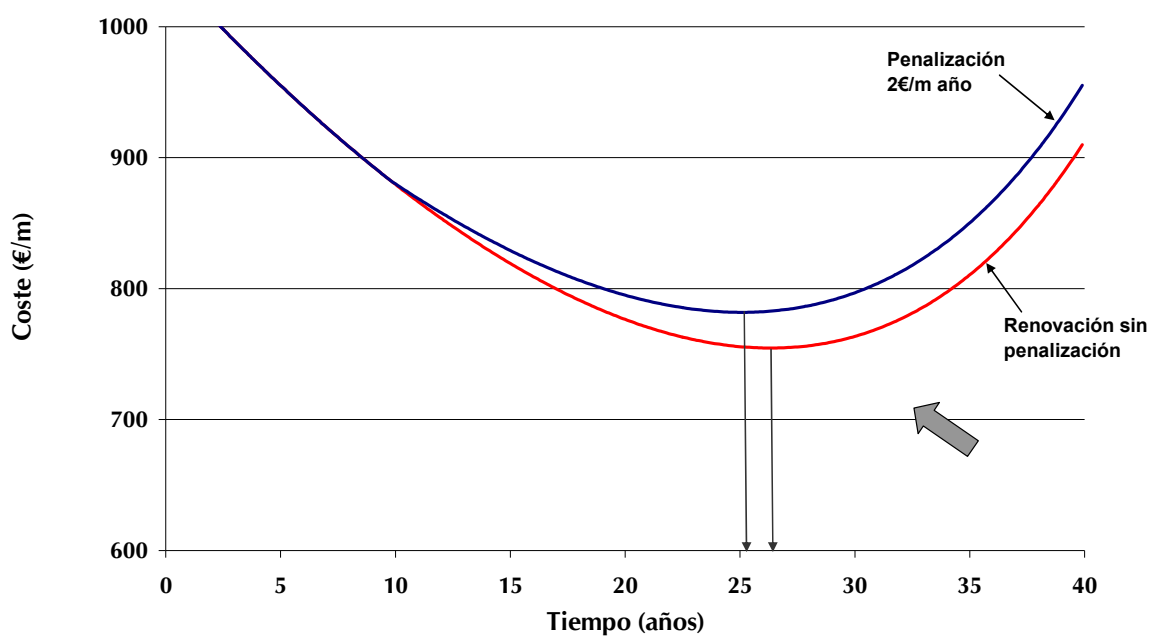

FIGURA 87. VARIACIÓN DEL COSTE TOTAL CUANDO SE INCUMPLEN LOS ESTÁNDARES DE SERVICIO A PARTIR DEL DÉCIMO AÑO PARA EL CASO DE LAS INFINITAS RENOVACIONES.

En el caso del coste de oportunidad, éste interviene sólo si la obra se ejecuta el año $t_{c}$, con $t_{c}<t_{r}$ ) la curva de costes (Figura 88) se desplaza verticalmente y en sentido descendente un valor igual al coste de oportunidad negativo $C_{5}$. La comparación entre las curvas desplazadas (para distintos valores de $C_{5}$ ) y la original indica a partir de cuántos años es razonable anticipar la obra. Y así, para un ahorro de $5 € / m$, convendría anticipar la obra si la oportunidad sucede entre los 23.5 y los 26.4 años. Valores mayores $\left(C_{5}=10\right.$ ó $\left.15 € / \mathrm{m}\right)$ aumentan el periodo de tiempo en el cual resulta conveniente anticipar la renovación (desde los 21.2 ó 19 hasta los 26.4 años respectivamente). 


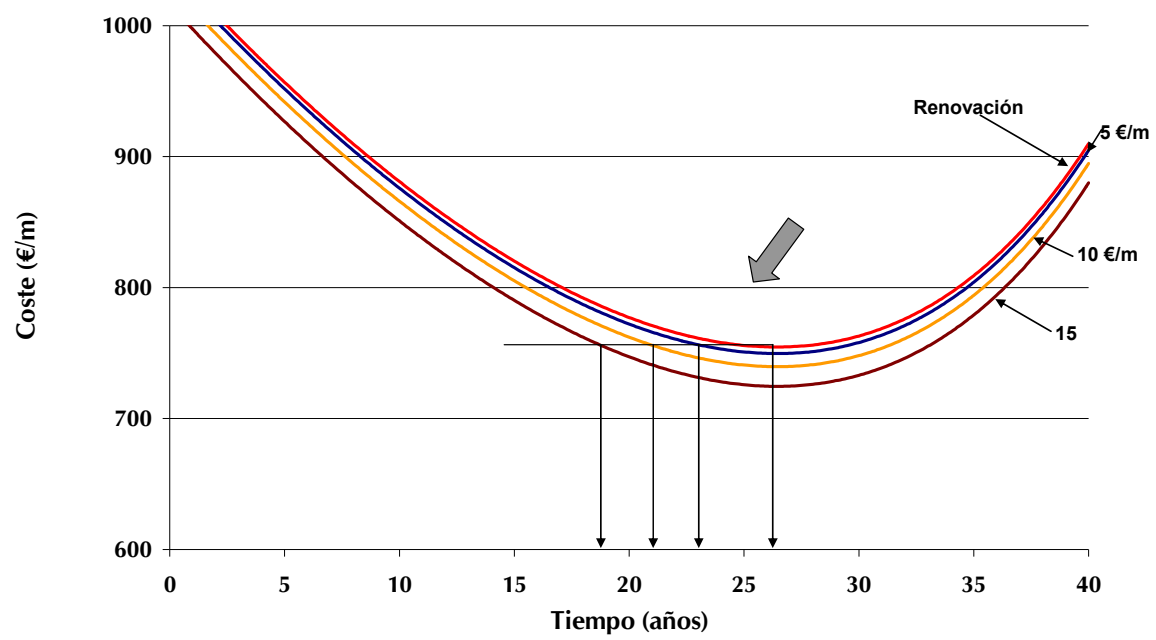

FIGURA 88. REPERCUSIÓN TEMPORAL DEL AHORRO CONSECUENCIA DE LA OPORTUNIDAD PARA EL CASO DE LAS INFINITAS RENOVACIONES.

\subsubsection{Influencia del coste del agua}

Para observar cómo influye el coste del agua en el óptimo de renovación, se varía el primero entre los valores de 0.1 y $0.4 € / \mathrm{m}^{3}$ y se obtienen valores de 27.4 y 24.8 años respectivamente. El aumento de este coste provoca una reducción en el periodo óptimo de renovación (Figura 89 y Tabla 62).

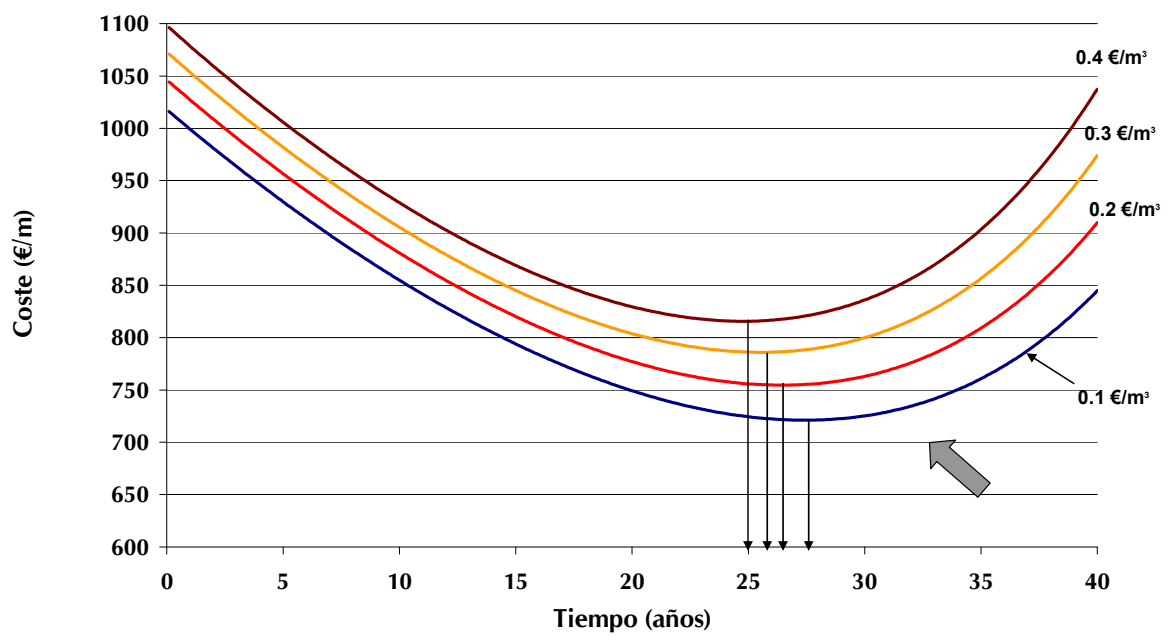

FIGURA 89. EVOLUCIÓN DE LA CURVA DE COSTES TOTALES SEGÚN EL PRECIO DE PRODUCCIÓN DEL AGUA PARA EL CASO DE LAS INFINITAS RENOVACIONES. 
TABLA 62. RELACIÓN ENTRE EL COSTE DEL AGUA Y EL PERIODO ÓPTIMO DE RENOVACIÓN PARA EL CASO DE LAS INFINITAS RENOVACIONES.

\begin{tabular}{ccc}
\hline $\begin{array}{c}\text { Coste del agua } \\
(\boldsymbol{(} / \mathbf{m})\end{array}$ & $t_{r_{j}}^{*}$ & $C_{T}\left(t_{r_{j}}^{*}\right)$ \\
\hline 0.1 & 27.4 & 720.7 \\
0.2 & 26.4 & 754.2 \\
0.3 & 25.6 & 786.5 \\
0.4 & 24.8 & 816.0 \\
\hline
\end{tabular}

El cálculo de este óptimo así como del coste total lleva una serie de cálculos intermedios que no se muestran por simplicidad en el ejemplo. Al igual que en el apartado 5.4.2, cada valor de $C_{W}$ tiene un valor de $M$ distinto, así como sus propios valores de $T_{t_{j}}^{* *}$ y $C_{\text {inf }}\left(T_{t_{j}}^{* *}\right)$. Esta situación se trata igualmente en todos los apartados siguientes hasta el 5.4.3.

\subsubsection{Influencia de la huella energética del energía}

Si se modifican los valores de la huella energética del agua definida en el rango 0.05 y $0.3 € / \mathrm{m}^{3}$, se obtienen los valores mostrados por la Tabla 63 y la Figura 78 .

TABLA 63. RELACIÓN ENTRE LA HUELLA ENERGÉTICA DEL AGUA Y EL PERIODO ÓPTIMO DE RENOVACIÓN PA
\begin{tabular}{ccc} 
DE LAS INFINITAS RENOVACIONES \\
$\qquad \begin{array}{ccc}\text { Coste energético del agua } \\
(€ / \mathbf{m})\end{array}$ & $t_{r_{j}}^{*}$ & $C_{T}\left(t_{r_{j}}^{*}\right)$ \\
\hline 0.05 & 26.9 & 737.9 \\
0.1 & 26.4 & 754.2 \\
0.2 & 25.6 & 786.5 \\
0.3 & 24.8 & 816.0 \\
\hline
\end{tabular}




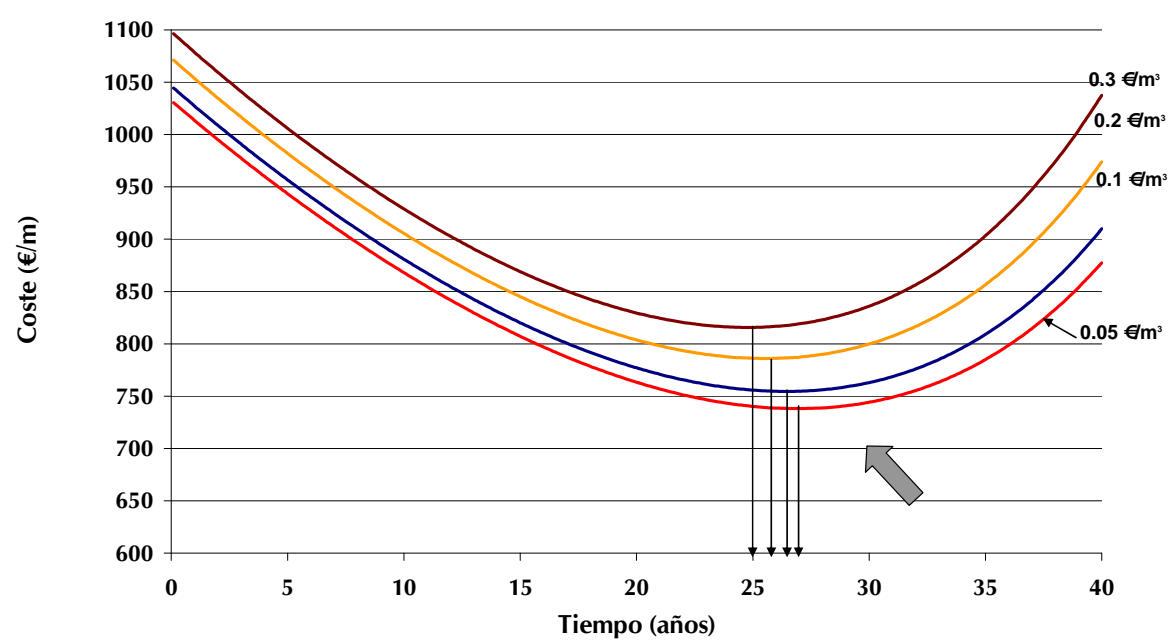

FIGURA 90. EVOLUCIÓN DE LA CURVA DE COSTES TOTALES SEGÚN LA HUELLA ENERGÉTICA DEL AGUA EN EL CASO DE LAS INFINITAS RENOVACIONES.

\subsubsection{Influencia del caudal medio unitario por fuga}

El caudal medio que se escapa por una fuga afecta tanto al coste asociado con el agua como a la energía perdida a través de una fuga. Los valores obtenidos del periodo óptimo de renovación se muestran en la Tabla 64 y la evolución temporal de los costes en la Figura 91.

TABLA 64. RELACIÓN ENTRE EL CAUDAL MEDIO DE FUGAS Y EL PERIODO ÓPTIMO DE RENOVACIÓN PARA EL CASO DE LAS INFINITAS RENOVACIONES.

\begin{tabular}{ccc}
\hline $\begin{array}{c}\text { Caudal medio fugado } \\
\left(\mathbf{m}^{3} / \mathbf{d} \mathbf{a}\right)\end{array}$ & $t_{r_{j}}^{*}$ & $C_{T}\left(t_{r_{j}}^{*}\right)$ \\
\hline 10 & 28.1 & 701.8 \\
20 & 26.4 & 754.2 \\
30 & 25.1 & 802.7 \\
\hline
\end{tabular}




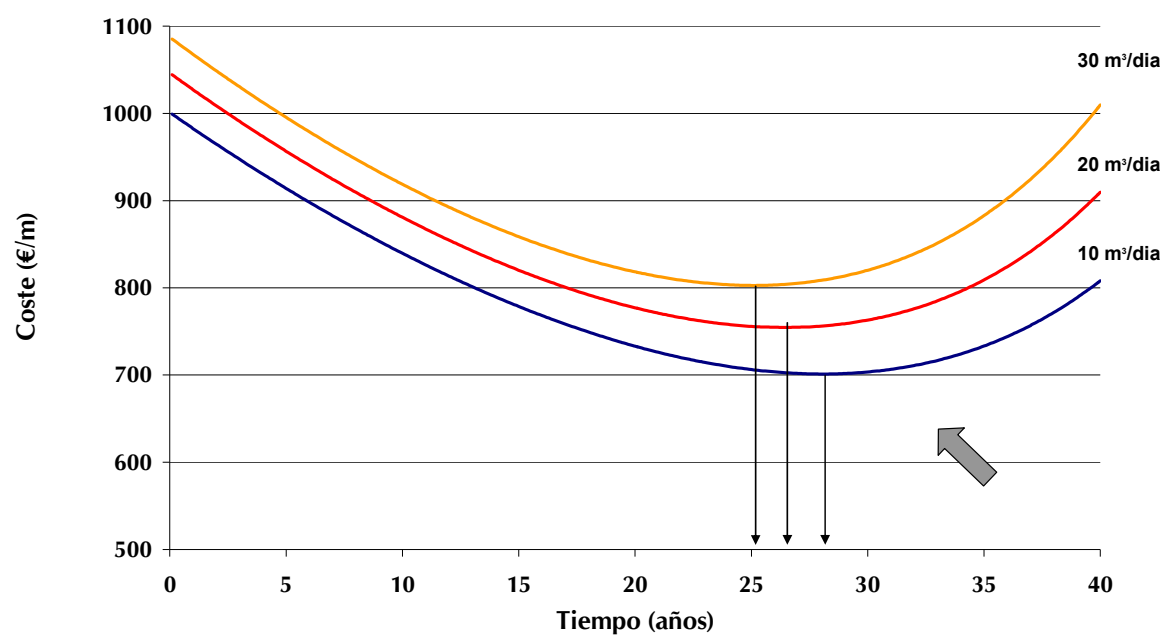

FIGURA 91. EVOLUCIÓN DE LA CURVA DE COSTES TOTALES SEGÚN EL CAUDAL MEDIO UNITARIO POR FUGA EN EL CASO DE LAS INFINITAS RENOVACIONES.

\subsubsection{Influencia del tiempo medio de actividad de la fuga}

Al igual que el caudal medio unitario por fuga, el tiempo medio de actividad de la fuga influye sobre el coste asociado con el agua y con la energía perdida a través de una rotura. Los valores obtenidos del periodo óptimo de renovación y la evolución temporal de los costes se muestran en la Tabla 65 y en la Figura 92.

TABLA 65. RELACIÓN ENTRE EL TIEMPO MEDIO DE ACTIVIDAD DE LA FUGA Y EL PERIODO ÓPTIMO DE RENOVACIÓN PARA EL CASO DE LAS INFINITAS RENOVACIONES.

\begin{tabular}{ccc}
\hline $\begin{array}{c}\text { tiempo medio de } \\
\text { actividad de la fuga (días) }\end{array}$ & $t_{r_{j}}^{*}$ & $C_{T}\left(t_{r_{j}}^{*}\right)$ \\
\hline 90 & 27.8 & 707.9 \\
120 & 27.2 & 728.7 \\
160 & 26.4 & 754.2 \\
200 & 25.7 & 778.7 \\
\hline
\end{tabular}




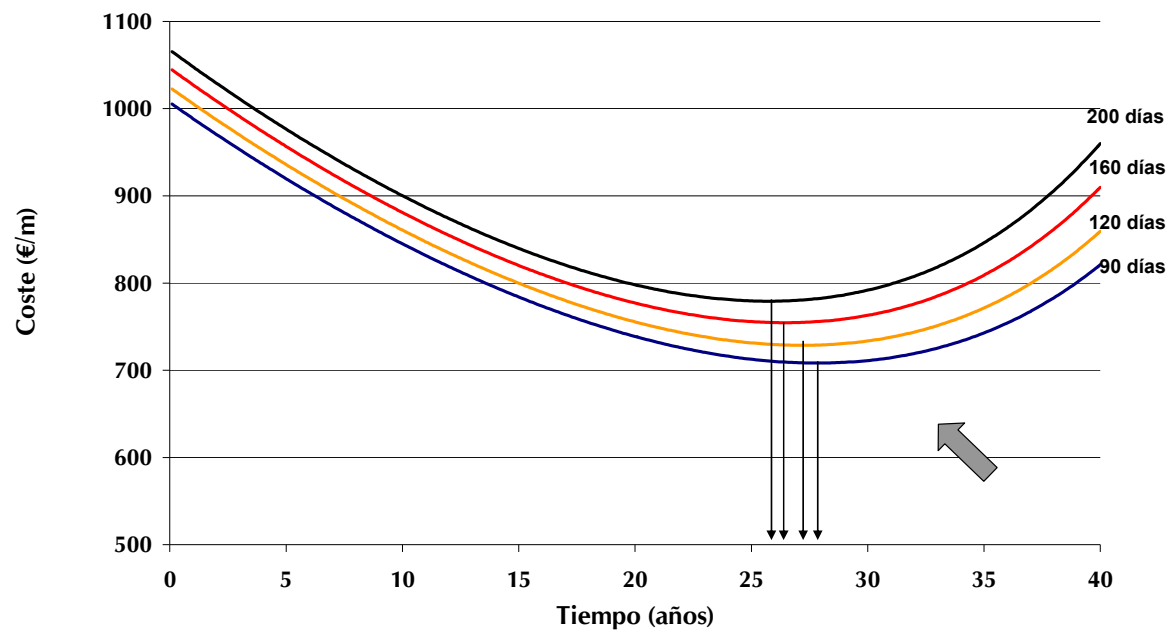

FIGURA 92. EVOLUCIÓN DE LA CURVA DE COSTES TOTALES SEGÚN ELTIEMPO MEDIO DE ACTIVIDAD DE LA FUGA PARA EL CASO DE LAS INFINITAS RENOVACIONES.

\subsubsection{Influencia de la tasa continua de actualización equivalente}

La tasa continua de actualización equivalente afecta muy significativamente en el análisis de costes, y una pequeña variación en la determinación de dicha tasa provoca mucha variación en el coste mínimo asociado, aunque su influencia es mucho menor en el cálculo del periodo óptimo de renovación (Figura 93).

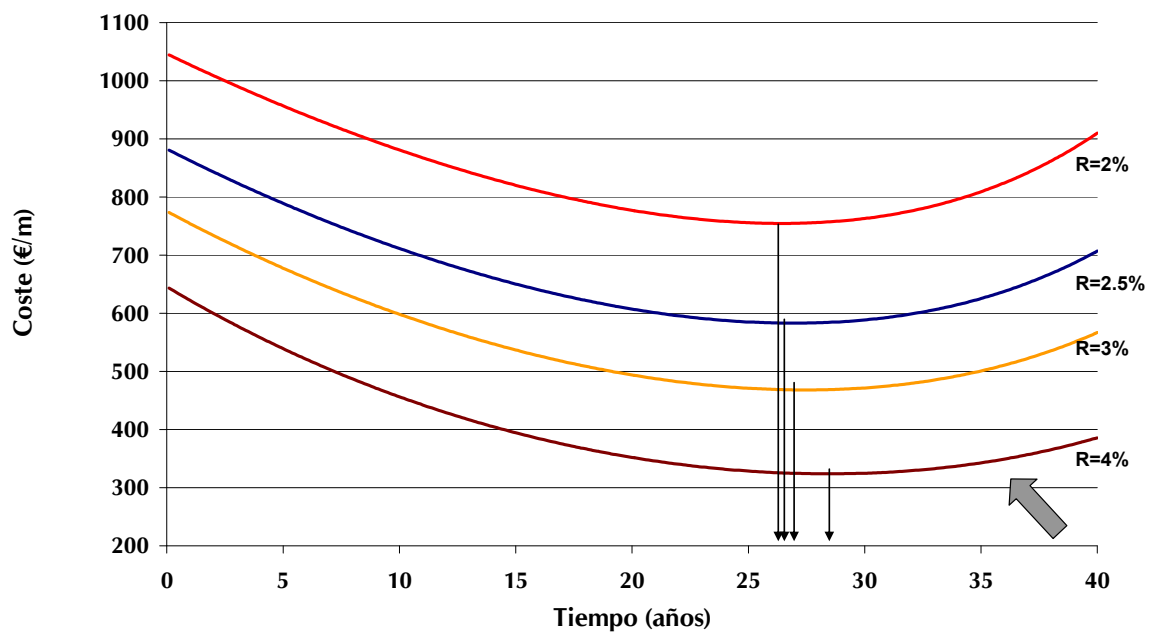

FIGURA 93. REPERCUSIÓN DE LA VARIACIÓN DE LA TASA CONTINUA DE ACTUALIZACIÓN EQUIVALENTE PARA EL CASO DE LAS INFINITAS RENOVACIONES.

El efecto de dicha variación se puede calcular analíticamente, obteniendo los siguientes valores (Tabla 66). 
TABLA 66. RELACIÓN ENTRE LA TASA CONTÍNUA DE ACTUALIZACIÓN Y EL PERIODO ÓPTIMO DE RENOVACIÓN PARA EL CASO DE LAS INFINITAS RENOVACIONES.

\begin{tabular}{ccc}
\hline $\begin{array}{c}\text { Tasa continua de } \\
\text { actualización (\%) }\end{array}$ & $t_{r_{j}}^{*}$ & $C_{T}\left(t_{r_{j}}^{*}\right)$ \\
\hline 2 & 26.4 & 754.2 \\
2.5 & 26.9 & 582.6 \\
3 & 27.4 & 467.8 \\
4 & 28.4 & 323.6 \\
\hline
\end{tabular}

\subsubsection{Influencia del coeficiente de crecimiento de roturas, $A$}

La Figura 94 representa tres situaciones en las que se observa la influencia del parámetro del crecimiento de roturas.

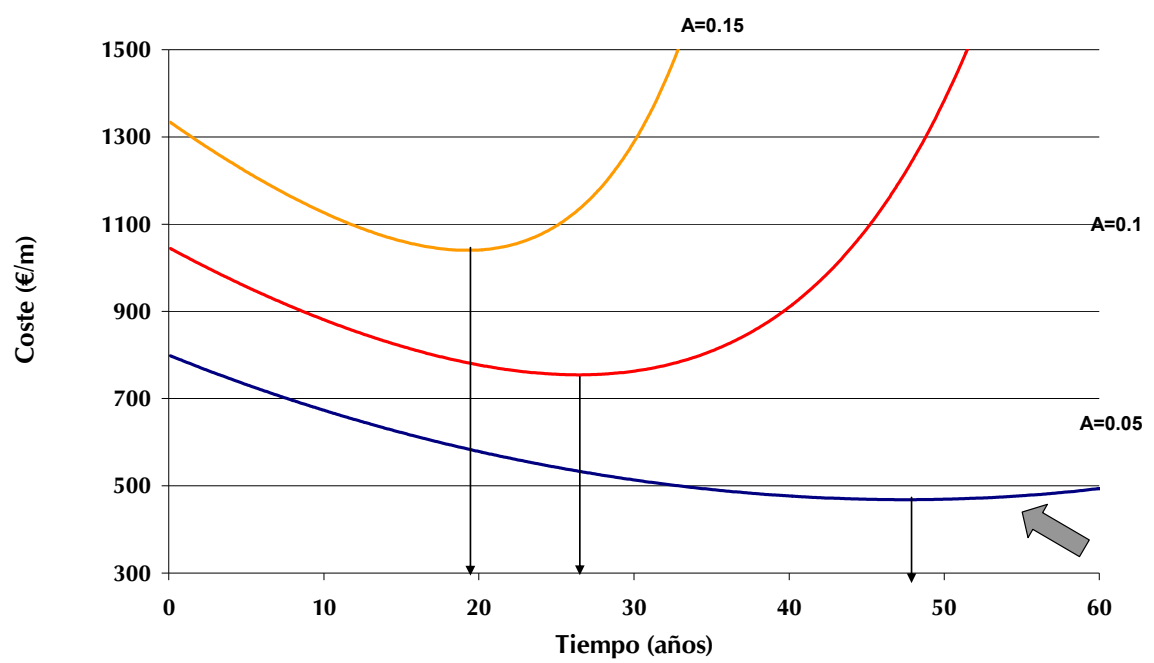

FIGURA 94. REPERCUSIÓN DE LA VARIACIÓN DE LA TASA CONTINUA DE ACTUALIZACIÓN EQUIVALENTE PARA EL CASO DE LAS INFINITAS RENOVACIONES.

Y en la Tabla 59, se muestran los puntos singulares de la figura anterior.

TABLA 67. RELACIÓN ENTRE EL COEFICIENTE DE CRECIMIENTO DE ROTURAS Y EL PERIODO ÓPTIMO DE RENOVACIÓN. PARA EL CASO DE LAS INFINITAS RENOVACIONES.

\begin{tabular}{ccc}
\hline $\mathbf{A}\left(\mathbf{a n ̃ o s}^{-1}\right)$ & $t_{r_{j}}^{*}$ & $C_{T}\left(t_{r_{j}}^{*}\right)$ \\
\hline 0.05 & 47.5 & 468.2 \\
0.10 & 26.4 & 754.2 \\
0.15 & 19.2 & 1041.0 \\
\hline
\end{tabular}




\subsubsection{Influencia de las particularidades propias de una técnica sin zanja. El caso del entubado por deslizamiento}

Las técnicas sin zanja presentan características especiales, entre ellas limitaciones en su utilización en cuanto a longitud y diámetro, por ejemplo. El entubado por deslizamiento sliplining no es diferente al resto, y por su propia naturaleza presenta ciertas restricciones en su empleo. El entubado se realiza mediante la introducción de una tubería de menor diámetro dentro de la conducción existente (para ello se suelen insertar tuberías de polietileno, PVC o PRFV).

Por tanto, esta introducción de un tubo sobre otro conlleva una inevitable reducción de la sección eficaz de paso (que puede ser de hasta un $10 \%$ el diámetro) y es por ello que esta técnica no se puede aplicar sucesivamente. La obtención del periodo óptimo de renovación para las infinitas renovaciones se realiza considerando una renovación según la técnica de entubado por deslizamiento que alterna con una renovación según el método tradicional con apertura de zanja.

Por tanto se calculan tanto los parámetros de inversión asociados a estas técnicas, $\iota_{j}=420.3 € / \mathrm{m}$ (renovación tradicional) y $340 € / \mathrm{m}$ (entubado por deslizamiento), como el de mantenimiento $M=2679.4$ ( $€$ /rotura $m$ ). Con éstos, se puede calcular el periodo óptimo entre sucesivas renovaciones con la técnica tradicional (calculado en el apartado 5.4.2) con una duración $T_{t_{j}}^{* *}=36.5$ años, y con el coste asociado a una renovación en el año 36.5 es $c_{T}(36.5)=322.1 € / \mathrm{m}$ y un coste total de $C_{\text {inf }}\left(T_{t_{j}}^{* *}\right)=625.9 € / \mathrm{m}$.

Sin embargo, no es válido realizar el mismo cálculo para el caso de la técnica de entubado por deslizamiento, ya que no se puede aplicar más de una vez de manera sucesiva. Por tanto se plantean los costes de las renovaciones ilustrados en la Figura 95, que considera la renovación utilizando la técnica de entubado por deslizamiento y una vez transcurrido un tiempo ( $\mathrm{x}$ años) una sustitución con apertura de zanja (con un coste de $322.11 € / \mathrm{m}$ ). Tras ésta, se producirá (36.5 años después) otra renovación con entubado por deslizamiento. Este proceso sucede cíclicamente considerando las infinitas renovaciones. 
El objetivo de nuestro problema es encontrar el número de años, $x$, en el que la tubería está en funcionamiento tras haberla renovado con la técnica del entubado por deslizamiento, que minimiza el coste total de las infinitas renovaciones. Este problema se resuelve numéricamente, ya que los costes de renovación con la técnica del entubado dependen del tiempo solución x.

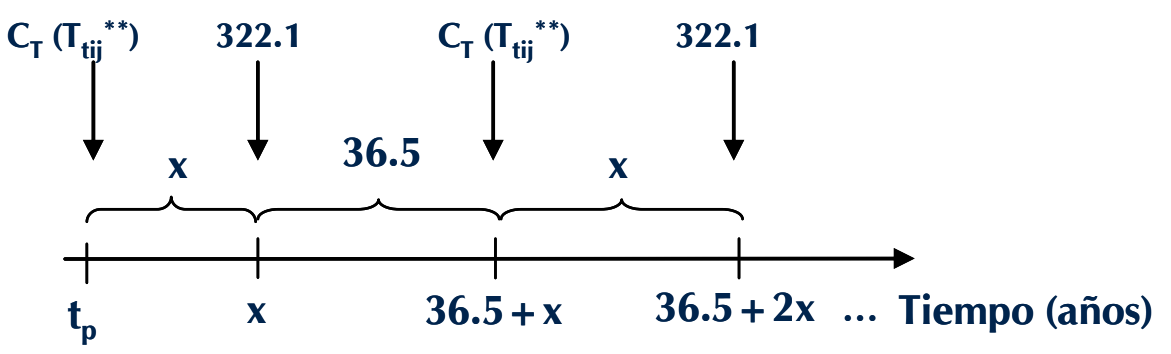

FIGURA 95. DISTRIBUCIÓN DE LOS COSTES EN LA DETERMINACIÓN DE LAS INFINITAS RENOVACIONES DE UNA CONDUCCIÓN CON LA TÉCNICA DE ENTUBADO POR DELIZAMIENTO Y TÉCNICA TRADICIONAL. LA SEGUNDA RENOVACIÓN SE REALIZA CON EL MÉTODO DE ENTUBADO POR DESLIZAMIENTO.

En el caso descrito por la Figura 95, el valor que minimiza el coste de las infinitas renovaciones es $\mathrm{x}=T_{t_{j}}^{* *}=37.5$ años (empleando en primer lugar la técnica de entubado por deslizamiento). El coste asociado es $C_{T}(37.5)=276.8 € / \mathrm{m}$, mientras que el coste total de las infinitas renovaciones se calcula como:

$C_{\text {inf }}\left(T_{t_{j}}^{* *}\right)=276.8+322.1 \cdot e^{-37.5 \cdot r}+276.8 \cdot e^{-74 \cdot r}+\ldots=574.2 € / \mathrm{m}$

Sin embargo, en el año presente todavía no hay que renovar, por lo que se considera por separado una primera renovación que depende del estado actual particular de la conducción (número de roturas) y del coste asociado a las infinitas renovaciones que se producen en un futuro con las particularidades ya conocidas. Este coste se calcula con la ecuación (5.6) en la que todos los términos son conocidos y solamente se ha de matizar el valor de la inversión $\iota_{j}$. En los casos anteriores, ese valor era único, ya que únicamente existía una técnica a la hora de realizar la renovación, pero ahora, el valor de la inversión depende de la técnica empleada en primer lugar en la determinación de las infinitas renovaciones. En este caso particular, como la segunda renovación comienza con la técnica de entubado por deslizamiento, la primera será realizada con técnica tradicional y el término de inversión empleado en la ecuación anterior será $\iota_{j}=420.3(€ / \mathrm{m})$. 
En la parte superior de la Figura 96 se pueden observar los años en los que renueva. En la parte central, se observa como cada técnica de renovación (en $€ / m$ del año en que se realiza la anterior renovación). Esto es, cuando se realiza el entubado por deslizamiento es en el año $t_{r}+36.5$, pero la inversión de $276.8 € / \mathrm{m}$ está expresado en $€$ del año tr. En la Figura 96 inferior, se agrupan las inversiones realizadas a lo largo del tiempo.

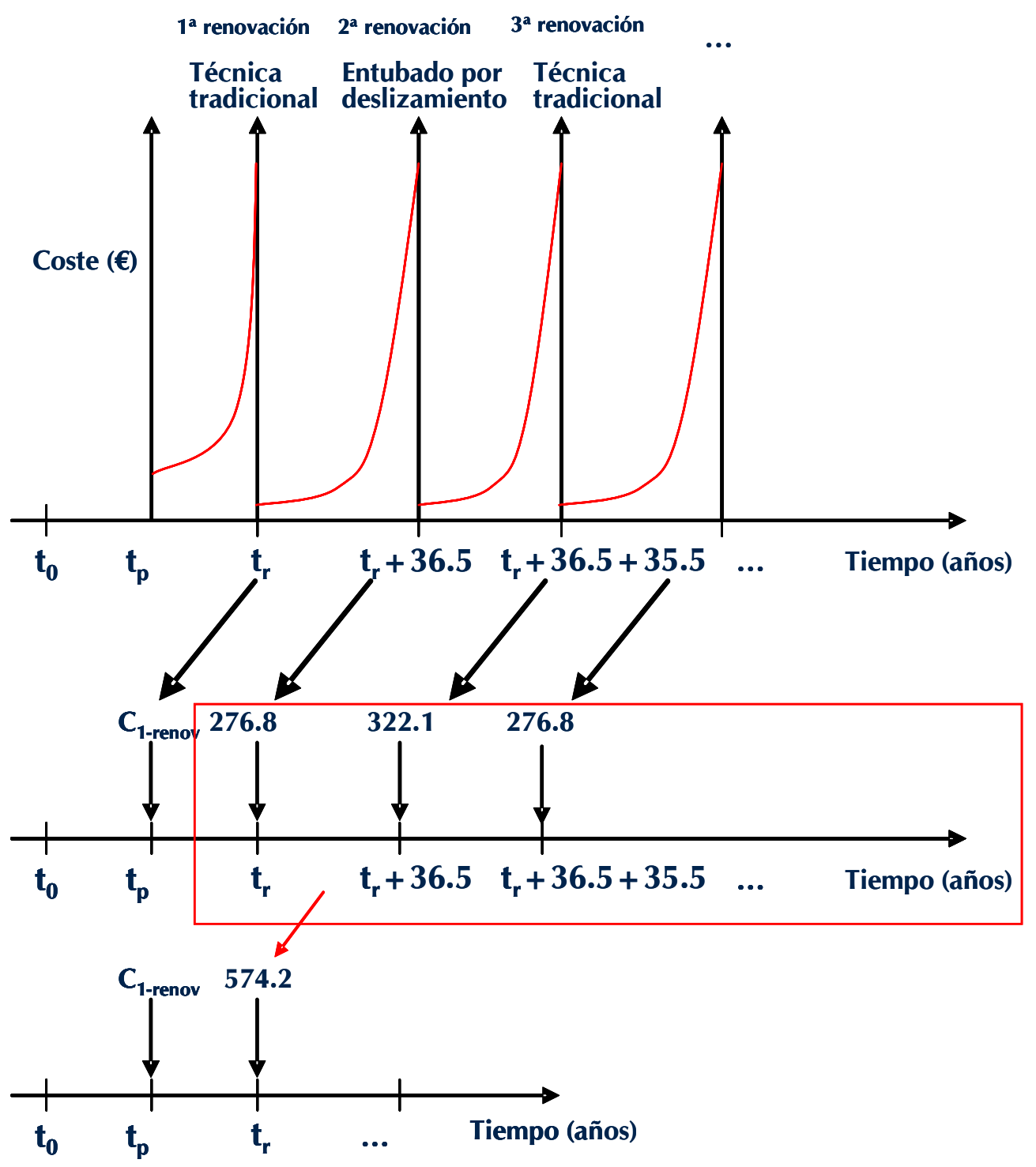

FIGURA 96. REPRESENTACIÓN DE LAS INVERSIONES A LO LARGO DEL TIEMPO.

Finalmente, se calcula el valor de $T_{f_{j}}$ que minimiza el coste total de todas las renovaciones (en definitiva, el periodo óptimo de renovación) es:

- $t_{r_{j}}^{*}=25.9$ años

- $C_{1-\text { renov }}=379.8 € / \mathrm{m}$

- $C_{T}\left(t_{r_{j}}^{*}\right)=379.8+574.2 \cdot e^{-25.9 \cdot r}=723.5 € / \mathrm{m}$ 
Estos resultados suponen que la primera renovación se realiza con la técnica tradicional (Figura 96). Asimismo, el problema se puede resolver con la hipótesis de que la primera renovación se realiza con la técnica del entubado por deslizamiento. Para ello, se vuelve a plantear el problema de minimizar el coste de las infinitas renovaciones según el tiempo $x$ que, tras el entubado por deslizamiento, la tubería está instalada. En el caso anterior (Figura 95) el coste de las infinitas renovaciones comienza utilizando la técnica de entubado por deslizamiento (la primera renovación será, por tanto, realizada según el método tradicional), mientras que en el caso que a continuación se resuelve (Figura 97) el cálculo del coste de las infinitas renovaciones comienza utilizando la técnica tradicional (la primera renovación será realizada con un entubado por deslizamiento).

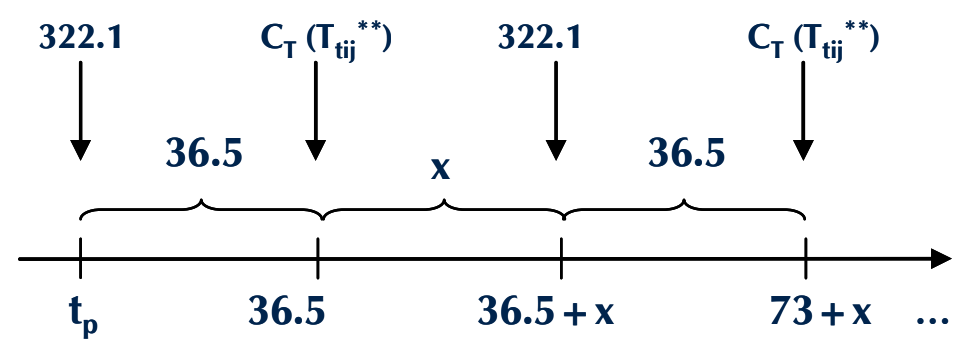

FIGURA 97. DISTRIBUCIÓN DE LOS COSTES EN LA DETERMINACIÓN DE LAS INFINITAS RENOVACIONES DE UNA CONDUCCIÓN CON LA TÉCNICA DE ENTUBADO POR DELIZAMIENTO Y TÉCNICA TRADICIONAL. LA SEGUNDA RENOVACIÓN SE REALIZA CON EL MÉTODO TÉCNICA TRADICIONAL.

El valor de $\mathrm{x}$ es ahora diferente al caso anterior, $\mathrm{x}=T_{t_{j}}^{* *}=35.4$ años, el coste asociado es $c_{T}(35.4)=276.2 € / \mathrm{m}$, y el coste total de las infinitas renovaciones es $C_{\text {inf }}\left(T_{t_{j}}^{* *}\right)=600.7 € / \mathrm{m}$. 
Si se observan estos últimos datos en comparación con los obtenidos para el caso anterior (si la segunda renovación se realiza mediante entubado por deslizamiento, $\mathrm{x}=T_{t_{j}}^{* * *}=37.5$ años, el coste asociado es $C_{T}(37.5)=276.8 € / \mathrm{m}$, y el coste total de las infinitas renovaciones es $C_{\text {inf }}\left(T_{t_{j}}^{* *}\right)=574.2 € / \mathrm{m}$ ) los resultados reflejan lo esperado. Por una parte tenemos que el coste en el infinito es mayor para el último caso, lo cual se comprende fácilmente comparando la Figura 97 y la Figura 95, ya que el coste que se ha de realizar en el año 0, es mayor en este segundo caso, mayor inversión inicial, y ese término es el más influyente en la obtención del $C_{\text {inf }}\left(T_{t_{j}}^{* *}\right)$, ya que no se ve afectado por la actualización del valor monetario al año presente.

A continuación y análogamente al problema anterior, se calcula el coste de las infinitas renovaciones (incluida la primera, ecuación 5.6) con el valor de la inversión propia del entubado por deslizamiento, $l_{j}=340(€ / \mathrm{m})$.

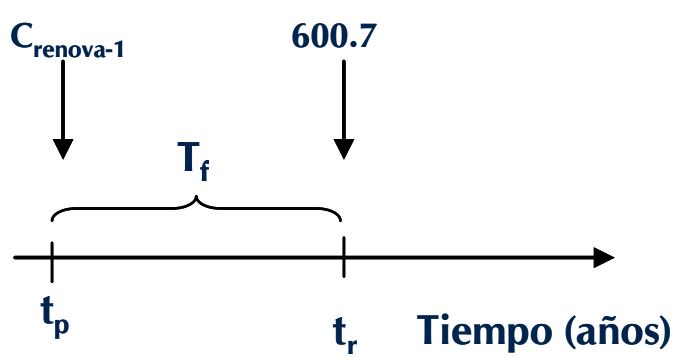

FIGURA 98. DISTRIBUCIÓN DE LAS INVERSIONES EN EL TIEMPO EN EL CASO DE RENOVACIÓN MEDIANTE EL ENTUBADO POR DESLIZAMIENTO.

El valor de $T_{t_{i j}}$ que minimiza el coste de todas las renovaciones es:

- $t_{r_{j}}^{*}=25.4$ años

- $C_{1-\text { renov }}=376.9 € / \mathrm{m}$

- $C_{T}\left(t_{r_{j}}^{*}\right)=376.9+600.7 \cdot e^{-25.4 \cdot r}=740.3 € / \mathrm{m}$

Por último se representan los costes totales asociados a las infinitas reposiciones de una tubería en los dos casos que se han presentado anteriormente (Figura 99). El primer caso de los dos analizados aquí se define en la siguiente figura como primera renovación con técnica tradicional (los costes se muestran en la Figura 96), mientras que el segundo se muestra como primera renovación con entubado por deslizamiento (según los costes de la Figura 98). 


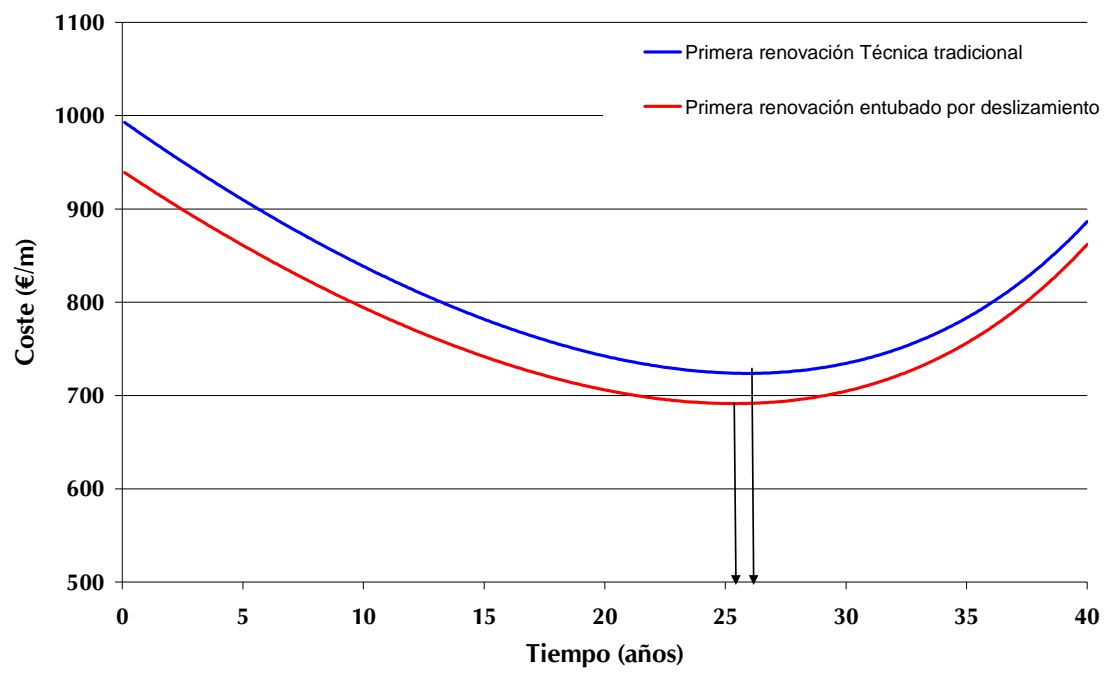

FIGURA 99. COSTES TOTALES ( $€ / M)$ ASOCIADOS A LAS INFINITAS RENOVACIONES PARA LAS TÉCNICAS DE ENTUBADO POR DESLIZAMIENTO Y TÉCNICA TRADICIONAL 

6

Auditoría energética 



\subsection{Introducción}

Que el interés por optimizar el uso de la energía es proporcional a su precio lo evidencia la correlación que existe entre las evoluciones temporales del gasto en I+D en los países de la International Energy Agency, IEA, en este área (Figura 100) y del precio del barril de petróleo (Figura 101). La comparación entre ambas, bien que referidas a dólares de años distintos y a periodos de tiempo diferentes, así lo demuestra. Asimismo, cabe significar que la Figura 101, por finalizar en el 2006, no registra el máximo comentado de julio de 2008 (147.25 dólares). Con todo, principio de acción y reacción, se aprecia un ligero retraso del gasto en I+D con relación al precio del crudo. Las gráficas muestran con claridad la crisis de 1973 y dejan en el aire el desenlace de la actual cuyo final, obviamente, aún se desconoce. $\mathrm{Y}$ ello porque a las innegables consecuencias derivadas del encarecimiento del precio del petróleo hay que añadir un nuevo factor antaño inexistente, la necesidad de reducir las emisiones de gases de efecto invernadero. Un asunto que adquiere máxima relevancia a partir del Protocolo de Kioto (diciembre de 1997). Doce años más tarde (diciembre de 2009) ha sido revisado en Copenhague con ocasión de la Cumbre del Clima de la ONU.

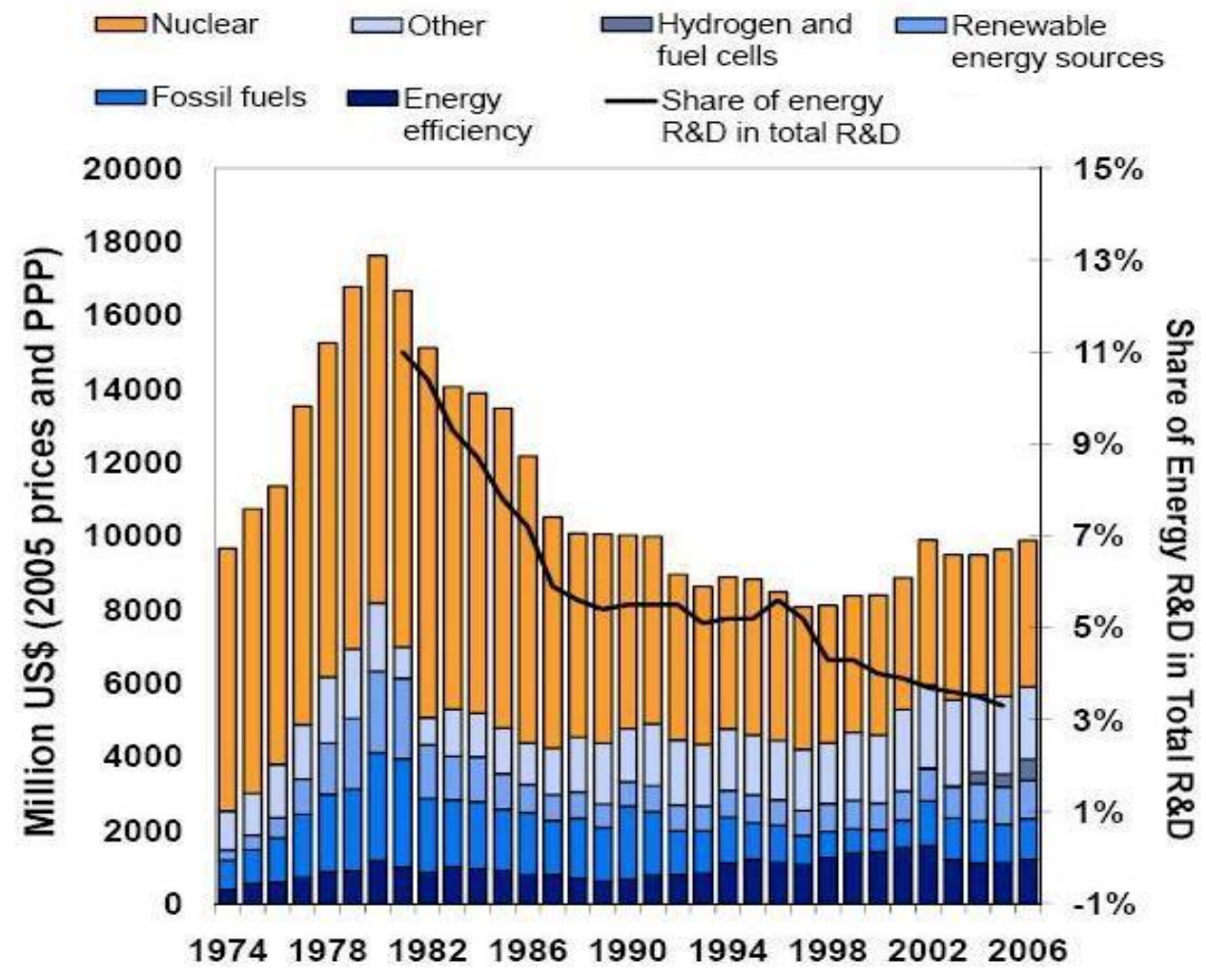

FIGURA 100. INVERSIONES EN I + D EN LOS PAÍSES IEA (IEA, 2008) 


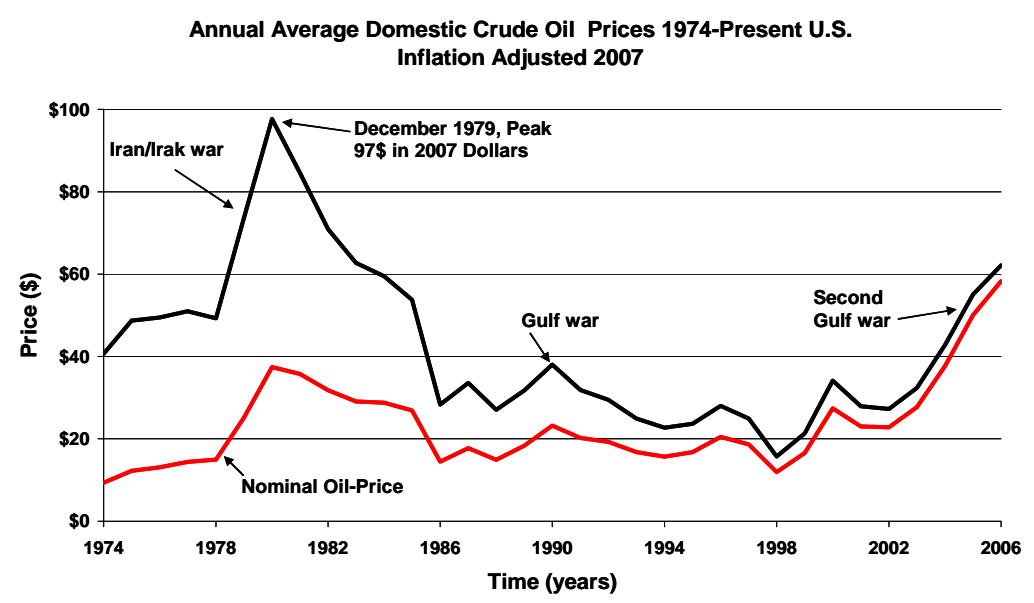

Figura 101. PRECIO DEL PETRÓlEO EN \$ 2007 (WWW.INFLATIONDATA.COM)

La estrecha relación que existe entre ahorro de agua, ahorro de energía y de emisiones viene recibiendo una atención creciente (Díaz y col., 2005; McMahon y col., 2006). Con todo, el ahorro energético es muy dependiente del lugar del ciclo en el que se racionaliza el uso del agua. La reparación de una fuga tiene, desde la óptica energética, una implicación distinta a la del ahorro de agua doméstico.

Hasta hace bien poco el ahorro de energía en la industria del agua había sido estudiado mucho más desde la óptica de la mejora de la operación de las bombas y su rendimiento (Lingireddy y Wood, 1998; Budris, 2008) y sobre todo de la mejora de los procesos, de entre los que destaca los habidos en la desalación de agua (NRC, 2008), toda vez que son costes directos asumidos por las compañías.

Por ello, la relación agua-energía no ocupa un lugar destacado entre las preocupaciones de las compañías que gestionan las redes de abastecimiento. En una reciente encuesta (Runge y Mann, 2008) se encontraba en el décimo puesto de entre los catorce retos planteados. La preocupación por la energía crece con el precio del petróleo, y este aún no había llegado a sus máximos históricos (la encuesta se realiza en marzo de 2008 y el valor máximo se alcanzó a finales de ese junio). Fácil es, pues, concluir que la preocupación de una utility depende mucho de los consumos energéticos $\left(\mathrm{kWh} / \mathrm{m}^{3}\right)$ que tenga en cada una de las etapas del ciclo urbano del agua que estén bajo su responsabilidad (Figura 102). Y así, si el agua que suministra procede de una desaladora (el gasto energético de la potabilización en ningún caso será inferior a $3.5 \mathrm{kWh} / \mathrm{m}^{3}$; NRC, 2008) la preocupación será máxima mientras que si procede de una fuente natural y de calidad (el coste energético de la potabilización es muy bajo, casi nulo) el interés por la energía descenderá de manera importante. 
Para que la industria del agua sea sensible de manera directa al trinomio "ahorrar agua ahorra energía y emisiones" es menester que el regulador se implique muy directamente. Porque como el ahorro de agua (por parte de los usuarios) comporta una disminución en los ingresos de la compañía, el sistema tarifario debe, de algún modo, compensar esta pérdida de ingresos, una problemática a la que la sociedad es cada vez más sensible. En cualquier caso, es incuestionable el interés por ahondar en un mejor conocimiento de la relación agua energía en cada una de las etapas del ciclo urbano del agua.

El presente trabajo comienza con el análisis de los estudios realizados en el ámbito que nos ocupa (la relación agua y energía), con especial atención a los estudios de los EE.UU., Europa, y el más reciente en la ciudad de Valencia. A continuación profundiza en el conocimiento de la relación agua-energía en la etapa de distribución de agua en las redes urbanas, mientras que la relación energía-emisiones, entre otros objetivos, se detalla en el capítulo 7 de la tesis.

El primer estudio que planteó la relación agua-energía en una red de distribución de manera integral (Pelli y Hitz, 2000) proponía dos indicadores del sistema, el de infraestructura (similar al que se define más adelante como procedencia de la energía, $C_{1}$ ) y el de calidad (equivalente al de suficiencia en el cumplimiento de estándares $\left(I_{5}\right)$ que aquí se considera). Éste fue un interesante enfoque práctico que mezclaba elementos externos a la red de distribución (como el rendimiento de las bombas) e ignoraba la energía que se disipa por fricción en la red, debida tanto al caudal que circula para atender demanda de los usuarios como al caudal fugado. Ésta última cuestión sí la abordaron Colombo y Karney (2002) aunque no en la totalidad de la red, y cuando lo hicieron (Colombo y Karney, 2005) lo particularizaron a un sistema concreto. Filion y col. (2004) abordaron el consumo energético asociado a la vida útil de una tubería y ya más recientemente Filion (2008) analizó la relación entre el consumo energético y la distribución espacial de las tuberías que conforman la red.

Hasta ahora, los más de los análisis de carácter global se han limitado a cuantificar el consumo energético (en kWh) que corresponde a esta etapa por el agua entregada a los usuarios $\left(\mathrm{m}^{3}\right)$. Este cociente permite estimar de manera aproximada el gasto energético que a esta etapa le corresponde (en California, 0.18 y 0.32 $\mathrm{kWh} / \mathrm{m}^{3}$; Figura 102). Con todo, es un valor global que no aporta información sobre como se invierte esa energía a lo largo del proceso de distribución, precisamente el objetivo final de la auditoría energética que se presenta a continuación. 
El presente trabajo efectúa, a partir de la ecuación de la energía, una auditoría energética completa del sistema de distribución asociado a un volumen de control que puede identificarse con el conjunto del sistema o con un distrito hidrométrico concreto. La condición para aplicar el teorema de arrastre de Reynolds particularizado a la propiedad energía es conocer el valor de los términos que la integran sobre la superficie de control. Por ello, para poder integrar esta ecuación en el tiempo es necesario haber realizado la auditoría hídrica del sistema (conocer los caudales de agua entrante y saliente del sistema) y disponer del modelo matemático de la red para poder evaluar el comportamiento de los elementos que lo integran. En otras palabras, es necesario previamente haber resuelto el problema hidráulico, lo que equivale a conocer los caudales circulantes por las líneas y las alturas de presión en los nudos. Porque si el fluido es incompresible (White, 1974) y el agua lo es, las ecuaciones mecánicas y las térmicas se desacoplan y el problema energético puede resolverse tras el hidráulico.

El volumen de control seleccionado no incluye a los equipos de bombeo. Éstos sólo aportan potencia hidráulica (trabajo en el eje) a través de sus rodetes por lo que su eficiencia debe evaluarse al margen de la auditoría energética que se presenta $^{43}$. De este modo, los elementos externos más significativos son las bombas cuyo análisis energético debe realizarse al margen de la auditoría energética del sistema y que puede valorarse para diferentes estados del sistema. Por tanto, es muy fácil determinar con extremada precisión la contribución de las fugas a la factura energética. Basta con analizar energéticamente el sistema con y sin fugas. También es inmediato, cuantificando la disminución de la energía disipada, conocer los beneficios derivados de renovar la red. Poder valorar diferentes escenarios y cuantificar mejor la relación coste/beneficio de una determinada actuación tanto para una red real como para un distrito hidrométrico de esa red es una poderosa herramienta que justifica el interés del análisis que sigue.

${ }^{43}$ La auditoría energética se refiere a energía hidráulica, no eléctrica. 
La mayor novedad del balance energético que se presenta es el cálculo de los usos finales de la energía inyectada al sistema, y muy especialmente la pérdida de energía asociada a las fugas de agua. Dicha pérdida es la suma de dos términos: el inherente a la propia pérdida de agua presurizada más el correspondiente a la energía disipada por la mayor fricción de unos caudales circulantes superiores a los estrictamente requeridos por la demanda. El balance, con los usos finales de la energía, lo resumen los indicadores que más adelante se definen. Permite valorar tanto la eficiencia energética de la red como, con análisis coste-beneficio, determinar la influencia de las pérdidas energéticas en el periodo óptimo de renovación de las tuberías. Los balances globales hasta ahora planteados (Todini, 2000) no contemplan explícitamente las pérdidas asociadas a las fugas. En un escenario de cambio climático el interés de relacionar directamente dos recursos tan básicos como el agua y la energía, está fuera de toda duda.

\subsection{El estudio de la relación agua-energía}

En el incierto y complejo marco energético actual (con la dependencia energética del petróleo, las presiones por la reducción de las emisiones, etc.) crece la necesidad de utilizar de modo eficiente y sostenible otro recurso natural clave, el agua. $\mathrm{Y}$ ello exige un gasto energético importante. Esta necesidad ha motivado la realización de numerosos estudios de la relación agua-energía que, por su abundancia y excelencia, permiten advertir que es el tema más candente de la actualidad de la industria del agua. 


\subsubsection{Estudios realizados en EE.UU.}

Por ser un referente escala mundial, destaca el trabajo realizado en California hace escasos años (CEC, 2005) y cuyo resultado más notable, Figura 102, es la determinación de la horquilla correspondiente al gasto de energía unitario asociado a cada una de las etapas del ciclo del agua (en $\mathrm{kWh} / \mathrm{m}^{3}$ ).

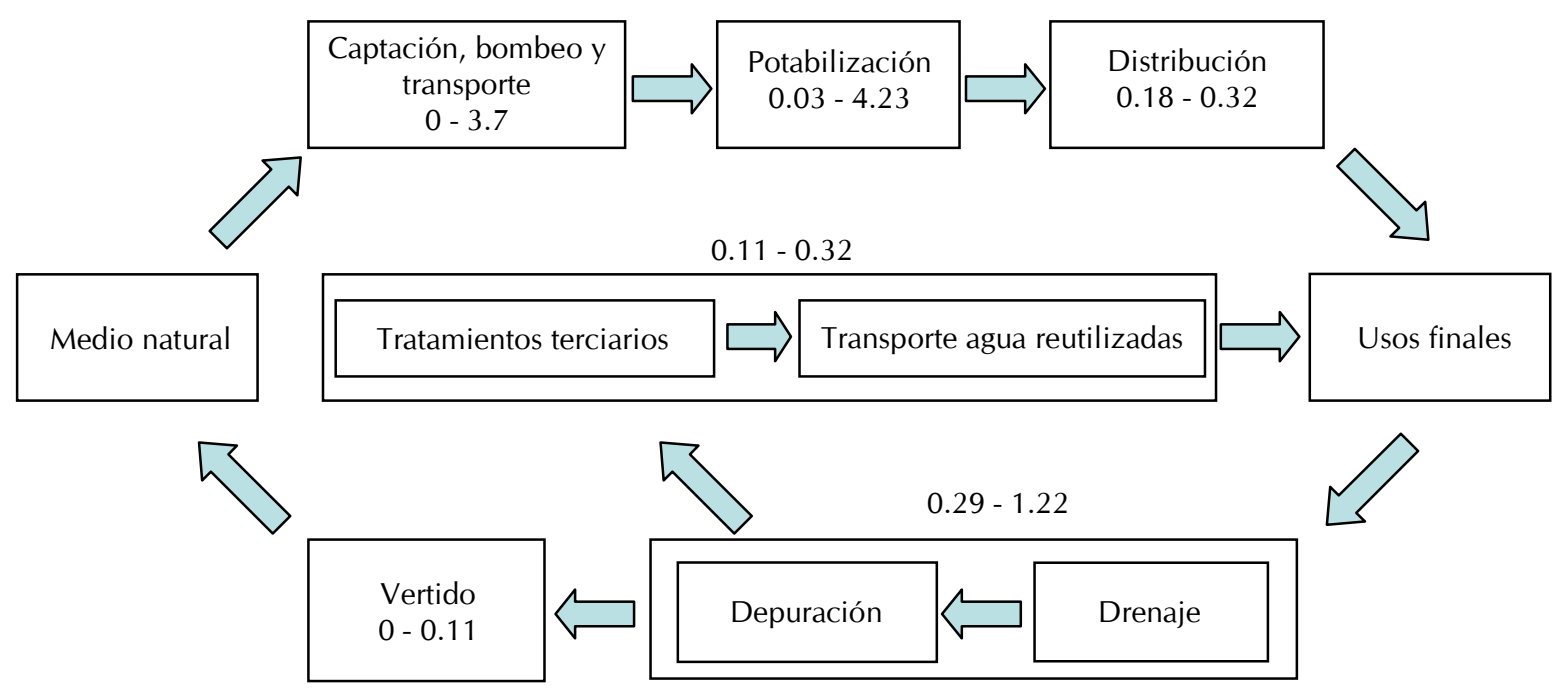

Figura 102. ETAPAS DEL CICLO DEL AGUA Y ENERGIA NECESARIA PARA CADA UNA DE ELLAS EN KWH/M³ (CEC, 2005).

El estudio de California va más allá del establecimiento de los consumos energéticos unitarios en cada una de las etapas del ciclo integral del agua, ya que analiza el consumo total de energía relacionado con el agua. Y la conclusión es sorprendente. Representa más de un 19\% del consumo de energía de dicho

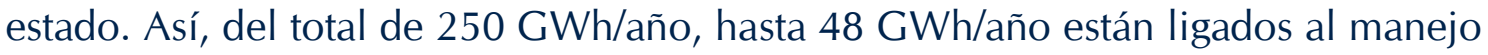
del agua. No extraña, pues, que hasta el mismo Congreso de los USA se haya interesado por este asunto encargando al Departamento de Energía un estudio sobre la relación entre los dos recursos estratégicos más importantes del siglo XXI, el agua y la energía (USDE, 2006).

La propia Comisión de la Energía de California (CEC) revisa los resultados del primer estudio (CEC, 2006) y concluye que aún cuando la metodología seguida no es del todo sólida, las conclusiones principales son razonables. 
Desde entonces, no sólo en California sino en todos los Estados Unidos, el interés por el asunto sigue creciendo. $Y$ de entre la infinidad de publicaciones que han visto la luz se comentan, a continuación, por su carácter estratégico e institucional dos de ellas.

- La primera es el informe que eleva el Departamento de Energía al Congreso de los USA en 2006 (DOE, 2006). Un informe que abunda en muchos de los aspectos que en este trabajo se subrayan. Además de destacar que en gran medida el progreso habido en los USA lo ha propiciado la construcción de las grandes infraestructuras hidráulicas y energéticas, subraya que la prioridad máxima es coordinar mejor las dos políticas y buscar sinergias, una cuestión que por su importancia se retoma más adelante.

- El segundo informe son las conclusiones del taller organizado por la Environmental Protection Agency (EPA). Sus conclusiones (EPA, 2008) resumen muy bien los retos y oportunidades que tiene planteados el binomio agua - energía.

\subsubsection{El interés en Europa}

El interés por la relación agua - energía en Europa es más reciente. Hay que esperar a 2008 para que vea la luz en Inglaterra el primer informe institucional. Publicado por la Environment Agency (EA, 2008), éste centra el problema en el ámbito urbano mientras ignora el riego porque en ese país la agricultura es una cuestión menor. Aborda con notable detalle el cálculo de la huella de los Gases de Efecto Invernadero (GEI) correspondiente al uso de agua de una procedencia concreta, huella que incluye también el impacto energético de los Ciclos de Coste Vida.

Por lo que específicamente a la Unión Europea se refiere, las iniciativas son recientes. Una de las primeras la llevó a cabo en febrero de 2008 la Global Water Research Coalition. El taller "Agua y Energía" celebrado en Londres se centró en la mejora de la eficiencia de los procesos de depuración, y se planteó el objetivo de reducir el consumo de energía un 20\% (GWRC, 2008). Un análisis tan parcial del binomio agua energía se debe a que en la coalición participan empresas distribuidoras de agua. Sin embargo, sí realiza un análisis global de la interacción agua-energía el taller celebrado en Bruselas en enero de 2009 "The Energy-Water Nexus: Managing the Links between Energy and Water for a Sustainable Future" organizado por la oficina COST de la Unión Europea. También cabe subrayar que a finales de octubre de este 2009 se celebró en Copenhague la Conferencia Water \& Energy, promovida por la IWA, anticipo a la Cumbre del Clima de la ONU. 
Por último, y como prueba evidente del interés que para la Unión Europea tiene el binomio agua-energía conviene referirse a la convocatoria del VII Programa Marco (EU, 2009). El work programme anexo a la convocatoria detalla los contenidos. En el tema VI, Medio Ambiente (cambio climático incluido), el área 6.3.1.1 está referida al agua, centrándose el epígrafe 6.3.1.1-1 en las "Technologies and systems for urban water cycle services". Tras sintetizar los objetivos a cubrir por las proyectos indica como conclusión que sus resultados permitirán "Assist water authorities and utilities in formulating appropriate urban water polices and levels of service criteria and their subsequent implementation. Increase understanding of urban water-energy relationship and develop tools and techniques to implement urban integrated water and energy resource management".

\subsubsection{La situación a escala nacional y local}

En España, como en el resto de países, el interés de reducir el consumo energético del agua también se torna de actualidad. Empiezan a realizarse estudios que cuantifican el consumo energético asociado al ciclo urbano del agua, entre ellos el más detallado es el que se está realizando en Valencia y del que, al final del presente apartado, se detallan los primeros resultados obtenidos.

El 27 y 28 de octubre de 2009, se desarrolló en Madrid (organizadas por el CEDEX) las $1^{\text {a }}$ Jornadas de Ingeniería del Agua (JIA, 2009) que por primera vez incluyen un taller monográfico dedicado a agua y energía.

Asimismo, destaca la iniciativa aquaenergía (una trascripción al castellano del concepto sajón watergy) desarrollada por la empresa que gestiona la red de distribución en Sevilla (EMASESA). Ésta consume en la actualidad 61679 MWh/año y produce 38505 MWh/año (Buendía, 2009), y presentan el objetivo de la autosuficiencia de la compañía para el año 2015. Para ello, pretenden reducir sensiblemente el consumo energético (hasta 60000 MWh/año) y aumentar la producción de energía. Para ello, los planes de actuación son dos, el primero orientado al aumento de la producción eléctrica (construcción de plantas solares fotovoltaicas y de biogás) y el segundo, orientado a la reducción del consumo energético (reutilización de aguas domésticas y comerciales, campañas de concienciación de los consumidores que aboguen por la reducción de la demanda de agua, instalación de dispositivos de reducción de la demanda y realización de auditorías hídricas). 
Pero con independencia de lo que al respecto hagan las compañías o la administración también se puede, bien que más lentamente, avanzar. Por ejemplo calculando las huellas energéticas del agua y las emisiones de gases de efecto invernadero. En este contexto se enmarca el trabajo de estimación de los consumos energéticos en la ciudad de Valencia (Murgui y col, 2009). La Figura 103 sintetiza los resultados (con las horquillas de una misma etapa reflejando su casuística). Éste es, hasta ahora el único trabajo realizado en España en estos términos, aunque debido al creciente interés por la gestión eficiente de ambos recursos, agua y energía, será sin duda, el preludio de estudios en mayor profundidad del consumo energético asociado al agua.

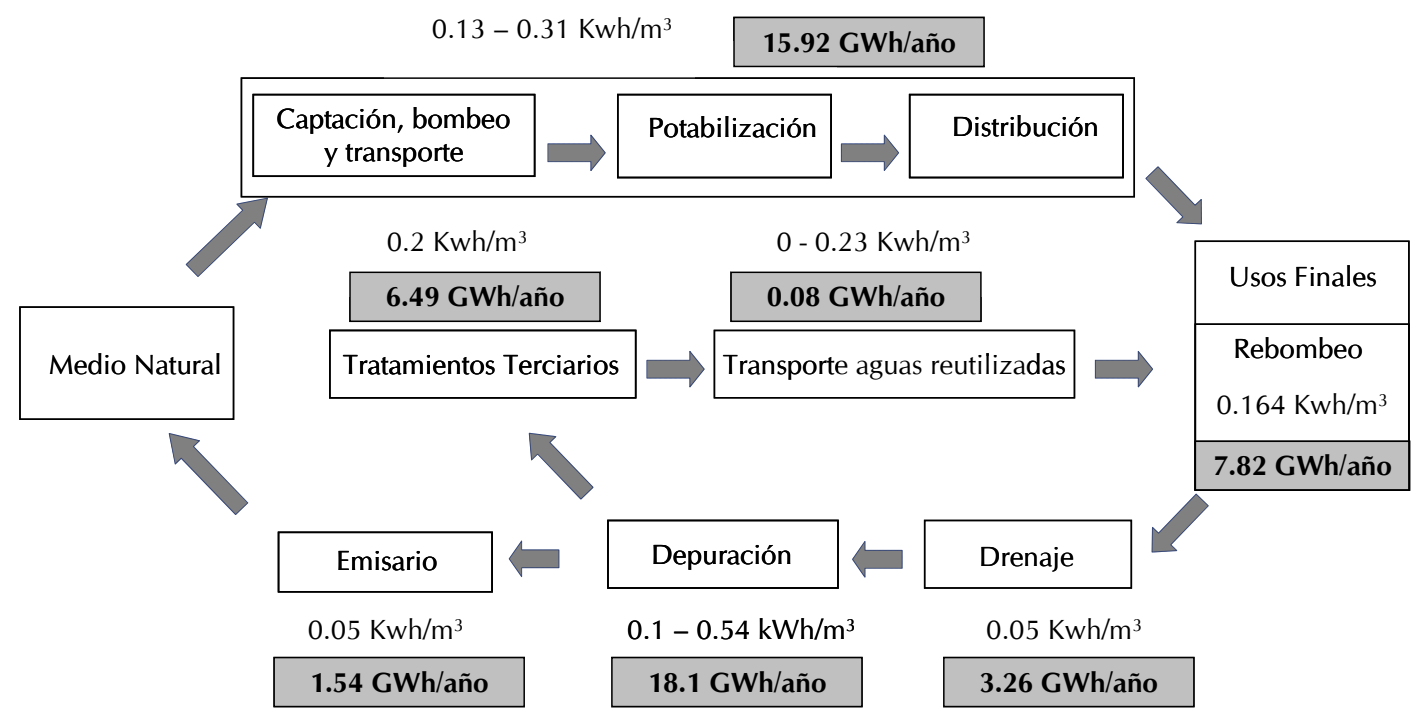

Figura 103. CONSUMO dE ENERGía del CICLO URBANO DEL AGUA EN LA CIUDAD DE VALENCIA. MURGUI Y COL (2009) 


\subsection{Planteamiento del problema}

La ecuación integral de la energía se aplica a un volumen de control limitado por una superficie atravesada por flujos hídricos y energéticos conocidos, lo que exige haber resuelto la auditoría hídrica y conocer el modelo matemático de la red previamente. El volumen de control se puede definir según convenga. Los elementos que no forman parte de él contribuyen con energía de flujo, mientras que los internos son susceptibles de almacenar más o menos energía. Para evidenciar la diferencia entre unos y otros, el caso que se presenta (Figura 104) incluye un depósito de cada tipo, uno externo (embalse) y otro interno (de compensación). Las bombas siempre van a aportar un trabajo de eje, mientras que la superficie de salida del sistema son las acometidas de los usuarios y las fugas. El modelo matemático de la red es imprescindible para, a partir de los flujos de energías entrantes, conocer los salientes. La Figura 104 representa el volumen de control junto a los flujos de agua y energía, entrantes y salientes.

\section{Volumen de control}

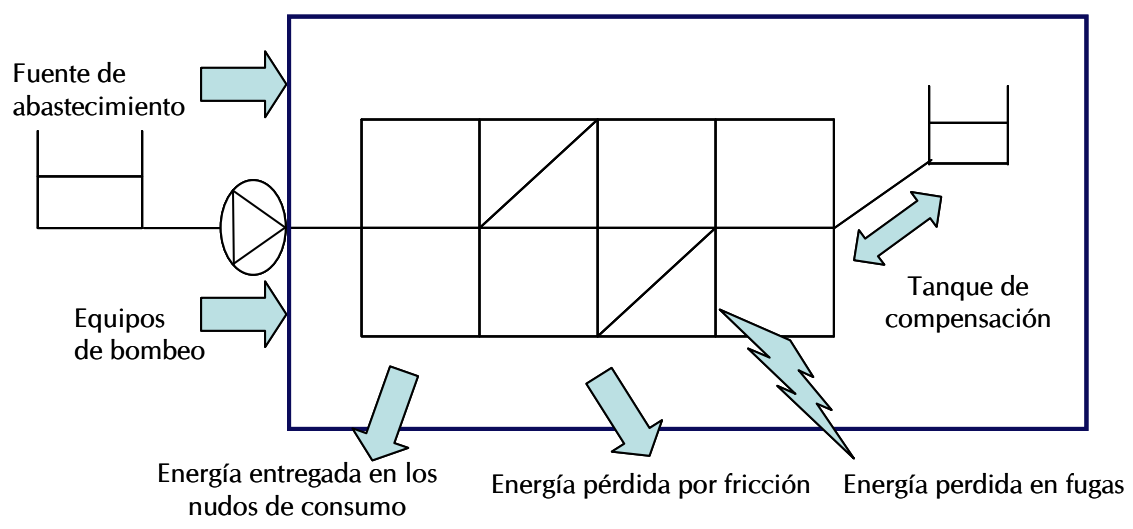

FIGURA 104. TÉRMINOS QUE INTERVIENEN EN LA AUDITORÍA ENERGÉTICA DE UNA RED

La aplicación de la ecuación de la energía, (en realidad un balance de potencias) en su forma más general (White, 2003) al volumen de control de la Figura 104 permite escribir:

$\frac{d E}{d t}=\frac{d Q}{d t}+\frac{d W}{d t}=\frac{\partial}{\partial t} \iiint_{V C} e \rho d V+\iint_{S C} e \rho(\nabla \cdot d \vec{A})$

Donde $\frac{d E}{d t}$ representa el intercambio de energía por unidad de tiempo entre el entorno y el volumen de control, (suma del intercambio térmico, $\frac{d Q}{d t}$, y de trabajo, $\left.\frac{d W}{d t}\right)$, e es la energía total por unidad de masa, y $\rho$ es la densidad del fluido (agua en este caso). 
Desarrollando el término de la energía unitaria se obtiene una nueva forma para la ecuación (6.2) más adecuada para el caso que se está tratando.

$$
\frac{d Q}{d t}+\frac{d W_{e j e}}{d t}=\frac{\partial}{\partial t} \iiint_{V C}\left(g z+u+\frac{v^{2}}{2}\right) \rho d V+\iint_{S C}\left(\frac{P}{\rho}+g z+u+\frac{v^{2}}{2}\right) \rho(\nabla \cdot d \vec{A})
$$

La ecuación (6.2) se simplifica admitiendo:

- El agua es incompresible y su densidad $\rho$ constante.

- El flujo de calor a través de la superficie de control (las tuberías de la red) es nulo $\left(\frac{d Q}{d t}=0\right)$, hipótesis razonable pues la temperatura del medio que envuelve el sistema (el terreno que cubre la tubería) y la del agua que circula por su interior es, aproximadamente, la misma y por tanto el salto térmico es nulo. Sin flujo térmico, el calor que se disipa por fricción calentará el agua, pero el aumento de temperatura resultante es, como se vera, inapreciable, lo que refuerza esta hipótesis.

- El trabajo de eje, $W_{\text {eje }}$, es el aportado por las bombas $\left(\frac{d W_{e j e}}{d t}=\sum_{i}^{n_{P}} \chi_{P i} H_{P i}\right)$.

- El término cinético $\left(\frac{v^{2}}{2}\right)$ se desprecia como es habitual en el análisis de redes.

- El análisis energético que se plantea es cuasi-estático y su extensión en el tiempo es una simulación energética en periodo extendido. En cada intervalo de cálculo la energía en el interior del volumen de control es, por lo que a las tuberías se refiere, constante y su variación temporal nula. Sin embargo la energía potencial en los depósitos sí que puede cambiar.

- El flujo en las superficies de entrada y salida del flujo (secciones rectas de las tuberías) es uniforme.

En estas condiciones la ecuación de la energía se escribe:

$$
\sum_{i}^{n_{P}} \mathcal{P}_{P i} H_{P i}=\rho g \frac{\partial}{\partial t} \iint_{V C} z d V+\rho \sum_{\text {Salidas }} Q_{S i}\left[\frac{P_{S i}}{\rho}+g z_{S i}+u_{S i}\right]-\rho Q_{E}\left[\frac{P_{E}}{\rho}+g z_{E}+u_{E}\right]
$$

Tres son los elementos de contorno característicos de las redes de agua embalses, depósitos y bombas (Rossman, 2000). La aportación energética de los embalses, exteriores al sistema, es constante e igual a su cota. Desde la óptica del sistema que se analiza es una energía "natural" $z_{N}$, en contraposición con la "artificial" de bombeo. La aportación de un depósito es también de tipo natural, $z_{N}(t)$, pero con una cota variable en el tiempo. En cuanto a los flujos de salida a través de los nudos, las energías unitarias son las alturas piezométricas, de tal manera que para un nudo genérico de salida i será $H_{S i}=\frac{P_{S i}}{\gamma}+z_{S i}$, valor que depende del origen de 
cotas y que, cual se verá, también condiciona el valor final de los indicadores energéticos. Por ello es razonable asignar como referencia, $z=0$, para el nudo de la red con menor cota.

A partir de cuanto antecede, para un sistema con $n$ nudos de consumo alimentado desde $n_{N}$ embalses, con $n_{P}$ bombeos que aportan energía al sistema, y con $n_{c}$ depósitos de compensación, la ecuación (6.4) queda:

$$
P_{0}=\sum_{i}^{n_{N}} \gamma_{N i} H_{N i}+\sum_{i}^{n_{P}} \gamma_{P_{P i}} H_{P i}=\sum_{\text {Salidas }} \gamma_{S i} H_{S i}+\rho\left[\sum_{\text {Salidas }} Q_{S i} u_{S i}-\sum_{\text {Entradas }} Q_{N} u_{N}\right]+\gamma \frac{\partial}{\partial t} \iiint_{V C} z d V
$$

El precedente balance de potencias referido a todo el sistema recuerda el balance energético de Bernouilli aplicado a los extremos de una conducción. En efecto, de izquierda a derecha, los términos de la ecuación (6.4) representan lo que sigue:

- $\quad$ La potencia de entrada, que los embalses y depósitos ponen a disposición del sistema es $P_{N}=\sum_{i}^{n_{N}} \ell_{N i} H_{N i}$. Es, desde la óptica del sistema que se analiza, una potencia "natural".

- La potencia que aportan las bombas es $P_{P}=\sum_{i}^{n_{P}} \mathcal{L}_{P_{i}} H_{P i}$. Es una potencia "artificial" pues requiere una fuente de alimentación externa, en general un motor eléctrico.

- La potencia de entrada total $\left(P_{0}\right)$ es la suma de las dos precedentes.

- El término $\sum_{\text {salidas }} Q_{S i} H_{S i}$ es la potencia saliente del sistema por los nudos de la red. Es la suma de la potencia a disposición de los usuarios o potencia útil $P_{U}$ y las pérdidas de potencia que con las fugas $P_{L}$ escapan de la red.

- El término $\rho\left[\sum_{\text {Salidas }} Q_{S i} u_{S i}-\sum_{E n t r a d a s} Q_{N} u_{N}\right]$ representa la variación por unidad de tiempo de la energía interna del agua en el interior del sistema. En ausencia de intercambio de calor con el entorno, ese aumento temporal de energía interna $P_{F}$ es igual a potencia requerida para vencer la fricción entre fluido y la tubería.

- $\quad$ Finalmente, el término $\gamma \frac{\partial}{\partial t} \iiint_{V C} z d V=\sum_{i}^{n_{C}} \pm \Delta P_{C i}= \pm \Delta P_{C}$ es la variación en el tiempo, positiva o negativa, de la energía potencial de los $n_{c}$ depósitos que forman parte del sistema.

Por cuanto antecede, la ecuación (6.4) puede expresarse de manera mucho más compacta según (6.5).

$P_{0}=P_{N}+P_{P}=P_{U}+P_{L}+P_{F} \pm \Delta P_{C}$ 
Una ecuación de lectura inmediata. La potencia cedida a la red de distribución desde el exterior más la potencia de eje es igual a la potencia entregada a los usuarios, más la suma de las pérdidas (fugas y fricción mecánica) más el término de compensación del depósito de cola. Cual se verá, el término de compensación pierde relevancia a medida que se alarga el periodo temporal de integración, de tal manera que cuando la auditoría de energías se extiende a lo largo de un año su contribución es inapreciable. La nueva auditoría permite, además de considerar el término $P_{c}$, separar la potencia interna (Todini, 2000) en los dos sumandos que la integran $\left(\mathrm{P}_{L}\right.$ y $\left.\mathrm{P}_{\mathrm{F}}\right)$, siendo ésta la principal ventaja de este enfoque.

La ecuación (5), aunque es mucho más general, recuerda la de Bernoulli. Los balances energéticos que cada una establece se asemejan mucho, aunque en el caso que nos ocupa se aplica a un sistema complejo, en particular a una red de distribución de agua y no, como en el caso de la ecuación de Bernouilli, a dos puntos de una misma tubería.

\subsection{Integración en periodo extendido de la ecuación de la energía}

La ecuación (6.5) se integra a lo largo del tiempo mediante un proceso totalmente análogo al que se sigue para simular en el tiempo el comportamiento hidráulico de la red, una integración que convierte los términos de potencia en términos de energía.

Previamente es necesario adoptar una notación que indique el origen de cada término, el elemento de la red y el intervalo de tiempo al que está referido. La notación adoptada la detalla la Figura 105:

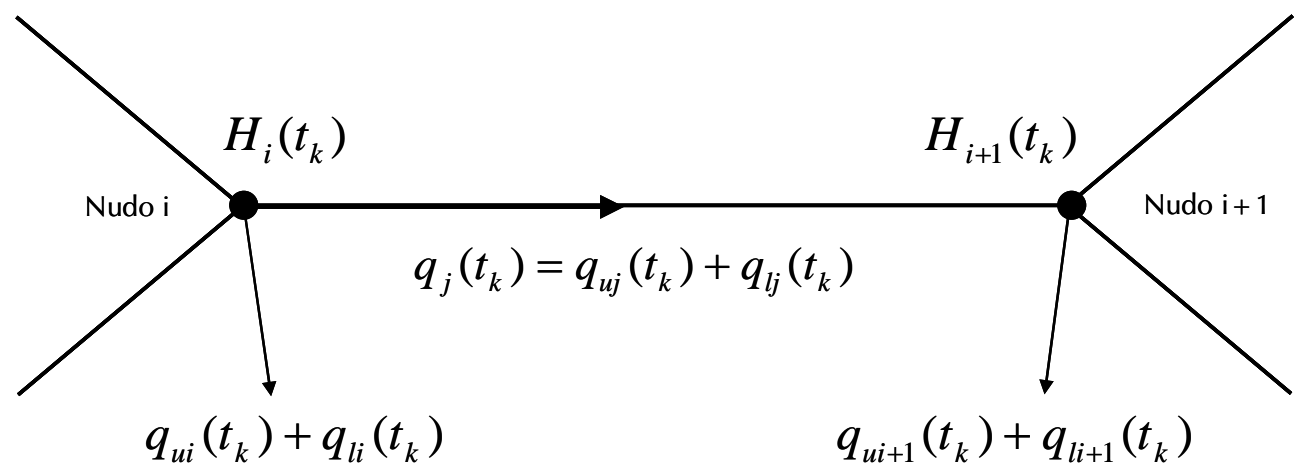

FIGURA 105. NOTACIÓN UTILIZADA PARA LOS NUDOS Y LÍNEAS DE LA RED DE DISTRIBUCIÓN

$q_{u j}\left(t_{k}\right)$ Caudal consumido útil que circula por la línea j en el instante $t_{k}$.

$q_{l j}\left(t_{k}\right)$ Caudal fugado en la línea $\mathrm{j}$ en el instante $t_{k}$.

$H_{i}\left(t_{k}\right)$ Altura piezométrica en el nudo i a la hora $t_{k}$. 
La notación empleada para representar las energías resultantes de la integración con respecto a un periodo de tiempo $\left(t_{p}{ }^{44}\right)$ de la ecuación 6.5) son:

TABLA 68. NOTACIÓN EMPLEADA EN LA DEFINICIÓN DE LAS ENERGÍAS ACTUANTES EN EL SISTEMA

\begin{tabular}{lc}
\hline Tipo de energía & Notación \\
\hline Energía natural (procedente del embalse) & $E_{N}\left(t_{p}\right)$ \\
Energía de eje (suministra por el grupo de bombeo) & $E_{P}\left(t_{p}\right)$ \\
Energía útil entregada a los usuarios & $E_{U}\left(t_{p}\right)$ \\
Energía pérdida en fugas & $E_{L}\left(t_{p}\right)$ \\
Energía disipada en por fricción en las tuberías & $E_{F}\left(t_{p}\right)$ \\
Energía de compensación (asociada a depósitos del sistema) & $E_{C}\left(t_{p}\right)$ \\
\hline
\end{tabular}

La diferencia entre la energía natural y de eje tiene especial importancia. Antes de su inyección en red, el agua ya presenta una huella energética determinada en $\mathrm{kWh} / \mathrm{m}^{3}$ (esto es, ha requerido un consumo energético debido a las etapas previas de captación, transporte y potabilización). Ahora bien, la inyección desde un embalse no incrementa la huella energética que ya tiene el agua, puesto que no necesita energía adicional, mientra que la inyección mediante bombeo sí que añade un nuevo término energético a la huella previa.

\subsubsection{Energía entrante en la red, aportada por el embalse}

La energía externa suministrada por el embalse o depósito de cabecera es:

$$
E_{N}\left(t_{p}\right)=\gamma \cdot \sum_{i=1}^{i=n_{N}}\left(\sum_{t_{k}=t_{1}}^{t_{k}=t_{p}} Q_{N i}\left(t_{k}\right) \cdot H_{N i}\left(t_{k}\right) \cdot \Delta t_{k}\right)
$$

Donde $\gamma$ es el peso específico del agua, $Q_{N i}\left(t_{k}\right)$ es el caudal $\left(\mathrm{m}^{3} / \mathrm{s}\right)$ aportado por el embalse en el instante $t_{k}, H_{N i}\left(t_{k}\right)$ es su altura piezométrica (m.c.a.) en el instante $t_{k}$ (esto es, el nivel del agua), y $\Delta t_{k}$ el intervalo de tiempo (s) considerado. Dado que se realiza un análisis en periodo extendido, durante un intervalo de tiempo establecido, hay que sumar los $n_{i}$ intervalos que integran el periodo de análisis $\left(t_{p}=n_{i} \cdot \Delta t\right)$. Si la altura del embalse es, a lo largo del periodo de integración, constante la expresión (6.6) se simplifica, resultando:

$$
E_{N}\left(t_{p}\right)=\gamma \cdot \sum_{i=1}^{i=n_{N}} \forall_{N i} \cdot H_{N i}
$$

\footnotetext{
${ }^{44}$ El periodo de tiempo en el que se calcula la energía $\left(t_{p}\right)$ no tiene ninguna relación con ningún tiempo definido en el capítulo 4 de la presente tesis.
} 
Donde $\forall_{N i}$ es el volumen $\left(\mathrm{m}^{3}\right)$ aportado por el embalse $i$ durante todo el periodo de análisis y $H_{N i}$ es la altura piezométrica (m) del agua en ese embalse. La ecuación (6.7) refleja la energía entrante en el sistema para el análisis del gasto unitario (en $\mathrm{kWh} / \mathrm{m}^{3}$ ) en esta fase de distribución, con independencia del historial previo seguido por el agua hasta ingresar en el sistema (la Figura 102 muestra las etapas anteriores). El hecho de que el agua proceda de una fuente natural o de una desaladora, aunque esencial en un planteamiento energético global, para nada condiciona los resultados de esta fase.

\subsubsection{Energía entrante en la red, aportada por el equipo de bombeo (energía de eje)}

El trabajo de eje aportado por la bomba es:

$$
E_{P}\left(t_{p}\right)=\gamma \cdot \sum_{i=1}^{i=n_{P}}\left(\sum_{t_{k}=1}^{t_{k}=t_{P}} Q_{P i}\left(t_{k}\right) \cdot H_{P i}\left(t_{k}\right)\right) \cdot \Delta t
$$

Donde $Q_{P_{i}}\left(t_{k}\right)$ es el caudal $\left(\mathrm{m}^{3} / \mathrm{s}\right)$ trasegado por el equipo de bombeo en el instante $t_{k}, H_{P}\left(t_{k}\right)$ es la altura (m.c.a.) de bombeo, y $\Delta t$ el intervalo de tiempo (s) considerado. Este cálculo debe realizarse para el total de las $n_{p}$ estaciones de bombeo que suministran trabajo de eje al sistema en los diferentes $t_{k}$ instantes de tiempo. En este análisis el rendimiento de las estaciones de bombeo, un parámetro esencial a la hora de optimizar la energía total demandada por el sistema, no interviene de manera directa.

\subsubsection{Energía entregada a los usuarios en los nudos de consumo}

El objetivo de una red es satisfacer las necesidades de los usuarios entregando el agua, y la energía asociada a ella, a los usuarios. La energía útil entregada es:

$$
E_{U}\left(t_{p}\right)=\gamma \cdot \sum_{i=1}^{i=n}\left(\sum_{t_{k}=t_{1}}^{t_{k}=t_{p}} q_{u i}\left(t_{k}\right) \cdot H_{i}\left(t_{k}\right)\right) \cdot \Delta t
$$

Donde $\mathrm{n}$ es el número de nudos de consumo de la red de distribución, $q_{u i}\left(t_{k}\right)$ es el caudal $\left(\mathrm{m}^{3} / \mathrm{s}\right)$ entregado a los abonados en el nudo i en el instante $t_{k}$, y $H_{i}\left(t_{k}\right)$ es la altura piezométrica (m.c.a.) en el nudo i en el instante $t_{k}$. 


\subsubsection{Energía saliente de la red, a través de las fugas existentes}

Las fugas reales de la red, cuyo valor depende de la presión, se incluyen en el modelo concentradas en los nudos del mismo, y representan una salida de energía de la red, formalmente análoga a la entregada a los usuarios. Su cuantía es:

$$
E_{L}\left(t_{p}\right)=\gamma \cdot \sum_{i=1}^{i=n}\left(\sum_{t_{k}=t_{1}}^{t_{k}=t_{p}} q_{l i}\left(t_{k}\right) \cdot H_{i}\left(t_{k}\right)\right) \cdot \Delta t
$$

Con n número de nudos con fugas de la red, $q_{l i}\left(t_{k}\right)$ es el caudal fugado $\left(\mathrm{m}^{3} / \mathrm{s}\right)$ en las tuberías adyacentes al nudo i (y, por tanto, asociadas a él) en el instante $t_{k}, y$ $H_{i}\left(t_{k}\right)$ es la altura piezométrica $(\mathrm{m})$ en el instante $t_{k}$ en el nudo donde se localiza la fuga $q_{l i}\left(t_{k}\right)$.

\subsubsection{Energía disipada en la fricción del agua con las tuberías}

La energía disipada debida al rozamiento del agua con las tuberías del sistema es:

$$
E_{F}\left(t_{p}\right)=\gamma \cdot \sum_{j=1}^{j=n_{L}}\left(\sum_{t_{k}=t_{1}}^{t_{k}=t_{p}}\left(q_{u j}\left(t_{k}\right)+q_{l j}\left(t_{k}\right)\right) \cdot \Delta h_{j}\left(t_{k}\right)\right) \cdot \Delta t
$$

Donde $n_{L}$ es el número de líneas de la red de distribución, $\Delta h_{j}\left(t_{k}\right)$ la pérdida de carga $(m)$ de la línea $j$ en el instante $t_{k}$ (este término es la diferencia de alturas piezométricas entre el nudo final e inicial de la tubería j, razón por la cual se precisa el modelo matemático de la red), $q_{u j}\left(t_{k}\right)$ es el caudal de línea j necesario para atender la demanda de los usuarios y $q_{l j}\left(t_{k}\right)$ es el caudal de línea $\mathrm{j}$ que finalmente se perderá en fugas. De este modo el caudal total de la línea j $q_{j}\left(t_{k}\right)$ es la suma de los precedentes (Figura 105) e igual a:

$q_{j}\left(t_{k}\right)=q_{u j}\left(t_{k}\right)+q_{l j, l}\left(t_{k}\right)$

La relación (6.11) evidencia que el caudal fugado, que circula por parte de la red antes de escapar de la misma, genera una pérdida de carga adicional. La auditoría energética que se propone permitirá conocer la cuantía de esta energía adicional. Bastará con simular el comportamiento de la red con y sin fugas. 


\subsubsection{Término energético de compensación del depósito de cola}

Son muchas las redes de abastecimiento que disponen de un depósito que acumula agua en horas valle y lo suministra en horas punta. El flujo neto de agua y energía integrado a lo largo de un tiempo suficientemente largo es nulo por lo que al no contribuir aportando flujos netos lo razonable es que formen parte del mismo sistema. Obviamente durante la operación normal del sistema, actúan alternativamente como fuentes y sumideros de masa y energía por lo que al final de la simulación se debe valorar su contribución final. Si el nivel en el instante inicial es mayor que en el instante final, el depósito ha actuado como fuente de masa y de energía mientras que en caso contrario será un sumidero.

A partir de la energía potencial que almacena un tanque (supuesto en este caso de sección constante) y de su variación temporal, con el nivel de agua se obtiene la energía de compensación en el intervalo de tiempo considerado. Fácilmente se deduce que:

$$
\Delta E_{C}\left(t_{p}\right)=\sum_{i=1}^{i=n_{c}}\left(E_{C i}\left(t_{p}\right)-E_{C i}\left(t_{p}\right)\right)=\sum_{i=1}^{n_{c}} \frac{\gamma \cdot A_{i}}{2}\left(z_{i}^{2}\left(t_{f}\right)-z_{i}^{2}\left(t_{i}\right)\right)
$$

Donde $A_{i}$ es la sección del i-ésimo depósito $\left(\mathrm{m}^{2}\right)$ mientras $z_{i}\left(t_{f}\right)$ y $z_{i}\left(t_{i}\right)$ son los niveles $(m)$ de la superficie libre de agua en el depósito $i$ en los instantes de tiempo extremos. La máxima variación $\left(\Delta E_{C \max }\right)$ de esta energía corresponde, obviamente, a una oscilación entre los niveles mínimos y máximos de todos los depósitos del sistema. 


\subsection{Auditoría global de energías}

El balance energético para el periodo considerado, resultado de integrar en el tiempo la ecuación (6.4), mantiene un paralelismo completo con esta ecuación de partida, bien que ahora los diferentes términos son energías y no potencias. Energías que, aparte de la de compensación cuando interviene, entran, se disipan o salen del sistema, lo que permite escribir ${ }^{45}$ :

$E_{\text {input }}=E_{N}\left(t_{p}\right)+E_{P}\left(t_{p}\right)=E_{U}\left(t_{p}\right)+E_{L}\left(t_{p}\right)+\Delta E_{C}\left(t_{p}\right)+E_{F}\left(t_{p}\right)=E_{\text {Output }}+\Delta E_{\text {compensation }}+E_{\text {Dissipated }}$

O, bien, desarrollando los términos:

$$
\begin{aligned}
\gamma \cdot \sum_{i=1}^{i=n_{N}}\left(\sum_{t_{k}=t_{1}}^{t_{k}=t_{p}} Q_{N i}\left(t_{k}\right) \cdot H_{N i}\left(t_{k}\right) \cdot \Delta t\right)+\gamma \cdot \sum_{i=1}^{i=n_{P}}\left(\sum_{t_{k}=t_{1}}^{t_{k}=t_{p}} Q_{P i}\left(t_{k}\right) \cdot H_{P i}\left(t_{k}\right) \cdot \Delta t\right)= \\
=\gamma \cdot \sum_{i=1}^{i=n}\left(\sum_{t_{k}=t_{1}}^{t_{k}=t_{p}} q_{u i}\left(t_{k}\right) \cdot H_{i}\left(t_{k}\right)\right) \cdot \Delta t+\gamma \cdot \sum_{i=1}^{i=n}\left(\sum_{t_{k}=t_{1}}^{t_{k}=t_{p}} q_{l i}\left(t_{k}\right) \cdot H_{i}\left(t_{k}\right)\right) \cdot \Delta t+ \\
+\sum_{i=1}^{n_{c}} \frac{\gamma \cdot A_{i}}{2}\left(z_{i}^{2}\left(t_{f}\right)-z_{i}^{2}\left(t_{i}\right)\right)+\gamma \cdot \sum_{j=1}^{j=n_{L}}\left(\sum_{t_{k}=t_{1}}^{t_{k}=t_{p}}\left(q_{u j}\left(t_{k}\right)+q_{l j}\left(t_{k}\right)\right) \cdot \Delta h_{j}\left(t_{k}\right)\right) \cdot \Delta t
\end{aligned}
$$

El término de compensación, sólo es relevante en simulaciones con periodos de tiempo cortos, ya que éste término tiene un valor máximo independiente de la duración del análisis, al contrario que el resto. Por ello, es importante definir cuando una simulación es a corto y cuando a largo plazo (en el primero el término de energía almacenada en el depósito de compensación es significativo mientras que en el segundo no). Para ello, se define el tiempo "frontera" $\left(t_{p, B}\right)$ imponiendo que la máxima energía de compensación $\left(\Delta E_{C \max }\right)$ sea un mínimo porcentaje de la energía entrante en el sistema $\left(E_{\text {lnput }}\right)$. Si se fija el $1 \%$, resulta la siguiente expresión:

$$
t_{p, B}(\text { días })=\frac{\Delta E_{c, \max }}{\frac{1}{100} \cdot E_{\text {Input }}(\text { diaria })}
$$

\footnotetext{
45 Por mantener la misma nomenclatura que la empleada en el artículo "Energy audit of Water Networks" (Cabrera y col., 2009), no se traducirán al castellano los términos de la ecuación anterior.
} 
Por tanto, si la auditoria energética se realiza en un periodo anual, el término de compensación, puede ser eliminado de la (6.15), resultando la ecuación simplificada (6.17), válida para tiempos de cálculo mayores que el tiempo $t_{p, B}$.

$E_{\text {lnput }}=E_{N}\left(t_{p}\right)+E_{P}\left(t_{p}\right)=E_{U}\left(t_{p}\right)+E_{L}\left(t_{p}\right)+E_{F}\left(t_{p}\right)=E_{\text {Output }}+E_{\text {Dissipated }}$

La auditoría energética necesita previamente la hídrica (tal y como se ha justificado previamente). El balance hídrico se acostumbra a plantear sobre periodos anuales, para permitir el cálculo adecuado de indicadores hídricos de gestión (IWA 2006), lo habitual será plantear la auditoría energética (a partir de la ecuación anterior) también en ese periodo de tiempo. Ésta se puede representar de manera gráfica cual sigue (Tabla 69):

TABLA 69. ESQUEMA DE LA AUDITORÍA ENERGÉTICA EN EL LARGO PLAZO EN UNA RED.

\begin{tabular}{|c|c|c|c|}
\hline \multirow{3}{*}{$E_{\text {Input }}$} & \multirow{2}{*}{$\begin{array}{c}E_{N}\left(t_{p}\right) \\
\text { (Energía natural suministrada) }\end{array}$} & $\begin{array}{c}E_{U}\left(t_{p}\right) \\
\text { (Energía útil cedida con la demanda de } \\
\text { caudal de los usuarios) }\end{array}$ & \multirow{2}{*}{$E_{\text {Output }}$} \\
\hline & & $\begin{array}{c}E_{L}\left(t_{p}\right) \\
\text { (Energía asociada a las fugas) }\end{array}$ & \\
\hline & $\begin{array}{c}E_{P}\left(t_{p}\right) \\
\text { (Energía de eje) }\end{array}$ & $\begin{array}{l}\qquad E_{F}\left(t_{p}\right) \\
\text { (Energía invertida en vencer el } \\
\text { rozamiento) }\end{array}$ & $E_{\text {Dissipated }}$ \\
\hline
\end{tabular}




\subsection{Indicadores energéticos básicos}

El indicador energético tradicional se plantea exclusivamente para los equipos de bombeo de la red y se expresa en $\mathrm{kWh} / \mathrm{m}^{3}$, resultado de dividir el trabajo de eje y el volumen de agua inyectado. Los indicadores propuestos a continuación proporcionan una idea rápida y calibrada de aspectos básicos relacionados con la totalidad del servicio y tienen sentido, en línea con lo expresado, en el largo plazo, lo que permite ignorar el término de compensación. Las energías piezométricas están referidas al nudo de cota menor, al que se le asigna el valor $\mathrm{Z}=0$.

En principio, se definen dos indicadores de contexto y seis indicadores energéticos de gestión. Los primeros, tal y como se define en el manual de indicadores de gestión del IWA (Alegre y col., 2006), son independientes de la gestión del sistema y que dependen por tanto de las características físicas particulares de la red. Los segundos sí que facilitan información concreta del estado de la red y son por tanto modificables de acuerdo con las políticas orientadas a reducir el consumo energético).

\subsubsection{Indicadores de contexto del sistema}

Cada abastecimiento tiene, desde la óptica energética, unas características físicas diferentes. Pueden existir o no desniveles entre las distintas zonas del mismo y requerir bombeos en cabecera o intermedios. Por ejemplo, el caso más favorable energéticamente hablando sería una red abastecida por un embalse en cabecera sin necesidad de bombeo, mientras que el caso contrario sería el suministro de agua procedente de aguas subterráneas. La diferencia entre estas dos situaciones extremas la visualizaría el indicador de contexto $c_{1}$ Tabla 70.

El valor máximo que puede tomar $c_{1}$ es igual la unidad cuando toda la energía inyectada en la red es gravitatoria, gracias a la cota suficiente de los depósitos de cabecera. Sería cero en caso contrario, es decir, cuando toda la energía inyectada procede de bombeos. Los valores intermedios de la horquilla $(0,1)$ dependen, para un mismo sistema, de las cotas de la red. 
Además de la procedencia de la energía, también es de interés conocer la mayor o menor dificultad de gestionar una red energéticamente, es decir manteniendo el nivel de presiones ligeramente superior al mínimo exigido y lo más constante posible. Así que, el segundo indicador de contexto $c_{2}$ resume las exigencias energéticas de la red. Es el cociente entre la energía mínima útil necesaria ( $\left.E_{\text {min,useful }}\right)$ definida en cada nudo a partir de la altura mínima de servicio $\left(h_{\text {Min }, i}=z_{i}+P_{\text {Min }} / \gamma\right)$ y la energía mínima teórica requerida por una red plana e ideal

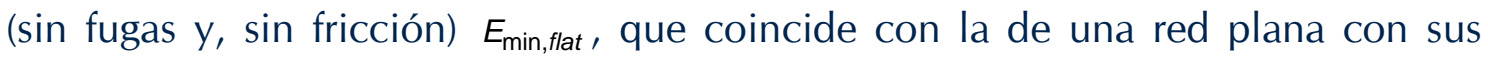
nudos de consumo ubicados a la cota máxima, $Z_{\max }$. Los valores que $c_{2}$ puede tomar quedan tan sólo restringidos a los números positivos, y cuanto mayor sea su cuantía, mayor serán los desniveles topográficos entre los nudos de la red. El valor más favorable de $C_{2}$ es la unidad, red completamente plana.

TABLA 70. INDICADORES DE CONTEXTO DEL SISTEMA.

\begin{tabular}{|c|c|}
\hline $\begin{array}{c}C_{1} \\
\text { Procedencia de la } \\
\text { energía }\end{array}$ & $\begin{array}{l}\qquad C_{2} \\
\text { Exigencia energética de la red }\end{array}$ \\
\hline$C_{1}=\frac{E_{N}\left(t_{p}\right)}{E_{\text {Input }}\left(t_{p}\right)}$ & $C_{2}=\frac{E_{\min , u s e f u l}}{E_{\min , f l a t}}=\frac{\gamma \cdot \sum_{t_{k}=t_{1}}^{t_{k}=t_{p}} \sum_{i=1}^{i=n} q_{u i}\left(t_{k}\right) \cdot\left(h_{\min }\right)_{i} \cdot \Delta t}{\gamma \cdot \frac{P_{\min }}{\gamma} \cdot \forall_{U}\left(t_{p}\right)}=\frac{\sum_{i=1}^{i=n} \theta_{u, i}\left(t_{p}\right) \cdot h_{\min , i}}{\frac{P_{\min }}{\gamma} \cdot \forall_{U}\left(t_{p}\right)}$ \\
\hline
\end{tabular}

\subsubsection{Indicadores energéticos del sistema}

Los indicadores energéticos definidos (Tabla 71) permiten determinar cuan eficiente es la operación de la red y son modificables mediante las operación del sistema.

- El primer indicador $\left(l_{1}\right)$ es el cociente entre la energía real entrante en el sistema y la energía mínima útil necesaria ya definida. Representa, pues, las veces en que la energía entrante real excede a la energía útil teórica necesaria.

- El segundo indicador $\left(I_{2}\right)$ es el cociente entre la energía útil y la entrante al sistema. El fin último de la energía aportada a una red es dar servicio a los abonados e $I_{2}$ representa un primer rendimiento y subraya el porcentaje de la energía inyectada en cabecera de red que es útil. Cuanto mayor sea el valor de $I_{2}$ mayor es la eficiencia energética en la distribución de agua, siendo físicamente imposible alcanzar el valor ideal de la unidad. 
- El tercer indicador $\left(I_{3}\right)$ representa la capacidad hidráulica de la red para cumplir adecuadamente con su función de distribución de agua, la cual exige, sobre todo, que el dimensionamiento de las conducciones sea correcto. Si ello no es así, las pérdidas de carga resultarían excesivas suponiendo un malgasto energético innecesario. Si bien este indicador no puede tomar el valor ideal de cero, puesto que eliminar las pérdidas de carga es imposible, debe mantenerse en cifras razonables (0.2-0.4).

- El cuarto indicador $\left(I_{4}\right)$ representa la energía perdida debida a las fugas, suma de la energía inherente a ellas $\left(E_{L}\left(t_{p}\right)\right)$ más la energía de fricción adicional que generan (diferencia entre la energía de fricción real $\left(E_{F}\left(t_{p}\right)\right)$ y la energía de fricción de la misma red sin fugas, $\left.E_{F}^{\prime}\left(t_{p}\right)\right)$.

- El quinto indicador $\left(I_{5}\right)$ es directamente el cociente entre la energía entregada a los usuarios y la energía mínima útil necesaria. A primera vista, $I_{5}$ puede adoptar los siguientes valores:

$I_{5}<1$. Este sería un rango de valor propio para redes con un nivel insuficiente de presiones, y por tanto una calidad deficiente del servicio a los usuarios. El valor mínimo para una red sería el correspondiente al caso particular de que suministrase el agua directamente a aljibes subterráneos que los usuarios tengan instalados en sus domicilios. La presión de suministro sería entonces la atmosférica, que, tomando un valor cero como presión relativa, daría lugar a su vez a que el numerador de $I_{5}$ (Tabla 71) sea igual a: $\gamma \cdot \sum_{i=1}^{i=n}\left(\sum_{t_{k}=t_{1}}^{t_{k}=t_{p}} q_{u i}\left(t_{k}\right) \cdot z_{i}\right) \cdot \Delta t$.

$I_{5}>1$. Probablemente la situación más frecuente, ya que por seguridad en el servicio, la gestión de la red mantendrá niveles de presión por encima (aunque sólo sea ligeramente) de los mínimos necesarios. Cuanto más se acerque a la unidad el valor de este indicador, mayor será la eficiencia en la gestión de presiones de la red desde la perspectiva del servicio a los usuarios. De otra parte, ese exceso de energía, potencialmente recuperable, depende fundamentalmente del umbral mínimo de sobrepresión $\Delta$ pmin (el menor valor de la diferencia pservicio - pmin para todos los nudos y todos los intervalos de simulación). Sin embargo, la posibilidad real de recuperar esa energía potencial depende de las características y del modo de operación de la red. 
También puede acontecer que, aun siendo $I_{5}>1$, algún nudo no satisfaga el estándar de presión, en cuyo caso $\Delta$ pmin sería negativo.

- El sexto indicador $(k)$ es el cociente entre la energía aportada por los equipos de bombeo en la red con fugas y el mismo término para la red completamente renovada. Se denomina $k$ y no $l_{6}$ por mantener la nomenclatura utilizada en la obtención del periodo óptimo de renovación (capítulo 4). Se refiere únicamente a la energía consumida por las bombas por ser la que es de tipo artificial y la que supone un gasto económico para la compañía que gestiona la red. Siempre adopta valores iguales o mayores a 1.

TABLA 71. INDICADORES DE EFICIENCIA ENERGÉTICA

\begin{tabular}{|c|c|c|}
\hline $\begin{array}{c}\qquad l_{1} \\
\text { Exceso de energía suministrada }\end{array}$ & $\begin{array}{l}I_{2} \\
\text { Eficiencia de la red }\end{array}$ & $\begin{array}{l}\qquad I_{3} \\
\text { Energía de fricción }\end{array}$ \\
\hline$I_{1}=\frac{E_{\text {input }}\left(t_{p}\right)}{\sum_{i=1}^{n} \theta_{u, i}\left(t_{p}\right) \cdot h_{\min , i}}$ & $I_{2}=\frac{E_{U}\left(t_{p}\right)}{E_{\text {Input }}\left(t_{p}\right)}$ & $I_{3}=\frac{E_{F}\left(t_{p}\right)}{E_{\text {Input }}\left(t_{p}\right)}$ \\
\hline $\begin{array}{l}\qquad I_{4} \\
\text { Energía total asociada a las fugas }\end{array}$ & $\begin{array}{c}I_{5} \\
\text { Suficiencia en el } \\
\text { cumplimiento de estándares }\end{array}$ & $\begin{array}{l}\qquad k \\
\text { Energía de bombeo adicional } \\
\text { generado por fugas }\end{array}$ \\
\hline$I_{4}=\frac{E_{L}\left(t_{p}\right)+E_{F}\left(t_{p}\right)-E_{F}^{\prime}\left(t_{p}\right)}{E_{\text {Input }}\left(t_{p}\right)}$ & $I_{5}=\frac{E_{U}\left(t_{p}\right)}{\gamma \cdot \sum_{i=1}^{n} \theta_{u, i}\left(t_{p}\right) \cdot h_{\min , i}}$ & $k=\frac{E_{P}\left(t_{p}\right)}{E_{P}^{\prime}\left(t_{p}\right)}$ \\
\hline
\end{tabular}

\subsection{Energía asociada a las fugas existentes de una red}

El análisis de los términos energéticos evidencia que las fugas de agua existentes en una red de tuberías tienen una influencia directa en dos de ellos:

- En la energía que escapa de la red con el agua fugada, puesto que ésta "vierte" al exterior, sin ningún provecho, la presión que tiene en el interior de la tubería.

- En la energía empleada en vencer la fricción con las tuberías. Evidentemente, el agua fugada primero ha circulado por las tuberías de la red y ha obligado a un gasto de energía adicional.

Así la auditoría energética presentada, y que se ilustra con un ejemplo numérico en el apartado siguiente, proporciona una idea cuantificada del origen y destino de cada término energético, también de los dos términos relacionados con la existencia de fugas (los dos anteriores), aunque no ofrece en una única cifra del 
sobreconsumo total de energía que las fugas conllevan. En una palabra, el peaje energético que representan.

Calcular tal peaje energético, sin embargo, no resulta difícil utilizando de nuevo, la propia auditoría energética. Para ello, bastaría con realizar una simulación y balance de la red de distribución en la que se hayan eliminado todas las fugas (idealmente, todas ellas habrían sido reparadas). Los resultados de la auditoría en esta situación mostrarían las cifras de términos energéticos (entrantes y salientes) que tendría nuestra red en una situación ideal de ausencia de fugas. Restando de forma conjunta los términos entrantes correspondientes a la situación real (con fugas) menos los términos entrantes de la situación ideal (sin fugas) se obtendría la influencia total de la existencia de las fugas en la fase de distribución, el peaje buscado. Obviamente, igual resultado se tendría restando los términos salientes y de consumo por fricción de ambas situaciones.

\subsection{Ejemplo numérico}

Para ilustrar la auditoría presentada, así como el uso de los indicadores, a continuación se va a aplicar la misma en un caso de estudio, a lo largo del cual se van a destacar las distintas particularidades de cálculo de cada término energético en un análisis tanto a largo como a corto plazo. Si bien, desde un punto de vista conceptual, resulta coherente realizar la auditoría para los dos periodos de tiempo indicados, desde un punto de vista pragmático, es la aplicación a largo plazo (anual), la que resulta de mayor utilidad ya que es la utilizada como referencia para la comparación de resultados e indicadores. Como los balances hídricos se plantean coincidiendo con periodos de lectura de los contadores (mensual, trimestral o anual), lo habitual es plantear auditorías en el largo plazo.

\subsubsection{Planteamiento del caso}

La Figura 106 muestra el esquema de la red y la Tabla 72 detalla los datos de nudos y líneas. Al nudo 33, el de menor cota, se le asigna el valor cero y a él se refieren el resto de cotas. Las simulaciones se realizan utilizando el toolkit de EPANET 2.0 


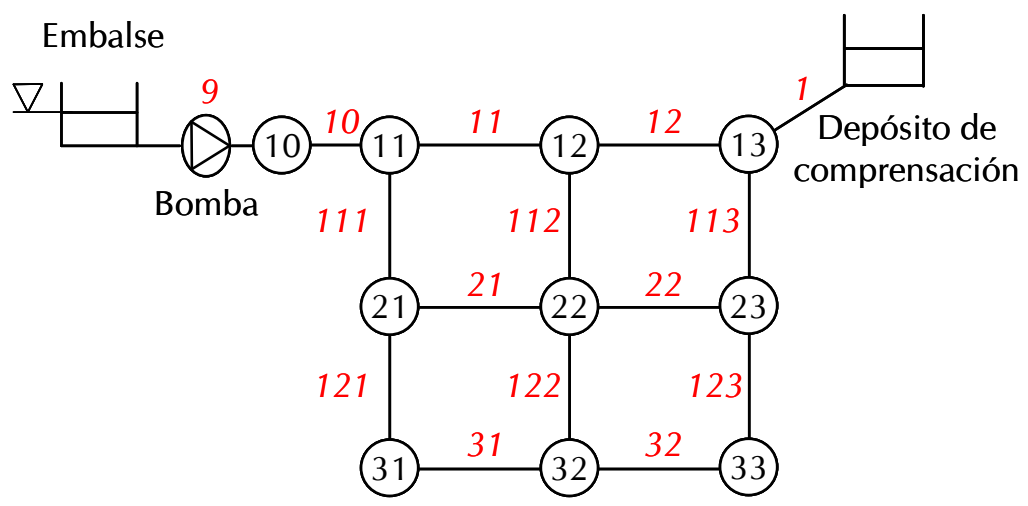

FIGURA 106. ESQUEMA GENERAL DE LA RED.

TABLA 72. CARACTERÍSTICAS PROPIAS DE LOS NUDOS Y LÍNEAS DE LA RED.

\begin{tabular}{ccc|cccc}
\hline Línea & $\begin{array}{c}\text { Longitud } \\
(\mathbf{k m})\end{array}$ & $\begin{array}{c}\text { Diámetro } \\
(\mathbf{m m})\end{array}$ & Nudo & $\begin{array}{c}\text { Demanda } \\
\text { Base }(\mathbf{l} / \mathbf{s})\end{array}$ & Cota $(\mathbf{m})$ & $\begin{array}{c}\text { Emisor } \\
\left(\mathbf{m}^{3-\alpha} / \mathbf{s}\right)\end{array}$ \\
\hline 10 & 2 & 400 & 10 & 0 & 5.8 & 0.002611285 \\
11 & 2 & 300 & 11 & 5 & 5.8 & 0.010445142 \\
12 & 2 & 350 & 12 & 5 & 4 & 0.010445142 \\
21 & 2 & 200 & 13 & 3 & 2 & 0.010445142 \\
22 & 2 & 200 & 21 & 5 & 4 & 0.013056427 \\
31 & 2 & 200 & 22 & 6.5 & 2 & 0.015667712 \\
111 & 4 & 200 & 23 & 5 & 0 & 0.013056427 \\
112 & 4 & 250 & 31 & 3 & 4 & 0.007833856 \\
113 & 4 & 300 & 32 & 3 & 5 & 0.010445142 \\
121 & 4 & 200 & 33 & 3 & 0 & 0.007833856 \\
122 & 4 & 200 & Embalse & - & 25 & - \\
123 & 4 & 200 & Depósito & - & 32 & - \\
32 & 2 & 200 & & & & \\
1 & 2 & 400 & & & & \\
\hline
\end{tabular}

TABLA 73. COEFICIENTES DE MODULACIÓN HORARIA DEL CAUDAL.

\begin{tabular}{ccccccccccccc}
\hline Hora & $\mathbf{1}$ & $\mathbf{2}$ & $\mathbf{3}$ & $\mathbf{4}$ & $\mathbf{5}$ & $\mathbf{6}$ & $\mathbf{7}$ & $\mathbf{8}$ & $\mathbf{9}$ & $\mathbf{1 0}$ & $\mathbf{1 1}$ & $\mathbf{1 2}$ \\
Coeficiente & 0.6 & 0.5 & 0.45 & 0.45 & 0.5 & 0.5 & 0.9 & 1.3 & 1.4 & 1.1 & 1.5 & 1.4 \\
\hline Hora & $\mathbf{1 3}$ & $\mathbf{1 4}$ & $\mathbf{1 5}$ & $\mathbf{1 6}$ & $\mathbf{1 7}$ & $\mathbf{1 8}$ & $\mathbf{1 9}$ & $\mathbf{2 0}$ & $\mathbf{2 1}$ & $\mathbf{2 2}$ & $\mathbf{2 3}$ & $\mathbf{2 4}$ \\
Coeficiente & 1.4 & 1.45 & 1.45 & 1.3 & 1.2 & 1.2 & 1.1 & 1.1 & 1.2 & 1.1 & 0.9 & 0.7 \\
\hline
\end{tabular}

La rugosidad de las tuberías es $0.1 \mathrm{~mm}$, el diámetro del depósito de compensación $20 \mathrm{~m}$, con su nivel oscilando entre $2.5 \mathrm{~m}$ (valor mínimo e inicial en la simulación) y $7 \mathrm{~m}$ (valor máximo). La curva de la bomba encargada de mantener la presión de servicio mínima (22 m.c.a.) en todos los nudos de consumo es $H=93.33-0.003646 \cdot Q^{2}$. Ésta arranca y para con los niveles extremos del depósito. Los dos períodos de simulación son un día para el corto plazo y un año para el largo plazo, valor que rebasa ampliamente el tiempo frontera entre el corto y el largo plazo (en este ejemplo, se verá, $\mathrm{t}_{\mathrm{p}, \mathrm{B}}=16$ días). 
La auditoría hídrica anual, con las pérdidas aparentes sumadas al agua suministrada, de la que se parte es:

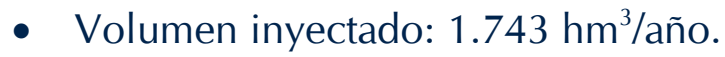

- Volumen consumido: 1.214 hm3/año.

- Volumen fugado: $0.529 \mathrm{hm}^{3} /$ año.

Tanto la demanda total de los abonados como los coeficientes de modulación horarios son los mismos cualquier día del año.

Los caudales de fuga nodales se determinan admitiendo que son proporcionales tanto a la presión del nudo como a la longitud de las tuberías que en él convergen (hipótesis de distribución uniforme) e imponiendo, además, el cumplimiento de la ecuación de continuidad (la suma en el tiempo de los volúmenes nodales fugados debe coincidir con el resultado de la auditoría volumétrica de partida). Cada fuga nodal se caracteriza con su correspondiente coeficiente de emisor (que es similar a una válvula de descarga a la atmósfera, Tabla 72) cuyos valores se determinan mediante aproximaciones sucesivas en un proceso de rápida convergencia descrito en Almandoz y col. (2005). El dimensionamiento de cada emisor se ha realizado siguiendo a Rossman (2000), según la ecuación (6.18).

$q_{l i}\left(t_{k}\right)=C_{E} \cdot \Delta H^{\alpha}$

Donde $C_{E}\left(\mathrm{~m}^{3-\alpha} / \mathrm{s}\right)$ es el coeficiente del emisor asignado a cada nudo del sistema, $\Delta H(\mathrm{~m})$ representa el salto de presiones que experimenta el agua al atravesar el orificio de fuga y $\alpha=1.2$ es el exponente de emisor que representa las características propias del material de la tubería y que adopta valores diferentes según el tipo de material de la tubería.

\subsubsection{Resultados}

La auditoría se resuelve para cuatro casos que se corresponden a la simulación diaria y anual tanto de la red real (con fugas) como de la ideal (sin fugas). Se analiza el consumo energético en ambas redes con la intención de mostrar la reducción del mismo en el caso de la eliminación de las fugas. Asimismo, estos cálculos se realizan en el corto plazo (recogiendo datos cada minuto para el cálculo de la auditoría) y en el largo plazo (datos obtenidos cada 15 minutos) para mostrar la desaparición de la influencia del depósito de compensación.

El periodo en el que se realiza la simulación a corto plazo es $t_{p}=1$ día, mientras que en la simulación a largo plazo $t_{p}=1$ año, un plazo de tiempo muy superior al 
tiempo frontera $\left(t_{p, B}=16\right.$ días, ecuación 6.16). Éste se ha calculado a partir de la energía diaria entrante (que se obtiene con la simulación diaria (Tabla 74), $E_{\text {input }}\left(t_{p}\right)=1364.41 \mathrm{kWh} /$ día) y la máxima variación en el depósito de compensación $\left(\Delta E_{c, \max }=218.62 \mathrm{kWh}\right)$.

Los cuatro casos calculados se muestran en la Tabla 74.

TABLA 74. AUDITORÍA ENERGÉTICA EN LA RED CON FUGAS Y SIN FUGAS.

\begin{tabular}{|c|c|c|c|c|c|}
\hline \multirow{2}{*}{} & \multicolumn{2}{|c|}{ Red con fugas } & \multicolumn{2}{c|}{ Red sin fugas } \\
\cline { 3 - 6 } \multicolumn{2}{|c|}{ Energía } & $\begin{array}{c}\text { Corto Plazo } \\
t_{p}<t_{p, B} \\
(\mathrm{kWh} / \mathrm{d} \text { ía) }\end{array}$ & $\begin{array}{c}\text { Largo Plazo } \\
t_{p}>t_{p, B} \\
(\mathrm{MWh} / \mathrm{año})\end{array}$ & $\begin{array}{c}\text { Corto Plazo } \\
t_{p}<t_{p, B} \\
(\mathrm{kWh} / \mathrm{d} \text { áa })\end{array}$ & $\begin{array}{c}\text { Largo Plazo } \\
t_{p}>t_{p, B} \\
(\mathrm{MWh} / \mathrm{año})\end{array}$ \\
\hline \multirow{2}{*}{$E_{\text {lnput }}\left(t_{p}\right)$} & $E_{N}\left(t_{p}\right)$ & $386.66(28.3 \%)$ & $118.75(28.7 \%)$ & $322.52(27.3 \%)$ & $82.79(27.7 \%)$ \\
& $E_{P}\left(t_{p}\right)$ & $977.75(71.7 \%)$ & $294.76(71.3 \%)$ & $857.95(72.7 \%)$ & $215.60(72.3 \%)$ \\
\hline \multirow{2}{*}{$E_{\text {Output }}\left(t_{p}\right)$} & $E_{U}\left(t_{p}\right)$ & $453.20(33.2 \%)$ & $169.13(40.9 \%)$ & $501.71(42.5 \%)$ & $179.73(60.2 \%)$ \\
& $E_{L}\left(t_{p}\right)$ & $232.67(17.1 \%)$ & $77.53(18.8 \%)$ & $-(0 \%)$ & $-(0 \%)$ \\
\hline$E_{\text {Dissipated }}\left(t_{p}\right)$ & $\Delta E_{C}\left(t_{p}\right)$ & $128.87(9.4 \%)$ & $0.17(0.0 \%)$ & $217.28(18.4 \%)$ & $0.20(0.1 \%)$ \\
\hline
\end{tabular}

Las energías teóricas definidas, $E_{\text {min,useful }}$ y $E_{\text {min,flat }}$, son en este caso iguales a $251.99 \mathrm{kWh} /$ día (80.18 MWh/año) (red real con fugas y en el corto y el largo plazo respectivamente) y $219.67 \mathrm{kWh} /$ día (91.98 MWh/año) (red ideal sin fugas). Ambos valores son similares entre sí lo cual se corresponde a una red casi plana. De otra parte, los resultados de la Tabla 74 muestran que:

- En una red sin fugas no sólo hay un ahorro de energía neta entrante (298.40 MWh/año frente a 413.51 MWh/año), sino que también sus prestaciones mejoran de modo significativo. Una clara evidencia es la mayor cantidad de energía que reciben los usuarios (179.73 MWh/año frente a $169.13 \mathrm{MWh} / \mathrm{año}$ ), con todas las posibilidades de mejora que esto ofrece (y que se muestra en el indicador $I_{5}$ ). Una red sin fugas implica un mayor valor de $I_{5}$, una mayor capacidad hidráulica del sistema (que permite un mejor posicionamiento de la infraestructura frente a ampliaciones futuras) y un mayor nivel de presiones (que básicamente representan una oportunidad de reducción de los bombeos). La cuantificación de estas mejoras la proporciona la diferencia de presiones mínimas $\left(\Delta \mathrm{p}_{\min }\right)$ que para la red con fugas es 1.05 m.c.a. en la simulación a corto plazo, y 0.21 m.c.a. en el largo plazo. Valores que aumentan hasta 6.85 m.c.a y 6.69 m.c.a., respectivamente, en el caso de la red sin fugas. Estos mínimos se registran cuando la red se alimenta desde el depósito de 
compensación en el nudo 31. La recuperación (parcial o total) de estos sobrantes de energía requiere optimizar las condiciones de operación del sistema.

- La energía perdida inherente a las fugas es 77.53 MWh/año pero el total de pérdidas que generan es aún mayor porque a esta cifra hay que añadirle la mayor exigencia en energía de fricción (la diferencia entre los 166.86 $\mathrm{MWh}$ /año de la red con fugas por los 118.63 MWh/año de la red ideal). En definitiva, el ahorro total anual es de $125.76 \mathrm{MWh} / a n ̃ o$ (un $30.4 \%$ de la energía puesta en juego).

- Si se observan los términos porcentuales, la auditoría indica que mientras en el caso de la energía entrante apenas hay variación, la diferencia es notable cuando se observa la energía útil entregada a los usuarios. La diferencia que al analizar los dos escenarios se observa se debe a la significativa participación en el corto plazo de la energía de compensación del depósito.

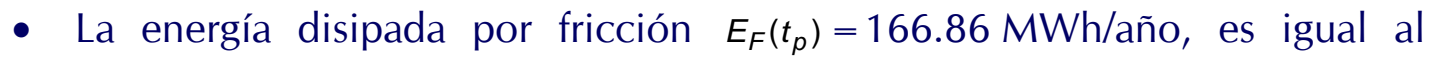
incremento de energía interna $\rho \cdot\left(\sum_{i=1}^{i=n} Q_{O i} u_{O i}-\sum_{i=1}^{i=n_{N}} Q_{N i} u_{N i}\right)=E_{F}\left(t_{p}\right)$ ya que no hay calor intercambiado. Bajo estas condiciones, la temperatura del agua aumenta $0.08^{\circ} \mathrm{C}$ en media (siendo $\rho=1000 \mathrm{~kg} / \mathrm{m}^{3}, C_{p}=4180 \mathrm{~J} / \mathrm{kg} / \mathrm{K}$ y $\left.\Delta u=C_{p} \cdot \Delta T\right)$.

\subsubsection{Valoración de la gestión energética de la red con los nuevos indicadores.}

Antes de proceder a valorar de qué modo los indicadores definidos pueden contribuir tanto a mejorar la gestión energética de una red como a posibilitar la comparación entre los niveles de eficiencia de las distintas redes de agua, convendrá, como cuestión previa, decir que los indicadores pueden calcularse con los resultados de cualquier auditoría aunque en las realizadas sobre un periodo de tiempo corto la presencia de depósitos de compensación puede distorsionar el valor de los indicadores definidos. Al igual que muchos indicadores del manual del IWA (Alegre y col., 2006), los indicadores aquí presentados se tienen que plantear sobre un balance anual.

Unos indicadores que amplían la información básica del habitualmente empleado por las compañías de agua, el consumo de energía en las bombas por metro cúbico $\left(\mathrm{kWh} / \mathrm{m}^{3}\right)$, y que puede referirse a dos volúmenes, agua inyectada o consumida. En el ejemplo numérico los valores obtenidos son $\left(0.17 \mathrm{kWh} / \mathrm{m}^{3}\right.$ inyectado 
y $0.24 \mathrm{kWh} / \mathrm{m}^{3}$ registrado) para la red con fugas y $\left(0.18 \mathrm{kWh} / \mathrm{m}^{3}\right.$, pues en este caso los dos volúmenes coinciden) en el caso sin fugas. Este indicador calculado con el caudal inyectado es más favorable en una red real con fugas que en otra sin éstas $\left(0.17 \mathrm{kWh} / \mathrm{m}^{3}\right.$, frente a $\left.0.18 \mathrm{kWh} / \mathrm{m}^{3}\right)$ valor ligeramente superior porque en este supuesto se entrega más energía útil a los usuarios (Tabla 74). Si este indicador se refiere al caudal entregado, el asunto no admite discusión $\left(0.24 \mathrm{kWh} / \mathrm{m}^{3}\right.$ por 0.18 $\left.\mathrm{kWh} / \mathrm{m}^{3}\right)$.

Los gestores de la red son sensibles al indicador anterior (energía por unidad de volumen) cuando el coste energético del agua es elevado (agua provinente de desaladora o subterránea). Aunque los sistemas abastecidos por gravedad (la energía entrante a la red es toda de tipo natural) no tengan interés por optimizar el uso de la energía porque para su consumo no tiene ningún coste, sí que las características del escenario actual (con escasez de agua, con precios elevados del agua, de la energía, y con la responsabilidad de reducir las emisiones de gases de efecto invernadero para mitigar las consecuencias del cambio climático) generan la necesidad de reducir el consumo energético, aumentar la capacidad hidráulica y recuperar parte de la energía invertida. Ésta última se puede realizar con el empleo de pequeñas turbinas que aprovechen los excesos de presión en ciertos sectores de la red y produzcan energía eléctrica.

La Tabla 75 presenta, para ambos escenarios, el valor de los nuevos indicadores energéticos calculados con los resultados de las auditorías anuales. Todos ellos, excepto los de contexto, que son independientes de las fugas, mejoran al eliminar éstas, si bien el repunte de $I_{5}$ se debe a la entrega al usuario de más energía útil. Particularmente relevante es la mejora de $I_{4}$, aunque estando este indicador directamente ligado a las fugas, no podía ser de otro modo.

TABLA 75. INDICADORES DE GESTIÓN ENERGÉTICOS.

\begin{tabular}{ccccccccc}
\hline & $C_{1}$ & $C_{2}$ & $I_{1}$ & $I_{2}$ & $I_{3}$ & $I_{4}$ & $I_{5}$ & $k$ \\
\hline Escenario con fugas & 0.28 & 1.15 & 5.16 & 0.41 & 0.40 & 0.30 & 2.11 & 1.37 \\
Escenario sin fugas & 0.28 & 1.15 & 3.72 & 0.60 & 0.40 & 0 & 2.24 & 1 \\
\hline
\end{tabular}

Pero además, como precedente de la comparación global, cada indicador ofrece información relevante por sí mismo. Siendo los dos primeros de contexto, apenas dependen del escenario. El primero indica que sólo un $28 \%$ de la energía entrante es natural mientras el segundo, con un valor muy próximo a la unidad, indica que la red es prácticamente plana. Por lo que a los cinco indicadores energéticos se refiere, el primero $l_{1}$ indica que la energía entrante en la red es más de 5 veces superior a la estrictamente necesaria, por lo que el margen de mejora de la gestión energética la red es notable. Así lo evidencia la supresión de las fugas, que reduce 
a 3.72 este indicador. Para mejorarlo más habría que recurrir a otras estrategias, tales como redimensionar la red haciéndola menos resistiva o bien instalando una bomba de velocidad variable que ajustase mejor la presión a los valores requeridos.

El segundo indicador energético $I_{2}$ indica qué porcentaje del total de energía ( $41 \%$ en la red con fugas) se entrega a los usuarios. Su valor complementario, 59\%, expresa la parte de energía no útil (perdida en fugas o en fricción). Eliminando las fugas, este indicador pasa a ser de un $60 \%$, es decir mejora en casi un $50 \%$.

El tercer indicador $I_{3}$ representa el porcentaje de energía invertida en vencer el rozamiento de las tuberías. Un valor tan alto, 40\%, indica que la longitud de la red es notable, que sus diámetros están un tanto ajustados o, en fin, una combinación de ambos. En nuestro ejemplo, tal cifra de $40 \%$ para ambos escenarios (disminuyendo las fugas, la energía por fricción disminuye, pero también lo hace la energía entrante) resulta un tanto alta por lo que conviene estudiar la sustitución de algunas tuberías clave por otras de diámetro mayor.

Pero de entre todos los indicadores es el cuarto $I_{4}$ el más novedoso. Indica qué parte del total de energía inyectada se pierde con las fugas. Con todo, si se desease contabilizar toda la energía perdida con las fugas (y no sólo las que corresponden a la fase de distribución), hay que contemplar el origen del agua fugada, pues no es lo mismo que el agua proceda de una desaladora que de una fuente natural. Dicho de otro modo, habría que considerar las huellas energéticas del agua correspondientes a las fases precedentes (desde la captación hasta el ingreso en la red de distribución).

El indicador $I_{5}$ expresa cuánta energía de más se entrega a los usuarios o, de otro modo, el exceso en el cumplimiento del estándar de presión previamente establecido. Cualquier elemento de regulación, como una válvula o bien una bomba de regulación variable, mejoraría este indicador.

Por último, el indicador $k$ muestra que por efecto de las fugas, la energía aportada por los equipos de bombeo es un 37\% mayor de la estrictamente necesaria. Este valor es similar al empleado en el ejemplo numérico de los capítulos 4 y 5.

A partir de estos indicadores se puede discernir de entre las estrategias posibles, cuál conviene abordar para mejorar la gestión energética del sistema, así como el margen de mejora que es razonable esperar conseguir. 


\subsection{El camino a seguir en España y principales obstáculos a vencer}

El reto final que el trinomio agua, energía y cambio climático contemplado como un todo plantea es racionalizar el uso de dos recursos (el agua y la energía) clave para el bienestar de la sociedad. Un objetivo con beneficios colaterales notables como la reducción de la emisión de gases de efecto invernadero, la mejora de la garantía de suministro y el amortiguamiento de los impactos derivados de un cambio climático que acecha. Para conseguirlo hay dos vías de actuación, la mejora de los procesos y la mejora de la gestión. La primera, desde siempre considerada, tiene la ventaja de poder abordarse de manera aislada para cada una de las etapas, una razón que explica la apuesta por la desalación del Ministerio de Medio Ambiente y del IDAE.

Sin embargo mejorar la gestión, pese a su superior margen, no ha merecido hasta ahora la menor atención. Sin duda porque es una tarea mucho más compleja y de resultados palpables en el medio - largo plazo. Exige coordinar administraciones, educar a los ciudadanos e introducir mecanismos económicos que propicien el uso racional del agua. Los obstáculos a salvar son tan complejos como evidentes. Superar las barreras institucionales (el estado de las autonomías y la atomización de competencias plantea retos formidables) comenzando por las de la administración del agua. Y con la política hídrica bien coordinada integrar también la política energética. Sólo de esta manera será de utilidad Ilevar a la práctica las acciones (la lista no es exhaustiva) que seguidamente se enumeran:

- Auditar todos los usos del agua. Al respecto existe un notable déficit dado que la administración no tiene un buen conocimiento de los consumos. No sabe ni el agua que pierden las redes, ni se conocen los consumos reales (urbanos o agrícolas). No extraña, pues, que en los planes de cuenca las demandas se estimen. La determinación de estos consumos con total precisión, si bien es una decisión política, únicamente requiere del empleo de los medios humanos y técnicos necesarios.

- Desarrollar buenas métricas de cálculo de las huellas energéticas del agua (HEA) correspondientes a los distintos ciclos del agua. A partir de ellas, y del conocimiento (que no estimación) de los usos, es inmediato relacionar los ahorros de agua con los energéticos.

- Implantar mecanismos económicos y sistemas tarifarios que propicien el uso eficiente del agua y, en consecuencia, de la energía.

- Incluir en los análisis tanto los costes ambientales como los costes energéticos asociados a los ciclos de vida de los materiales que intervienen en las soluciones que se exploren. 
- Optar siempre por la solución que presente la mejor relación coste beneficio.

- Educar y sensibilizar a la ciudadanía. Introducir mecanismos económicos y de control no es, pese a su necesidad, plato de buen gusto. El ciudadano debe entender la razón del esfuerzo que se le pide para, de este modo, apoyar una acción política a priori impopular.

Con todo, una relación de acciones, tan extensa pese a lo incompleta, debe ser ordenada en el tiempo. Por ello la respuesta a la pregunta ¿por dónde empezar? es única. Por la coordinación de las administraciones implicadas, para que todas juntas, apoyándose en un comité de expertos, delineen un Plan de Actuación integrado. Ya hay casuística al respecto, la liderada por el Departamento de Energía (DOE) del Congreso de los Estados Unidos que, en los primeros meses de 2005, encarga a los Laboratorios Sandia una hoja de ruta que conduzca a optimizar el uso conjunto del agua y la energía. Tras un proceso bien descrito en la literatura (Hightower, 2005) el resultado final es el ya citado informe (DOE, 2006) que el Departamento de Energía eleva al Congreso de los Estados Unidos. Su contenido está basado, obviamente, en el trabajo de más de un año de una amplia Comisión de Expertos.

Un informe que concreta el papel del Gobierno Federal en tres acciones:

- Coordinar las administraciones.

- Plantear análisis globales porque lo que conviene desde una óptica puede que no sea lo mejor desde otra óptica alternativa.

- Optimizar las sinergias de las infraestructuras hídricas y energéticas.

La Figura 107 es la imagen que resumen las tres acciones precedentes. Un puzzle complejo de encajar que, trasladado a nuestro país, sugiere que la Secretaría de Estado de Cambio Climático, que es dependiente del Ministerio de Medio Ambiente, no debiera estar tan ligada a una óptica determinada y que estaría mejor adscrita a la Presidencia de Gobierno. Así sería más fácil realizar planteamientos en beneficio del todo y no de algunas de las partes. Porque el trinomio agua-energía-cambio climático es cuestión que afecta de manera muy directa a dos Ministerios (Medio Ambiente e Industria), pero no sólo a ellos. También, por las implicaciones económicas del asunto, afecta, y no poco, al Ministerio de Economía y Hacienda. 


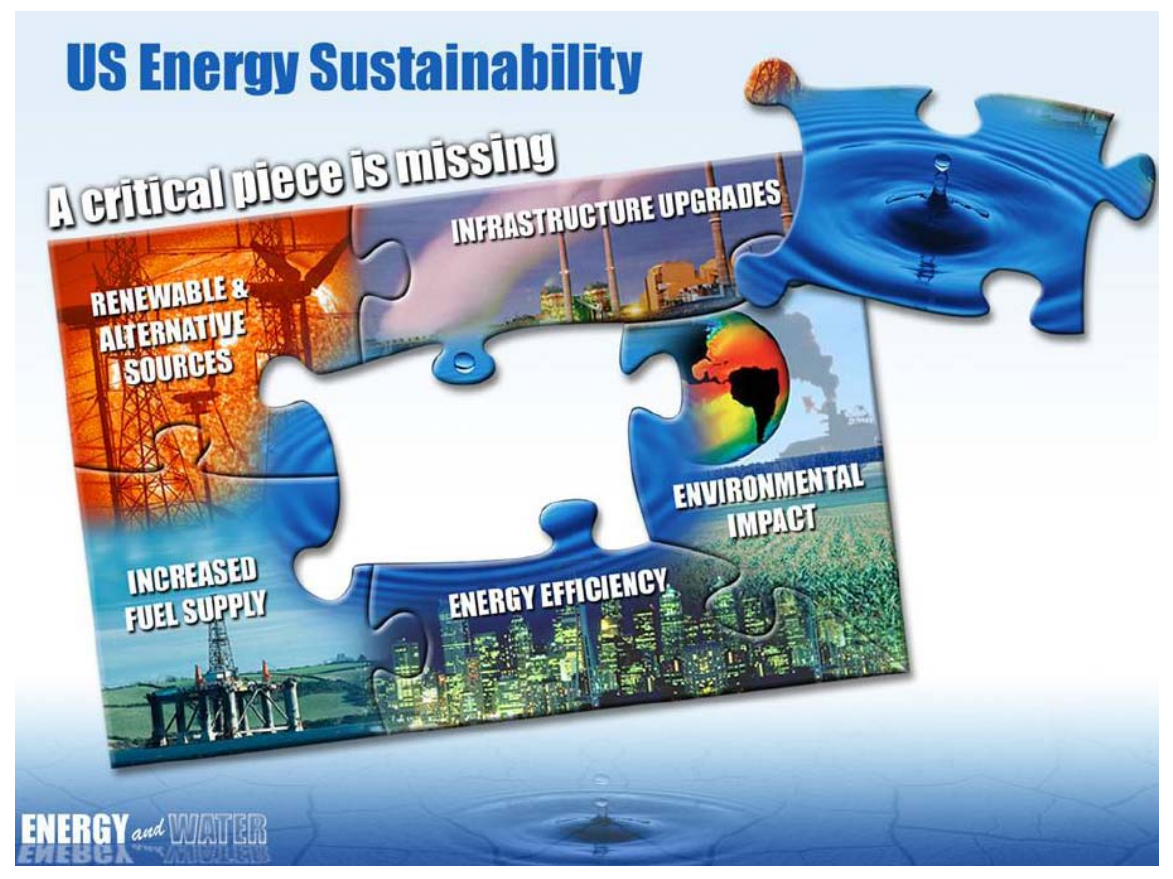

FIGURA 107. El COMPLEJO PUZZLE AGUA - ENERGÍA - CAMBIO CLIMÁTICO (HIGHTOWER, 2005). 

Utilización del modelo de análisis energético. Búsqueda de una gestión más sostenible. 



\subsection{Introducción}

La gestión eficiente de la energía no es un objetivo nuevo de los gestores de las infraestructuras urbanas. Tampoco lo es la gestión eficiente del agua. Dado que los planes de actuación que reducen el consumo de agua también consiguen una reducción en el consumo de la energía y viceversa, efecto sinergético, parece imprescindible la gestión integral de estos dos recursos.

Numerosos estudios abordan la gestión conjunta de ambos recursos. Los planteamientos son diversos, desde aquéllos que cuantifican las pérdidas energéticas en una fuga según la posición de la misma y el material de la tubería (Colombo y Karney, 2002), o los centrados en la regulación con equipos de bombeo de velocidad variable (Colombo y col., 2005; Zhengfu y col., 2005), hasta los que determinan la reducción del consumo energético a partir de la reducción de la demanda (Díaz y col., 2005). Sin embargo, la propuesta más destacada hacia la gestión sostenible del agua y la energía en este campo es la realizada por Cabrera y col. (2010), ya que permite cuantificar la energía perdida en fugas y evaluar el efecto energético de las decisiones tomadas por el gestor de la red (regulación con bombas de velocidad variable, instalación de válvulas de regulación y reducción de la demanda).

En el presente trabajo, se relacionan las pérdidas de energía en la red de distribución con las emisiones de contaminantes. Para ello se utiliza el modelo desarrollado por el Pacific Institute (Wolff y col., 2004) que permite calcular todos los gases emitidos, aunque el presente estudio se centra en las emisiones de $\mathrm{CO}_{2}$ y determina los créditos de carbono equivalentes ${ }^{46}$. La relación entre el consumo energético y las emisiones no es directa sino que existen otros factores que la influencian. Entre ellos, los más significativos son la huella energética del agua (cantidad de energía invertida para la obtención del agua, $\mathrm{kWh} / \mathrm{m}^{3}$ ), así como el origen de la energía (las emisiones son diferentes si la procedencia de la energía es nuclear $0 \mathrm{~g} / \mathrm{kWh}$ o si es térmica de carbón $1432 \mathrm{~g} / \mathrm{kWh}$ ).

\footnotetext{
${ }^{46}$ Un crédito de carbono es igual a una tonelada de $\mathrm{CO}_{2}$.
} 


\subsection{Gestión de la demanda}

En el año 2002, se consumieron en el mundo casi $4000 \mathrm{~km}^{3}$ de agua potable (Ghimire y Barkdoll, 2007). Sin embargo, el desigual reparto de los recursos, y el agua no es una excepción, impidió que se satisficiese la demanda de todos los usuarios y se estima que más de un millón de personas no tuvieron acceso a agua potable. Asimismo, la demanda de agua ha crecido paulatinamente, un $1.2 \%$ anual desde el 2004 hasta el 2007 (Deneen y Gross, 2004), por lo que la perspectiva futura no puede ser otra más que presumir que dicha tendencia alcista se mantenga. En cualquier caso, y siendo conscientes de que es muy difícil invertir ésta, se plantean programas que pretenden reducir el consumo final de agua potable.

La demanda de agua española, de acuerdo con las estimaciones de los planes de cuenca vigentes (MIMAM, 2000) es de $35000 \mathrm{hm}^{3} / a n ̃ o$, de los cuales un $68 \%$ corresponde al regadío, un $18 \%$ al abastecimiento a poblaciones e industrias, y el $14 \%$ restante se destina a la refrigeración de centrales productoras de energía. El consumo agrícola es $23800 \mathrm{hm}^{3} / a n ̃ o$, mientras que el urbano se queda en los $6300 \mathrm{hm}^{3}$ /año. Con estos valores y admitiendo consumos energéticos unitarios de $3 \mathrm{kWh} / \mathrm{m}^{3}$ para el ciclo integral del agua y $0.2 \mathrm{kWh} / \mathrm{m}^{3}$ para el regadío, la demanda de energía eléctrica que el manejo del agua requiere en España es la mostrada por la Tabla 76.

Tabla 76. Demanda estimada de energía eléCtrica ligada al uso del agua en España (MIMAM, 2000).

\begin{tabular}{lccc}
\hline \multicolumn{1}{c}{ Uso } & Demanda de agua & $\begin{array}{c}\text { Consumo unitario } \\
\text { medio }\end{array}$ & Energía necesaria \\
\hline Urbano e Industrial & $6300 \mathrm{hm}^{3} / \mathrm{año}$ & $3.0 \mathrm{kWh} / \mathrm{m}^{3}$ & $18900 \mathrm{GWh}$ \\
Riego & $23800 \mathrm{hm}^{3} / \mathrm{año}$ & $0.2 \mathrm{kWh} / \mathrm{m}^{3}$ & $4760 \mathrm{GWh}$ \\
\hline
\end{tabular}

La reducción de la demanda no es una política de gestión frente a fugas, aunque sí que aboga por la conservación de los recursos y el uso eficiente del agua. Por éste se entiende cualquier actividad dirigida a mantener en el punto de consumo del abonado el nivel de calidad en servicio pero con una reducción de la cantidad de agua captada del entorno. 
Los programas de gestión de la demanda no son únicamente campañas informativas o de concienciación, sino que engloban ciertas actuaciones que tienen como finalidad reducir el volumen consumido por parte de los usuarios finales. La gestión de la demanda presenta una serie de ventajas tanto para los abastecimientos como para los consumidores, aunque la principal se muestra desde la óptica de la sostenibilidad en el uso de recursos y el medio ambiente. Un análisis de la gestión de la demanda más detallado se encuentra en Cobacho (2000).

Si se compara el ahorro energético obtenido con programas de mejora de eficiencia eléctrica (calculado en años precedentes y estimado para años venideros) con el derivado de un uso más eficiente del agua, se obtiene que la segunda estrategia es incuestionablemente superior a la primera (CEC, 2005; Tabla 77). Esto es, a igual inversión, la racionalización del uso del agua produce mayores beneficios energéticos (ahorra más kWh). Sin embargo, este hecho no significa que deban abandonarse los programas de mejora de eficiencia energética, sino tan sólo que presentan una relación coste-beneficio energético menor.

TABLA 77. AHORRO DE ENERGía POR un uSO MÁS EFICIENTE DEL AGUA EN CALIFORNIA (CEC, 2005).

\begin{tabular}{|c|c|c|c|}
\hline & \multicolumn{2}{|c|}{$\begin{array}{l}\text { Logros de las compañías eléctricas } \\
\text { con programas de mejora de eficiencia }\end{array}$} & \multirow{2}{*}{$\begin{array}{c}\text { Potencial de } \\
\text { ahorro } \\
\text { por uso eficiente } \\
\text { del agua }\end{array}$} \\
\hline & 2004-05 & 2006-08 (estimado) & \\
\hline GWh/año & 2745 & 6812 & 6500 \\
\hline Demanda punta (MW) & 690 & 1417 & 850 \\
\hline Inversión ${ }^{47}\left(\$ \cdot 10^{6}\right)$ & 762 & 1500 & 826 \\
\hline 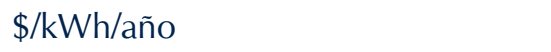 & 0.28 & 0.22 & 0.13 \\
\hline $\begin{array}{l}\text { Coste de la energía ahorrada por } \\
\text { uso eficiente del agua como } \\
\text { porcentaje del coste del programa } \\
\text { de mejora de la eficiencia (relación } \\
\text { de los respectivos } \$ / k W h / a n ̃ o) ~\end{array}$ & $46 \%$ & $58 \%$ & $100 \%$ \\
\hline
\end{tabular}

La influencia energética de la reducción de la demanda en una red de distribución se puede calcular gracias a la auditoría energética. Para ello, se comparan dos escenarios similares con distinta demanda hídrica, y así se observa la relación entre el volumen demandado y el consumo energético.

${ }^{47}$ En USA dólares del año 2005. 


\subsection{La reducción de la presión}

Es evidente que el consumo de agua muestra una variación estacional, semanal y diaria. Por tanto, una red de abastecimiento debe estar diseñada para satisfacer la demanda (cumpliendo los estándares de servicio definidos, presión, caudal y calidad) en el instante más desfavorable, aquél en que la demanda es máxima (consumo punta). Este hecho, implica que en las más de las horas, el consumo es menor (consumos valle, fundamentalmente periodos nocturnos) y la presión en determinadas zonas de la red, superior a la de servicio. La presión de servicio es aquélla mínima a la que la compañía encargada del abastecimiento de agua se compromete a entregar el recurso. En Valencia, por ejemplo, este umbral se cifra en 25 m.c.a. (BOPV, 2004), mientras que en Alemania se determina la presión mínima de servicio según el número de plantas permitido por el plan de ordenación urbano, de acuerdo con la expresión $20+3 \mathrm{~N}$ m.c.a. y siendo $\mathrm{N} \leq 5$ el número de plantas (Hirner, 2001).

El exceso de presión puede, a simple vista, considerarse un problema menor aunque un análisis más sosegado permite valorar la verdadera influencia del mismo, ya que causa:

- Aumento del número de roturas en las tuberías. Las oscilaciones del nivel de presiones aumentan notablemente las roturas en la red (Thornton y Lambert, 2005). Hasta tal punto que, por ejemplo, en Valencia, no se permite una presión superior a los 50 m.c.a. (BOPV, 2004), y en Alemania la presión de la red está limitada por la Norma DVGW planning rule w 403 (Hirner, 2001), hasta el valor de 80 m.c.a.

Por tanto, los valores de la presión en las acometidas de nuestro sistema deben pertenecer a los rangos anteriores, ni por debajo del umbral de servicio, ni por encima por del valor máximo. 
- Aumento de las fugas. El principal problema reside en que aumentan los consumos dependientes de la presión, como por ejemplo las fugas. Cierto es, por otra parte, que el nivel de fugas depende de otros factores como longitud de las tuberías, densidad de acometidas, características de la instalación o del terreno, etc.

En relación a las fugas, la presión es el único término modificable por el gestor del abastecimiento (al contrario que la longitud de las tuberías y la densidad de acometidas, que son parámetros intrínsecos de nuestro sistema). Ante estos hechos, la conclusión es clara, si se reduce la presión en las horas de consumo valle, se obtiene un significativo ahorro hídrico y energético. Por tanto, la regulación del sistema conlleva un beneficio económico asociado, mayor cuanto peor gestionada está la red.

La regulación de la presión se puede hacer de múltiples maneras. A continuación se estudian las más comunes, la instalación de una válvula de regulación y el equipamiento de variadores de velocidad en los equipos de bombeo. La regulación de la presión con válvula y con bombas de velocidad variable es muy habitual en redes de abastecimiento urbano, mientras que en redes de riego, la válvula es prácticamente el único elemento regulador. La válvula de regulación se instala en situaciones en las que exista bien una notable variación en las cotas de la red, o bien una elevada variación horaria del consumo, características habituales en redes de riego y no tan comunes en redes urbanas.

\subsubsection{Válvulas de regulación}

Los ahorros hídricos obtenidos gracias a la reducción de la presión con válvulas ha sido un tema desarrollado por numerosos investigadores, conscientes de las ventajas que acarrean. Estos trabajos están orientados a obtener la posición óptima de las válvulas tanto desde la óptica de la operación del sistema (Sterling y Bargiela, 1984), como desde la minimización del volumen fugado (Jowitt y Xu, 1990). Otros estudios se centran en la elección de la ubicación óptima de la válvula en la red (Reis y col., 1997), o en determinar el punto adecuado de funcionamiento, con consumo de energía mínimo, tanto de válvulas de regulación como de los equipos de bombeo (Rao y col., 2006). Ésta último representa la primera vez en la que se plantea esta problemática desde la óptica energética y no únicamente hídrica. 
En todo el mundo, se han desarrollado numerosos proyectos de regulación de la presión con válvulas (Brasil, Dinamarca, Canadá, Chipre, Hong-Kong, Israel, Malasia, Malta, Sudáfrica, España, Taiwan, etc.). Si bien, en los últimos 20 años, ha sido en Reino unido y Japón donde se ha demostrado su efectividad en la gestión de las fugas (Thornton, 2003). El método PRESMAC, desarrollado por la South African Water Research Comission (McKenzie, 2001) cuantifica el ahorro hídrico obtenido a partir de la instalación de una válvula de regulación de la presión. Otros autores (García y col., 2007) proponen una metodología simplificada en comparación con el método PRESMAC, que resulta muy útil en sistemas con escasez de datos.

Desde la óptica energética, la reducción de la presión conlleva una reducción en la energía entrante en el sistema (tal y como demuestra el anexo E). Esta reducción se puede cuantificar realizando una auditoría de la red en dos escenarios, con y sin válvula de regulación. En el escenario mostrado en la Figura 108, se observan los aportes y detracciones de energía en el volumen de control seleccionado.

\section{Volumen de control}

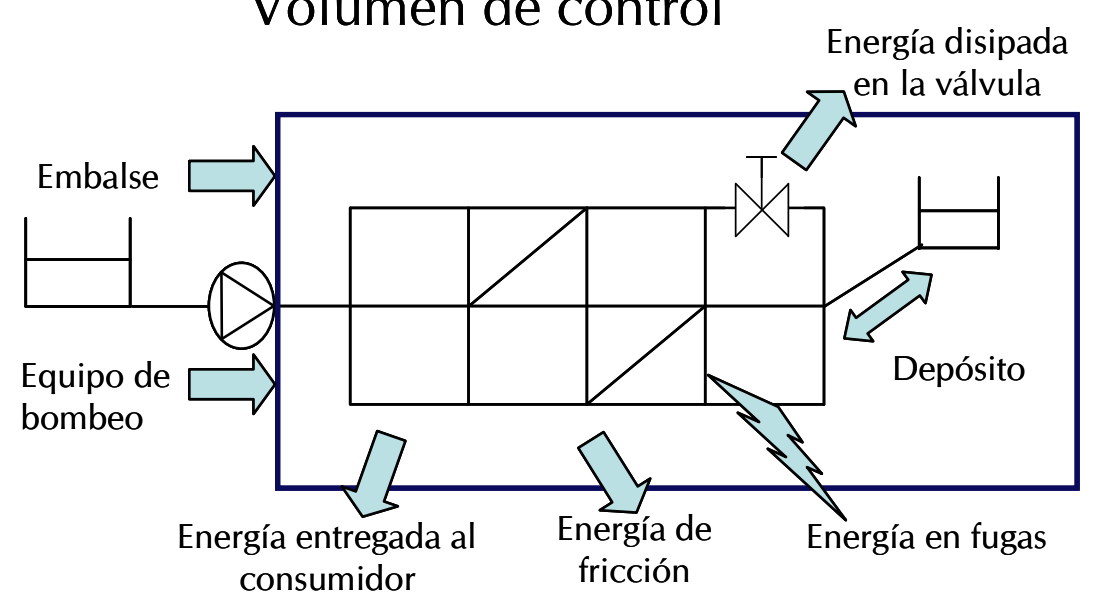

FIGURA 108. NUEVO ESCENARIO SOBRE EL QUE CALCULAR LA ENERGÍA INVERTIDA EN LA RED DE DISTRIBUCIÓN

La energía disipada por la válvula, es una componente de la energía disipada por fricción. De hecho, para el cálculo de dicha energía, se puede sustituir la válvula por una longitud de tubería equivalente. Por mor de clarificar el efecto de la válvula, se muestra como un término más de la auditoría energética.

$E_{E}(t)+E_{p}(t)=E_{d}(t)+E_{f}(t)+E_{L}(t)+E_{V}(t)$

En el balance anterior aparece el término correspondiente a la energía que disipa la válvula $\left(E_{v}(t)\right)$. La expresión matemática con la que se obtiene este término es la siguiente: 
$E_{v}=\gamma \cdot \sum_{t_{k}=t_{1}}^{t_{k}=t_{p}} q_{v}\left(t_{k}\right) \cdot \Delta H_{v}\left(t_{k}\right) \cdot \Delta t$

Donde $q_{v}\left(t_{k}\right)$ es el caudal $\left(\mathrm{m}^{3} / \mathrm{s}\right)$ que atraviesa la válvula en el instante $t_{k}$ y $\Delta H_{v}\left(t_{k}\right)$ es la altura piezométrica (m.c.a.) que se pierde en la válvula (calculada como la diferencia entre los nudos situados aguas arriba y aguas abajo de la misma). La propia definición de este término justifica la afirmación anterior de que representa una energía disipada por fricción, ya que es análoga a la definida para la energía disipada por rozamiento en tuberías $\left(E_{f}\left(t_{p}\right)\right)$.

\subsubsection{Bombas de velocidad variable}

Los variadores de velocidad han supuesto una mejora muy importante en la regulación de sistemas hidráulicos. Inicialmente, se idearon como elemento regulador que permitía el control de procesos, aunque pronto el ahorro energético asociado a los mismos se convirtió en la principal mejora introducida. Aunque existen numerosos dispositivos que permiten regular la velocidad de giro de los equipos de bombeo, de tipo mecánico, motores de corriente continua, el más utilizado es el motor asíncrono con variación de la frecuencia de alimentación.

Ésta se realiza con un rectificador de onda que convierte la corriente alterna de la red $(50 \mathrm{~Hz}$ en Europa, por $60 \mathrm{~Hz}$ en EE.UU.) en continua. A continuación, la tensión de la corriente continua se modifica con un rectificador a tiristores o con un conversor conmutado (troceador o chopper) y por último, un inversor transforma la corriente continua en alterna con otra frecuencia. El diseño y funcionamiento de estos dispositivos (objeto de estudio de la electrónica de potencia) escapa a los objetivos de la presente tesis, y en ella, el variador de velocidad se considerará una caja negra donde únicamente importa la frecuencia de salida de la onda que alimentará al equipo de bombeo.

La curva característica del equipo de bombeo es $H=C+B Q+A Q^{2}$. Las curvas características de una bomba girando a velocidad diferente de la nominal se pueden obtener a partir de la curva anterior haciendo uso de la teoría de la semejanza. En función de la relación $\alpha=\frac{N}{N_{0}}$ (siendo $N_{0}$ la velocidad de giro nominal y $N$ la velocidad de giro real) se obtiene la nueva curva característica $\left(H=C \alpha^{2}+B Q \alpha+A Q^{2}\right)$. La variación de la velocidad de giro de la bomba modifica la curva característica (parte superior Figura 109) con lo que se puede fijar el punto de funcionamiento del equipo según los requerimientos del sistema. De este 
modo, se puede trabajar siguiendo la curva de consigna ${ }^{48}$ de la red, que representa la solución óptima de la regulación.

El rendimiento del equipo también se puede obtener con las leyes de semejanza, con lo que a partir de una curva de rendimiento definido por: $\eta=F Q+E Q^{2}$, se obtiene un nuevo rendimiento expresado como: $\eta=\frac{F Q}{\alpha}+\frac{E Q^{2}}{\alpha^{2}}$. La expresión anterior y la Figura 109 muestran que el rendimiento de la bomba es diferente según el punto de funcionamiento del equipo, y la unión de los puntos con un mismo rendimiento da lugar a las curvas de isorrendimiento en forma de elipses (colinas de isorrendimiento, parte superior de la Figura 109). Si la velocidad de rotación se aleja de la velocidad nominal, el rendimiento del equipo cae porque las pérdidas internas y mecánicas del motor no cumplen la teoría de la semejanza. Los fabricantes no recomiendan trabajar por debajo de $30-35 \mathrm{~Hz}$ (siendo $50 \mathrm{~Hz} \mathrm{la}$ frecuencia existente en Europa).

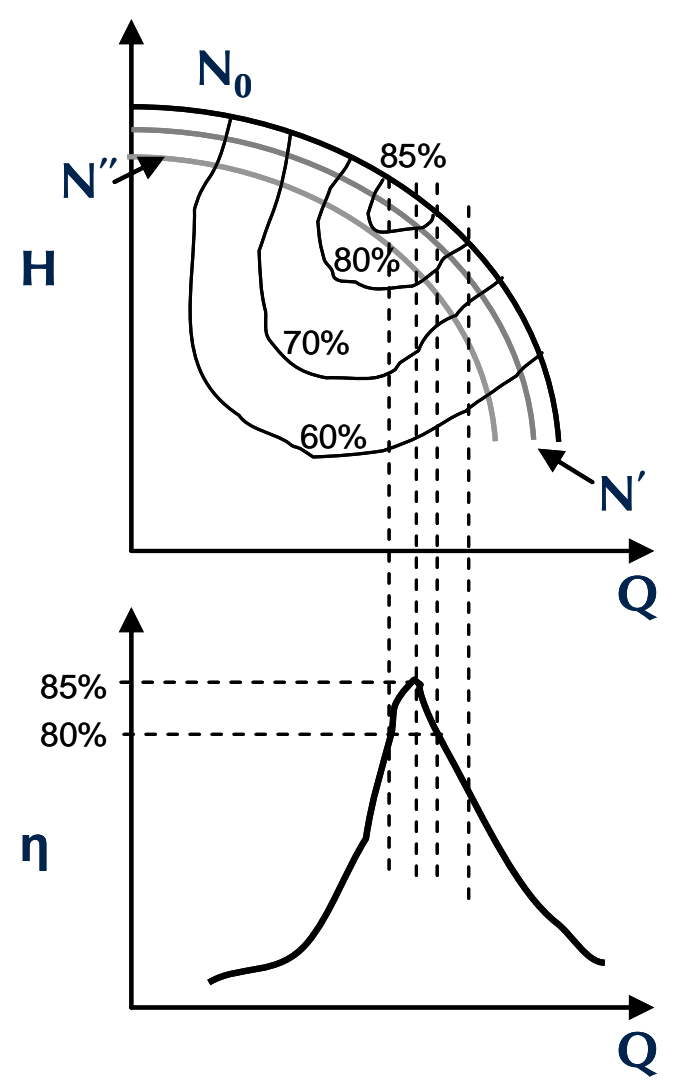

FIGURA 109. CURVA CARACTERÍSTICA, CURVA DEL RENDIMIENTO Y COLINAS DE ISORRENDIMIENTO DE UN EQUIPO DE BOMBEO A DIFERENTES VELOCIDADES DE GIRO.

\footnotetext{
48 Por curva de consigna se entiende la curva resistente de una red de distribución. De tal manera que cada valor del caudal se relaciona con la presión en cabecera necesaria para obtener una presión de servicio mínima en todos los nudos del sistema.
} 
La regulación del caudal inyectado a red con equipos de velocidad variable, conlleva las siguientes ventajas que se traducen en mejoras energéticas:

- Mínimas pérdidas hidráulicas, al ajustarse siempre el punto de funcionamiento a la curva de consigna de la red.

- Mantenimiento de un rendimiento próximo al óptimo. En general, el equipo de bombeo debe ser escogido para que trabaje cercano a su velocidad nominal (con un rendimiento elevado). Este requisito se cumplirá fácilmente si la demanda es plana (si el consumo se mantiene constante a lo largo del día, propio de redes de riego) y, por el contrario, en redes con grandes diferencias entre el consumo punta y el valle, el punto de funcionamiento del equipo de bombeo (y por ende el rendimiento) si que variará mucho.

- Disminución del número de grupos de bombeo necesarios para la regulación.

Quizá el único inconveniente estriba en que el coste de inversión es mayor al incluir el variador de velocidad, pero su inclusión en sistemas que funcionan durante muchas horas al año puede estar justificada.

\subsection{Efecto energético de las políticas analizadas orientadas hacia una gestión hídrico-energética más sostenible}

El efecto de la implantación de las políticas de gestión y operación descritas anteriormente sobre el consumo energético se puede predecir cualitativamente (Tabla 78). Ésta ha sido, la única posibilidad hasta que se ha definió la auditoría energética, que permite el análisis cuantitativo.

TABLA 78. ANÁLISIS CUALITATIVO DE LOS CONSUMOS ENERGÉTICOS ESPERADOS.

\begin{tabular}{|c|c|c|c|}
\hline \multirow[b]{2}{*}{ Nomenclatura } & \multicolumn{2}{|c|}{ Reducción de la Presión } & \multirow{2}{*}{$\begin{array}{c}\text { Gestión de la } \\
\text { demanda }\end{array}$} \\
\hline & $\begin{array}{l}\text { Válvula de } \\
\text { regulación }\end{array}$ & $\begin{array}{c}\text { Bomba de } \\
\text { velocidad variable }\end{array}$ & \\
\hline \multicolumn{4}{|l|}{$E_{N}\left(t_{p}\right)$} \\
\hline \multicolumn{4}{|l|}{$E_{P}\left(t_{p}\right)$} \\
\hline \multicolumn{4}{|l|}{$E_{U}\left(t_{p}\right)$} \\
\hline \multicolumn{4}{|l|}{$E_{L}\left(t_{p}\right)$} \\
\hline$E_{\text {Dissipated }}\left(t_{p}\right)$ & & & \\
\hline
\end{tabular}


La reducción de la presión con válvula merece una explicación especial. Ya que incluye una mayor energía disipada, agrupada en un nuevo término de energía perdida en la válvula, y sin embargo, la reducción del consumo energético es tal que compensa la nueva energía disipada. Por otra parte, la instalación de una válvula siempre se plantea en sistemas con un excedente de energía en ciertos sectores de la red. El objetivo fundamental es el ahorro hídrico, aunque la mejora en la gestión del sistema y el ahorro energético representan, sin duda, una fenomenal consecuencia.

En el caso de la bomba de velocidad variable, se consigue fijar la presión hasta el valor deseado, por lo que todos los términos presentan un valor menor. Tanto la energía entregada al usuario, como la energía perdida en fugas y la disipada en fricción presentan un menor valor numérico.

La reducción de la demanda implica una reducción generalizada en todos los términos que componen el balance energético de dicha red de distribución excepto el término de energía perdida por fugas que se incrementa por aumentar el nivel medio de presión en la red. La conclusión es inmediata, al existir menor caudal circulante por la red de distribución, se pierde menos energía por fricción, menor energía empleada en el bombeo y menor energía aportada por el embalse, únicamente la energía fugada aumenta ligeramente por existir un mayor nivel de presiones. 


\subsection{El concepto de huella energética del agua}

Las fugas de agua no representan únicamente una pérdida de agua sino también de energía. En el capítulo 6 de la presente tesis, se definió el peaje energético del agua en la etapa de distribución a partir del efecto que la fuga realiza sobre dos términos de la auditoría, la energía que escapa directamente con el agua fugada $\left(E_{L}\left(t_{p}\right)\right)$ y la energía empleada en vencer la fricción con las tuberías.

Sin embargo, la energía total asociada a las fugas no comprende únicamente la energía perdida en la etapa de distribución, ya que el volumen fugado también se debe haber detraído del medio, potabilizado e inyectado en red. Por tanto, toda la energía previamente consumida también se pierde con ésta.

La huella energética del agua se define como la energía empleada desde la detracción del medio natural del recurso (el agua) hasta la etapa del ciclo que se está considerando. En nuestro estudio, se analiza la energía perdida por fugas en un sistema de distribución, por lo que la huella energética del agua ${ }^{49}$ fugada se refiere a la energía de las etapas de captación, bombeo y transporte, potabilización y distribución, tal y como se señala en la Figura 102.

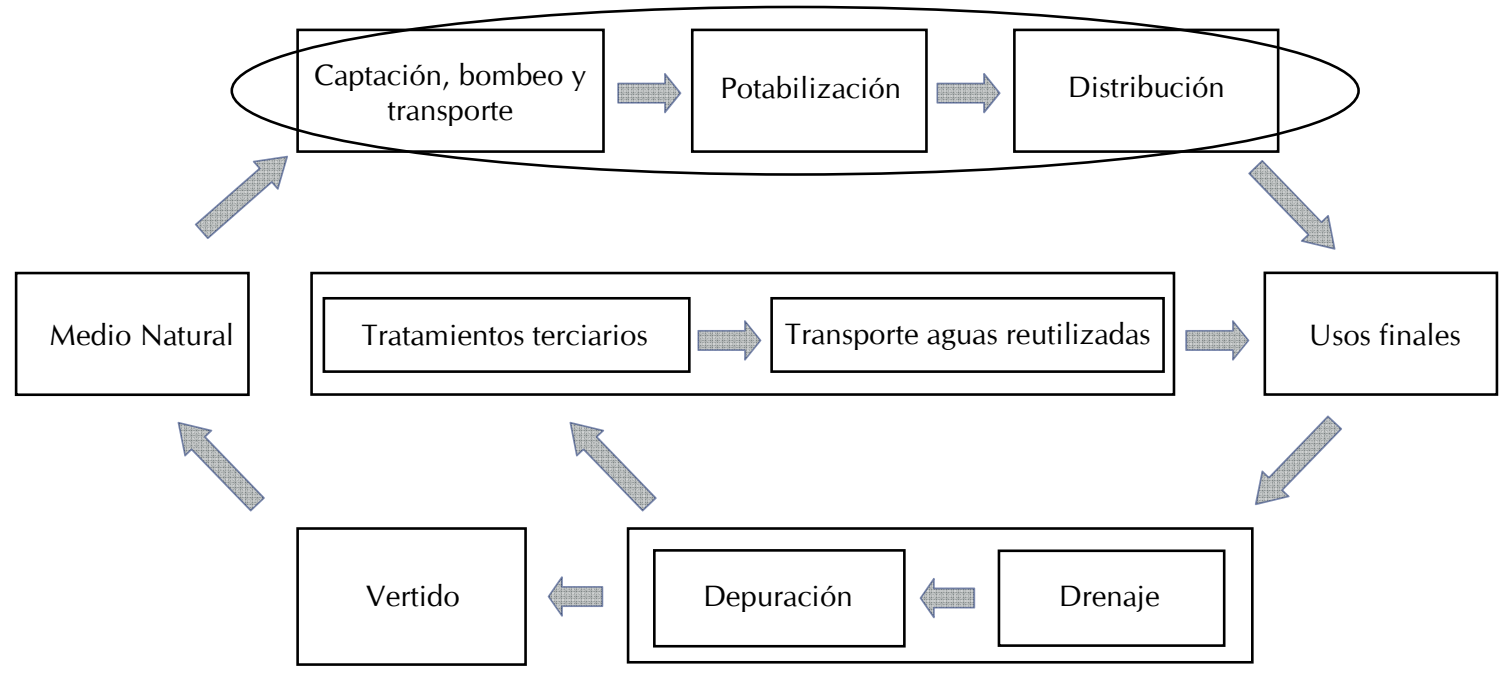

FIGURA 110. ETAPAS DEL CICLO DEL AGUA.

${ }^{49}$ En el capítulo 4 la huella energética del agua $\left(C_{W E}\right)$ se definió como coste energético del agua. 


\subsubsection{Etapa de captación bombeo y transporte del agua en alta}

La huella energética del agua depende del origen del recurso. El coste energético asociado a las fugas y relativo a los procesos de captación, bombeo y transporte se puede calcular como la diferencia entre el consumo energético en la etapa de captación, bombeo y transporte para dos escenarios, uno con y otro sin fugas. Se expresa analíticamente como:

$$
\left(E_{c b}\left(t_{p}\right)-E_{c b}^{\prime}\left(t_{p}\right)\right)=\left(V_{R}-V_{R}^{\prime}\right) \cdot C_{E c b}
$$

Donde $E_{c b}\left(t_{p}\right)$ es la energía asociada a la captación de agua, bombeo y transporte en alta en un escenario con fugas, $E_{c b}^{\prime}\left(t_{p}\right)$ es la misma energía obtenida en un escenario ideal sin fugas, $\left(v_{R}-v_{R}^{\prime}\right)$ el sobreconsumo que se produce debido a las fugas (entendido como la diferencia de volúmenes inyectados en un escenario con y sin fugas). Por último, $c_{E c b}$ es el coste energético (en $\mathrm{kWh} / \mathrm{m}^{3}$ ) necesario para la captación, bombeo y transporte del agua desde el origen hasta el embalse de cabecera de red. Esta expresión analítica no considera las pérdidas de agua existentes en el transporte desde el origen hasta la planta potabilizadora.

\subsubsection{Etapa de potabilización}

La segunda etapa del ciclo del agua (Figura 102) es la de potabilización. El consumo energético de esta fase adopta el valor de $0.47 \mathrm{kWh} / \mathrm{m}^{3}$ para los abastecimientos en Austin (Hoffman, 2006), y en California el valor puede variar entre $0.03-4.23 \mathrm{kWh} / \mathrm{m}^{3}$ (CEC, 2005), ya que el valor superior de la horquilla se debe a que la desalación se considera un proceso de potabilización. En cualquier caso, los valores mostrados pueden ser tomados como referencia en ausencia de datos. La energía empleada en potabilización del volumen fugado se expresa como:

$\left(E_{p o t}\left(t_{p}\right)-E_{p o t}^{\prime}\left(t_{p}\right)\right)=\left(V_{R}-V_{R}^{\prime}\right) \cdot C_{E p o t}$

Donde $E_{p o t}\left(t_{p}\right)$ es la energía asociada a la potabilización del volumen inyectado en un escenario con fugas, $E_{p o t}^{\prime}\left(t_{p}\right)$ es la misma energía obtenida en un escenario ideal sin fugas y $c_{E p o t}$ es el coste energético $\left(\right.$ en $\left.\mathrm{kWh} / \mathrm{m}^{3}\right)$ necesario para la potabilización de un $\mathrm{m}^{3}$ de agua. Al igual que el término anterior, no se consideran las pérdidas de agua en la planta potabilizadora. 
De algún modo, la energía natural de entrada a una red de distribución (en la auditoría representado como $\left.E_{N}\left(t_{p}\right)\right)$ representa la energía útil de las dos primeras etapas del ciclo urbano del agua. Esto es, representa la cantidad de energía que queda disponible en el embalse de cabecera de la red de distribución urbana tras el consumo energético de las etapas previas.

\subsubsection{Etapa de Distribución}

Se define la energía perdida por fugas en la etapa de distribución como la diferencia entre la energía empleada en la presurización del volumen inyectado en un escenario con fugas y otro sin fugas. La principal característica del cálculo de este término es que se puede obtener mediante la auditoría energética propuesta.

Para ello, nuevamente se plantean los dos escenarios habituales, con y sin fugas. El término relativo a la red de distribución se obtiene como:

$$
E_{\text {dist }}\left(t_{p}\right)=\left(E_{P}\left(t_{p}\right)-E_{p}^{\prime}\left(t_{p}\right)\right)
$$

Donde $E_{P}\left(t_{p}\right)$ y $E_{P}^{\prime}\left(t_{p}\right)$ son las energías empleadas en el bombeo en los escenarios con y sin fugas respectivamente.

\subsubsection{Huella energética del agua}

La huella energética se estima a partir de mediciones realizadas en las etapas previas a la distribución. El cálculo es sencillo, simplemente es el cociente entre los $\mathrm{kWh}$ consumidos y los $\mathrm{m}^{3}$ transportados y potabilizados. En cambio, con las expresiones anteriores, se puede calcular la huella energética de modo analítico. Los datos necesarios se resumen a continuación.

- Auditoría hídrica. Ésta permite obtener el volumen fugado en la red de distribución

- Costes de los bombeos y de potabilización ( $C_{E c b}$ y $C_{E p o t}$ respectivamente). Junto con el volumen fugado en la distribución permite calcular la huella energética de las dos primeras etapas del ciclo urbano del agua.

- Auditoría energética. Permite el cálculo de la huella energética de etapa de distribución.

Agrupando los términos definidos anteriormente, se puede expresar la huella energética del agua fugada. La expresión analítica es: 


$$
\begin{array}{r}
E_{H E}\left(t_{p}\right)=\left(E_{c b}\left(t_{p}\right)-E_{c b}^{\prime}\left(t_{p}\right)\right)+\left(E_{p o t}\left(t_{p}\right)-E_{p o t}^{\prime}\left(t_{p}\right)\right)+\left(E_{P}\left(t_{p}\right)-E_{P}^{\prime}\left(t_{p}\right)\right)= \\
=\left(V_{R}-V_{R}^{\prime}\right) \cdot\left(C_{E c b}+C_{E p o t}\right)+\left(E_{P}\left(t_{p}\right)-E_{P}^{\prime}\left(t_{p}\right)\right)
\end{array}
$$

Donde $E_{H E}\left(t_{p}\right)$ es la huella energética del agua para el caso que se está estudiando.

\subsection{Créditos de carbono}

En este apartado, se enmarca la situación actual y la historia del mercado de créditos o bonos de carbono. Posteriormente, se analiza el ahorro de las emisiones, de los créditos de carbono utilizando el modelo desarrollado por el Pacific Institute (Wolff y col., 2004).

El objetivo perseguido con este modelo es convertir la energía que se ahorra gracias a la reducción del volumen fugado, en toneladas de $\mathrm{CO}_{2}$. Las emisiones no se relacionan directamente con el ahorro energético ya que existen otros factores como la huella energética del agua y como el origen de la energía que influencian esta relación.

\subsubsection{Definición e historia}

En 1997, el protocolo de Kioto fue el primero que originó un compromiso internacional de obligado cumplimiento (acuerdo vinculante) para reducir las emisiones de los gases que producen el calentamiento global, entre ellos el dióxido de carbono $\left(\mathrm{CO}_{2}\right)$, metano $\left(\mathrm{CH}_{4}\right)$ y óxido nitroso $\left(\mathrm{N}_{2} \mathrm{O}\right)$. Se acordó una reducción del 5\% de las emisiones de dichos contaminantes en el periodo 2008 2012, con respecto a las emisiones del año 1990. Esto no significa que cada país deba reducir las emisiones de gases de efecto invernadero en un 5\%, sino que éste es un porcentaje a nivel global y cada país tiene sus propios porcentajes de emisión que debe cumplir.

Los créditos o bonos de carbono son un mecanismo ideado para reducir la emisión de contaminantes al medio ambiente. Un crédito de carbono representa el derecho a emitir una tonelada de dióxido de carbono. El mercado de los créditos de carbono lo administra una autoridad competente, por ejemplo el gobierno, que determina un límite o máximo sobre la cantidad de $\mathrm{CO}_{2}$ que puede emitirse. Dicha autoridad asigna las emisiones permitidas a cada empresa, y aquéllas que necesiten aumentar su concesión pueden comprar créditos a otras que contaminen menos. Por tanto, el comprador paga para poder contaminar, mientras que el vendedor recibe recompensas económicas por reducir las emisiones de $\mathrm{CO}_{2}$. 
Todos los países industrializados (excepto Estados Unidos) establecieron en Kioto unas metas cuantificadas de reducción de emisiones para el año 2012. Para cumplir éstas, se financiaron proyectos de captura o abatimiento de estos gases en países en vías de desarrollo, acreditando tales disminuciones y considerándolas como si hubiesen sido hechas en su territorio. La Unión Europea se comprometió a reducir sus emisiones totales medias durante el periodo 2008-2012 en un 8\% respecto de las de 1990, otorgando a cada país un margen distinto según diversas variables económicas y medioambientales (Tabla 79).

TABLA 79. VARIACIÓN DE LAS EMISIONES PERMITIDAS PARA PAÍSES DE LA UNIÓN EUROPEA CON RESPECTO A LAS EMISIONES DE 1990.

\begin{tabular}{cccccc}
\hline País & Variación & País & Variación & País & Variación \\
\hline Alemania & $-21 \%$, & España & $+15 \%$ & Italia & $-6,5 \%$ \\
Austria & $-13 \%$, & Irlanda & $+13 \%$ & Luxemburgo & $-28 \%$ \\
Bélgica & $-7,5 \%$ & Suecia & $+4 \%$ & Holanda & $-6 \%$ \\
Dinamarca & $-21 \%$ & Grecia & $+25 \%$ & Reino Unido & $-12,5 \%$ \\
Finlandia & $-2,6 \%$ & Portugal & $+27 \%$ & Francia & $1,9 \%$ \\
\hline
\end{tabular}

La evolución de las emisiones de gases de efecto invernadero en España desde el año utilizado como base de la comparación (1990) han sido espectaculares (MMA, 2008). España se comprometió a aumentar las emisiones en un máximo del $15 \%$ y en el año 2006 las emisiones habían aumentado más de un 50\% con respecto a las emisiones del año base, por lo que las posibilidades de cumplir con el compromiso son muy escasas (Figura 111). Sin duda, el elevado crecimiento económico se tradujo en un aumento del transporte y del consumo energético industrial y doméstico. 
Evolución de las emisiones de $\mathrm{CO}_{2}$ en España

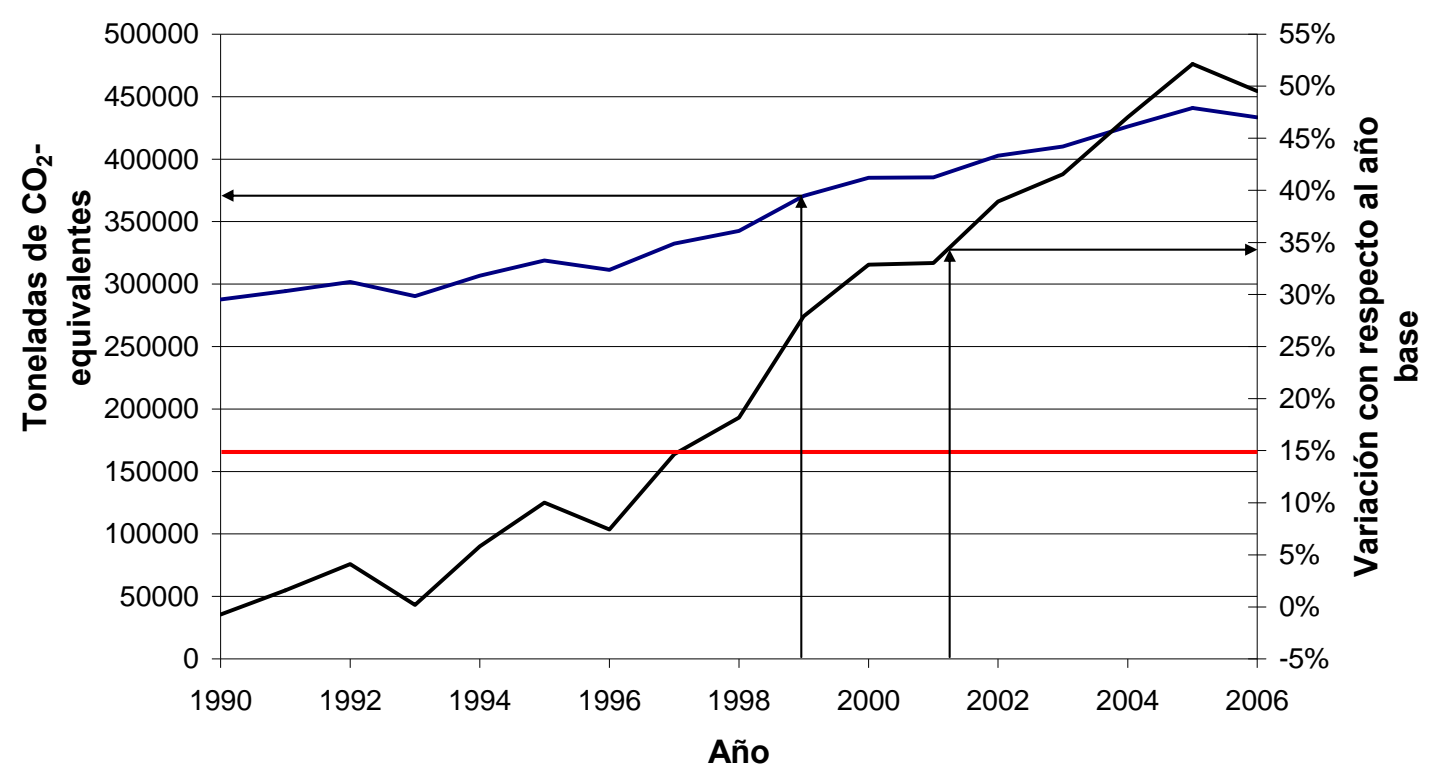

FIGURA 111. EVOLUCIÓN DE LAS EMISIONES EN ESPAÑA (MMA, 2008)

En diciembre de 2007, en Bali, Indonesia, se llevó a cabo la tercera reunión de seguimiento, así como la $13^{\mathrm{a}}$ cumbre del clima. El primer objetivo que se concreta en esa reunión es limitar el calentamiento global a no más de $2^{\circ} \mathrm{C}$ por encima de la temperatura media existente antes de la revolución industrial, un límite ya adoptado por la unión europea y otros países. Se estima que para cumplir esta condición, se debe reducir la emisión de gases invernadero, para el año 2050, un $50 \%$ con respecto a los niveles del año 1990. A largo plazo, las concentraciones de dichos gases deben estabilizarse por debajo de las 450 ppm.

En Bali, se Ilega a un acuerdo sobre un proceso de dos años, u "hoja de ruta de Bali", que tiene como objetivo establecer un régimen posterior al año 2012 que se acordará en la XV Conferencia sobre Cambio Climático, que se ha celebrado en Diciembre de 2009, en Copenhague, Dinamarca. Antes de ésta el objetivo era claro: "Lograr acuerdos concretos y vinculantes de la comunidad internacional sobre la reducción de las emisiones de Gases de Efecto Invernadero". La preocupación mundial por el cambio climático se acrecienta, así como el escepticismo de la sociedad con relación a los resultados que se puedan obtener en dicho evento. 
Se ha criticado bastante que los eventos preparatorios a la cumbre de Copenhague, en Bangkok y Barcelona, no aportaron nuevos elementos de avance. Es más, EE.UU. propuso en Bangkok un protocolo con el mismo nivel de compromiso para los países industrializados y en desarrollo. Es decir, un nuevo enfoque que no consideraba los distintos niveles de responsabilidad de los países industrializados con respecto a los países en desarrollo.

En la cumbre de Copenhague, la idea que se pretendía imponer a sus participantes es que el momento actual es crítico para la Tierra, la humanidad debía escoger su futuro. El desafío sigue pendiente y reclama un cambio radical en la conciencia y voluntad de los mandatarios, políticos y funcionarios de gobierno, con justicia social y ambiental. Prueba de estas medidas de presión es la publicidad mostrada en el aeropuerto de Copenhague con la que recibieron a todos los políticos a su Ilegada a la cumbre. En ella, los líderes mundiales, en el año 2020, se disculpan por su fracaso a la hora de detener el cambio climático y cambiar el futuro (Figura 112).

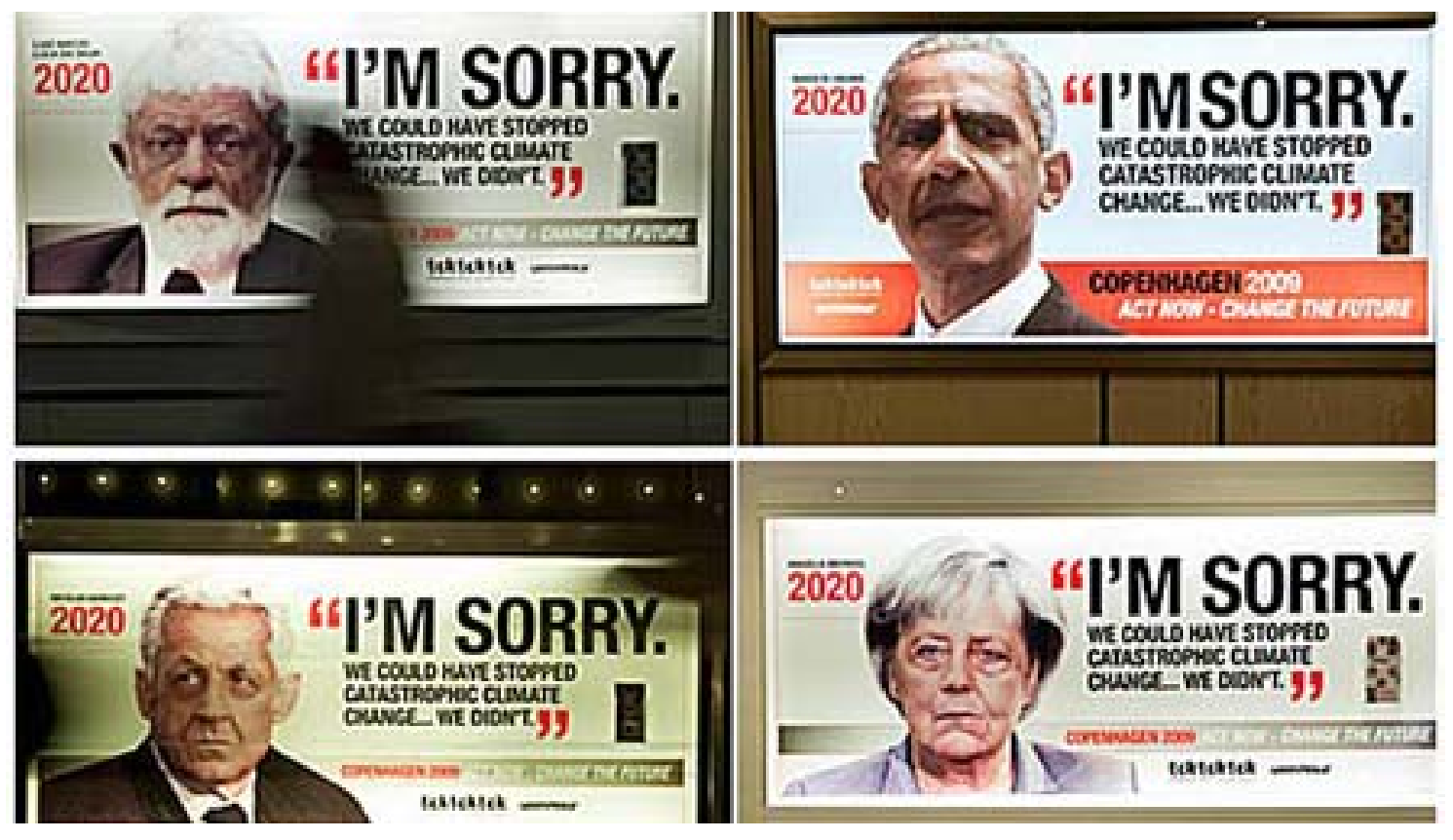

FIGURA 112. CAMPAÑA DE PUBLICIDAD DE LA ORGANIZACIÓN GREENPEACE PREVIA A LA REUNIÓN DEL COP 15 EN EL AEROPUERTO DE LUFTHAVNEN, COPENHAGUE. 
Dos países (China y los EE.UU.) representan más del 40\% de las emisiones de $\mathrm{CO}_{2}$ del mundo, y asistieron a Copenhague monopolizando los debates previos a la misma. China fue acusada por el jefe de la delegación estadounidense, Todd Stern, de ser "el país cuyas emisiones han subido de manera más radical, siendo el que más contamina del mundo ${ }^{50 "}$ y descartó la integración de los EE.UU. al protocolo de Kioto, que expira en el año 2012 y que era precisamente el principal requerimiento desde Pekín.

El acuerdo que se obtuvo en Copenhague se decidió en una sala cerrada del centro de convenciones de la cumbre del clima. En una reunión entre el presidente de EE.UU., Barack Obama; de China, Wen Jiabao; de Brasil, Lula da Silva y de la India, Manmohan Singh propusieron un pacto que posteriormente ratificaron $^{51}$ la Unión Europea, en primer lugar, y con posterioridad el resto de países de la reunión excepto Venezuela, Bolivia, Nicaragua, Cuba y Sudán. La ONU exige que todos los países aprueben los textos obtenidos, y tras la negociación con todos los países y los presidentes de Venezuela y Bolivia (Hugo Chávez y Evo Morales) anunciaron que bloquearían cualquier acuerdo por no haber sido invitados a la reunión donde éstos se decidieron. "El tratado que suscribieron los líderes de 183 países no se puede parar por los intereses de Chávez", declaró el ministro británico Ed Miliband y tras las reuniones con el gabinete jurídico, se aprobó el Acuerdo de Copenhague de 18 de diciembre de 2009, y entró en vigor en ese instante.

En él se subraya que el cambio climático es uno de los grandes retos de nuestro tiempo y que el aumento de la temperatura global debe estar por debajo de los $2^{\circ} \mathrm{C}$ (algo ya definido en la reunión de Bali). Para ello, los países se comprometen a cooperar para que cese el aumento de las emisiones nacionales lo antes posibles. Esto no incluye la cuantificación de la concentración de $\mathrm{CO}_{2}$ emitida (menor que 450 p.p.m. como se acordó en Bali), ni el año máximo de dichas emisiones (entre 2015 y 2020 según el IPCC), ni la necesidad de que las emisiones para el año 2050 sean la mitad que en el año de referencia de Kioto (1990).

\footnotetext{
${ }^{50}$ China se convirtió en el país con mayores emisiones de $\mathrm{CO}_{2}$ en Junio del año 2007. Durante ese año China emitió 6029.7 millones de toneladas de CO2, por 5769.3 de EE.UU. (IEA, 2009).

${ }^{51}$ El presidente de la comisión Durao Barroso declaró "La UE lidera cuando se trata de elevar los objetivos, pero no está cuando se trata de reducir la ambición".
} 
El acuerdo establece que se medirán las emisiones de gases de efecto invernadero de los países en desarrollo, pero no mediante un organismo independiente, sino que ellos mismos realizarán las mediciones, declaraciones y verificaciones cada dos años. Asimismo, el acuerdo establece unas ayudas ${ }^{52}$ de 30000 M\$ entre 2010 y 2012 para los países más pobres, y a partir del año 2020, las cantidades serán de 100000 M€. Sin embargo, el texto no indica quién pagará esta cantidad, y únicamente la Unión Europea se ha comprometido a asumir el pago de $7200 \mathrm{M} €$ para el periodo 2010 - 2012.

En definitiva tras este acuerdo, el escenario actual depende de las decisiones voluntarias de cada estado. Por último, COP 15 se cerró con la declaración del principal artífice del acuerdo, el presidente Obama, "Sabemos que con esto no basta, y que queda mucho camino por recorrer. Creo que hace falta un tratado vinculante". Los textos previos (acordados en la reunión del G8 en el verano del 2009 o el pactado en Bali en 2007) eran más precisos y pedían la reducción mínima de emisiones del $25 \%$, y en reuniones previas a la reunión de Copenhague se había determinado que la reducción estaría comprendida entre el 26 y el 33\%. Asimismo, la propuesta de la reducción del 50\% de los gases de efecto invernadero para el año 2050 fue vetada por China, según declaró el presidente de la comisión europea Durao Barroso. La sensación de fracaso y de incapacidad para avanzar en la lucha contra el cambio climático fue la que presidió el final de una cumbre de la que 119 líderes mundiales regresaron a casa sin la tradicional foto de familia, una nueva escenificación de la actual falta de consenso mundial, nuevamente los intereses económicos propios primaron sobre el medio ambiente.

${ }^{52}$ El texto no detalla quién gestionará y repartirá las ayudas. 


\subsubsection{El modelo agua-aire desarrollado por el Pacific Institute}

El modelo agua-aire o water to air model permite a los usuarios cuantificar las emisiones originadas en un abastecimiento cualquiera o en redes de riego. En caso de ausencia de datos facilita unos valores por defecto. El modelo permite que se puedan comparar los consumos energéticos en dos escenarios diferentes ${ }^{53}$.

El consumo energético no se calcula según el volumen circulante en cada etapa del ciclo, sino por unidad de volumen consumido. Esta hipótesis es incorrecta para muchas etapas consideradas individualmente, aunque es apropiada para obtener el valor del consumo energético medio, ya que se ha obtenido con la misma referencia.

Si en vez del método de cálculo utilizado, se calcula la energía por unidad de volumen circulante en cada etapa en el ciclo, no se pueden sumar los consumos unitarios por no estar referidos al mismo volumen, ya que a lo largo del ciclo del agua se producen pérdidas. Por ejemplo, un consumo de $2 \mathrm{kWh} / \mathrm{m}^{3}$ de agua entregada a los consumidores no se puede sumar con un consumo de $1 \mathrm{kWh} / \mathrm{m}^{3}$ de agua entrante a la planta depuradora ya que un elevado porcentaje de agua no llega a ser agua depurada (por ejemplo, se evapora). La energía empleada en entregar el agua al usuario más la empleada en la planta de tratamiento es ó 2.5 $\mathrm{kWh} / \mathrm{m}^{3}$ consumidos ó (si sólo se depura el $50 \%$ del agua) $5 \mathrm{kWh} / \mathrm{m}^{3}$ entrantes en la planta depuradora. Si se define únicamente la energía unitaria en $\mathrm{kWh} / \mathrm{m}^{3}$ no es un valor preciso, al contrario que los anteriores, porque no queda claro a qué unidad de volumen está referida.

El modelo requiere como dato de entrada la huella energética del agua y del origen de la energía consumida (en una planta en la que se quema gas natural, petróleo, carbón, una central nuclear, eólica, solar, etc.).

\subsubsection{Influencia de la huella energética del agua}

La huella energética se puede estimar, calcular a partir de mediciones o bien con la ecuación (7.6) y su valor numérico depende fundamentalmente del origen del agua. En la Tabla 80, se muestran los valores tipo empleados (en $\mathrm{kWh} / \mathrm{m}^{3}$ ) para considerar la energía consumida desde la detracción del medio natural hasta la fase de distribución. Por eso, los consumos energéticos en redes de saneamiento, tratamiento de las aguas y vertido al medio no se muestran en dicha tabla porque por ellas no circula el agua fugada.

${ }^{53}$ Tanto el propio modelo como el manual del usuario se pueden descargar gratuitamente en la página web del Pacific Institute (www.pacinst.org). 
TABLA 80. VALORES TIPO DE LA HUELLA ENERGÉTICA DEL AGUA, DESDE EL ORIGEN HASTA LA FASE DE DISTRIBUCIÓN.

\begin{tabular}{cccc}
\hline Etapa & Origen & Orden de magnitud & Referencia \\
\hline $\begin{array}{c}\text { Captación, bombeo y } \\
\text { transporte }\end{array}$ & Agua subterránea & $0.35 \mathrm{kWh} / \mathrm{m}^{3}$ por & - \\
& Agua superficial & $00 \mathrm{~m} \mathrm{de} \mathrm{elevación}$ & $($ Sala, 2007) \\
\hline \multirow{2}{*}{ Potabilización } & Desalación & $3.5 \mathrm{kWh} / \mathrm{m}^{3}$ & $(\mathrm{NRC}, 2008)$ \\
& Tratamiento & $0.47 \mathrm{kWh} / \mathrm{m}^{3}$ & (Hoffman, 2006) \\
\hline \multirow{2}{*}{ Distribución } & Energía de eje & $\begin{array}{c}\text { Calculado mediante la } \\
\text { auditoria hídrica }\end{array}$ & (Cabrera y col., 2009) \\
\hline
\end{tabular}

\subsubsection{Influencia de la fuente de energía}

El modelo agua-aire requiere que se defina la procedencia de la energía consumida y a partir de éstos, se calculan las emisiones atmosféricas de la relación agua-energía. Para ello, se pueden seleccionar nueve fuentes diferentes de energía y se pueden trazar hasta ocho escenarios diferentes con combinaciones de las procedencias anteriores. Si los usuarios del modelo conocen el origen de la electricidad, que proviene de una central en particular, pueden contactar con la misma y averiguar los porcentajes que se deben utilizar para crear un escenario mixto local en el que se reproduzcan las condiciones particulares.

Las fuentes de energía mostradas en el modelo también incluyen algunas opciones no eléctricas, como alimentación directa mediante equipos de bombeo accionados por motores diésel, muy empleados en agricultura. Las emisiones de contaminantes están consideradas en el modelo para cada una de los nueve orígenes de la energía. El modelo no permite en la actualidad que se cambien las emisiones según el origen de la energía.

La energía consumida se calcula según dos unidades: kilovatios eléctricos por hora y kilovatios hora equivalente. El kWh equivalente es la energía que habría sido generada si el combustible fósil u otras fuentes de energía se hubieran empleado en generar electricidad en la central correspondiente en vez de emplearse como fuente de alimentación directa. Cada fuente de energía tiene su propia cantidad de $\mathrm{CO}_{2}$ emitida por kWh producido. La Tabla 81 muestra los valores tipo empleados.

TABLA 81. CANTIDAD DE CO2 EMITIDA A LA ATMÓSFERA SEGÚN ORIGEN DE LA ENERGÍA.

\begin{tabular}{lccccc}
\hline Emisiones g/kWh & Gas Natural & Petróleo & Carbón & Eólica/ Solar /Viento & Nuclear \\
\hline Dióxido de Carbono & 554 & 865 & 1432 & 0.0 & 0.0 \\
\hline
\end{tabular}




\subsubsection{Cálculo del ahorro en las emisiones a partir de la reducción de las fugas}

En el capítulo 6 de la Tesis ya se expuso que la reducción de las fugas conlleva una reducción energética. En éste, todavía se profundiza más en la problemática y se comprueba que la reducción energética implica una reducción en las emisiones de gases invernadero. Para ello, simplemente se deben comparar dos escenarios, con mayor y menor tasa de fugas. De esta manera se calcula la energía y toneladas de $\mathrm{CO}_{2}$ ahorradas por la reducción de la tasa de fugas.

Los valores mostrados en la Tabla 80 y la Tabla 81 indican que si el agua es desalada y la fuente de energía es una central térmica de carbón, el ahorro en las emisiones que se produce tras la eliminación total o parcial de las fugas será mucho mayor que la misma red abastecida de agua subterránea o superficial y la energía sea obtenida en una central nuclear o eólica. Estos hechos, que aparentemente son obvios, se refrendan numéricamente en el posterior apartado 7.7. Asimismo, el modelo agua-aire se puede extender a otros contaminantes como $\mathrm{CO}, \mathrm{NO}_{x}, \mathrm{SO}_{x}$, etc. Sin embargo, aunque el procedimiento es exactamente el mismo, estos cálculos no se muestran en este capítulo y se centra únicamente en la cantidad de $\mathrm{CO}_{2}$ emitido a la atmósfera.

\subsection{Ejemplo numérico}

El objetivo es cuantificar la energía necesaria para satisfacer la demanda de una red sintética y observar la influencia que sobre este consumo tienen algunas decisiones de gestión adoptadas (instalación de una válvula de regulación, regulación con bomba de velocidad variable y reducción de la demanda). Asimismo, se calcularán los indicadores de gestión energéticos (capítulo 6) y los créditos de carbono ahorrados. Por último, se plantea un escenario que considera varias actuaciones simultáneas orientadas a la reducción del consumo hídricoenergético y que representaría la mejor gestión posible del sistema con las actuaciones descritas.

\subsubsection{Planteamiento del caso}

La Figura 113 muestra el esquema de la red que tiene dos zonas bien diferenciadas. Los nudos de la primera (nudos 1, 2, 3, 4 y 5) están situados a cota cero, mientras que los de la segunda (el resto) tienen cotas entre los 20-25 m. Las características de nudos y líneas se detallan en la Tabla 72, mientras que los coeficientes de modulación (los mismos para cualquier día del año) se muestran en la Tabla 83. Las simulaciones se realizan utilizando el software EPANET 2.0. (Rossman, 2000). 


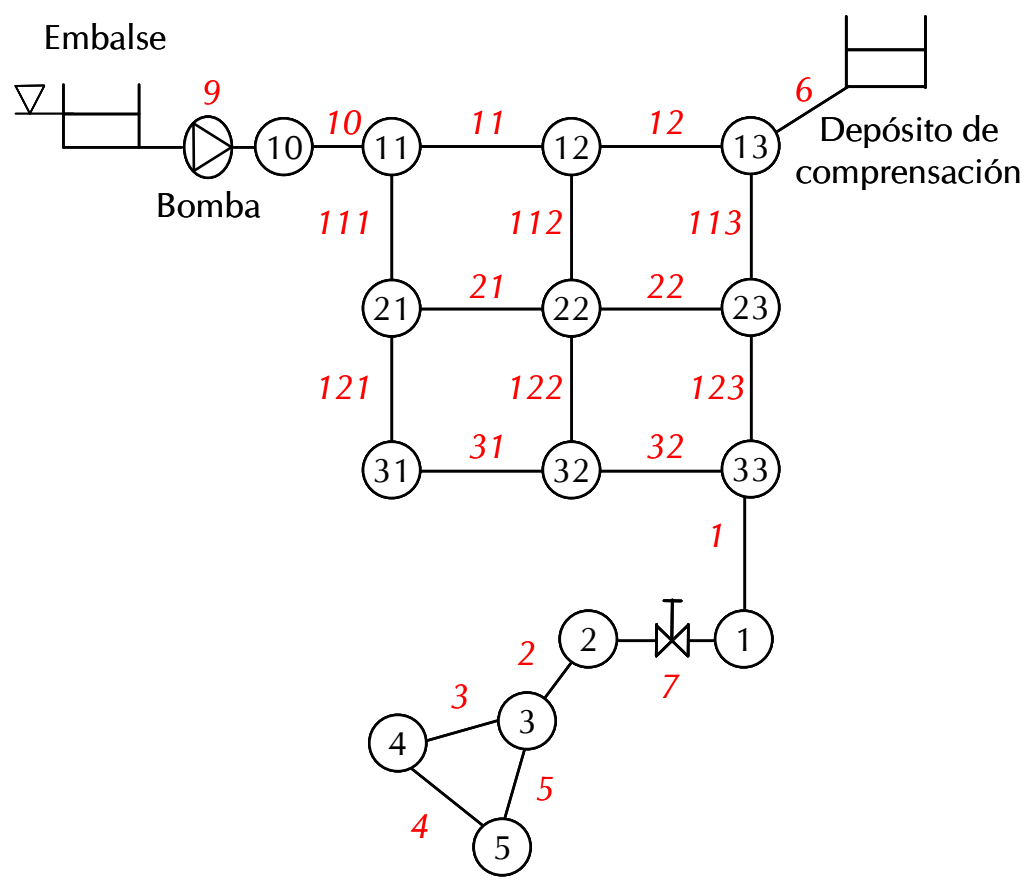

FIGURA 113. ESQUEMA GENERAL DE LA RED.

TABLA 82. CARACTERÍSTICAS PROPIAS DE LOS NUDOS Y LÍNEAS.

\begin{tabular}{ccccccc}
\hline Línea & $\begin{array}{c}\text { Longitud } \\
(\mathbf{k m})\end{array}$ & $\begin{array}{c}\text { Diámetro } \\
(\mathbf{m m})\end{array}$ & Nudo & $\begin{array}{c}\text { Demanda } \\
\text { Base }(\mathbf{l} / \mathbf{s})\end{array}$ & Cota $(\mathbf{m})$ & $\begin{array}{c}\text { Emisor } \\
\left(\mathbf{m}^{3-\alpha} / \mathbf{s}\right)\end{array}$ \\
\hline 10 & 2 & 300 & 10 & 0 & 25.8 & 0.003993 \\
11 & 2 & 250 & 11 & 5 & 25.8 & 0.015972 \\
12 & 2 & 250 & 12 & 5 & 24 & 0.015972 \\
21 & 2 & 100 & 13 & 3 & 22 & 0.015972 \\
22 & 2 & 100 & 21 & 4 & 23 & 0.019964 \\
31 & 2 & 150 & 22 & 8.5 & 22 & 0.023957 \\
111 & 4 & 200 & 23 & 4 & 20 & 0.019964 \\
112 & 4 & 200 & 31 & 2 & 21 & 0.011979 \\
113 & 4 & 200 & 32 & 5 & 20 & 0.015972 \\
121 & 4 & 150 & 33 & 2 & 20 & 0.011979 \\
122 & 4 & 150 & 1 & 0 & 0 & 0.015972 \\
123 & 4 & 200 & 2 & 0 & 0 & 0.015972 \\
32 & 2 & 200 & 3 & 5 & 0 & 0.011979 \\
1 & 1 & 200 & 4 & 4 & 0 & 0.011979 \\
2 & 1 & 200 & 5 & 5 & 0 & 0.011979 \\
3 & 1 & 150 & Embalse & - & 10 & - \\
4 & 1 & 150 & Depósito & - & 75 & - \\
5 & 1 & 150 & & & & \\
6 & 2 & 300 & & & & \\
\hline
\end{tabular}


TABLA 83. COEFICIENTES DE MODULACIÓN HORARIA DEL CAUDAL.

\begin{tabular}{ccccccccccccc}
\hline Hora & $\mathbf{1}$ & $\mathbf{2}$ & $\mathbf{3}$ & $\mathbf{4}$ & $\mathbf{5}$ & $\mathbf{6}$ & $\mathbf{7}$ & $\mathbf{8}$ & $\mathbf{9}$ & $\mathbf{1 0}$ & $\mathbf{1 1}$ & $\mathbf{1 2}$ \\
Coeficiente & 0.6 & 0.5 & 0.45 & 0.45 & 0.5 & 0.5 & 0.9 & 1.3 & 1.4 & 1.1 & 1.5 & 1.4 \\
\hline Hora & $\mathbf{1 3}$ & $\mathbf{1 4}$ & $\mathbf{1 5}$ & $\mathbf{1 6}$ & $\mathbf{1 7}$ & $\mathbf{1 8}$ & $\mathbf{1 9}$ & $\mathbf{2 0}$ & $\mathbf{2 1}$ & $\mathbf{2 2}$ & $\mathbf{2 3}$ & $\mathbf{2 4}$ \\
Coeficiente & 1.4 & 1.45 & 1.45 & 1.3 & 1.2 & 1.2 & 1.1 & 1.1 & 1.2 & 1.1 & 0.9 & 0.7 \\
\hline
\end{tabular}

La rugosidad de las tuberías es $0.1 \mathrm{~mm}$, el diámetro del depósito de compensación $20 \mathrm{~m}$, y su nivel oscila entre $2 \mathrm{~m}$ (valor inicial en la simulación) y $7 \mathrm{~m}$ (valor máximo). La curva de la bomba encargada de mantener la presión de servicio mínima (30 m.c.a.) en todos los nudos de consumo es $H=146.67-0.004063 \cdot Q^{2}$. Arranca y para con los niveles extremos del depósito. Existe una válvula de regulación que en el estado inicial, que se supone abierta durante toda la simulación. Se realiza una simulación para un plazo de un año, valor que rebasa ampliamente el tiempo frontera entre el corto y el largo plazo. En este ejemplo, $\Delta E_{C \max }=307.23 \mathrm{kWh}$ (máxima energía almacenada en el depósito, se corresponde con un cálculo en el que en el instante inicial de la simulación el nivel en el depósito sea mínimo y en el final tenga nivel máximo) y $E_{\text {Input }}=2553.17 \mathrm{kWh} / \mathrm{día}$, por lo que el depósito representa menos del $1 \%$ a partir del tiempo frontera, $t_{p, B}$ (días) $=\frac{\Delta E_{c, \text { max }}}{\frac{1}{100} \cdot E_{\text {lnput }}(\text { diaria })} \sim 12$ días.

La auditoría hídrica anual es:

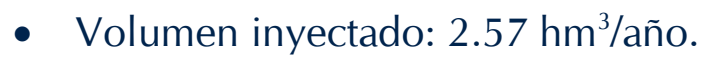

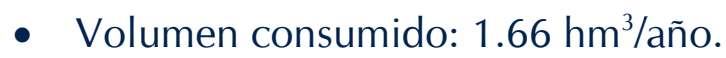

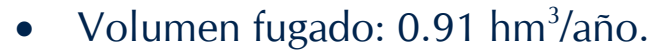

Los caudales de fuga por cada nudo se determinan con las mismas hipótesis que en el capítulo anterior. Se admite que son proporcionales tanto a la presión del nudo como a la longitud de las tuberías que en él convergen (hipótesis de distribución uniforme) y se impone, además, el cumplimiento de la ecuación de continuidad (la suma en el tiempo de los volúmenes nodales fugados debe coincidir con el resultado de la auditoría volumétrica de partida). Las fugas se caracterizan con un coeficiente de emisor obtenido mediante aproximaciones sucesivas (Almandoz y col. 2005) y un exponente de emisor que representa las características propias del material de la tubería, que en esta aplicación numérica adopta un valor medio $\alpha=1.2$. 


\subsubsection{Programa de gestión de la demanda}

Para cuantificar la influencia energética de la reducción de la demanda, se supone el mismo escenario que el planteado en el apartado 7.7.1, y se analizan tres situaciones nuevas, que son:

- Una reducción del $5 \%$ en la demanda. Puede ser un descenso en la demanda obtenida tras una etapa de concienciación de la población en un abastecimiento. El programa de gestión de la demanda (reducción de consumos), con respecto a la situación inicial, supondría un ahorro hídrico de $0.08 \mathrm{hm}^{3} /$ año, con un volumen inyectado de $2.48 \mathrm{hm}^{3} /$ año y un volumen registrado igual a $1.57 \mathrm{hm} /$ año. Al exigir idéntico nivel de presiones con caudales circulantes menores, se produce un leve aumento del agua fugada, que ahora es de $0.92 \mathrm{hm}^{3} /$ año.

- Reducción del $10 \%$ de la demanda. Un ahorro del $10 \%$ en la demanda puede ser propio de la instalación de dispositivos que produzcan una reducción en el consumo tras una etapa de concienciación ciudadana. El volumen inyectado sería en este caso $2.42 \mathrm{hm}^{3} /$ año (ahorro hídrico 0.15 $\mathrm{hm}^{3} /$ año), mientras que el volumen registrado es $1.49 \mathrm{hm}^{3} /$ año y las fugas son $0.93 \mathrm{hm}^{3} /$ año.

- Una reducción muy elevada de la demanda, 15\%. En éste último caso, se corresponde con un ahorro notable del consumo por parte de los usuarios. El volumen inyectado sería de $2.34 \mathrm{hm}^{3} /$ año lo que supone una reducción de $0.23 \mathrm{hm}^{3} /$ año con respecto al estado inicial del sistema. El volumen

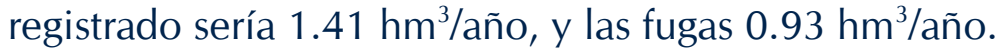

En estos casos, todas las condiciones de la red son exactamente iguales al estado inicial definido en el apartado 7.7.1, y únicamente se han modificado todos los valores de la demanda base de todos los nudos, con lo que se la reducción de la demanda está uniformemente repartida a lo largo de la red.

\subsubsection{Instalación de una válvula de regulación}

Las propias características topográficas de la red (Figura 113) sugieren la instalación de una válvula de regulación para reducir la sobrepresión en la zona de menor cota. Este análisis no pretende justificar la instalación de la válvula, ya que es una decisión obvia, sino cuantificar el beneficio energético de tal instalación. 
Tras su instalación, se fija la consigna a 35 m.c.a. para asegurar una presión en los nudos aguas abajo de la misma siempre superior al umbral mínimo de servicio (30 m.c.a.). El volumen inyectado en este caso es $2.46 \mathrm{hm}^{3} / \mathrm{año}$, el volumen

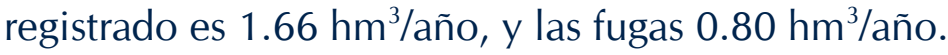

\subsubsection{Instalación de una bomba de velocidad variable}

Por último, se analiza el efecto energético de la instalación de una bomba de velocidad variable. La regulación con bomba de velocidad variable se realizará sin el depósito de compensación, ya que el depósito distorsiona la caracterización del consumo de los usuarios finales (es otro elemento de regulación adicional) e impide al equipo de bombeo trabajar a ciertas velocidades de giro (por no proporcionar la suficiente presión para Ilenarlo). El depósito no permite que la bomba se ajuste a la curva de consigna, y genera problemas en la simulación porque éste tiende a vaciarse. 
Una vez eliminado el depósito, se ajusta el giro de la bomba para conseguir que ésta siga la curva de consigna de la red (con la presión en el nudo más desfavorable de la red igual al estándar mínimo de presión, 30 m.c.a.). Para cada hora del día y cuando se consigue que el sistema cumpla la condición anterior, se registra la presión en el nudo aguas abajo de la bomba y el caudal inyectado. Como el caudal inyectado varía horariamente se obtiene una serie de puntos que generan la curva de consigna. En la presente aplicación numérica, ésta adopta la ecuación: $H=0.0029 \cdot Q^{2}+0.2075 \cdot Q+20.649$ (Figura 114).

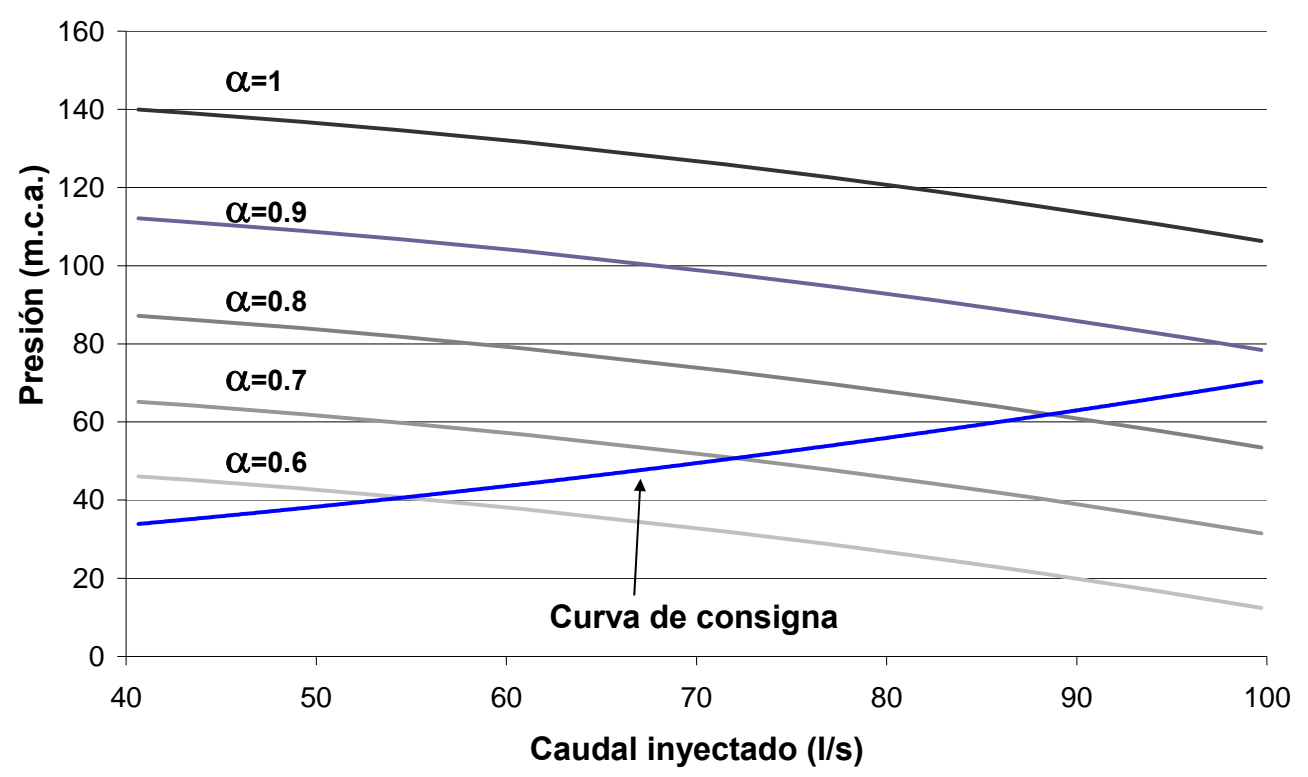

FIGURA 114. CURVA DE CONSIGNA Y CURVA DE FUNCIONAMIENTO DEL EQUIPO DE BOMBEO A DIFERENTES VELOCIDADES DE GIRO.

Una vez se conoce la curva de consigna, se calcula qué velocidad de giro es necesaria para proporcionarla. Esto es, para cada punto conocido de la curva de consigna se ha de resolver la ecuación $H=C \alpha^{2}+B Q \alpha+A Q^{2}$. En esta ecuación, los coeficientes A, B y C son los propios de la curva característica de la bomba y $(\mathrm{H}, \mathrm{Q})$ son los puntos de la curva de consigna. Para nuestra aplicación numérica ( $\mathrm{A}=-0.004063, \mathrm{~B}=0$ y $\mathrm{C}=146.67)$. De acuerdo con estas características, los $\alpha$ para cada hora de la simulación son los mostrados en la Tabla 84.

TABLA 84. COEFICIENTES DE MODULACIÓN DE LA VELOCIDAD DE GIRO DEL EQUIPO DE BOMBEO.

\begin{tabular}{ccccccccccccc}
\hline Hora & $\mathbf{1}$ & $\mathbf{2}$ & $\mathbf{3}$ & $\mathbf{4}$ & $\mathbf{5}$ & $\mathbf{6}$ & $\mathbf{7}$ & $\mathbf{8}$ & $\mathbf{9}$ & $\mathbf{1 0}$ & $\mathbf{1 1}$ & $\mathbf{1 2}$ \\
$\alpha$ & 0.66 & 0.63 & 0.62 & 0.62 & 0.63 & 0.66 & 0.68 & 0.80 & 0.86 & 0.83 & 0.80 & 0.77 \\
\hline Hora & $\mathbf{1 3}$ & $\mathbf{1 4}$ & $\mathbf{1 5}$ & $\mathbf{1 6}$ & $\mathbf{1 7}$ & $\mathbf{1 8}$ & $\mathbf{1 9}$ & $\mathbf{2 0}$ & $\mathbf{2 1}$ & $\mathbf{2 2}$ & $\mathbf{2 3}$ & $\mathbf{2 4}$ \\
$\alpha$ & 0.8 & 0.91 & 0.93 & 0.86 & 0.83 & 0.80 & 0.80 & 0.85 & 0.86 & 0.90 & 0.77 & 0.72 \\
\hline
\end{tabular}


Las velocidades de giro mostradas en la tabla anterior provocan que las presiones a lo largo del día en el nudo más desfavorable sean las mostradas en la Figura 115. En ellas se mantiene la presión por encima del valor umbral deseado.

Por último, la auditoría calcula la energía hidráulica, y no la eléctrica consumida por los equipos de bombeo. Por tanto, el ahorro eléctrico no se corresponde directamente con el energético, y si la velocidad de giro es muy inferior a la nominal, el rendimiento del motor decae. En la aplicación numérica, aunque se trate de un ejemplo teórico, se ha intentado que la velocidad de giro sea siempre mayor que los $30 \mathrm{~Hz}(\alpha>0.6 \mathrm{~m})$ tal y como recomiendan los principales fabricantes de bombas.

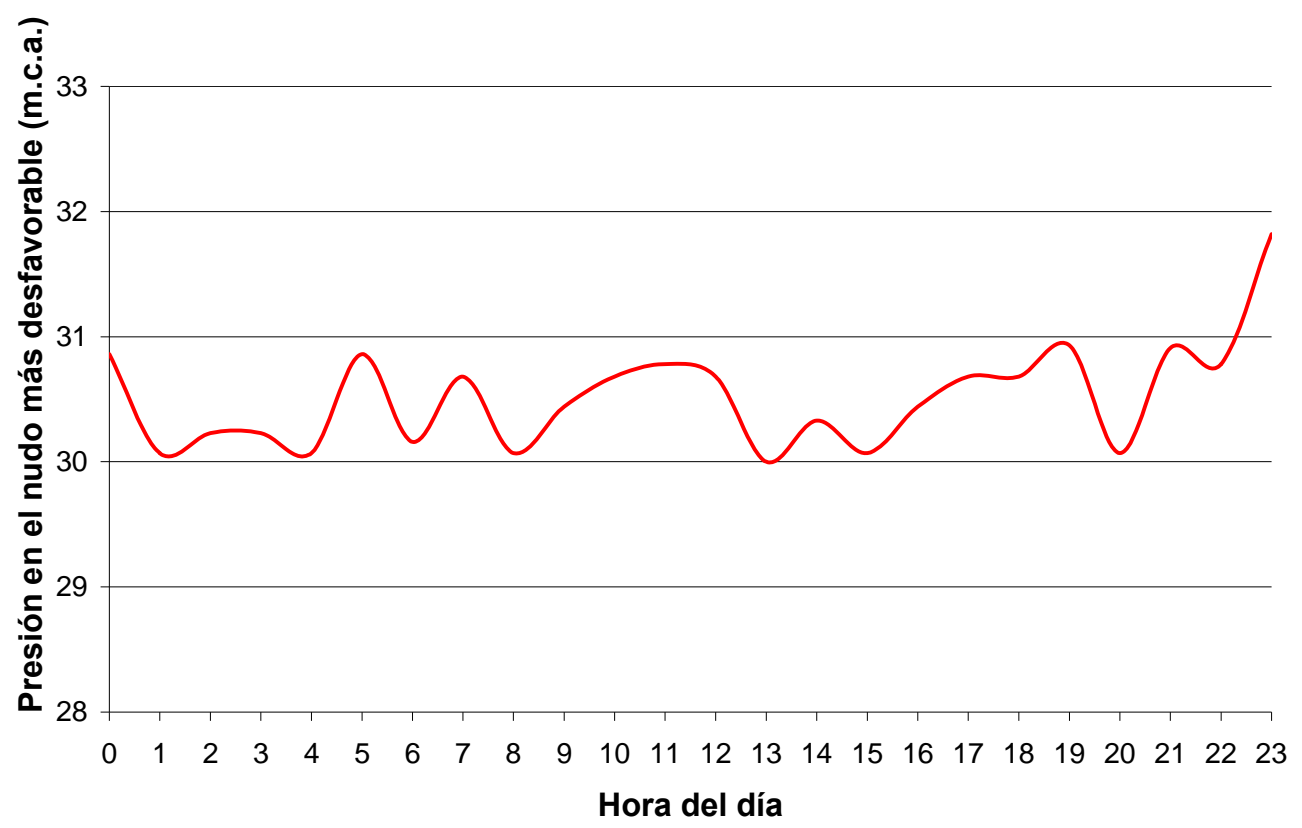

FIGURA 115. PRESIÓN HORARIA EN EL NUDO MÁS DESFAVORABLE. 


\subsubsection{Orígenes del agua y energía para el cálculo de los créditos de carbono emitidos a la atmósfera}

El ahorro de las emisiones depende tanto del origen del agua como de la energía. La influencia del origen del agua (con diferentes huellas energéticas) se plasma en los casos A y B. El primero se refiere a una población abastecida a partes iguales por agua superficial y subterránea. Mientras que en segundo, el agua procede en su totalidad de una planta desaladora. Los cálculos numéricos se realizan con una huella energética de $0.296 \mathrm{kWh} / \mathrm{m}^{3}$ y $3.65 \mathrm{kWh} / \mathrm{m}^{3}$ para el caso A y B respectivamente.

Por otra parte, la influencia del origen de la energía se considera con los casos I y II. El primero (caso I), se refiere a la energía total producida en España (MITYC, 2007), mientras que el segundo (caso II) se refiere a una energía obtenida con una combinación que produce unas mayores emisiones de toneladas de $\mathrm{CO}_{2}$.

TABLA 85. FUENTES DE ENERGÍA

\begin{tabular}{lcccccc}
\hline & Gas Natural & Petróleo & Carbón & Nuclear & Hidráulica & Otros \\
\hline caso I & $29.8 \%$ & $7.9 \%$ & $22.4 \%$ & $19.8 \%$ & $9.7 \%$ & $10.4 \%$ \\
\hline caso II & $33.3 \%$ & $33.3 \%$ & $33.4 \%$ & $0 \%$ & $0 \%$ & $0 \%$ \\
\hline
\end{tabular}

Por tanto, para cada uno de los 6 escenarios descritos, (red inicial, los tres ejemplos de reducción de la demanda, reducción mediante válvula y mediante bomba de velocidad variable) existen 4 combinaciones diferentes (casos Al, All, BI y BII). En todas ellas se calculará el ahorro de emisiones en una red con y sin fugas.

\subsubsection{Auditoría hídrica}

En la descripción de los 6 escenarios se mostraban los valores de la auditoría hídrica. Para facilitar la comparación entre los escenarios, y a modo de resumen se presentan nuevamente en la Tabla 86. 
TABLA 86. AUDITORÍA HÍDRICA (HM³/AÑO)

\begin{tabular}{|c|c|c|c|c|c|c|}
\hline \multirow{2}{*}{ Volumen } & \multirow{2}{*}{ Inicial } & \multicolumn{3}{|c|}{ Reducción de la demanda } & \multirow{2}{*}{$\begin{array}{c}\text { Regulación } \\
\text { con } \\
\text { válvula }\end{array}$} & \multirow{2}{*}{$\begin{array}{c}\text { Regulación } \\
\text { con bvv }\end{array}$} \\
\hline & & $5 \%$ & $10 \%$ & $15 \%$ & & \\
\hline Volumen inyectado & 2.57 & 2.48 & 2.42 & 2.34 & 2.46 & 2.25 \\
\hline Volumen registrado & 1.66 & 1.57 & 1.49 & 1.41 & 1.66 & 1.66 \\
\hline Volumen fugado & 0.91 & 0.92 & 0.93 & 0.93 & 0.81 & 0.60 \\
\hline Error & $0.20 \%$ & $-0.41 \%$ & $0.17 \%$ & $0.18 \%$ & $0.11 \%$ & $0.00 \%$ \\
\hline
\end{tabular}

Tras esto, ya se han descrito todos los escenarios y a partir de éstos se puede calcular la energía y emisiones que la distribución del agua comporta. A ello se dedica el siguiente apartado.

\subsubsection{Resultados}

Se presentan (Tabla 74) los resultados de los seis escenarios analizados. Corresponden a la simulación anual de la red real. Se realiza la simulación en periodo extendido de la red y se recogen los datos cada 15 minutos. 
TABLA 87. AUDITORÍA ENERGÉTICA (MWH/AÑO) EN LOS DIFERENTES CASOS ESTUDIADOS, RED REAL.

\begin{tabular}{|c|c|c|c|c|c|c|c|}
\hline \multirow{2}{*}{\multicolumn{2}{|c|}{ Energía }} & \multirow{3}{*}{$\begin{array}{c}\text { Inicial } \\
70.06 \\
(8.90 \%)\end{array}$} & \multicolumn{3}{|c|}{ Reducción de la demanda } & \multirow{3}{*}{$\begin{array}{c}\begin{array}{c}\text { Regulación } \\
\text { con } \\
\text { válvula }\end{array} \\
\begin{array}{c}67.14 \\
(8.89 \%)\end{array}\end{array}$} & \multirow{3}{*}{$\begin{array}{c}\begin{array}{c}\text { Regulación } \\
\text { con bvv }\end{array} \\
61.44 \\
(12.48 \%)\end{array}$} \\
\hline & & & $5 \%$ & $10 \%$ & $15 \%$ & & \\
\hline \multirow{2}{*}{$E_{\text {Input }}\left(t_{p}\right)$} & $E_{N}\left(t_{p}\right)$ & & $\begin{array}{c}67.58 \\
(8.88 \%)\end{array}$ & $\begin{array}{c}66.00 \\
(8.86 \%)\end{array}$ & $\begin{array}{c}63.87 \\
(8.83 \%)\end{array}$ & & \\
\hline & $E_{P}\left(t_{p}\right)$ & $\begin{array}{c}717.35 \\
(91.10 \%)\end{array}$ & $\begin{array}{c}693.42 \\
(91.12 \%)\end{array}$ & $\begin{array}{c}678.88 \\
(91.14 \%)\end{array}$ & $\begin{array}{c}659.25 \\
(91.17 \%)\end{array}$ & $\begin{array}{c}688.43 \\
(91.11 \%)\end{array}$ & $\begin{array}{c}430.69 \\
(87.52 \%)\end{array}$ \\
\hline \multicolumn{2}{|c|}{ Energía total de entrada } & 787.41 & 761.01 & 744.88 & 723.13 & 755.58 & 492.13 \\
\hline \multirow{3}{*}{$E_{\text {Output }}\left(t_{p}\right)$} & $E_{U}\left(t_{p}\right)$ & $\begin{array}{c}325.93 \\
(41.43 \%)\end{array}$ & $\begin{array}{c}312.29 \\
(40.91 \%)\end{array}$ & $\begin{array}{c}298.99 \\
(40.17 \%)\end{array}$ & $\begin{array}{c}281.88 \\
(39.01 \%)\end{array}$ & $\begin{array}{c}297.62 \\
(39.40 \%)\end{array}$ & $\begin{array}{c}255.49 \\
(51.93 \%)\end{array}$ \\
\hline & $E_{L}\left(t_{p}\right)$ & $\begin{array}{c}184.41 \\
(23.44 \%)\end{array}$ & $\begin{array}{c}186.45 \\
(24.42 \%)\end{array}$ & $\begin{array}{c}189.54 \\
(25.46 \%)\end{array}$ & $\begin{array}{c}191.44 \\
(26.49 \%)\end{array}$ & $\begin{array}{c}159.72 \\
(21.14 \%)\end{array}$ & $\begin{array}{c}91.67 \\
(18.63 \%)\end{array}$ \\
\hline & $\Delta E_{C}\left(t_{p}\right)$ & $\begin{array}{c}0.28 \\
(0.04 \%)\end{array}$ & $\begin{array}{c}0.20 \\
(0.03 \%)\end{array}$ & $\begin{array}{c}0.29 \\
(0.04 \%)\end{array}$ & $\begin{array}{c}0.24 \\
(0.03 \%)\end{array}$ & $\begin{array}{c}0.24 \\
(0.03 \%)\end{array}$ & - \\
\hline \multirow{2}{*}{$E_{\text {Dissipated }}\left(t_{p}\right)$} & $E_{F}\left(t_{p}\right)$ & $\begin{array}{c}276.01 \\
(35.09 \%)\end{array}$ & $\begin{array}{c}264.46 \\
(34.64 \%)\end{array}$ & $\begin{array}{c}255.50 \\
(34.33 \%)\end{array}$ & $\begin{array}{c}249.05 \\
(34.46 \%)\end{array}$ & $\begin{array}{c}253.39 \\
(33.55 \%)\end{array}$ & $\begin{array}{c}144.81 \\
(29.44 \%)\end{array}$ \\
\hline & $E_{V}\left(t_{p}\right)$ & 0 & 0 & 0 & 0 & $\begin{array}{c}44.40 \\
(5.88 \%)\end{array}$ & 0 \\
\hline \multicolumn{2}{|c|}{ Energía total de salida } & 786.64 & 763.39 & 744.30 & 722.61 & 755.37 & 491.98 \\
\hline \multicolumn{2}{|c|}{ Error $^{54}$} & $0.10 \%$ & $-0.31 \%$ & $0.08 \%$ & $0.07 \%$ & $0.03 \%$ & $0.03 \%$ \\
\hline
\end{tabular}

El análisis de los datos mostrados en la Tabla 74 no depara muchas sorpresas. De hecho, se corrobora la bondad de los análisis cualitativos ya realizados (Tabla 78). Estas son las principales conclusiones obtenidas:

- A partir de la situación inicial, todas las actuaciones producen una reducción en la energía total entrante y en todas se mantiene la proporción entre la energía natural y la de eje. La red analizada se caracteriza porque casi toda la energía entrante en el sistema se obtiene mediante bombeos y una pequeña parte (menor que el 10\%) es de tipo natural.

- La reducción de la demanda provoca un aumento en el nivel de presiones y por tanto un aumento en el volumen fugado (Tabla 86), y en consecuencia, en la energía que se pierde en fugas. Pese a todo, la reducción en la energía entregada útil y la menor energía disipada en fricción compensa sobradamente este incremento. De esta manera, la energía de entrada en nuestro sistema se reduce en $26.4,42.53$ y $64.28 \mathrm{MWh} / \mathrm{año}$ para los casos en los que se reduce la demanda un 5,10 y $15 \%$ respectivamente.

${ }^{54}$ El error es debido a redondeos en el cálculo numérico. Éste se puede reducir si los valores obtenidos del modelo hidráulico de la red (con los que se calcula la auditoría) se registran con mayor frecuencia (5 ó 10 minutos frente a los 15 del ejemplo), aunque esto ralentizaría el cálculo. 
- $\quad$ Si se puede regular con válvula, esto es si existe un excedente de energía, se obtiene un ahorro hídrico (Tabla 86), así como la consiguiente reducción en la energía útil, fugas y fricción, (28.31, 24.69 y 22.61 MWh/año respectivamente), que compensan la energía disipada en la válvula (44.40 MWh/año) y generan un ahorro de 31.21 MWh/año.

- La regulación con bomba de velocidad variable supone la máxima mejora posible desde la óptica de la gestión (la energía total de entrada disminuye un $45 \%$ con respecto al escenario inicial). No en vano, las presiones están muy ajustadas en el presente ejemplo (Figura 115). El ahorro tan elevado se obtiene por ser la que mayores ahorros hídricos comporta, junto con una presión ajustada a los requerimientos mínimos del problema, proporciona el valor más bajo de los consumos energéticos.

- La energía disipada por fricción es similar en los seis casos, salvo en el caso de regulación con bomba de velocidad variable. La energía disipada produce una variación en la temperatura media del agua igual a $0.09^{\circ} \mathrm{C}^{55}\left(0.06^{\circ} \mathrm{C}\right.$ en el caso de la regulación con bomba de velocidad variable).

Las energías teóricas definidas ( $E_{\min , u s e f u l}$ y $E_{\min , f l a t}$; Tabla 88) tienen valores numéricos similares y siempre presentan una relación propia de una red bastante plana $E_{\text {min,useful }} \approx 1.3 E_{\text {min,flat }}$. Si no existe variación en la demanda, muestran el mismo valor numérico, ya que únicamente dependen del caudal entregado al consumidor y del umbral de presión definido para todos los casos. Por tanto, los casos estudiados ideales sin fugas (los resultados se muestran en la Tabla 89) presentan exactamente el mismo valor que su correspondiente real, con fugas.

${ }^{55}$ Datos obtenidos con $\rho=1000 \mathrm{~kg} / \mathrm{m}^{3}, C_{p}=4.18 \mathrm{KJ} / \mathrm{kg} / \mathrm{K}$ y $\Delta u=C_{p} \cdot \Delta T$ 
TABLA 88. ENERGÍAS TEÓRICAS DEFINIDAS

\begin{tabular}{|c|c|c|c|c|c|c|}
\hline \multirow{2}{*}{ Energía } & \multirow{2}{*}{ Inicial } & \multicolumn{3}{|c|}{ Reducción de la demanda } & \multirow{2}{*}{$\begin{array}{c}\text { Regulación } \\
\text { con } \\
\text { válvula }\end{array}$} & \multirow{2}{*}{$\begin{array}{l}\text { Regulación } \\
\text { con bvv }\end{array}$} \\
\hline & & $5 \%$ & $10 \%$ & $15 \%$ & & \\
\hline$E_{\min , \text { useful }}$ & 172.82 & 164.18 & 155.54 & 146.89 & 172.82 & 172.82 \\
\hline$E_{\min , f l a t}$ & 135.35 & 128.58 & 121.81 & 115.05 & 135.35 & 135.35 \\
\hline
\end{tabular}

Los resultados de este mismo cálculo para los mismos 6 casos en su estado ideal sin fugas se muestran en la Tabla 89

TABLA 89. AUdiTORÍA ENERGÉTICA (MWH/AÑO) EN UNA RED IDEAL SIN FUGAS.

\begin{tabular}{|c|c|c|c|c|c|c|c|}
\hline \multirow{2}{*}{\multicolumn{2}{|c|}{ Energía }} & \multirow{3}{*}{$\begin{array}{c}\text { Inicial } \\
45.10 \\
(8.57 \%)\end{array}$} & \multicolumn{3}{|c|}{ Reducción de la demanda } & \multirow{3}{*}{$\begin{array}{c}\begin{array}{c}\text { Regulación } \\
\text { con } \\
\text { válvula }\end{array} \\
45.10 \\
(8.57 \%)\end{array}$} & \multirow{3}{*}{$\begin{array}{c}\begin{array}{c}\text { Regulación } \\
\text { con bvv }\end{array} \\
45.12 \\
(10.90 \%)\end{array}$} \\
\hline & & & $5 \%$ & $10 \%$ & $15 \%$ & & \\
\hline \multirow{2}{*}{$E_{\text {Input }}\left(t_{p}\right)$} & $E_{N}\left(t_{p}\right)$ & & $\begin{array}{c}42.93 \\
(8.54 \%)\end{array}$ & $\begin{array}{c}40.44 \\
(8.51 \%)\end{array}$ & $\begin{array}{c}37.90 \\
(8.48 \%)\end{array}$ & & \\
\hline & $E_{P}\left(t_{p}\right)$ & $\begin{array}{c}481.24 \\
(91.43 \%)\end{array}$ & $\begin{array}{c}459.87 \\
(91.46 \%)\end{array}$ & $\begin{array}{c}434.64 \\
(91.49 \%)\end{array}$ & $\begin{array}{c}408.92 \\
(91.52 \%)\end{array}$ & $\begin{array}{c}481.24 \\
(91.43 \%)\end{array}$ & $\begin{array}{c}368.75 \\
(89.10 \%)\end{array}$ \\
\hline \multicolumn{2}{|c|}{ Energía total de entrada } & 526.33 & 502.79 & 475.08 & 446.82 & 526.33 & 413.87 \\
\hline \multirow{3}{*}{$E_{\text {Output }}\left(t_{p}\right)$} & $E_{U}\left(t_{p}\right)$ & $\begin{array}{c}347.46 \\
(65.95 \%)\end{array}$ & $\begin{array}{c}332.39 \\
(66.15 \%)\end{array}$ & $\begin{array}{c}316.79 \\
(66.45 \%)\end{array}$ & $\begin{array}{c}300.71 \\
(66.71 \%)\end{array}$ & $\begin{array}{c}303.95 \\
(57.69 \%)\end{array}$ & $\begin{array}{c}348.55 \\
(84.24 \%)\end{array}$ \\
\hline & $E_{L}\left(t_{p}\right)$ & 0.00 & 0.00 & 0.00 & 0.00 & 0.00 & 0.00 \\
\hline & $\Delta E_{C}\left(t_{p}\right)$ & $\begin{array}{c}0.18 \\
(0.03 \%)\end{array}$ & $\begin{array}{c}0.11 \\
(0.02 \%)\end{array}$ & $\begin{array}{c}0.08 \\
(0.02 \%)\end{array}$ & $\begin{array}{c}0.09 \\
(0.02 \%)\end{array}$ & $\begin{array}{c}0.18 \\
(0.03 \%)\end{array}$ & - \\
\hline \multirow{2}{*}{$E_{\text {Dissipated }}\left(t_{p}\right)$} & $E_{F}\left(t_{p}\right)$ & $\begin{array}{c}179.23 \\
(34.02 \%)\end{array}$ & $\begin{array}{c}170.01 \\
(33.83 \%)\end{array}$ & $\begin{array}{c}159.83 \\
(33.53 \%)\end{array}$ & $\begin{array}{c}149.95 \\
(33.27 \%)\end{array}$ & $\begin{array}{c}179.23 \\
(34.02 \%)\end{array}$ & $\begin{array}{c}65.23 \\
(15.76 \%)\end{array}$ \\
\hline & $E_{V}\left(t_{p}\right)$ & 0.00 & 0.00 & 0.00 & 0.00 & $\begin{array}{c}43.50 \\
(8.26 \%)\end{array}$ & 0.00 \\
\hline \multicolumn{2}{|c|}{ Energía total de salida } & 526.86 & 502.51 & 476.70 & 450.75 & 526.86 & 413.77 \\
\hline \multicolumn{2}{|c|}{ Error } & $-0.10 \%$ & $0.06 \%$ & $-0.34 \%$ & $-0.87 \%$ & $-0.10 \%$ & $0.02 \%$ \\
\hline
\end{tabular}


Los resultados de la Tabla 74 y la Tabla 89 muestran que:

- En una red sin fugas se produce un ahorro de energía neta entrante (787.41 MWh/año frente a 526.33 MWh/año), así como una mejora significativa de las prestaciones. Una clara evidencia es la mayor cantidad de energía que reciben los usuarios (347.46 MWh/año frente a 325.93 $\mathrm{MWh}$ /año), así como un mejor posicionamiento frente a futuras ampliaciones de la red.

- La energía total asociada a las fugas en la red de distribución, obtenida como suma de perdida inherente a las fugas y el ahorro en energía de fricción se muestra en la Tabla 90. Nótese que para la obtención de esta energía total se ha de calcular la auditoría para el sistema sin fugas.

TABLA 90. VALORES DE LAS ENERGÍAS TOTALES (MWH/AÑO) ASOCIADAS A LAS FUGAS EN LA RED DE DISTRIBUCIÓN

\begin{tabular}{|c|c|c|c|c|c|c|}
\hline \multirow{2}{*}{ Energía } & \multirow{2}{*}{ Inicial } & \multicolumn{3}{|c|}{ Reducción de la demanda } & \multirow{2}{*}{$\begin{array}{c}\text { Regulación } \\
\text { con } \\
\text { válvula }\end{array}$} & \multirow{2}{*}{$\begin{array}{c}\text { Regulación } \\
\text { con bvv }\end{array}$} \\
\hline & & $5 \%$ & $10 \%$ & $15 \%$ & & \\
\hline$E_{L}\left(t_{p}\right)$ & 184.41 & 186.45 & 189.54 & 191.44 & 159.72 & 91.67 \\
\hline$E_{F}\left(t_{p}\right)-E_{F}\left(t_{p}\right)_{\sin f u g a s}$ & 96.78 & 94.44 & 95.67 & 99.10 & $75.06^{56}$ & 79.59 \\
\hline$E_{L}\left(t_{p}\right)+E_{F}\left(t_{p}\right)-E_{F}\left(t_{p}\right)_{\text {sinfugas }}$ & 281.19 & 280.89 & 285.20 & 290.54 & 233.89 & 171.26 \\
\hline Ahorro total anual & $35.7 \%$ & $36.9 \%$ & $38.3 \%$ & $40.2 \%$ & $31.0 \%$ & $34.8 \%$ \\
\hline
\end{tabular}

\subsubsection{Valoración de la gestión energética de la red con los nuevos indicadores.}

Los indicadores definidos en el capítulo 6 de la tesis, adoptan los valores mostrados en la Tabla 75. En ésta se observa en primer lugar que los indicadores de contexto, como no puede ser de otra forma, muestran los mismos valores para todas las simulaciones realizadas, con lo que se demuestra que son independientes de la gestión y de las fugas existentes en la red de distribución. En el caso de la regulación con bomba de velocidad variable, el indicador $c_{1}$ difiere de los restantes casos, aunque esto se justifica por no consistir exactamente en el mismo escenario ya que se eliminó el depósito de almacenamiento.

\footnotetext{
${ }^{56}$ Aunque se hace referencia a la energía de fricción, también se ha de considerar la diferente energía disipada en la válvula para los escenarios en los que se encuentre instalada. En éste, $(253.39+44.40)-(179.23+43.50)=75.06 \mathrm{Mwh} /$ año.
} 
En cambio, los indicadores, si que dependen del estado del sistema. El primero $\left(I_{1}\right)$ muestra la cantidad de energía de tipo natural. Tal y como se ha comentado previamente, adopta valores similares a los obtenidos en el escenario inicial con fugas en comparación con el resto de actuaciones $\left(I_{1} \approx 4.56\right)$. Se observa una gran mejora en el caso de la regulación con bomba de velocidad variable $\left(I_{1}=2.85\right)$, ya que la energía de entrada es muy inferior a la obtenida en el resto de escenarios.

TABLA 91. INDICADORES DE GESTIÓN ENERGÉTICOS PARA LOS CASOS ESTUDIADOS.

\begin{tabular}{|c|c|c|c|c|c|c|}
\hline \multirow{2}{*}{ Indicadores } & \multirow{2}{*}{ Inicial } & \multicolumn{3}{|c|}{ Reducción de la demanda } & \multirow{2}{*}{$\begin{array}{c}\text { Regulación } \\
\text { con } \\
\text { válvula }\end{array}$} & \multirow{2}{*}{$\begin{array}{l}\text { Regulación } \\
\text { con bvv }\end{array}$} \\
\hline & & $5 \%$ & $10 \%$ & $15 \%$ & & \\
\hline \multicolumn{7}{|c|}{ Red con fugas } \\
\hline $\mathrm{kWh} / \mathrm{m}^{3}$ inyectado & 0.28 & 0.28 & 0.28 & 0.28 & 0.28 & 0.19 \\
\hline $\mathrm{kWh} / \mathrm{m}^{3}$ registrado & 0.43 & 0.44 & 0.46 & 0.47 & 0.42 & 0.26 \\
\hline$C_{1}$ & 0.09 & 0.09 & 0.09 & 0.09 & 0.09 & 0.12 \\
\hline$C_{2}$ & 1.28 & 1.28 & 1.28 & 1.28 & 1.28 & 1.28 \\
\hline$l_{1}$ & 4.56 & 4.64 & 4.79 & 4.92 & 4.37 & 2.85 \\
\hline$I_{2}$ & 0.41 & 0.41 & 0.40 & 0.39 & 0.39 & 0.52 \\
\hline$I_{3}$ & 0.35 & 0.35 & 0.34 & 0.34 & 0.34 & 0.29 \\
\hline$I_{4}$ & 0.36 & 0.37 & 0.38 & 0.40 & 0.31 & 0.35 \\
\hline$I_{5}$ & 1.89 & 1.90 & 1.92 & 1.92 & 1.72 & 1.48 \\
\hline k & 1.49 & 1.51 & 1.56 & 1.61 & 1.43 & 1.17 \\
\hline \multicolumn{7}{|c|}{ Red sin fugas } \\
\hline $\mathrm{kWh} / \mathrm{m}^{3}$ inyectado & 0.29 & 0.29 & 0.29 & 0.29 & 0.29 & 0.22 \\
\hline $\mathrm{kWh} / \mathrm{m}^{3}$ registrado & 0.29 & 0.29 & 0.29 & 0.29 & 0.29 & 0.22 \\
\hline$C_{1}$ & 0.09 & 0.09 & 0.09 & 0.08 & 0.09 & 0.12 \\
\hline$C_{2}$ & 1.28 & 1.28 & 1.28 & 1.28 & 1.28 & 1.28 \\
\hline$l_{1}$ & 3.05 & 3.06 & 3.05 & 3.04 & 3.05 & 2.39 \\
\hline$I_{2}$ & 0.66 & 0.66 & 0.67 & 0.67 & 0.58 & 0.84 \\
\hline$I_{3}$ & 0.34 & 0.34 & 0.34 & 0.34 & 0.34 & 0.16 \\
\hline$I_{4}$ & 0 & 0 & 0 & 0 & 0 & 0 \\
\hline$I_{5}$ & 2.01 & 2.02 & 2.04 & 2.05 & 1.76 & 2.02 \\
\hline k & 1 & 1 & 1 & 1 & 1 & 1 \\
\hline
\end{tabular}


La cantidad total de energía que es útil $\left(I_{2}\right)$ presenta valores que rondan el $40 \%$ para todos los casos de la red real y del 50\% para el caso de la bomba de velocidad variable. En los casos de la red ideal sin fugas, aumentan notablemente el valor numérico, hasta el $66 \%$ los primeros, y hasta el $84 \%$ en el segundo.

El indicador de la energía disipada en fricción $\left(I_{3}\right)$ adopta valores del 35\%. Esto se debe a que la longitud de la red es notable, a que sus diámetros están un tanto ajustados o a la combinación de ambas circunstancias. Asimismo, la mejora obtenida en el caso de la red sin fugas no es sustancial. Por tanto, el elevado valor de este indicador sugiere el estudio de la sustitución de algunas tuberías clave por otras de diámetro mayor.

El indicador $I_{4}$ cuantifica la parte de la energía inyectada que se pierde con las fugas. En los casos reales, la energía perdida en fugas en la red de distribución ronda el $35-40 \%$ de energía total de entrada al sistema, y obviamente, en los casos ideales sin fugas adopta el valor 0 .

La energía de más se entrega a los usuarios o, de otro modo, el exceso en el cumplimiento del estándar de presión previamente establecido lo expresa el indicador $t_{5}$. Los valores cercanos a $t_{5}=1.9$ (casos inicial y reducción de la demanda) son propios de redes donde no se regula la presión en la red. El valor $I_{5}=1.72$ para la instalación de una válvula de regulación ya muestra un primer esfuerzo hacia la gestión eficiente del sistema. El caso en el que se regula con un equipo de velocidad variable muestra el valor $t_{5}=1.48$, un valor numérico muy bueno dado que existen nudos a diferentes cotas (nudos 2, 3, 4 y 5; Figura 113). Esto induce a pensar que la combinación de regulación con bomba de velocidad variable y válvula de regulación actuando sobre los nudos comentados proporciona un valor mucho más cercano a la unidad. Sin duda, este caso representaría una regulación muy ajustada y la minimización de los consumos energéticos con las herramientas disponibles por el gestor de la red ${ }^{57}$.

\footnotetext{
${ }^{57}$ La gestión de la demanda, aunque sea un plan de actuación por parte del gestor de la red, depende igualmente del usuario final.
} 
Por último, el indicador k compara la energía entrante extra debido a las fugas. El valor numérico $\mathrm{k}=1.5$ es propio de un red con un nivel medio de fugas, mientras que si ese valor se acerca a la unidad para sistemas con un bajo ratio de fugas (aproximadamente $0.2 \mathrm{~m}^{3} / \mathrm{km} / \mathrm{h}$ ) y los valores mayores de $\mathrm{k}$ (alrededor de 2) son propios en redes con elevadas fugas $\left(2 \mathrm{~m}^{3} / \mathrm{km} / \mathrm{h}\right)$. La reducción de la demanda aumenta el valor de este indicador, lo cual es lógico ya que no es una política orientada a la reducción de las fugas. La regulación con válvula produce una cierta mejoría por la reducción del volumen fugado, aunque como se limita a la reducción en una zona de la red, no muestra un descenso significativo en el indicador $\mathrm{k}$. En el caso de la regulación con bomba de velocidad variable sí que dicho indicador desciende hasta un valor cercano a la unidad $(k=1.17)$. Para el caso sin fugas siempre adopta el valor unidad.

\subsubsection{Ahorro de los créditos de carbono}

Se ha calculado el ahorro de los créditos de carbono en los cuatro casos definidos anteriormente, con orígenes de la energía I y II (Tabla 85) y con huella energética del agua definida para los casos A y B (apartado 7.7.1.4).

En la Tabla 92, se muestra cómo la variación en las emisiones para el caso real es muy importante (cerca de 10 veces superior) entre el caso Al (agua subterránea y superficial y un origen de la energía con un elevado porcentaje obtenido en centrales que no emiten $\mathrm{CO}_{2}$ a la atmósfera) y el BII (con toda el agua obtenida mediante desaladora y la energía obtenida en centrales térmicas).

Para el ejemplo numérico seleccionado, se observa que la huella energética del agua es un factor más importante que el origen de la energía. Esto se observa comparando la variación de toneladas de $\mathrm{CO}_{2}$ emitidas a la atmósfera en el escenario inicial y red real para los casos All (con un origen de la energía más contaminante) y $\mathrm{BI}$ (con mayor huella energética del agua) con respecto al caso inicial Al. Por ejemplo, en el caso inicial A1 (1165.99 toneladas de $\mathrm{CO}_{2}$ ) las emisiones aumentan un $170 \%$ (hasta las 1999.53 toneladas) si cambia el origen de la energía y un $513 \%$ (hasta las 5988.89 toneladas) si lo hace la huella energética del agua. 
La comparación entre los escenarios (sin valorar el origen del agua y de la energía) no produce una variación notable en las emisiones. No en vano, su influencia está limitada únicamente a las tres primeras etapas del ciclo urbano del agua (Figura 102). Las distintas políticas adoptadas muestran una menor cantidad de emisiones por el descenso del consumo hídrico. Por tanto, aunque siempre la reducción de la energía produce un descenso en las emisiones, el efecto del mismo no es tan significativo como el que produce tras la modificación de los orígenes del agua y de la energía.

En caso de que se desee comparar cómo afectan las fugas a las emisiones, se deben calcular las toneladas de carbono emitidas en los 6 escenarios estudiados sin la presencia de fugas (parte central de la Tabla 92). Para analizar el efecto de las mismas, se muestra también la diferencia entre las emisiones en los casos con y sin fugas (parte inferior de la Tabla 92).

La mayor parte de las conclusiones que se pueden obtener con esta comparación son obvias. Es evidente que en los casos en que la red no tenga fugas, se produce una menor reducción en las emisiones si se mejora la gestión del sistema. Asimismo, en estos ejemplos, las emisiones son menores si se reduce la demanda. Las mejoras energéticas producen un efecto mejor cuanto mejor gestionado se encuentre el sistema. $\mathrm{Y}$ en este caso, la inexistencia de fugas es propia de una gestión ideal. 
TABLA 92. TONELADAS DE CARBONO EMITIDAS PARA CADA UNO DE LOS CASOS REALES (CON FUGAS), IDEALES (SIN FUGAS) Y AHORROS ENTRE AMBOS CASOS.

\begin{tabular}{|c|c|c|c|c|c|c|}
\hline & \multirow{2}{*}{ Inicial } & \multicolumn{3}{|c|}{ Reducción de la demanda } & \multirow{2}{*}{$\begin{array}{c}\text { Regulación } \\
\text { con } \\
\text { válvula }\end{array}$} & \multirow{2}{*}{$\begin{array}{c}\text { Regulación } \\
\text { con bvv }\end{array}$} \\
\hline & & $5 \%$ & $10 \%$ & $15 \%$ & & \\
\hline \multicolumn{7}{|c|}{ Red real con fugas } \\
\hline Caso Al & 1165.99 & 1120.83 & 1102.86 & 1045.91 & 1131.67 & 953.06 \\
\hline Caso All & 1999.53 & 1922.97 & 1891.27 & 1794.44 & 1941.57 & 1635.14 \\
\hline Caso BI & 5988.89 & 5772.98 & 5646.14 & 5442.66 & 5753.55 & 5181.97 \\
\hline Caso BII & 10270.26 & 9904.53 & 9682.49 & 9337.81 & 9871.19 & 8890.55 \\
\hline \multicolumn{7}{|c|}{ Red ideal sin fugas } \\
\hline Caso Al & 878.83 & 836.91 & 792.01 & 747.26 & 878.83 & 816.49 \\
\hline Caso All & 1507.78 & 1435.85 & 1358.83 & 1282.05 & 1507.79 & 1400.83 \\
\hline Caso BI & 3984.41 & 3791.77 & 3587.06 & 3387.01 & 3984.44 & 3922.10 \\
\hline Caso BII & 6835.93 & 6502.46 & 6154.21 & 5810.99 & 6835.97 & 7143.79 \\
\hline \multicolumn{7}{|c|}{ Comparación entre escenarios } \\
\hline $\begin{array}{c}\text { Ahorros en las } \\
\text { emisiones Caso Al }\end{array}$ & 287.16 & 283.92 & 310.84 & 298.65 & 252.84 & 136.57 \\
\hline $\begin{array}{c}\text { Ahorros en las } \\
\text { emisiones Caso All }\end{array}$ & 491.76 & 487.11 & 532.44 & 512.39 & 433.78 & 234.31 \\
\hline $\begin{array}{c}\text { Ahorros en las } \\
\text { emisiones Caso BI }\end{array}$ & 2004.48 & 1981.21 & 2059.08 & 2055.65 & 1769.12 & 1259.88 \\
\hline $\begin{array}{c}\text { Ahorros en las } \\
\text { emisiones Caso BII }\end{array}$ & 3434.34 & 3402.07 & 3528.28 & 3526.82 & 3035.22 & 1746.76 \\
\hline
\end{tabular}

Es fácil constatar que en el caso Bll se producen unos mayores ahorros en las emisiones. Se parte de una peor situación inicial, con elevada emisión de toneladas de carbono. Ya que los orígenes del agua y de la energía son independientes de la operación y gestión del sistema, las emisiones se pueden reducir únicamente con las políticas que definen los 6 casos estudiados. Esto es, sólo se podría modificar las emisiones a partir de la instalación de una válvula, etc. Por tanto, las posibilidades de reducción de las emisiones son limitadas. Sin embargo, no debe cejarse en el empeño por reducir el consumo hídrico, energético y de emisiones por todas las ventajas que comportan, ya que además del ahorro en si, también se obtienen mejoras en la operación y mantenimiento, así como una mejor disposición del sistema frente a ampliaciones futuras. 


\subsubsection{Combinación de todas las actuaciones descritas}

Hasta este instante el ahorro energético se ha centrado en los efectos individuales de cada una de las actuaciones. Ahora se va a cuantificar la acción combinada de todos ellos (regulación con equipos de velocidad variable, instalación de una válvula de regulación y reducción de la demanda en un 15\%).

El nuevo escenario ${ }^{58}$ se obtiene a partir de la combinación de los anteriores del siguiente modo. En primer lugar se reduce la demanda en un $85 \%$, con posterioridad se tantea la presión de tarado de la válvula hasta conseguir que la presión en los nudos 3, 4 y 5 (Figura 113) sea superior a la presión mínima de servicio. Debido a que se ha reducido la demanda, el caudal circulante por las tuberías es menor, así como las pérdidas de carga del sistema. Por eso, la presión de tarado de la válvula pasa a ser 33 m.c.a. (por los 35 m.c.a. anteriores). Por último, se obtiene la curva de consigna de modo análogo al caso anterior. Ésta tiene por ecuación $H=0.0036 \cdot Q^{2}+0.0805 \cdot Q+24.429$, y se ajusta el giro de la bomba. Se obtienen los valores mostrados en la Tabla 93, que son sensiblemente inferiores a los de la Tabla 84, algo lógico puesto que circula menor caudal y la válvula está en funcionamiento.

TABLA 93. COEFICIENTES DE MODULACIÓN DE LA VELOCIDAD DE GIRO DEL EQUIPO DE BOMBEO EN EL ESCENARIO COMBINADO.

\begin{tabular}{ccccccccccccc}
\hline Hora & $\mathbf{1}$ & $\mathbf{2}$ & $\mathbf{3}$ & $\mathbf{4}$ & $\mathbf{5}$ & $\mathbf{6}$ & $\mathbf{7}$ & $\mathbf{8}$ & $\mathbf{9}$ & $\mathbf{1 0}$ & $\mathbf{1 1}$ & $\mathbf{1 2}$ \\
$\alpha$ & 0.62 & 0.60 & 0.59 & 0.59 & 0.6 & 0.62 & 0.63 & 0.71 & 0.76 & 0.73 & 0.71 & 0.69 \\
\hline Hora & $\mathbf{1 3}$ & $\mathbf{1 4}$ & $\mathbf{1 5}$ & $\mathbf{1 6}$ & $\mathbf{1 7}$ & $\mathbf{1 8}$ & $\mathbf{1 9}$ & $\mathbf{2 0}$ & $\mathbf{2 1}$ & $\mathbf{2 2}$ & $\mathbf{2 3}$ & $\mathbf{2 4}$ \\
$\alpha$ & 0.71 & 0.79 & 0.80 & 0.76 & 0.73 & 0.71 & 0.71 & 0.75 & 0.76 & 0.78 & 0.69 & 0.65 \\
\hline
\end{tabular}

Las velocidades de giro mostradas en la Tabla 93 hacen que las presiones a lo largo del día en el nudo más desfavorable (nudo 33) sean las mostradas en la Figura 116.

\footnotetext{
${ }^{58}$ En adelante escenario combinado.
} 


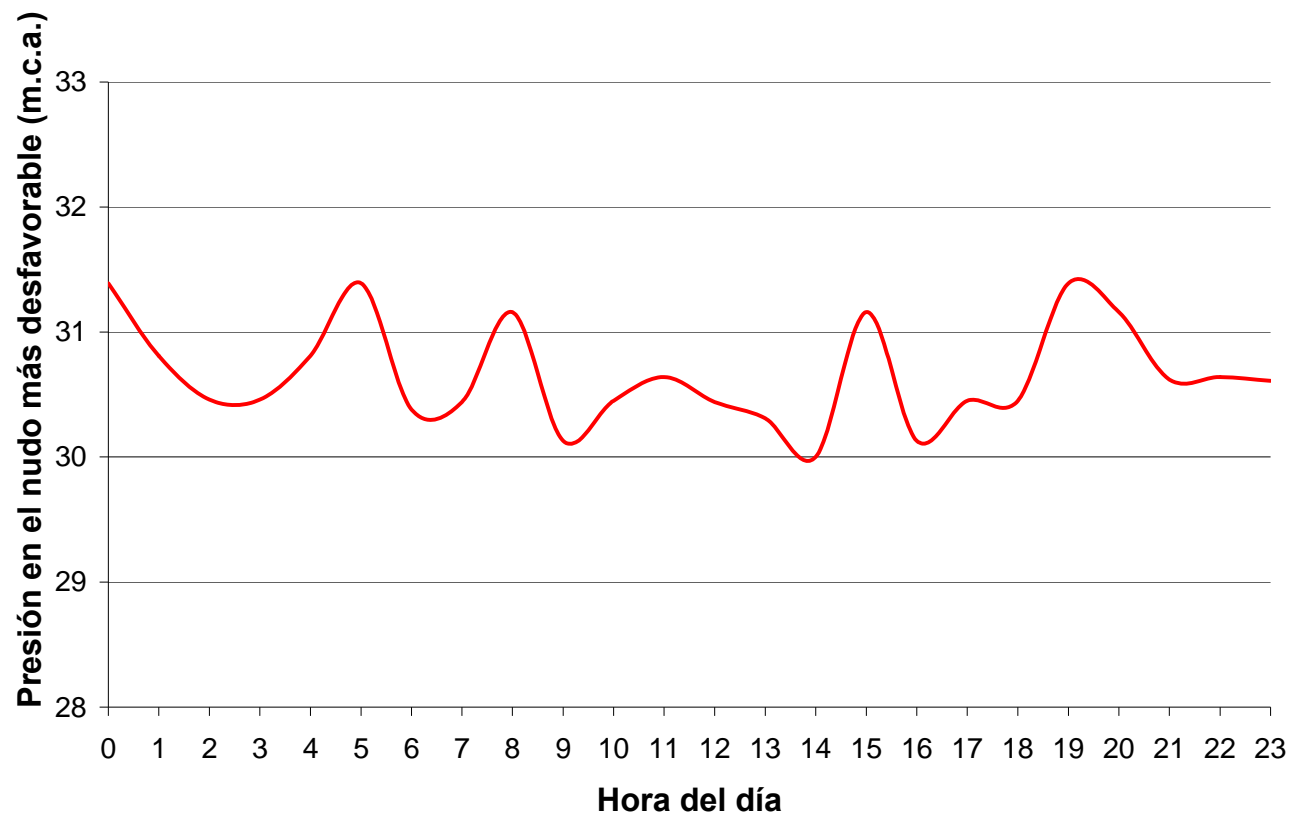

FIGURA 116. PRESIÓN HORARIA EN EL NUDO MÁS DESFAVORABLE EN EL ESCENARIO COMBINADO.

\subsubsection{Auditoría hídrica del escenario combinado}

La auditoría hídrica muestra los valores que se resumen en la Tabla 94.

TABLA 94. AUDITORÍA HÍDRICA DEL ESCENARIO COMBINADO ( $\left.\mathrm{HM}^{3} / A N \tilde{O}\right)$.

\begin{tabular}{l|c|c}
\hline \multicolumn{1}{c|}{ Energía } & Con Fugas & Sin Fugas \\
\hline Volumen inyectado & 1.81 & 1.31 \\
\hline Volumen registrado & 1.31 & 1.31 \\
\hline Volumen fugado & 0.50 & 0.00 \\
\hline Error & $0.00 \%$ & $0.00 \%$ \\
\hline
\end{tabular}




\subsubsection{Análisis energético del escenario combinado}

Se realiza la auditoría energética en el escenario combinado real e ideal (Tabla 95).

TABLA 95. AUDITORÍA ENERGÉTICA (MWH/AÑO) ESCENARIO COMBINADO.

\begin{tabular}{c|c|c|c}
\hline \multicolumn{2}{c|}{ Energía } & Real (con fugas) & Ideal (sin fugas) \\
\hline \multirow{2}{*}{$E_{\text {Input }}\left(t_{p}\right)$} & $E_{N}\left(t_{p}\right)$ & $49.33(14.48 \%)$ & $35.77(13.04 \%)$ \\
\cline { 2 - 4 } & $E_{P}\left(t_{p}\right)$ & $291.23(85.52 \%)$ & $238.55(86.96 \%)$ \\
\hline Energía total de entrada & 340.56 & 274.32 \\
\hline \multirow{2}{*}{$E_{\text {Output }}\left(t_{p}\right)$} & $E_{U}\left(t_{p}\right)$ & $183.39(53.86 \%)$ & $218.83(79.78 \%)$ \\
\cline { 2 - 4 } & $E_{L}\left(t_{p}\right)$ & $68.71(20.18 \%)$ & 0.00 \\
\hline \multirow{2}{*}{$E_{\text {Dissipated }}\left(t_{p}\right)$} & $E_{F}\left(t_{p}\right)$ & $71.08(20.87 \%)$ & $30.80(11.23 \%)$ \\
\cline { 2 - 4 } & $E_{V}\left(t_{p}\right)$ & $17.33(5.09 \%)$ & $24.66(8.99 \%)$ \\
\hline \multicolumn{2}{c}{ Energía total de salida } & 340.51 & 274.29 \\
\hline \multicolumn{2}{c}{ Error } \\
\hline
\end{tabular}

Como no puede ser de otra manera, los efectos conjuntos de cada actuación individual provocan una mayor reducción en el consumo energético. Se muestra una reducción de la energía de entrada en la red de un $56.7 \%$ con respecto al caso inicial. La proporción de energía natural y de eje con respecto a los seis casos anteriores se mantiene aunque se detecta un ligero aumento del consumo de la energía natural en la red (en éste llega casi al 15\% y en el inicial era cercano al $9 \%$ ). Con respecto al caso inicial, se reduce la energía entregada útil, la energía disipada en fricción y la energía en fugas y aunque existe una nueva energía, la disipada en la válvula, su efecto es mucho menor que los ahorros energéticos de los otros términos.

La energía disipada por fricción para todos los casos definidos proporciona una variación en la temperatura media del agua igual a $0.03^{\circ} \mathrm{C}$. Las energías teóricas definidas para el escenario combinado son $E_{\text {min,useful }}=141.22 \mathrm{MWh} /$ año $\mathrm{y}$ $E_{\text {min,flat }}=107.31 \mathrm{MWh} / \mathrm{año}$. La energía total asociada a las fugas en la red de distribución, obtenida como suma de perdida inherente a las fugas y el ahorro en energía disipada en tubería y válvulas, es de $68.71+32.95=101.66$ MWh/año. 


\subsubsection{Valoración de la gestión energética de la red}

Los indicadores para este último caso adoptan los valores mostrados en la Tabla 96.

TABLA 96. INDICADORES DE GESTIÓN ENERGÉTICOS EN EL ESCENARIO COMBINADO.

\begin{tabular}{c|c|c}
\hline Indicadores & Con fugas & Sin fugas \\
\hline $\mathrm{kWh} / \mathrm{m}^{3}$ inyectado & 0.16 & 0.18 \\
\hline $\mathrm{kWh} / \mathrm{m}^{3}$ registrado & 0.22 & 0.18 \\
\hline$C_{1}$ & 0.14 & 0.13 \\
\hline$C_{2}$ & 1.32 & 1.32 \\
\hline$I_{1}$ & 2.41 & 1.94 \\
\hline$I_{2}$ & 0.54 & 0.80 \\
\hline$I_{3}$ & 0.21 & 0.11 \\
\hline$I_{4}$ & 0.32 & 0.00 \\
\hline$I_{5}$ & 1.30 & 1.55 \\
\hline $\mathrm{k}$ & 1.22 & - \\
\hline
\end{tabular}

Los indicadores de contexto muestran los mismos valores para todas las simulaciones realizadas. El indicador $l_{1}$ muestra valores inferiores a los anteriores, Tabla 75 , ya que eran del orden de $\left(I_{1} \approx 4.5\right)$ y ahora se reduce hasta $\left(I_{1}=2.41\right)$. Por tanto, la energía de entrada es más cercana a la energía mínima requerida por el sistema $\left(E_{\text {min,useful }}\right)$.

La cantidad total de energía que es útil presenta un valor $I_{2}=0.54$ y llega hasta 0.8 para el caso sin fugas. Esto es, el $54 \%$ de la energía aportada es entregada al usuario final, lo cual es un valor bastante elevado. En el caso sin fugas, el indicador de 0.8 es inferior al de regulación con bomba de velocidad variable que tenía como valor 0.84. Lo cual es lógico, ya que en el escenario inicial no se regulaba la presión y en los nudos situados en la parte baja de la red la presión a la que se entregaba el agua era superior a la de servicio (la presión mínima en esos nudos es 42-45 m.c.a.). Por tanto, este indicador muestra la proporción de energía total entrante al sistema es energía útil, aunque no es el único que se debe considerar para saber si la regulación de la red es la apropiada, ya que en el escenario combinado sin fugas adopta un valor $\left(I_{2}=0.80\right)$ inferior al calculado en el escenario con regulación con un equipo de velocidad variable y sin fugas $\left(I_{2}=0.84\right)$, aunque si se observa la energía entrante al sistema queda claro que es más eficiente el último. En cualquier caso, estos dos escenarios son ideales y ambas muestran valores cercanos a la unidad. 



\section{8}

\section{Thesis conclusions and future research}

Nota: Las conclusiones y desarrollos futuros se han escrito en inglés para la obtención de la mención europea del título de Doctor, RD 56/2005. Las mismas se pueden encontrar en castellano en el Anexo F. 



\subsection{Thesis conclusions}

The work presented here shows the influence of water and energy costs on the optimum renovation period of pipes, together with a methodology to quantify energy use in water distribution networks. The main results are highlighted in the following, including the answers to the questions which motivated this thesis.

\section{How much money does renovation require?}

In chapter 1, renovation or rehabilitation investment in Valencia, Spain and Europe is presented. As the US is taken as a point of reference worldwide, the research is also extended to this country. Investment in renovation is very high and as environmental concerns increase so does the urgency of the need to renovate mains. Moreover, numerical values of common indicators (such as $€$ /inhabitant or $€ /$ length of the network) are presented.

\section{Which are the widely used mains in water distribution systems? What are the renovations criteria?}

Each type of water main has its own advantages and disadvantages. Consequently, there is not a universally used one and many of them are currently installed in the same, which is to say in heterogeneous, water networks.

The relative incidences of the different types of pipes are quite similar in the US, almost all of Europe, Spain and Valencia. The most installed pipe is made of cast iron $(30-50 \%$ of the whole system) only in Finland and the Netherland's its incidence is lower (less than 20\%). Asbestos cement is widely used in water networks (though not as commonly in the US as in Europe, both as a whole, and, more particularly in Spain, the country where this material is most used). Anyway, as plastic mains such as those made of PVC and PE, increase their relative incidence in networks, they become more and more relevant.

Moreover, some criteria concerning renovation or rehabilitation are highlighted. Most of the time, renovation is a political decision (especially in urban areas) although it is quite important to get a decision support system: a tool to equally evaluate all criteria and to adopt a predictive policy as opposed to the traditional reactive one (in high diameters, this is critical if systems failures are not to have catastrophic consequences).

Lastly, fuzzy applications used in taking renovation decisions are explained. These ascertain the consistency of the initial hypothesis and which procedures should be used to calculate a particular solution. It also helps to make sensivity analyses to quantify the importance of the weighting assigned to each selected criterion. 
What is a water audit? How does it influence the optimum renovation period? How much water is lost through leaks in water distribution systems?

A water audit reports a wide range of information concerning water losses (apparent and real ones, including those resulting from customer metering inaccuracies and unauthorised consumption). After the audit, water companies are able to estimate the unmeasured components of water delivered, which helps to take decisions about renovation, reduction of pressure in district metering areas, etc.

Moreover, water losses are related to the maintenance costs of networks. So, if the investment in maintenance decreases, the cost of water losses increases (as does the number of failures, chapter 2). Both terms (leaked water and maintenance investment) are inversely related and there is an optimum relation that minimises the sum of maintenance and water loss costs.

A water audit is necessary in order to calculate an energy audit (chapter 6). So as to apply Reynolds transport equation to energy, the different flow terms at all boundaries need to be known. Therefore, a water audit and a calibrated model are required. In other words, the hydraulic problem must first be solved. Since water is incompressible, the mechanical and thermal equations are not coupled (White, 1974), and the energy problem can only be solved after the hydraulic one.

\section{When does a main have to be renewed?}

In chapter 4, a modification of the traditional methodology (Shamir and Howard, 1979) is presented. It deals with the problem holistically. So, it takes into account variable cost related to lost water (actual costs of the water lost through leakage (production and environmental costs) and energy cots resulting from an increased energy use when pressurizing leaked water, and consequently greater energy losses), social and opportunity costs. Quantitatively, it seems quite obvious that the expressions used to assess the new costs must be adapted to each context. The ones included here allow this consideration with a certain degree of accuracy the influence of these costs which are usually neglected. In any case, it seems clear that the water lost through leakage must be taken into account, since the production and environmental costs are significant, and they reduce the optimum renovation period considerably. 
This modification presented here pretends to be universal, although every supply has its own particularities and the data needed to calculate the optimum renovation period is scarce. But it solves the problem from a broader perspective. The numerical example may show surprising values, as it is not common to renovate a water main every 30 years. This is due to a high failure rate and a high number of initial ruptures in pipes. On the other hand, newly considered costs (usually met by consumers not by water companies) reduce the renovation period.

It is quite difficult to take advantage of the opportunity cost, as bureaucracy and lack of mutual knowledge among companies are almost impassable issues. This quantification must be an indication of potential savings to companies.

\section{Would it be possible to use a trenchless technology?}

Trenchless technologies represent alternatives ways of renovating water mains. The International Society of Trenchless Technology (ISTT), founded in 1986, supports the use of these new techniques. In this work, a functional classification of the different trenchless technologies is outlined. It shows their salient characteristics and arguments for and against each of them. These techniques represent new renovation options, in contradiction to the open-cut method.

Some studies show how renovation costs relate to these technologies. These (including a study located in Spain, Pardo (2006)) are presented herein. Homogeneous results are desirable and all researchers dealt with the same topic, since every project is different and final costs depends on multiple factors (number of connections, state of the previous main, etc.). So, results shown here only represent an order of magnitude, referring only to direct costs and neglecting social ones (quantified at annex D).

Further developments will surely reduce costs and cause these techniques to be more competitive in the near future. This is already taking place in sewerage networks, where a technique (cured in place pipe) is even cheaper than that of the open-cut method. Consequently, it justifies its widespread use in the US. On the other hand, the use of these technologies in water distribution systems is more problematic, as water is pressurized and must be safe for human consumption. The key objective of manufacturers is to satisfy this requirement so as to expand their market share. The future of these techniques seems to be promising. 


\section{How do the short-term policies (rehabilitation) influence the long-term ones (renovation)?}

An integral solution to link short-term policies (rehabilitation) to long-term ones (renovation) is proposed herein. It shows a different point of view as it indicates their interdependence.

The influence of water and energy on this question is also addressed. It comes as no surprise, that the higher they are, and the more expensive maintenance (it requires greater investment in rehabilitation). This is logical consequence; higher values of water and energy results in lower minimum optimum leakage volume, in other words, higher resources to minimise leakage.

Moreover, an analytical equation shows the relationship between maintenance investment and leaked volume. This allows the calculation of the optimum economic leakage volume, an expression that takes into account energy costs (obtained by energy audit, chapter 6).

What is the most relevant factor in the reviewed methodology to calculate the optimum renovation period?

The most relevant factor is the rate of growth of the number of ruptures. It only depends on the type of water main and the installation conditions. So, a first step when trying to enlarge the renovation period should be to install pipes (best practices) or to take prevention measures agains corrosion (linings or cathodic protection). On the other hand, water companies can not modify the initial conditions of the water main (the type of installation, etc.) and so, it is hardly able to change the number of ruptures. All efforts must be focused on management parameters as average volume lost per fault and day, or average life for each fault, etc.

Other key factors are the cost of water and energy. The first may include environmental costs (considered in some countries with greater environmental conciousness, but not in Spain) and the second is one of the hottest topics in the water industry, especially since water is obtained from desalination (with high energy consumption). Moreover, the stages in the urban water cycle may be very energy hungry (water energy footprint in $€ / \mathrm{m}^{3}$ ) and energy cost is revealed as a relevant factor in optimum renovation period calculation. The energy effect may be addressed with the energy audit of water networks (chapter 6). It quantifies the whole energy invested in a water network and allows the calculation of the parameter k (with low influence at the renovation period as shown herein) and energy costs (chapter 4). 
What is the relationship between trenchless technologies and the optimum renovation period? And, what about the possibility of considering infinite pipe replacement cycles?

The renovation and social costs (those that influence the investment parameter) depend on the technique used. So, each one shows a different value for this parameter, which in turn, modifies the optimum renovation period. The key advantage that trenchless technologies have over the open-cut method is lower social costs.

Moreover, the influence of infinite pipe replacement cycles is described. The results are not the same if one consider infinite cycles or just one renovation. On the other hand, a particular result is presented here. If the calculation of the optimum renovation period considers the cycles as infinite and the renovation alternative is sliplinning, it will not be possible to use it consecutively (due to the reduction of the cross section of the pipe). The provided solution is to alternate this technique with the open-cut method.

\section{How water and energy are related? What is an energy audit?}

Until a decade ago, the most relevant aspect of the water-energy relationship was hydroelectric production. Today, the focus has shifted towards water as an energyconsuming agent. This new perspective has turned water distribution into a very relevant stage and has brought attention not only on how much energy is consumed but also on how that energy is used. A proper assessment of how much energy is wasted as a result of network leakage is one of the main targets of this thesis. Such energy loss results not only from the energy leaving the system through leaks (which can be quite significant depending on the energy footprint of the produced water, e.g., desalinated water) but also the energy needed to overcome additional friction losses created by higher circulating flow rates through the pipes.

The audit presented in this work can be used to identify the end uses of the energy entering the network and thus to define a performance assessment system that characterizes the network from an energy perspective through context information items and evaluates its energetic performance. The energy audit approach can also be supplemented with water and energy price information, as well as estimates of carbon and GHG impacts for the sources and amounts of energy use, in order to form part of a more holistic evaluation of system performance improvement options, such as might be undertaken in a cost-benefit analysis framework. As a matter of fact, these tools could easily be used from a regulatory or administrative perspective to create incentives for a more sustainable urban energy management in water distribution systems. 
The energy audit, like associated indicators, requires a previous water audit and that both of them are applied in similar conditions (either to the whole network or a sector). The energy audit can be extended to any period of time, but as the water balance is usually available for a year, the audit should cover the same period.

The energy audit is carried out with a simple but lengthy calculation process, manipulating EPANET result files. The software is not able by itself to calculate the suggested indicators. Should EPANET incorporate this option, the energy audit of the system would become an instant tool available for all technical network managers.

\section{How much energy is outgoing through leaks in a water distribution system?}

Leakage influences directly two energy parameters, the outgoing energy leaving the network with leaked water (identified in the audit and the water energy footprint of previous steps of urban water cycle) and the energy spent overcoming friction losses of leaked water which previously circulated through the network pipes generating such additional losses, an amount to be determined (because it requires audits of the network with and without leaks) indirectly. As already mentioned, both of them can be calculated with the energy audit.

\section{How do the management policies affect energy use? What about water conservation?}

The efficient performance of a water networks is strongly influenced by main features of the networks themselves (diameters, age, water energy footprint, network elevation, etc.). In order to evaluate each case, water and energy audits are required. Due to the complexity of the network (hundreds of underground pipes with thousands of domestic connections), the distribution stage of the water cycle is the most difficult one to audit.

Hydraulic and energetic benefits due to the policies adopted by water companies are shown. Regulation of pressure using a valve or a variable speed pump is widely used in water networks to assess performance. The first is used when there are district metering areas with an excess of pressure (generally related to low values of nodes elevation in a district) or as a method to reduce night-flows, while the second matches the pressure to selected values. The improvement of this last regulation procedure may not produce an economic benefit although the energetic one is proved. Sometimes it is even cheaper to pump to a regulation tank without any speed modification of the electric motor than to vary the speed of the pump to reach the proper pressure, because of variations in the electric rate (with a temporal variation of energy cost). 
Water conservation is not a policy to reduce leaks, but it is on sustainable management of water and so, huge energetic benefits are linked to hydraulic ones. In chapter 7, the effect on the energy consumption is shown. The key objective of this part of the research is not the value in the numerical example, as every water supply system is different, but the procedure to calculate the energy involved in this process and indicators that help to manage data for each specific problem. Results confirm the qualitative ideas that have been extracted from the experience but this has to be backed up by facts and not just by words. So, from quantitative evaluations, rational sensitivity analysis can be performed to identify the best cost benefit measure to manage water in the most sustainable way.

The effects of all combined policies are also analysed in the last numerical example. Each one of them (regulation of pressure using a valve or a variable speed pump, water demand reduction) involves reduction in energy use but it highlights the synergy created among all of them and the results show a desirable scenario. Management of water networks may always be improved and the limits are defined by the budget, not by the requirements of the network.

How many credit carbons are saved due to reduction of leaked water? And, how does a management policy affect to carbon emissions?

Results from the energy audit in two scenarios, an ideal leak-free network and a real, leaky one, show energy savings associated to the complete elimination of leakage. This comparison may be used to determine the energetic effect of a specific action.

Moreover, the relationship between energy and emissions may be calculated using one of the various existing models. The water to air model was developed by the Pacific Institute (Wolff et al. 2004) was the one selected here. Results show that energy and emissions are strongly linked, are both valuable resources and depend very much on the sources of water and energy. As these sources are not modifiable by water companies, the key objective is to proportion a methodology to calculate emission in a specific case. 


\subsection{Future research}

The content of the thesis show many ways of development in the near future. Sustainable performance of water and energy requires the attention of consumers, operators, manufacturers and other institutions (town halls, river basins, regulators, etc.). So, the development of these topics must consider the specific concerns of each institution.

Some of the future research will be pointed out later. The most relevant ones are shown in (8.2.3, 8.2.4 and 8.2.5). The first explores the future reseach related to the optimum renovation period (chapter 4), while the second deals with the influence of short-term policies (rehabilitation) on long-term ones (renovation). The last propose new development in the water energy audit (chapter 6) and the advantages of the efficient management of water systems and how this relates to emissions (chapter 7).

\subsubsection{Renovation investments}

Quantification of investment in water distribution networks must involve the owners themselves (in most cases town halls), operators (or sometimes a regulator, nonexistent in Spain ${ }^{59}$, similar to OFWAT in England and Wales). The work presented here reports the existing research. This can be easyly improved on simply by tabulating the data provided separately. Data could be shown homogeneously; in other words, it is easy to identify investment in pipe renovation, in active leakage-control, valves, etc. That would have to be taken in order to carry out an economic investment audit of a water network.

\subsubsection{Pipe materials and trenchless technologies}

Innovation in pipe materials is usually developed by manufacturers themselves or with support proportioned by research institutions such as universities.

The latest research has concentrated on plastics, as new pipes allow improvements in durability, functionality, etc. However, metallic pipe manufacturers have not researched new materials but, rather, the development of procedures to manufacture the existing materials.

\footnotetext{
${ }^{59}$ A regulator in Spain (which guarantees best practices, concrete the bills and demands investment to utilities) is an old claim. It was a proposal of the current govern from 2008-2012. Nowadays, due to the crisis, the foundation of this institution seems to be quite improbable.
} 
Trenchless technologies were developed in the US and UK. All of them concerned with better installation processes that enlarge the diameters, increase the length of the new pipe, etc. Moreover, research has focused on overcoming the disadvantages of each particular technique, for example:

1. Non structural lining. With regard to cement mortar lining, research tries to reduce lining thickness, while other polymeric linings deal with the cost reduction (trying to be more competitive than the previous one and to be available in higher diameters).

2. Structural lining. Research on sliplining is focused on decreasing the cross section reduction, while researchers are trying to make cured in place pipe usable at water distribution networks, not only at sewerage ones.

3. In-line replacement. Pneumatic pipe bursting uses a pneumatic hammer to break the existing pipe and so, the percussive actions cause ground vibrations and potential damage to neighboring utilities. Reduction of these vibrations is the main target of research. If the technique is hydraulic pipe bursting, an axially mounted hydraulic piston drives the lateral expansion and contraction of the bursting head and the main research give attention to increasing the length of the new pipe and reducing the insertion pit required.

4. Horizontal directional drilling. The scope of the research is, as before, to reduce the ground vibration caused. Other key goals are to extend the application of horizontal directional drilling to gravity sewers, to use this technique for pipe removal, to upsize existing pipes (as it would result in a significant reduction in setup time) and the use of polymer gels as drilling fluid to replace bentonite slurries. This eliminates the need for large truck to mix bentonite slurry (Najafi and Gokhale, 2004).

\subsubsection{Optimum renovation period}

The modification of the traditional methodology proposed herein (chapter 4) suggests a lot of future research. The first idea is to use other break rate models (not only the exponential one) and to evaluate their effect on the renovation period. It could even facilitate the calculation of optimum renovation breaks, which would minimise total costs associated with this issue.

On the other hand, this revision of the methodology might be used in exceptional situations; as for example, to increase the weighting of social cost or to reduce the cost of leaked water. So, every defined cost (renovation, maintenance, etc.) could be added to total cost with a fixed weighting to evaluate these specific circumstances. 
Another area of future research could be to consider costs as a probability function instead of a fixed value. Maybe the most easily investigated case would be that of the opportunity cost, whose distribution would be a binomial one, for example $95 \%$ of the time with one value and just $5 \%$ with another. The rest of the costs can adopt others functions, such as triangular, uniform, gaussian, etc.

Last of all, the final step so as to get a universal tool would be to link this methodology with hydraulic software (such as EPAnet). This would allow the calculation of the optimum renovation period with the simulated values obtained from the software (such as volume lost per day, or energy supplied by the pump). Moreover, this software could be linked to a geographic information system.

\subsubsection{Relationship between short-term policies and long-term ones}

Future research shown in 8.2.3 is quite similar to this. In this thesis, this relationship was determined for a specific scenario in mind (with a time exponential evolution of the failure index) with a homogeneous district metering area (similar types of pipes, diameters, age and evolution of the failure index) and with a defined maintenance policy (all ruptures are repaired). The modification of these initial hypotheses could widen the interaction between rehabilitation and renovation.

The disposal of a hydraulic calibrated model allows the calculation of the volume leaked and the pressure in every district metering area. With this, it becomes easy to evaluate the economic average level of leakage, the natural rate of rise (NRR), average flow rate through breaks, average life for each fault time, etc-

\subsubsection{Energy audit}

This is the most innovative part of the thesis. The relation between water and energy was not traditionally taken into account before, so further improvements can be made. It is the only advantage that comes out of being so careless about energy efficiency for so long.

This approach may be carried out using Matlab 2008 and EPAnet 2.0 (Rossman, 2000). As already mentioned, the audit requires the hydraulic model of the network to perform the results. The programme to obtain the results could be patented and it could become an additional tool for managing a distribution network. 
Due to the novelty of this proposal and the high expectation generated by it, this programme might be developed for commercial issues, and it could have some chances of becoming a viable project. On the other hand, and due to the use of EPAnet, developed by the Environmental Protection Agency as free water distribution network modelling software, it would appear that the free distribution of this modified software would make some savings (not only economic, but environmental and sustainable one).

Nowadays, a study to determine the energetic use in Valencia for the whole water cycle is being carried out with Ayuntamiento de Valencia and the foundation Agua y Progreso. This will quantify the energy requirements of every step of the water cycle. Without any doubt, this work represents a good starting point from which to know the real position of this city and results might be extrapolated to any other water supplies, etc. Moreover, it will reveal the state of networks arising from management decisions.

Other projects are now proposed. The project entitled "Adapting water policies to include footprints and energy impacts" WATERLIFE, promoted by Dirección General del Agua de la Comunidad Valenciana, was submitted to the European Union. If they accept it, it will be a project to determine the energy use of every step of the water cycle in the whole Comunidad Valenciana, similar to CEC (2005). In this project, the energy involved at the distribution stage will be evaluated using the energy audit. However, this ambitious project will only be possible if every institution involved makes an effort to work in coordination and look at this problem from a holistic point of view.

Lastly, several case studies will be carried out in Italy, where three networks in Pisa ATO (Ambito Territoriale Ottimale) will be audited (Ponsacco, Altopascio y Castelfiorentino). Some other projects are proposed in some water distribution networks, such as Murcia and Sevilla. A real case study of the Denia (Alicante) water network will be submitted to the conference, Water Distribution Systems Analysis (WDSA 2010) that will be held next September in Tucson, Arizona. 


\subsection{Notation}

A Coefficient of breakage rate growth $\left(\right.$ years $\left.^{-1}\right)$.

$b$ Wide of the trench/pit.

$C_{b}$ Unit cost of repairing a burst (€/burst).

$C_{E}$ Coste de la energía consumida (€/kWh).

$C_{E, i}$ Emitter coefficient at node i.

$C_{\text {inf }}\left(t_{r}\right)$ Value $\left(€ / m\right.$ of year $\left.t_{r}\right)$ of total cost associated with infinite cycles but the first.

$C_{\text {inf }}\left(T_{t_{j}}^{* *}\right)$ Minimum value of $C_{\text {inf }}\left(t_{r}\right)$. (€/m of year $\left.t_{r}\right)$.

$C_{\text {med }}$ Average losses of the stores in (€/day).

$C_{P}$ Penalty $(€ / m)$ imposed by the competent organism (town hall or regulator) to the operator.

$C_{r_{j}}$ Cost of rehabilitation measure $\mathrm{j}$ in a pipe $(€ / \mathrm{m})$.

$C_{S_{j}}$ Social cost of rehabilitation measure $\mathrm{j}$ in a pipe $(€ / \mathrm{m})$.

$C_{t}$ Cost due to time lost by an employee in $(€ / \mathrm{h})$.

$C_{T_{\text {inf }}}\left(t_{r}\right)$ Cost of the replacement cycles to infinity ( $€ / m$ of year $\left.t_{p}\right)$.

$C_{\text {up }}$ Unit cost of road rehabilitation $\left(€ / \mathrm{m}^{2}\right)$.

$C_{W}$ Total water cost $\left(€ / \mathrm{m}^{3}\right)$.

$C_{1}$ Energy nature coming into the system.

$C_{11}\left(t_{r}\right)$ Cost of the pipe itself $(€ / \mathrm{m})$.

$C_{12}\left(t_{r}\right)$ Cost of installation of the pipe $(€ / \mathrm{m})$.

$C_{2}$ Energy Management complexity of the network (context information).

$C_{2}\left(t_{r}\right)$ Cost of repairing a single break (€/m break).

$C_{31}\left(t_{r}\right)$ Variable cost related to water losses $(€ / \mathrm{m})$.

$C_{32}\left(t_{r}\right)$ Variable cost of energy lost in water losses $(€ / \mathrm{m})$.

$C_{40}$ Other social costs $(€ / \mathrm{m})$.

$C_{41}\left(t_{r}\right)$ Social cost associated to a renovation $(€ / \mathrm{m})$.

$C_{41 A}^{\prime}$ Cost associated to disruption of traffic $(€ / m)$.

$C_{42}\left(t_{r}\right)$ Social cost associated to lost of standards $(€ / \mathrm{m})$.

$C_{5}\left(t_{r}\right)$ Opportunity cost $(€ / \mathrm{m})$.

e Energy per mass unit.

$E_{C_{i}}\left(t_{1}\right)$ Energy compensation of the tank $i$ at the intital time of a simulation.

$E_{C_{i}}\left(t_{p}\right)$ Energy compensation of the tank $i$ at the final time of a simulation. 
$E_{\text {Dissipated }}\left(t_{p}\right)$ Energy losses due to friction for the simulation period. It includes friction losses in pipes and valves. If there are no valves, $E_{\text {Dissipated }}\left(t_{p}\right)=E_{F}\left(t_{p}\right)$.

$E_{F}\left(t_{p}\right)$ Friction energy for the simulation period.

$E_{F}^{\prime}\left(t_{p}\right)$ Friction energy in a leak-free network.

$E_{\text {Input }}\left(t_{p}\right)$ Input energy for the simulation period.

$E_{L}\left(t_{p}\right)$ Energy through leaks for the simulation period.

$E_{\text {min,useful }}$ Minimum useful energy needed in a frictionless, leak-free network served with the minimum required pressure.

$E_{\min , f l a t}$ Minimum theoretical energy needed in an ideal network, frictionless, leak-free and flat.

$E_{N}\left(t_{p}\right)$ Energy supplied by the reservoirs for the simulation period.

$E_{\text {Output }}\left(t_{p}\right)$ Output energy for the simulation period.

$E_{P}\left(t_{p}\right)$ Energy supplied by pumping stations for the simulation period.

$E_{U}\left(t_{p}\right)$ Energy supplied to users for the simulation period.

$h_{\text {dia }}$ Hours lost by employes due to a renovation.

$\left(h_{\text {Min }}\right)_{i}$ Minimum required piezometric head at node i.

$H_{i}\left(t_{k}\right)$ Piezometric head at node i at time interval $t_{k}$.

$H_{N i}$ Piezometric head of water at reservoir, $H_{N i}=H_{N i}\left(t_{k}\right)$.

$H_{N i}\left(t_{k}\right)$ Piezometric head at the reservoir i at time interval $t_{k}$.

$H_{P i}\left(t_{k}\right)$ Piezometric head of the i pump at time interval $t_{k}$.

$I_{1}$ - Excess of supplied energy (performance indicator).

$I_{2}$ - Network energy efficiency (performance indicator).

$I_{3}$ - Energy dissipated through friction (performance indicator).

$I_{4}$ - Leakage energy (performance indicator).

$I_{5}$ - Standards compliance (performance indicator).

$\iota_{j}$ Investment $(€ / \mathrm{m})$, technique $\mathrm{j}$.

$k$ Energy adjustment coefficient due to leaks.

$I_{z}$ Length of the trench/pit.

M Maintenance (€/m/break).

$n$ Number of demand nodes of the network.

$n_{C}$ Number of compensation tanks of the network.

$n_{i}$ Number of time intervals. $\left(t_{p}=n_{i} \cdot \Delta t\right)$.

$n_{L}$ Number of pipes of the network. 
$n_{N}$ Number of reservoirs.

$n_{P}$ Number of pumps

$N(t)_{i}$ Number of breaks per unit length.

$N\left(t_{0}\right)$ Number of breaks per unit length at year of installation of the pipe, to.

$P_{C}$ Power supplied by compensation tanks.

$P_{F}$ Power required to overcome friction losses.

$P_{L}$ Power lost through leaks.

$P_{N}$ Power provided by reservoirs.

$P_{0}$ Total power supplied.

$P_{P}$ Power provided by pumps.

$P_{U}$ Power delivered to users.

$\frac{P_{u i}\left(t_{k}\right)}{\gamma}$ Pressure at node i at time interval $t_{k}$.

$\frac{P_{\text {Min }}}{\gamma}$ Minimum pressure required by standards level at any node and any time

$\frac{p_{s}}{\gamma}$ Average pressure in a faulty pipe.

$q_{f}$ Average volume lost per fault and day ( $\mathrm{m}^{3} / \mathrm{break} /$ day).

$q_{j}\left(t_{k}\right)$ Flow rate at line $\mathrm{j}$ at time interval $t_{k}$.

$q_{l i}\left(t_{k}\right)$ Leakage flow rate at node i at time interval $t_{k}$.

$q_{l j}\left(t_{k}\right)$ Leakage flow rate at line $\mathrm{j}$ at time interval $t_{k}$.

$q_{u i}\left(t_{k}\right)$ Consumed flow rate at node i at time interval $t_{k}$.

$q_{u j}\left(t_{k}\right)$ Consumed flow rate at line $\mathrm{j}$ at time interval $t_{k}$.

$Q$ Heat exchange at the control volume.

$Q_{N i}\left(t_{k}\right)$ Flow rate supplied by reservoir i at time interval $t_{k}$.

$Q_{P_{i}}\left(t_{k}\right)$ Flow rate supplied by pumping station i at time interval $t_{k}$.

$r$ Equivalent continuous discount rate.

$R_{v u}$ Reduction of life cycle of a road due to a renovation.

$t_{c}$ Time when the opportunity occurs.

$t_{d u r}$ Time elapsed for renovation.

$t_{k}$ Time interval of the steady state simulation.

$t_{0}$ Year of installation of the existing pipe.

$t_{p}$ Total time of simulation (long or short).

$t_{p, T}$ Short-term/ long-term time threshold (days). 
$t_{p}$.Current year.

$t_{\text {perd }}$ Average time lost (h/day) per employee per day of renovation.

$t_{s}$ Year in which the service provided falls below the standard level.

$T_{t_{j}}^{* *}$ Value of $\mathrm{t}$ that minimizes $\mathrm{C}_{\text {inf }}$ at a pipe by rehabilitation alternative $\mathrm{j}$.

$t_{r_{j}}^{*}$ Time of the first replacement with rehabilitation alternative $\mathrm{j}$ that minimizes total cost associated with pipe from present to infinity. In other words, optimum renovation period for infinity cycles.

$u$ Internal energy per mass unit.

$\forall_{L}\left(t_{p}\right)$ Total leakage volume for the simulation period.

$\forall_{N}\left(t_{p}\right)$ Total volume injected for the simulation period.

$\forall_{U}\left(t_{p}\right)$ Total volume consumed by users for the simulation period.

$\forall_{\mathrm{u}, \mathrm{i}}\left(\mathrm{t}_{\mathrm{p}}\right)$ Total demand of node i during the simulation period $t_{p}$.

w Work Exchange at the control volume

$x_{t o}$ Other social cost weighted coefficient.

$x_{t 41}$ Disruption traffic technology coefficient.

$x_{t 43}$ Losses of productivity technology coefficient.

$x_{t 44}$ Losses in stores technology coefficient.

$x_{5}$ Oportunity technology coefficient.

$z_{i}$ Elevation of node $\mathrm{i}$

$z_{i}\left(t_{1}\right)$ Water level in the compensation tank $\mathrm{i}$ at the initial time of a simulation.

$z_{i}\left(t_{p}\right)$ Water level in the compensation tank $i$ at the final time of a simulation.

$\alpha$ Emitter exponent.

$\alpha_{\text {est }}$ Season disruption traffic coefficient.

$\beta_{c 5}$ Agreement coefficient.

$\gamma$ Specific weight of water $=9810 \mathrm{~N} / \mathrm{m}^{3}$.

$\Delta E_{C}\left(t_{p}\right)$ Total variation of the energy compensation of the tanks (from $t_{1}$ to $t_{p}$ ). $\Delta E_{C}\left(t_{p}\right)=\Delta E_{\text {Compensation }}\left(t_{p}\right)$

$\Delta E_{C \max }$ Maximum compensation energy of the tank.

$\Delta h_{j}\left(t_{k}\right)$ Friction losses in line $\mathrm{j}$ at time interval $t_{k}$.

$\Delta p_{\min }$ Excess pressure minimum value (for all nodes and simulations) calculated as the minimum difference between the real pressure and the minimum required pressure.

$\Delta t$ Time interval of integration ( $\left.\Delta t=t_{k+1}-t_{k}\right)$.

$\Delta t_{a_{i}}$ Average time of duration for the leak (days). 
$\Delta \forall_{T}\left(t_{p}\right)$ Volume stored in a regulation tank for the period simulation.

$\rho$ Density of water $=1000 \mathrm{Kg} / \mathrm{m}^{3}$

$\rho_{g}$ Average density of people affected by renovation per length of renovated pipe.

$\rho_{n}$ Average density of stores affected by renovation per length of renovated pipe.

$\varphi_{5}$ Opportunity weighted coefficient.

$\eta$ Efficiency of the pumps. 


\subsection{References}

ADF (2002) "Sénat: La qualité de l'eau et assainissement en France, quoting: Evaluation IFEN - Les données de l'environnement - décembre 2001 - Étude de l'Association des départements de France (ADF) ".

http://www.senat.fr/rap/l02-215-2/l02-215-262.html

AEAS (2000), "El suministro de agua potable en España". Madrid, 2000.

AEAS (2006), "Suministro de Agua potable y Saneamiento en España. X encuesta nacional". www.aeas.es

AICV (2008), "Anuario Estadístico de la Ciudad de Valencia". ISSN: 1989-2594. http://www.valencia.es/estadistica

Alegre, H., Baptista, J.M., Cabrera Jr., E., Cubillo, F., Duarte,P., Hirner, W., Merkel, W. and Parena, R. (2006). "Performance Indicators for Water suplí Services". Second Edition manual of Best Practices. London IWA. ISBN: 1843390515.

Allouche, D., and Freure, P. (2002). "Management and maintenance practices of storm and sanitary sewers in Canadian Municipalities". ICLR Research Paper Series, No. 18.

Almandoz, J.; Cabrera E., Gil, J. and Pellejero, I. (2003). "Evaluation of Leakage by means of night flow measurements and analytical discrimination. A comparative study". Proc. Of the IWA-IAHR International Conference PEDS 2003. Balkema publishers, pp 327-342.

Almandoz, J., Parra, J. and Cabrera, E. (2004). "Renovación de redes mediante sistemas de soporte de toma de decisiones multicriterio". Análisis, diseño, operación y gestión de redes de agua con EPAnet. Tomo II. Instituto tecnológico del Agua. ISBN 8460963845.

Almandoz, J., Cabrera E., Arregui, F., Cabrera Jr. E. and Cobacho R. (2005). "Leakage Assessment through Water Distribution Network Simulation". Journal of Water resources Planning and Management, 131(6), 458-466.

Arregui, F., Cabrera, E. and Cobacho, R. (2007). "Gestión integral de contadores de agua". Instituto Tecnológico del Agua- Universidad Politécnica de Valencia. ISBN: 84-608-0539-5 
ASCE (2009). "Report card for American infrastructure"

http://www.asce.org/reportcard

AWWA (1999). "Water audits and leak detection". Ed. American Water Works Association. Denver. Colorado. USA.

AWWA (2003). "Applying wordwide BMPs in water loss control". AWWA Water Loss Control Committee. Journal of the American Water Works Association. August 2003, pp 65-79.

AWWA, (2004). "Water Stats 2002 Distribution Survey". American Water Works Association, Denver, CO.

AWWA, (2004). "Water Stats 2002 Distribution Survey". American Water Works Association, Denver, CO.

BGW (2008). "Profile of the German Water Industry" (2008). Association of Drinking Water from Reservoirs (ATT), German Association of Energy and Water Industries (BDEW), German Alliance of Water Management Associations (DBVW), German Technical and Scientific Association for Gas and Water (DVGW), German Association for Water, Wastewater and Waste (DWA) y Association of Local Utilities (VKU). www.bgw.de

Boyce, G. M., and Bried, E. M. (1994). "Estimating the social cost savings of trenchless technique". No-dig Engineering, 1(2):12-14.

BOPV (2004). "Boletín Oficial de la Provincia de Valencia. Martes 14 de Septiembre de 2004". Edita: Diputación provincial de Valencia, № 219.

Budris, A.R. (2008). "Parallel pumps: Reduce Energy Cost without breaking the budget" American Water Works Association, 34 (2), 22-25.

Buendía, J. (2009). "Water and Energy: answers for the 21st Century. Self sufficiency 2015". Water and Energy 2009- mitigation in the water sector \& potential synergies with the energy sector. 29 y 30 de Octubre 2009. Copenhague.

Bush, G., y Simonson, J. (2001). "Rehabilitation of underground water and sewers lines... The costs beyond the bid". University of Houston. 
Cabrera, E., Almandoz, J., Arregui, F. and García-Serra, J. (1999). "Auditoría de Redes de Distribución de Agua". Ingeniería del Agua. Vol 6. № 4. Dic. 1999.

Cabrera E., Pardo M.A., Cobacho R. and Cabrera E. Jr., (2010). "Energy Audit of a water Distribution network". Journal of Water Resources Planning and Management American Society of Civil Engineering. (in press).

Cabrera, E., Pardo, M.A., Cobacho, R., Arregui, F.J. and Cabrera, E. Jr.(2009). "Evaluation of Carbon Credits Saved by Water Losses Reduction in Water Networks".Waterloss 2009. ISBN 978-1-920017-38-5. Páginas 90-97.

CBO (2002). "Future Investment in Drinking Water and Wastewater Infrastructure," Congressional Budget Office.

CEC (California Energy Commission), (2005). "California's Water-Energy Relationship report". California

CEC (California Energy Comisión), 2006. "Refining Estimates of Water- Related Energy Use in California". CEC 500 - 2006 - 118. California Energy Comisión. State of California. Diciembre 2006.

CEDEX (2006), "Guía Técnica sobre tuberías para el transporte de agua a presión". $3^{\text {a }}$ Edición, Ministerio de Fomento, Ministerio de Medio Ambiente. I.S.B.N. 847790-431-6.

Chatfield E., Dillon M. (1979) "A national study for asbestos fibres in Canadian drinking water supplies". Ottawa, Canada, Department of National Health and Welfare, 1979. Environmental Health Directorate Report 79-EHD-34.

Clark, R.M., Sivaganesan, M. Selvakulmar, A. and Sethi, V. (2002). "Cost Models for Water Supply Distribution Systems". Journal of Water Resources Planning and Management, 128(5), 312-321.

Cobacho R (2000) "La Gestión de la Demanda en el contexto de una nueva política integral del Agua. Su aplicación al suministro urbano" Tesis Doctoral. (In spanish).

Cobacho R., Cabrera E., Cabrera Jr. E.; Arregui, F., and Dubois, M. (2003). "The repair and maintenance cost curve: Ways to calculate it from a medium size utility". Proc., PEDS 2003. Swets and Zeitlinger, Lisse. ISBN 9058095606. 
Cobacho R. and Cabrera, E. (2009). “Determinación del nivel de fugas óptimo económico" Rehabilitación y Renovación de tuberías de Agua. Instituto Tecnológico del Agua. Universidad Politécnica de Valencia. (In Spanish).

Colombo, A. F. and Karney, B. W. (2002). "Energy Cost of Leaky Pipes: Toward Comprenhensive Picture". Journal of water Resources Planning and management, 128(6); 441-450, November 1, 2002.

Colombo A. F. and Karney B. W. (2005). "Impacts of leaks on Energy Consumption in Pumped Systems with storage". Journal of water resources, planning and management, 131(2). 146-155.

Conroy, P.J., Hughes, D.M., and Wilson, I. (1995). "Demonstration of an innovative water main rehabilitation technique: In situ epoxy lining" American Water Works Association Research Foundation, Denver.

Construction innovation (1999). "IRC researchers investigate cast-iron pipe failure". Volume 4, Number 3, Spring/Summer 1999.

http://irc.nrc-cnrc.gc.ca/pubs/ci/v4no3/v4no3_13_e.html

Cromwell, J. and Speranza, L. (2007). "Asset management, too complicated? Just think about your car". Journal AWWA, January 2007. 46-51.

Deb, A. K., Snyder, J. K., Chelius,J. J., and O’Day, D. K. (1990). "Assessment of existing and developing water main rehabilitation practices". American Water Works Association Research Foundation, Denver.

Deb, A. K., Snyder, J. K., Hammell, J. and Grablutz, F. (2009). "G.V. Loganathan 's Legacy on Water Distribution system Asset Managemet". Journal of Water Resources Planning and Management, 135(4), 216-226.

Deneen, M. and Gross,A.C. (2004). "The global market for Water Treatment Products". Bussiness Economics January 2005.

Di Federico, V.,Cintoli, S., Pacchioli,M., Vispi, P., Di Federico, I., Mazzacane, S. and Volta, M. (2002). "A conceptual model for rehabilitation of water distribution Networks". VI simpósio Ítalo Brasileiro de engeharia Sanitária e Ambiental. http://www.bvsde.paho.org/bvsacd/sibesa6/cxcviii.pdf 
Diaz, C.A., Karney, B.W. and Colombo, A.F. (2005) "Saving energy while managing demand in water delivery systems". Proc., CCWI 2005 8th Int. Conference on Computing and Control in the Water Industry., Research Studies Press, Hertfordshire,U.K.

DOE (2006). "Energy Demands on Water Resource. Report to Congress on the Interdependency of Water and Energy". US Department of Energy. Washington DC. USA.

EA (2008). "Greenhouse gas emissions of water supply and demand management options". Science Report - SC070010, Julio 2008. EA. Bristol. UK.

EPA (1973). "EPA's Position on the Health Implications of Airborne Lead". EPA Journal November 1973.

EPA (1999) "Drinking water Infrastructure Needs survey. Modeling the Cost of Infraestructure".

EPA (1999). "Collection systems O\&M Fact Sheet. Trenchless Sewer Rehabilitation". Office of Water, Washington, D.C. EPA 832-F-99-032 www.epa.gov/safewater

EPA (2002). "Clean Water and Drinking Water Infrastructure Gap Analysis".

EPA (2003). "Drinking water Infrastructure Needs survey and Assessment Third report to Congress".

EPA (2008). "Summary of EPA Water and Energy Efficiency meeting". Chicago. United States Environmental Protection Agency Office of Water

EPA (2009). "Drinking water Infrastructure needs Survey and Assessment. Fourth report to Congress". Office of Water (4606M) EPA 816-R-09-001 www.epa.gov/safewater

EPA (2009). "Rehabilitation of wastewater Collection and water distribution Systems". EPA/600/R-09/048 | May 2009 | www.epa.gov/nrmrl

EU (2000). “Directiva 2000/60/CE del parlamento europeo y del consejo por la que se establece un marco comunitario de actuación en el ámbito de la política de aguas". 
Farley, M. and Trow, S. (2003). "Losses in Water Distribution Networks". IWA publishing, Alliance House, 12 Caxton St, London SW1H 0QS, UK. ISBN: 1900222116.

Filion, Y., MacLean, H.L. and Karney B.W. (2004). "Life cycle Energy Analysis of a Water Distribution System". Journal of Infrastructure Systems, 10 (3), 120-130.

IEA (International Energy Agency), (2008). "Energy Technology Perspectives. Scenarios \& Strategies to 2050".

Filion, Y. (2008). "Impact of urban Form on Energy Use in Water Distribution Systems". Journal of Infrastructure Systems, 14(4). 337-346.

García, V.F., Cabrera, E., and Cabrera, E. Jr (2007). "Water saving evaluation applying a pressure management strategy". Proceedings of the Lessam 2007, Lisbon, Portugal. October 17-19.

Ghimire, S.R. and Barkdoll B.D.(2007), "Issues in energy consumption by municipal drinking water distribution systems" World Environmental and Water Resources Congress 2007.

Greenpeace (2001). "PVC-Free Future: A Review of Restrictions and PVC free Policies Worldwide". Greenpeace International, 8th edition, August 2001.

http://archive.greenpeace.org/toxics/reports/restrictions.pdf

Gregg, T., and Dewees, A. "Water Accountability moves forward in Austin, Texas". Proc. Of the 4th IWA specialist Conference on Efficient Use and Management of urban Water Supply. Efficient 2007.Pp 763- 768

Hightower M., (2005). "Energy-Water Research and Development Roadmap". Sandia National Laboratories. Albuquerque. New Mexico. USA.

Hirner, W. (1997a). "Technical, operational and economic performance indicators of water utilities". Actas del IWSA workshop on Performance indicators and distribution systems. LNEC. Lisboa. 5-7 Mayo 1997.

Hirner, W. (1997b). "Maintenance and rehabilitation policies for urban water systems". Water management international. 
Hirner (2001). "Regulation of Urban Water supply: Standards of quality and control". International seminar, Valencia, June26-28, 2001: The urban Water supply debate."

Hoffman, H. W. (2005). "Energy \& Water Relationships, Working together to promote water conservation" California Energy Commission. November 2005 CEC-700-2005-011-SF

Hong, H. P., Allouche, E.N. and Trivedi, M. (2006) "Optimal Scheduling of Replacement and Rehabilitation of Water Distribution Systems." Journal of Infraestructure systems, 12(3): 184-191. September 2006.

Hu,Y., and Hubble, D.W. (2007). "Factors contributing to the failure of asbestos cement water mains". NRC Research Press Web site. 15 th June 2007. Can.J. Civ. Eng. 34:608-621 (2007).

INE (2006). “Distribución por grandes grupos de usuarios y comunidad autónoma".

http://www.ine.es/jaxi/tabla.do?path =/t26/p067/p01/a2006/l0/\&file = 01004.px\&type = pcaxis\&L =0

IWA (2000). "Losses from Water Supply Systems: Standard Terminology and Recommended Performance Measures". IWA, International Water AssociationTask Force on Water Losses, London, August 2000.

Jeyapalan, J. (2003). "Future Outlook for pipelines material, methods and maintenance" Pipelines 2003 ASCE Conference, Baltimore, Maryland, July 2003.

Jonkergouw, P. M. (2007). "Simulating chlorine decay in water distribution systems". Thesis. Exeter University.

Jowitt, P.W. and Xu, C. (1990) "Optimal Valve Control in Water Distribution Networks". Journal of Water Resources Planning and Management, 116 (4), 455472

Kleiner, Y., and Rajani, B. (2002). "Forecasting variations and trends in water-main breaks" Journal of Infrastructure Systems, v. 8, no. 4, Dec. 2002, pp. 122-131.

Kleiner, Y, Adams, B. J. and Rogers, J.S. (2001). “Water Distribution network renewal planning". Journal of Computing in Civil engineering, Vol. 15, No 1, January, 2001. 
Lambert, A. O. (1994). "Accounting for Losses: the bursts and background concept (BABE)". IWEM Journal, April, 8(2), 205-14.

Lambert, A., Myers, S. and Trow,S. (1998). "Managing Water Leakage, Economic and technical issues". Financial Times energy, Tottenham Court Road, London W1P 9LL. ISBN: 1840830115.

Liemberger, R. (2005). "Real Losses and Apparent Losses and the new W392 Guidelines from Germany". Paper presented at the international Water Association Specialist Workshop, Radisson Ressort.

Lingireddy, S. and Wood, J. (1998) "Improved operation of water distribution systems using variable-speed pumps". Journal of Energy Engineering, 124 (3), 90103.

Lindley, T. R. and Buchberger, S. G. (2002) "Assessing intrusion susceptibility in distribution systems". J. Am. Water Works Assoc. 2002, 94 (6), 66-79. (21)

Logathan, G. V., Park, S. and H. D. Sherali (2002) "Threshold Brake Rate for Pipelines Replacement in Water Distributions Systems". Journal of Water Resources Planning and Management, 128(4): 271-279. July/August 2002.

Luong, H. T. and Fujiwara, O. (2002). "Fund allocation model for pipe repair maintenance in water distribution networks". European Journal of Operational Research 136 (2002) 403-421.

MacKellar, S. and Pearson, S. (2003). "Nationally Agreed Failure Data and Analysis Methodology for Water Mains Volume 1: Overview and Findings". Report Ref. No. 03/RG/05/7, UK Water. Industry Research, London, UK.

Male, J. W., T.M. Walski, and A. H. Slutski, (1990). "Analyzing Water Main Replacement Policies", Journal of Water Resources Planning and Management, ASCE, 116, 363-374.

May, J. (1994). "Pressure dependent leakage." World Water and Environmental Engineering, October 1994.

McKenzie (2001). "Presmac, Pressure Management Program". WRC Report No TT 152/01.http://www.wrc.org.za/downloads/report\%20lists/web\%20files/presmac/Presmac\%20Rpt\%20TT\%20152-01.PDF 
McKenzie, R.S., Seago, S. and Liemberger, R. (2007). "Benchmarking of losses from potable water reticulation systems - Results from IWA task team". Waterloss 2007. http://waterloss2007.com/pdf_vortraege/Montag/B2-2.pdf

McKim, R.A. (1997). "Bidding strategies for conventional and Trenchless Technologies considering social Costs", Canadian Journal of Civil engineering, Vol 24, pp. 819-827.

McMahon, J. E., Whitehead, C.D. and Biermayer, P. (2006). "Saving Water Saves Energy". Lawrence Berkeley National Laboratory. University of California.

Millette JR et al. (1983) "Asbestos in water supplies of the United States". Environmental Health Perspectives, 53:45-48.

Milly P., Betancourt J., Falkenmark M., Hirsch R., Kundzewicz W., Lettenmaier D. and Stouffer R., 2008. "Stationarity Is Dead: Whither Water Management?". Science Vol 319 February 2008 pp 573 - 574

MIMAM (2000). "Libro Blanco del Agua en España". Ministerio de Medio Ambiente. Madrid.

MITYC (2007). "La energía en España". , Ministerio de Industria, Turismo y Comercio, I.S.B.N.-13: 978-84-96275-52-2. (In spanish).

MMA (1998). "Libro blanco del agua".

http://www.mma.es/secciones/acm/fondo_docu_descargas/libro_blanco/pdf/sintesis.pdf

MMA (2008). "Inventario de Gases de Efecto Invernadero en España. Edición 2008".http://www.mma.es/secciones/calidad_contaminacion/atmosfera/emisiones/pdf/Sumario_inventario_GEI_Espania_ ed_2008_serie_1990-2006.pdf

Murgui, M., Cabrera, E., Pardo, M. A. and Cabrera R., E. (2009) "Estimación del consumo de energía ligado al uso del agua en la ciudad de valencia". Jornadas de Ingeniería del Agua, JIA 2009.

Najafi, M. and Gokhale, S. (2004). "Trenchless Technology, Pipeline and Utility Design, Construction, and Renewal”. Ed. Mc Graw-Hill Companies Inc. ISBN 0-07142266-8. 
Newport, R. (1981). "Factors influencing the occurrence of bursts in iron water mains. Severn Trent Water Authority, Great Britain". Journal Aqua, No 3, 1981 274-288.

NRC (1993). "Water Mains Break Data on Different Pipe Materials for 1992 and 1993". National Research Council. Ottawa. Canadá.

http://www.ipexinc.com/Content/en_ca/4_0_Thermo_Today/4_3_Economie/Water_Mains_Break.pdf

NRC. (2008) "Desalination. A national perspective". The national academies press, Washington, USA.

Ochoa, L. y Bourguett, O.V. (1998)."Reducción integral de pérdidas de Agua potable". Instituto méxicano de Tecnología del Agua. ISBN 968-7417-23-4. Juitepec. México.

OFWAT (2001). "Leakage and the Efficient use of Water". Birmingham. England. ISBN 1874234809

OFWAT (2002)." Financial performance and expenditure of the water companies in England and Wales 2007-08. Ofwat - Protecting consumers, promoting value and safeguarding the future". ISBN1-904655-45-9

OMS (1985). "Guidelines for drinking-water quality". Washington, D.C. (US), OPS, 1985. (OPS - scientific publication, No 481)

Pardo, M. and Cabrera, E. (2006). "Técnicas modernas de rehabilitación y renovación de tuberías. Análisis de Costes". Control de Pérdidas de agua en Redes Urbanas, Análisis de su incidencia en periodos secos. Instituto Tecnológico del Agua. Universidad politécnica de Valencia. (In spanish).

Pardo, M. A. (2007) "Periodo óptimo de renovación de tuberías, incluyendo costes variables del agua, sociales y de oportunidad". Diploma de Estudios Avanzados. Universidad Politécnica de Valencia. (In Spanish).

Parra, J. C. (2006). "Renovación de redes mediante sistemas soporte a la toma de decisiones multicriterio". Diploma de estudios avanzados. Universidad Politécnica de Valencia. (In Spanish).

PEAASA (2006).

http://www.portugal.gov.pt/NR/rdonlyres/2E4F1B13-B462-4EE7-927C-0D0F41BF129B/0/PEAASARII.pdf 
Pelli, T. and Hitz, H. U. (2000). "Energy Indicators and savings in water supply". Journal American Water Works Association, Vol92 (6), June 2000.55-62.

Peters, D.C. (1984). "The social costs of sewer rehabilitation" International Conference on the planning, Construction, Maintenance and Operation of Sewerage Systems, Reading, England, B3, pp. 79-91.

Rajani, B. (2009). "Inspección y rehabilitación de tuberías de grandes diámetros". Rehabilitación y Renovación de tuberías de Agua. Instituto Tecnológico del Agua. Universidad Politécnica de Valencia. (In spanish).

Rajani, B. (2009a). "Comportamiento de las redes de agua desde una perspectiva histórica". Rehabilitación y Renovación de tuberías de Agua. Instituto Tecnológico del Agua. Universidad Politécnica de Valencia. (In spanish).

Rajani, B. (2009b). "Tuberías de fundición dúctil". Rehabilitación y Renovación de tuberías de Agua. 9,10 y 11 de Junio 2009. ITA. Universidad Politécnica de Valencia. (In spanish).

Rajani, B. (2009c). "tuberías de Polietileno y PVC". Rehabilitación y Renovación de tuberías de Agua. Instituto Tecnológico del Agua. Universidad Politécnica de Valencia. (In spanish)..

Rajani, B. (2009d). "Funcionamiento de tuberías de materiales en desuso (fundición gris y fibrocemento)". Rehabilitación y Renovación de tuberías de Agua. Instituto Tecnológico del Agua. Universidad Politécnica de Valencia. (In spanish).

Rajani, B. (2009e). "Criterios para decidir si renovar o rehabilitar". Rehabilitación y Renovación de tuberías de Agua. Instituto Tecnológico del Agua. Universidad Politécnica de Valencia. (In spanish).

Rajani, B. and Kleiner, Y. (2003). "Protection of ductil iron water mains against external corrosion: review of methods and case stories". National Research Council Canada. http://irc.nrc-cnrc.gc.ca/ircpubs

Rao, Z., Wicks, J. and West, S. (2006) "Encoms - an energy cost minimisation system for real-time, operational control of water distribution networks". Water Management 160. Issue WM2. Optimising water supply and distribution operations. 95-101 
RASARP (2004). Volume 3.

http://www.irar.pt/PresentationLayer/ResourcesUser/docum/rasarp/vol3/RASARP\%20-\%20vol3_4.pdf

Reis, L. F. R., Porto, R. M. and Chaudhry, F. H. (1997) "Optimal Location of Control Valves in Pipe networks by Genetic Algorithm". Journal of Water Resources Planning and Management, 123 (6), 317-326

Rossman, L. A. (2000). "EPANET 2: User's manual". U.S. Environmental Protection Agency, Cincinnati.

Runge, J. and Mann, J. (2008) "State of the industry report, 2008". Journal American Water Works Association, 100 (10), 61-74.

Sala, L. "Balances energéticos del ciclo del agua y experiencias de reutilización planificada en municipios de la Costa Brava". Seminario Internacional Agua, Energía y cambio climático. Valencia, 29 - 31 Octubre 2007

Skaarda, B. C. (1997). "The Swiss experience with performance indicador ad special viewpoints on water Networks". IWSA Workshop on performance indicators and distribution Systems. LNEC. Lisboa. May 1997.

Selvakulmar, A., Clark, R. M., and Sivaganesan (2002). "Cost Models for Water Supply Distribution Systems Rehabilitation". Journal of Water Resources Planning and Management, 128(4), 303-307.

Shamir, U., and Howard, C. D. D. (1979). "Analitical approach to scheduling pipe replacement." J. AWWA, 71(5), 248-258

Spero, M. I. (1999). "Trenchless 101- For industrial applications." Proc., Underground Construction Technology, Int. Conf. and Exhibition, Houston.

Sterling, M. and Bargiela, A. (1984). "Leakage reduction by optimised control of valves in water networks". Trans. Inst. Meas. Control, 6, 293-298.

Thornton, J. (2003), "Managing Leakage by managing pressure: a practical approach". Water 21. October 2003, pp. 43-44. 
Thornton, C. I., Robeson, M. D., Girard L. G., and Smith (2005). "Culvert Pipe Liner Guide and Specifications". Publication No. FHWA-CFL/TD-05-003. http://www.cflhd.gov.

Thornton and Lambert (2005), "Progress in practical prediction of pressure: leakage pressure:burst frequency and pressure: consumption relationships". Proceedings of the Leakage 2005, Halifax, Canada. The world Bank Institute.

Tigue, S., Lee, T., McKim and Haas, R. (1999). "Traffic delay costs savings associated with trenchless technology". ASCE. Journal of Infraestructure Systems, $5(2): 45-51$.

Tigue, S., Knight, M., Papoutsis, D., Rodriguez, V. and Walker, C. (2002). "User Cost savings in eliminating pavement excavations using trenchless technology". Can. J. Civ. Eng. 29: 751-761.

Tiret (2008). "Fédération Professionnelle des Entreprises de I'Eau". 2e Rencontres des Maires- Symposium de Cannes. (en francés).

http://cms.sictiam.com/cms/30_adm06/upload/Gestion\%20de\%20leau.pdf

Todini E., (2000). "Looped water distribution networks design using a resilience index based heuristic apprach". Urban Water 2 (2000) pp 115-122.

Tsiflisi, S. and Kanakoudis, V. (2008). "Performance indicators implemented in the city of Larissa water distribution network". COST C18. Performance Assessment of Urban Infrastructure Services. ISBN: 1843391910. pp 497-508.

Tuhovcak, L. and Kucera, T. (2008). "WaBe project- performance indicators of Water utilities in Czech Republic". COST C18. Performance Assessment of Urban Infrastructure Services. ISBN: 1843391910. pp367-376. 
Tyco (2000). "Ductile Iron Pipelines Systems. Design manual". 4th Edition. ABN

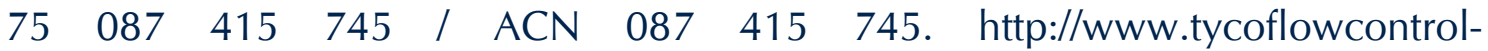
pc.com/getlit.asp?lit=Id/TWDIPS_00.pdf

USDE (2006). "Energy Demands on Water Resources. Report to congress on the interpendency of energy and Water".

Vewin (2007). "Water Supply stadistics". Association of Duch Water Companies, Available at:

www.vewin.nl/SiteCollectionDocuments/Publicaties/Overige\%20Vewin-

uitgaven/2007/Water\%20Supply\%20Statistics $\% 202006 . p d f$

Water UK (2009)." Water UK position paper on the revision of Council Directive 98/83/EC on the quality of water intended for human consumption (Drinking Water Directive)".

http://www.water.org.uk/home/policy/positions/legislation/council-directive-98-83-ec/wuk-position-paper-on-the-revision-ofthe-drinking-water-directive-march-2008.doc

Walski, T. M., and A. Pellicia, (1982). "Economic Analysis of Water Main Breaks". J. American Water Works Association, 74(3), 140-147.

Watson, C. (198). "Rehabilitation of potable water main- The changing policy of Northumbrian water". Proc., Int. Conf. on rehabilitation Technology for the Water Industry, Lille, France.

White, F.M. (1974) "Viscous fluid flow". B.J. Clark and Michael Gardner eds, McGraw-Hill, New York. Chapter 3. Solutions of the Newtonian viscous-flow equations.

WICS (2008a) "Cost and Performance Report 2007 - 08". Ochil House, Spreinkerse Business Park, Stirling FK7 7XE. Report available at http://www.watercommission.co.uk/UserFiles/Documents/WICS\% 20Costs\&Perfor mance \% 20FINAL.pdf

WICS (2008b). "Investment Report 2007 - 08". Ochil House, Spreinkerse Business Park, Stirling FK7 7XE. Report available at http://www.watercommission.co.uk/UserFiles/Documents/Investment \%20report\% $200708 \% 20 F I N A L . p d f$

WEF (2009). "Energy Vision Update 2009. Thirsty Energy: Water and Energy in the 21 st century". Report available at www.weforum.org. 
Webber, J., Covey, J., King, M. (1989) "Asbestos in drinking water supplied through grossly deteriorated A-C pipe". Journal of the American Water Works Association, 18:80.

Wegelin, W. and McKenzie, R. (2002). "Leakage reduction through Pressure Management in South Africa". Water research commission, TT 186/02. ISBN 1868458784.

White, F.M. (1974) "Viscous fluid flow". B.J. Clark and Michael Gardner eds, McGraw-Hill, New York. Chapter 3. Solutions of the Newtonian viscous-flow equations.

White, F.M. (2003) "Fluid Mechanics" 5th Ed. Mc Graw-Hilleds., New York. Chapter 3. Integral relations for a control volume.

WIN (2000), "Clean and Safe Water for the 21st Century - A Renewed National Commitment to Water and Wastewater Infrastructure," p. 3-1. Water Infrastructure Network.

Wolff, G. Sanjay, G. and Winslow, M. (2004). "User Manual for the Pacific Institute Water to Air Models". October 2004. www.pacinst.org

WSAAfacts (2001). "The Australian urban water Industry". Published by Water Services Association of Australia Inc., 469 La Trobe St, Melbourne, Victoria Australia,3000. ISSN 1328- 2751.

Zhao, J.Q., and Rajani, B. (2002). "Construction and Rehabilitation Costs for Buried Pipe with a Focus on Trenchless Technologies". Institute for Research in construction. National Research Council Canadá. Ottawa.http://www.irc.nrccnrc.gc.ca/ircpubs.

Zhao, J.Q., McDonald, S. E. and Rajani, B. (2001). "Guidelines for condition assessment and rehabilitation of large sewers". Institute for Research in construction. National Research Council Canadá. Ottawa.

Zhengfu, R., Wicks, J. and West, S. (2005) "Encoms - An Energy cost minimisation system for real-time, operational control of water distribution networks". Proceedings of CCWI 2005 Computing and Control in the Water Industry 'Water Management for the $21^{\text {st }}$ Century' 

ANEXOS 



\section{ANEXO A}

Técnicas de rehabilitación sin zanja 



\section{INTRODUCCIÓN.}

Si se pudieran colocar todas las tuberías activas que conforman el conjunto de las redes de abastecimiento de agua ${ }^{1}$ de España una detrás de otra en línea recta, se podría dar la vuelta a la tierra más de 3 veces $^{2}$ o casi se podría llegar hasta el sol $^{3}$, siendo la longitud total de aproximadamente $133000 \mathrm{Km}$.

Otros países, como Alemania, con una longitud de tuberías de aproximadamente $500000 \mathrm{Km}$, Gran Bretaña $408000 \mathrm{Km}$, Australia $90000 \mathrm{Km}$, y los EE.UU. con $1390000 \mathrm{Km}$ de tuberías; han invertido mayores cantidades de dinero en impedir el deterioro de sus redes de abastecimiento. Por contra, en España generalmente se ha seguido una política designada como Only crisis maintenance que alarga al máximo la decisión de renovar una conducción. Por otra parte, cabe reseñar que dentro del conjunto de abastecimientos españoles, siempre existen honrosas excepciones, y ciertos abastecimientos han renovado cuando debían y no tendrán que hacer frente a los grandes costes que otros abastecimientos han de realizar en un futuro no muy lejano si desean tener un bajo volumen de fugas y proporcionar servicio a los usuarios con una adecuada calidad y fiabilidad.

En el capítulo 1 de la presente Tesis se ha mostrado una relación entre los $\mathrm{Km}$ de tuberías de agua potable por habitante. Nuevamente, se muestran alguno de estos indicadores (Tabla A.1) para justificar las grandes longitudes de tubería que se encuentran instaladas en los abastecimientos urbanos. El indicador de $\mathrm{Km}$ de tubería por mil habitantes hace referencia a la concentración de los consumos en los abastecimientos de cada país. Ciertamente ese valor, siempre debe estar entre los valores 2 y 6 , con el límite inferior para redes muy malladas y 6 como valor propio de abastecimientos muy ramificadas.

\footnotetext{
1 Tuberías activas que conforman el conjunto de las redes de agua son las tuberías propias de una red de abastecimiento, sin incluir los kilómetros de tuberías que conforman las instalaciones interiores de los usuarios.

${ }^{2}$ Suponiendo que la tierra es una esfera que tiene por radio $6378 \mathrm{Km}$.

${ }^{3}$ Considerando la distancia media de la tierra al sol como 1 U.A. $149.675 .000 \mathrm{Km}$.
} 
TABLA A.1. RELACIÓN ENTRE POBLACIÓN Y KILÓMETROS DE TUBERÍAS PARA ALGUNOS PAÍSES.

\begin{tabular}{cccc}
\hline País & $\begin{array}{c}\text { Millones de } \\
\text { habitantes }\end{array}$ & $\begin{array}{c}\text { Miles de Km de } \\
\text { tuberías }\end{array}$ & $\mathbf{K m / \text { Mil habitantes }}$ \\
\hline España & 46.6 & 133 & 2.86 \\
Reino Unido & 59 & 408 & 6.92 \\
Alemania & 82.6 & 500 & 6.05 \\
Estados Unidos. & 306 & 1390 & 4.54 \\
Australia & 20.6 & 90 & 4.37 \\
\hline
\end{tabular}

Las inversiones en renovación de la red de abastecimiento tienen como consecuencia la reducción del volumen fugado. Por ejemplo en Australia el volumen fugado con respecto al volumen inyectado pasa del $17.8 \%$ en 1996 al 9.6\% en el año 2001 (WSAAfacts, 2001). En 1996, se perdían $0.42 \mathrm{hm}^{3}$ por $100 \mathrm{~km}$ de tubería y año, mientras que en el año 2001, este indicador se reduce

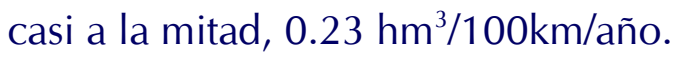

Por tanto, parece claro que el ejemplo Australiano subraya la necesidad de invertir en la renovación y rehabilitación de las redes de abastecimiento en aras de mejorar la gestión de un producto tan necesario y esencial como el agua. Esta misma solución, obvia por otra parte, se ha adoptado en EE.UU. tal y como reflejan los correspondientes informes de la EPA (ya comentados ampliamente en el Capítulo 1 de la presente Tesis) y que facilitaron las inversiones a realizar en los próximos 20 años en renovación de tuberías.

Por otra parte, el tipo de instalación de las tuberías ya no se refiere únicamente al método tradicional (excavación, instalación de tubería sobre una cama de arena, relleno y compactación, etc.), sino que se han desarrollado unas técnicas caracterizadas por la desaparición de la zanja. Éstas, que en España son relativamente nuevas, se vienen empleando desde hace muchos años en otros países, y eliminan (total o parcialmente) la excavación. En definitiva, se caracterizan por un mínimo movimiento de la superficie excavada.

El término general técnicas sin zanja o trenchless technologies abarca la instalación de conducciones de todo tipo, localización e inspección de conducciones, reparación de conducciones e incluso la hinca de tuberías en el terreno. 
En Estados Unidos, ya representan el $50 \%$ del total de obras ejecutadas en redes de saneamiento, mientras que en el campo del abastecimiento urbano solamente representan el $10 \%$ del total. En la Figura A.1, se representa el porcentaje de utilización de las diferentes técnicas para las obras realizadas en los EE.UU. en redes de saneamiento (Najafi y Gokhale, 2004). Las técnicas sin zanja, en especial encamisado térmico CIPP ${ }^{4}$, empiezan a ser muy comunes aunque la renovación tradicional continúa siendo la más utilizada.

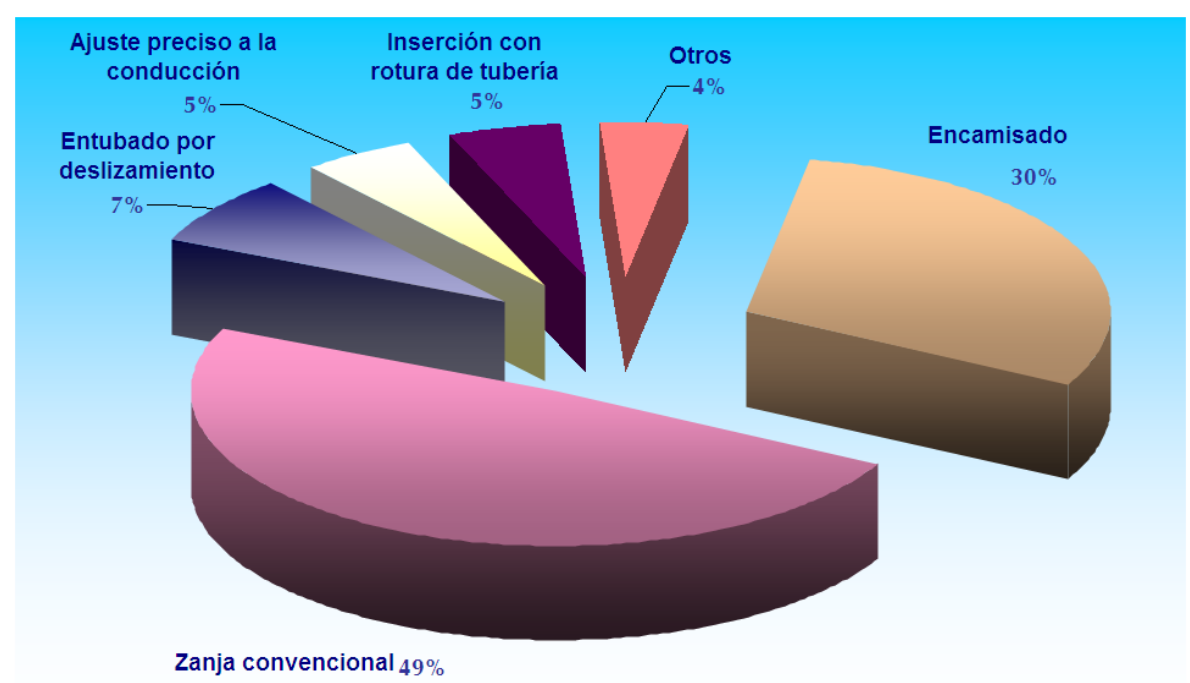

FIGURA A.1. UTILIZACIÓN DE LAS TÉCNICAS DE REHABILITACIÓN SIN ZANJA EN REDES DE SANEAMIENTO DE EE.UU. (NAJAFI Y GOKHALE, 2004).

Estas nuevas tecnologías suponen, evidentemente, una gran mejora en el ámbito de la rehabilitación y renovación de redes de abastecimiento o saneamiento urbano, y su implantación en el ámbito de la gestión de abastecimientos está produciendo, sin duda, una revolución, que ha despertado el interés de investigadores y empresas a nivel mundial.

De esta manera, el nuevo escenario que se plantea se caracteriza tanto por la necesidad de remodelación de la infraestructura y por otro lado por una emergente oleada de nuevas técnicas sin zanja, que abogan por la rapidez en la reparación y la disminución del impacto social. Sin duda, aunque la principal aplicación de las mismas es en redes de saneamiento, cada vez se depuran las técnicas y su incursión definitiva en el ámbito de las redes de distribución será más pronta que tardía.

${ }^{4}$ CIPP significa cured in place pipe. Traducido como encamisado térmico. 
El presente anexo se ordena en 3 bloques bien diferenciados. El primero se centra en la historia de las técnicas sin zanja mientras que el segundo muestra una clasificación de las mismas. Debido a lo reciente, muchas de ellas son desconocidas o no disponibles en España, y para esta clasificación se agrupan según el objetivo final de las mismas. Los grupos seleccionados son las técnicas orientadas a la limpieza, al revestimiento de las tuberías, los que instalan nuevas tuberías y aquellos que introducen una nueva tubería con o sin rotura de la existente. Asimismo se detallan las particularidades específicas de todas ellas. Finalmente, en el tercer bloque se exponen los costes de cada una y se revisa la literatura sobre este tema (generalmente con datos de Norteamérica) y se incluyen unos resultados de elaboración propia a escala nacional.

\section{UN PASEO POR LA HISTORIA DE LAS TECNOLOGÍAS SIN ZANJA.}

En 1986 se crea una organización a nivel mundial encargada de estudiar, aplicar y difundir los conocimientos de las técnicas sin zanja, la Internacional Society for Trenchless Tecnology (ISTT). La ISTT también promueve la formación y afiliación de nuevas sociedades que compartan estos objetivos en el ámbito de la renovación y rehabilitación de tuberías de agua potable, saneamiento, gas y fibra óptica. Así nace en el año 1995 la Iberian Society for Trenchless Tecnology (IbSTT) que engloba las empresas que trabajan realizando rehabilitación y renovación de redes en España y Portugal. Aunque, la historia de estas técnicas había comenzado mucho antes.

A mediados del siglo XIX, se tiene la primera referencia sobre técnicas sin zanja, concretamente en limpieza de las conducciones en la red de saneamiento urbano de la ciudad de París. Simplemente consistía en una carretilla montada sobre una barca que permitía a los operarios a acceder a las paredes de las conducciones de gran tamaño. Esta carretilla (Figura A.2 y Figura A.3) también podía ser utilizada apoyada en unos raíles y realizar la limpieza en conducciones de menor diámetro. 


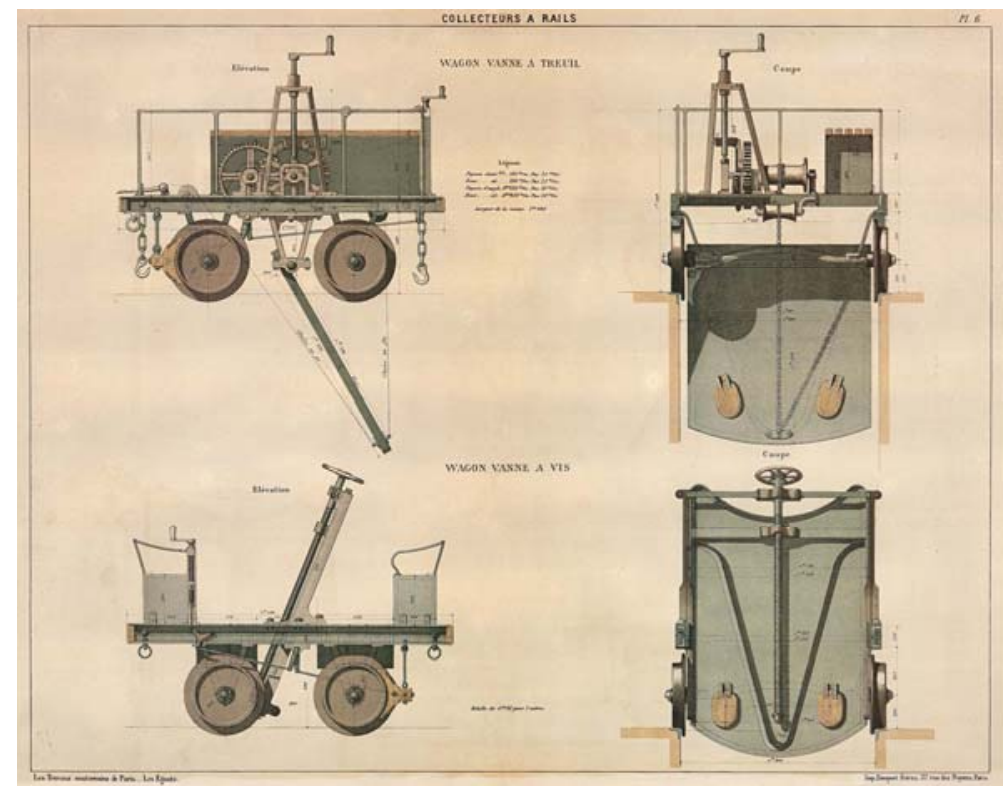

Figura A.2. BOCETO DE UN DISPOSITIVO DE LIMPIEZA DE UNA RED DE SANEAMIENTO EN LA CIUDAD DE PARÍS (WWW.SEWERHISTORY.ORG).

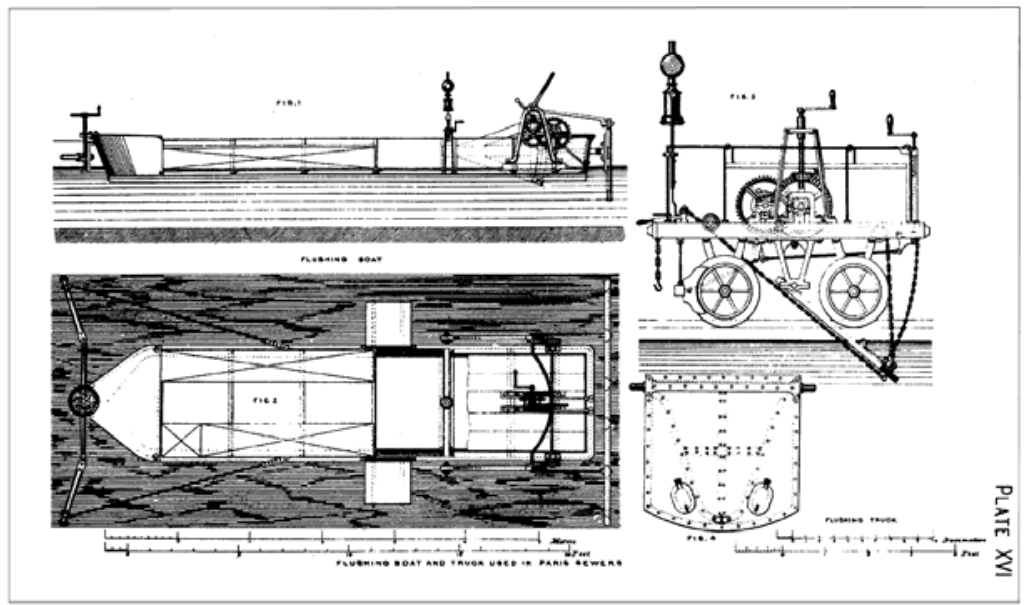

FIGURA A.3. CONJUNTO DE CARRETILLA Y BARCA QUE REALIZABAN LA PRIMERA LIMPIEZA EN PARIS (WWW.SEWERHISTORY.ORG).

En el año 1896, en la ciudad de Berlín, se utilizó el primer rascador con la finalidad de realizar la limpieza automática, Figura A.4. 


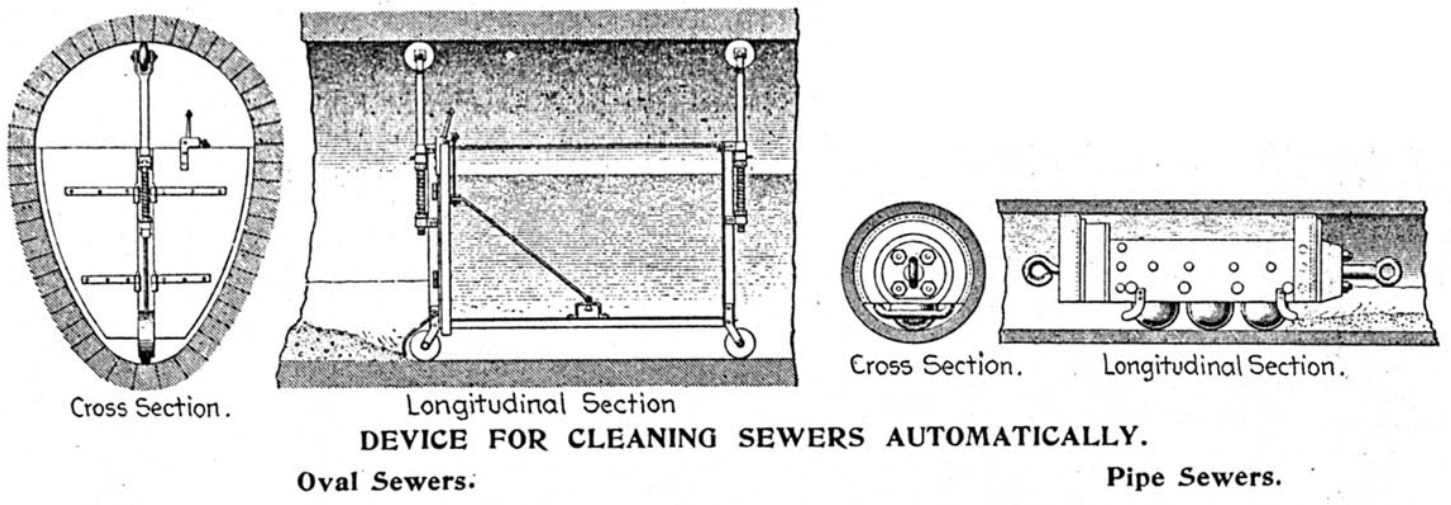

FIGURA A.4. PRIMEROS PROTOTIPOS DE RASCADORES AUTOMÁTICOS EN 1896 (WWW.SEWERHISTORY.ORG).

Simultáneamente se desarrollaron métodos de limpieza por descarga de agua. En casi todas las redes de saneamiento de aquella época (todavía es frecuente hoy en día) la evacuación de aguas pluviales y residuales se realizaba utilizando una misma conducción, por lo que, en ciertos lugares con una intensidad de lluvia alta, la limpieza de la conducción por descarga de agua se realizaba automáticamente.

En 1873, la ciudad de Memphis (EE.UU.) sufrió varias plagas de cólera y fiebre amarilla (1878 y 1879) con el resultado de 10000 muertos, lo cual motivó la separación de la red de residuales y de la red de pluviales. En las redes de saneamiento separativas pronto se descubrió la necesidad de instalar un sistema de limpieza como las descargas de agua, que antes eran automáticas por las Iluvias.

Para provocar la descarga de agua de manera manual ó automática, se construyeron unos tanques que aseguraban una limpieza efectiva en un tramo de 250 y $300 \mathrm{~m}$ de tubería. Los gestores de las redes pensaban que con las turbulencias generadas en las redes de saneamiento con las descargas de agua, se mezclaba oxígeno, lo cual era beneficioso para tratar el vertido antes de la descarga en el río o lago más próximo, Figura A.5. En el año 1925 se construyeron más de 200 tanques con este fin en Tucson (EE.UU.). 


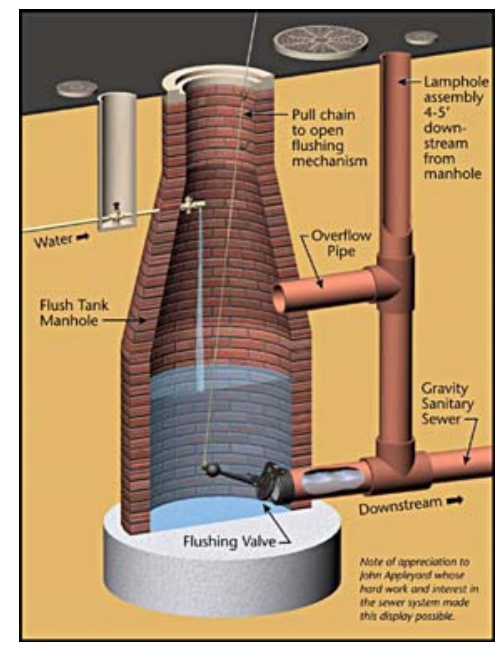

Figura A.5. Tanque Que permitía la descarga de agua (TuCsOn, Arizona, 1900-1925).

Al cabo de cierto tiempo, las descargas de agua no podían realizar la limpieza completa de las redes de saneamiento (especialmente si se pensaba que había piedras u otro tipo de residuo sólido) por lo que se debía de pensar en otro mecanismo. Se ideó una especie de cilindro que era arrastrado por el agua. Este procedimiento se considera el inicio de la técnica actualmente conocida como bala abrasiva.

Otro mecanismo de la época fue un disco (frecuentemente de madera) que se empujaba a lo largo de una conducción hasta un pozo de registro (Figura A.6). Este disco, junto con el rascador representado en la Figura A.4 son los primeros esbozos de la técnica actualmente empleada de rascado de tuberías.

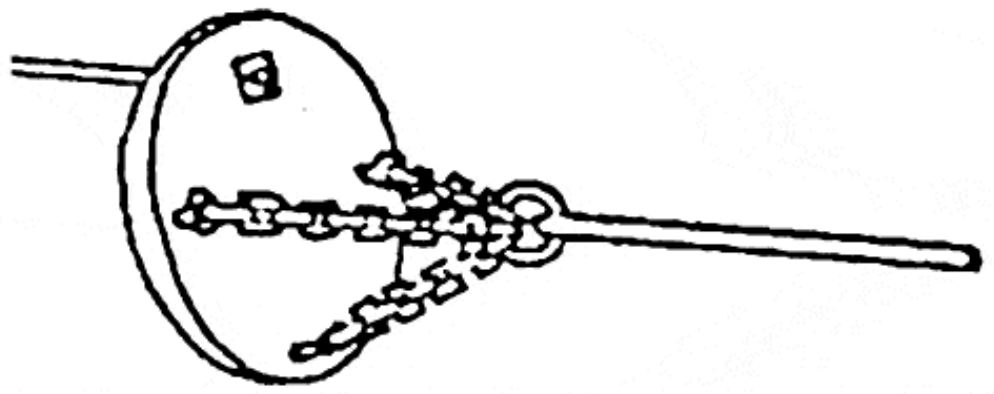


Las técnicas de limpieza se utilizaban sin conocer el estado final de la conducción tras la aplicación de la misma, ya que no se tenía información relativa al estado de la tubería. Por esta necesidad de obtención de información del sistema y a partir de la invención de las cámaras de televisión, surgió en el año 1946, el primer intento de obtención de un circuito cerrado de televisión por parte de la empresa Virginia Electric Power. Hasta entonces, dicha compañía (que gestionaba una central térmica de $1 \mathrm{MW}$ ) realizaba el control de unas calderas con un dispositivo formado por varios espejos que reflejaban la imagen de los manómetros hasta una zona de control. Debido a la explosión de una caldera se diseñó un sistema de control remoto mediante televisión, similar a los utilizados en los barcos de la segunda guerra mundial. Para ello, la empresa compró la patente que existía y el sistema de control mediante la imagen comenzó a fabricarse obteniendo unas cámaras muy grandes, pesadas y con elevado consumo energético.

En el principio de los años 50, RCA Corporation introdujo un modelo con un tubo de Vidicon que, con un diámetro de $25 \mathrm{~mm}$, se podía introducir en una conducción de al menos $200 \mathrm{~mm}$. Los ayuntamientos u otros organismos encargados de la gestión de las redes de abastecimiento y drenaje urbano empezaron a pedir prestado estas cámaras para comprobar el estado de sus redes.
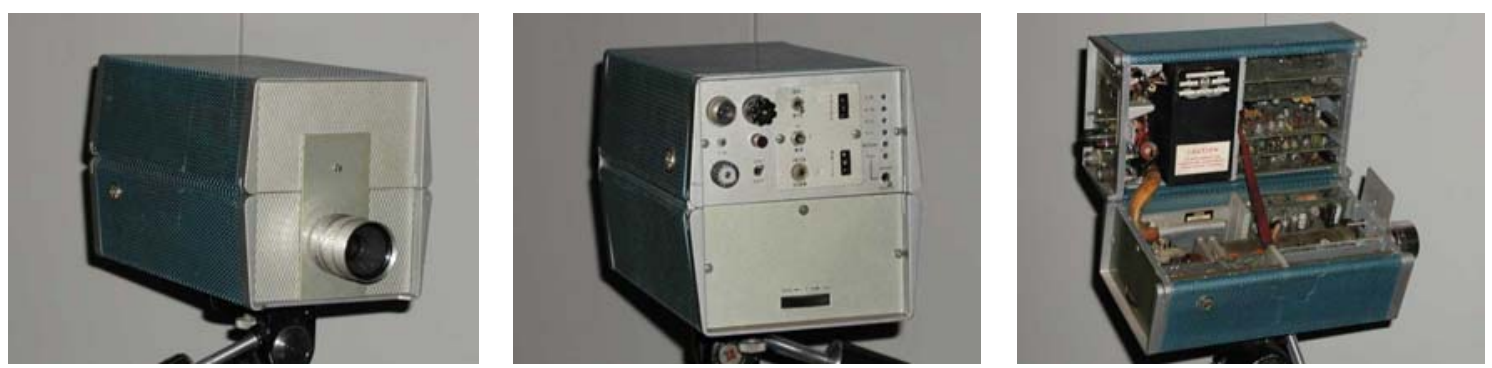

FIGURA A.7. CÁMARAS CON TUBO DE VIDICON DE LOS AÑOS 50 FABRICADAS POR RCA CORPORATION. 


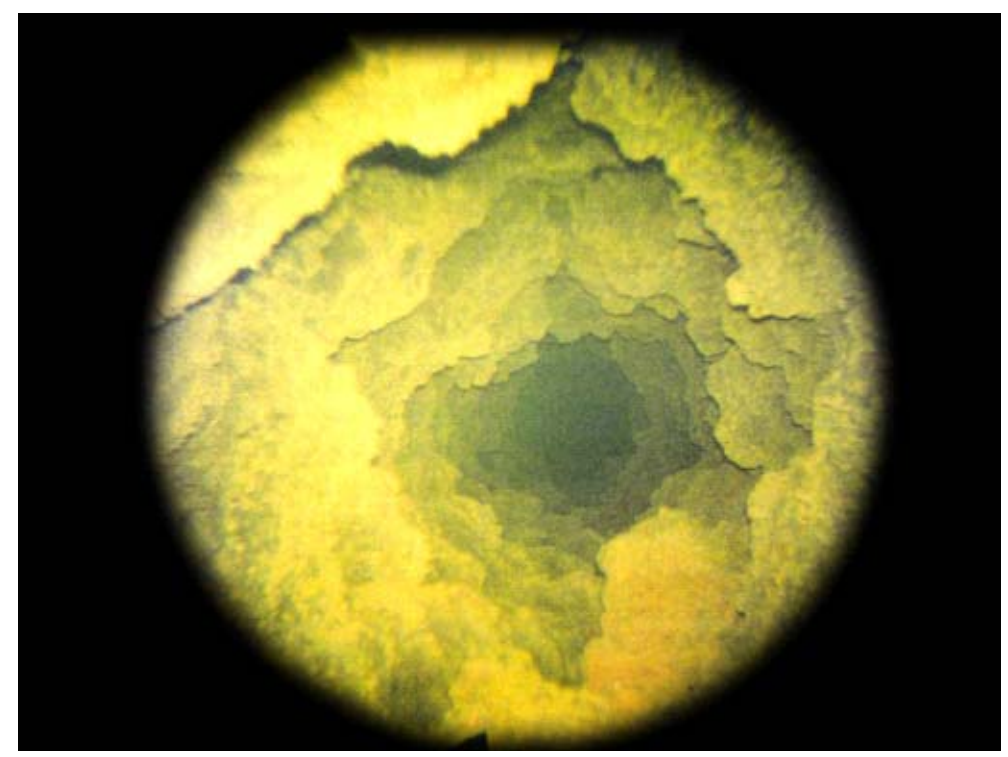

FIGURA A.8. INSPECCIÓN DE TUBERÍAS CON CÁMARA DE VIDEO.

Pero fue en 1963 cuando el gobierno federal de EE.UU. solicitó por primera vez a una empresa que ideara un sistema de sellara las grietas por donde se infiltra el agua en las conducciones. Esto significó el arranque definitivo de la conjunción de estas técnicas de inspección en tuberías y de rehabilitación. Actualmente, los dispositivos que se introducen en las conducciones sirven también para el fresado y para la reparación puntual, Figura A.9.

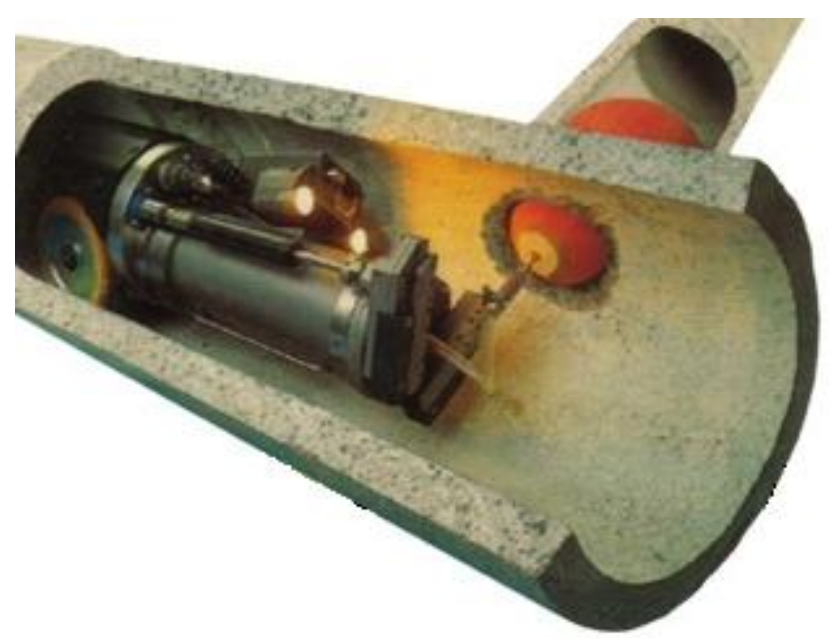

FIGURA A.9. VISTA DE UN MODERNO SISTEMA DE SELLADO, FRESADO EN TUBERÍAS CON CONTROL DE EQUIPOS DE TELEVISIÓN. 
Otro tipo de técnicas son las que proveen a la conducción de características estructurales. Dentro de estas, el método más simple, y uno de los que primero se desarrollaron, es el entubado por deslizamiento, sliplinning. Se sabe que se han realizado trabajos en tuberías de gas aplicando esta técnica a principios de los años 40 en la ciudad de Nueva York. Durante más de sesenta años, este método ha demostrado que es una buena alternativa económica frente al método tradicional.

En los años 70, Consolidated Edison Company realizó un proyecto durante 10 años en la ciudad de Nueva York, en el que se remplazaron tuberías de fundición de diámetros comprendidos entre 900-1100 mm con la inserción de tuberías de acero revestido. Cuando las tuberías de plástico irrumpieron en el mercado, y por su facilidad de instalación, pasaron a ser el material con el que se realizaría casi siempre el entubado en redes de agua, sustituyendo a la tubería de acero (que sigue siendo la utilizada en tuberías de gas). El polietileno no necesita el uso de elementos que faciliten el deslizamiento e impidan la rotura de la nueva conducción. El material plástico se desliza fácilmente debido a un menor coeficiente de fricción y a una flexibilidad que le permite superar cambios de dirección.

En 1984, se realizó en Central Park West (Nueva York), la primera técnica de entubado por deslizamiento con tubería de polietileno de alta densidad. Se rehabilitaron $580 \mathrm{~m}$ de tubería de $900 \mathrm{~mm}$ de diámetro y dos zonas de menor longitud con diámetro $750 \mathrm{~mm}$.

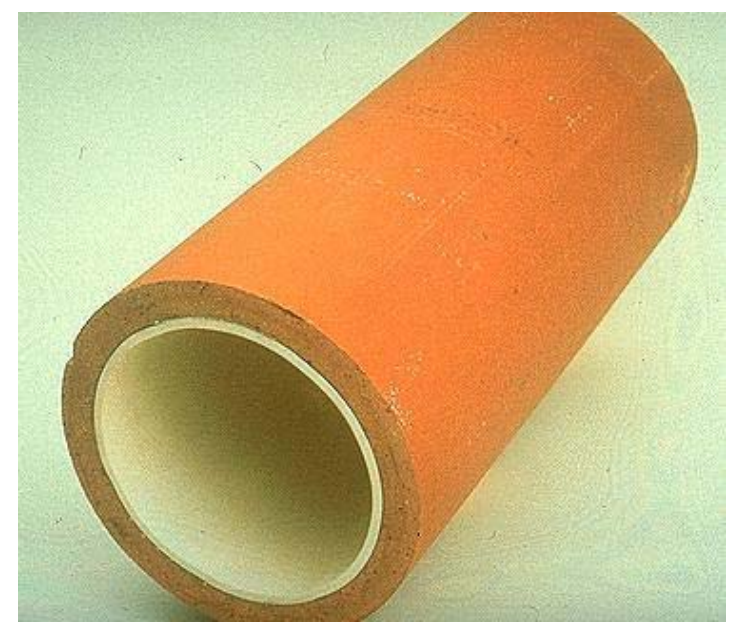

Figura A.10. ENTUBADO POR DESLIZAMIENTO, SLIPLINING. 
Asimismo, otras técnicas como encamisado térmico cured in place pipe se utiliza en el Reino Unido desde hace 30 años. La compañía Insituform inventó esta técnica en 1971 y la pudo explotar comercialmente en el año 1977. En los años 80, Ashimori Industries desarrolló un método hose-lining similar al encamisado térmico en tuberías de gas.

Otra tecnología, el ajuste por relajación natural o swagelinning, fue por primera vez empleada en los años 80 por la compañía British Gas. Más reciente es la técnica de ajuste mediante presión hidráulica o Rolldown ${ }^{5}$ que fue ideado en el Reino Unido por Stewarts \& Lloyds Plastic para tuberías de gas en el año 1986, y que se exportó para las redes de distribución y drenaje.

Por otra parte, el revestimiento no estructural con mortero de cemento se realizó por primera vez en Australia en 1905. Inicialmente, se aplicaba manualmente con la ayuda de una llana y fue a partir de 1930 cuando se comenzó a aplicar por inyección, fuerza centrífuga en un cabezal giratorio, en tuberías de grandes dimensiones en Estados Unidos. Fue en el Reino Unido (1950) cuando se redujo la dimensión de la máquina y se pudo emplear para realizar el revestimiento de tuberías de menor diámetro (en la actualidad es posible hasta en tuberías de calibre $100 \mathrm{~mm}$ ).

El revestimiento con resinas se ideó para solventar ciertos problemas derivados de la utilización del cemento. Se usó primera vez en el Reino Unido, año 1989. En ese momento solamente se inyectaba resina epoxi, pero en la actualidad se puede realizar el revestimiento con hasta otras cinco tipos de resinas, como por ejemplo poliéster y poliuretano.

${ }^{5}$ La técnica fue patentada por la compañía Reduced Diameter Pipe (RDP) 


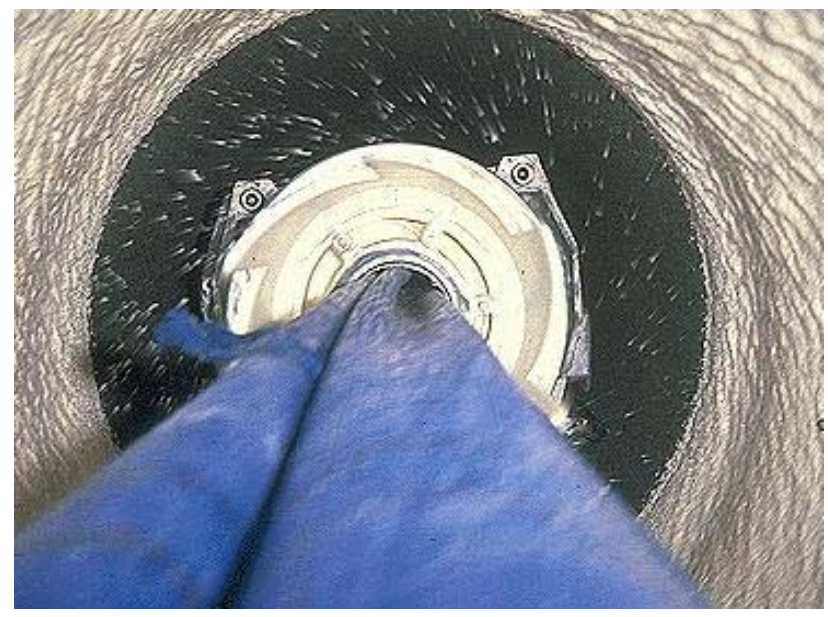

FIGURA A.11. MECANISMO DE INYECCIÓN DE RESINAS QUE SIRVEN COMO REVESTIMIENTO NO ESTRUCTURAL.

La inserción de tubería con tornillo sin fin o auger boring se desarrolló en los años 40 gracias al impulso proporcionado por Charlie Kandal que fundó la compañía Ka-Mo company (Somerset, Pensilvania) y diseñó una máquina de perforación a partir de la maquinaria utilizada en las minas de carbón.

Los primeros diseños resultaron máquinas operadas eléctricamente, que posteriormente pasan a ser de gasolina. En 1951, ya hay constancia de la existencia de máquinas que excavaron un agujero de $250 \mathrm{~mm}$ y con una longitud de $70 \mathrm{~m}$. Dicha compañía fue la principal impulsora de la perforación horizontal hasta 1961 cuando Richmond's Company diseñó otra máquina que se convirtió en muy popular gracias a una mayor rapidez en la perforación. Con ésta última se llegaron a perforar diámetros entre los 600 y 900 mm.

La tecnología siguió avanzando hasta 1970, cuando American Augers diseñó un sistema que incrementaba la fuerza en el extremo del varillaje si encontraba una roca, llegando hasta un par máximo que podía mantener durante un tiempo.

A partir de estas técnicas, se evolucionó hasta la perforación con control de la dirección. En 1964, la empresa Cherrington en (Sacramento, EE.UU.) construyó su primera máquina para taladrar el terreno, y se disponían a empezar a trabajar en este campo. En 1971, la citada empresa y la compañía de gas Pacific gas and electric Co pretendían cruzar el Pajaro River (Watsonville, California). La obra tenía $185 \mathrm{~m}$ de longitud y un diámetro de $100 \mathrm{~mm}$. Durante esta obra, surgió el problema de que el río tenía un terraplén muy pronunciado, de manera que la cata inicial que se debía realizar era tan profunda que disparaba el coste de la obra. 


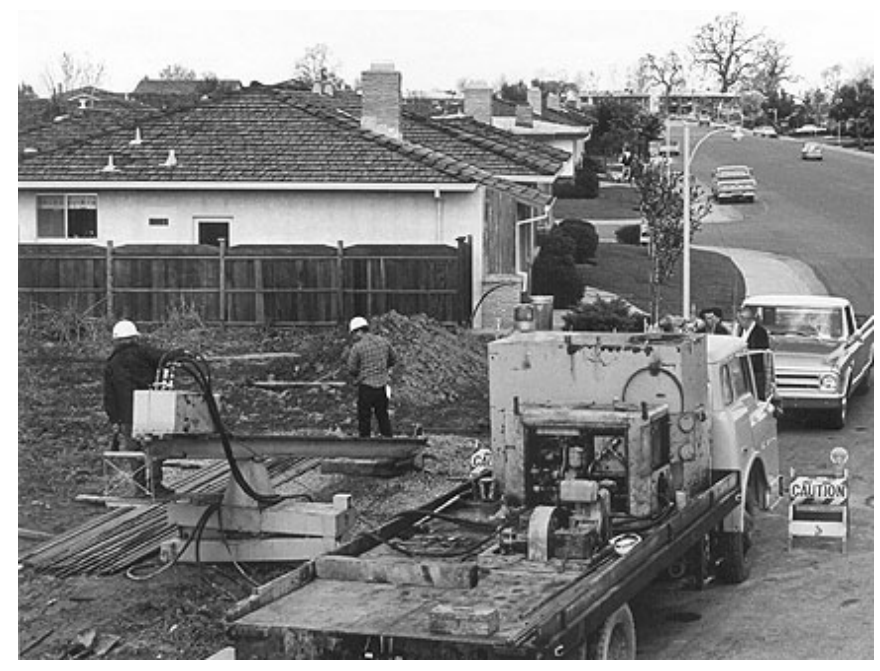

FIGURA A.12. PERFORACIÓN NO DIRIGIDA REALIZADA POR CHERRINGTON EN SACRAMENTO DURANTE LOS AÑOS SESENTA.

Además, cuando se perforaban ciertas zonas del terreno el cabezal tendía a ir hacia la superficie del terreno. Con frecuencia, el cabezal aparecía en superficie y las piezas de esa maquina eran rechazados y considerados como fallos de diseño. En una zona con unas características similares en cuanto a composición del suelo que la del Pajaro River, se decidió perforar en un terraplén cercano variando el ángulo de ataque, desde 10 hasta 30 grados, de la máquina.

Con un ángulo de entrada de $10^{\circ}$, la perforación realizada presentaba una salida a una distancia de $20 \mathrm{~m}$, se probó con un ángulo de $15^{\circ}$ y se aumentó la distancia hasta los $30 \mathrm{~m}$ y finalmente con un ángulo de entrada de $30^{\circ}$ la distancia de la perforación fue de $100 \mathrm{~m}$. Estos datos junto con posteriores análisis, sirvieron para comprender que con los dispositivos de perforación rescatados de la basura se había encontrado una nueva manera de perforación del terreno con control de la dirección. Posteriormente, se realizaron algunos ensayos para poder asegurar que dependiendo del ángulo de entrada, de las adecuadas técnicas de excavación y de la correcta maquinaria, se podría atravesar un río utilizando esta técnica, la perforación horizontal dirigida. Finalmente, se decidió contrastar el nuevo método de perforación de Cherrington con el propio de la compañía de gas, mejorando algunas técnicas que aumentaron las posibilidades de éxito y la obra se ejecutó satisfactoriamente. 
Esta técnica se difundió por el mundo y actualmente es una referencia dentro del campo de la instalación de nuevas tuberías sin zanja. Como ejemplo de la utilización de esta técnica se citan dos casos singulares, el primero es un proyecto en (Alaska, EE.UU.) realizado por la compañía Michael Baker corporation en la que se perforaba el terreno y se instalaba una tubería de gas, primera obra de perforación horizontal dirigida realizada en el Ártico. Debido a las condiciones climatológicas y la riqueza medioambiental, se decidió reducir los daños al medioambiente y se debía dimensionar una tubería capaz de soportar los esfuerzos que produce el deshielo. El segundo fue encargado por el Centro de Investigaciones Energéticas, Medioambientales y Tecnológicas (CIEMAT) para evitar la apertura de una zanja en un terreno utilizado como zona donde se almacenan materiales radioactivos.

\section{DESCRIPCIÓN DE LAS TÉCNICAS DE RENOVACIÓN SIN ZANJA.}

La clasificación general de las metodologías de rehabilitación y renovación de técnicas sin zanja se muestra en la Figura A.13. Éstas se agrupan en técnicas de limpieza, revestimientos estructurales y no estructurales, métodos con rotura de tuberías e instalación de nuevas tuberías.

A continuación se detalla cada una de las técnicas, y se pretende abordar las mismas desde una óptica global, técnica y pragmática.

\subsection{Métodos de limpieza}

Los métodos de limpieza se engloban en técnicas de rehabilitación sin zanja, ya que son frecuentemente un paso previo a la aplicación de otras tecnologías. La limpieza elimina los materiales que, sedimentados en las paredes de las conducciones, reducen notablemente la sección efectiva de la conducción.

La limpieza se debe realizar cada 2 años para tuberías antiguas y cada 3 ó 4 años si la tubería es nueva. Para ello, estas técnicas suelen estar coordinadas con inspecciones mediante cámaras de televisión. Se distingue entre limpieza de tuberías con métodos no agresivos y agresivos, ya que los primeros se encargan de eliminar las incrustaciones en el interior de las tuberías, mientras que con los segundos se intenta eliminar pequeños problemas relativos a la calidad del agua (coloración, sólidos en suspensión y olores, principalmente). 


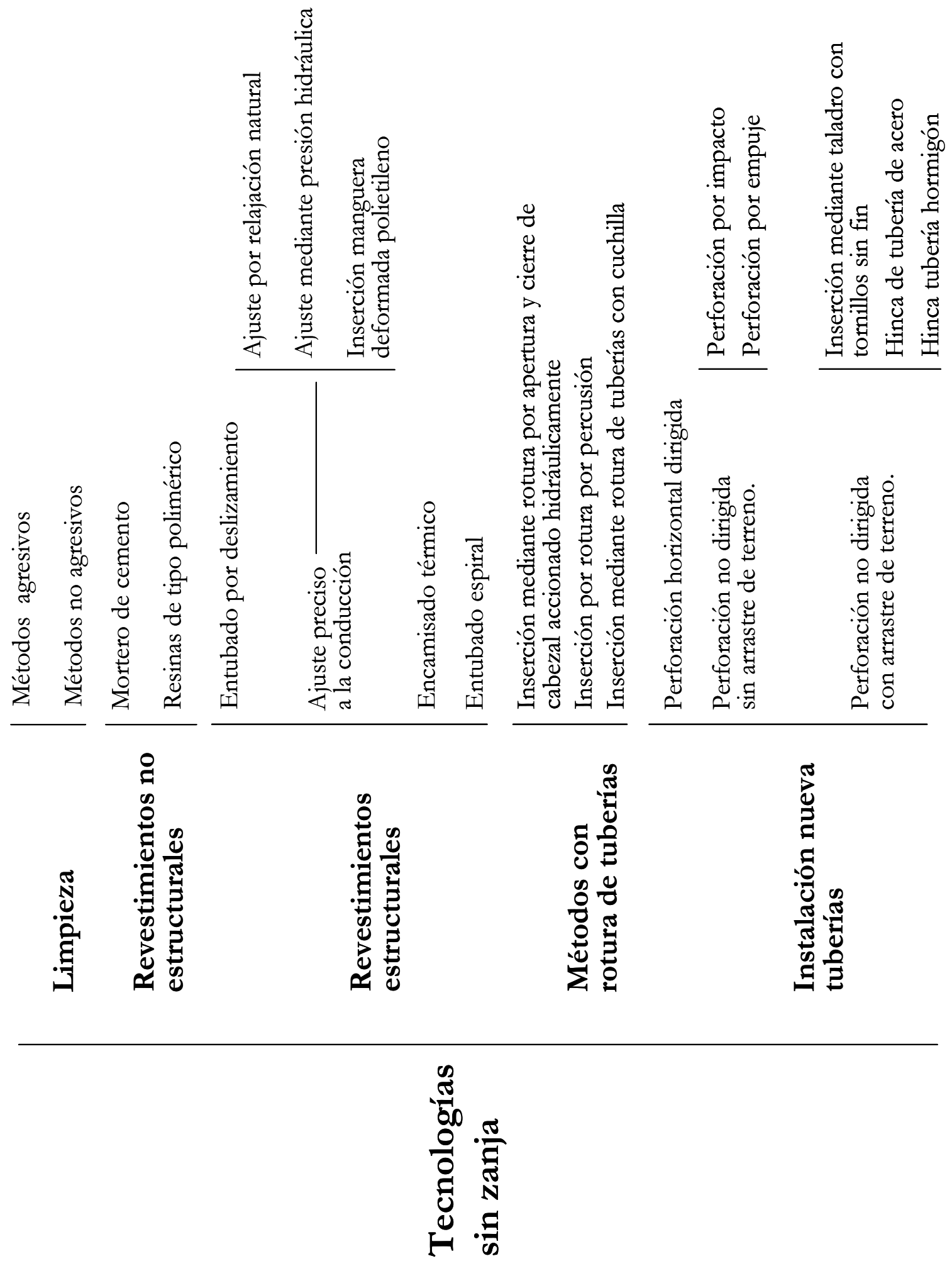

FIGURA A.13. CLASIFICACIÓN DE LAS PRINCIPALES TÉCNICAS DE REHABILITACIÓN O RENOVACIÓN SIN ZANJA. 


\subsubsection{Métodos no agresivos}

Existen diferentes métodos de limpieza no agresivos como la limpieza por descargas de aire comprimido o de agua. Dichas técnicas se utilizan para la eliminación de depósitos sueltos o blandos y para la eliminación de animales muertos en conjunción con un tratamiento químico usando piretrinas o permetrinas.

La descarga de agua o flushing elimina las deposiciones en la pared de una tubería por la circulación de un elevado caudal de agua a través de una conducción. Para ello, se provoca la circulación de un elevado caudal y se abre un hidrante o una válvula en derivación (por ejemplo, de alivio). Como el caudal desalojado es considerable, se eliminan los depósitos sueltos en las tuberías. Si la dirección del caudal es la inversa a la habitual y el lavado se realiza secuencialmente la limpieza es más efectiva, porque se garantiza que la tubería limpiada no vuelve a recibir agua que arrastra sedimentos.

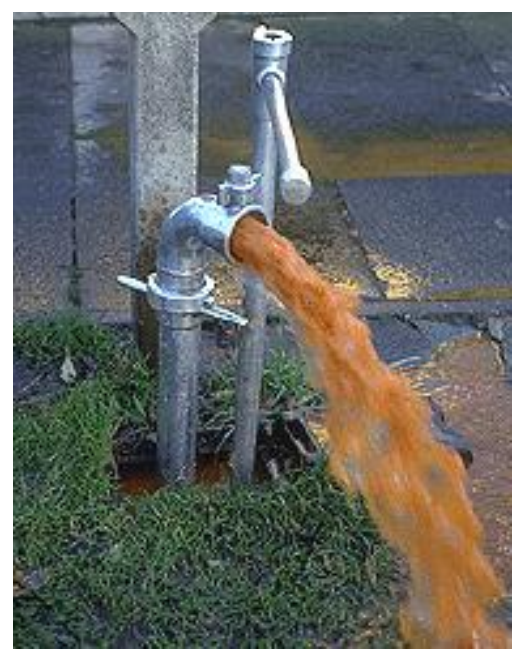

FIGURA A.14. SALIDA DE UNA DESCARGA DE AGUA.

Ésta es una técnica muy aplicable, que permite la limpieza de grandes longitudes de tubería y que no ocasiona molestias a los clientes. La única dificultad estriba en que hay que conseguir altas velocidades del fluido para que sea adecuada (2.5 $\mathrm{m} / \mathrm{s}$ ), y no es eficaz en los casos en que existen unas conducciones muy afectadas por protuberancias u otros organismos como bacterias o virus.

Se utiliza en diámetros hasta $150 \mathrm{~mm}$ y la longitud típica de la aplicación es de $500 \mathrm{~m}$. Con estas características se consigue la limpieza de 3 a 5 kilómetros diarios de tubería. 
La descarga de arie o Air Scouring es un método de limpieza de tuberías no agresivo que utiliza aire comprimido inyectado en una corriente continua de agua. Este chorro de aire elimina depósitos sueltos de tubería y pequeños animales.

El aire que inyecta se filtra previamente para asegurar que no contamina el agua de red. La inyección se realiza por un hidrante y se pretende propulsar una pequeña cantidad de agua hasta que alcance una alta velocidad. El agua arrastra los depósitos sueltos y se elimina mediante la apertura de un hidrante o válvula aguas abajo del tramo limpiado.

Esta técnica, bastante habitual, consigue limpiar tramos de hasta $8 \mathrm{Km}$ por día. El inconveniente radica en que, al igual que los restantes métodos de limpieza de conducciones, se imposibilita el servicio a los consumidores temporalmente. Se puede realizar para un rango de diámetros comprendidos entre los 75-200 mm y la longitud típica de la aplicación es de 1000 m.

\subsubsection{Métodos agresivos}

Los métodos de limpieza agresivos más comunes son el rascado de tuberías o pressure scrapping, inyección de agua a alta presión y bala abrasiva o pigging. Además de realizar su tarea fundamental de limpieza, consiguen que la conducción recobre su diámetro original tras la eliminación de todas las deposiciones. Por tanto, frecuentemente se emplean para mejorar problemas de insuficiencia de presión y de caudal. Con frecuencia son el paso previo a las técnicas de entubado (apartado 3.3).

Estos métodos agresivos pueden ocasionar problemas de calidad del agua, que serían fundamentalmente decoloración, mayor actividad de microorganismos y bacterias e incremento de los Hidrocarburos Aromáticos Policíclicos (HAPs) (un grupo de contaminantes formados por dos o más anillos de benceno fusionados). Los HAPs se producen por la exposición con el agua del alquitrán con el que se revistió algunas de las tuberías que actualmente están en servicio. Principalmente, el revestimiento tanto interno como externo de asfalto (concretamente la mezcla especial de asfalto agnus) se realizó en tuberías de principios del siglo XX. Dieciséis HAPs (naftaleno, acenaftileno, acenafteno, fluoreno, fenantreno, antraceno, etc.) son considerados como contaminantes prioritarios por EPA, la Organización Mundial de la Salud (OMS) y la Comunidad Europea (CE) debido a sus efectos cancerígenos. 
Los problemas de calidad deben llevar a considerar las técnicas de limpieza agresivas con cautela ya que el suministro de agua debe cumplir la directiva europea de calidad de agua para consumo humano 98/83/CE (transpuesta al derecho interno español en el real decreto RD 140/2003). En la actualidad, no existe constancia de problemas relacionados por la elevada concentración de HAPs en España, y la razón es evidente, ya que no se realizaron revestimientos internos con alquitrán. Pese a que no es un problema a escala nacional no debe, por ello, obviarse.

El rascado de tuberías o pressure scrapping utiliza un objeto cilíndrico, rascador, que se mueve por la tubería, generalmente por efecto de la presión del agua o bien sujeto con una cuerda o varilla guía, para eliminar las incrustaciones y los depósitos sueltos. La pieza que se emplea, rascador, se fabrica con tiras de acero, Figura A.15.
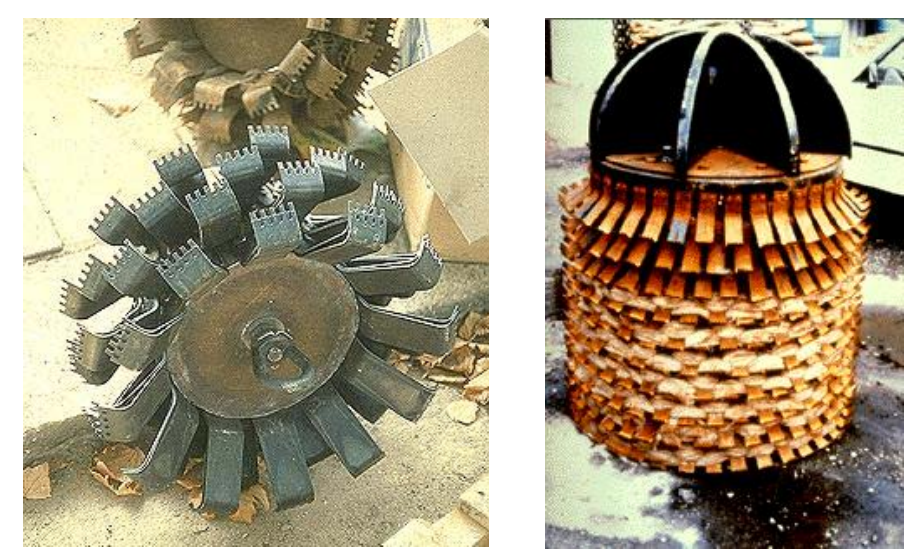

FIGURA A.15. DOS TIPOS DE RASCADORES.

El rascador se diseña para que se ajuste completamente a la tubería, de modo que impida el paso del agua casi completamente. En ocasiones incluso se añadirá un material textil que restrinja el paso de agua a través del rascador con el consiguiente aumento del salto de presiones y de velocidad de rascado. Con una presión diferencial de aproximadamente dos bares, variable según diámetro, el rascador arrastrará las incrustaciones y depósitos sueltos en la parte frontal del rascador. Éstos serán eliminados tras la apertura de un hidrante situado aguas abajo de la conducción rascada.

El hidrante (válvula de descarga) permite regular el avance del rascador (la velocidad ideal es de $0.3 \mathrm{~m} / \mathrm{s}$ ) y la cantidad de agua evacuada. El proceso de avance puede ser monitorizado y controlado, aunque no vía radio porque las vibraciones que produce el rascado generan interferencias que imposibilitan la comunicación. Por ello se emplean otos tipos de control como sistemas de televisión en circuito cerrado o georradar. 
El rascado se puede emplear para la limpieza de grandes longitudes de tubería, pero en la práctica se realiza en tramos pequeños porque las válvulas limitan su aplicabilidad ya que no permiten el paso del rascador. También tiene la limitación de que se utiliza para mayores que $400 \mathrm{~mm}$ y en tubería metálica. Se suele realizar este proceso de noche, ya que las presiones son más elevadas.

Con la inyección de agua a alta presión se eliminan toda clase de incrustaciones y depósitos resultantes de la corrosión. Esta técnica aplica un chorro de agua a presión sobre las paredes de la conducción. Para ello se hace un orificio de entrada y se introduce un dispositivo de inyección de agua a presión que puede limpiar hasta 200 ó 300 m de tubería al día. La presión del agua de limpieza está limitada a 200 bares ya que presiones mayores podrían dañar las tuberías. Pese a esta limitación de presión, el esfuerzo que se realiza sobre las conducciones es elevada y por eso los codos con ángulos superiores a $22.5^{\circ}$ deben ser retirados y en ocasiones se pueden emplear como zonas de acceso.
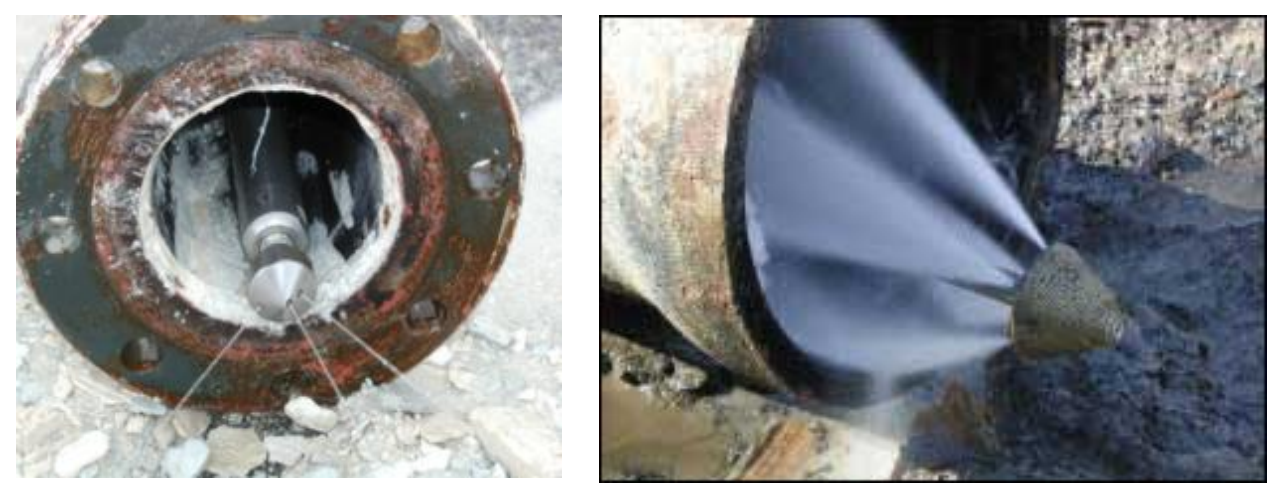

FIGURA A.16. INYECCIÓN DE AGUA A ALTA PRESIÓN.

Una vez se ha limpiado un tramo de tubería, se retira tanto el inyector por el orificio existente en la conducción (o por los codos que se habían retirado) como los materiales arrastrados por la inyección de agua.

Esta técnica se utiliza en tuberías con un rango de diámetros comprendidos entre los 50 y 1800 mm, con una longitud máxima de 100 m para materiales metálicos y $250 \mathrm{~m}$ para materiales plásticos.

Al igual que el resto de técnicas de limpieza agresivas, surgen problemas relacionados con el posible incremento de HAPs. Se recomienda no utilizar esta técnica sin un posterior recubrimiento. 
La técnica conocida como bala abrasiva, pigging o swabbing se utiliza tanto en redes de abastecimiento como de saneamiento. PIG es un acrónimo de pipe internal gage o medidores de la parte interna de la tubería. Estas balas, debido a su construcción flexible, producen la limpieza mediante rascado o abrasión. El tipo de material con el que se fabrican las distintas balas es función del estado de la conducción que se desea limpiar, y por tanto de la cantidad de material que se desea eliminar (Figura A.17).

Como paso previo a la limpieza, se aísla el sistema operando las válvulas instaladas aguas arriba y aguas abajo del tramo elegido, por lo que los consumidores se ven privados del servicio por un tiempo. También se necesita un dispositivo que permita el lanzamiento de la bala, introduciéndola en la conducción, aunque también se puede introducir a través de los hidrantes.

La bala se ajusta completamente a la tubería, por lo que cuando el sistema se presuriza, se utiliza el salto de presiones producido para provocar el movimiento de la misma a lo largo de la tubería. La velocidad de la bala se regula con las válvulas y se pretende conseguir aquélla que arrastre una mayor cantidad de material con un menor desgaste de la bala.

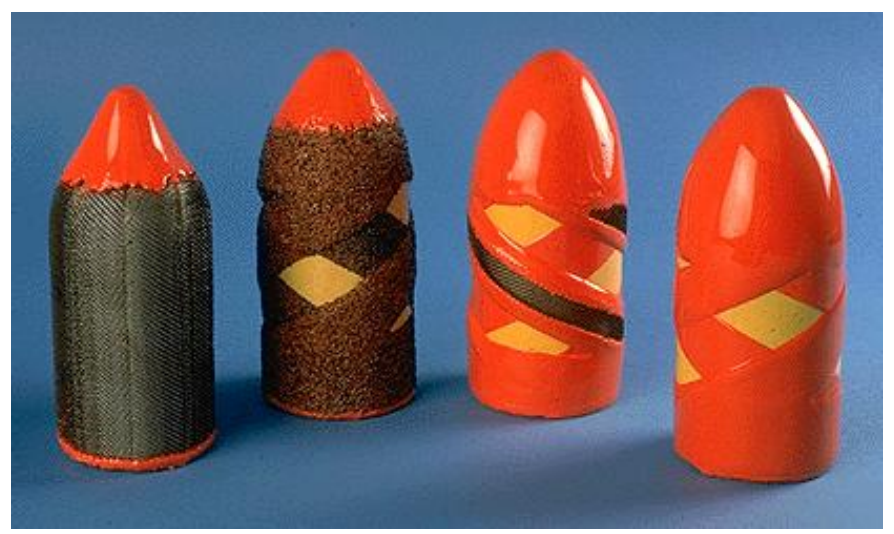

FIGURA A.17. DIFERENTES TIPOS DE BALAS ABRASIVAS.

La operación de limpieza con balas abrasivas, se realiza varias veces con un aumento de la dimensión de la misma, desde la sección efectiva hasta la nominal de la tubería. Como paso final tras el proceso de limpieza, la tubería se desinfecta antes de ser puesta en servicio.

Este tipo de limpieza suele ser previa a los procesos de entubado, encamisado térmico, etc., siendo aplicable en tuberías de cualquier material con diámetros comprendidos entre 75 y $3000 \mathrm{~mm}$ y con una longitud de hasta $2 \mathrm{Km}$. Al igual que otras técnicas de limpieza agresiva, se han observado ciertos problemas debido al aumento de los HAPs. 


\subsection{Revestimientos no estructurales}

Los revestimientos no estructurales se usan para proteger la superficie interna de la conducción frente a la corrosión y mejorar la calidad del agua, ya que evita el contacto con los microorganismos del fluido transportado. El recubrimiento no tiene ningún efecto sobre la corrosión externa y no proporciona mayor resistencia estructural a la tubería.

Estas técnicas presentan un efecto mínimo en la prevención de fugas, en cambio, producen un recubrimiento perfectamente liso en la superficie interior de la tubería que aumenta la capacidad hidráulica de la conducción.

Previamente al revestimiento, se deben haber eliminado todos los depósitos del interior de la tubería. Para ello, se usan generalmente los métodos de rascado e inyección de agua a alta presión.

La elección del material de revestimiento depende de la calidad del agua transportada, de la vida útil esperada para el mismo y de las condiciones hidráulicas. En general estos métodos son más económicos que los revestimientos estructurales.

\subsubsection{Revestimiento con mortero de cemento}

Esta técnica consiste en la aplicación de mortero de cemento sobre la parte interior de una tubería de manera que se conforme un revestimiento no estructural suficientemente liso y con protección frente a la corrosión interior. Se empezó a utilizar en el Reino Unido y actualmente es un procedimiento común, que supone la mayoría de los trabajos de revestimiento y es aplicable tanto en redes de saneamiento como en redes de abastecimiento de agua potable. En España, la tubería de fundición dúctil tiene revestimiento de mortero desde 1985.

El mortero de cemento sin aditivos es un material apto para el contacto con agua potable, evita una futura formación de corrosión e incrustaciones, elimina pequeñas fugas, mejora las cualidades hidráulicas de la tubería y dobla la vida útil de tuberías metálicas. 
El proceso comienza con la inspección con cámaras de televisión y con la limpieza de las conducciones para eliminar las incrustaciones, raíces, etc. También se realiza un secado de la tubería como paso previo a la aplicación de un mortero de $4 \mathrm{~mm}$ de espesor en el interior de las conducciones. Dicho recubrimiento puede ser alisado posteriormente para mejorar el rendimiento hidráulico. Una vez se ha aplicado el recubrimiento, se deja reposar durante 24 horas y posteriormente se realiza un proceso de cloración y lavado para volver a poner la tubería en funcionamiento. Una limitación de esta técnica viene dado por el hecho de que el tiempo de curado es significativamente alto.

El cemento suele ser de tipo Portland (cuya utilización no se recomienda en aguas con alcalinidades por debajo de 5.5 grados hidrométricos franceses) previene la corrosión generando un entorno alcalino. Se suele añadir ortofosfato para disminuir la corrosión interna. Recientemente se ha cuestionado la calidad del agua que ha estado en contacto con este revestimiento debido a un incremento del $\mathrm{pH}$. Cuando el agua es extremadamente blanda, se puede Ilevar a cabo un tratamiento posterior con $\mathrm{CO}_{2}$ a fin de reducir la alcalinidad del revestimiento de mortero de cemento mediante el carbonizado artificial de la superficie.

Se pueden añadir ciertos aditivos para mejorar las cualidades del revestimiento. Por ejemplo, si el revestimiento es de mortero de cemento con base de silicio, se puede utilizar en ambientes especialmente corrosivos; si se realiza con cemento rico en calcio y aluminio, es capaz de resistir la corrosión de tipo biológico producida por microorganismos o por procesos biológicos, y con otros aditivos químicos puede reducirse el periodo de reposo y permitir una rápida vuelta al servicio.

Si el revestimiento se realiza en diámetros nominales de tubería entre 100 y $600 \mathrm{~mm}$ se utiliza un robot para aplicar el recubrimiento, el cemento es bombeado hasta un cabezal que tiene forma cónica que gira a alta velocidad para impregnar con mortero las paredes de la conducción. La longitud del tramo a rehabilitar es el máximo posible entre válvulas, codos, etc.

Esta técnica es bastante económica para la renovación de conducciones metálicas, exceptuando aquéllas con pobres condiciones estructurales. El revestimiento es bastante grueso y por eso no se aplica en pequeñas conducciones. De hecho, se recomienda su empleo en diámetros desde 100 hasta $3000 \mathrm{~mm}$. 
El espesor del revestimiento de mortero de cemento depende del diámetro y el tipo de tubería, variando desde $3 \mathrm{~mm}$ hasta $10.2 \mathrm{~cm}$ en tuberías de $13 \mathrm{~mm}$ y $1500 \mathrm{~mm}$ respectivamente (Selvakulmar y col., 2002). Estás técnicas prolongan la vida útil de la tubería unos 50 años y mejoran el factor de fricción (Deb y col., 1990). En pequeños diámetros o en sistemas con poca capacidad hidráulica, se suele utilizar revestimientos con resinas de tipo polimérico por tener un menor espesor.

\subsubsection{Revestimiento con resinas de tipo polimérico}

Los materiales utilizados como revestimiento interior suelen ser generalmente poliuretanos y resinas epoxi. Su utilización comenzó en el Reino Unido. Los revestimientos no estructurales con materiales poliméricos han aumentado su uso paulatinamente ya que además de presentar un excepcionalmente bajo factor de fricción, eliminan los problemas en el $\mathrm{pH}$ del agua. Por tanto, son muy utilizadas en conducciones de pequeño diámetro y longitud. Para diámetros superiores a $225 \mathrm{~mm}$, la viabilidad económica es menor, ya que el coste del material desaconseja su uso a favor del revestimiento de mortero de cemento (Conroy y col., 1995). Se ha comprobado que estos revestimientos alargan la vida útil de la tubería hasta 75 años (Watson, 1998).

Los materiales son inyectados tras un proceso de inspección de la tubería (generalmente por sistemas de televisión) y de la limpieza de las tuberías que se intentan recubrir (rascado). Finalmente se ha de realizar un control final de seguridad que asegure el alisamiento de la conducción y la eliminación de todas las incrustaciones. Los materiales poliméricos son bombeados hacia el interior de la conducción, Figura A.18, y tras su mezcla se inyectan en las tuberías con un cabezal giratorio que lanza el material hacia las paredes de la misma.

La maquinaria con la que se aplica el revestimiento esta compuesta por un mezclador situado en la parte interior de la tubería, desde la cual se lanza la resina y los componentes de endurecimiento hacia las paredes de la tubería, así como un depósito de resinas que sirve de abastecimiento a un equipo de bombeo.

El revestimiento con resinas tiene un menor espesor (aproximadamente $1 \mathrm{~mm}$ ) que el de mortero de cemento. En este tipo de revestimiento no estructural, el tiempo de curado del material es de 16 horas. 

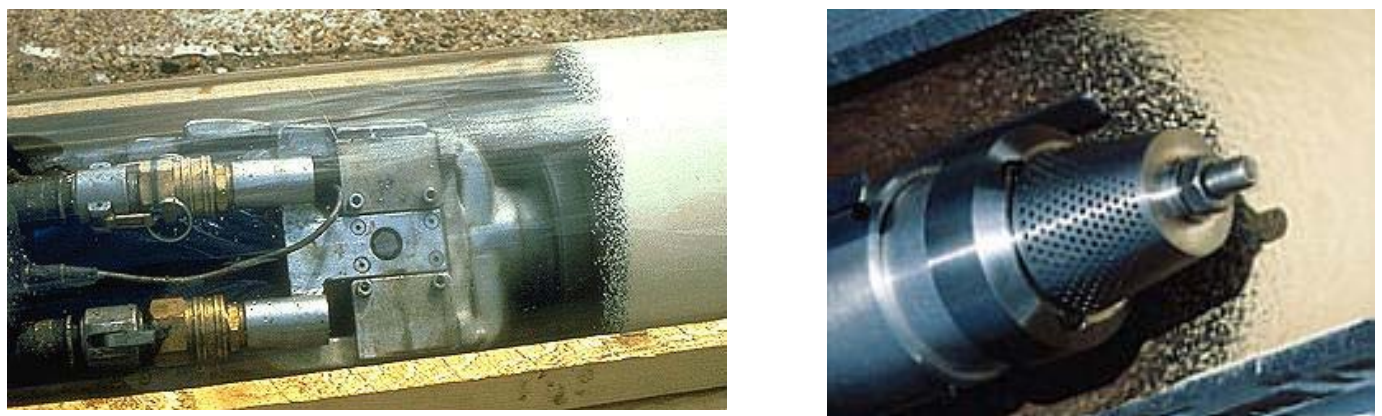

FIGURA A.18. DISPOSITIVOS DE INYECCIÓN DE RESINAS SOBRE LA CONDUCCIÓN.

El rango de diámetros de tubería en que es aplicable esta técnica oscila entre 75 y $300 \mathrm{~mm}$. La conducción sobre la que se aplica este recubrimiento puede ser desde acero hasta fibrocemento (siempre exceptuando las conducciones en las que las condiciones estructurales sean muy pobres). La longitud típica que se recubre suele ser de $100 \mathrm{~m}$. El poliuretano solamente se utiliza en redes de saneamiento, mientras que la resina epoxi puede ser utilizado también en abastecimiento.

\subsection{Revestimientos estructurales}

La clasificación de las técnicas de revestimiento estructural es bastante compleja. Se caracterizan por la introducción de una tubería dentro de otra. Las diferencias estriban en la técnica utilizada para la introducción, la deformación y el método de reversión de la tubería introducida, etc.

Por estas razones, y por la diversa nomenclatura (variable según el fabricante), la clasificación propuesta (al igual que la clasificación general que se puede observar en la Figura A.13) difiere de otras publicaciones. Las técnicas de inserción de manguera deformada de polietileno pertenecen al grupo de ajuste preciso a la conducción o close fit pipe. En cambio, Clark y col. (2002) sugieren que ésta es otra técnica independiente dentro del grupo de revestimientos estructurales.

En algunos textos, el entubado espiral o el entubado por deslizamiento se consideran técnicas de ajuste preciso a la conducción (Najafi y Gokhale, 2004). Tras estos comentarios, y aún a sabiendas de que ciertas tecnologías menos usadas no están incluidas en la clasificación realizada, se procede al análisis de los métodos más conocidos y utilizados. 


\subsubsection{Entubado por deslizamiento}

El entubado por deslizamiento es la técnica sin zanja más antigua y la más común. Se caracteriza por la introducción de una tubería dentro de otra y por el relleno el espacio con forma anular entre ambas. El material con el que se puede realizar esta técnica es polietileno, PVC o poliéster reforzado con fibra de vidrio. El proceso suele ser sencillo y relativamente barato, aunque la capacidad de transporte de flujo se puede reducir hasta el 35-60\% (Spero, 1999).

En principio, se realizan dos catas que permiten el acceso a la conducción y a la inspección con cámaras de televisión. A continuación, se limpia la tubería y se eliminen las incrustaciones o raíces existentes. La tubería se inserta por empuje o estirado (Figura A.19).

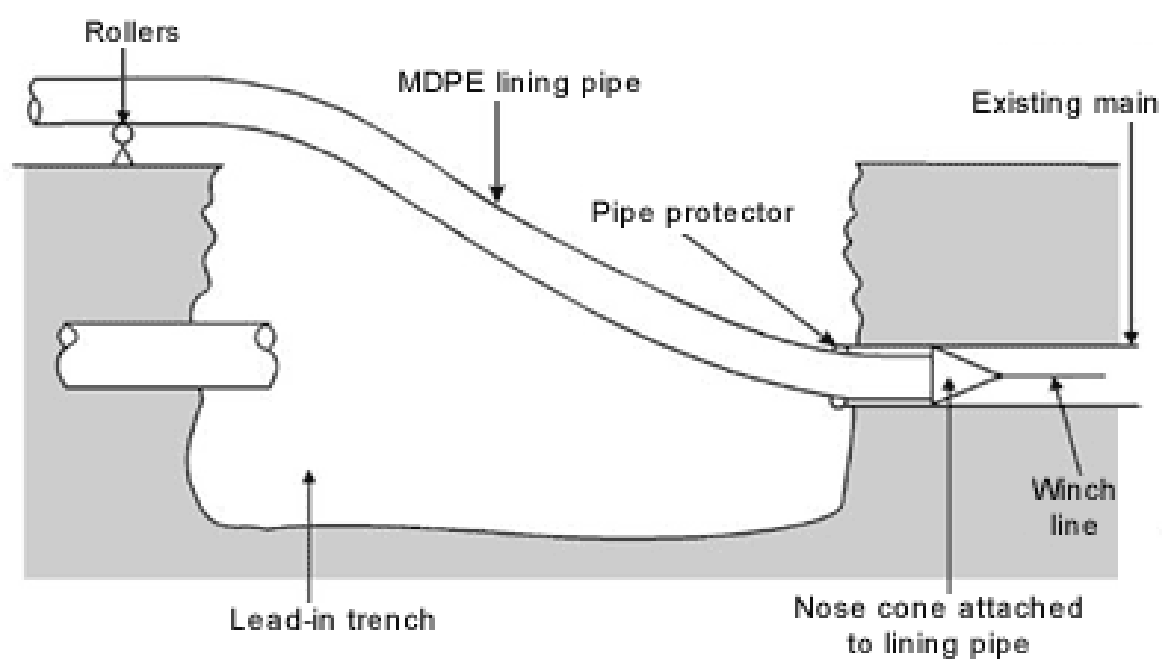

Figura A.19. MÉTOdO DE ENTUBADO POR DESLIZAMIENTO.

Simultáneamente en el exterior se produce un proceso de soldado u otra unión mecánica de la tubería que conforman la futura conducción, aunque también es posible realizar la unión de tuberías en la cata que se ha realizado, especialmente cuando la tubería es muy profunda y no se desea realizar una excavación muy elevada (Figura A.20). 


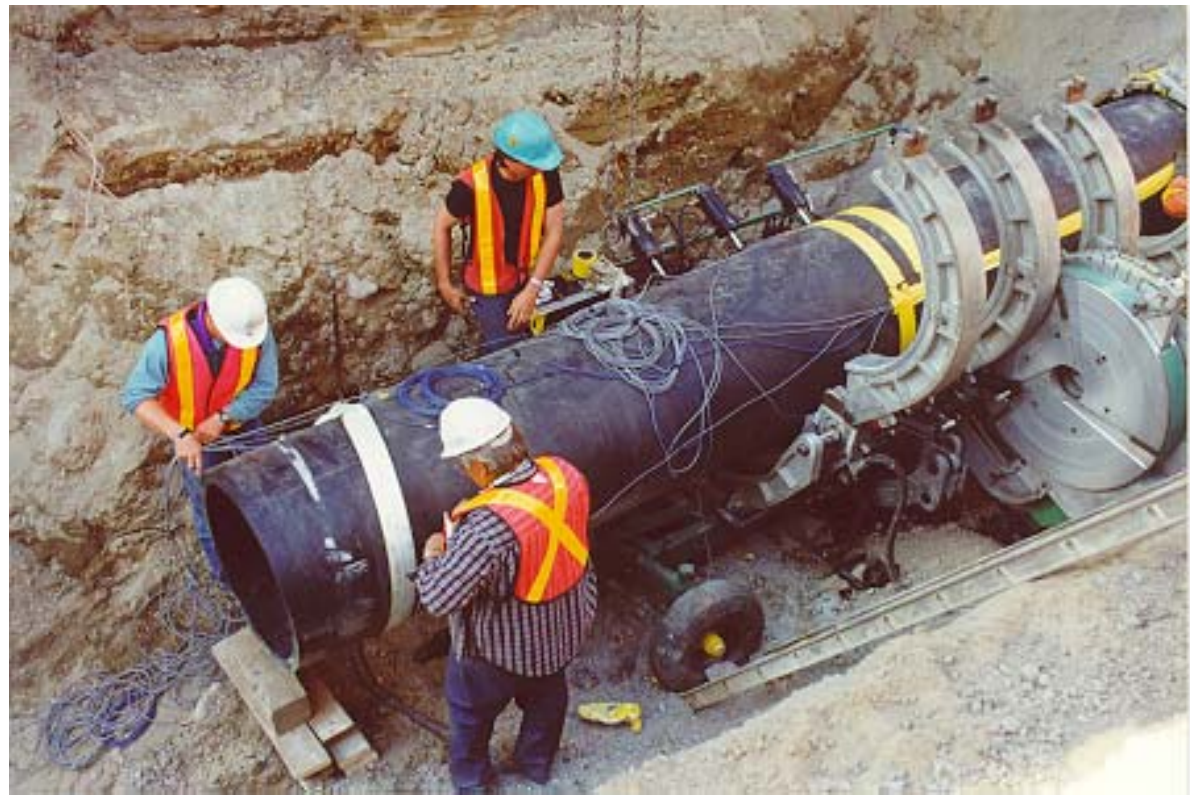

FIGURA A.20. UNIÓN POR SOLDADURA DE UNA TUBERÍA EN UNA CATA DE ENTRADA.

Si la tubería es de pequeño diámetro, se introducirá por estirado. La futura tubería se une a un cono en el extremo de la tubería con el objetivo de agarrarla a un cable que fije y guíe la misma. De este modo se previene de un posible golpe que dañe la nueva conducción. El estirado se realiza de manera continua y estable, con aplicación siempre de la misma fuerza.

En cambio, si la tubería se introduce mediante empuje (habitual en diámetros mayores) se utiliza una maquinaria que se ubica bien en la cata realizada o bien en el exterior. Dicho dispositivo agarra la conducción y la mueve accionando unos pistones hidráulicos o neumáticos. Posteriormente libera la conducción y recoge el brazo telescópico para volver a reiniciar el proceso de empuje.

A continuación, se debe realizar un proceso de relleno del espacio que está situado entre ambas conducciones. El material de relleno que se introduce en todas las técnicas de entubado tiene como objetivo evitar el colapso o el debilitamiento de la tubería nueva por el choque con la antigua. El mortero de cemento está regulado según ciertas normas americanas, cada una de ellas orientada a distintos aspectos del mismo, ASTM C 109 (tensión máxima de compresión del relleno), ASTM C 403 y 495 (resistencia al punzonamiento) y ASTM C 150 (especificaciones generales del Cemento Portland) (Thornton y col., 2005).

Por último, el entubado por deslizamiento finaliza con la restauración de las conexiones laterales y la realización de una prueba de estanqueidad de la tubería insertada. 
Esta técnica se puede aplicar tanto en redes de abastecimiento (Figura A.21) como en saneamiento. En estas últimas se utiliza muy poco, ya que las restantes técnicas presentan un coste asociado menor. Las principales desventajas con respecto a las otras son la reducción de la sección eficaz de paso (hasta un 10\% el diámetro) y un control de fugas futuro más complicado, ya que el volumen fugado será encubierto por la antigua tubería. La longitud característica rehabilitada es de $300 \mathrm{~m}$, y el rango de diámetros oscila entre 65 y $2500 \mathrm{~mm}$.

Esta técnica está bastante desarrollada para diversos tipos de tubería (EPA, 2009). Las innovaciones en las que se está trabajando actualmente y que permitirían instalaciones más económicas consistirían en:

- instalación en codos de curvatura moderada.

- instalación de una tubería que incorporase el relleno anular y que estuviese previamente desinfectada para su uso en agua potable (tubería prefilled).

- utilización de nuevos materiales, como tubería de fundición dúctil o PVC fundido.

- reinstalación remota de las conexiones con las acometidas.

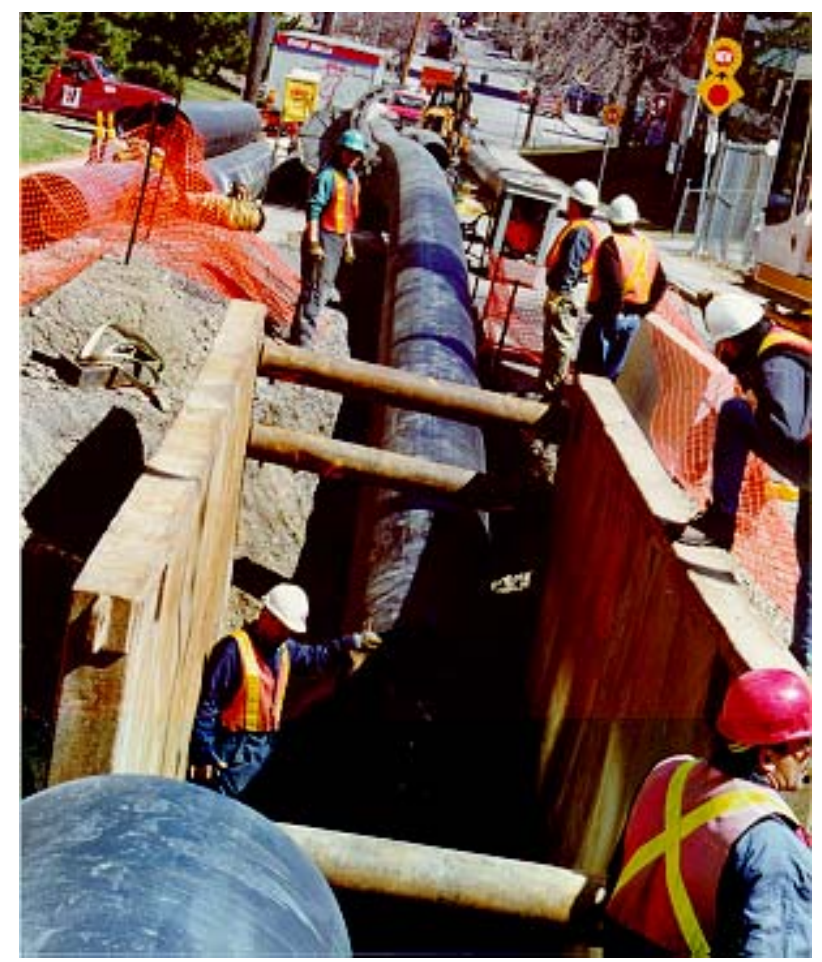

FIGURA A.21. CATA DE ENTRADA EN UNA RENOVACIÓN EN TUBERÍA DE 910 MM DE FUNDICIÓN GRIS MEDIANTE ENTUBADO POR DESLIZAMIENTO CON TUBERÍA DE POLIETILENO DE 840 MM, OTTAWA, CANADÁ. 


\subsubsection{Ajuste preciso a la antigua tubería}

Las técnicas de ajuste preciso a la tubería o close fit pipe ${ }^{6}$ son similares al entubado por deslizamiento (apartado 3.3.1) aunque la reducción del diámetro final de la nueva tubería es menor. Esto es, el espacio anular entre ambas conducciones se casi nulo y la pérdida de capacidad hidráulica es menor que en caso anterior. Bajo el nombre técnicas de ajuste preciso se engloban cuatro técnicas en las que la nueva tubería se deforma temporalmente para facilitar su instalación. Gracias a la nueva tubería, la vida útil de la antigua se alarga 50 años (Selvakulmar y col., 2002).

Cada una de las técnicas que componen este grupo utilizan diferentes combinaciones de deformación y método de reversión a las condiciones originales.

Para superar los diversos problemas del entubado, como mejorar la inserción de la tubería nueva sobre la antigua, se han desarrollado diversas técnicas de entubado (Figura A.22) como son:

- Ajuste por relajación natural, swage lining o die drawing.

- Ajuste mediante presión hidráulica o rolldown.

- Inserción de manguera deformada de polietileno (que difiere en nombre según se revierta la deformación, con vapor de agua se conoce como uliner $^{7}$ o fold and form pipe, y con agua a presión, subline.

\footnotetext{
${ }^{6}$ Estas técnicas también se les Ilama deformed pipe lining o mecanically folded pipe.

7 Dichas técnicas se han traducido al castellano como inserción de manguera deformada de polietileno con reversión con vapor de agua o con reversión con agua a presión.
} 


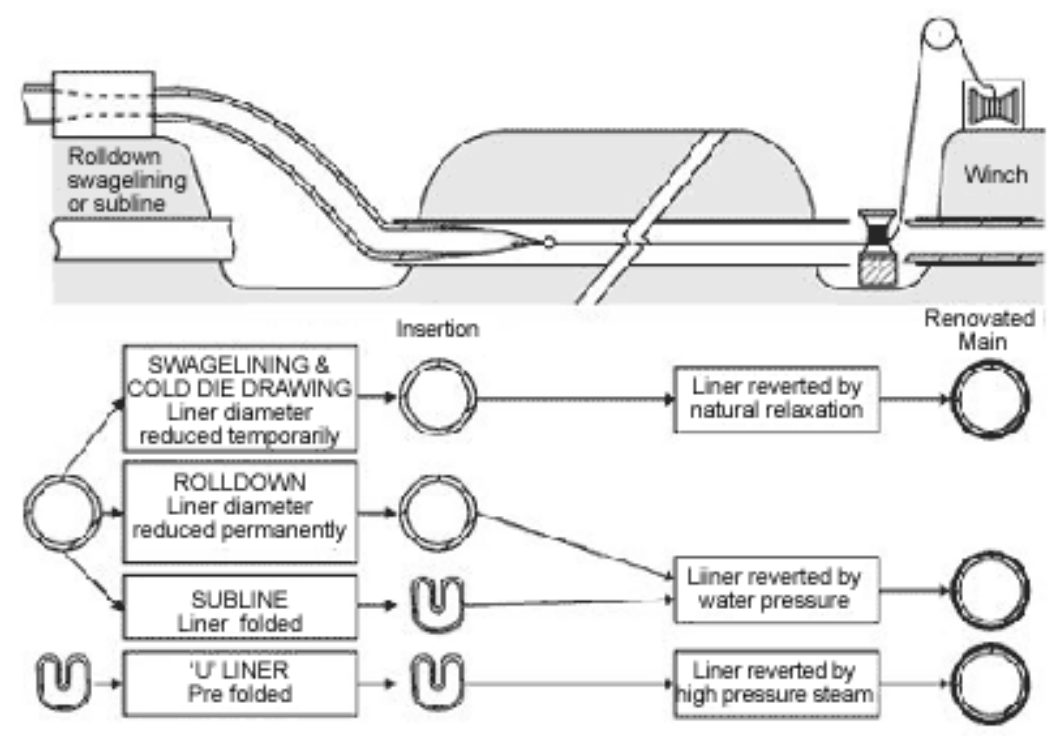

Figura A.22. ClasifiCACIÓN DE LAS DISTINTAS TÉCNICAS DE AJUSTE PRECISO A LA ANTIGUA TUBERÍA.

El ajuste por relajación natural utiliza tuberías de polietileno como tubería nueva con un diámetro exterior ligeramente mayor que el diámetro interior de la antigua tubería. Previo a la deformación del polietileno, se debe realizar una inspección mediante cámara de televisión de la conducción que se desea rehabilitar, para poder observar el estado de la misma y la presencia de acometidas, codos, válvulas, etc.

Posteriormente se realiza un proceso de limpieza de la tubería, mediante bala abrasiva o rascado) y otra inspección con cámara de televisión, donde se presta especial atención al estado de la superficie interna de la conducción limpiada y tal que asegure la perfecta sección circular de la conducción a lo largo de la longitud del tramo seleccionado.

El polietileno, como la mayoría de materiales utilizados en la reparación o renovación de tuberías, se transporta en piezas de una determinada longitud, (6 ó $12 \mathrm{~m}$ ) y la unión de los tramos se realiza en superficie, habitualmente mediante un proceso de soldadura donde es especialmente relevante asegurar la alineación de los tubos. A continuación se añade un lubricante al tubo de polietileno y con éste ya se han realizado todos los pasos previos a la reducción de diámetro. 
El diámetro de la tubería de polietileno se reduce hasta un 6\% sobre el inicial por la acción conjunta de un sistema calefactor, que alcanza los $100^{\circ} \mathrm{C}$, y de unos rodillos, junto con la fuerza axial realizada por una máquina tractora que tira de la conducción. Esta reducción facilita la inserción en la tubería existente y el diámetro reducido no se revierte mientras se mantenga la fuerza de tracción. Durante el proceso de inserción, se registra la posición exacta de la cabeza de tiro que arrastra a la conducción y se controla la velocidad de inserción, evitando que supere una velocidad concreta y que las fuerzas de tracción no sobrepasen los límites fijados.

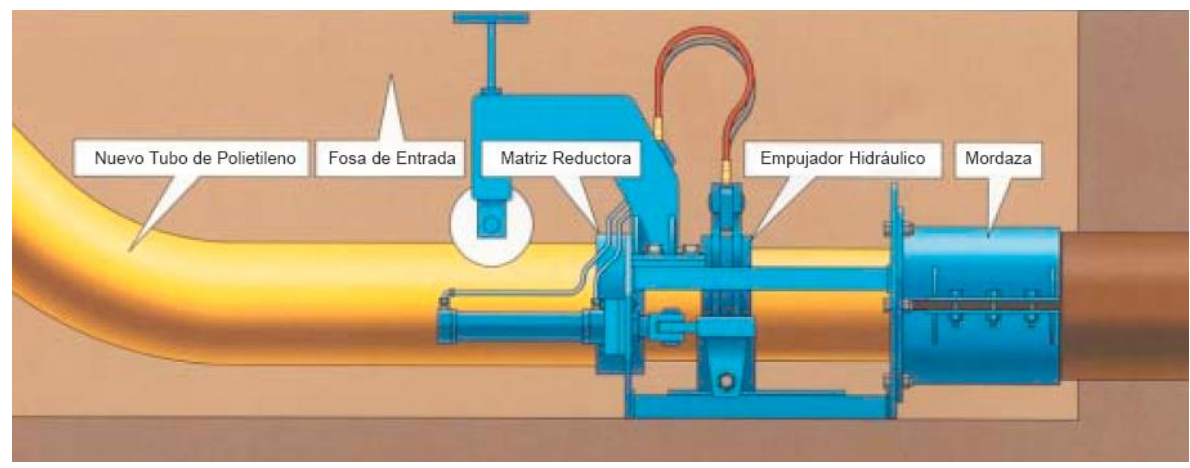

Figura A.23. MECANISMO DE REDUCCIÓN DE LA TUBERÍA DE POLIETILENO.

La tubería de polietileno recupera su diámetro inicial de acuerdo con un proceso de relajación natural y transcurrido un tiempo desde el cese de aplicación de la fuerza. La superficie exterior de la tubería de polietileno se aprieta en contacto con la parte interior de la tubería rehabilitada. El espesor de la tubería de polietileno disminuye ligeramente con su nuevo diámetro que es casi igual al original, y se incrementa ligeramente su longitud.

Los bordes de la tubería se unen al resto de la red de tuberías mediante unión soldada por arco eléctrico. Para ello la superficie se limpia y elimina cualquier resto que perjudique la soldadura. De esta manera se conecta la nueva conducción rehabilitada con el sistema de abastecimiento ó saneamiento urbano. Los diferentes elementos, tales como válvulas, codos, etc. también se pueden insertar en este proceso realizando un corte a la tubería y uniendo mediante soldadura por arco eléctrico.

Se pueden rehabilitar tuberías con un diámetro nominal comprendido entre 75 y $600 \mathrm{~mm}$ y con unas longitudes de aproximadamente $1000 \mathrm{~m}$. Esta técnica se utiliza fundamentalmente en redes de saneamiento. 
La tubería de polietileno es sometida a una serie de pruebas en laboratorio que simulan el funcionamiento de la misma tanto en el ensamblado como en funcionamiento. Para ello se reduce el espesor de la conducción hasta un $10 \%$ en varias zonas delimitadas de la tubería y se realiza una prueba de resistencia a la fatiga para garantizar el correcto funcionamiento de la conducción durante al menos 50 años. Todo ello junto con las pruebas de resistencia a la tracción, flexión, temperatura, etc.

Otra técnica de entubado similar al ajuste por relajación natural sería la técnica ajuste por relajación natural en frío o cold die drawing, que es exactamente igual aunque no necesita la aplicación de calor en el proceso de reducción del diámetro de la tubería. Ambas técnicas se ejecutan in-situ, ya que la reducción se debe realizar justo antes de la introducción de la conducción.

El método conocido como ajuste mediante presión hidráulica o rolldown es similar a la técnica de ajuste por relajación natural. La diferencia fundamental es que la reducción del diámetro es mayor a temperatura ambiente (hasta un 10\% por efecto de unos rodillos hemisféricos especialmente diseñados, Figura A.24). Esta reducción de diámetro es de tipo permanente, por lo que las tuberías se pueden almacenar.
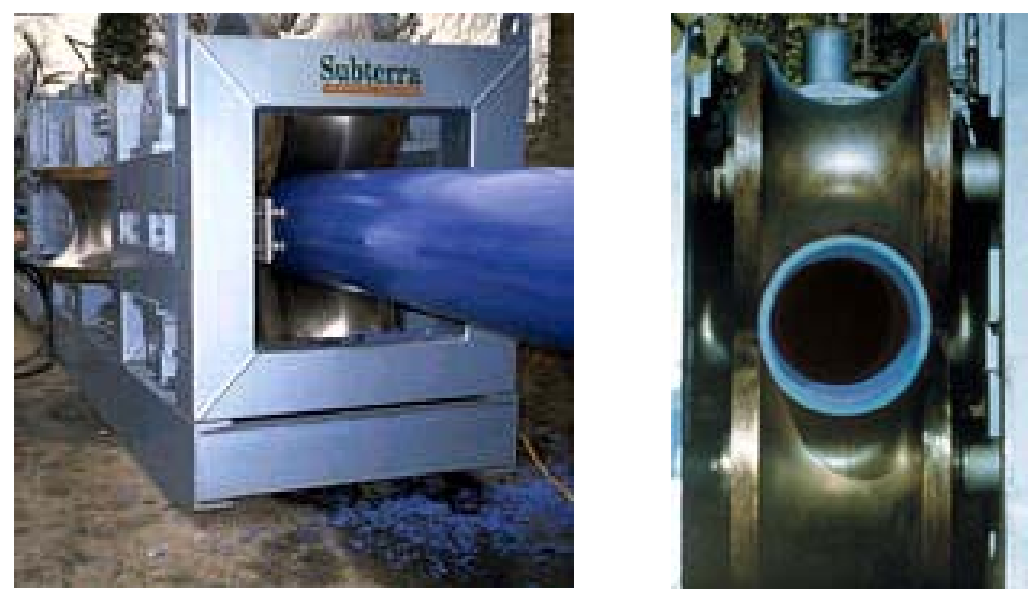

FIGURA A.24. RODILLOS QUE PRODUCEN LA DEFORMACIÓN EN LAS TÉCNICAS DE AJUSTE MEDIANTE PRESIÓN HIDRÁULICA.

El proceso de instalación es igual al definido anteriormente. Comienza con una inspección, continua con una limpieza y se ha de asegurar el resultado previo a la inserción sea una tubería lo más homogénea posible para facilitar el proceso de entubado. 
La reducción del diámetro es considerable, y la fuerza axial para introducir la tubería nueva en la antigua es menor que en el caso del ajuste por relajación natural. De esta manera, se pueden rehabilitar mayores longitudes, ya que solamente se tiene que realizar la fuerza para desplazar una tubería dentro otra.

A continuación se revierte la tubería de polietileno a su antiguo diámetro. Para ello se obturan los extremos de la conducción, se llena de agua y se presuriza, consiguiendo que la tubería vuelva a su diámetro inicial encajando perfectamente con la antigua tubería. Esta técnica no deja huecos entre la tubería antigua y la nueva y por tanto no existe un espacio anular entre tubos.

La mayor ventaja de la aplicación de esta técnica estriba en el mecanismo empleado para la reversión del diámetro. Éste reduce el tiempo de instalación y minimiza las fuerzas y tensiones aplicadas. Además, el espacio requerido en superficie es menor que en la técnica de ajuste por relajación natural.

En contrapartida, la reducción de diámetro es mayor que en otras técnicas, y no se debe emplear en conducciones con espesor pequeño. Así, no se debe utilizar con polietileno de media densidad $\mathrm{con} \mathrm{SDR}^{8}>30 \mathrm{ni}$ en polietileno de alta densidad con $\mathrm{SDR}>33$, ya que en el proceso de reducción del diámetro nominal, dichos materiales pueden romperse.

Esta técnica se emplea para rehabilitar cualquier tipo de tuberías con diámetros comprendidos entre 75 y $600 \mathrm{~mm}$, y con una longitud máxima rehabilitada de $1000 \mathrm{~m}$. Se utiliza generalmente en redes de saneamiento.

La inserción de una manguera de polietileno con deformación previa en forma de $U$, se utiliza generalmente para rehabilitación de tuberías de gas y de agua potable, aunque también puede emplearse en saneamiento. Existen otras posibles deformaciones de la tubería, con forma de $\mathrm{H}$, y la habitual deformación en $\mathrm{U}$ en algunos textos se designa también deformación en C. La conducción de polietileno que se inserta en el interior de una antigua tubería se utiliza para prevenir corrosiones internas, fugas en las juntas, tapa los agujeros provocados por la corrosión y provoca que la superficie interior de la nueva conducción tenga una menor rugosidad, con lo que, en algunos casos y pese a la reducción del diámetro, incluso se puedan reducir las pérdidas de carga en el tramo.

\footnotetext{
${ }^{8}$ Standard dimension ratio (SDR) es el cociente entre el diámetro exterior y el espesor de la tubería.
} 
Las tuberías de polietileno son especialmente diseñadas para cada obra concreta, y se determina el diámetro exterior, interior y el SDR a conveniencia de la obra. Si no se fabrica especialmente, los tubos de polietileno pueden ser soldados, antes de la deformación, hasta obtener la longitud deseada de la conducción final. Este proceso se puede realizar in-situ o bien para tramos cortos de tubería a rehabilitar se puede realizar en fábrica. El proceso de instalación es análogo a los anteriores.
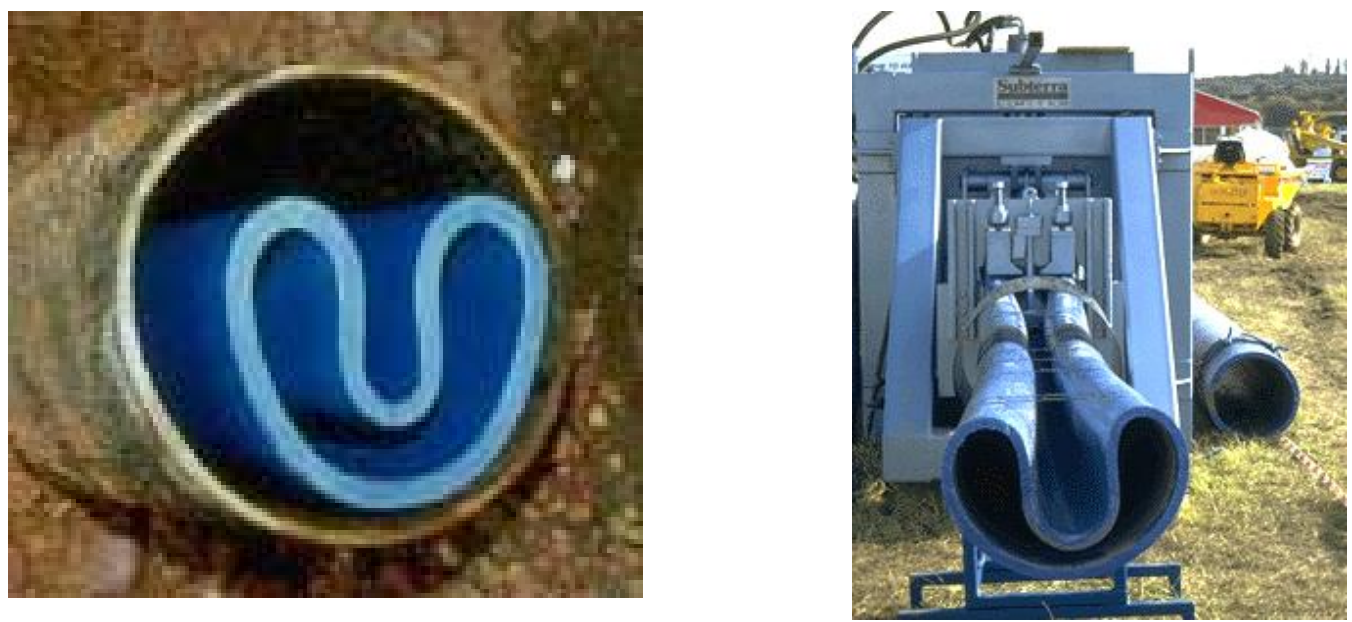

FIGURA A.25. VISTA DE LA DEFORMACIÓN REALIZADA SOBRE LA TUBERÍA DE POLIETILENO Y UN EJEMPLO DE DEFORMACIÓN IN-SITU.

La deformación de la tubería de polietileno (proceso sin elongación ni variación en el espesor del polietileno) se realiza con una maquinaria especial que a temperatura ambiente deforma la tubería el diámetro tal y como se muestra en la Figura A.25. Algunos fabricantes deforman la tubería de polietileno con presencia de calor, aunque es más general el caso descrito. Para mantener la deformación se requiere la utilización de varias correas que impiden la reversión. Cuando la tubería está deformada, la sección de la tubería es un $40 \%$ de la sección total.

Se introduce el tubo deformado de polietileno y se procede a la reversión del proceso de deformación, para ello se utiliza vapor de agua (u-liner) o agua caliente a presión durante 12 horas, subline. Las correas que se han colocado para impedir la vuelta de la conducción a la posición inicial se deben romper con la acción del fluido a presión. Esta técnica es que no deja hueco entre la tubería antigua y la nueva de polietileno. La longitud máxima de conducción reparada es 1000 m y en un rango de diámetros de 75-1600 mm. 


\subsubsection{Encamisado térmico}

Un método bastante utilizado en la actualidad es el encamisado térmico cured in place pipe (CIPP) que es el revestimiento interior de tuberías mediante manga invertida. Se aplica exclusivamente para redes de saneamiento y es utilizada en todo el mundo desde hace 40 años. Es la técnica más versátil dentro del conjunto de técnicas de rehabilitación sin zanja y puede ser utilizada en un amplio rango de diámetros, desde 150 hasta 3000 mm, además de poderse aplicar en canalizaciones de todo tipo, acero, hormigón, hierro, etc. Además por las características propias de este tipo de rehabilitación de conducciones, la manga se acopla a cualquier tipo de sección de la conducción, redonda, cuadrada, ovalada, etc.

Esta técnica exige una primera parte dedicada a la inspección previa de la conducción con unos equipos de televisión móvil para detectar la situación de los puntos en los que se aprecien defectos. Posteriormente, se debe haber procedido con la limpieza total de la conducción. Esta limpieza consiste en la eliminación de posibles obstáculos como podrían ser acometidas penetrantes, incrustaciones, raíces, sedimentos, etc.

De acuerdo con las dimensiones y las características propias de la conducción, se opta por un tamaño de manga y por unos materiales de impregnación determinados. El tipo de proceso utilizado para que la manga se acople completamente a la antigua conducción depende de cada fabricante. Éstos varían los compuestos para obtener diferentes cualidades según sea el tipo de rehabilitación, aunque habitualmente se utiliza resina epoxi como material con el que se impregna la manga. También se pueden utilizar mangas de poliéster sin costura sobre las que se extrude un polietileno de pequeño espesor ó una impregnación de resinas de poliéster. Otro revestimiento de la manga sería la fibra de vidrio con resinas. En este caso, el conjunto de la manga tiene un pequeño espesor, aproximadamente de $1.5 \mathrm{~mm}$, y se elimina materiales elimina la formación de moho ó incrustaciones calcáreas debido a su mínima rugosidad.

En definitiva, los distintos tipos de impregnación deben de ser resistentes a la corrosión de manera que, al polimerizar, la tubería resultante cumpla con los requisitos de la Norma ASTM F 1216 y UNE- EN 13566-4. La manga tendrá una resistencia tal que soporte la carga o presiones debidas a la propia instalación, poseerá suficiente resistencia para tapar posibles agujeros existentes en la conducción a rehabilitar y será capaz de dilatarse, de tal manera que se ajuste a posibles secciones irregulares de la tubería. 


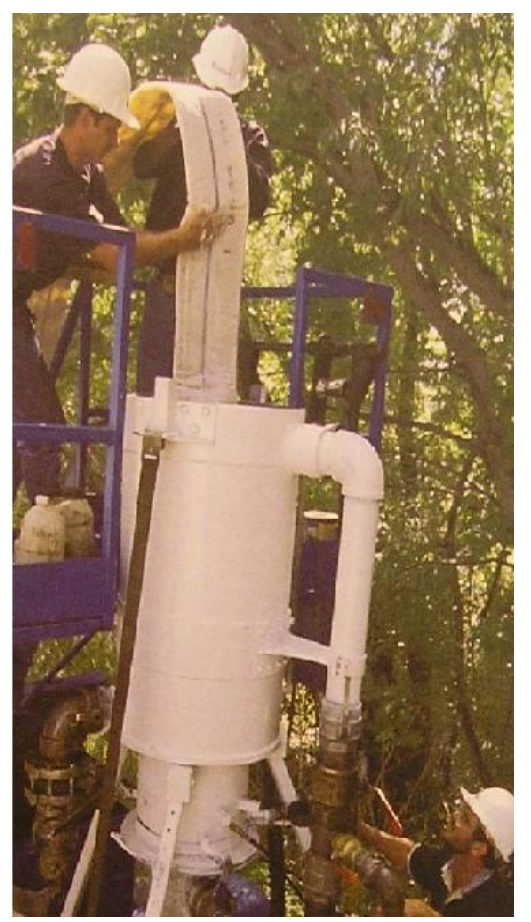

FIGURA A.26. INSTALACIÓN DE MANGA INVERTIDA PARA REHABILITACIÓN

Finalmente se ha obtenido una manga con un revestimiento en la parte interior de la misma (ya que se ha realizado un proceso de mezclado de la resina) y con unas características adecuadas (longitud, diámetro, etc.). Una vez la resina se ha extendido completamente, se prepara la manga para la reversión, se hace un corte por donde se invertirá la vuelta a la tubería en una máquina encargada de realizar ese proceso.

El extremo de la manga se fija en la boquilla de salida y se va introduciendo la manga en el interior de la canalización mediante la aportación de un fluido como agua, vapor de agua de manera que este fluido provoque un empuje necesario para que la punta de la manga vaya dándose la vuelta (con una velocidad de avance de 3-4 $\mathrm{m} / \mathrm{min}$ ) quedándose la parte de la manga impregnada con la resina en contacto con la antigua tubería. 


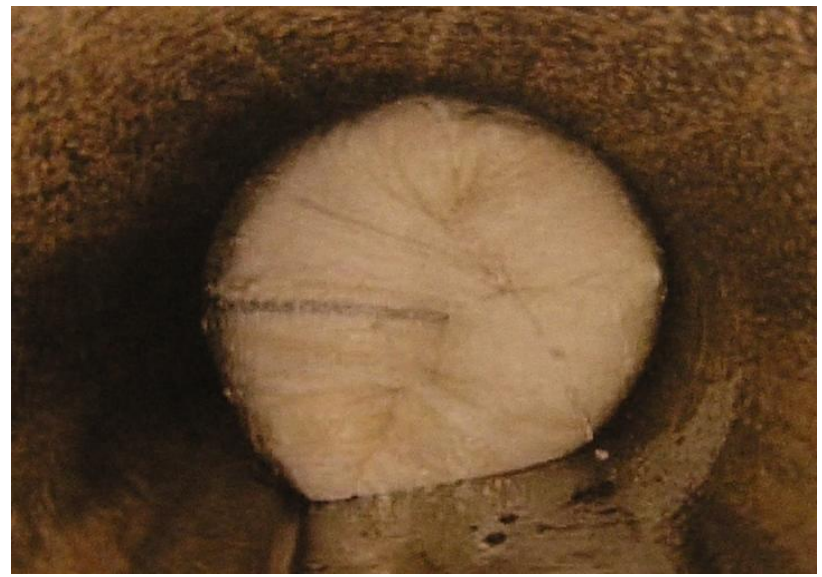

FIGURA A.27. PROCESO DE REVERSIÓN DE LA MANGA SOBRE LA ANTIGUA CONDUCCIÓN.

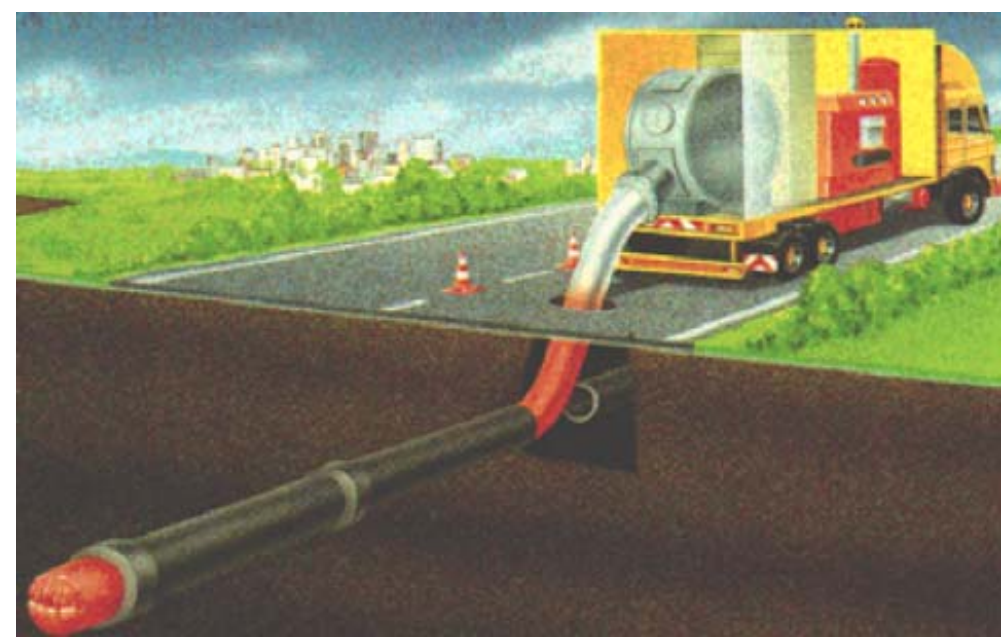

FIGURA A.28. REHABILITACIÓN D EUNA TUBERÍA MEDIANTE ENCAMISADO TÉRMICO.

La polimerización, es una reacción química en la cual el material con el que se ha impregnado la tubería se endurece y encola. Esta polimerización se puede realizar mediante vapor de agua a presión, agua caliente o rayos ultravioleta (UV). Este proceso tiene una duración de 4-5 horas si se realiza con agua caliente y debe ser realizado con un aumento gradual de la temperatura y con un control adecuado.

En cambio si se realiza la fotopolimerización por rayos UV (en tuberías de PRFV), se debe haber rellenado la manga con aire a presión para que se adapte al diámetro interior del tubo antiguo, y la modificación de las propiedades de la tubería de PRFV es inmediata tras la incidencia de la unidad lumínica de UV. 


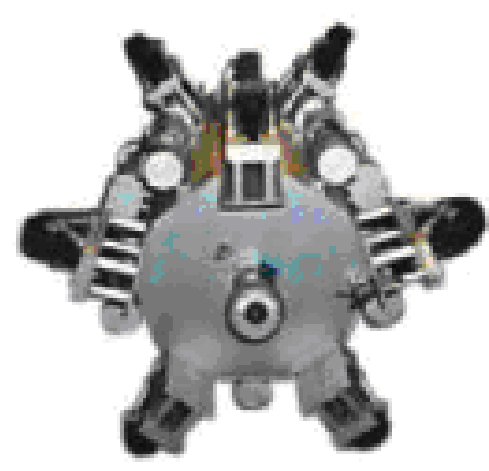

FIGURA A.29. UNIDAD CON LA QUE SE REALIZA EL FRAGUADO CON RAYOS UV.

Una vez fijada la manga, se debe recortar el tramo sobrante, instalar los collarines en los extremos de la nueva tubería y fijar con una resina de secado rápido. También se realiza un control final con la cámara de televisión para observar el estado final de la manga. Las acometidas que han sido localizadas mediante la inspección, son puestas en servicio desde el interior del colector mediante un sistema de fresado de tuberías que vuelven a habilitar las conexiones de aquellas tuberías que conecten con la tubería reparada.

El ámbito de aplicación de esta técnica es mayor al del resto de las técnicas y así, se ha implantado en todo el mundo, es la técnica más universal. En la actualidad, se utiliza exclusivamente en redes de saneamiento, se está trabajando mejorar su aplicabilidad para redes de agua potable, intentando controlar los elementos químicos que pueden quedar en la parte interna de la tubería y evitar el arrastre de materiales una vez finalizada la instalación.

Por ultimo, existe una nueva mejora, Performance Liner, sobre la técnica de encamisado térmico que consiste básicamente en que la manga revertida se cura a temperatura ambiente y en un proceso que únicamente dura dos horas. 


\subsubsection{Entubado espiral}

El entubado espiral o spiral wound lining consiste en la formación de una tubería de PVC que se ajusta a la superficie interior de la antigua tubería, independientemente de que la conducción tenga forma circular o cualquier otra, así como a su diámetro, de manera que la reducción sea mínima.

Como otras técnicas de entubado, se requiere una primera inspección con cámara de TV y en la mayoría de los casos se demanda una limpieza de las paredes internas de la conducción.

El material se encuentra dispuesto en forma de lámina de PVC con un espesor igual al deseado en la tubería final. Se introduce en el pozo de registro donde una máquina la corta con forma helicoidal en un proceso simultáneo con la introducción del PVC en la antigua tubería. Las uniones entre las láminas de PVC con forma helicoidal se realizan de manera diferente según el fabricante.

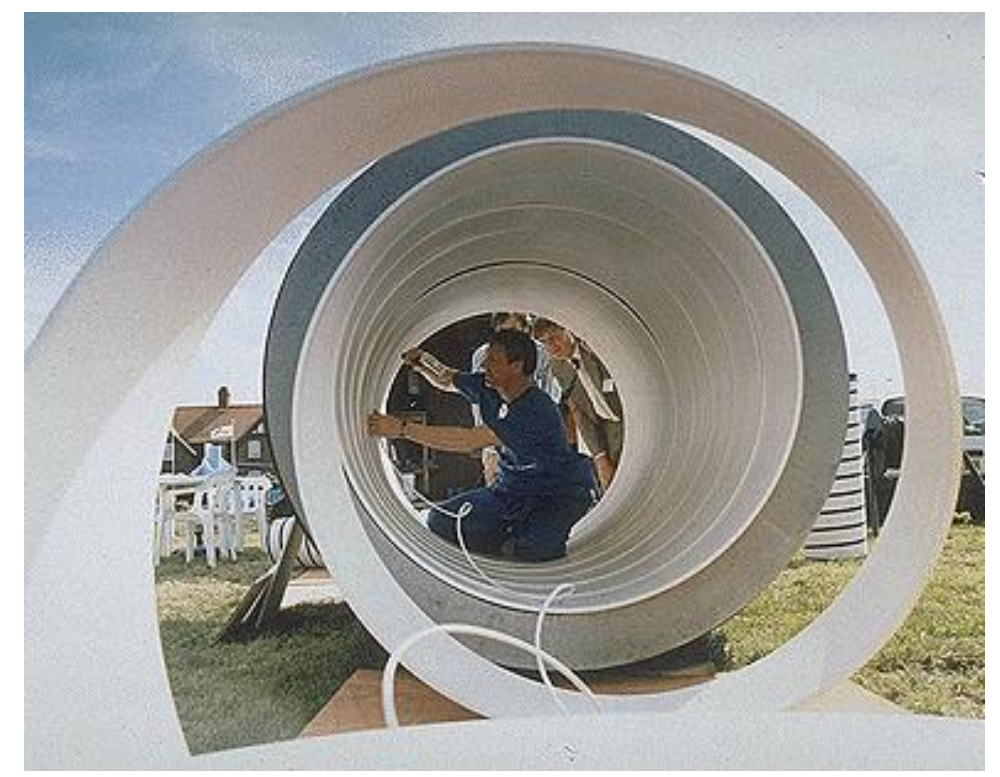

FiguRA A.30. LAMINA DE PVC CORTADA HELICOIDALMENTE.

El diámetro exterior de la nueva tubería es sensiblemente inferior al diámetro interior de la antigua, por lo que es casi siempre necesario rellenar el espacio anular que queda entre ambas. Algunos fabricantes han desarrollado un proceso mediante el cual la nueva tubería de PVC se expande dentro de la tubería original hasta que contacta con sus paredes y evita el relleno. 
Esta técnica permite la rehabilitación de largas longitudes de tubería con diámetros comprendidos entre 150 y 1000 m. También permite solucionar los cambios de sección, sin embargo solamente se utiliza en redes de saneamiento. También puede ser utilizada para proporcionar un revestimiento estructural ó no estructural. Por último, se pueden realizar fácilmente las incisiones en el entubado para permitir las conexiones laterales con acometidas, válvulas, etc. Para grandes diámetros, la nueva tubería de PVC es realizada en el exterior y colocada en el alojamiento de forma manual.

Las ventajas principales son la eliminación total de la zanja (ya que la maquinaria se introduce por el pozo de registro), la posibilidad de rehabilitación de cualquier diámetro y la ausencia de almacenamiento de la tubería.

\subsection{Métodos con rotura de tubería}

Agrupadas bajo el término de técnicas con rotura de tubería se distinguen aquéllas en las que la rotura se debe a la apertura y cierre de un cabezal accionado hidráulicamente pipe bursting, a la percusión pipe cracking o a una cuchilla pipe splitting. Pueden ser utilizadas para mantener el diámetro de la antigua conducción o se puede utilizar para aumentar el diámetro de la misma hasta un $25 \%$. Se utiliza habitualmente en tuberías de abastecimiento urbano de agua, aunque también puede ser utilizado en redes de saneamiento, gas, etc.

Se puede aplicar a cualquier tipo de material de tubería existente, fundición, hierro, hormigón, PVC, etc. La antigua tubería se renueva y se instala una nueva de polietileno o PVC con una longitud máxima de $80 \mathrm{~m}$ aproximadamente y con un diámetro comprendido entre los 50 y $450 \mathrm{~mm}$.

Se necesita un grupo compresor con la suficiente capacidad de tracción como para poder introducir la nueva conducción, así como un grupo de mezclado de ciertos lodos y bentonita que facilitan la rotura de las diferentes conducciones y refrigeran el sistema de rotura de la conducción antigua.

Requieren una excavación que se utiliza para introducir la tubería y ubicar toda la maquinaria en una zona desde la que se puede iniciar la renovación. Se procede al corte de la tubería tras situar la máquina tractora en uno de los extremos de la antigua conducción (Figura A.31). 


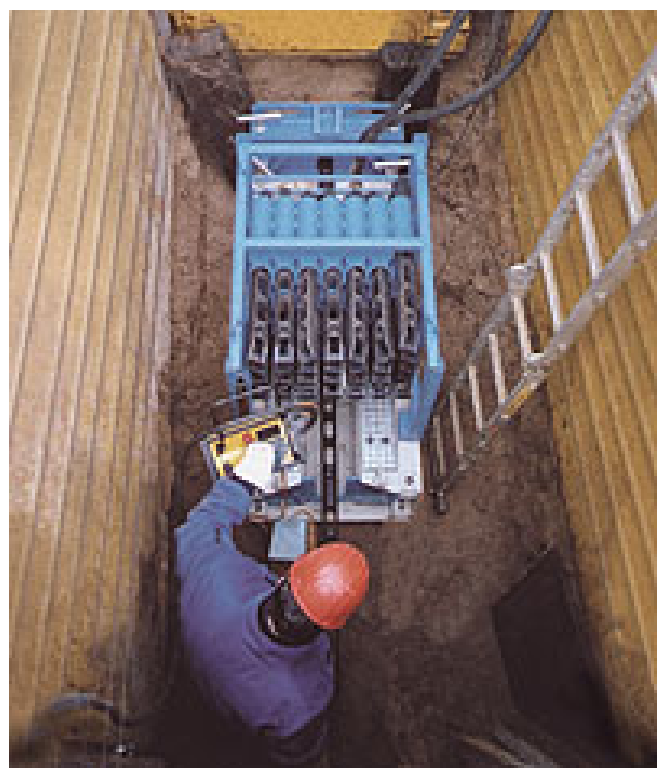

Figura A.31. CATA DESDE LA QUE SE REALIZAN DISTINTAS TÉCNICAS.

Se introduce una pequeña varilla que sirve de guía para la futura conducción y cuando el extremo de la varilla ha llegado al final de la conducción, se sustituye por un cabezal (con el que se aplica la fuerza de tiro que arrastra la nueva tubería), conos de expansión y de compactación.

\subsubsection{Inserción mediante rotura de tubería por apertura y cierre de un cabezal accionado hidráulicamente}

En el caso de los sistemas de accionamiento hidráulico pipe bursting, la cabeza de tiro tiene unas cuchillas de corte que se abren y cierran según la variación de presión de un fluido, Figura A.32. Estas cuchillas se abren para romper la antigua tubería y posteriormente se cierran para permitir el movimiento del cabezal. Se destruye la antigua tubería, que se queda en contacto con la nueva conducción. Detrás del cabezal de tiro, se dispone un cono expansor y fijado a él la nueva tubería.

El cono expansor elimina los trozos de la antigua tubería, aumenta las dimensiones y alisa el agujero por donde se introduce la nueva. También compacta el terreno colindante a medida que avanza la nueva tubería que queda instalada en el mismo alojamiento existente.

La tubería introducida (generalmente polietileno soldado a tope o PVC) se estira por dentro de la antigua conducción según la dirección fijada por la varilla guía que inicialmente se había insertado en la antigua conducción. 


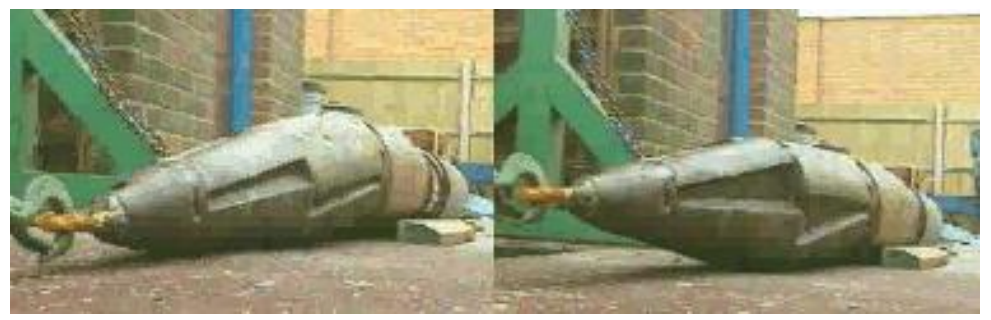

FIGURA A.32. MOVIMIENTO DEL CABEZAL DE TIRO QUE PRODUCE LA ROTURA DE LA CONDUCCIÓN.

Una vez la varilla guía llega a la cata donde fue introducida, se extrae sistemáticamente. Éstas están especialmente diseñadas para que se desmonten fácilmente mediante una unión roscada o una unión específica (Figura A.33). La longitud de cada varilla es de $60-70 \mathrm{~cm}$.
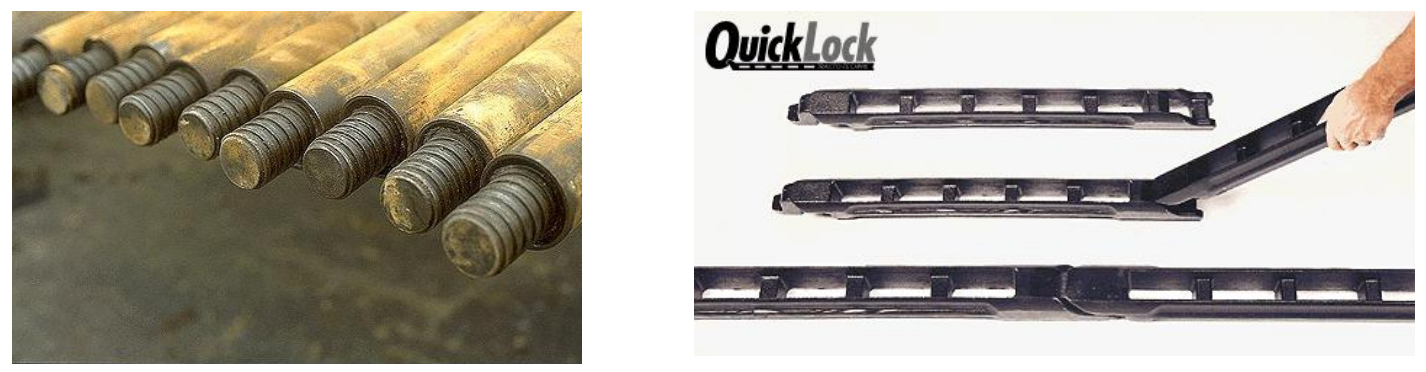

FIGURA A.33. VARILLAS GUÍA DE FACIL MONTADO

El proceso de extracción continúa hasta que aparecen y se desmontan las cuchillas de corte, el cono expansor y la pieza que engancha la tubería de polietileno.

Tras la instalación de la tubería, se obturan los dos extremos y se realiza una prueba de estanqueidad con la que se comprueba el estado de la tubería instalada.

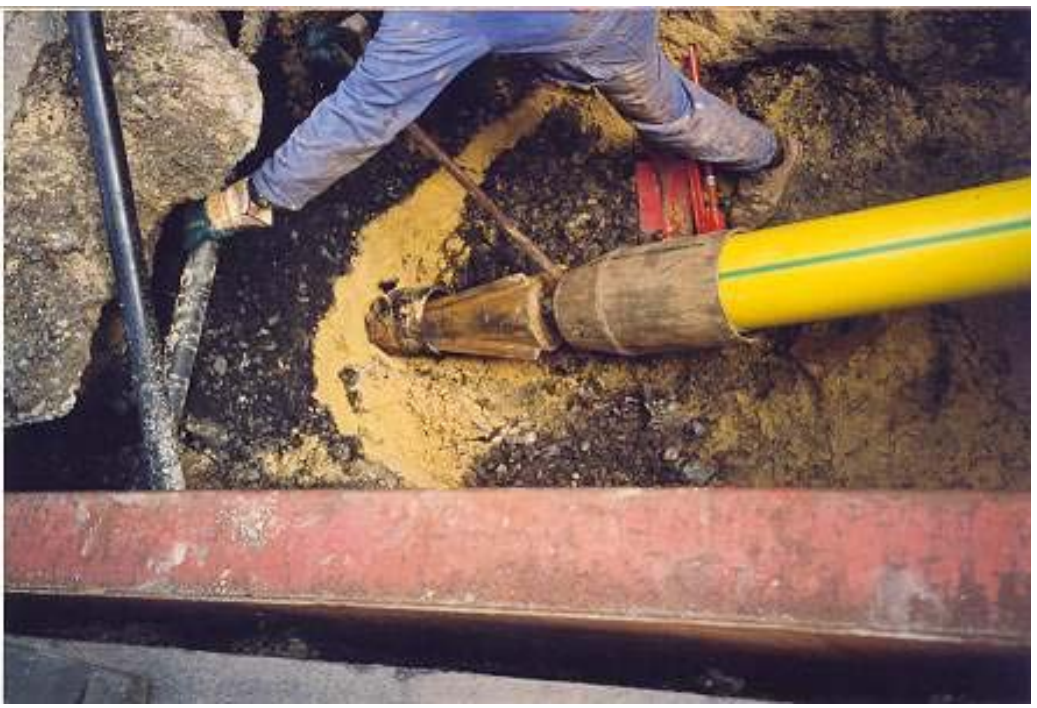

FIGURA A.34. UNIÓN DEL CABEZAL DE TIRO Y LA PIEZA UTILIZADA PARA EL ENSANCHAMIENTO. 
Esta técnica se suele emplear en tanto en redes de saneamiento como en abastecimiento, y para un rango de diámetros comprendidos entre los 150$1000 \mathrm{~mm}$. La longitud máxima de tubería que se puede renovar es de aproximadamente 150-200 m, aunque se recomienda que la longitud máxima no sea superior a $80 \mathrm{~m}$. Esta limitación en cuanto a longitud provoca un mayor número de catas para poder renovar el tramo total de tubería, siendo este hecho un factor determinante a la hora de estimar la viabilidad económica de esta técnica.

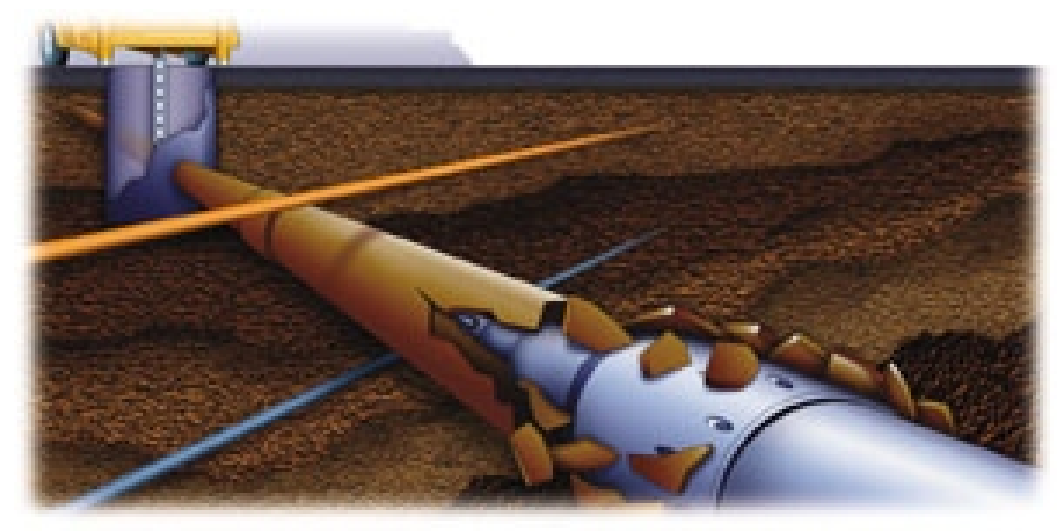

FIGURA A.35. INSERCIÓN DE NUEVA TUBERÍA CON ROTURA DE LA ANTIGUA CONDUCCIÓN CON MOTOR ACCIONADO HIDRÁULICAMENTE.

La principal ventaja reside en la ausencia de vibraciones debido al modelo estático de operación. Los esfuerzos que sufre la nueva tubería son claramente inferiores a los resultantes de otras técnicas (por ejemplo pneumatic pipe bursting descrita en el apartado 3.4.2).

\subsubsection{Inserción de tubería mediante rotura por percusión}

Si el motor de accionamiento del cabezal de rotura es de tipo neumático, la técnica de denomina inserción de tubería mediante rotura por percusión, pneumatic pipe bursting o crack. Se caracteriza por la fractura por percusión de la antigua tubería por efecto de un equipo neumático. La nueva tubería puede ser de polietileno, acero dúctil y fundición. Este proceso requiere que la nueva tubería se haya soldado y se introduzca en su totalidad. Este mecanismo de inserción es más agresivo que el anterior y que afecta más al terreno. 


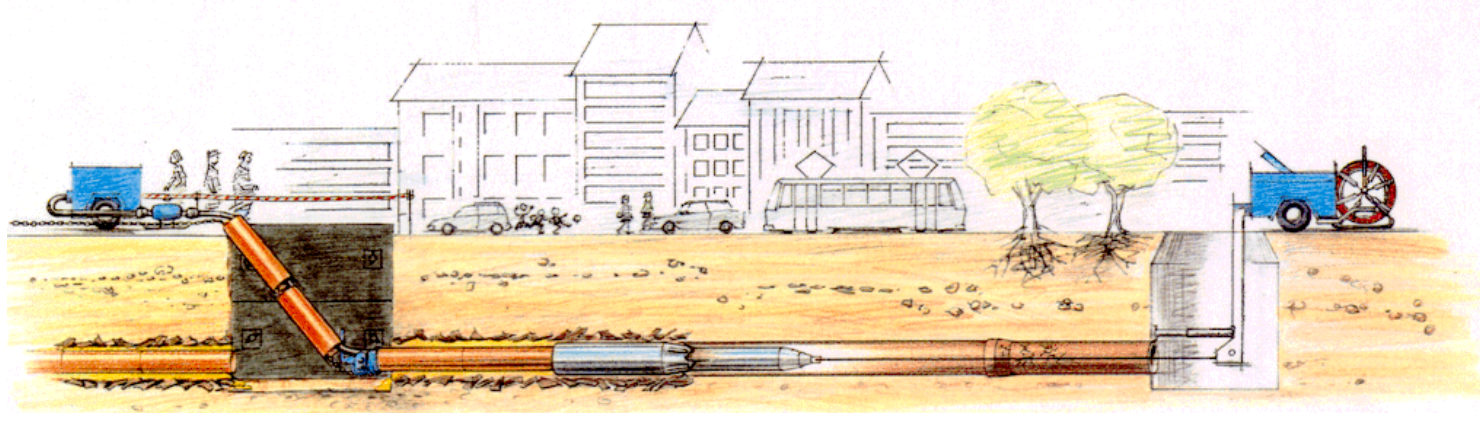

FIGURA A.36. INSERCIÓN DE NUEVA TUBERÍA CON ROTURA DE LA ANTIGUA CONDUCCIÓN CON MOTOR ACCIONADO NEUMÁTICAMENTE.

Por tanto, se instala una varilla (guiado), un ensanchador (ensanchado del agujero, alisado y compactado del terreno) y la nueva tubería. Esta técnica está encaminada principalmente hacia tuberías a presión y para diámetros entre los 100 y los $500 \mathrm{~mm}$. La longitud característica de la aplicación es de $80 \mathrm{~m}$.

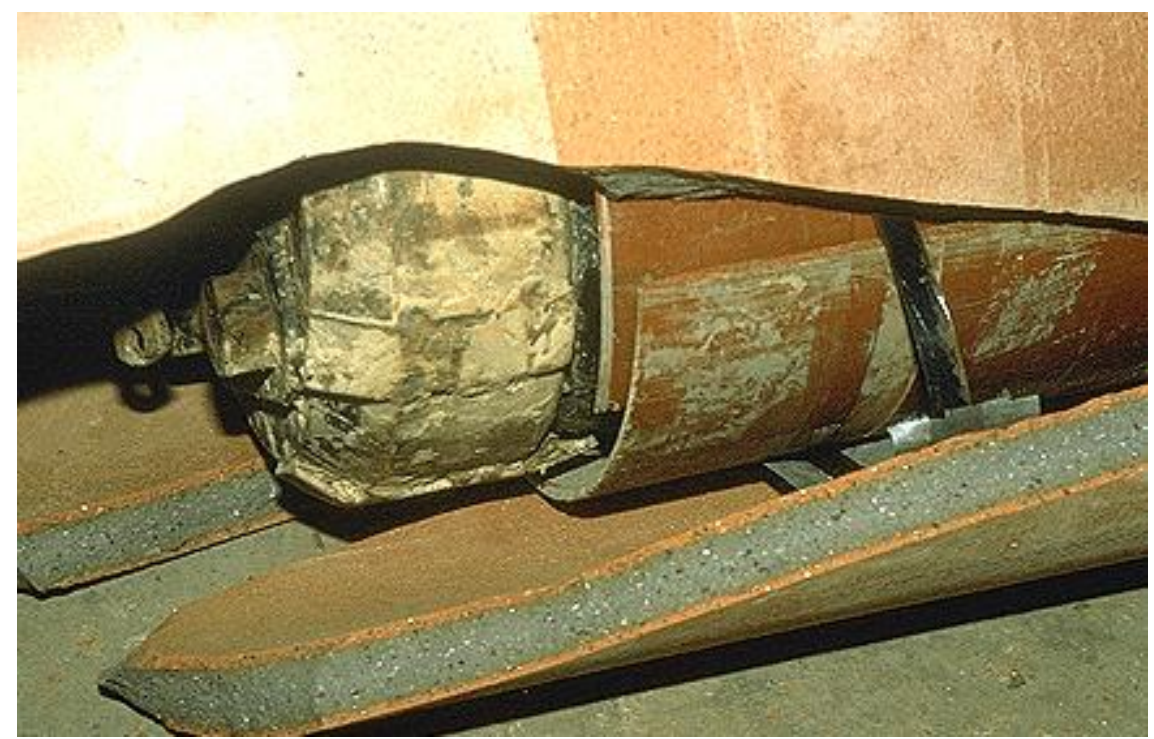

FIGURA A.37. CABEZAL DE TIRO QUE PRODUCE UNA ROTURA EN LA TUBERÍA MEDIANTE PERCUSIÓN NEUMÁTICA. 


\subsubsection{Inserción mediante rotura de tubería con cuchilla}

La inserción mediante rotura de tubería con cuchilla o pipe splitting es una técnica ligeramente diferente a las dos anteriores. Se ha desarrollado específicamente para reparar tuberías de acero en abastecimientos de agua (solo exige que la antigua tubería sea dúctil). El sistema de funcionamiento es el mismo que en los sistemas de renovación de tuberías con rotura de la conducción existente, pero varía dicho sistema de rotura. El cabezal está compuesto por un conjunto de discos que se introducen dentro de la tubería y por una cuchilla que corta la tubería en dos.

Una vez la cuchilla rompe la tubería, un cono expansor aumenta la incisión realizada con la cuchilla. De este modo, la velocidad de ejecución de la reparación de la tubería es mayor. El diámetro de la conducción puede aumentar, aunque la superficie de terreno que se desplaza puede ser un problema en terrenos duros de difícil compactación.

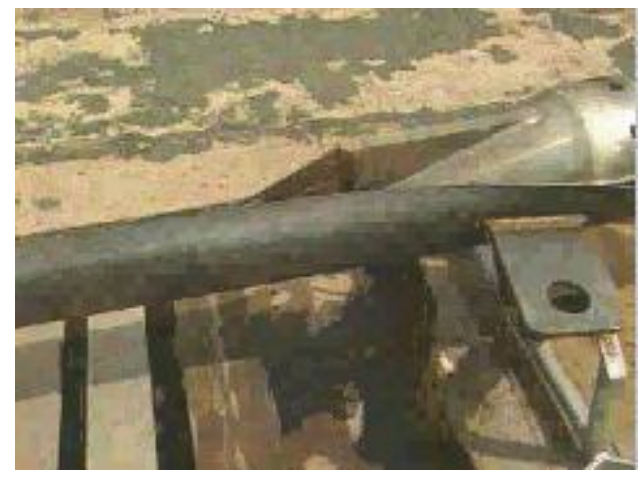

FIGURA A.38. EJEMPLO DEL CORTE DE TUBERÍAS MEDIANTE UNA CUCHILLA.

La longitud máxima de tubería a reparar es de $150 \mathrm{~m}$ y los diámetros posibles entre 50 y $150 \mathrm{~mm}$. El material utilizado en el nuevo tubo es polietileno.

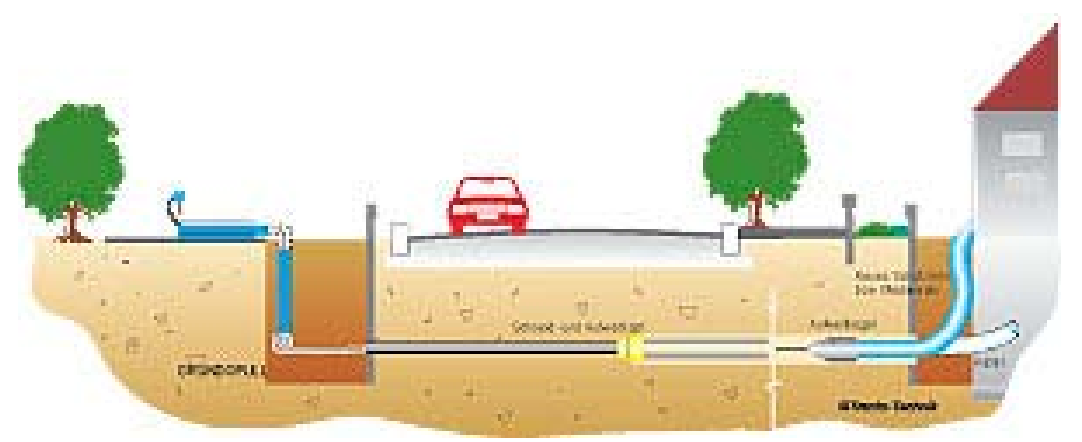

FIGURA A.39. ESQUEMA GENERAL DE LA TÉCNICA INSERCIÓN MEDIANTE ROTURA DE TUBERÍA CON CUCHILLA. 


\subsection{Instalación de nuevas tuberías}

En esta clasificación es importante distinguir entre perforación con y sin control de la dirección de la misma. Asimismo, dentro de la perforación no dirigida se distinguen los dos grupos siguientes:

- Perforación sin necesidad de extracción del terreno, simplemente se desplaza y comprime al paso de la máquina.

- Métodos con extracción del terreno excavado.

En España, las más conocidas son las hincas por empuje hidráulico de tuberías de hormigón para saneamiento y la hinca de acero (o camisa de chapa por barrenado).

\subsubsection{Perforación horizontal dirigida}

Cuando se quiere instalar una nueva conducción y no es posible la apertura de una cata (bien porque se quiere atravesar una carretera, un río o simplemente no se desea afectar un enclave concreto), existe una técnica relativamente novedosa que es la perforación horizontal dirigida. Esta técnica puede ejecutarse con materiales como acero, polietileno o fundición dúctil, adaptando el proceso de perforación a los radios de giro admisibles según el material.

Para realizar una adecuada perforación horizontal, es muy importante un correcto estudio del terreno donde se va a ejecutar la obra. En este primer estudio se busca la obtención de datos acerca de los diferentes estratos que conforman el terreno, utilizando sistemas de georradar que permitan conocer adecuadamente la presencia de otras conducciones, zonas de mayor dureza, etc. Otras técnicas empleadas para la realización de una completa zona topográfica, podrían ser catas y sondeos con recuperación de testigo (siendo éste el único contacto real que se tiene con los estratos a perforar). 


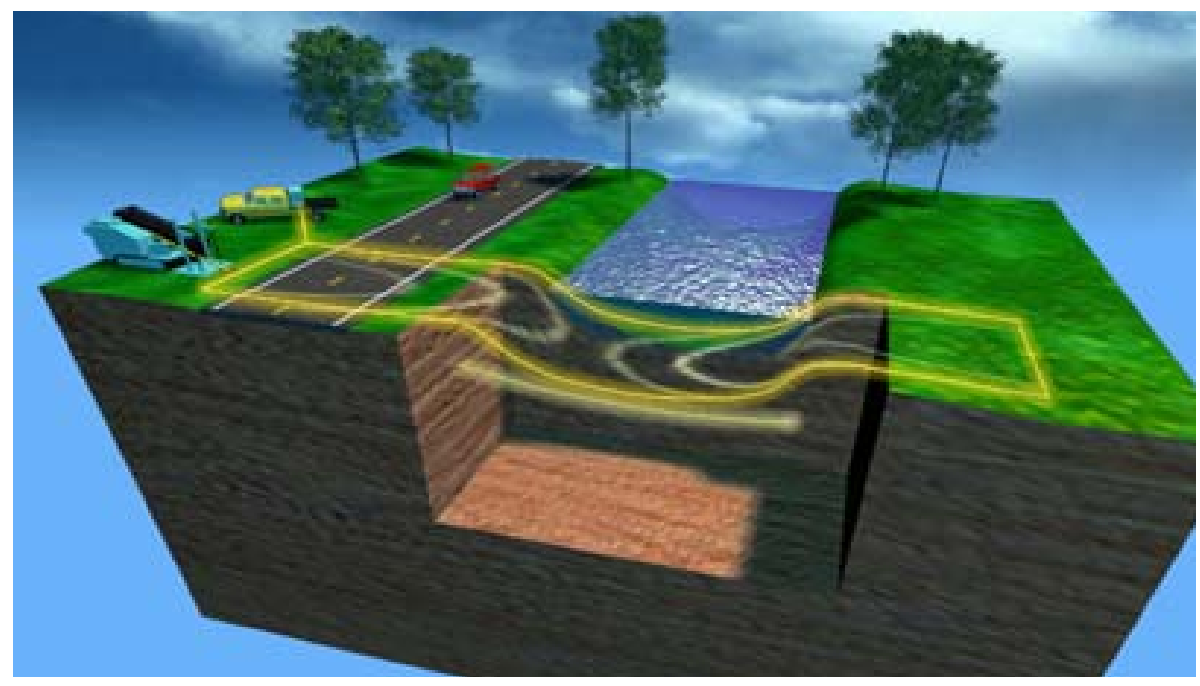

FIGURA A.40. EJEMPLO DEL ESTUDIO DEL TERRENO PREVIA A LA REALIZACIÓN DE LA PERFORACIÓN HORIZONTAL DIRIGIDA.

Posteriormente, se procede a un análisis detallado de estas condiciones del terreno. Este proceso es de vital importancia, ya que permite la elección de la maquinaria adecuada para cada obra concreta, la trayectoria que deberá seguir el piloto en la excavación y la gestión de los distintos elementos adicionales que son necesarios en los procesos de perforación.

Se abren dos catas, una de entrada (en el lado de la máquina) y otra en el lado de salida para el control y almacenaje de los lodos. Si el terreno es blando, se equipa una lanza con un cabezal especial, mientras que si el terreno es duro se necesita mayor potencia en el extremo del varillaje. La potencia se transmite a través del fluido utilizado en la perforación. Este sistema evita el martilleo, precisamente por la perforación progresiva que realiza.

Los lodos mantienen el material excavado en suspensión, y evitan que el conjunto lodo y material excavado se pierda por poros u otras discontinuidades. Según las características que se deseen conseguir se utilizan diversos tipos de lodos, orientados a mantener el detritus ${ }^{9}$ en suspensión, o con especial función como sellante o simplemente como agente refrigerante y lubricante, etc.

${ }^{9}$ El detritus es el material excavado resultante. 
Una vez se han decidido todos estos parámetros, se moviliza la maquinaria y se realiza la perforación piloto que sigue la trayectoria inicial fijada con un cabezal móvil que permite cambios de dirección según se vaya realizando la obra. A veces se realiza la perforación simultánea de dos pilotos desde el exterior y se encuentran en una posición intermedia. La maquinaria utilizada para realizar la perforación horizontal dirigida requieren fuerzas de tracción del orden de 450 hasta $2500 \mathrm{KN}$. La velocidad de penetración del piloto es de $15-250 \mathrm{~m} / \mathrm{h}$, aunque depende de las condiciones geológicas del terreno. El tipo de cabezal depende de la dureza del terreno, así para rocas se emplean los triconos (Figura A.41) y para entonos blandos y plásticos se emplean fly-cutters.

Posteriormente, se ensancha la perforación inicial. Para ello, se emplean nuevos cabezales que aumenten progresivamente la perforación inicial. Se utilizan diferentes escariadores según la dureza del terreno, aunque los más comunes son los escariadores con forma de barril barril reamer que se recomiendan en terrenos de baja dureza.

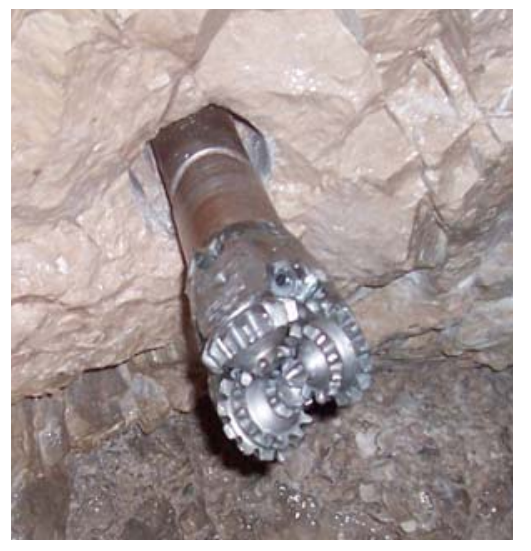

FIGURA A.41. CABEZAL UtILIZAdos PARA LA EXCAVACIÓN EN ROCA. 


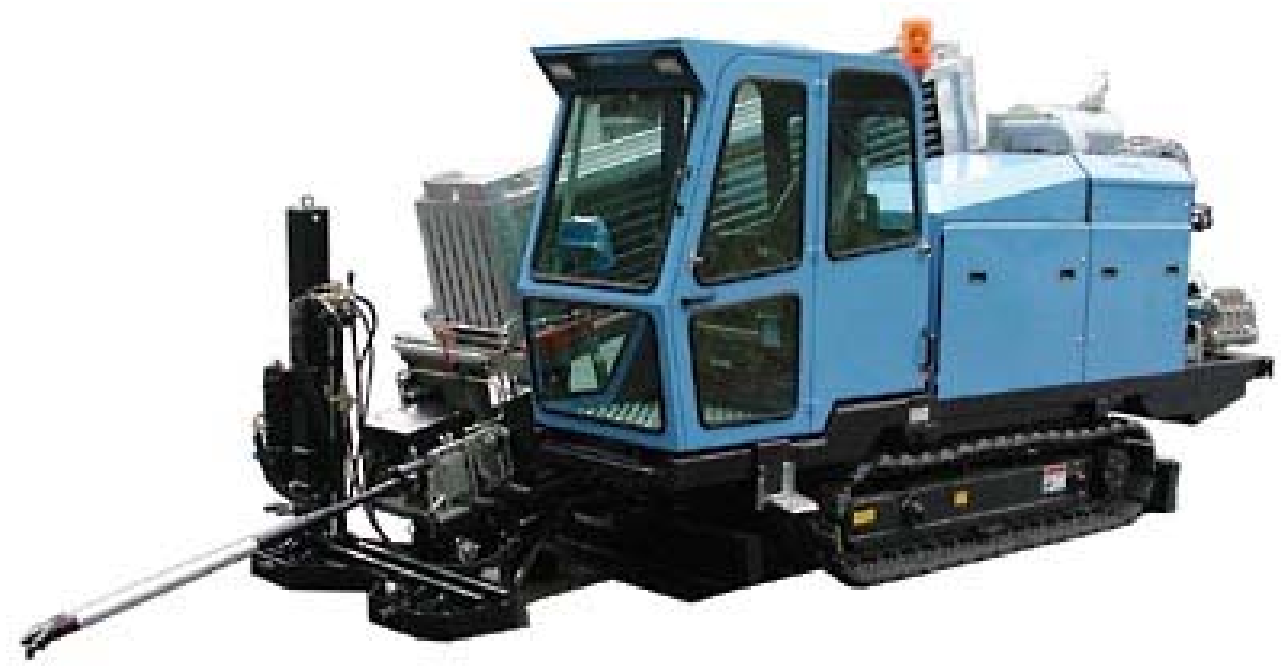

FIGURA A.42. MÁQUINA UTILIZADA PARA PERFORACIÓN HORIZONTAL DIRIGIDA.

El túnel excavado se queda relleno de agua y lodos con el fin de asegurar una determinada presión hidrostática que impida derrumbamientos. Esto justifica el objetivo del fluido como material sellante, para que no escape por poros u otras discontinuidades.

La tubería se debe montar perfectamente alineada en un proceso realizado en paralelo con la excavación, y poder realizar así una prueba de estanqueidad previa a la inserción de la tubería en su emplazamiento posterior.

En este instante se procede con la introducción de la nueva tubería. Ésta se arrastra con un cabezal de tiro y un último ensanchador o escariador, que asegura una perforación completamente cilíndrica. El cabezal de tiro permite mantener un registro de la tracción realizada a lo largo de todo el proceso. Por tanto, se tiene constancia del esfuerzo máximo que se debe realizar para la completa instalación de la conducción. Se puede realizar una prueba previa a la introducción de la tubería consistente en desplazar la futura conducción durante un tramo concreto y aplicando la máxima fuerza de arrastre. Así se comprueba el correcto funcionamiento del cabezal de tiro y se evitan posibles problemas en el interior de la perforación. 
Entre la borna de tiro y el cabezal, se instala un accesorio de unión rodante que permite un movimiento de giro para facilitar el movimiento y proteger a ambas. Por último, se inserta la tubería. Este proceso se realiza de diversas maneras en función del material de la misma. Si el material de la tubería es de acero soldado o polietileno, la tubería se debe encontrar dispuesta de manera que se minimicen los esfuerzos que sufren las conducciones en el proceso de inserción. La longitud máxima de la perforación sería de aproximadamente $1500 \mathrm{~m}$, el rango de diámetros estaría comprendido entre 100-1500 mm.

\subsubsection{Perforación no dirigida sin extracción del terreno}

En aquellos sistemas de instalación en los que no hay posibilidad de dirigir la perforación, la precisión de la misma se verá influida por las propiedades del terreno, estratificación, inclusiones y la longitud total. Se tiene que recoger la información suficiente sobre la existencia de otros servicios, con objeto de evitar posibles daños. Las dos técnicas que aquí se detallan son la perforación horizontal por impacto y por empuje y expansión. Éstas solo se emplean en terrenos que se puedan compactar.

La primera se caracteriza por la inserción de un cilindro metálico propulsado por un equipo neumático, accionada por un compresor (ello requiere la realización de una cata para introducir y extraer el equipo neumático). En la parte posterior del cilindro se sujeta la tubería que se introduce en el terreno arrastrado y deja tras de sí un túnel donde queda colocado el tubo. El primer tubo, lleva un aro de corte que facilita la penetración del mismo en el terreno.

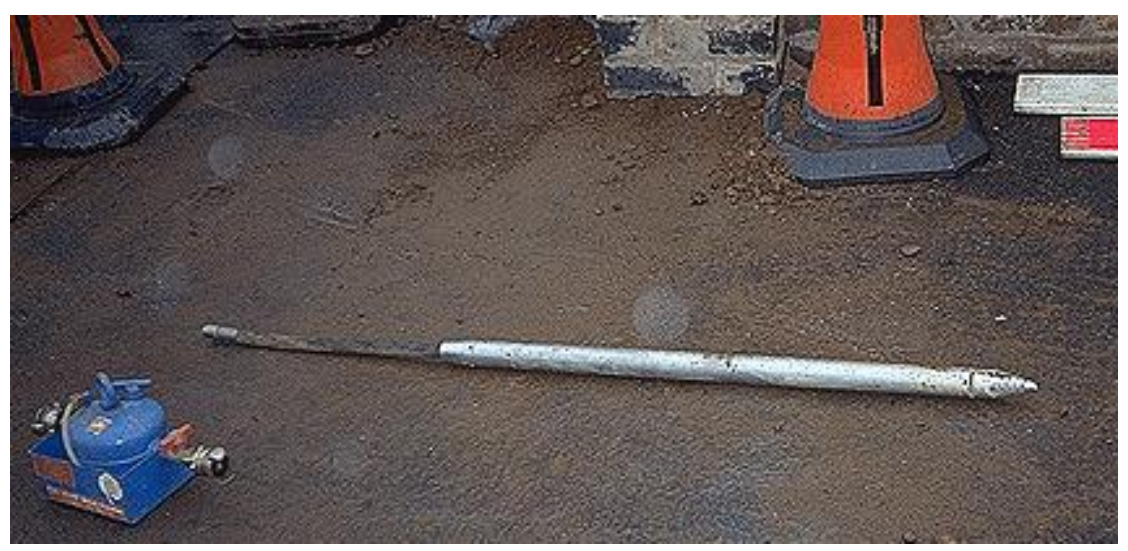

FIGURA A.43. CiLINDRO METÁLICO QUE SE INSERTA EN EL TERRENO. 
La tubería que se instala será acero, polietileno (en bobina o bien soldado a tope) o de un tipo de PVC (con mayor resistencia a los esfuerzos de tracción). Esta técnica se aplica para diámetros entre los $45 \mathrm{~mm}$ y $180 \mathrm{~mm}$. La longitud máxima de instalación depende del diámetro $(15$ m para el diámetro menor y 70 m. para el mayor).

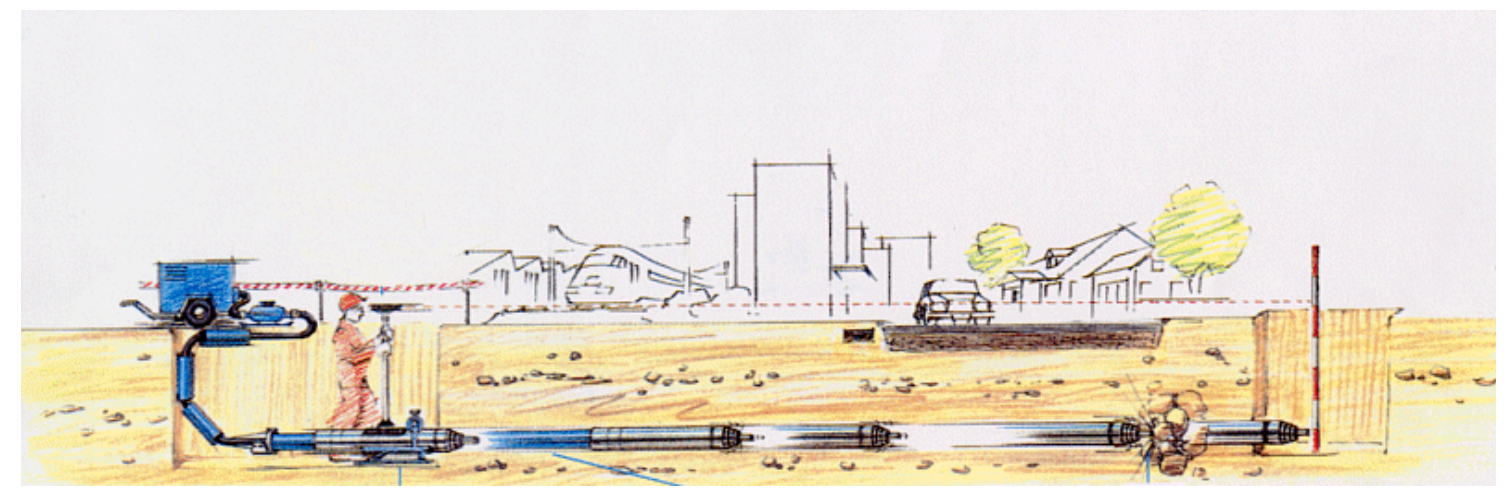

Figura A.44. PERFORACIÓN HORIZONTAL POR IMPACTO.

Esta técnica con estos materiales presenta como principales ventajas:

- Rapidez: Se alcanzan velocidades medias de 7 a 12 metros cada hora en función del tipo de terreno: la ejecución de un cruce de, por ejemplo, $15 \mathrm{~m}$. de longitud, necesita tan sólo de cuatro horas, incluyendo la realización de las catas.

- Limpieza de obra: al no haber productos de excavación, ni acopios de zahorras o arenas para relleno.

El método conocido como perforación horizontal por impacto es similar a la técnica de renovación de redes con rotura de tubería denominada inserción de tubería mediante rotura por percusión o crack (de hecho, esta última técnica se considera heredera de la hinca por percusión y la única diferencia que hay entre ambos es el tipo de cabezal instalado (de rotura para substitución y de apoyo para la hinca).

La perforación por empuje y expansión es una técnica muy similar a la técnica conocida como burst. Un cilindro hidráulico empuja una barra maciza y rígida, hincándola en el terreno. Sucesivamente, se van uniendo más barras que vuelven a ser empujadas. La principal diferencia con respecto a otros métodos consiste en que el empuje es de tipo constante y no percutor. 
Posteriormente, en el extremo de la primera barra se coloca un cono ensanchador del terreno, que forma así un túnel donde instalar la conducción, consiguiendo instalaciones de diámetros menores de $150 \mathrm{~mm}$ y longitud hasta $50 \mathrm{~m}$. Debido a la manera de incrustación del cabezal, la longitud de aplicación de esta técnica es pequeña y no se puede emplear en terrenos duros.

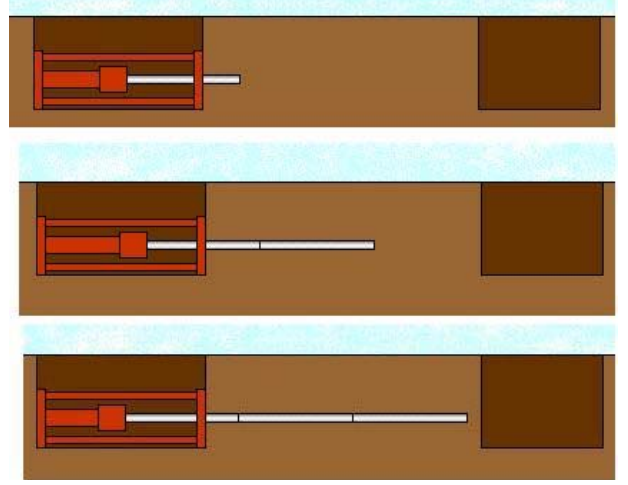

FIGURA A.45. EJEMPLO DE LA PERFORACIÓN POR EMPUJE.

\subsubsection{Perforación no dirigida con arrastre del terreno}

Se consideran dentro de esta clasificación de perforación no dirigida con arrastre del terreno, técnicas como son hinca de tubería de acero o pipe ramming, Inserción de tubería mediante el taladro con tornillo sin fin o auger boring e hinca de tubería de hormigón o pipe jacking.

La hinca de tubería de acero consiste en la introducción en el terreno de una tubería a través del subsuelo por la fuerza que le imprime un martillo neumático. Ésta debe ser capaz de aguantar los esfuerzos producidos, por lo que el espesor es un parámetro de diseño muy importante.

En principio, se realiza un estudio del suelo sobre el que se quiere realizar la instalación de una nueva tubería. Habitualmente se realiza una inspección mediante georradar, o con sondas testigo para obtener los detalles relativos a la composición del suelo.

A continuación, se realiza una cata en el suelo que permita la introducción de la maquinaria adecuada ( $3 \times 3$ metros es suficiente para una instalación de una tubería de $300 \mathrm{~mm}$ ). Desde esa cata se tiene un acceso permanente al frente de la excavación, con un control total del terreno y de la dirección de la hinca. 


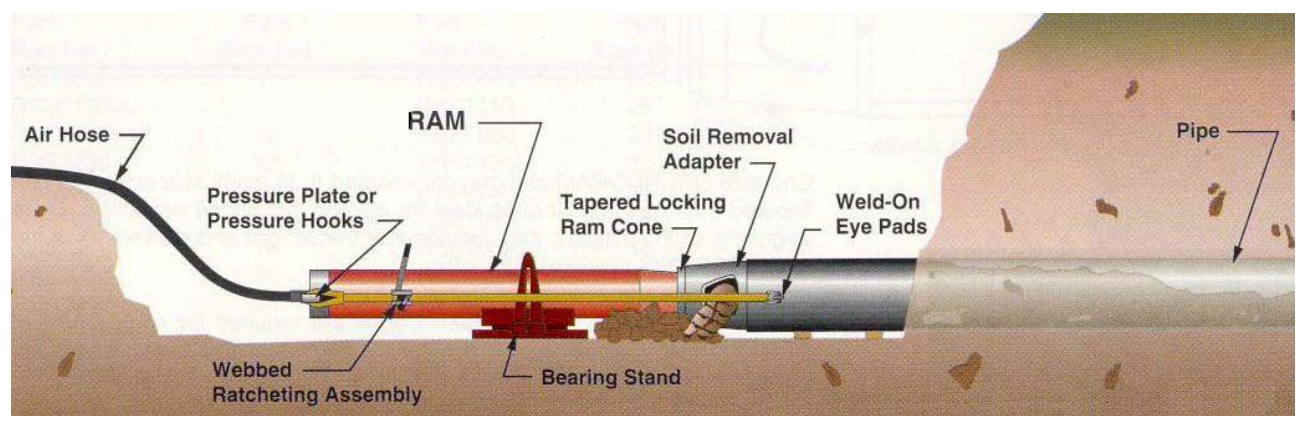

FIGURA A.46. ESQUEMA DE LA HINCA DE TUBERÍA DE ACERO.

Se debe instalar un cono que sirva de unión entre la tubería y la parte sobre la que se aplica la fuerza el dispositivo neumático, así como para prevenir la deformación de la tubería (Figura A.46).

Una vez se sitúa la tubería en la cata de entrada (esto requiere un soporte especial de apoyo de la tubería), se determina la dirección a seguir por la misma, se añade el equipo neumático y la perforación puede comenzar. El equipo neumático nunca se introducirá en el terreno y siempre permanecerá en la cata de entrada. Durante la perforación, el interior de la camisa de chapa se llena del terreno original y se este material se elimina por aire o agua a presión. Una vez limpio el interior de la camisa, se instalará la conducción deseada.

Si la longitud de la tubería instalada es elevada, tras la introducción de una parte de la conducción, se quita el dispositivo neumático y se une un nuevo tramo de tubería (generalmente por soldadura) y el hincado de la tubería continúa hasta finalizar la instalación.

La mayoría de los procesos no requiere la inyección de líquidos para realizar la perforación, aunque en algunos terrenos (arcillosos o arenosos) la inyección exterior e interior de líquidos lubricantes se convierte en necesario (refrigerantes para facilitar el movimiento del terreno, o reducir la fricción o mantener la integridad del agujero realizado). Entre cada tubería se coloca una sufridera de aglomerado, de forma que reparta los esfuerzos del empuje y evite que las imperfección de las caras en contacto provoquen tensiones puntuales.

Este sistema es complementario al comentado de perforación horizontal por impacto, pues aquel alcanzaba, como mucho, diámetros de $180 \mathrm{~mm}$ mientras que con este procedimiento se abarca desde los $200 \mathrm{~mm}$ hasta los $2.000 \mathrm{~mm}$ y con una longitud máxima de 150 m (longitud habitual de la instalación 100 m). 
La tubería vibra por la aplicación de la fuerza de percusión. Estas vibraciones no han sido estudiadas aunque sus efectos son iguales a los producidas por otras técnicas como perforación por impacto (en la que son rápidamente atenuadas) y no causan ningún daño a las instalaciones colindantes. La vibración se puede considerar despreciable a una distancia de dos ó tres diámetros nominales de distancia desde el origen de la vibración para elementos enterrados (como otras tuberías) y aproximadamente ocho diámetros para estructuras.

Como no hay desplazamiento de volumen de tierra, se reduce el riesgo de grietas o movimientos en la superficie. Esta técnica se utiliza típicamente para cruzar carreteras, vías del tren y ríos.

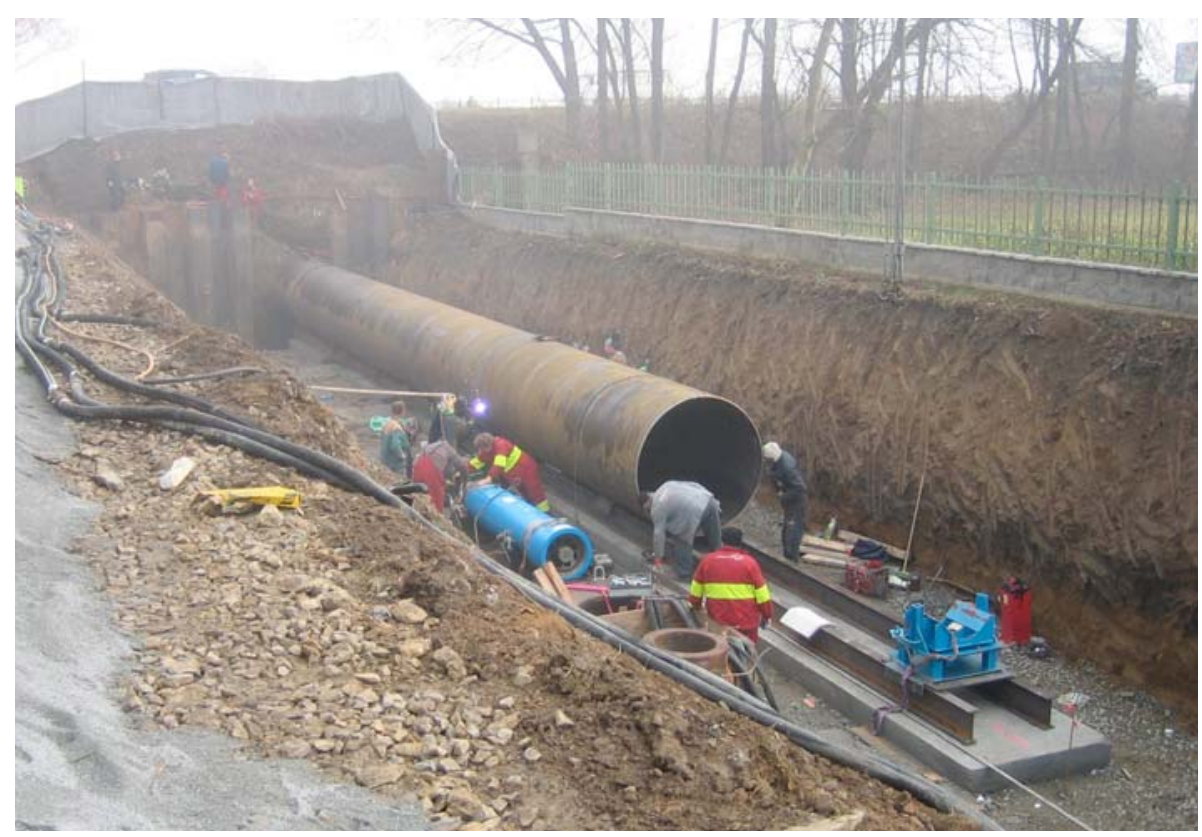

FIGURA A.47. HINCA DE TUBERÍA DE ACERO DE 1800 MM QUE CRUZA UNA AUTOPISTA EN PRAGA, DICIEMBRE DE 2006.

La técnica conocida como inserción de tubería mediante el taladro con tornillo sin fin o auger boring es muy común para la instalación de tuberías de acero. Se caracterizan porque las varillas perforación son unos tornillos de Arquímedes (Figura A.48). La forma helicoidal sirve para aprovechar el movimiento de rotación del cabezal cortante y provocar la extracción del detritus excavado. Estas varillas se encuentran dentro de una tubería de acero que es la que se inserta en el agujero creado gracias a la perforación producida por el cabezal. 


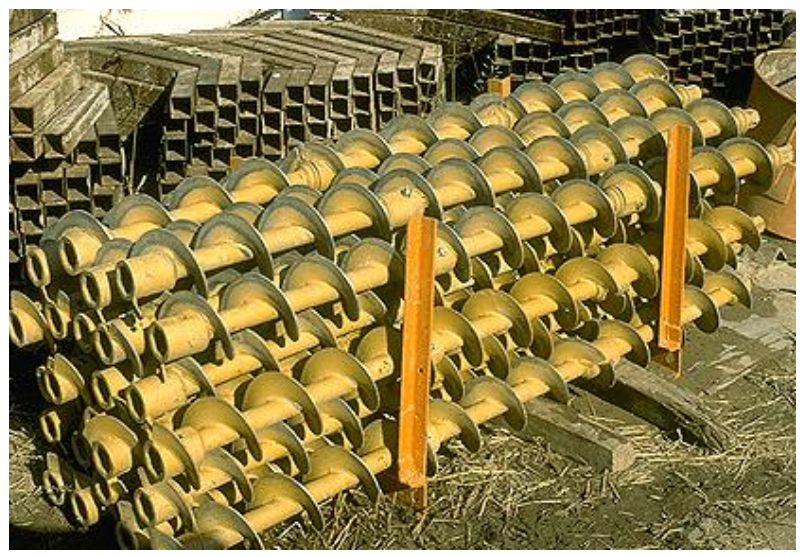

FIGURA A.48. VARILLAS EMPLEADAS EN LA TÉCNICA INSERCIÓN DE TUBERÍA MEDIANTE EL TALADRO CON TORNILLO SIN FIN.

Esta técnica sigue una dirección fija desde la cata de inserción de la maquinaria. Sin embargo, a veces la presencia de rocas o zonas duras pueden provocar cambios de la dirección de la perforación. Estos cambios de dirección se han conseguido corregir con la articulación de la varilla y tubería que se encuentra más cerca del cabezal de corte (Figura A.49).

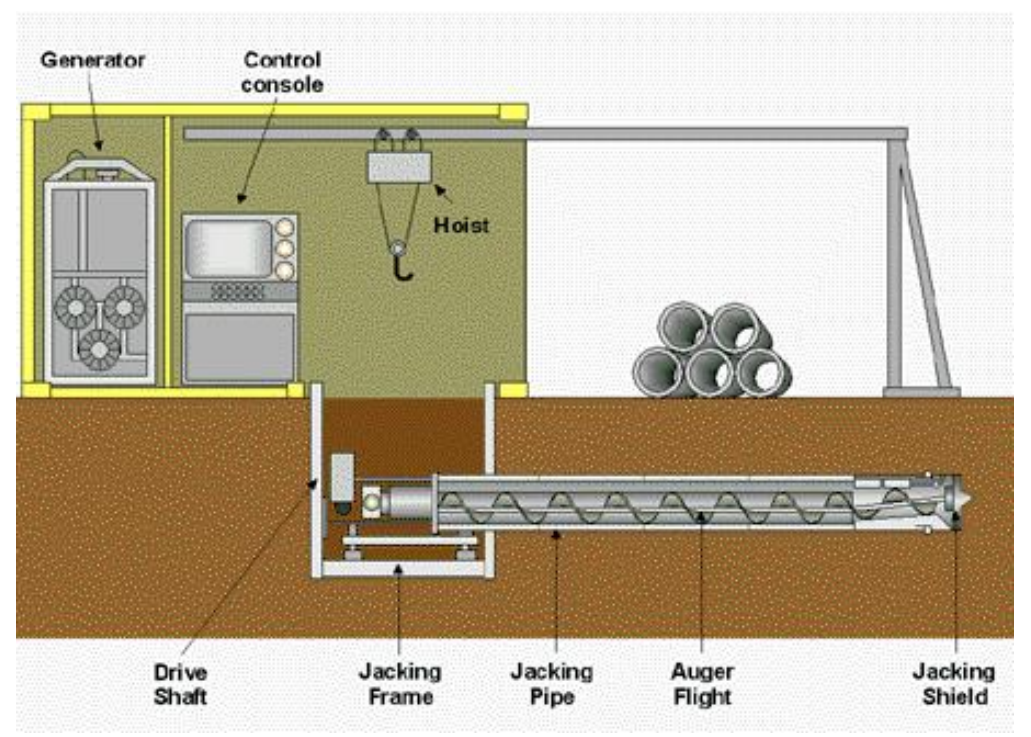

FIGURA A.49. ESQUEMA DE INSERCIÓN DE TUBERÍA MEDIANTE EL TALADRO CON TORNILLO SIN FIN.

La principal limitación de esta técnica son los problemas derivados de la aplicación de la misma cuando existen terrenos duros, por lo que es muy importante el estudio previo del terreno. La longitud típica de perforación es $60 \mathrm{~m}$ y el rango de diámetros está comprendido entre 150 y 1500 mm.

Una variante de ésta consiste en realizar la perforación sin la introducción de la tubería (free boring) aunque se emplea para diámetros más pequeños entre 50 y 150 mm y presenta el problema de que colapse la perforación. 
Por último, la hinca de hormigón o pipe jacking se utiliza para diámetros comprendidos entre 700 y hasta 1800 mm y con una longitud típica de 80-120 m. Para ello, se realiza una cata desde donde se posicionan los dispositivos que producen la excavación. El avance de la tubería se produce por empuje mediante pistones hidráulicos con una fuerza tractora de hasta 1000 toneladas. El cabezal de ataque, es un tubo metálico, de cantos biselados, orientable, para poder corregir en lo posible las desviaciones que pudieran existir. Este cabezal Ileva acoplado un elemento de corte o rozadura para ir abriendo el agujero necesario.

Una vez hincado el cabezal de ataque, se coloca posteriormente, los tubos de hormigón, que son empujados simultáneamente al avance de la perforación, con el objeto de no descomprimir el terreno.

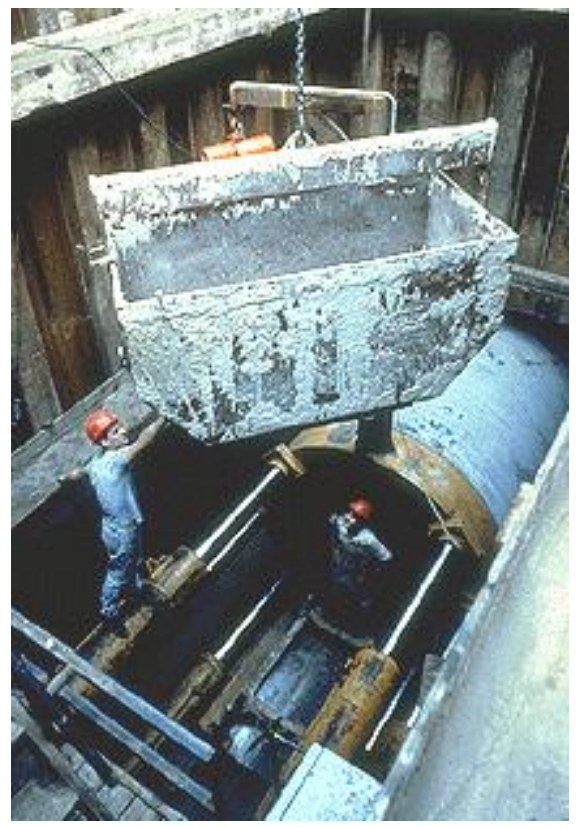

FIGURA A.50. DISPOSITIVOS HIDRÁULICOS DE PERFORACIÓN.

El detritus es enviado a una cinta transportadora, que a su vez carga unas vagonetas que son evacuadas a la superficie después de recorrer el interior de los tubos de hormigón (Figura A.50).

La longitud máxima de una hinca de este tipo viene dada por la resistencia de los tubos, la fricción del terreno y la fuerza de empuje de los pistones. En caso de ser necesario, se utilizan estaciones intermedias, las cuales se colocan entre dos tubos de hormigón especialmente diseñados para este fin. También se puede utilizar otro dispositivo para añadir lubricante, de manera que se reduce la fricción del orden del $20-50 \%$ aplicando bentonita a la cara externa de la tubería de hormigón. 


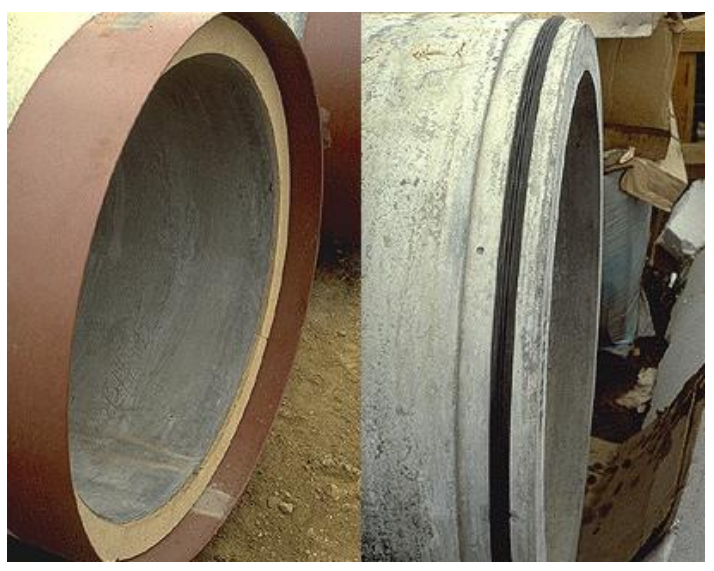

FIGURA A.51. TUBERÍAS MACHO Y HEMBRA UTILIZADAS EN LAS HINCAS.

Esta técnica puede disponer de un sistema de control de la dirección por láser. Durante la inserción de la tubería, el operario puede comprobar la señal entre el cabezal y el punto de control, de forma que si se detecta una desviación, se puede articular ligeramente la cabeza para proseguir con la alineación deseada.

El terreno adecuado para la esta técnica de perforación es el terreno compacto, aunque también es posible la utilización en suelos inestables en los que se debe eliminar el agua y sistemas para igualar la presión en el terreno. 


\subsection{Características generales de la renovación de tuberías con técnicas sin zanja.}

Una vez descritas las principales técnicas de renovación sin zanja, se pretende analizar sus características generales. Sin duda, estas técnicas amplían las posibilidades de renovación y su introducción en el mercado se debe a las ventajas que comportan. En lo que sigue se muestran éstas, así como sus desventajas.

Las ventajas frente al método clásico de renovación y rehabilitación son:

- Causa menores molestias al entorno, desde el punto de vista de tráfico, áreas de trabajo o medioambiental.

- Requiere un menor espacio de trabajo, con lo que existen ciertas mejoras en la seguridad de los operarios.

- Existe la oportunidad de aumentar la dimensión de la antigua tubería.

- Requiere un menor espacio subterráneo, minimizando las posibilidades de interferir con el resto de instalaciones o tuberías abandonadas.

- Se reduce la cantidad de pavimento que se debe reponer, que en costes puede llegar a suponer hasta el $60 \%$ del coste asociado a la obra.

Las desventajas del empleo de las técnicas sin zanja son:

- Pueden necesitar la instalación de una tubería auxiliar como derivación del suministro.

- En algunos casos también se necesita una excavación.

- Los esfuerzos de percusión pueden causar movimientos de tierras, por lo que la reducción de molestias al entorno no siempre es completa.

- No se pueden utilizar todos los materiales existentes en el mercado. También existe limitación en cuanto a longitud y a diámetro, por lo que el proceso de decisión de la elección de la técnica se convierte en fundamental para la realización eficiente de la obra.

- En algunas técnicas se reduce el diámetro de la antigua tubería.

- El control de fugas una vez aplicada la nueva técnica se volverá más complicado, especialmente en técnicas de entubado.

- Algunas técnicas necesitan un tiempo para que se adopten las características definitivas de la tubería. 
Una de las desventajas de las técnicas sin zanja es la limitación de su empleo según diámetro o longitud, algo que no sucede con la técnica tradicional. Estos condicionantes influyen en el precio final de la reparación, y son:

- Longitud de la tubería a reparar (ciertos métodos presentan una limitación de uso marcada por la longitud máxima).

- Rango de diámetros de la conducción que pueden ser reparados o rehabilitados para cada una de las posibles técnicas utilizadas.

- Material de la tubería existente. Cada una de las posibles técnicas a utilizar puede ser válida en función del material de la tubería remplazada o rehabilitada.

- Facilidad de acceso. Algunas técnicas necesitan para su correcta aplicación que la obra presente un fácil acceso a la tubería, por lo que esta limitación impide su uso en múltiples situaciones.

- Limpieza del conducto. Algunas técnicas de rehabilitación necesitan un proceso inicial de limpieza y este proceso se debe considerar a la hora del análisis económico.

- Instalación de tubería auxiliar. Esto sucede en caso de que el coste social de la reparación de la tubería sea muy elevada y por tanto se tenga que disponer una tubería auxiliar que permita el funcionamiento continuo de la conducción que se está reparando.

En estos momentos, el CEN, Comité Europeo de Normalización, se encuentra en fase de elaboración de una norma europea a este respecto (CEN 12889), por lo que en lo que sigue se utilizará en parte la clasificación que en él se hace de las distintas técnicas de instalación. En España, las más conocidas son las hincas de tubería de acero y la de hormigón, empleadas mayoritariamente para el cruce de vías férreas o carreteras.

A continuación se exponen, de manera esquemática, los diámetros (apartado 3.6.1) y longitudes (apartado 3.6.2) en los que se pueden utilizar las técnicas descritas con anterioridad. 
3.6.1 Resumen de la aplicabilidad de las técnicas según el diámetro nominal.

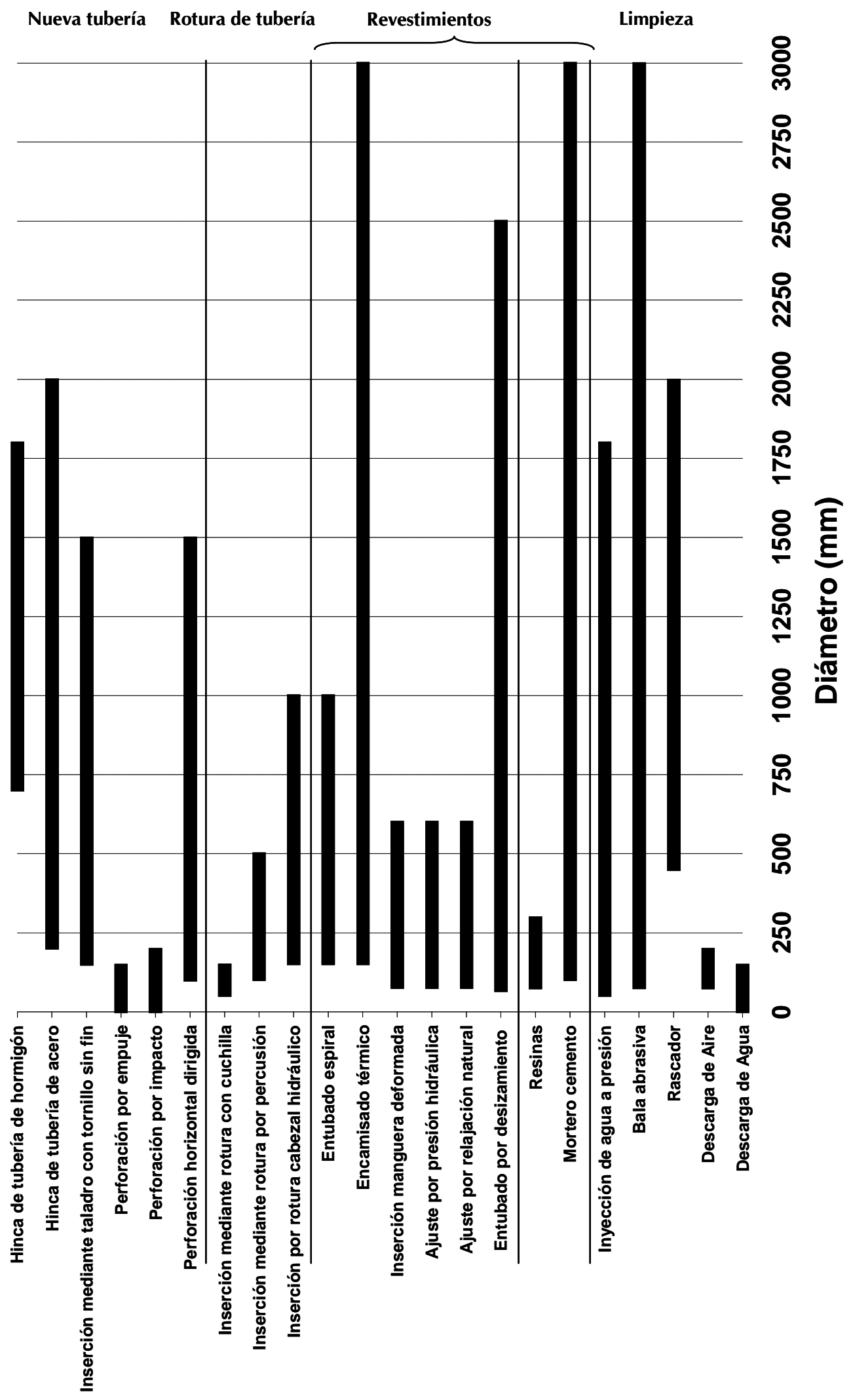

FIGURA A.52. APLICABILIDAD DE LAS TÉCNICAS SEGÚN DIÁMETRO. 
3.6.2 Resumen de la aplicabilidad de las distintas técnicas según la longitud del tramo a rehabilitar.

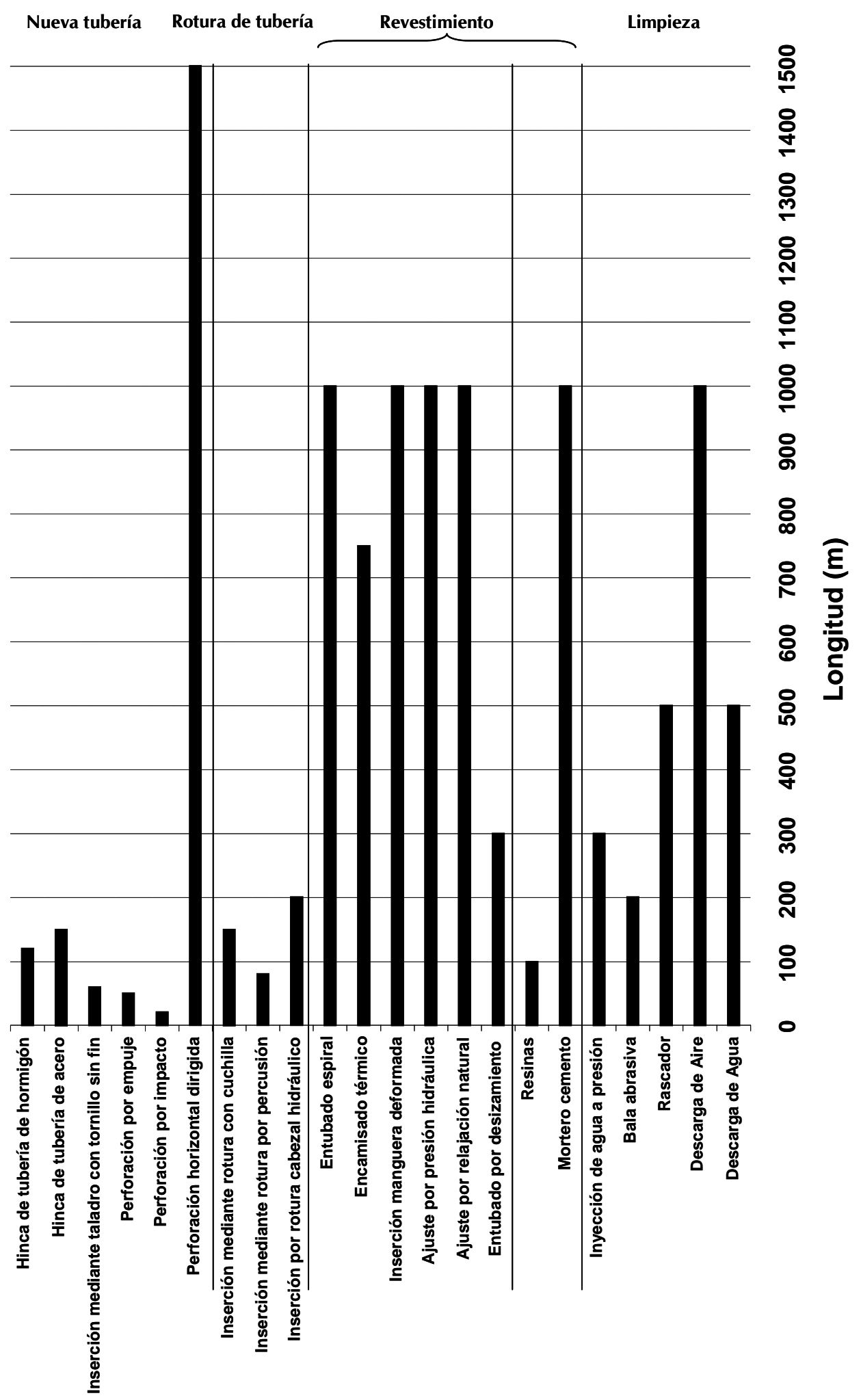

FIGURA A.53. APLICABILIDAD DE LAS TÉCNICAS SEGÚN LONGITUD. 


\subsubsection{Aplicabilidad de las técnicas sin zanja en redes de distribución.}

Existe un amplio abanico de técnicas sin zanja que prolongan la vida de las tuberías en redes de distribución o renovar las mismas. En la práctica, la aplicabilidad de cada técnica se evalúa según las condiciones de la instalación, el coste y la disponibilidad local de la técnica, así como la posibilidad de que la misma cumpla los requerimientos por un largo plazo.

Aunque en la definición de las técnicas se ha comentado la aplicabilidad particular de cada una, se enumeran aquéllas empleadas en redes de agua a presión:

1. Entubado por deslizamiento. Se utiliza con tubería de polietileno de alta densidad, PVC, y poliéster reforzado con fibra de vidrio. Siempre con relleno del espacio anular entre tuberías. Es la única que se puede realizar en España, aunque no está tan implantada como en Estados Unidos, Canadá y Reino Unido (Figura A.21).

2. Encamisado térmico. Generalmente es de aplicación en saneamiento, aunque si el tubo es de polietileno o poliéster reforzado con fibra de vidrio y con resina epoxi también se puede utilizar en abastecimiento. En la actualidad, esta técnica no se encuentra disponible en España, aunque sí en Estados Unidos (en fase experimental).

3. Métodos de ajuste preciso a la tubería. Al igual que las anteriores, su utilización a aguas potables se reduce a los países que han desarrollado esta técnica. La nueva tubería instalada puede ser tanto de poliéster reforzado con fibra de vidrio (la empleada en abastecimiento) como de polietileno (fundamentalmente en saneamiento).

4. Revestimientos internos de mortero de cemento, de resina epoxi y otros revestimientos de poliuretano. Esta técnica se emplea a escala nacional y existen varias compañías que lo realizan en la actualidad.

5. Métodos de inserción mediante rotura de tubería, bien con sistema hidráulico, por percusión o con corte mediante cuchilla.

6. Instalación de nuevas tuberías. Perforación horizontal dirigida, hincas de tubería de acero, hincas de hormigón etc. Son las más empleadas a escala nacional. Éstas ya se han empleado para la instalación de nuevas tuberías que crucen carreteras, caminos, etc. Sin duda, presentan un futuro prometedor aunque se emplean en situaciones excepcionales debido a su elevado precio. Tanto a escala nacional como internacional, son muy empleadas en otros países. 
Una vez enumeradas las técnicas que se pueden emplear en abastecimiento y su utilización actual, se muestran las ventajas presentadas por cada técnica de renovación sin zanja empleada en abastecimiento (Tabla A.2) y el estado de desarrollo de las mismas cita el estado de desarrollo (EPA, 2009).

TABLA A.2. VISIÓN GENERAL DE LAS CARACTERÍSITICAS DE LAS TÉCNICAS SIN ZANJA EN REDES DE ABASTECIMIENTO (EPA, 2009).

\begin{tabular}{|c|c|c|c|c|c|c|c|c|c|}
\hline \multirow[b]{2}{*}{ Método } & \multicolumn{3}{|c|}{ Parámetros de la tubería } & \multicolumn{3}{|c|}{ Requerimientos del trabajo } & \multicolumn{3}{|c|}{ Características } \\
\hline & $\begin{array}{l}\text { Rango } \\
\varnothing(\mathrm{mm})\end{array}$ & $\begin{array}{l}\text { Long. } \\
\text { reparación }\end{array}$ & $\begin{array}{c}\text { Cata } \\
\text { entrada }\end{array}$ & Revest. & $\begin{array}{c}\text { Relleno } \\
\text { espacio } \\
\text { anular }\end{array}$ & $\begin{array}{c}\text { Excav. } \\
\text { para } \\
\text { servicio }\end{array}$ & $\begin{array}{l}\text { Clasif. } \\
\text { AWWA }\end{array}$ & $\begin{array}{l}\text { Cambio } \\
\text { sección }\end{array}$ & $\begin{array}{l}\text { Estado } \\
\text { actual } \\
\text { técnica }\end{array}$ \\
\hline \multicolumn{10}{|c|}{ Nivel de limpieza requerido: Bueno } \\
\hline CIPP & $200-2400$ & $<2500$ & $S / N^{10}$ & Si & No & No & IIII & Bajo & Nueva \\
\hline $\begin{array}{c}\text { Deformación } \\
\text { PRP }\end{array}$ & $75-300$ & $<1000$ & $\mathrm{~S} / \mathrm{N}$ & No & No & No & III & Bajo & Nueva \\
\hline $\begin{array}{c}\text { Deformación } \\
\text { PE }\end{array}$ & $75-1200$ & $<1000$ & $\mathrm{~S} / \mathrm{N}$ & No & No & No & III & Bajo & Consolidada \\
\hline $\begin{array}{l}\text { Revestim. } \\
\text { Con mortero }\end{array}$ & $75-600$ & $<1000$ & $\mathrm{~S} / \mathrm{N}$ & Mínimo & No & No & I & Bajo & Consolidada \\
\hline $\begin{array}{l}\text { Revestim. } \\
\text { Epoxi }\end{array}$ & 75- 900 & $<1000$ & $\mathrm{~S} / \mathrm{N}$ & $\mathrm{Si}$ & No & No & I & Bajo & Consolidada \\
\hline \multicolumn{10}{|c|}{ Nivel de limpieza requerido: Normal } \\
\hline $\begin{array}{l}\text { Entubado } \\
\text { deslizam. }\end{array}$ & $>200$ & $<5000$ & L & No & Variable & $\mathrm{Si}$ & III & Disminuye & Consolidada \\
\hline \multicolumn{10}{|c|}{ Nivel de limpieza requerido: Ninguno o no aplicable } \\
\hline $\begin{array}{c}\text { Burst- Rotura } \\
\text { sistema } \\
\text { hidráulico }\end{array}$ & $50-900$ & NK & M & No & No & Si & IV & $\begin{array}{l}\text { Igual / } \\
\text { aumenta }\end{array}$ & Consolidada \\
\hline $\begin{array}{c}\text { Crack- } \\
\text { Rotura } \\
\text { sistema } \\
\text { neumático }\end{array}$ & $50-900$ & $20-500$ & M & No & No & $\mathrm{Si}$ & IV & $\begin{array}{l}\text { Igual / } \\
\text { aumenta }\end{array}$ & Consolidada \\
\hline
\end{tabular}

A excepción del Reino unido, en toda Europa, y en particular en España, la utilización de estas técnicas aunque progresiva está siendo más lenta de lo esperado. Asimismo, las metodologías que se utilizan se aplican en el campo de las redes de saneamiento, mientras que en abastecimiento prácticamente a excepción del entubado por deslizamiento, los revestimientos con mortero de cemento y las hincas no se ha realizado casi ninguna obra de este tipo. Ciertamente, aunque muchas técnicas están consolidadas y se vienen utilizando desde hace cierto tiempo, fundamentalmente en EE.UU. (donde se han desarrollado la mayoría de éstas, han encontrado su propio nicho de mercado y compiten unas con otras en varias situaciones Figura A.1), en España la mayoría no se han implantado todavía.

\footnotetext{
${ }^{10} \mathrm{~S} / \mathrm{R}$, reducción simétrica; $\mathrm{S} / \mathrm{N}$, pequeño o ninguno; $\mathrm{NK}$, desconocido; $\mathrm{M} / \mathrm{L}$ mediano o grande; $\mathrm{L}$ grande.

${ }^{11}$ La clasificación AWWA es I = no estructural, III semiestructural con anillos de conexión, IV= estructural
} 


\subsubsection{Criterios de selección del tipo de renovación o rehabilitación de la tubería.}

Cuando se aborda la cuestión de renovar o rehabilitar una tubería, se plantea un problema como el mostrado en la Figura A.54. En ella, a partir de un sistema de soporte a la decisión (uno de los definidos en el capítulo 2 de la tesis) se elige la tubería que se renueva. A continuación se ha de analizar la técnica empleada de todas las propuestas anteriores, y por último, se analiza económicamente el instante óptimo en el que realizar la renovación (por ejemplo con un modelo como el definido en el capítulo 4 del presente trabajo).

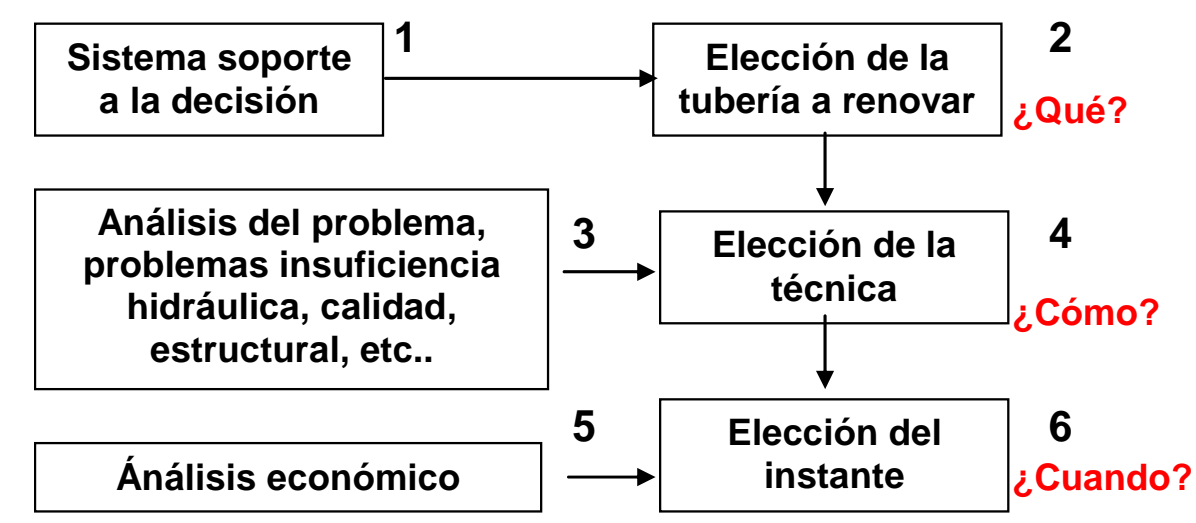

FIGURA A.54. DIAGRAMA DE FLUJO DE LAS OPCIONES DE RENOVACIÓN.

Aunque la respuesta a estos tres interrogantes que definen la renovación se detalla en la presente tesis, es la segunda cuestión la que en este punto se trata. Para ello, se muestran dos modelos recientes que permiten seleccionar la técnica adecuada para realizar la renovación o rehabilitación (Figura A.55 y Figura A.56).

El primero fue realizado por Rajani (2009) y analiza el tipo de problema existente en la tubería (estructural, insuficiencia hidráulica o de calidad) para sugerir el empleo de una u otro grupo de técnicas. Además, incluye la renovación tradicional como solución a los problemas de tipo estructural, por lo que este trabajo no se refiere únicamente a técnicas sin zanja. 


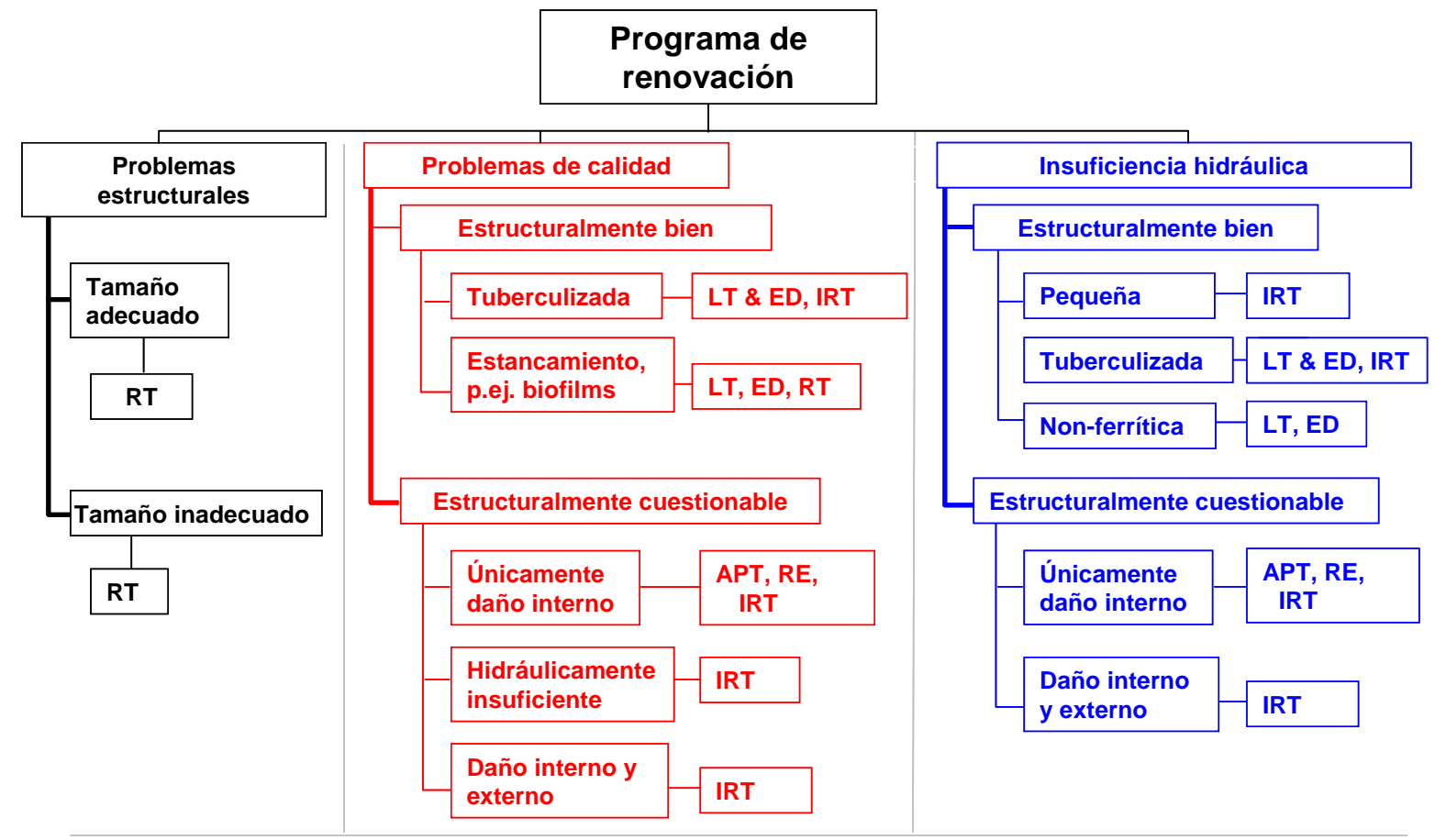

RE: Revestimiento estructural; APT: Ajuste preciso a tubería; IRT: Inserción con rotura de tubería; RT: Renovación tubería; LT: Limpieza de tubería; ED: Entubado por deslizamiento

Figura A.55. SELECCIÓN DE LA TÉCNICA DE RENOVACIÓN (RAJANI, 2009).

El segundo estudio mostrado también se orienta a determinar la técnica a partir de una serie de cuestiones referentes al estado de la red (Deb y col., 2009). La clasificación de las decisiones a adoptar por el gestor de la red se muestra en la Figura A.56. Algunas de las indicaciones mostradas merecen cierta explicación. Si se renueva con aumento de diámetro se refiere a la técnica de renovación tradicional, a los métodos de rotura con sistema hidráulico y por percusión, a la perforación horizontal dirigida y a las hincas en el terreno. En cambio por revestimiento estructural se entiende entubado por deslizamiento y métodos de ajuste preciso de tuberías. Por último, por revestimiento semiestructural se refiere a entubado por deslizamiento y encamisado térmico (CIPP para tuberías de abastecimiento, una técnica en expansión en Estados Unidos y el Reino Unido y todavía no existente en España). 


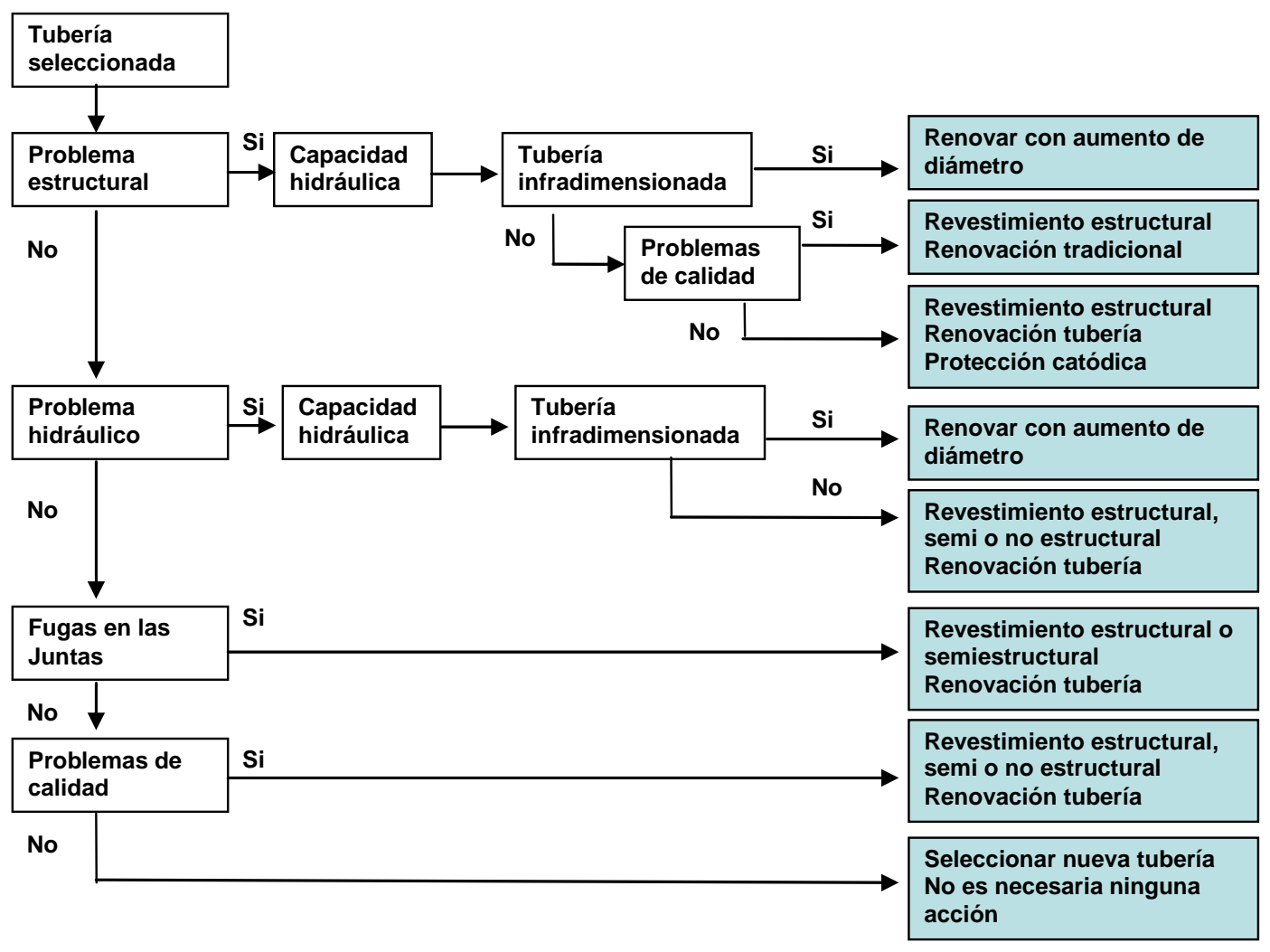

FIGURA A.56. SELECCIÓN DE LA TÉCNICA DE RENOVACIÓN. (DEB Y COL., 2009). 


\section{COSTES ASOCIADOS A LAS DIFERENTES TÉCNICAS}

Las técnicas sin zanja, hasta ahora, no han tenido una gran incidencia en el conjunto de las obras civiles debido a que con frecuencia, los gestores de los abastecimientos, ayuntamientos e ingenierías no han considerado los ahorros imputables a estas tecnologías en comparación con la tradicional obra civil con zanja. Con frecuencia, solamente se valoran los costes directos de la obra y se obvian otros asociados al proyecto. El coste total de la realización de un proyecto es la suma de los costes directos de la obra más los costes previos y posteriores a la realización del proyecto (Tabla A.3). Esta idea ha sido denominada el coste del ciclo de la vida, life cycle cost, y en ella se considera no solamente el coste de ejecución, sino también el coste previo y posterior de la rehabilitación o renovación de la tubería.

Los costes previos a la realización de la obra son los relacionados con la preparación en campo, los procesos de ingeniería y diseño, las autorizaciones legales, la aclimatación del terreno, las investigaciones en el subsuelo y la preparación de los documentos para el concurso previo a la obra.

Los costes durante la ejecución de la obra son los costes directos (movilización de maquinaria, materiales empleados, mano de obra, desecación del terreno, etc.) los costes indirectos (personal de oficina y en campo, contingencias en la obra, etc.) y los costes sociales (daños a edificios cercanos, seguridad de los viandantes, quejas de los ciudadanos, ruidos y vibraciones, daños asociados a las calzadas por las que se desvía el tráfico, coste asociado a la interrupción del tráfico).

Finalmente los costes posteriores a la obra son los relacionados con la operación de las redes, mantenimiento y las pérdidas de ingresos debido a las reparaciones de emergencia futuras.

TABLA A.3. COSTE DEL CICLO DE LA VIDA LIFE-CYCLE-COST DE UN PROYECTO DE RENOVACIÓN.

\begin{tabular}{ccc}
\hline Preconstrucción & Construcción & Post Construcción \\
\hline Preparación en campo & & Operación \\
Procesos de ingeniería y diseño & Costes directos & Mantenimiento \\
Autorizaciones legales & Costes indirectos & Depreciación de la \\
Aclimatación del terreno & Costes sociales & conducción \\
Investigaciones en el subsuelo & & Pérdidas por emergencias \\
Preparación de documentos & & \\
\hline
\end{tabular}


Aunque el análisis de todas estos condicionantes del precio total no se realiza casi nunca ya que comporta una tremenda dificultad y la necesidad de muchos datos para que el modelo se ajuste a la realidad, es obvio que considerar todos los componentes definidos anteriormente durante el periodo de planificación y diseño de la obra puede mostrar que algunas técnicas sin zanja sean más económicos que los métodos tradicionales.

Dentro de los costes durante la realización de la obra, se encuentran los costes sociales, que comportan las mayores ventajas de las técnicas sin zanja frente al método tradicional. Estos son muy difíciles de evaluar, ya que no se puede definir ningún método o modelo universal que permita el cálculo completo.

El coste social se debe calcular como la suma de los costes asociados a los siguientes términos (Najafi y Gokhale, 2004).

- Interrupciones del tráfico rodado.

- Daños al pavimento excavado.

- Daños a las instalaciones colindantes.

- Ruidos y vibraciones.

- $\quad$ Seguridad de los viandantes.

- Daños a las estructuras aledañas.

- Pérdidas en los negocios.

- Daños en las carreteras debido a la existencia de una zanja que impide el tráfico.

- Quejas de los ciudadanos que se ven afectados por las obras.

- Impacto ambiental de las obras.

El principal problema para comparar los costes entre las distintas técnicas consiste en que cada obra realizada presenta características particulares que impiden concretar un valor numérico universal, y se suele facilitar un intervalo de soluciones. En cualquier caso, siempre se aconseja consultar los precios con el fabricante para cada proyecto, ya que cualquier peculiaridad de la obra comporta un ahorro o encarecimiento significativo.

Por último, se muestra un análisis de la situación española obtenida por Pardo y Cabrera en el año 2006, y se pueden consultar otros estudios similares (Zhao y Rajani, 2002; Clark, 2002). Los estudios que a continuación se presentan se refieren al coste de otros procesos necesarios en la rehabilitación y renovación de redes, como las inspecciones con cámaras de televisión en circuito cerrado. La extensa literatura en la materia es una prueba del interés que estas técnicas despiertan. 


\subsection{Relación de costes de las diferentes técnicas de rehabilitación y renovación sin apertura de zanja empleadas en redes urbanas.}

Zhao y Rajani (2002) recopilaron los trabajos realizados en redes de saneamiento en Canadá y Estados Unidos, obteniendo los resultados mostrados en la Tabla A.4. En él se realiza una comparación entre los costes de la ejecución de las renovaciones con técnicas sin zanja y la renovación tradicional.

TABla A.4. Costes AsOciados a tÉCniCAS SIN ZANJA PARA SANEAMIENTO (ZhaO Y RAJANI, 2002).

\begin{tabular}{|c|c|c|c|c|c|c|}
\hline Técnica & $\begin{array}{l}\text { Coste }(\$ / \mathrm{mm} \\
\text { de diámetro } \\
\text { /m longitud) }\end{array}$ & $\begin{array}{c}\text { Pequeño } \\
<300 \mathrm{~mm} \\
(\$ / \mathrm{m})\end{array}$ & $\begin{array}{c}\text { Mediano } \\
330- \\
940 \mathrm{~mm} \\
(\$ / \mathrm{m})\end{array}$ & $\begin{array}{c}\text { Grande } \\
960- \\
1830 \mathrm{~mm} \\
(\$ / \mathrm{m})\end{array}$ & $\begin{array}{c}\text { Muy } \\
\text { Grande } \\
>1830 \mathrm{~mm} \\
(\$ / \mathrm{m})\end{array}$ & $\begin{array}{l}\text { Número } \\
\text { de datos }\end{array}$ \\
\hline $\begin{array}{l}\text { Inserción de tubería } \\
\text { con tornillo sin fin }\end{array}$ & 2.53 & - & 1325.68 & 4792.57 & 5384.46 & 24 \\
\hline Encamisado térmico & 0.93 & 202.03 & 358.78 & 1793.24 & - & 39 \\
\hline $\begin{array}{c}\text { Perforación horizontal } \\
\text { dirigida }\end{array}$ & 2.01 & 179.05 & 1210.14 & 4215.54 & - & 10 \\
\hline $\begin{array}{l}\text { Entubado por } \\
\text { deslizamiento }\end{array}$ & 0.93 & 156.08 & 667.57 & 1649.32 & 1734.46 & 16 \\
\hline $\begin{array}{l}\text { Rotura de tubería por } \\
\text { cabezal hidráulico }\end{array}$ & 1.49 & 490.54 & 787.16 & - & - & 11 \\
\hline $\begin{array}{c}\text { Hinca de tubería de } \\
\text { hormigón }\end{array}$ & 2.90 & - & - & 5094.59 & 6429.05 & 6 \\
\hline $\begin{array}{l}\text { Revestimiento no } \\
\text { estructural }\end{array}$ & 0.64 & 199.32 & - & - & - & 6 \\
\hline Técnica tradicional & 2.60 & 411.49 & 1563.51 & 1503.38 & - & 14 \\
\hline
\end{tabular}

Según este estudio, la técnica más cara sería la hinca de hormigón $(2.9 \$ / \mathrm{mm} / \mathrm{m})$, con un valor incluso superior más caros que la técnica tradicional con apertura de zanja $(2.6 \$ / \mathrm{mm} / \mathrm{m})$. Como cabía esperar, las técnicas más baratas son los revestimientos no estructurales. Asimismo, en tuberías mayores de $960 \mathrm{~mm}$, ninguna técnica sin zanja es más barata que la tradicional. 
Las técnicas específicas utilizadas se eligen para realizar una renovación en concreto según, entre otros condicionantes, la condición inicial de la tubería que se desea rehabilitar. En numerosas ocasiones, a estos costes se han de añadir los relativos a las inspecciones de las tuberías. Éstos son similares tanto en redes de abastecimiento como de saneamiento. En la Tabla A.5 se muestran los costes de inspección de las tuberías de saneamiento en EE.UU. (Zhao y Rajani (2001); Allouche y Freure, 2002).

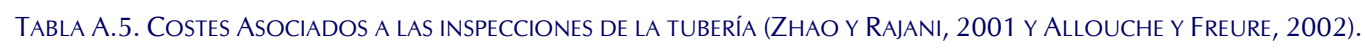

\begin{tabular}{ccc}
\hline Técnica & Zhao y Rajani (2001) & Allouche y Freure (2002) \\
\hline Inspección con cámara de televisión & $1.35-6.76$ & $1.18-9.46$ \\
Sonar & $4.05-6.76$ & $4.05-6.76$ \\
Inspección de un operario & $1.35-13.5$ & $0.90-13.5$ \\
Utilización conjunta de Sonar y \\
cámara de televisión \\
Zoom Camera
\end{tabular}

La environmental protection agency también cuantifica los costes para las técnicas sin zanja más utilizadas en renovación de pequeñas tuberías de saneamiento, (EPA, 1999).

TABLA A.6. RANGo DE COSTES PARA REDES DE SANEAMIENTO (EPA, 1999).

\begin{tabular}{ccc}
\hline Técnica & Diámetro $\mathbf{( m m )}$ & Coste $\mathbf{( \$ \mathbf { m } )}$ \\
\hline Rotura de tubería por cabezal & 203 & $130-160$ \\
Entubado por deslizamiento & 457 & $260-550$ \\
Encamisado térmico & 203 & $80-215$ \\
Ajuste preciso a la conducción & 203 & $58-162$ \\
\hline
\end{tabular}


Selvakulmar y col (2002) cuantifican los costes de las distintas técnicas en EE.UU. en red de distribución urbana. Los costes facilitados sólo consideran la instalación de la tubería y no incluyen otros como los asociados a quitar las válvulas, hidrantes ni otros trabajos como instalación de tuberías en by-pass, etc.

TABla A.7. Costes Asociados a las téCNICAS SIN ZANJA (SELVAKUMAR Y COL., 2002).

\begin{tabular}{ccc}
\hline Técnica & $\begin{array}{c}\text { Rango de Diámetros } \\
(\mathbf{m m})\end{array}$ & Coste $(\boldsymbol{€} / \mathbf{m m} / \mathbf{m})$ \\
\hline Revestimiento de Mortero & $100-1500$ & $0.129-0.388$ \\
Revestimiento Epoxi & $100-300$ & $1.16-1.94$ \\
Entubado por deslizamiento & $100-2750$ & $0.51-0.78$ \\
Encamisado térmico & $150-1400$ & $0.78-1.8$ \\
Encamisado previa deformación en $\mathrm{U}$ & $200-460$ & 0.78 \\
Ajuste preciso a la tubería & $50-1060$ & $0.51-0.78$ \\
Inserción por rotura & $100-900$ & $0.9-1.16$ \\
Perforación horizontal & $50-1500$ & $1.29-3.23$ \\
\hline
\end{tabular}

\subsection{Costes de las técnicas sin zanja en España}

Por último, Pardo y Cabrera (2006) realizan un estudio similar a los anteriores en España. Para ello consultaron a empresas en el ámbito nacional. Los costes referidos a las técnicas de encamisado térmico, revestimientos con mortero de cemento o con resinas y los de entubado por deslizamiento hacen referencia a redes de saneamiento, mientras que las técnicas de limpieza e inspección se refieren tanto a redes de abastecimiento y de saneamiento, y por último, las técnicas restantes hacen referencia únicamente a abastecimiento, Tabla A.8. 
Tabla A.8. Costes Asociados a teCniCAS Sin Zanja. (PARdo y Cabrera, 2006).

\begin{tabular}{|c|c|c|c|c|c|c|c|}
\hline $\begin{array}{l}\text { Tipo de } \\
\text { técnica }\end{array}$ & $\begin{array}{l}\text { Diámetro } \\
(\mathrm{mm})\end{array}$ & $\begin{array}{l}\text { Longitud } \\
\text { (m) }\end{array}$ & $\begin{array}{l}\text { Coste } \\
(€ / \mathrm{mm} / \mathrm{m})\end{array}$ & $\begin{array}{c}\text { Pequeño } \\
\varnothing<300 \mathrm{~mm}\end{array}$ & $\begin{array}{c}\text { Mediano } \\
300-1000 \\
\mathrm{~mm}\end{array}$ & $\begin{array}{c}\text { Grande } \\
1000- \\
2000 \mathrm{~mm}\end{array}$ & $\begin{array}{c}\text { Muy } \\
\text { grande } \\
\varnothing>300 \mathrm{~mm}\end{array}$ \\
\hline $\begin{array}{l}\text { Inserción por } \\
\text { rotura sistema } \\
\text { neumática }\end{array}$ & $100-500$ & 80 & 0.23 & 0.23 & 27.5 & 66.5 & - \\
\hline $\begin{array}{l}\text { Inserción por } \\
\text { rotura sistema } \\
\text { hidráulico }\end{array}$ & $\begin{array}{l}150- \\
1000\end{array}$ & 200 & 0.44 & 0.44 & 64.3 & 168.8 & - \\
\hline $\begin{array}{c}\text { Encamisado } \\
\text { térmico }\end{array}$ & $\begin{array}{l}150- \\
3000\end{array}$ & 750 & 0.53 & 0.53 & 235 & 482.5 & - \\
\hline $\begin{array}{l}\text { Revestimiento } \\
\text { con mortero } \\
\text { de cemento }\end{array}$ & $\begin{array}{l}100- \\
3000\end{array}$ & 1000 & $0.09-0.13$ & $35-65$ & $64-80$ & $97-118$ & $140-180$ \\
\hline $\begin{array}{c}\text { Revestimiento } \\
\text { con resinas }\end{array}$ & $75-300$ & 100 & - & 66.5 & - & - & - \\
\hline Limpieza & $75-1000$ & 1000 & $\begin{array}{c}0.0014- \\
0.0017\end{array}$ & $0.45-0.55$ & $0.5-0.6$ & - & - \\
\hline $\begin{array}{l}\text { Entubado por } \\
\text { deslizamiento } \\
\text { Inspección }\end{array}$ & $65-2500$ & 300 & $\begin{array}{c}0.171- \\
0.205\end{array}$ & $35-60$ & $129-139$ & $190-205$ & - \\
\hline $\begin{array}{c}\text { con cámara } \\
\text { de televisión }\end{array}$ & $0-3000$ & - & - & $1.1-3$ & - & - & - \\
\hline
\end{tabular}

\section{AGRADECIMIENTOS}

Deseo mostrar mi más profundo agradecimiento a las personas y compañías que han facilitado información concreta sobre las distintas tecnicas. En especial:

Jorge Sánchez Marín

Víctor Muñoz

Pedro Miguel López

Cristoph Wubbe
Aguas de Murcia

ACSA

Grupo AGE

Jonasson. 



\section{ANEXO B}

\section{Conceptos relacionados con los nuevos costes considerados para la obtención del periodo óptimo de renovación}





\section{CONCEPTOS ECONÓMICOS BÁSICOS UTILIZADOS EN LA DETERMINACIÓN DEL PERIODO ÓPTIMO DE RENOVACIÓN.}

Las inversiones sólo se pueden comparar entre sí si se expresan en unidades monetarias de un mismo año. Por tanto, existe la necesidad de expresar todos los costes en una misma unidad temporal (por comodidad se elige el año actual) y se observa que existen dos condicionantes:

1. El valor del dinero cambia con el tiempo (tasa de actualización r')

2. La inflación (s) produce un aumento sostenido y generalizado del nivel de precios de bienes y servicios (el coste de un bien aumenta sin modificar su valor).

Los efectos de la tasa de actualización r' y de la inflación s se combinan a partir del término tasa de actualización real $\mathrm{R}$ (o también tasa de actualización deflactada) que se define como:

$$
R=\frac{1+r^{\prime}}{1+S}-1
$$

De tal manera, un coste en el presente año $C_{0}$ se expresa en un año futuro $\mathrm{n}$ de acuerdo con:

$$
C_{n}=(1+R)^{n} \cdot C_{0}=\left(\frac{1+r^{\prime}}{1+s}\right)^{n} \cdot C_{0}
$$

En el presente ejemplo, se desea expresar los costes futuros en el año actual (año $\left.t_{p}\right)$, por lo que se obtiene:

$$
C_{0}=\frac{C_{n}}{(1+R)^{n}}
$$

El parámetro tasa de actualización real $R$ produce variaciones significativas en los costes totales calculados. Si presenta un valor elevado implica valores elevados de r' y por tanto, se espera obtener una mayor rentabilidad del proyecto. También implica que ciertos costes del agua fugada, de la energía extra necesaria y de los costes de reparaciones trasladadas al año presente tengan menor relevancia debido a la traslación al año actual. 
En el análisis económico que se ha realizado, se utiliza para expresar costes futuros en unidades monetarias actuales el parámetro $r$ definido como tasa continua de actualización equivalente del coste en tanto por uno. Se utiliza este parámetro ya que permite representar la variación entre costes de manera continua, mientras que la tasa de actualización real $\mathrm{R}$ sólo permitía este cálculo de año a año. La relación entre ambos parámetros es simple.

$r=\ln (1+R) \quad$ O bien $R=e^{r}-1$

Asimismo, los términos definidos por Shamir y Howard de coste asociado a la renovación al mantenimiento de tuberías se pueden expresar actualizando los costes con la tasa continua de actualización, obteniéndose las expresiones anteriormente comentadas (A4.1) y (A4.5).

$$
\begin{aligned}
& C_{1}\left(t_{p}\right)=\frac{C_{r i j}}{(1+R)^{T_{f i j}}}=\frac{C_{r i j}}{\left(1+e^{r}-1\right)^{T_{f i j}}}=C_{r i j} \cdot e^{-r T_{i j i}} \\
& C_{2}\left(t_{p}\right)=\sum_{0}^{T_{i j}} \frac{C_{m}(t)_{i}}{(1+R)^{t}}=\sum_{0}^{T_{i j}} \frac{C_{m}(t)_{i}}{\left(1+e^{r}-1\right)^{t}}=\sum_{0}^{T_{i j}} C_{m}(t)_{i} \cdot e^{-r \cdot t} \cong \int_{0}^{T_{i j}} C_{m}(t)_{i} \cdot e^{-r \cdot t} \cdot d t
\end{aligned}
$$

\section{COSTE SOCIAL ASOCIDO A LA PÉRDIDA DE ESTÁNDARES DE SERVICIO}

La pérdida de estándares de servicio como calidad del agua y presurización en los puntos de acometida se puede penalizar si se ha pactado entre el gestor del abastecimiento y la entidad competente correspondiente.

Las pérdidas de estándares de servicio pueden ser de dos tipos, o bien de tipo hidráulico o bien de calidad del agua. Por ello, se analiza de manera separada la influencia de ambas fuentes de pérdidas de calidad del agua.

\subsection{Pérdidas de estándares de servicio relacionados con la hidráulica.}

Conforme van envejeciendo las conducciones, la rugosidad, la tasa de roturas, el caudal circulante y el volumen fugado tienden a aumentar; por lo que los equipos de bombeo encargados de la presurización del sistema cada vez tienen que funcionar durante un mayor número de horas, en mayor número o alimentados a mayor frecuencia. El aumento en la energía utilizada se ha considerado en el apartado destinado a los costes asociados a las pérdidas de energía, pero este proceso continuo de pérdida de capacidad hidráulica de la red acaba desembocando en que los consumidores no reciban el producto convenientemente. 
En algunos abastecimientos, en los que no se ha renovado cuando era menester, se ha Ilegado hasta un punto todavía más dramático, en el que la capacidad hidráulica de la red es completamente insuficiente y directamente se debe adoptar la resolución de renovar una serie de conducciones. En ocasiones el incumplimiento del estándar de presión minima en una acometida acarrea la instalación de un aljibe que permita el consumo pese a la insuficiencia del servicio.

Por tanto, el primer parámetro que se observa es la presión en determinadas zonas del abastecimiento. Ésta debe ser superior a un umbral mínimo fijado o el gestor del abastecimiento debería pagar una compensación $C_{p h}$, según el cual se aumenta el coste social asociado a la pérdida del estándar de servicio presión en la acometida.

Sin embargo, la sobrepresión no se penaliza porque aunque su presencia ocasiona problemas en la gestión y operación del sistema (capítulo 7), la solución a ésta no es la renovación, sino la instalación de una válvula que permita el adecuado consumo en ciertos sectores de la red.

Sin embargo, otro caso completamente diferente sería el hecho de que debido a una nueva zona residencial, se añada un número considerable de consumidores en una zona de la red sometida a estudio. En este punto, el estudio sería completamente diferente ya que la pérdida de estándares de servicio sería debido al aumento del consumo. Este descenso brusco en la capacidad de transporte hidráulico de la conducción y la consiguiente caída de presión en una determinada zona provoca una renovación inmediata en aras de permitir el consumo, pero esta renovación sería imputable a los constructores de esta nueva zona residencial y tendría un coste nulo para los gestores de la red de abastecimiento. 


\subsection{Pérdidas de estándares de servicio relacionados con la calidad}

Resulta sumamente difícil encontrar una relación directa entre la calidad del agua y adoptar la decisión de renovar una conducción. De hecho, la calidad del agua depende en primer lugar del recurso hídrico disponible, del proceso de tratamiento del agua en la estación de tratamiento del agua potable y finalmente de las reacciones químicas que suceden a lo largo de la red de distribución.

Uno de los tratamientos fundamentales en la estación de tratamiento del agua potable consiste en la desinfección del agua, destrucción de los microorganismos patógenos que causan enfermedades. Este proceso suele realizarse generalmente con la adición de cloro, ya que es un método eficaz, barato y deja un remanente en la red de distribución.

Los problemas de calidad del agua relacionados con la distribución del agua son básicamente derivados de la corrosión en las tuberías (color, sabor y sólidos en suspensión), de la presencia de bacterias, hongos que crecen en las tuberías formando biopelículas y de la intrusión patógena debido a las roturas. De todos los problemas asociados con la calidad del agua (tanto en la estación de tratamiento como en la red de distribución), solamente se puede imputar el último a la tubería.

El decaimiento del cloro por el contacto con las tuberías de distribución ha sido objeto de numerosos estudios aunque la suposición de que el cloro decrece con el tiempo siguiendo una reacción química de primer orden es, de lejos, la más empleada. Jonkergouw (2007) analizó los modelos empleados habitualmente para simular este decaimiento y subrayó las ventajas y desventajas de los mismos y propuso un nuevo modelo que se ajustaba a los decaimientos observados. En este trabajo se realiza un extenso análisis de esta problemática que escapa al objetivo de esta tesis.

En definitiva, si aumenta el tiempo de permanencia del agua en red disminuye el contenido de cloro y, por tanto, la capacidad desinfectante. El nivel de cloro en los puntos de acometida se ha de mantener en concentraciones entre los 0.2-1 ppm. La elección de estos valores límite en la anterior horquilla merece una explicación. El valor inferior es superior a 0 como signo de calidad, ya que la presencia de cloro libre (residual) demuestra que no se ha introducido materia orgánica (que consume cloro). Por otra parte, el superior se fija a este valor porque valores mayores serían excesivos para agua de boca. La Organización Mundial de la Salud OMS (1985) afirma que no existe ningún efecto perjudicial para la salud en el caso de concentraciones de cloro libre de hasta $2.5 \mathrm{mg} / \mathrm{l}$. 
Finalmente, se piensa en un valor $c_{p c}$, que penalice la caída del cloro por debajo de la concentración 0.2 p.p.m. en ciertos puntos de la red. Este valor $c_{p c}$ provoca un aumento del coste social por pérdida del estándar de servicio calidad.

\section{COSTE DE OPORTUNIDAD}

Tal y como se ha comentado previamente, el coste de oportunidad es el ahorro obtenido de aprovechar la realización de las obras por parte de otra compañía. Por tanto, este coste presenta un marcado carácter probabilístico, ya que su valor depende de que otra compañía realice una apertura de zanja.

La expresión utilizada en la cuantificación de dicho coste es:

$C_{5}\left(t_{r}\right)=-x_{5} \cdot \varphi_{5} \cdot \beta_{c 5} \cdot C_{12}\left(t_{p}\right)$

Donde $C_{5}\left(t_{r}\right)$ representa el coste de oportunidad, $\varphi_{5}$ es un coeficiente utilizado para ponderar el coste de oportunidad, y presenta un valor menor que la unidad para computar los ahorros que en ningún caso pueden ser tales que se correspondan con la magnitud de la renovación realizada (en caso de que tuviese valor 0.5 significaría que debido a la oportunidad de realización de una obra conjunta no se emplea la mitad del capital habitualmente destinado a la realización de la renovación), $x_{5}$ es el coeficiente de tecnología para el coste de oportunidad, dependiente únicamente del método de renovación empleado, $\beta_{c 5}$ es un coeficiente de acuerdo entre ambas compañías, y por último, $c_{12}\left(t_{r}\right)$ representa el coste de instalación de la tubería en el proceso de renovación obtenido en (€) de acuerdo con el Apartado 4.2 del capítulo 4.

El coeficiente $\beta_{c 5}$, se encarga de plasmar el acuerdo al que ambas compañías Ilegan a la hora de ejecutar las obras. Existen cuatro posibles soluciones:

- Caso I: El coste de apertura de la zanja es sufragado totalmente por la otra compañía. $0.8<\beta_{c 5}<1$

- Caso II: El coste de apertura de la zanja es sufragado por ambas empresas. $0.4<\beta_{c 5}<0.6$

- Caso III: El coste de apertura de la zanja es sufragado totalmente por la empresa suministradora de agua potable. En este caso el coste de oportunidad negativo es para la otra compañía que no emplea sus recursos en la apertura de la zanja. $0<\beta_{c 5}<0.2$ 
- Caso IV: Ambas compañías se deciden por realizar una renovación de sus conducciones con tecnologías sin zanja. Con lo que el coste será menor para ambas. $0.1<\beta_{c 5}<0.3$

Con los valores de $\beta_{c 5}$, se consigue representar el coste de oportunidad en ejemplos como el Caso I, en el que el ahorro es total y en otros como el Caso III en el que los gastos de de realización de la obra por parte de la compañía suministradora de agua potable es aprovechada por otra compañía (gas, de fibra óptica, etc.).

Cuando el coste de oportunidad es posible, se tiene que considerar que el coste de oportunidad de las técnicas sin zanja es 0 , ya que al haber realizado la zanja, se ha eliminado la principal ventaja de dichas técnicas. Por tanto, el coeficiente de tecnología presenta los siguientes valores según la técnica empleada:

$x_{5}=1$, si se emplea la técnica tradicional con apertura de zanja o en el caso de que ambas empresas hayan decidido realizar renovación con técnicas sin zanja (Caso IV, $0.1<\beta_{c 5}<0.3$ ).

$x_{5}=0$, en los casos restantes.

En cualquier caso, el coste de oportunidad varía entre el valor 0 y el valor $-C_{12}\left(t_{r}\right)$, ya que el término relativo al coste de la tubería transportada hasta la obra donde se está realizando la renovación $C_{11}\left(t_{r}\right)$ no representa un ahorro imputable.

$\lim C_{5}\left(t_{r}\right)=-C_{12}\left(t_{r}\right)$

En la Figura B.1, se puede observar una simulación de una posible evolución del coste de oportunidad en un periodo de tiempo. En el transcurso del año 19 al 20 sucede una oportunidad que se modela como perteneciente al Caso I con coeficiente de acuerdo entre compañías $\beta_{c 5}=1$. Esto es, el coste de la zanja la sufraga completamente la otra compañía, el coste de instalación es completamente nulo y es el caso que representa el límite del ahorro. 


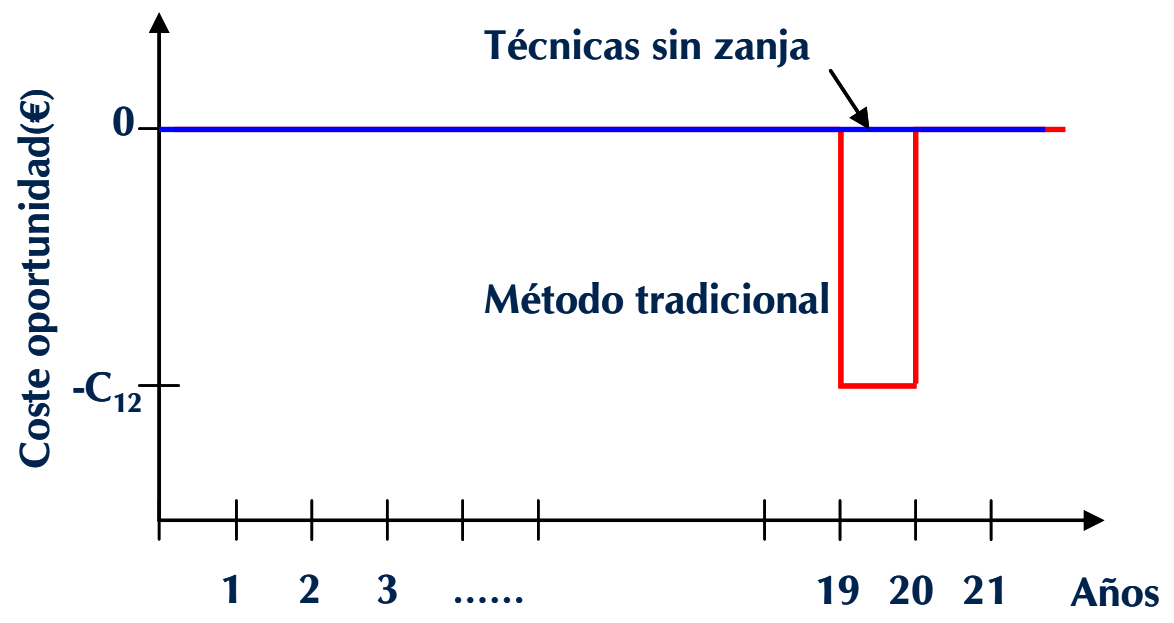

FIGURA B.1. REPRESENTACIÓN GRÁFICA DE LA EVOLUCIÓN DEL COSTE DE OPORTUNIDAD 



\section{ANEXO C}

Políticas de gestión de fugas en redes de abastecimiento en el corto y largo plazo 



\section{INTRODUCCIÓN}

Los gastos en reparaciones y las pérdidas económicas relacionadas con las fugas (tanto debidas al agua en sí como a la energía) están relacionadas y se pueden expresar analíticamente. Conforme aumentan los recursos empleados en mantenimiento, éstos serán menos eficientes, ya que cada vez existen menos fugas a reparar. A su vez, si apenas se repara, las fugas y la energía perdida en las mismas serán elevadas. Por tanto, debe existir un valor tal que los gastos en mantenimiento se equilibren con los del agua fugada, en definitiva, aquél en que los costes totales (suma de los dos anteriores) sean mínimos. Este punto de funcionamiento del sistema está relacionado con un volumen de fugas óptimo económico (desde otras ópticas como la operativa, el volumen de fugas óptimo sería la ausencia de las mismas).

El nivel de fugas óptimo depende del precio de venta del agua. A medida que el precio de venta aumente, el rendimiento de la red (definido en el capítulo 3) se aproximará, de manera natural a la unidad. Algunos países, Inglaterra a través del OFWAT o Italia a través de la Ley Galli permiten aumentar el precio de venta del agua si lo hace el rendimiento de la red de distribución que la transporta. En definitiva, cuanto más fielmente se repercutan en el recibo que paga el abonado los costos reales de gestión (amortización, gestión técnico económica, gastos energéticos, etc.) el abastecimiento tenderá de manera natural, a mejorar su gestión.

La metodología habitual para el cálculo de la relación entre los gastos de mantenimiento y las fugas es bien conocida. Cobacho y col. (2003) proponen una metodología para obtener la curva de costes totales en mantenimiento, y son los primeros en plantear la evolución temporal de la misma.

La principal aportación del planteamiento mostrado a continuación es que, por primera vez, se considerará en el cálculo el valor de la energía pérdida en fugas. Este término se calculará con la auditoría energética (capítulo 6 de la presente tesis) y gracias a ella se observará su relevancia. Los capítulos 4 y 5 subrayan la influencia de la energía en la obtención del periodo de renovación y aquí se determina su efecto sobre el coste total de mantenimiento (obtenido como la suma de los costes del agua fugada y los de mantenimiento del sistema). 
Asimismo, y al igual que Cobacho y col. (2003) se considerará la influencia temporal sobre el coste total de mantenimiento, algo no habitual ya que en éstos análisis se plantean estrategias en un periodo corto de tiempo, por ejemplo un año. Que la red envejece no es desconocido (en el capítulo 2 ya se mostraron algunos ejemplos de la evolución temporal del número de roturas), aunque sí que lo es el planteamiento de una estrategia integral de renovación y reparación en la que se agrupen las actuaciones frente a las fugas a corto plazo (reparación) con las definidas a largo plazo (sustitución).

\section{Punto ÓPtimo de COStes de MANTENIMIENTo}

Son numerosos los trabajos que persiguen identificar el nivel óptimo de costes en mantenimiento dentro de la gestión general de una red de distribución de agua (Cobacho y col., 2009; Cabrera y col., 1999). Las directrices que siguen, y de las que se parte en el presente trabajo, bien que hacia desarrollos distintos, son las siguientes:

1. Relacionar las pérdidas de agua con los costes de mantenimiento, por una parte.

2. Relacionar las pérdidas de agua con sus costes de producción, por otra.

Ambas relaciones se pueden expresar analíticamente $y$, en consecuencia, representar mediante dos curvas distintas, situadas sobre los mismos ejes: $X$ (pérdidas de agua) e $Y$ (cantidades monetarias).

Como ya se ha dicho, los costes totales de mantenimiento son la suma del coste de mantenimiento de la red (apartado 2.1) y el coste del agua que se pierde en fugas (apartado 2.2). Si el gestor de la red invierte más recursos en mantenimiento, la inspección de la red se realiza con mayor frecuencia, las fugas se encuentran activas durante menor tiempo y el coste asociado al agua y energía fugada es menor.

Por tanto suceden dos fenómenos contrapuestos, en ciertos casos el aumento de los costes de mantenimiento es menor que el beneficio hídrico-energético, por lo que existen ahorros del cambio de política (por el aumento de la inversión en mantenimiento). En cambio, conforme aumenta la frecuencia de inspecciones y reparaciones, el beneficio hídrico es cada vez menor hasta un punto en que incluso es más costosa la reparación que la reducción de las fugas que comporta. Esta situación justifica la existencia de un valor mínimo de fugas que depende, entre otros parámetros, del número de inspecciones en la red $\left(n_{d}\right)$ y de la vida promedio de la fuga $\left(\Delta t_{a}\right)$. El cálculo de la curva total de costes en mantenimiento (y en definitiva, del valor óptimo de fugas que hace mínimo ésta) se describe a continuación. 


\subsection{Curva de gastos en reparaciones y mantenimiento}

La relación entre los gastos en reparaciones y mantenimiento y el volumen fugado es función de las características propias del abastecimiento. Representa los costes de reparación frente al volumen fugado, o bien la cantidad monetaria que se debe invertir para mantener el sistema en la situación actual. Siempre presenta la misma tendencia general con valores numéricos diferentes (Figura C.1). La curva tiende a una asíntota vertical cuando el agua fugada adopta un valor cercano a cero, lo cual indica que por muchos recursos que se destinen a mantenimiento, la cantidad de agua fugada nunca es completamente cero, sino que como máximo se puede reducir hasta el umbral mínimo de fugas (UMF, un indicador definido en el capítulo 3).

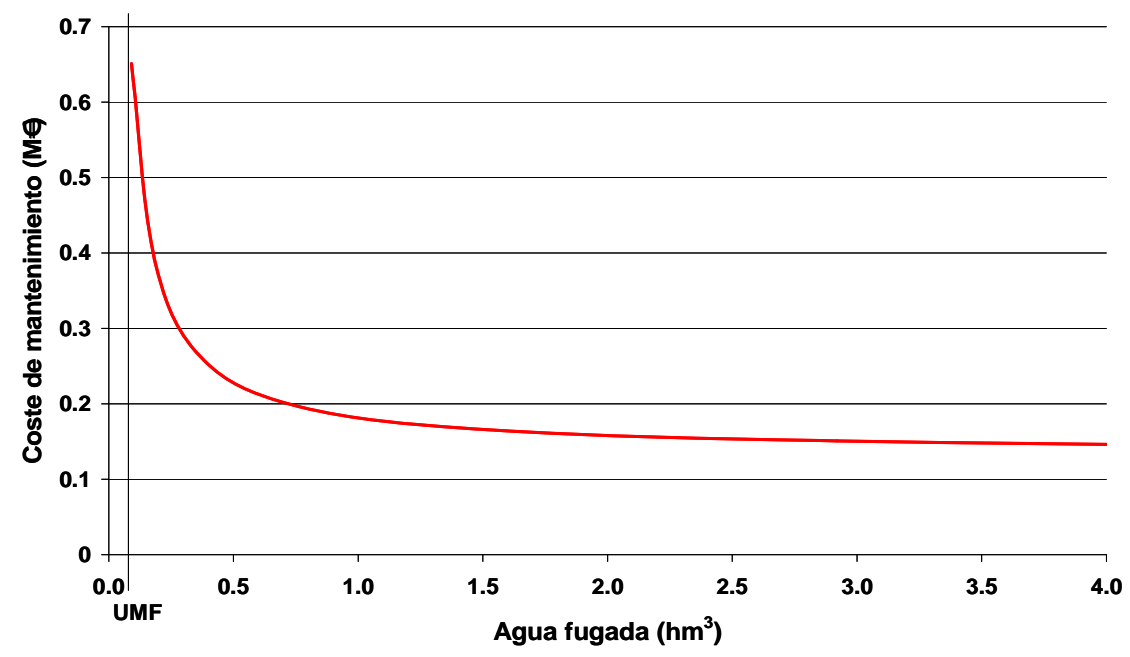

Figura C.1. CurVa de Gastos En REPARACIÓN Y MANTENIMIENTO, CGRM(VF).

Existen muchas metodologías para la obtención de la curva de gastos y reparaciones $\operatorname{CGRM}\left(V_{f}\right)$. Cobacho y col. (2009) define tres métodos para su cálculo:

1. Utilización de datos anteriores y posteriores a una campaña de reducción de fugas.

2. Clasificación de los tipos de defectos y el agua perdida.

3. Históricos de agua perdida y sus costes de mantenimiento.

En el presente trabajo se pretende obtener la curva de gastos y reparaciones si se sigue la política de actuación delineada en el capítulo $4^{1}$. Asimismo, se considera que a corto plazo el número de roturas es constante y la red no envejece (por lo que en un periodo de tiempo corto el volumen de fugas aumenta por el tiempo que la rotura se encuentra activa).

\footnotetext{
${ }^{1}$ Se analiza un sector de la red homogéneo, con tuberías de similares diámetros, en el que todas las roturas (que tienen un patrón de roturas exponencial) se reparan.
} 
La Figura C.2 muestra el caudal medio fugado en una red con una frecuencia de muestreo anual (Política 1, con un número de inspecciones igual a $n_{d}=1$ inspección/año y tiempo de vida media de la fuga, $\Delta t_{a}=1 / 2$ año) o bianual (Política 2, con dos inspecciones al año $n_{d}=2$ inspecciones/año, y la fuga tiene una vida media de $\Delta t_{a}=1 / 4$ año) (Lambert, 1998). Se observa como el número de roturas es el mismo en los dos años mostrados ya que el índice natural de aumento de fugas (INAF), pendiente de las diagonales, es la misma. Este último término representa el aumento de las fugas en un periodo de tiempo determinado (generalmente un año) y se expresa en $\left(\mathrm{m}^{3} / \mathrm{h} / \mathrm{año}\right)$.

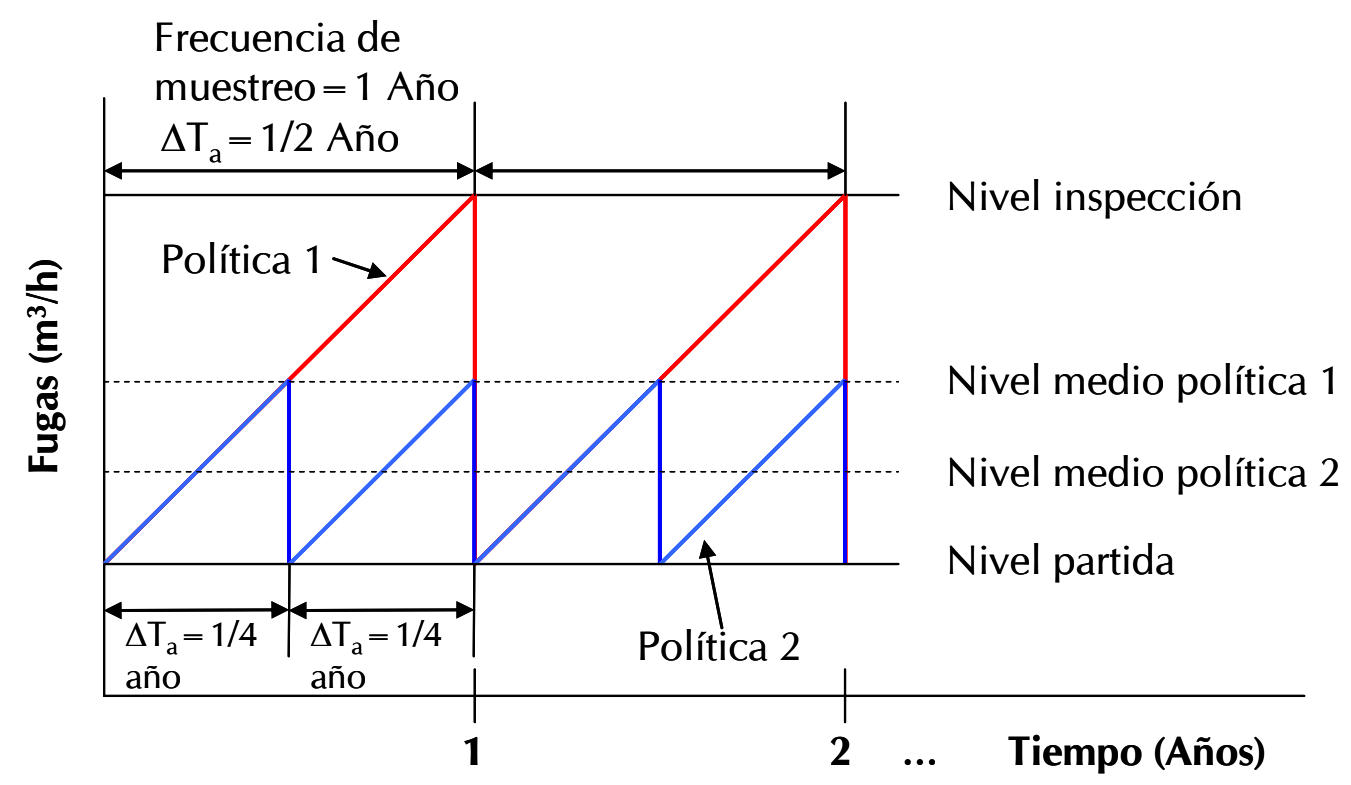

FIGURA C.2. NIVEL PROMEDIO DE FUGAS PARA DOS POLÍTICAS DE MANTENIMIENTO DIFERENTES (LAMBERT, 1998).

Las hipótesis del cálculo de la relación entre el coste de mantenimiento y el volumen fugado en el corto plazo son:

1. El coste unitario de reparación por rotura y el de inspección de la red se consideran constantes $\left(c_{b_{i}}\right.$ y $c_{d}$ respectivamente).

2. El caudal unitario por rotura $\left(q_{f}\right)$ también es constante.

3. El número de roturas en el año to es un valor conocido y constante $N\left(t_{0}\right)$.

Con lo que el coste total de la reparación de la conducción se puede calcular como la suma de los costes de inspección y los de reparación:

$\operatorname{CGRM}(t)=n_{d} \cdot C_{d}+C_{b} \cdot N\left(t_{0}\right)$

Donde $c_{b}$ es el igual al coste unitario de reparación (obtenido a partir de los costes de apertura de zanja, mano de obra, etc.), $c_{d}$ el coste de las inspecciones de la red 
(brigadas de detección de fugas, instrumentación utilizada, etc.) y $n_{d}$ el número de inspecciones.

Según la estructura de costes definida en el capítulo 4, todas las roturas se reparan cuando se encuentran por lo que se puede suponer que éstas están activas un tiempo medio $\left(\Delta t_{a}\right)$ igual a la mitad del tiempo entre sucesivas inspecciones. Dicha política de actuación representa un punto de la curva de costes totales asociados a las fugas y se pretende determinar el valor del tiempo medio de actividad de una fuga para que el volumen fugado sea el óptimo (esto es, los costes totales de mantenimiento sean mínimos).

Los defectos representados por las líneas diagonales de la Figura C.2 y que se reparan tras cada inspección, son siempre los mismos en el corto plazo. Como se ha supuesto un caudal unitario por rotura constante $\left(q_{f}\right)$ se puede calcular el volumen fugado como:

$V_{f}(t)=q_{f} \cdot N\left(t_{0}\right) \cdot \Delta t_{a}$

Asimismo, se puede calcular el índice natural de aumento de fugas (INAF²), según el caudal unitario de fuga:

$\operatorname{INAF}(t)=q_{f} \cdot N\left(t_{0}\right)=\frac{V_{f}(t)}{\Delta t_{a}}$

Por último, por la propia definición de INAF, se puede mostrar la siguiente relación:

$n_{d}=\frac{\operatorname{INAF}(t)}{Q_{S_{i}}-Q_{i_{i}}}$

Donde se denomina nivel de partida de las fugas $\left(Q_{i_{i}}\right)$ al valor del caudal de fugas que los gestores consideran suficientemente bueno como para cesar la inspección (o ajustar la magnitud de las fugas que se buscan), por ello es a este al que se reduce el caudal fugado tras las inspecciones. Asimismo, se denomina nivel de inspección $\left(Q_{s_{i}}\right)$ al valor que los gestores consideran inaceptable y por ello al detectar que el caudal de fuga ha alcanzado dicho nivel, se pone automáticamente en marcha una inspección en el sector (Figura C.2). Evidentemente, si el número de inspecciones aumenta (en la figura la política 2 presenta un mayor número de inspecciones), el nivel de inspección $\left(Q_{S_{i}}\right)$ disminuye ya que el índice natural de aumento de fugas es constante y el tiempo en que la fuga está activa es menor.

2 La variación del índice con el tiempo, pese a ser considerado como constante en el corto plazo, aumentará cuando pase el tiempo tal y como se comprobará más adelante. 
Si se sustituyen las expresiones anteriores (ecuaciones (C.3 y (C.4)) en la (C.1), se obtiene la relación entre los costes totales de la reparación de la conducción y el volumen fugado:

$$
\begin{aligned}
\operatorname{CGRM}(t) & =n_{d} \cdot C_{d}+C_{b} \cdot N\left(t_{0}\right)=C_{d} \cdot \frac{\operatorname{INAF}(t)}{Q_{s_{i}}-Q_{i_{i}}}+C_{b} \cdot \frac{\operatorname{INAF}(t)}{q_{f}}= \\
& =C_{d} \cdot \frac{V_{f}(t)}{\left(Q_{S_{i}}-Q_{i_{i}}\right) \cdot \Delta t_{a}}+C_{b} \cdot \frac{V_{f}(t)}{q_{f} \cdot \Delta t_{a}}=V_{f}(t) \cdot\left(\frac{C_{d}}{\left(Q_{S_{i}}-Q_{i_{i}}\right) \cdot \Delta t_{a}}+\frac{C_{b}}{q_{f} \cdot \Delta t_{a}}\right)
\end{aligned}
$$

La expresión analítica anterior representa la curva de gastos en reparación y mantenimiento. En ella se observa que, efectivamente, es función del volumen fugado, de los costes definidos y del tiempo medio de actividad de la fuga. Si se representan varios estados de la red de abastecimiento (varias políticas de actuación), se obtiene una curva similar a la representada en la Figura C.1.

Por último, esta curva muestra la relación entre la cantidad de dinero invertido y el volumen perdido en fugas. Cada política específica de mantenimiento del sistema se relaciona con un punto perteneciente a la curva y si cambia ésta (en definitiva, si existen nuevos valores de los parámetros, $n_{d}, Q_{i_{i}}, Q_{s_{i}}$ y $\Delta t_{a}$ ), la gestión del sistema se desplaza a lo largo de la curva de gastos en reparaciones y mantenimiento aún cuando ésta no puede ser modificada. Precisamente, el objetivo a corto plazo consiste en determinar el número y frecuencia de inspecciones necesarias para encontrar el punto óptimo del sistema, esto es, el que minimiza los costes totales de mantenimiento (apartado 2.3).

\subsection{Curva del valor del agua fugada}

Más sencilla es la relación entre el volumen del agua fugada y el coste asociado al mismo $\left(\operatorname{CVFA}_{f}(t)\right)$. Sobre dicha curva se puede leer cual es el valor monetario del agua perdida. Sin embargo, su obtención no consiste únicamente en considerar el coste de producción del agua fugada $\left(C_{31}(t)\right)$ sino que también hay que cuantificar la energía perdida en fugas, bien la energía que se escapa con el agua en sí misma $\left(C_{32 a}(t)\right)$ como el extra energético perdido por fricción $\left(C_{32 b}(t)\right)^{3}$.

\footnotetext{
${ }^{3}$ Los valores de $C_{31}(t), C_{32 a}(t)$ y $C_{32 b}(t)$ son los definidos en el capítulo 4 de la tesis aunque en el corto plazo no se considera su variación exponencial, ya que el número de roturas es fijo $\left(N\left(t_{0}\right)\right)$. En el presente anexo se definen como función del tiempo $t$ y no sobre $t_{r}$ porque no dependen del tiempo en el que se realiza la renovación.
} 
Por tanto, la curva del valor del agua fugada con respecto al tiempo con la estructura de costes definida se obtiene como:

$$
\begin{gathered}
C V A_{f}(t) \equiv C_{31}(t)+C_{32 a}(t)+C_{32 b}(t)=C_{W} \cdot q_{f} \cdot N\left(t_{0}\right) \cdot \Delta t_{a}+C_{W E} \cdot q_{f} \cdot N\left(t_{0}\right) \cdot \Delta t_{a}+ \\
+\frac{k \cdot \gamma \cdot C_{E}}{\eta} \cdot \frac{p_{S}}{\gamma} \cdot q_{f} \cdot N\left(t_{0}\right) \cdot \Delta t_{a}=\left(C_{W}+C_{W E}+\frac{k \cdot \gamma \cdot C_{E}}{\eta} \cdot \frac{p_{S}}{\gamma}\right) \cdot q_{f} \cdot N\left(t_{0}\right) \cdot \Delta t_{a}= \\
=\left(C_{W}+C_{W E}+\frac{k \cdot \gamma \cdot C_{E}}{\eta} \cdot \frac{p_{S}}{\gamma}\right) \cdot V_{f}(t)
\end{gathered}
$$

Con la expresión anterior se muestra la relación lineal entre los costes y el volumen fugado. Dicha curva es una recta ascendente $y$, como no puede ser de otra manera, depende del valor del agua $\left(c_{W}\right)$ y de su coste energético $\left(c_{W E}\right)\left(\right.$ ambos en $\left.€ / \mathrm{m}^{3}\right)$. De manera indirecta, también depende del número de inspecciones que se realizan en la red, ya que éste determinará el volumen fugado (ecuación (C.2)).

\subsection{Curva de costes totales relacionados con el mantenimiento}

Las dos curvas ya presentadas, engloban las variables del problema que se quiere analizar. Es decir, según un determinado nivel de mantenimiento del sistema, traducido

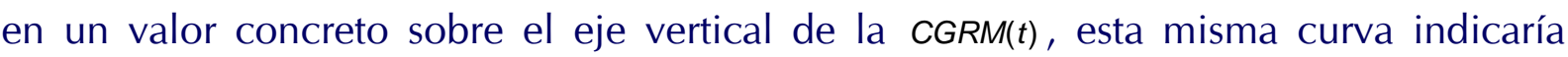
sobre su eje horizontal qué volumen de agua se pierde en los defectos correspondientes a dicho nivel de mantenimiento. Y sobre la $C A_{f}(t)$ podría leerse el valor monetario del agua pérdida (que engloba el coste del agua y de la energía).

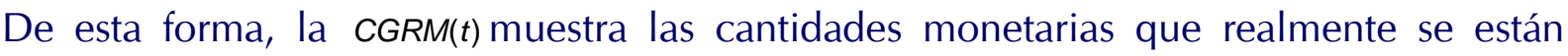
invirtiendo para mantener el sistema en las condiciones actuales, mientras que $c V A_{f}(t)$ muestra el valor real del agua que se está perdiendo. La curva de costes totales $($ CCTM $(t))$ la muestra la Figura C.3. Las características fundamentales de la $\operatorname{CCTM(t)}$ es que presenta valores similares a $\operatorname{CGRM}(t)$ para niveles de fugas bajos, cercanos al umbral mínimo de fugas, mientras que para un nivel elevado de fugas, es prácticamente similar a $C V A_{f}(t)$. Aunque la principal característica de la curva es que existe un mínimo, el punto óptimo para la planificación a corto plazo del abastecimiento. Dicho punto mínimo, se corresponde con una vida media de la fuga y una frecuencia de inspección de la red óptimas. El objetivo a corto plazo del gestor de la red sería conseguir que el sistema funcionase en esas condiciones determinadas, ya que presenta un coste menor. 
La expresión que define dicha curva es:

$$
\begin{gathered}
\operatorname{CCTM}(t)=\operatorname{CGRM}(t)+\operatorname{CVA}_{f}(t)=\left(\frac{C_{d}}{\left(Q_{S_{i}}-Q_{i_{i}}\right) \cdot \Delta t_{a}}+\frac{C_{b}}{q_{f} \cdot \Delta t_{a}}\right) \cdot V_{f}(t)+\left(C_{W}+C_{W E}+\frac{k \cdot \gamma \cdot C_{E}}{\eta} \cdot \frac{p_{S}}{\gamma}\right) \cdot V_{f}(t)= \\
=\left(\frac{C_{d}}{\left(Q_{S_{i}}-Q_{i_{i}}\right) \cdot \Delta t_{a}}+\frac{C_{b}}{q_{f} \cdot \Delta t_{a}}+C_{W}+C_{W E}+\frac{k \cdot \gamma \cdot C_{E}}{\eta} \cdot \frac{p_{S}}{\gamma}\right) \cdot V_{f}(t)
\end{gathered}
$$

Donde se observa que esta relación depende del volumen fugado, aunque no linealmente ya que los parámetros $Q_{i_{i}}, Q_{s_{i}}$ y $\Delta t_{a}$ están relacionados con el volumen fugado.

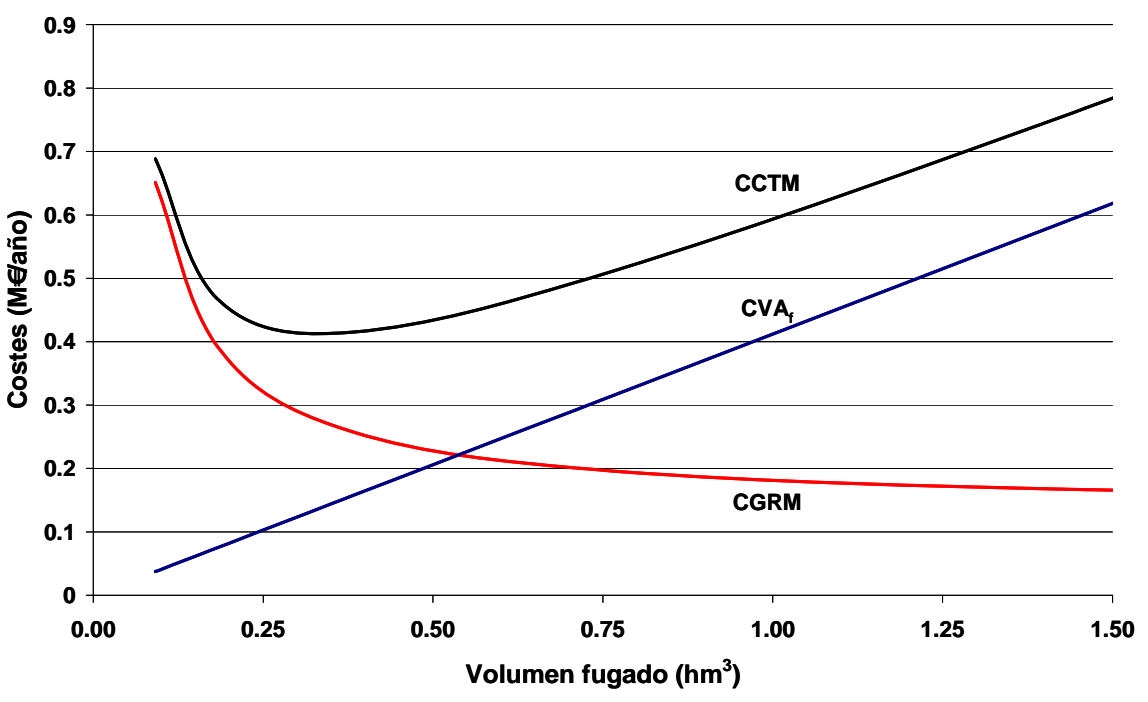

Figura C.3. CURVA DE COSTES TOtAlES EN MANTENIMIENTO. 


\section{OPTIMIZACIÓN A LARGO PLAZO: LA RENOVACIÓN}

Hasta este punto se ha presentado todo lo relativo a la optimización de fugas en un periodo corto de tiempo. Es de suponer que, a corto plazo, la red no se deteriora de forma significativa debido a la edad, y así, una optimización como la presentada (por cualquier método) puede continuar siendo válida durante un pequeño número de años ( 1 a 3, 5 a lo sumo, dependiendo de las particularidades del sistema). Sin embargo, sea mayor o menor dicho plazo, es indudable que con el deterioro asociado al paso del tiempo, las condiciones principales cambian. Y así, no sólo cambia el punto óptimo de reparaciones, sino que también entra en juego una nueva medida que es preciso tomar en consideración: la renovación de la red.

Efectivamente, por más que se optimice a corto plazo, con el paso del tiempo en la red aparecen cada vez más roturas, lo que implica mayores costes de mantenimiento (los ligados a la $\operatorname{CGRM}(t)$ ) y en algún momento hay que plantear su renovación.

El planteamiento para resolver la renovación en el tiempo de una tubería o, incluso, un sector de red ya fue resuelto por Shamir y Howard (1979) (también en el capítulo 4 de la tesis y en Pardo, 2007) considerando toda la serie temporal de los costes de las reparaciones necesarias a medida que el sector envejece, así como el coste de su renovación. Sin embargo, obviaban la posibilidad de que los costes de las reparaciones cada año (en el corto plazo) pueden optimizarse como ya se ha visto en el presente documento. De modo que, sobre los planteamientos anteriores (el de de Shamir y Howard (1979) es el principal y el resto son propuestas de mejora del mismo) cabe añadir todo lo visto hasta aquí, a modo de breve corolario de este trabajo. Con todo, es preciso adelantar que lo que se va a desarrollar es una versión simplificada del problema.

\subsection{Modelación del deterioro debido a la edad del sistema}

Es evidente que en la optimización económica del abastecimiento surge la incógnita de qué ocurre cuando, debido al paso de los años un sistema es significativamente más viejo y dicha optimización queda desfasada. La respuesta es sencilla. De nuevo, haciendo referencia a Shamir y Howard (1979), éstos representaron el envejecimiento de un sistema, utilizando una ley exponencial para modelar el número creciente de defectos que van apareciendo cada año, tal y como muestra la ecuación siguiente:

$N(t)=N\left(t_{0}\right) \cdot \exp \left(-A \cdot\left(t-t_{0}\right)\right)$ 
Donde:

$N(t)$ es el número defectos que aparecerán y habrá que reparar en el año t.

$A$ es el coeficiente que representa el ritmo de deterioro de la red (ritmo de aparición de los defectos).

Los defectos representados por las líneas diagonales de la Figura C.2 y que se reparan tras cada inspección, son siempre los mismos en el corto plazo. Ahora bien, cuando aumentan de forma significativa, debido al envejecimiento de la red, lo hacen de acuerdo con la ecuación (C.8). Por lo tanto, ligando el número de defectos inicial al INAF, según el caudal unitario de fuga (algo que ya se ha dado por supuesto implícito más arriba), se tiene la relación entre el corto plazo (INAF) y el largo plazo $(\exp (-A \cdot t))$ tal y como muestra la ecuación siguiente:

$\operatorname{INAF}(t)_{j}=q_{f} \cdot N\left(t_{0}\right) \cdot \exp \left(-A \cdot\left(t-t_{0}\right)\right)$

Donde $\operatorname{INAF}(t)_{j}$ hace referencia al periodo j considerado, y su valor depende del instante t de tiempo (Figura C.4). Asimismo, el volumen fugado en ese mismo periodo se define como:

$V_{f}(t)_{j}=q_{f} \cdot \Delta t_{a} \cdot N\left(t_{0}\right) \cdot \exp \left(-A \cdot\left(t-t_{0}\right)\right)=\operatorname{INAF}(t)_{j} \cdot \Delta t_{a}$

Por último, por la propia definición de INAF en el largo plazo, se puede mostrar la siguiente relación:

$n_{d_{j}}=\frac{\operatorname{INAF}(t)_{j}}{Q_{s_{i j}}-Q_{i_{i j}}}$

Donde $n_{d_{i}}$ es el nivel de inspecciones en el periodo j, mientras que $Q_{i_{i j}}$ y $Q_{S_{i}}$ representan respectivamente el nivel de partida y de inspección de la política i de reparación de las roturas en el mismo periodo j (Figura C.2).

La mejor forma representar este hecho es gráficamente. Supongamos que se ha optimizado una red en concreto en el corto plazo, y que el periodo de tiempo de dicho corto plazo, por centrar ideas, son 2 años. Ello querría decir que transcurridos los dos primeros años, el envejecimiento del sistema da lugar al aumento significativo del número de defectos que aparecen. Ocurre lo mostrado por la ecuación (C.9) pero que lo ilustra la Figura C.4 más adecuadamente ya que en el año $3^{\circ}$ y $4^{\circ}$ se tiene una mayor pendiente de las líneas diagonales (un mayor INAF), y lo mismo volverá a suceder en los años $5^{\circ}$ y $6^{\circ}$. Si, como sigue representando el caso de la Figura C.4, el objetivo de los gestores del sistema es mantener el nivel promedio de fugas en el mismo valor, ello les 
obliga a aumentar el número de inspecciones al año, pasando en ese caso primero de 1 a 2 inspecciones año y, a continuación de 2 a 3.

Sin embargo, lo que no se puede ver en esa Figura C.4 es que si los costes se habían optimizado económicamente para los dos primeros años, para cada pareja de los cuatro siguientes (es decir, $3^{\circ}$ y $4^{\circ}$ por un lado, $5^{\circ}$ y $6^{\circ}$ por otro) esa optimización seguro que se ha perdido, ya que las inspecciones y reparaciones de la red de cada uno de esos periodos de dos años se ha configurado con la condición de mantener el mismo nivel promedio, no sus costes totales en el mínimo posible.

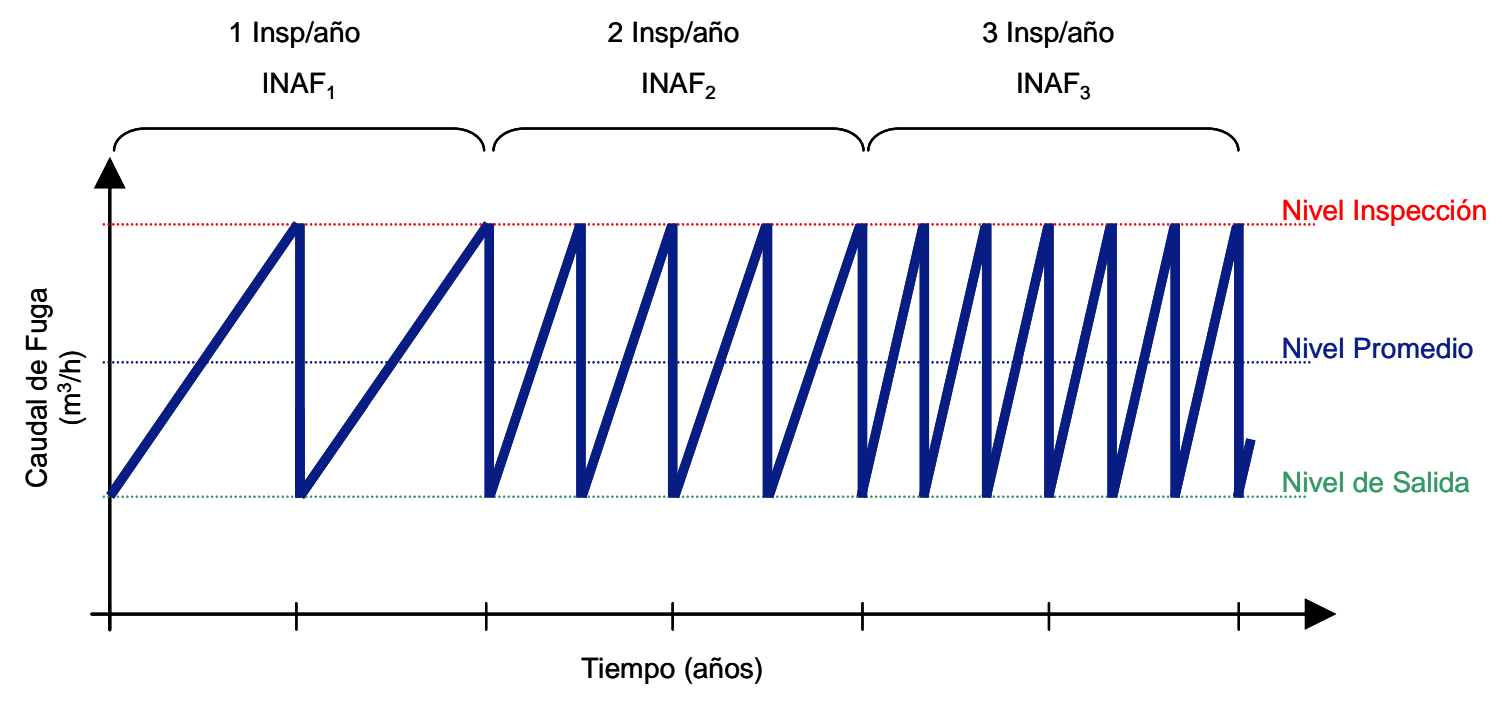

Figura C.4. AUMENTO DEL INAF A LARGO PLAZO. 


\subsection{Optimización del control activo de fugas con envejecimiento del sistema}

En el caso de optimizar económicamente el control activo de fugas, es prácticamente seguro (lo contrario sería una difícil casualidad) que cada nuevo intervalo de tiempo haya de asumir niveles de inspección y promedio algo mayores cada vez (y menos inspecciones), como contrapartida por mantener los costes totales en su mínimo posible.

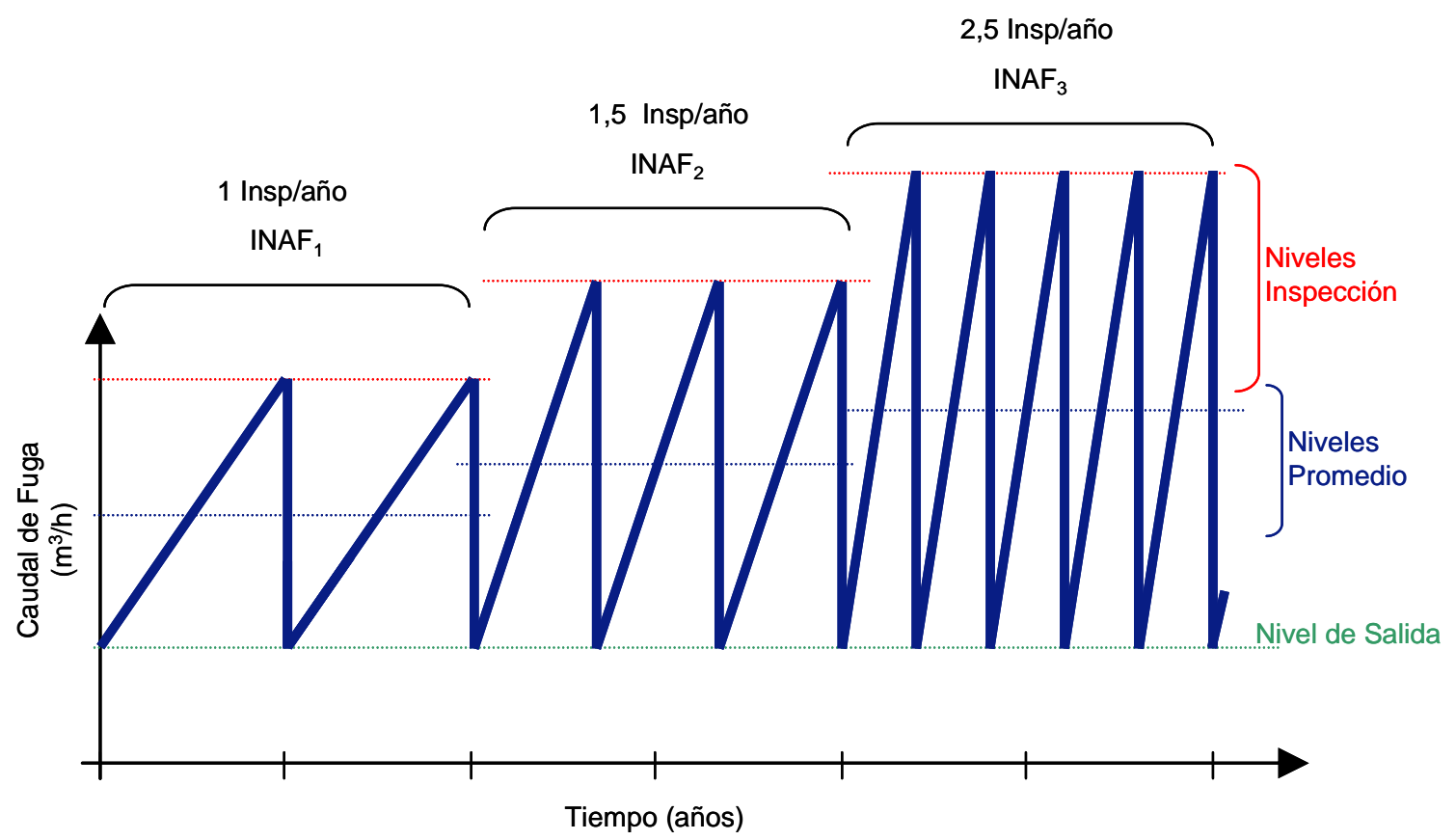

FIGURA C.5. TRES PERIODOS DE TIEMPO OPTIMIZADOS EN EL LARGO PLAZO

La Figura C.5 muestra la configuración que podrían tener dichos periodos de tiempo una vez optimizados económicamente, aunque, en realidad, en la misma no es posible apreciar el origen real de dicha optimización, que es su cálculo en función de los costes económicos. Para poder Ilevarla a cabo, hay dos factores fundamentales a tener en cuenta a la hora de resolverla en cada corto plazo:

- El diferente INAF debido al envejecimiento del sistema (ecuación (C.9)).

- El descuento temporal de las cantidades monetarias que se puede plantear de forma continua, en lugar de discreta, a partir de la misma tasa continua de actualización anual, r.

Estos dos nuevos factores dan lugar al hecho de que cada optimización (cada corto plazo) debe resolverse de forma independiente a las demás, según su propia configuración de curvas de costes, como las mostradas por la Figura C.5. El proceso de cálculo para la optimización es análogo al presentado en el apartado 2 del presente anexo. Para ello, se define la curva de costes totales en mantenimiento $\left(\operatorname{CCTM}(t)_{j}\right)$ para 
cada corto plazo considerado. Por tanto, primeramente se ha de calcular las curvas de gastos en reparaciones y mantenimiento para cada periodo de tiempo j, éstas sería la expresión que lo define:

$$
\begin{aligned}
\operatorname{CGRM}(t)_{j}=\left(n_{d_{j}} \cdot\right. & \left.C_{d_{j}}+C_{b} \cdot N(t)\right) \cdot e^{(-r \cdot t)}= \\
& =\left(\frac{C_{d_{j}}}{\left(Q_{s_{i j}}-Q_{i_{i j}}\right) \cdot \Delta t_{a_{j}}}+\frac{C_{b}}{q_{f_{j}} \cdot \Delta t_{a_{j}}}\right) \cdot V_{f}(t)_{j} \cdot e^{(-r \cdot t)}
\end{aligned}
$$

La curva del valor del agua fugada con respecto al tiempo se obtiene como:

$$
\begin{gathered}
\operatorname{CVA}_{f}(t)_{j}=C_{W} \cdot q_{f_{j}} \cdot N(t) \cdot \Delta t_{a_{j}} \cdot e^{(-r \cdot t)}+C_{W E} \cdot q_{f_{j}} \cdot N(t) \cdot \Delta t_{a_{j}} \cdot e^{(-r \cdot t)}+ \\
+\frac{k \cdot \gamma}{\eta} \cdot C_{E} \cdot \frac{p_{s_{j}}}{\gamma} \cdot q_{f_{j}} \cdot N(t)_{j} \cdot \Delta t_{a_{j}} \cdot e^{(-r \cdot t)}= \\
=\left(C_{W}+C_{W E}+\frac{k \cdot \gamma \cdot C_{E}}{\eta} \cdot \frac{p_{s_{j}}}{\gamma}\right) \cdot V_{f}(t)_{j} \cdot e^{(-r \cdot t)}
\end{gathered}
$$

Por lo que la curva de los costes totales en mantenimiento es:

$$
\operatorname{CCTM}(t)_{j}=\left(\frac{C_{d_{j}}}{\left(Q_{s_{i j}}-Q_{i_{i j}}\right) \cdot \Delta t_{a_{j}}}+\frac{C_{b_{j}}}{q_{f_{j}} \cdot \Delta t_{a_{j}}}+C_{W}+C_{W E}+\frac{k \cdot \gamma \cdot C_{E}}{\eta} \cdot \frac{p_{s_{j}}}{\gamma}\right) \cdot v_{f}(t)_{j} \cdot e^{(-r \cdot t)}
$$

La Figura C.6 muestra un ejemplo de la evolución de la curva $\operatorname{CCTM}(t)_{j}$ con el tiempo. En ella, se observa que el volumen óptimo de fugas va aumentando con el tiempo, algo esperado y también mostrado con en la Figura C.5.

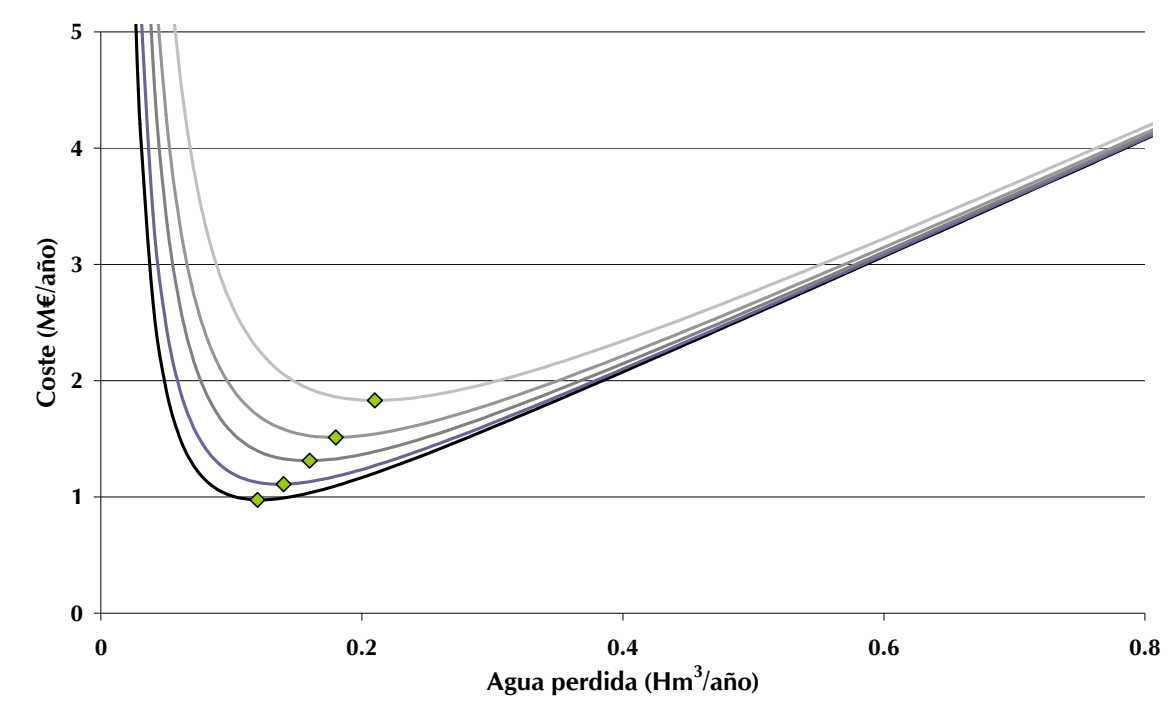

FIGURA C.6. EJEMPLO DE LA EVOLUCIÓN TEMPORAL DE LA CURVA DE COSTES TOTALES CON EL PASO DEL TIEMPO. 


\section{RELACIÓN ENTRE LAS POLÍTICAS A CORTO Y LARGO PLAZO}

Las políticas de gestión frente a las fugas tanto a corto plazo se han analizado por separado. Todo ello, pese a que es innegable que las decisiones adoptadas en el control de las fugas influirán en el largo plazo ya que modificarán el volumen de fugas y en consecuencia los costes de las fugas (definidos en el capítulo 4 de la tesis).

La cuantificación de esta influencia se puede resolver siguiendo con las indicaciones que a continuación se proponen. La idea principal es la discretización del tiempo que transcurre hasta que se produzca la renovación en un conjunto de políticas a corto plazo (Figura C.7). De este modo, para cada intervalo seleccionado (en el que no se considera el envejecimiento) se calculan sus propias incógnitas. Se proponen los siguientes pasos para determinar la influencia de las reparaciones en la renovación y se muestra una representación gráfica del mismo (Figura C.8).

1) En principio, se calcula el periodo óptimo de renovación siguiendo la propuesta del capítulo 4. Así, se obtiene el periodo óptimo de renovación y su coste asociado $\left(t_{r_{j}}^{*}\right.$ y $c_{T}\left(t_{r_{j}}^{*}\right)$ ) considerando que la vida media de las fugas es constante para todo el cálculo. Tanto es así, que si se obvian las influencias de las políticas a corto plazo, se podría considerar el problema como resuelto. De hecho, los trabajos que consideran este problema se quedan en este punto (Shamir y Howard, 1979; Cabrera y col., 2007 y Pardo, 2007).

2) Se concreta qué periodo de tiempo se entiende exactamente por corto plazo. Generalmente, un valor entre los 1 - 3 años suele ser la elección habitual, ya que mayores valores de tiempo provocan que la condición impuesta de que la red no envejezca pierda validez. Una vez se ha seleccionado este valor (diferencia entre $\mathrm{t}_{1}$ y to, Figura C.7) se determina el número de inspecciones y el volumen fugado (correspondiente con el coste total mínimo, apartado 2.3) para todos los intervalos desde el año actual to hasta el $t_{n+1}$ que cumple $t_{n+1}>t_{r_{j}}^{*}$.

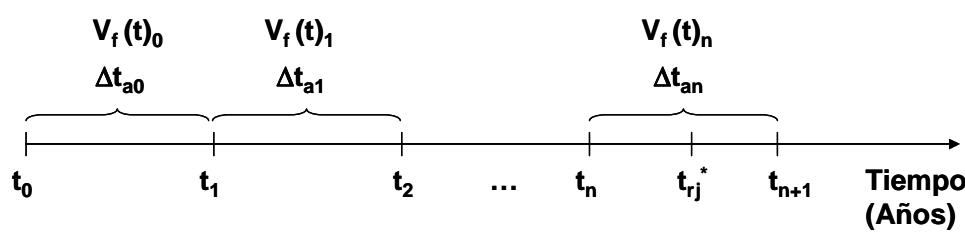


En este paso se ha discretizado el tiempo entre $\left[t_{0}, t_{r_{j}}^{*}\right]$ en un conjunto de intervalos en los que se plantean una política a corto plazo diferente. En el intervalo $\left[t_{n}, t_{n+1}\right]$, la política a corto plazo de inspecciones y reparaciones tiene validez hasta el instante de tiempo $t_{r_{j}}^{*}$, en el que se procede a la renovación.

3) Para cada intervalo de tiempo seleccionado (entre $t_{1}$ y $t_{0}, t_{2} y t_{1}$, etc.) se obtienen las curvas CCTM correspondientes. Esto devuelve los valores particulares de cada volumen de fuga óptimo $\left(v_{f}(t)_{j}\right)$ y por tanto, de cada tiempo medio de vida de la fuga $\Delta t_{a_{j}}$ y cada $\operatorname{INAF(t)}$ (parámetros relacionados entre sí con la ecuación (C.10).

4) Se plantea el análisis a largo plazo considerando las nuevas características facilitadas por los cálculos del punto anterior (de las políticas a corto plazo). Así, se obtienen el nuevo valor del periodo óptimo de renovación y su coste asociado $\left(t_{r_{j}}^{*}\right.$ y $\left.C_{T}\left(t_{r_{j}}^{*}\right)\right)$.

Esta propuesta que considera la influencia de las políticas de reparación en las de renovación produce un resultado diferente del tradicional. Obviamente, si siempre se gestiona una red con la política óptima, se prolonga la vida útil de la tubería y se alarga la renovación. Parece evidente que la duración de los intervalos en los que no se considera que la red envejezca es otro parámetro que influencia este estudio, cuanto más pequeño, más cercano a la realidad aunque también requerirá un mayor tiempo de cálculo. 
Este cálculo devuelve, desde la óptica económica, un mínimo minimorum, ya que el coste de inversión es mínimo tanto en el corto como en el largo plazo. Asimismo, considera el coste del agua y la energía.

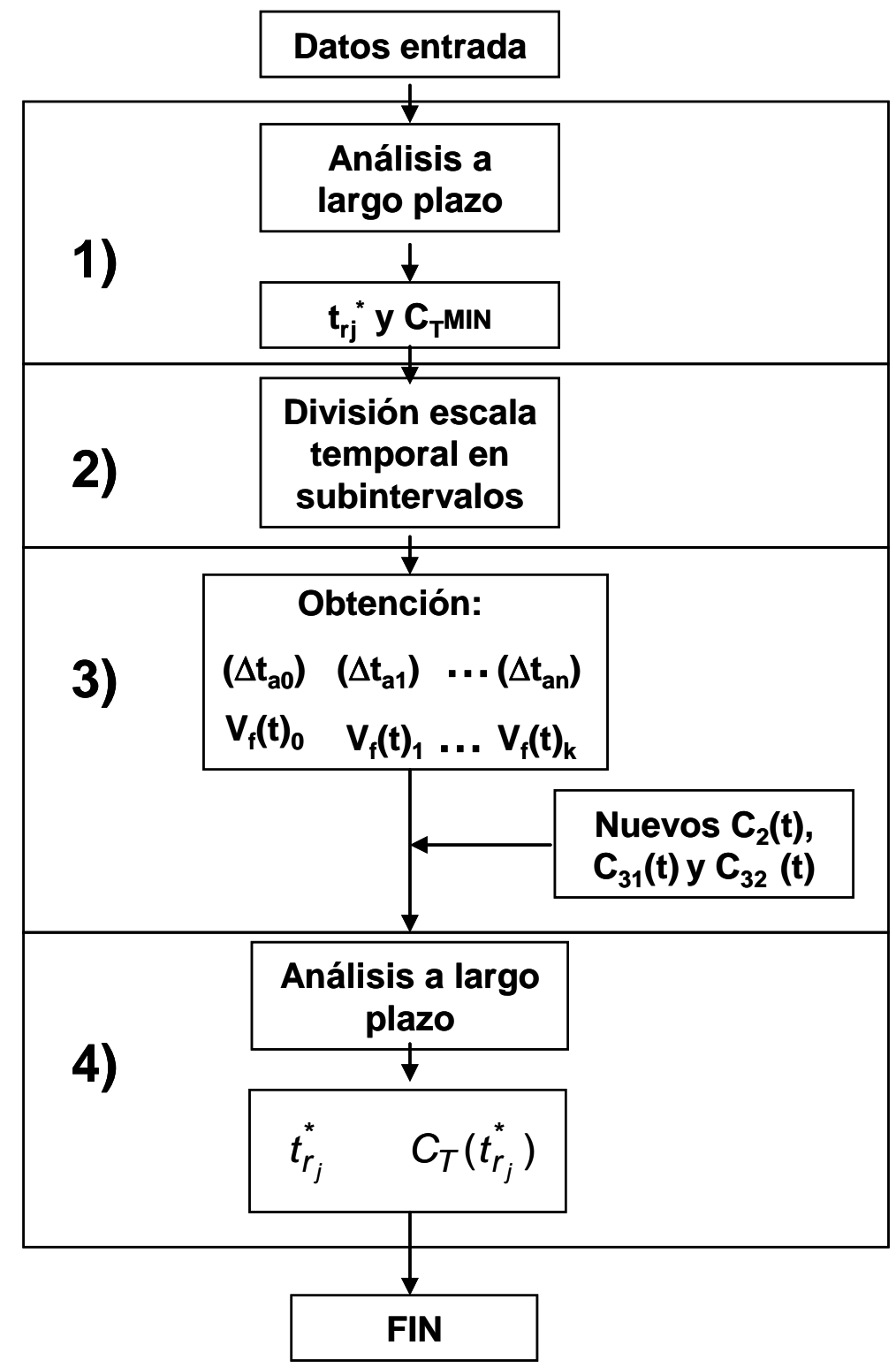

Figura C.8. PROCESO REALIZAdo PARA CONJUGAR LOS PERIODOS A LARGO Y A CORTO PLAZO. 


\section{ANEXO D}

Cuantificación del coste social 



\section{COSTES SOCIALES ASOCIADOS A LA RENOVACIÓN DE TUBERÍAS}

En el presente anexo se presenta una propuesta de cálculo del coste social asociado a una renovación. Con frecuencia, los trabajos que cuantifican los costes de una renovación únicamente se han orientado a los costes directos y han soslayado tanto los indirectos como los sociales.

Los costes sociales son más elevados para la alternativa de renovación tradicional que para las técnicas sin zanja. Precisamente por esto se han desarrollado las segundas, para paliar las molestias a comerciantes, viandantes, conductores, etc. y en definitiva, minimizar la excavación necesaria y en consecuencia, el coste social.

El primer trabajo que muestra la variabilidad los costes sociales en escenarios diferentes se centró en trabajos en redes de saneamiento (Peters, 1984). En éste se observó que el coste social llegó a ser desde un 88 hasta un 381\% del coste total de renovación. Los resultados del mismo se detallan en la Tabla D.1 y están expresados en libras del año 1982, con lo cual su estudio no es muy válido en la actualidad, pero el hecho de ser el primero en cuantificar estos costes justifica su incursión en el presente anexo.

Tabla D.1. C ostes sociales en Redes de Saneamiento (Peters, 1984).

\begin{tabular}{|c|c|c|c|}
\hline Proyecto & $\begin{array}{l}\text { Costes totales } \\
(£, 1982)\end{array}$ & $\begin{array}{c}\text { Costes sociales } \\
(£, 1982)\end{array}$ & $\begin{array}{c}\text { Porcentaje respecto } \\
\text { al total }\end{array}$ \\
\hline Union St. Glasgow 1984 & 410000 & 716000 & 175 \\
\hline Riversway, Lancashire 1981 & 32000 & 28000 & 88 \\
\hline $\begin{array}{l}\text { Mottram Road, } \\
\text { Manchester } 1981\end{array}$ & 38000 & 63000 & 166 \\
\hline $\begin{array}{l}\text { Petersham Road, } \\
\text { Surrey, 1978-79 }\end{array}$ & 2100000 & $5-8 M$ & $238-381$ \\
\hline
\end{tabular}

McKim (1997) también estima los costes sociales para 14 proyectos, y los resultados en lo cuantitativo no deparan sorpresa. La técnica tradicional originó unos costes sociales que variaron entre el 44 y el $492 \%$ del coste total de renovación, mientras que las técnicas sin zanja mostraron un valor menor del coste social (del 0 al $11 \%$ del coste total). 
Najafi y Gokhale (2004) muestran los términos que componen los costes sociales para la técnica tradicional con apertura de zanja, estos son:

- Interrupciones del tráfico rodado.

- Daños en el pavimento.

- Daños a las instalaciones colindantes.

- Ruidos y vibraciones.

- Seguridad de los viandantes.

- Daños a las estructuras contiguas.

- Pérdidas en los negocios.

- Daños en las carreteras que presentan una mayor densidad de tráfico debido a la existencia de una zanja que impide el tráfico.

- Quejas de los ciudadanos que se ven afectados por las obras.

- Daños en las infraestructuras cercanas, por ejemplo, en la red de saneamiento, o de gas, etc.

- Impacto ambiental de las obras.

Asimismo, se detalla una propuesta concreta para cada uno de los anteriores. De entre los descritos, destaca el cálculo del coste social debido a retrasos en el tráfico que ya fue descrito en Bush y Simonson (2001). En la cuantificación de las pérdidas de productividad por ruidos y vibraciones, tampoco propone nada nuevo porque utiliza el modelo de Boyce y Bried (1994).

En definitiva, el cálculo del coste social es complejo ya que muchos costes son indirectos (por ejemplo, pérdidas en negocios cercanos) y no los abona la compañía que realiza ejecuta la obra. Además, su cuantía será diferente para cada proyecto específico porque factores externos lo influencian (como densidad del tráfico, negocios afectados, etc.). En lo que sigue, se muestra una propuesta para la obtención del coste social que pretende ser aplicable a todas las técnicas existentes y en todos los casos particulares. En los siguientes apartados se detallan todos los costes que conforman los denominados costes sociales. 


\subsection{Interrupción del tráfico rodado $\left(\mathrm{C}_{41 \mathrm{~A}}\right)$.}

Un primer término a cuantificar sería el coste de la interrupción del tráfico rodado, en el que se pretende calcular el coste del tiempo debido a atascos o retrasos de los viandantes y conductores. Tighe y col (1999) definen el coste asociado según tres casos de actuación frente a la realización de una obra.

- Interrupción de un carril de circulación, circulando en ambas direcciones en un carril colindante.

- Corte de un carril de circulación, pero en el que se desvía el tráfico por el arcén sin molestar al carril aledaño.

- Corte total de una carretera, con el desvío del tráfico por calles cercanas.

Con estas tres alternativas posibles y a partir de la densidad media anual de vehículos que circulan por día por una calzada de una carretera ( $A A D T)$ se obtuvo $C_{41 A}^{\prime}$, que es el coste en $(€)$ de la interrupción del tráfico rodado (Tighe y col., 1999). La expresión de éste en (€/m del año presente) es:

$C_{41 A}\left(t_{r}\right)=x_{t 41} \cdot \frac{\alpha_{e s t} \cdot C_{41 A}^{\prime}(A A D T)}{I_{z}} \cdot e^{-r T_{f j}}$

Donde $C_{41 A}\left(t_{r}\right)$ representa el coste asociado a la interrupción del tráfico rodado, $x_{t 41}$ es el coeficiente de tecnología (variable según la alternativa empleada para la renovación), $\alpha_{\text {est }}$ es un coeficiente de estacionalidad utilizado para ponderar la densidad del tráfico en la época del año en que se ejecute la obra y $I_{z}$ representa la longitud de la zanja (este valor se utiliza para representar el coste asociado a la interrupción del tráfico rodado por metro lineal de zanja).

El coeficiente de estacionalidad $\alpha_{\text {est }}$ es función de la calle considerada y presenta valores valle en épocas estivales y punta en días como fiestas locales, etc. Este término, con valores cercanos a la unidad se debe cuantificar para cada renovación que se realice.

Los valores del coeficiente de tecnología son:

- $x_{t 41}=1$, si se emplea la técnica tradicional.

- $\quad x_{t 41}=0.1-0.2$, si se utiliza alguna técnica de renovación sin zanja. 
Con los valores anteriores se representa matemáticamente la situación real. El empleo de técnicas sin zanja reduce el coste social de interrupción de tráfico rodado, ya que no se desvía el tráfico, ni se corta un carril, etc. En cambio, la técnica tradicional si que tiene un mayor coste social.

\subsection{Daños que se realizan en el pavimento de carreteras cercanas a la obra}

$\left(\mathbf{C}_{41 B}\right)$.

Cuando se realiza una obra se producen dos tipos de daño al pavimento de las carreteras. El primero es el causado en las calles que se encuentran alrededor de la obra, y se deben a las tensiones generadas en una renovación y repercuten en la vida útil del pavimento. Algunas técnicas de renovación sin zanja, como inserción de tubería mediante el taladro con tornillo sin fin, hinca de tubería de hormigón y otros como perforación horizontal dirigida presentan arrastre de material subterráneo, por lo que provocan daños al pavimento colindante. Por otra parte, otros métodos como los englobados dentro de los revestimientos estructurales y no estructurales, perforación horizontal por impacto e hinca de tubería de acero no se caracterizan por la extracción del material y por tanto dañan el pavimento cercano.

El segundo sería el daño que se genera en las carreteras por las que se desvía el tráfico. En éstas la densidad de tráfico aumenta aunque no se puede considerar éste como representativo en el deterioro del pavimento, ya que el aumento puntual de la densidad de tráfico la duración de la obra (3 ó 4 meses) es despreciable frente a los 25 años de vida útil de la carretera.

Por tanto, en lo que sigue se pretende determinar únicamente el causado en el pavimento situado junto a la obra, ya que el coste de la reposición del pavimento excavado por una renovación se contempla en los costes de renovación $\left(c_{1}\left(t_{p}\right)\right.$, capítulo 4) y por eso no se considerará aquí nuevamente.

El indicador más común para determinar el estado del asfalto de carreteras es el pavement condition index (PCI). Éste adopta valores comprendidos entre 100 para un pavimento en perfecto estado y 0 para un pavimento roto o en mal estado. Los valores intermedios, que dependen del tipo de daño, la severidad y la cantidad de los fallos existentes se detallan en la Tabla D.2. 
TABLA D.2. RANGOS DE CALIFICACIÓN DEL PCI.

\begin{tabular}{cc}
\hline Rango & Clasificación del PCI \\
\hline $100-86$ & Excelente \\
$85-71$ & Muy bueno \\
$70-56$ & Bueno \\
$55-41$ & Regular \\
$40-25$ & Malo \\
$25-10$ & Muy Malo \\
$10-0$ & Roto \\
\hline
\end{tabular}

El criterio que se adopta para tomar la decisión de cambiar el pavimento, se corresponde con el intervalo de valores de PCI 55-60 para calles con importante densidad de tráfico (vías principales), mientras que ese intervalo se puede flexibilizar un poco más (PCl 45-50) para vías menos transitadas.

La vida media del asfalto en una arteria principal del tráfico urbano que ha sido asfaltada hace 1 ó 7 años se reduce en un 31 ó en un 34\% si renueva con el método clásico (Tighe y col., 2002), mientras que si la renovación se realiza en una vía secundaria la vida media se reduce en un $28 \%$ o un $42 \%$ respectivamente (según el número de años que han transcurrido desde que se realizó el último asfaltado).

El parámetro con el que se describe la reducción de la vida útil $\left(R_{v u}\right)$ adopta valores distintos según la técnica empleada para la renovación (Tabla D.3). Algunas técnicas sin zanja provocan esfuerzos de tracción al pavimento con deterioro estructural (en especial las de inserción de tuberías mediante rotura de tubería por percusión), por lo que se reduce la vida útil de la conducción. En cambio si se extrae el material excavado durante la instalación de la nueva tubería, las tensiones en el asfalto son menores y el término $R_{v u}$ adoptará valores menores que los anteriores aunque siempre superiores a 0.

El coste asociado a los daños que se realizan en las carreteras (en $€$ del año presente) se calcula como:

$C_{41 B}\left(t_{r}\right)=R_{v u} \cdot b \cdot C_{u p} \cdot e^{-r T_{t j}}$

Donde $C_{41 \mathrm{~B}}\left(t_{r}\right)$ es la evolución temporal del coste asociado a los daños que se realizan en las carreteras, $R_{v u}$ es la reducción de la vida útil de la carretera, $b$ es el ancho de la zanja y $C_{u p}$ es el coste unitario de reparación de carreteras en $\left(€ / \mathrm{m}^{2}\right)$. 
TABLA D.3. REDUCCIÓN DE LA VIDA UTIL DEL PAVIMENTO.

\begin{tabular}{|c|c|c|c|}
\hline \multirow[b]{2}{*}{ Tipo de técnica } & \multicolumn{2}{|c|}{$\begin{array}{c}\text { Reducción en vida útil } \\
(\%)\end{array}$} & \multirow{2}{*}{$\begin{array}{c}\text { Años } \\
\text { transcurridos } \\
\text { desde asfaltado }\end{array}$} \\
\hline & $\begin{array}{c}\text { Vía } \\
\text { principal }\end{array}$ & $\begin{array}{l}\text { Vía } \\
\text { secundaria }\end{array}$ & \\
\hline Método clásico con apertura de zanja & $31^{1}$ & $28^{1}$ & 1 \\
\hline Método clásico con apertura de zanja & $34^{1}$ & $42^{1}$ & 7 \\
\hline Revestimientos no estructurales & 0 & 0 & 1 \\
\hline Revestimientos no estructurales & 0 & 0 & 7 \\
\hline Revestimientos estructurales & 0 & 0 & 1 \\
\hline Revestimientos estructurales & 0 & 0 & 7 \\
\hline $\begin{array}{l}\text { Inserción de tubería mediante un sistema } \\
\text { accionado hidráulicamente }\end{array}$ & 0 & 0 & 1 \\
\hline $\begin{array}{l}\text { Inserción de tubería mediante un sistema } \\
\text { accionado hidráulicamente }\end{array}$ & 0 & 0 & 7 \\
\hline Inserción de tubería mediante rotura por percusión & 20 & 18 & 1 \\
\hline Inserción de tubería mediante rotura por percusión & 22 & 27 & 7 \\
\hline Inserción mediante rotura de tubería con cuchilla & 0 & 0 & 1 \\
\hline Inserción mediante rotura de tubería con cuchilla & 0 & 0 & 7 \\
\hline Perforación horizontal dirigida & 10 & 9 & 1 \\
\hline Perforación horizontal dirigida & 11 & 14 & 7 \\
\hline $\begin{array}{l}\text { Inserción de tubería mediante el taladro con tornillo } \\
\qquad \sin \text { fin }\end{array}$ & 8 & 7 & 1 \\
\hline $\begin{array}{l}\text { Inserción de tubería mediante el taladro con tornillo } \\
\qquad \sin \text { fin }\end{array}$ & 7 & 9 & 7 \\
\hline Hinca de tubería de hormigón & 12 & 11 & 1 \\
\hline Hinca de tubería de hormigón & 13 & 16 & 7 \\
\hline Perforación horizontal por impacto & 20 & 18 & 1 \\
\hline Perforación horizontal por impacto & 22 & 27 & 7 \\
\hline Hinca de tubería de acero & 15 & 13 & 1 \\
\hline Hinca de tubería de acero & 17 & 21 & 7 \\
\hline
\end{tabular}

\footnotetext{
${ }^{1}$ Valores obtenidos según Tighe y col. (2002).
} 


\subsection{Pérdida de productividad por ruidos y vibraciones $\left(C_{41 c}\right)$.}

Otro coste social originado por una renovación de tuberías son las pérdidas de productividad por ruidos y vibraciones. La cuantificación de éstos tampoco es sencilla ya que la gente reacciona de manera diferente frente al ruido. Algunas personas siguen trabajando exactamente igual, otras reducen levemente su productividad, mientras algunas dejan de trabajar ante la imposibilidad de la concentración. Sin duda el tipo de trabajo también condiciona esta respuesta.

La expresión que se propone para cuantificar estas pérdidas de productividad (en $€$ del año actual) se calcula como:

$C_{41 C}\left(t_{r}\right)=x_{t 43} \cdot \frac{t_{\text {perd }} \cdot \rho_{g} \cdot C_{t} \cdot t_{\text {dur }}}{h_{\text {dia }}} \cdot e^{-r T_{f j}}$

Donde $C_{41 C}\left(t_{r}\right)$ es la evolución temporal del coste asociado a las pérdidas de productividad por ruidos y vibraciones, $x_{t 43}$ es el coeficiente de tecnología, $t_{\text {perd }}$ es el tiempo medio perdido en horas por trabajador y día, $\rho_{g}$ es la densidad de trabajadores afectados, $h_{\text {dia }}$ es el número medio de horas de trabajo al día de los operarios encargados de la realización de la renovación, $c_{t}$ es el coste medio de la hora trabajada en $(€ / h)$ y $t_{\text {dur }}$ es el tiempo de duración de la renovación (en horas).

En la expresión anterior, se adopta un tiempo medio perdido y una densidad media de personas afectadas (número de personas por unidad de longitud), aunque si se quisiera afinar más en el cálculo, se podría separar estos datos personalizando en el tipo de trabajo, el número de trabajadores según la tarea desarrollada etc.

Para cuantificar el efecto que supone el uso de tecnologías sin zanja en este término, se ha definido el coeficiente de tecnología que varía entre 0 y 1 . El valor inferior se asimila al empleo de una técnica que no produce ni ruidos ni vibraciones mientras que el superior será para la técnica más ruidosa. Los valores numéricos propuestos se muestran a continuación (Tabla D.4). 
TABLA D.4. COEFICIENTE DE TECNOLOGÍA EMPLEADOS EN LA CUANTIFICACIÓN DE LAS PÉRDIDAS DE PRODUCTIVIDAD POR RUIDOS Y VIBRACIONES.

\begin{tabular}{lc}
\hline \multicolumn{1}{c}{ Tipo de técnica } & $x_{t_{43}}$ \\
\hline Método clásico & 1 \\
Revestimientos no estructurales & 0 \\
Revestimientos estructurales & 0 \\
Inserción de tubería mediante un sistema & 0,2 \\
Inserción de tubería mediante rotura por percusión & $0.7-0.6$ \\
Inserción mediante rotura de tubería con cuchilla & 0.2 \\
Perforación horizontal dirigida & 0.5 \\
Inserción de tubería mediante el taladro con tornillo sin fin & 0.3 \\
Hinca de tubería de hormigón & $0.7-0.6$ \\
Perforación horizontal por impacto & $0.5-0.6$ \\
Hinca de tubería de acero & $0.5-0.6$ \\
\hline
\end{tabular}

\subsection{Pérdidas en los negocios cercanos $\left(\mathrm{C}_{41 \mathrm{D}}\right)$.}

En las más de las ocasiones, algunos negocios se ven afectados por las obras. Por ejemplo, recientemente en Madrid, la construcción del metro en la propia puerta del sol afectó significativamente todos los negocios allí instalados, desde cafeterías hasta vendedores de lotería. Sin duda, la renovación de una tubería no es una obra tan grande como la construcción de una estación de metro, aunque también afecta a los ingresos de los negocios afectados. Por ejemplo, una cafetería que no pueda instalar una terraza ya que el ruido, el polvo y la contaminación visual de la obra lo impide.

La expresión que cuantifica las pérdidas en los negocios cercanos es:

$C_{41 D}\left(t_{r}\right)=x_{t 44} \cdot \frac{\rho_{n} \cdot C_{m e d} \cdot t_{d u r}}{h_{d i a}} \cdot e^{-r T_{f j}}$ 
Donde $C_{41 D}\left(t_{r}\right)$ es la evolución temporal del coste asociado a pérdidas en los negocios cercanos a la realización de obras (en $€$ del año presente), $x_{t 44}$ es el coeficiente de tecnología que varía entre según el método de renovación empleado, $\rho_{n}$ es la densidad media de negocios afectados por la obra se calcula como el número de negocios afectados por metro lineal de tubería, $h_{\text {dia }}$ es el número medio de horas de trabajo al día de los operarios encargados de la realización de la renovación, $c_{\text {med }}$ es el coste medio perdido por los negocios afectados expresado en $\left(€ /\right.$ día) y $t_{d u r}$ es el tiempo de duración de la rehabilitación (día).

Por último, el coeficiente de tecnología para el término pérdidas en los negocios cercanos presenta los valores

$x_{t 44}=1$, si se emplea el método tradicional

$x_{t 44}=0$, con las técnicas sin zanja.

\subsection{Otros}

Los costes sociales considerados más frecuentemente son los definidos en los Apartados 1.1, 1.2, 1.3 y 1.4. El resto, que seguidamente se enumeran, son menos importantes cuantitativamente.

- $\quad C_{41 F}$, coste de las quejas de los ciudadanos afectados por la realización de obras.

- $\quad C_{41 G}$, coste de las limpiezas adicionales para eliminar la cantidad extra de polvo en las zonas cercanas a las obras.

- $\quad C_{41 H}$, coste del aumento de la probabilidad de accidentes que afectan a viandantes, conductores y operarios por efecto de la obra.

- $C_{411}$, coste del deterioro de las estructuras e instalaciones colindantes a la obra.

- $\quad C_{41 \mathrm{~J}}$, coste de los problemas por las inclemencias meteorológicas.

Éstos se pueden contabilizar con el cálculo de cada uno de los anteriores o como un porcentaje de la suma de todos los costes definidos en los apartados 1.1, 1.2, 1.3 y 1.4. La expresión que los cuantifica es:

$C_{4 O}\left(t_{r}\right)=x_{t O} \cdot\left(C_{41 A}+C_{41 B}+C_{41 C}+C_{41 D}\right) \cdot e^{-r T_{f j}}$ 
Donde $C_{4 O}$ representa la suma de los otros costes sociales y $x_{t O}$ un coeficiente de ponderación en tanto por uno que representa la importancia de estos costes sociales en comparación con los definidos en los apartados anteriores.

\subsection{Obtención del Coste social}

El coste social de la renovación se obtiene con la expresión siguiente:

$$
C_{41}\left(t_{r}\right) \equiv C_{41 A}\left(t_{r}\right)+C_{41 B}\left(t_{r}\right)+C_{41 C}\left(t_{r}\right)+C_{41 D}\left(t_{r}\right)+C_{4 O}\left(t_{r}\right)=C_{S_{j}} \cdot e^{-r T_{t_{j}}}
$$

Donde el término $C_{S i j}$ se obtiene como:

$$
\begin{aligned}
C_{S_{j}}=\left(x_{t 41} \cdot \frac{\alpha_{\text {est }} \cdot}{C_{41 A}^{\prime}(A A D T)}\right. & I_{z}+R_{v u} \cdot b \cdot C_{u p}+ \\
& \left.+x_{t 43} \cdot \frac{t_{\text {perd }} \cdot \rho_{g} \cdot C_{t} \cdot t_{\text {dur }}}{h_{\text {dia }}}+x_{t 44} \cdot \frac{\rho_{n} \cdot C_{\text {med }} \cdot t_{\text {dur }}}{h_{\text {dia }}}\right) \cdot\left(1+x_{t O}\right)
\end{aligned}
$$

A partir de la expresión anterior, se definen los siguientes términos.

$$
\begin{array}{ll}
A=\frac{\alpha_{\text {est }} \cdot C_{41 A}^{\prime}(A A D T)}{I_{z}} & B=b \cdot C_{\text {up }} \\
C=\frac{t_{\text {perd }} \cdot \rho_{g} \cdot C_{t} \cdot t_{\text {dur }}}{h_{\text {dia }}} & D=\frac{\rho_{n} \cdot C_{\text {med }} \cdot t_{\text {dur }}}{h_{\text {dia }}}
\end{array}
$$

Donde se observa que los términos A, B, C y D (en €/m) en son independientes de la técnica empleada en la renovación y únicamente dependen del tipo de obra realizada. El parámetro $\mathrm{D}$, por ejemplo, se refiere a las pérdidas en los negocios cercanos, mientras que el $\mathrm{A}$ se refiere a los cortes de tráfico rodado.

El término que expresa la reducción de la vida útil para el asfalto ( $R_{v u}$, Tabla D.3), se vuelve a definir análogamente a los restantes coeficientes de tecnología como el término $x_{t 42}$ asociado a los daños que se realizan al pavimento de las carreteras. De este modo se homogeneiza la nomenclatura y se compactan las expresiones siguientes (ecuación A5.8).

Con lo que obtenemos que el coste social asociado a las perturbaciones por obras, $c_{S_{j}}$ se calcula como:

$$
C_{S_{j}}=\left(A \cdot x_{t 41}+B \cdot x_{t 42}+C \cdot x_{t 43}+D \cdot x_{t 44}\right) \cdot\left(1+x_{t O}\right)
$$


Los coeficientes $x_{t 4 i}$ dependen única y exclusivamente de la técnica empleada en la renovación. Por tanto, se ha conseguido convertir una expresión dependiente del tipo de coste social considerado y tipo de técnica como un producto de dos funciones, una exclusivamente dependiente del tipo de coste social y otra de la alternativa de la renovación utilizada. En otras palabras, se han separado las variables. En la Tabla D.5 se muestran a modo de resumen los valores de dichos coeficientes.

TABLA D.5. COEFICIENTES DE TECNOLOGÍA EMPLEADOS EN LA CUANTIFICACIÓN DE LOS COSTES SOCIALES.

\begin{tabular}{|c|c|c|c|c|}
\hline Técnica & $x_{t 41}$ & $x_{t 42}$ & $x_{t 43}$ & $x_{t 44}$ \\
\hline Método clásico & 1 & 0.32 & 1 & 1 \\
\hline Revestimientos no estructurales & 0.15 & 0 & 0 & 0 \\
\hline Revestimientos estructurales & 0.15 & 0 & 0 & 0 \\
\hline $\begin{array}{l}\text { Inserción mediante rotura de tubería por } \\
\text { apertura y cierre de un cabezal accionado } \\
\text { hidráulicamente }\end{array}$ & 0.15 & 0 & 0.2 & 0 \\
\hline $\begin{array}{l}\text { Inserción de tubería mediante rotura por } \\
\text { percusión }\end{array}$ & 0.15 & 0.21 & 0.65 & 0 \\
\hline $\begin{array}{l}\text { Inserción mediante rotura de tubería con } \\
\text { cuchilla }\end{array}$ & 0.15 & 0 & 0.2 & 0 \\
\hline Perforación horizontal dirigida & 0.15 & 0.105 & 0.5 & 0 \\
\hline $\begin{array}{l}\text { Inserción de tubería mediante el taladro } \\
\text { con tornillo } \sin \text { fin }\end{array}$ & 0.15 & 0.075 & 0.3 & 0 \\
\hline Hinca de tubería de hormigón & 0.15 & 0.12 & 0.65 & 0 \\
\hline Perforación horizontal por impacto & 0.15 & 0.21 & 0.55 & 0 \\
\hline Hinca de tubería de acero & 0.15 & 0.16 & 0.55 & 0 \\
\hline
\end{tabular}

Por tanto, si se expresa la ecuación 5.8 de forma matricial², se obtiene:

$\left(\begin{array}{l}C_{S Z} \\ C_{S R N E} \\ C_{S R E} \\ \cdots \\ C_{S H D D}\end{array}\right)=\left(\begin{array}{cccc}x_{t 41 Z} & x_{t 42 Z} & x_{t 43 Z} & x_{t 44 Z} \\ x_{t 41 R N E} & x_{t 42 R N E} & x_{t 43 R N E} & x_{t 44 R N E} \\ x_{t 41 R E} & x_{t 42 R E} & x_{t 43 R E} & x_{t 44 R E} \\ \ldots & \ldots & \ldots & \cdots \\ x_{t 41 H D D} & x_{t 42 H D D} & x_{t 43 H D D} & x_{t 44 H D D}\end{array}\right) \cdot\left(\begin{array}{l}A \\ B \\ C \\ B\end{array}\right) \cdot\left(1+x_{t O}\right)$

\footnotetext{
${ }^{2}$ Los subíndices de los coeficientes de tecnología y del coste social se refieren al tipo de técnica y están definidos en el ejemplo numérico, apartado 1.7 del presente anexo.
} 
La matriz de coeficientes es adimensional y se puede particularizar utilizando los datos de la Tabla D.5. El vector columna que depende del tipo de coste adopta diferentes valores numéricos para cada obra concreta y son por tanto constantes. Con esta expresión se puede calcular los costes sociales en función de una alternativa específica, tal y como se detalla en el siguiente ejemplo numérico.

\subsection{Ejemplo Numérico}

En lo que sigue se propone un ejemplo numérico que evalúe los costes sociales de la renovación de una tubería mediante la técnica tradicional y las alternativas sin zanja. Para facilitar la identificación de cada técnica se han definido unos subíndices que se muestran a continuación junto con el nombre de la alternativa, estos son:

- Renovación con apertura de zanja, Z.

- Revestimientos no estructurales, RNE

- Revestimientos estructurales, RE

- Inserción mediante rotura de tubería por apertura y cierre de un cabezal accionado hidráulicamente, HPB.

- Inserción de tubería mediante rotura por percusión, NPB.

- Inserción mediante rotura de tubería con cuchilla, PS.

- Perforación horizontal dirigida, HDD.

- Inserción de tubería mediante el taladro con tornillo sin fin, PTSF.

- Hinca de tubería de hormigón, HTH.

- Perforación horizontal por impacto, PHI.

- Hinca de tubería de acero, HTA.

\subsubsection{Planteamiento del caso}

La renovación considerada presenta las siguientes características. Se abre una cata de longitud $I_{z}=4 \mathrm{~m}$ y una anchura de $b=3.75 \mathrm{~m}$, durante el mes de Junio (un mes que no es estival, aunque tampoco es de los que presenta una mayor densidad de tráfico) por lo que $\alpha_{\text {est }}=1$. 1 . La densidad de tráfico de esa calle es $\mathrm{AADT}=2500$ vehículos/día y la obra se ejecutará en un tiempo $t_{\text {dur }}=160$ horas y para ello se desviará el tráfico por una calle cercana.

El coste de reparación del pavimento en una vía urbana es $C_{u p}=29\left(€ / \mathrm{m}^{2}\right)$. En la calle no existen muchos trabajadores a pie de obra, tanto es así que se estima que la renovación genera molestias a un $\rho_{g}=0.015$ personas $/ \mathrm{m}$ (similar a decir que 3 
trabajadores por cada $200 \mathrm{~m}$ ) y éstos se estima que pierden $t_{\text {perd }}=2 \mathrm{~h} /$ día de las 8 horas que trabajan al día y que se pagan en media a $C_{t}=12(€ / \mathrm{h})$.

Tampoco existen muchos negocios en las inmediaciones de la obra, y se estima que ésta afecta a $\rho_{n}=0.02$ negocios $/ \mathrm{m}$. El coste medio perdido por cada negocio es $C_{\text {med }}=60 € /$ día. Por último, se estima que los otros costes sociales son un $10 \%$ de los costes sociales calculados $\left(x_{t o}=0.1\right)$.

\subsubsection{Resultados}

Con un ancho de cata de 3.75m, 160 horas de duración de la obra y con el desvío del tráfico por una calle cercana, se calcula el coste asociado a la interrupción del tráfico rodado $\left(C_{41}^{\prime}\right)$ con la siguiente expresión (Tighe y col., 1999):

$\log \left(C_{41}^{\prime}\right)=0.00051 \cdot A A D T+1.179$, de donde se obtiene que $C_{41}^{\prime}=284.4 €$.

Con este dato, ya se pueden calcular los valores del parámetro A. Asimismo se calculan los otros términos $B, C, D$ y $E$.

$$
\begin{aligned}
& A=\frac{\alpha_{\text {est }} \cdot C_{41 A}^{\prime}\left(A A D T_{\text {tr }}\right)}{I_{z}}=\frac{1.1 \cdot 284.4}{4}=78.2(€ / \mathrm{m}) \\
& B=b \cdot C_{\text {up }}=3.75 \cdot 29=108.8(€ / \mathrm{m}) \\
& C=\frac{t_{\text {perd }} \cdot \rho_{g} \cdot C_{t} \cdot t_{\text {dur }}}{h_{\text {dia }}}=\frac{2 \cdot 0.015 \cdot 12 \cdot 160}{8}=7.2(€ / \mathrm{m}) \\
& D=\frac{\rho_{n} \cdot C_{\text {med }} \cdot t_{\text {dur }}}{h_{\text {dia }}}=\frac{0.02 \cdot 60 \cdot 160}{8}=24(€ / \mathrm{m})
\end{aligned}
$$

Seguidamente se plantea la ecuación en su forma matricial (ecuación 5.9):

$$
\left(\begin{array}{l}
C_{S_{Z}} \\
C_{S R N E} \\
C_{S R E} \\
\ldots . . \\
C_{S H D D}
\end{array}\right)=\left(\begin{array}{cccc}
1 & 0.32 & 1 & 1 \\
0.15 & 0 & 0 & 0 \\
0.15 & 0 & 0 & 0 \\
\ldots & \ldots & \ldots & \ldots \\
0.15 & 0.105 & 0.5 & 0
\end{array}\right) \cdot\left(\begin{array}{c}
78.2 \\
108.8 \\
7.2 \\
24
\end{array}\right) \cdot(1+0.1)
$$

Y se obtienen los siguientes valores: 
$\left(\begin{array}{c}C_{S Z} \\ C_{S R N E} \\ C_{S R E} \\ C_{S H B} \\ C_{S \text { SPB }} \\ C_{S P S} \\ C_{S H D D} \\ C_{\text {STSF }} \\ C_{\text {SHTH }} \\ C_{\text {SPHI }} \\ C_{\text {SHTA }}\end{array}\right)=\left(\begin{array}{c}158.64 \\ 12.91 \\ 12.91 \\ 14.49 \\ 43.18 \\ 14.49 \\ 34.81 \\ 24.25 \\ 32.41 \\ 42.38 \\ 36.40\end{array}\right)(€ / \mathrm{m})$

Donde se observa que el mayor coste social era, como cabía esperar, el asociado a la técnica tradicional. Los costes sociales de los revestimientos, tanto estructurales como no estructurales, representan el $8.95 \%$ del coste social máximo. Mientras que otras técnicas como la inserción de tubería mediante rotura por percusión no presenta tantas ventajas en coste social y su coste $43.18 € / \mathrm{m}$ representa casi un $30 \%$ del máximo de la técnica con apertura de zanja. En general los resultados muestran un coste social muy inferior de las técnicas sin zanja.

Se ha obtenido el término $c_{S_{j}}$ con el que se puede calcular $c_{41}\left(t_{r}\right)$ (ecuación A5.6). Análogamente se puede calcular el coste social total en euros del presente año para cada una de las técnicas seleccionadas (Figura D.1). Dicha evolución temporal es similar, como no puede ser de otra forma, a la obtenida para el coste de la renovación de la conducción $c_{1}\left(t_{r}\right)$.

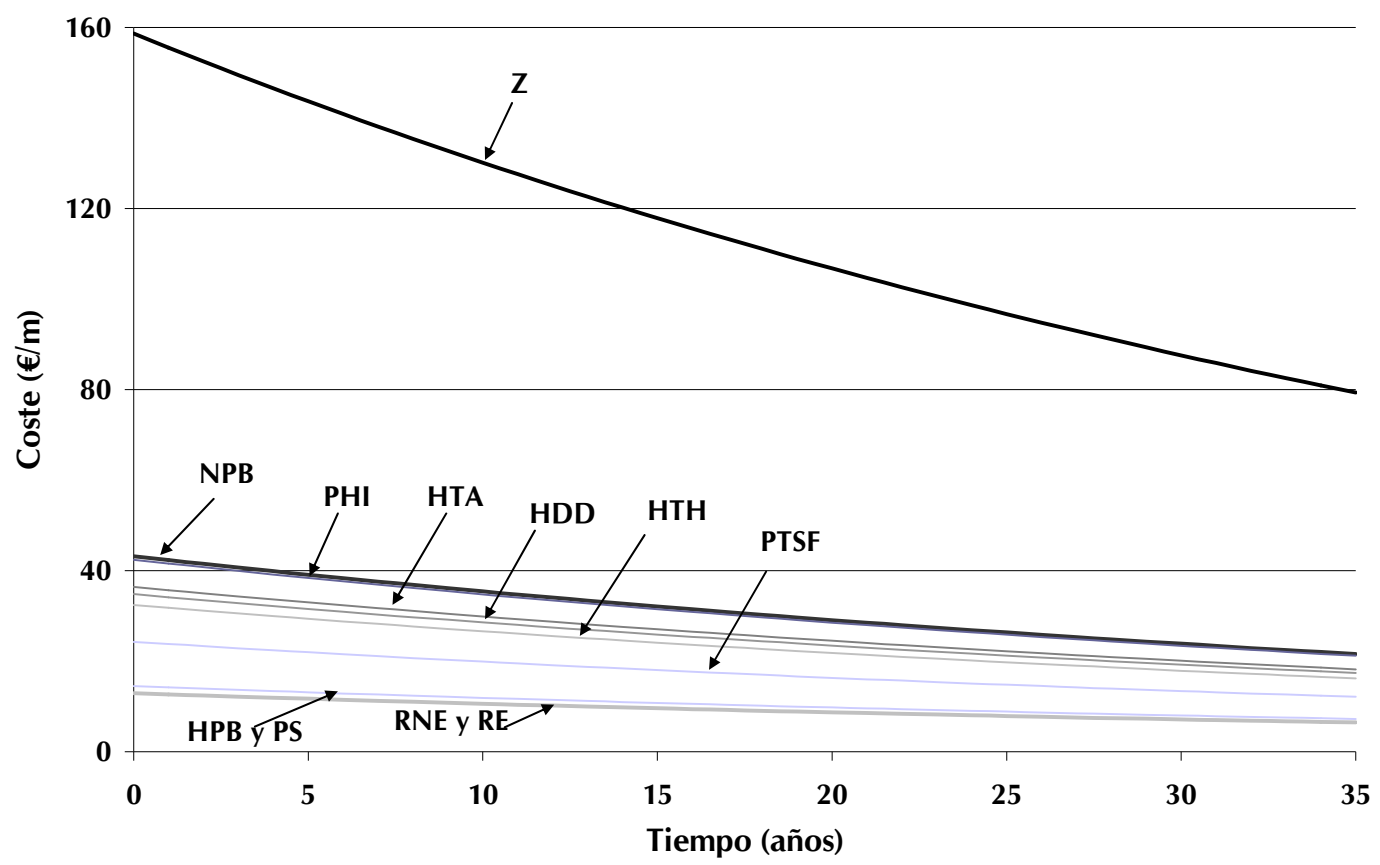

FIGURA D.1. COSTES SOCIALES ASOCIADOS A DISTINTAS TÉCNICAS DE RENOVACIÓN. 
Si se considera por separado la influencia de cada uno de los costes definidos en el coste social total, se obtiene que el presente ejemplo numérico (y específicamente, en caso del empleo de la renovación con zanja abierta) los costes asociados a la interrupción del tráfico y daños al pavimento son los más significativos, mientras que las pérdidas de productividad en el trabajo son los menos influyentes, Figura D.2.

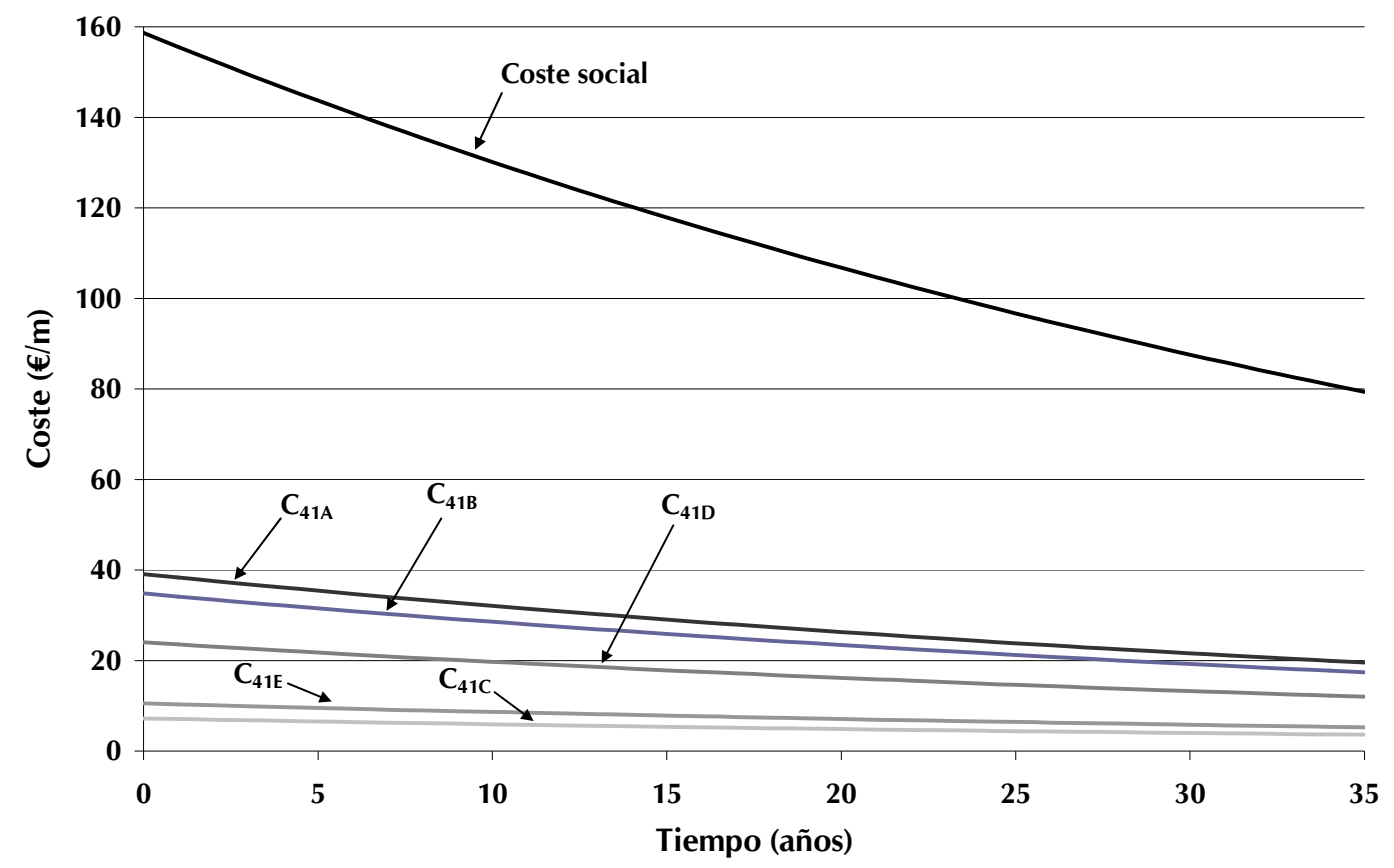

FIGURA D.2. COSTES SOCIALES DE LA RENOVACIÓN DE UNA TUBERÍA CON LA TÉCNICA DE APERTURA DE ZANJA. 



\section{ANEXO E}

Evaluación del consumo energético para un sistema con y sin válvula 



\section{Evaluación del CONSUmo energético PARA UN SISTEMa CON Y SIN VÁLVULA.}

En el presete anexo se pretende comprobar analíticamente que la instalación de una válvula de regulación en una red de distribución, aún cuando representa una energía perdida por disipación, genera una disminución de la energía que se ha de aportar a la red.

La instalación de una válvula siempre se plantea en sistemas con un excedente de energía en ciertos sectores o zonas de la red. Hasta ahora, el principal objetivo ha sido la cuantificación de los ahorros hídricos asociados a la reducción de las sobrepresiones (habitualmente en periodos nocturnos de menor consumo). Sin embargo, otro beneficio de igual magnitud cobra relevancia, el ahorro de energía.

A continuación se plantea la auditoría energética en dos redes equipada con y sin válvula de regulación. En el apartado 1.1 se plantea en un sistema ideal (sin fugas) y en el 1.2 para uno real (con fugas). De este modo, se puede calcular la energía que se consume en ambos casos para una misma red y por comparación, obtener cuál es el mayor y bajo qué condiciones.

\subsection{Incidencia energética de la instalación de una válvula en una red sin fugas.}

Para cuantificar la incidencia energética de la instalación de una válvula en redes ideales sin fugas se propone un sistema muy sencillo, una tubería que une un embalse de diámetro suficientemente grande como para poder considerar que la altura de cabecera es constante $H_{1}$, y que satisface un consumo $\left(q_{u 2}\right)$ en un nudo (2) en un sistema que no tiene fugas. Se definen los dos escenarios (A y B) (Figura E.1) que sólo se diferencian en que el primero tiene instalada una válvula de regulación.

La altura piezométrica en el escenario $\mathrm{A}\left(H_{2 A}\right)$ es menor que en el $\mathrm{B}\left(H_{2 B}\right)$. La pérdida de carga en la tubería desde 1 hasta 2 es la misma en ambos escenarios, y en el escenario A existe además una válvula de regulación, por lo que si la válvula está regulando $H_{2 A}<H_{2 B}$. La condición de igualdad podría existir si la pérdida de carga en la válvula completamente abierta fuese exactamente la misma que la existente si se hubiera instalado un tramo recto de tubería, situación muy infrecuente porque aun a válvula abierta se modifica la sección de paso del agua por la misma. 


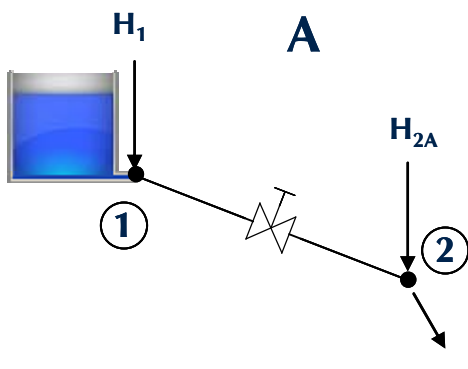

$\mathbf{q}_{\mathrm{u} 2}$

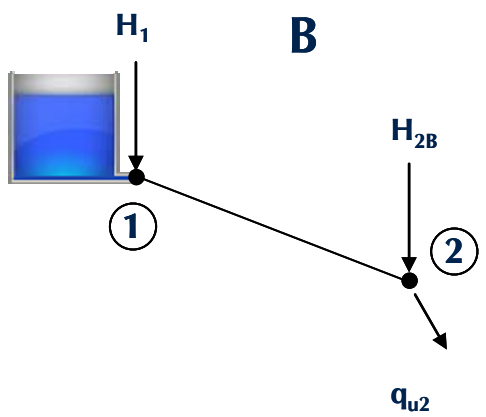

$\mathbf{q}_{\mathrm{u} 2}$

FIGURA E.1. PLANTEAMIENTO DEL PROBLEMA EN UNA RED IDEAL SIN FUGAS.

Por tanto, la relación entre alturas piezométricas se acota como sigue: $0<H_{2 A}<H_{2 B}<H_{1}$. El límite inferior es la presión de servicio, que debe ser superior a cero para satisfacer la demanda exigida por el usuario en el punto 2. El límite superior es debido a que entre los puntos 1 y 2 existen ciertas pérdidas de carga en la tubería (no en vano, circula un caudal $q_{u 2}$ ) por lo que la piezométrica en el punto 2 siempre es inferior al valor de $H_{1}$.

Con estos requisitos se plantea la auditoría energética del sistema y se obtiene que la energía consumida en el escenario A en un periodo de cálculo $t_{p}$ es:

$$
E_{\text {InputA }}\left(t_{p}\right)=E_{U}\left(t_{p}\right)+E_{L}\left(t_{p}\right)+E_{F}\left(t_{p}\right)=\gamma \cdot \Delta t\left(q_{\mathrm{u} 2} \cdot H_{2 A}+0+q_{\mathrm{u} 2} \cdot\left(H_{1}-H_{2 A}\right)\right)
$$

En la ecuación (E.1) se pueden observar los términos relativos a la energía entregada al usuario $\left(\gamma \cdot q_{u 2} \cdot H_{2 A} \cdot \Delta t{ }^{1}\right)$ y la consumida en fricción $\left(\gamma \cdot q_{u 2} \cdot\left(H_{1}-H_{2 A}\right) \cdot \Delta t\right)$, que se cuantifica con la diferencia de piezométricas en los nudos del sistema, por lo que se considera conjuntamente la fricción en la tubería y la energía disipada en la válvula.

Análogamente, en el caso B, la energía consumida se calcula con la expresión:

$$
E_{\text {InputB }}\left(t_{p}\right)=E_{U}\left(t_{p}\right)+E_{L}\left(t_{p}\right)+E_{F}\left(t_{p}\right)=\gamma \cdot \Delta t\left(q_{u 2} \cdot H_{2 B}+0+q_{u 2} \cdot\left(H_{1}-H_{2 B}\right)\right)
$$

Se desea conocer cuál de las dos energías calculadas con las anteriores expresiones es menor, y si es menor para todos los casos mostrados. Se calcula el cociente entre ambas.

$$
\frac{E_{\text {Input } A}}{E_{\text {Input } B}}=\frac{\gamma \cdot \Delta t\left(q_{u 2} \cdot H_{2 A}+q_{u 2} \cdot\left(H_{1}-H_{2 A}\right)\right)}{\gamma \cdot \Delta t\left(q_{u 2} \cdot H_{2 B}+q_{u 2} \cdot\left(H_{1}-H_{2 B}\right)\right)}=\frac{q_{u 2} \cdot\left(H_{2 A}+\left(H_{1}-H_{2 A}\right)\right)}{q_{u 2} \cdot\left(H_{2 B}+\left(H_{1}-H_{2 B}\right)\right)}=1
$$

\footnotetext{
${ }^{1} \Delta t$ es el intervalo de tiempo de integración considerado para en el cálculo de la auditoría. Para más detalles ver capítulo 6 de la tesis.
} 
A partir de la expresión anterior, se obtiene que la energía de entrada en la red A y en la B es igual en la ausencia de sin fugas. Esto es equivalente a decir que la energía que se disipa en la válvula es igual a la que se deja de entregar al usuario. La energía útil en el caso $A$ es menor que en el caso $B, \gamma \cdot q_{u 2} \cdot H_{2 A} \cdot \Delta t<\gamma \cdot q_{u 2} \cdot H_{2 B} \cdot \Delta t$, $y$ en cambio la energía disipada es mayor en $A$ que en $B$, $\gamma \cdot q_{u 2} \cdot\left(H_{1}-H_{2 A}\right) \cdot \Delta t>\gamma \cdot q_{u 2} \cdot\left(H_{1}-H_{2 B}\right) \cdot \Delta t$ ya que se incluye la pérdida de carga generada en la válvula.

\subsection{Incidencia energética de la instalación de una válvula en una red con fugas}

Para cuantificar la incidencia energética de la instalación de una válvula en redes reales se estudian los mismos escenarios que anteriormente con fugas en la tubería. La válvula de regulación (escenario A) genera una reducción de la presión aguas abajo, una reducción del caudal fugado (que depende de la presión) y en consecuencia una disminución del caudal circulante. Todo ello implica menores energías perdidas por fricción y por fugas, así como menor energía entregada al usuario final.

Las hipótesis adoptadas para los cálculos son:

- En ambos escenarios, la altura piezométrica de entrada en el punto 1 es igual. $H_{1 A}=H_{1 B}=H_{1}$.

- La altura piezométrica en el escenario $\mathrm{A}\left(H_{2 A}\right)$ es menor que en el $\mathrm{B}\left(H_{2 B}\right)$. Esto se justifica porque la pérdida de carga del punto 1 al 2 es la misma en el tramo de tuberías y en el caso A existe además una perdida adicional en la válvula de regulación.

- El caudal saliente por el nudo 2 se compone de dos sumandos. Por una parte $q_{u 2}>0$, que representa el caudal consumido útil en el nudo. Por otra, $C_{E} \cdot \Delta H^{\alpha}$ representa el caudal fugado por la tubería dispuesta entre 1 y 2. El caudal de fugas depende de la presión, y que se modela como sugiere Rossman (2000), con un coeficiente que representa el tipo de rotura $\left(C_{E}\right)$ y con la presión afectada de un exponente $(\alpha)$ propio del material de la conducción. La expresión habitualmente utilizada es: $q_{F}\left(t_{k}\right)=C_{E} \cdot \Delta H^{\alpha}$, donde $q_{F}\left(t_{k}\right)$ representa el caudal fugado, mientras que el resto de términos se definen a continuación.

o $C_{E}$ es el coeficiente de emisor del nudo. Representa el número de roturas de la tubería. Adopta el mismo valor $>0$ para ambos escenarios, esto es, en ambos existen las mismas fugas. Un emisor representa una rotura y la ausencia de roturas se simula con el valor numérico 0 . Un valor negativo carece de significado físico. 
o El salto de presiones es $\Delta H=H_{2 X}-H_{G W}>0$, donde $H_{2 x}$ es la piezométrica existente en el nudo 2 y en un escenario $x$ cualquiera y $H_{G W}$ es la contrapresión del terreno en el instante en el que el agua pasa a través de la rotura. Por simplicidad de los cálculos, se supone que $H_{G W}=0$, esto es, descarga a la atmósfera, una hipótesis muy común en gestión de redes.

o $\alpha$ es el exponente de emisor que representa las características del material con el que se construye la tubería. Los valores de este exponente están comprendidos en la horquilla [0.5, 2.5].

- El caudal saliente por el nudo 2 en el caso B es: $q_{u 2}+C_{E} H_{2 B}{ }^{\alpha}$

- Por último, se obtiene la siguiente relación entre las piezométricas: $0<H_{2 A}<H_{2 B}<H_{1}$. Se incluyen los límites inferiores y superiores porque, por una parte, se ha de satisfacer la demanda con una presión superior al umbral de servicio, y por otra, las pérdidas de carga en la tubería (recordemos que está circulando un caudal determinado) provocan que la piezométrica en el punto 2 sea inferior.
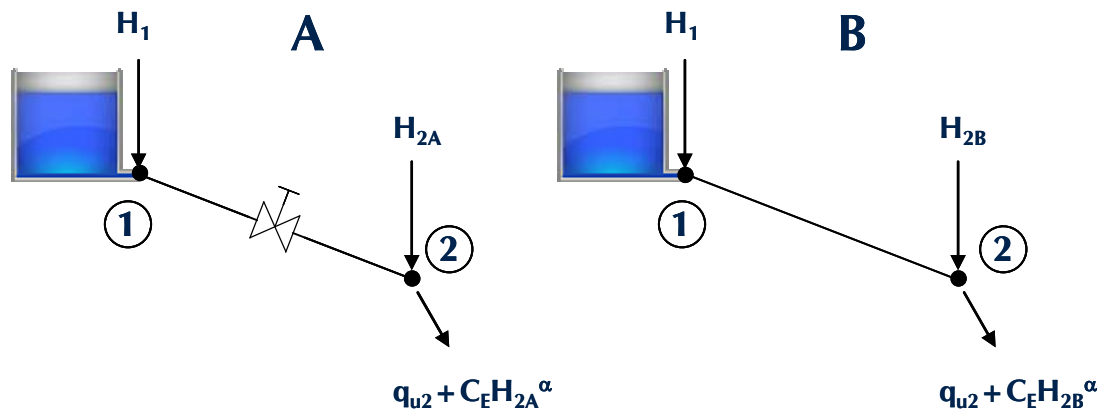

Figura E.2. Planteamiento Del PROBlema en una Red REAl.

La energía consumida en el caso A en un intervalo de tiempo $t_{p}$ es:

$$
\begin{aligned}
E_{\text {Input } A}\left(t_{p}\right) & =E_{U}\left(t_{p}\right)+E_{L}\left(t_{p}\right)+E_{F}\left(t_{p}\right)= \\
& =\gamma \cdot \Delta t\left(q_{U 2} \cdot H_{2 A}+C_{E} \cdot H_{2 A}{ }^{\alpha} \cdot H_{2 A}+\left(q_{U 2}+C_{E} \cdot H_{2 A}{ }^{\alpha}\right) \cdot\left(H_{1}-H_{2 A}\right)\right)
\end{aligned}
$$

En la ecuación (E.4) se pueden observar los términos relativos a la energía entregada al usuario $\left(\gamma \cdot q_{u 2} \cdot H_{2 A} \cdot \Delta t\right)$, a la pérdida por fugas $\left(\gamma \cdot \Delta t \cdot C_{E} \cdot H_{2 A}{ }^{\alpha} \cdot H_{2 A}\right)$ y consumida en fricción $\left(\gamma \cdot\left(q_{u 2}+C_{E} \cdot H_{2 A}{ }^{\alpha}\right) \cdot\left(H_{1}-H_{2 A}\right) \cdot \Delta t\right)$. 
Análogamente, en el escenario B, la energía consumida se calcula con:

$$
\begin{aligned}
E_{\text {InputB }}\left(t_{p}\right) & =E_{U}\left(t_{p}\right)+E_{L}\left(t_{p}\right)+E_{F}\left(t_{p}\right)= \\
& =\gamma \cdot \Delta t\left(q_{u 2} \cdot H_{2 B}+C_{E} \cdot H_{2 B}{ }^{\alpha} \cdot H_{2 B}+\left(q_{u 2}+C_{E} \cdot H_{2 B}{ }^{\alpha}\right) \cdot\left(H_{1}-H_{2 B}\right)\right)
\end{aligned}
$$

Se desea conocer cuál de ambas energías es menor así como bajo que condiciones se cumple la desigualdad. Para ello se calcula el cociente:

$$
\begin{array}{r}
\frac{E_{\text {InputA }}}{E_{\text {InputB }}}=\frac{\gamma \cdot \Delta t\left(q_{u 2} \cdot H_{2 A}+C_{E} \cdot H_{2 A}{ }^{\alpha} \cdot H_{2 A}+\left(q_{u 2}+C_{E} \cdot H_{2 A}{ }^{\alpha}\right) \cdot\left(H_{1}-H_{2 A}\right)\right)}{\gamma \cdot \Delta t\left(q_{u 2} \cdot H_{2 B}+C_{E} \cdot H_{2 B}{ }^{\alpha} \cdot H_{2 B}+\left(q_{u 2}+C_{E} \cdot H_{2 B}{ }^{\alpha}\right) \cdot\left(H_{1}-H_{2 A}\right)\right)}= \\
=\frac{q_{u 2} \cdot H_{2 A}+C_{E} \cdot H_{2 A}{ }^{\alpha} \cdot H_{2 A}+\left(q_{u 2}+C_{E} \cdot H_{2 A}{ }^{\alpha}\right) \cdot\left(H_{1}-H_{2 A}\right)}{q_{u 2} \cdot H_{2 B}+C_{E} \cdot H_{2 B}{ }^{\alpha} \cdot H_{2 B}+\left(q_{u 2}+C_{E} \cdot H_{2 B}{ }^{\alpha}\right) \cdot\left(H_{1}-H_{2 B}\right)}= \\
=\frac{C_{E} \cdot H_{2 A}{ }^{\alpha+1}+q_{u 2} \cdot H_{1}+C_{E} \cdot H_{2 A}{ }^{\alpha} \cdot\left(H_{1}-H_{2 A}\right)}{C_{E} \cdot H_{2 B}{ }^{\alpha+1}+q_{u 2} \cdot H_{1}+C_{E} \cdot H_{2 B}{ }^{\alpha} \cdot\left(H_{1}-H_{2 B}\right)}
\end{array}
$$

Y utilizando la relación mostrada en el planteamiento del problema, y que relaciona las alturas piezométricas $H_{2 A}<H_{2 B}$ y para valores de $\alpha$ pertenecientes a la horquilla [0.5, 2.5], se obtiene:

$$
\frac{E_{\text {Input } A}}{E_{\text {InputB }}}<\frac{C_{E} \cdot H_{2 B}{ }^{\alpha+1}+q_{42} \cdot H_{1}+C_{E} \cdot H_{2 A}{ }^{\alpha} \cdot\left(H_{1}-H_{2 A}\right)}{C_{E} \cdot H_{2 B}{ }^{\alpha+1}+q_{u 2} \cdot H_{1}+C_{E} \cdot H_{2 B}{ }^{\alpha} \cdot\left(H_{1}-H_{2 B}\right)}
$$

Con lo que el primer sumando de numerador y denominador es el mismo. Se designa $X=C_{E} \cdot H_{2 B}{ }^{\alpha+1}+q_{u 2} \cdot H_{1}$ y se obtiene:

$\frac{E_{\text {lnputA }}}{E_{\text {lnputB }}}<\frac{X+C_{E} \cdot H_{2 A}^{\alpha} \cdot\left(H_{1}-H_{2 A}\right)}{X+C_{E} \cdot H_{2 B}^{\alpha} \cdot\left(H_{1}-H_{2 B}\right)}$

Donde el resultado de la desigualdad depende de qué término sea mayor, el correspondiente al numerador $\left(C_{E} \cdot H_{2 A}{ }^{\alpha} \cdot\left(H_{1}-H_{2 A}\right)\right)$ ó al denominador, $\left(C_{E} \cdot H_{2 B}{ }^{\alpha} \cdot\left(H_{1}-H_{2 B}\right)\right)$. El cociente entre ambos lo indica.

$$
\frac{C_{E} \cdot H_{2 A}{ }^{\alpha} \cdot\left(H_{1}-H_{2 A}\right)}{C_{E} \cdot H_{2 B}{ }^{\alpha} \cdot\left(H_{1}-H_{2 B}\right)}=\frac{H_{2 A}{ }^{\alpha} \cdot H_{1}-H_{2 A}{ }^{\alpha+1}}{H_{2 B}{ }^{\alpha} \cdot H_{1}-H_{2 B}{ }^{\alpha+1}}<\frac{H_{2 B}{ }^{\alpha} \cdot H_{1}-H_{2 A}{ }^{\alpha+1}}{H_{2 B}{ }^{\alpha} \cdot H_{1}-H_{2 B}{ }^{\alpha+1}}
$$


A continuación, como $H_{2 A}<H_{2 B}$, se obtiene que $H_{2 B}{ }^{\alpha} \cdot H_{1}-H_{2 B}{ }^{\alpha+1}>H_{2 B}{ }^{\alpha} \cdot H_{1}-H_{2 A}{ }^{\alpha+1}$, la ecuación (E.9) queda como:

$\frac{H_{2 B}{ }^{\alpha} \cdot H_{1}-H_{2 A}{ }^{\alpha+1}}{H_{2 B}{ }^{\alpha} \cdot H_{1}-H_{2 B}{ }^{\alpha+1}}<\frac{H_{2 B}{ }^{\alpha} \cdot H_{1}-H_{2 A}{ }^{\alpha+1}}{H_{2 B}{ }^{\alpha} \cdot H_{1}-H_{2 A}{ }^{\alpha+1}}=1$

Se sustituye en la ecuación (E.8):

$\frac{E_{\text {Input } A}}{E_{\text {InputB }}}<\frac{X+C_{E} \cdot H_{2 A}{ }^{\alpha} \cdot\left(H_{1}-H_{2 A}\right)}{X+C_{E} \cdot H_{2 B}{ }^{\alpha} \cdot\left(H_{1}-H_{2 B}\right)}<\frac{X+C_{E} \cdot\left(H_{2 B}{ }^{\alpha} \cdot H_{1}-H_{2 A}{ }^{\alpha+1}\right)}{X+C_{E} \cdot\left(H_{2 B}{ }^{\alpha} \cdot H_{1}-H_{2 A}{ }^{\alpha+1}\right)}=1$

Lo que demuestra que $\frac{E_{\text {InputA }}}{E_{\text {InputB }}}<1$ con las hipótesis planteadas. La energía invertida en el caso en el que se ha instalado la válvula es menor que en el caso en el que no se instala. Sin embargo esta afirmación debe ser entendida en el contexto mostrado, que presenta las siguientes características:

1. Se aplica la auditoría energética definida en el capítulo 6. Por lo que se está contabilizando como energías salientes del sistema la entregada a los consumidores, la que escapa por las fugas y la energía disipada en fricción en tuberías y en la válvula.

2. Se exige una presión mínima de servicio, que para la aplicación se ha supuesto adopta un valor 0 . Es evidente que si no se exige mantener esa presión de servicio los escenarios no admiten comparación posible, ya que no cumplirían los requisitos iniciales del sistema. 


\section{APLICACIÓN NUMÉRICA DEL PROBLEMA}

Se realiza una demostración numérica del ejemplo analítico, se proponen diferentes valores habituales y se calcula el cociente entre las energías (ecuación (E.6)).

Los valores utilizados para la realización de los cálculos son:

$$
\begin{aligned}
& H_{1}=60,50,40 \text { y } 30 \text { m.c.a. } \\
& C_{E}=0.001,0.01,0.1 \text { y } 0.5\left(\mathrm{~m}^{3-\alpha} / \mathrm{s}\right) \\
& q_{\mathrm{U} 2}=1,10 \mathrm{~m}^{3} / \mathrm{s} \\
& \alpha=0.5,1,1.5,2 \text { y } 2.5
\end{aligned}
$$

Para la altura piezométrica en el punto 2, se suponen los siguientes valores: $H_{2 A}=50,40,30,20$ y 10 m.c.a. $H_{2 B}=50,40,30,20$ y 10 m.c.a.

$Y$ en todas las simulaciones del sistema, se ha de cumplir $0<H_{2 A}<H_{2 B}<H_{1}$, por lo que para $H_{1}=50$, se podían considerar los valores de $H_{2 B}=40,30,20$ y 10 . Asimismo, según el valor elegido de $H_{2 B}$, se podía elegir $H_{2 A}$ como uno inferior.

Finalmente, se realizan 1360 combinaciones según la variación de las alturas piezométricas, coeficientes de emisor, el caudal consumido y los exponentes de emisor. Se calcula el cociente entre la energía del escenario A y B (Figura E.3). 


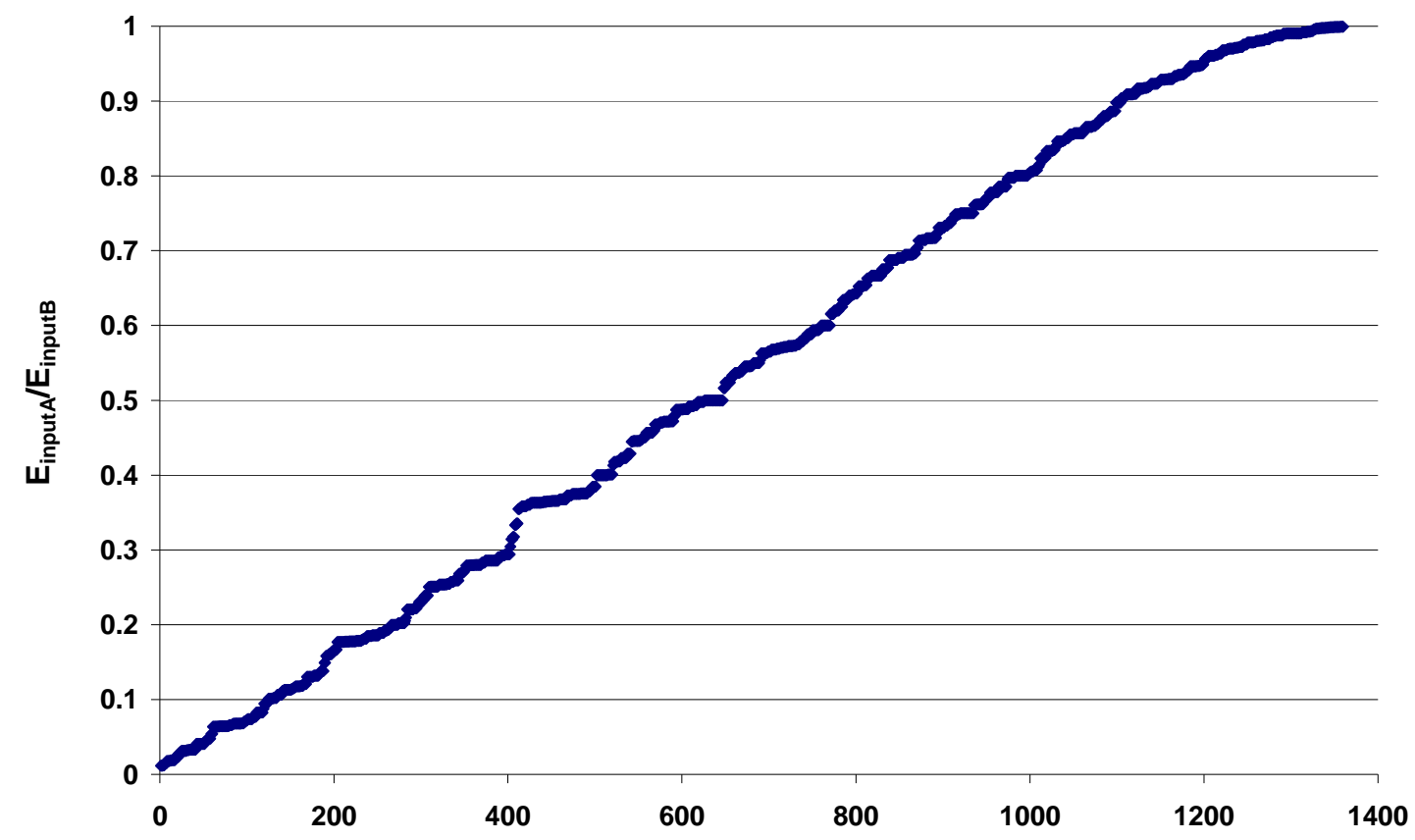

FIGURA E.3.RELACIÓN ENTRE LA ENERGÍA CONSUMIDA EN EL CASO A Y B PARA LAS COMBINACIONES MOSTRADAS.

Se obtiene que efectivamente todas las combinaciones posibles proporcionan un valor menor o igual a 1. En la Figura E.3 se han ordenado los valores desde el máximo hasta el mínimo.

El valor el máximo es $\frac{E_{\text {InputA }}}{E_{\text {InputB }}}=0.9993$, con los valores:

- $H_{1}=60$ m.c.a.

- $H_{2 B}=60$ m.c.a.

- $H_{2 A}=50$ m.c.a.

- $C_{E}=0.01\left(\mathrm{~m}^{3-\alpha} / \mathrm{s}\right)$

- $q_{\mathrm{u} 2}=10 \mathrm{l} / \mathrm{s}$

- $\alpha=0.5$.

Mientras que el valor mínimo es $\frac{E_{\text {InputA }}}{E_{\text {InputB }}}=0.0114$, obtenido a partir de los valores:

- $H_{1}=60$ m.c.a.

- $H_{2 B}=60$ m.c.a.

- $H_{2 A}=10$ m.c.a.

- $C_{E}=0.5\left(\mathrm{~m}^{3-\alpha} / \mathrm{s}\right)$

- $q_{\mathrm{u} 2}=1 \mathrm{l} / \mathrm{s}$

- $\alpha=2.5$ 


\section{ANEXO F}

Conclusiones y desarrollos futuros (En castellano). 



\section{APORTACIONES DE LA TESIS}

La tesis que aquí se presenta en primer lugar analiza la influencia de los costes del agua y la energía en el periodo óptimo de renovación y en segundo propone una metodología para la cuantificación de la energía consumida en una red de distribución de agua.

La tesis comienza con un análisis de la situación actual, para ello se han analizado los puntos que a continuación se describen.

- La inversión necesaria en renovación. En el capítulo 1 se cuantifican las necesidades de inversión en renovación y rehabilitación de tuberías tanto a escala local, la ciudad de Valencia, como nacional y Europea. Por ser un país de referencia mundial, el estudio también se extiende a los Estados Unidos. Las inversiones previstas en renovación de redes de abastecimiento son muy elevadas y según aumenta la preocupación medioambiental, lo hace en consonancia la urgencia para acometer dichas renovaciones. Asimismo, se muestran los valores numéricos de los indicadores típicos, unidades monetarias invertidas por habitante y por longitud.

- Los principales tipos de tuberías empleadas en redes de distribución urbana y el empleo de las mismas. Cada tipo de tubería presenta una serie de ventajas e inconvenientes. Precisamente por esto no existe una tubería universal y se han instalado distintos materiales en las redes de distribución. Éstos conforman, por tanto, un sistema heterogéneo.

La disposición de tuberías de distintos materiales en Estados Unidos, en casi toda Europa, en España y en Valencia presenta más o menos la misma configuración, siendo la tubería de fundición gris la más instalada (en general siempre representa el $30-50 \%$ de la longitud total de la red, y únicamente en Finlandia y Holanda es menor del 20\%). También se muestra que el fibrocemento está muy implantado en los abastecimientos, (en menor medida en Norteamérica y mucho más en Europa, donde España es el país con mayor porcentaje de este material). Por otra parte, los materiales plásticos, PVC y polietileno empiezan a ser parte representativa de la red. 
- Los criterios que se adoptan para renovar. Se subrayan una serie de criterios (por ejemplo de tipo hidráulico, de calidad, etc.) que se deben emplear para renovar o rehabilitar las tuberías. Aún siendo las más de las ocasiones una decisión política, especialmente en el entorno urbano, sí que es importante disponer de un sistema de soporte a la decisión, una herramienta que evalúe de igual manera todos los criterios en todas las tuberías del sistema, que permita adoptar una política activa frente a la tradicional política reactiva (en grandes diámetros, se ha comprobado que esta política es imprescindible para evitar los fallos que tienen efecto catastrófico). Asimismo, se subrayan las aplicaciones de la matemática difusa, que permite al usuario conocer tanto la consistencia de las hipótesis de partida y de los cálculos una vez obtenido una solución particular, así como facilitar la posibilidad de realizar un análisis de sensibilidad que cuantifique la importancia de los pesos asignados a cada criterio elegido.

Tras este análisis inicial, se subrayan los principales resultados obtenidos como respuestas a las cuestiones que motivaron la realización de la presente tesis doctoral.

\section{¿Qué es una auditoría hídrica? ¿Cómo influye en la renovación? ¿Cuánta agua se pierde por fugas en la red de distribución?}

La auditoría hídrica en una red de distribución de agua proporciona como resultado un mejor conocimiento de los componentes de las pérdidas totales, tanto de las pérdidas reales como de las aparentes (que incluyen los errores de medición y los robos en el sistema). Tras la auditoría, el gestor del abastecimiento tiene una idea del estado del sistema de distribución y esto le permite adoptar decisiones de todo tipo, desde renovación de tuberías hasta reducción de la presión en sectores, etc.

Asimismo, se puede plantear la relación entre las pérdidas totales y los costes de mantenimiento de la red. De este modo, si se disminuyen los recursos empleados en rehabilitación y mantenimiento, las pérdidas de agua aumentarán con el paso del tiempo (al igual que las roturas en las tuberías, capítulo 2). Por tanto, ambas variables (agua fugada y recursos invertidos en mantenimiento) están inversamente ligadas y debe ser posible llegar a un punto óptimo en el que los costes totales (los de mantenimiento y los del agua fugada) sean mínimos. 
La auditoría hídrica es necesaria si se desea plantear la energética (capítulo 6 de la tesis). Las únicas condiciones para realizar la segunda, aplicar el teorema de arrastre de Reynolds a la propiedad energía, es conocer las entradas y salidas hídricas a lo largo de la superficie de control (en definitiva, haber resuelto la auditoría hídrica) y disponer de un modelo matemático de la red para evaluar el comportamiento de los elementos que lo integran. En otras palabras, es necesario haber resuelto previamente el problema hidráulico.

\section{¿Cuándo se debe renovar una tubería?}

En el capítulo 4 se plantea una revisión de la metodología clásica (Shamir y Howard, 1979) que aborda el problema desde una óptica más global. Para ello, se considera la influencia de los costes del agua fugada (coste del agua en sí misma y de la energía), costes sociales y de oportunidad. En lo cuantitativo, las expresiones propuestas permiten calcular con precisión la influencia de unos costes que, aún existiendo, no acostumbran a considerarse, por tanto, el periodo óptimo de reposición se anticipa, tanto más cuanto mayores éstos sean. De otra parte, los costes asociados a la renovación de la tubería, al aumentar la inversión, alargan el periodo óptimo de renovación.

Se pretende que esta propuesta sea aplicable a todos los abastecimientos y por tanto, considera las particularidades propias de los mismos y permite el cálculo con los datos disponibles (con frecuencia escasos). El problema se resuelve desde una óptica distinta gracias a la aparición de estos nuevos términos influyentes en el periodo óptimo de renovación. La aplicación numérica resuelta puede presentar valores sorprendentes, ya que no es común la renovación de las tuberías cada 30 años. Esto se debe a la adopción de un patrón de roturas que tiene elevados valores tanto de la tasa de crecimiento como del número de roturas inicial. Por otra parte, habitualmente no se considera el coste del agua fugada o el coste social, ya que dichos costes está cubierto por los consumidores del agua y no por el gestor del abastecimiento.

Es tremendamente difícil el aprovechamiento del coste de oportunidad, ya que los problemas burocráticos y de desconocimiento entre empresas son cuestiones casi infranqueables. La cuantificación de este coste se debe entender como aviso que permita, a los gestores de la red de abastecimiento, percatarse del ahorro. 


\section{¿Es posible utilizar alguna nueva técnica de renovación sin zanja?}

Las técnicas de renovación sin zanja representan una alternativa más a la hora de plantearse la renovación. Tienen ya una larga historia, si bien comienzan a tomar fuerza a partir de 1986, cuando se crea la International Society of Trenchless Technology (ISTT). En el presente trabajo (anexo A) se ha realizado una clasificación de estas técnicas según las particularidades generales de las mismas, con mención de las ventajas e inconvenientes de su empleo en una renovación particular. Con éstas, el gestor del abastecimiento dispone de nuevas posibilidades cuando afronta una renovación y este nuevo enfoque amplía la visión tradicional.

Se detallan varios estudios que han recopilado los costes de ejecución de las diferentes técnicas en casos particulares. Asimismo, se realiza un análisis del mercado de los costes (en el año 2006) de las técnicas en España. Aunque se realiza un esfuerzo para garantizar la homogeneidad en los resultados, todos los fabricantes subrayan la misma idea, cada proyecto es único y su coste dependerá de múltiples factores (número de acometidas, estado de la anterior tubería, etc.) y los resultados deben ser entendidos como un primer orden de magnitud. Éstos hacen referencia a los costes directos y obvian los sociales, que se pueden cuantificar tal y como se detalla en el anexo D.

Se prevé que el desarrollo de las técnicas sin zanja reducirá los costes de las mismas, y por tanto serán más competitivas. Esto ya sucede en la rehabilitación de redes de saneamiento, donde la técnica de encamisado térmico es incluso más barata que la convencional. Así, se justifica su gran empleo en las redes de EE.UU. Por otra parte, la utilización de estas técnicas en redes de abastecimiento es más compleja ya que el agua que circula por las redes de agua potable lo hace a presión y debe mantener su calidad para poder ser consumida como agua de boca. Sin duda, el reto de los fabricantes es asegurar esa calidad y el futuro de estas técnicas es prometedor.

\section{¿Cómo interactúan las políticas delineadas en el corto plazo (rehabilitación) con las directrices en el largo plazo (renovación)?}

Se ha realizado una propuesta de solución integral del problema que relaciona las políticas a corto (rehabilitación) y a largo plazo (renovación) en redes de distribución de agua potable, aportando un enfoque diferente a los tradicionales por determinar las relaciones entre ambas. 
Enmarcada en esta propuesta, la influencia de los costes del agua y la energía en la determinación de las políticas a corto plazo no depara sorpresas, cuanto mayores éstos sean, mayores costes totales de mantenimiento (mayor inversión económica en rehabilitación). Esta consecuencia es lógica, ya que mayor coste del agua y de la energía que se fuga repercutirá en un volumen óptimo de fugas menor, esto es, mayor empleo de recursos para minimizar las fugas.

Asimismo, se muestra una expresión analítica que relaciona la inversión en mantenimiento y el volumen fugado que permite determinar el nivel óptimo económico de fugas. Dicha expresión es más completa que otras anteriores por considerar el coste de la energía (que se podrá calcular con la auditoría energética para la obtención de este coste total mínimo.

\section{¿Cuál es el parámetro más influyente a la hora de determinar el periodo óptimo de renovación de acuerdo con la metodología propuesta?}

El parámetro más influyente en el periodo óptimo de renovación es el índice de crecimiento del número de roturas. Éste únicamente depende del tipo de tubería y de las condiciones de instalación. Por tanto, un primer intento de alargar la renovación consistiría en mejorar la instalación o en disponer sistemas de protección frente a la corrosión de las mismas, revestimientos o protección catódica. Por otra parte, el gestor de la red se encuentra que la misma ya presenta unas condiciones definidas y la modificación del número de roturas es un parámetro sobre el que es difícil actuar, por lo que los esfuerzos se deben centrar en los parámetros de gestión del sistema, el caudal unitario de fugas, el tiempo de vida media de la fuga, etc.

Otros parámetros que influyen en el periodo óptimo de manera significativa son el precio del agua y de la energía. El primero puede incluir los costes medioambientales, en España todavía no considerados, aunque sí en otros países Europeos con una superior sensibilidad ambiental, mientras que el segundo ha despertado una creciente preocupación en el campo de la gestión del agua, especialmente desde que se el agua se obtiene por desalación, con fuerte consumo energético. Asimismo, las etapas previas a la distribución en el ciclo urbano del agua también requieren un elevado consumo energético, huella energética en $€ / \mathrm{m}^{3}$, por lo que el coste de la energía se revela como factor de influencia en el cálculo del periodo óptimo de renovación. Así, el efecto de la energía se puede obtener adecuadamente en el capítulo 6, en el que se desarrolla una metodología para cuantificar la energía interviniente en una red de distribución. Ésta auditoría permite, entre otros, el cálculo del parámetro k (que aquí se ha demostrado como poco influyente en la renovación de las tuberías) y la obtención del coste asociado a las pérdidas de energía (capítulo 4). 
¿Cuál es la influencia de las técnicas de renovación sin zanja en el periodo óptimo de renovación? ¿Y la posibilidad de considerar las infinitas renovaciones?

El coste de instalación de una tubería y el coste social (en definitiva los términos de los que depende el parámetro de inversión) dependen de la técnica empleada. Por tanto, cada técnica tiene un valor distinto del término de inversión y, por ende, del periodo óptimo de renovación. Precisamente, la mayor ventaja de las técnicas sin zanja es la reducción de los costes sociales en comparación con la instalación tradicional.

Asimismo, se describe la influencia de la consideración de las infinitas renovaciones para la obtención del periodo óptimo de renovación, ya que el resultado no es el mismo si el problema se aborda considerando una o las infinitas renovaciones de una tubería cualquiera. Por otra parte, se resuelve el caso particular que representa el cálculo del periodo óptimo de las infinitas renovaciones si se emplea la técnica del entubado por deslizamiento. Debido a la reducción de la sección útil, ésta no se podrá utilizar sucesivamente y se alternará su empleo con la técnica tradicional con apertura de zanja.

\section{¿Cómo se relacionan el agua y la energía? ¿Qué es la auditoría energética?}

Hasta hace una década la relación agua-energía de mayor interés era la producción de la energía hidroeléctrica. Hoy, porque el manejo sostenible del agua consume mucha energía, es la relación inversa, el agua consumidora de energía, objeto de una atención mucho mayor. En el marco de esta relación inversa, la distribución de agua es una etapa relevante y, por ello, también lo es conocer la energía que se consume pero, sobre todo, saber en qué se consume. De entre estos consumos energéticos destaca la energía que se pierde con las fugas, cuya cuantificación es una de las principales aportaciones de esta tesis.

La auditoría presentada identifica los usos finales de la energía entrante en la red, unos usos que permiten definir indicadores energéticos que, por una parte, plasman desde la óptica energética las características de la red (los dos de contexto), y por otra, evalúan su gestión (los otros cinco), así como posibles mejoras que convendría introducir. Los costes de los consumos energéticos deberían también incluir aspectos ambientales (los ahorros de energía se traducen en ahorros de emisiones de dióxido de carbono a la atmósfera). Ello permitirá, cual se hace con la hídrica, incentivar la eficiencia energética.

La auditoría energética, y en consecuencia los indicadores que de ella se derivan, se aplican en condiciones semejantes a la auditoría hídrica. Por tanto, aunque la auditoría energética puede extenderse a cualquier periodo de tiempo, se calcula en un periodo anual como exige el cálculo de los indicadores hídricos del sistema. 
Si se disponen de datos de los costes del agua y de la energía, estimaciones de las emisiones de gases de efecto invernadero para la energía consumida, y los resultados de la auditoría energética, se pueden evaluar las opciones de la gestión según un análisis coste/beneficio más preciso. A partir de la simulación de dos estados del sistema (el real y el renovado) y de su comparación, se puede conocer el coste energético de las fugas.

La auditoría que se presenta se ha realizado a partir de los ficheros de resultados de EPAnet mediante un proceso de cálculo simple pero laborioso. EPAnet ya calcula de manera sistemática uno de los seis términos de la auditoría energética de la red, la energía de bombeo. Sería especialmente útil que, incorporando las rutinas de cálculo correspondiente, EPAnet también evaluase los cinco términos adicionales del balance, que se reducen a cuatro cuando el periodo de cálculo es largo y pierde relevancia el término de compensación de energía del sistema. De este modo el gestor de la red dispondría de manera automática de una información relevante, la auditoría energética del sistema.

\section{¿Cuánta energía se pierde por fugas en una red de distribución?}

Tal pérdida es suma de la que se escapa con el agua fugada (y que puede ser muy notable si la huella energética del agua hasta llegar a la fase de distribución es importante, como ocurre con el agua desalada) y de la fricción adicional debido al aumento de los caudales circulantes por fugas. Ambas se pueden calcular con la auditoría energética como previamente se ha indicado.

\section{¿Cómo afectan las políticas de gestión de la red al consumo energético? ¿Y la reducción de la demanda?}

La gestión eficiente de una red de distribución de agua está fuertemente condicionada por las características propias del abastecimiento (diámetros y edad de tuberías, huella energética del agua, topología de la red, etc.). Para evaluar cada caso concreto, se utilizan las auditorías hídrica y energética. Debido a la complejidad de la red de distribución (kilómetros de tuberías con numerosas acometidas domiciliarias), la fase de distribución es quizá la etapa del ciclo que resulta más difícil de auditar.

Se pretende mostrar los beneficios hídricos y energéticos de algunas de las políticas de actuación adoptadas por los gestores de la red. La regulación de la presión con válvulas y con bombas de velocidad variable es habitual en la gestión de redes de distribución de agua potable. La primera se emplea en casos en los que existan zonas con exceso de presión o como un método para la reducción de las fugas en periodos nocturnos, mientras que la segunda se puede emplear en sistemas en los que se desea ajustar la presión a unos valores determinados. El tipo 
de regulación depende de las características propias de la red, y en ocasiones, la mejora energética no siempre se traduce en mejora económica (debido fundamentalmente a los rendimientos de los equipos de bombeo y a las tarifas eléctricas que presentan variación horaria). Por lo que puede ser incluso más económico bombear por la noche con bomba de velocidad fija para llenar un depósito de compensación que estar bombeando con regulación de la velocidad a todas las horas del día (aunque la ventaja energética esté probada).

La gestión de la demanda no es una política de gestión frente a las fugas, aunque sí que es una acción encaminada hacia la gestión eficiente del agua, por lo que se obtienen notables beneficios energéticos ligados a los hídricos.

En el capítulo 7 se muestra la influencia que sobre la energía produce cada una de las anteriores políticas. La importancia de este trabajo no radica en el valor numérico obtenido en el ejemplo práctico, ya que cada red de abastecimiento es diferente, sino en la demostración de que es posible obtener resultados numéricos e indicadores que faciliten información en cada problema específico. Los resultados obtenidos confirman las ideas cualitativas previas que dicta la experiencia del gestor, aunque tras esta aplicación, éstas se pueden apoyar en hechos, y no únicamente en palabras. Desde las evaluaciones cuantitativas, factibles desde la propuesta de auditoría, un análisis racional debe realizarse para identificar la forma más eficiente de gestionar el agua.

Por último, los efectos combinados de todas las políticas de actuación descritas se analizan en un ejemplo. Éste refleja un menor consumo energético del sistema por una mejor gestión y se subraya que aunque se han delineado cada una de las políticas (con bomba de velocidad variable, válvula y reducción de la demanda) de manera individual y se han observado los efectos de las mismas, también es posible, y deseable, su empleo conjunto. Sin duda, la gestión de una red siempre se puede mejorar y las limitaciones del gestor son debidas a la existencia de presupuesto, y no a las necesidades de la red. 
¿Cuántos créditos de carbono se deja de emitir tras reducir el volumen de fugas en la red? ¿Cómo afecta energéticamente la política que he adoptado?

La relación energía-emisiones se puede calcular utilizando alguno de los modelos existentes. En el presente trabajo se emplea el modelo water to air desarrollado por el pacific institute (Wolf y col., 2004). Los resultados evidencian que la relación energía-emisiones está fuertemente influenciada por la huella energética del agua y el origen de la energía. Estos dos últimos parámetros son propios del sistema (no modificables por el gestor del abastecimiento) y la importancia del trabajo radica en proporcionar una metodología para el cálculo aplicable al ejemplo concreto estudiado. No solamente se puede calcular la reducción de las emisiones tras la reducción del volumen de fugas en la red, sino también el efecto de actuaciones como regulación de la presión, reducción de la demanda, etc.

\section{DESARROLLOS FUTUROS}

Las cuestiones abordadas a lo largo de la presente tesis tienen muchas posibilidades de desarrollo en un futuro más próximo que tardío. En el manejo y la gestión del agua y la energía confluyen los intereses bien diferenciados de varias entidades, desde consumidores y fabricantes hasta compañías que gestionan el abastecimiento, ayuntamientos y otros organismos competentes (como organismos reguladores, si existen, confederaciones hidrográficas, etc.). Por tanto, el desarrollo de estas cuestiones debe realizarse considerando las preocupaciones particulares de cada organismo.

En lo que sigue se detallan los posibles desarrollos futuros de los principales temas expuestos en la tesis. De entre éstos, los más importantes (precisamente por ser aquéllos que son objeto de la investigación desarrollada en la presente tesis) se detallan en tres apartados $(2.3,2.4$ y 2.5). El primero explora los posibles desarrollos en la determinación del periodo óptimo de renovación (capítulo 4 de la presente tesis). El segundo está relacionado con la influencia de las políticas de rehabilitación sobre la obtención del periodo óptimo de renovación (anexo C de la tesis). Por último, el tercer apartado propone todas las posibilidades que surgen a partir de la auditoría energética (capítulo 6), así como de las ventajas de la adecuada gestión del sistema y de la relación existente con las emisiones de contaminantes a la atmósfera (capítulo 7). 


\subsection{Inversión en renovación}

La determinación de la inversión en las redes de abastecimiento debe involucrar tanto a los propietarios de los mismos (generalmente ayuntamientos) como a las compañías que explotan el abastecimiento (o bien a un organismo regulador, inexistente a escala nacional en la actualidad ${ }^{1}$, similar al IRAR en Portugal o el OFWAT en Inglaterra y Gales). En el trabajo aquí mostrado, se ha recopilado la información existente en la bibliografía, aunque las más de las ocasiones, se presenta sin estar convenientemente disgregada. Precisamente, esta opción representa la principal mejoría a realizar, esto es, poder mostrar las inversiones en renovación, en control de fugas, en válvulas, etc. Por último, se podría obtener una auditoría de la inversión necesaria en redes de abastecimiento.

\subsection{Tuberías de distinto material y técnicas de renovación sin zanja}

La innovación en el campo de los materiales se realiza casi por completo por los fabricantes, bien individualmente $\mathrm{o}$ en colaboración con entidades de investigación (como universidades).

La investigación se ha centrado en los materiales plásticos, con la aparición de nuevas tuberías que permiten mejoras sustanciales en la durabilidad, funcionalidad, etc. En cambio, para los materiales metálicos, la investigación se centra no tanto en obtener nuevos materiales sino en mejoras de los procesos de fabricación.

Las técnicas sin zanja fueron desarrolladas por fabricantes de EE.UU. y del Reino Unido. En general, todas pretenden la mejora de las condiciones de instalación que permitan un mayor rango de utilización en cuanto a diámetros, longitudes, etc. Asimismo, la investigación desarrollada para cada tipo de técnica se centra en resolver las limitaciones particulares de la misma, por ejemplo:

- Revestimientos no estructurales. Si el revestimiento es con mortero de cemento, la investigación se centra en reducir el espesor final del revestimiento, mientras que si es con resinas de tipo polimérico el principal objetivo es la reducción del coste del mismo, con lo que será más competitivo frente al anterior y aplicable a un mayor rango de diámetros.

\footnotetext{
${ }^{1}$ La implantación de un organismo regulador de los abastecimientos españoles (que entre otras funciones vele por las buenas prácticas, fije las tarifas y garantice la inversión en las redes) es una propuesta que viene de largo. Incluso forma parte del programa del gobierno para la legislatura 2008-2012. En la actualidad, parece improbable que éste se cree en la actual legislatura por mor de la crisis económica.
} 
- Revestimientos estructurales. En el caso del entubado por deslizamiento, la investigación se centra en conseguir una menor reducción de la sección útil, mientras que en la técnica de encamisado térmico pretende ampliar su campo de utilización y para ello, se centra en las redes de abastecimiento (ya que actualmente sólo se emplea en saneamiento).

- Métodos con rotura de tubería. En el caso de que la rotura se realice por percusión, se pretende reducir las vibraciones que se transmiten al terreno y tanto en esta técnica como en la de inserción mediante rotura de tubería por la apertura y cierre de un cabezal hidráulico, se trabaja en aumentar la longitud posible instalada para minimizar el número de catas necesarias.

- Perforación no dirigida. La investigación se centra, al igual que las anteriores, en reducir las tensiones y deformaciones existentes en la inserción de la nueva tubería. Otro objetivo futuro es expandir el segmento de mercado hacia las redes de saneamiento y hacia la instalación con rotura de tubería, desplazando los métodos con rotura de tubería. Por último, una innovación reciente consiste en la utilización de un gel impregnado con un polímero como sustituto de la bentonita en la perforación (reduciendo la cantidad de material necesario). Estos desarrollos se describen en Najafi y Gokhale (2004).

\subsection{Determinación del periodo óptimo de renovación}

La modificación de la metodología clásica de obtención del periodo óptimo de renovación detallada en la presente tesis (capítulo 4) sugiere algunas de las siguientes formas de desarrollo futuro.

La primera idea que surge consiste en suponer diferentes modelos de evolución del número de roturas, observando las diferencias que éstos originan en el periodo óptimo de renovación. Asimismo, se podría determinar la influencia entre el número de roturas y el periodo óptimo de renovación, e incluso obtener el número de roturas óptimo para la renovación, que sería aquel que minimizara los costes totales asociados a la renovación de tuberías.

Por otra parte, el proceso de determinación del periodo óptimo de renovación podría aplicarse a situaciones excepcionales en las que se desease, por ejemplo, primar la utilización de técnicas con bajo coste social o disminuir al máximo las fugas en la red de abastecimiento. Cada uno de los costes (de inversión, de mantenimiento, etc.) se podría computar con un determinado peso que permita representar las circunstancias particulares concretas. 
Otra posibilidad sería en considerar cada uno de los costes como una función de probabilidad en vez de como un valor único. El ejemplo más claro podría ser el coste de oportunidad que, con un cierto valor el 95\% de las ocasiones y otro en el $5 \%$ restante, seguiría una distribución de tipo binomial, mientras que otros costes pueden adoptar otras distribuciones de sobra conocidas, como triangular, rectangular, normal, etc.

Por último, el paso definitivo hacia la obtención de una herramienta de total aplicabilidad estaría marcado por integrar en un software la propuesta de obtención del periodo óptimo de renovación y un programa de cálculo hidráulico de redes. De ésta forma, a partir de una serie de datos entrada, se podría refinar la obtención de algunos parámetros como el caudal fugado o como la energía consumida en el bombeo. Asimismo, el software puede disponer de un interfaz que permita la entrada de datos y salida de resultados de forma tabulada y gráfica (enlazado con un sistema de información geográfica).

\subsection{Relación entre las políticas a corto plazo (rehabilitación) y a largo plazo (renovación)}

Todos los desarrollos planteados en el apartado 2.3 son aplicables en la relación entre las políticas de rehabilitación y renovación. La relación entre ambas políticas se ha planteado para un caso particular (el propuesto por la metodología clásica), con un número de roturas que aumenta exponencialmente, en un sector homogéneo (mismo tipo de tuberías, con similares diámetros, edad y variación frente a las roturas) y con la condición de que todas las roturas se reparan. La modificación de estas hipótesis iniciales permitiría universalizar la interacción entre la rehabilitación y la renovación.

La disposición de un modelo hidráulico calibrado de la red permite determinar, entre otros, el volumen fugado y las presiones en cada sector abastecimiento. A partir de éstos se podría fijar en la red estudiada los parámetros necesarios para obtener el nivel de fugas óptimo, el índice natural de aumento de fugas, el caudal medio perdido a través de las fugas, el tiempo medio de vida de las fugas, etc. 


\subsection{Auditoría energética}

Sin duda, la parte más innovadora de la presente tesis doctoral es la auditoría energética y sus desarrollos futuros. No en vano, en cierto modo, la relación aguaenergía poco se ha tenido en cuenta hasta ahora, por lo que el margen de mejora existente es imponente. Es la única ventaja de haber sido hasta la fecha tan poco eficientes.

La metodología propuesta para la obtención de la auditoría se ha programado en un programa informático como Matlab 2008b y ejecuta las simulaciones energéticas utilizando la librería dinámica (DLL) del programa EPAnet 2.0, Rossman (2000). Con esta aplicación, se puede realizar un módulo informático que permita el cálculo de la auditoría de manera simple, en la que el usuario de esta herramienta informática únicamente debe presentar como datos de entrada al sistema, el modelo de la red en la versión del programa utilizado, EPAnet 2.0. Esta aplicación informática se podría patentar y de esta forma conseguir que la propuesta del proyecto se distribuya como un elemento adicional de gestión por parte de cualquier entidad (bien sea pública o privada) que se encarga de la operación de una red de abastecimiento.

Dado el carácter novedoso del presente trabajo, y de la expectación suscitada, se puede pensar en comercializar este software. Sin duda, este posible software podría ser muy demandado en numerosos abastecimientos. Aunque, por otra parte, debido a la singularidad, escasez y valor de los recursos utilizados (agua y energía), y por la utilización de software libre y gratuito para su realización (EPAnet fue desarrollado por la Environmental Protection Agency y se distribuye libremente en su página web) casi parece sugerir la distribución gratuita de esta herramienta. Pese a todo, un proyecto empresarial que ejecute el software desarrollado tendría posibilidades económicas reales de ser viable económicamente, mucho más si se consideran los ahorros económicos indirectos asociados a la utilización del mismo. Especialmente si se considera que se podría calcular el coste energético económico asociado a todas las políticas de decisión que se realizan en un sistema de abastecimiento. Y no únicamente desde la óptica económica, sino desde la óptica de la sostenibilidad medioambiental.

En la actualidad, se está realizando un estudio de los consumos energéticos de todas las etapas que componen el ciclo integral del agua conjuntamente con el ayuntamiento de Valencia y la Fundación Agua y Progreso, a partir del cual se obtendrá una primera aproximación al gasto energético de cada una de las etapas de una red de distribución real, y se particulariza en la ciudad de Valencia. Sin duda, este trabajo representa un fenomenal punto de partida que nos permitirá 
conocer resultados reales de la investigación realizada, y se podrá extrapolar a otros abastecimientos españoles, etc. Asimismo, se permitirá conocer el estado de la red, las posibles actuaciones tras la sectorización de la red, el análisis de la energía perdida en fugas, etc.

También pueden plantearse objetivos más ambiciosos como los que abordará, si Bruselas lo aprueba, el proyecto WATERLIFE promovido por la Dirección General del Agua de la Comunidad Valenciana (Adapting water policies to include footprints and energy impacts) que ha sido presentado a la última convocatoria y en cuya redacción se ha trabajado activamente. Pero, sin duda, sólo aunando esfuerzos (el primer obstáculo a salvar es que la administración del agua actúe de modo coordinado) y haciendo planteamientos globales a escala nacional podrá afrontarse con garantías de futuro un reto tan formidable y que tanto condiciona el futuro de las generaciones venideras. Este proyecto tiene como objetivo la realización de un estudio similar al de California en el ámbito regional, con carácter conciso y detallado, donde se obtienen de manera precisa todos los consumos asociados a cada una de las etapas del ciclo urbano del agua. En éste, la auditoría sería una pieza angular para obtener el consumo energético en la etapa de distribución de agua.

Por último, se ha propuesto la aplicación de la auditoría energética en tres redes de distribución pertenecientes al ATO (Ambito Territoriale Ottimale) de Pisa (Ponsacco, Altopascio y Castelfiorentino) y se han iniciado conversaciones para la realización de un trabajo similar en otras ciudades españolas como Murcia y Sevilla. Asimismo, se está realizando un trabajo que cuantificará la energía en un sector de la red de Denia (Alicante) y que se presentará en la conferencia internacional Water Distribution Systems Analysis (WDSA 2010) que este año se celebrará en Tucson, Arizona. 


\section{GlosARIO DE TÉRMINOS}

A Coeficiente de crecimiento del número de roturas (años-1).

$b$ Ancho de la zanja.

$C_{b}$ Coste unitario de una reparación puntual (€/rotura).

$C_{E}$ Coste de la energía consumida (€/Kwh).

$C_{E, i}$ Coeficiente de emisor en el nudo i.

$C_{\text {inf }}\left(t_{r}\right)$ Coste asociado todas las renovaciones de una conducción excepto la primera. ( $€ / \mathrm{m}$ del año $t_{r}$ ).

$C_{\text {inf }}\left(T_{t_{j}}^{* *}\right)$ Valor mínimo de $C_{\text {inf }}\left(t_{r}\right)$ que se obtiene para el tiempo óptimo. (€/m del año $\left.t_{r}\right)$.

$C_{\text {med }}$ Coste medio perdido por los negocios en (€/día).

$C_{P}$ Penalización $(€ / \mathrm{m})$ impuesta al gestor de la red de abastecimiento por el organismo competente.

$C_{r_{j}}$ Coste de renovación de una tubería cualquiera con la técnica $\mathrm{j}(€ / \mathrm{m})$.

$C_{S_{j}}$ Coste social asociado a las perturbaciones originadas en la ejecución de la obra.

$C_{t}$ Coste asociado al tiempo medio perdido por trabajador en $(€ / \mathrm{h})$.

$C_{T \text { inf }}\left(t_{r}\right)$ Coste asociado todas las renovaciones de una conducción. ( $€ / m$ del año $\left.t_{p}\right)$.

$C_{u p}$ Coste unitario de reparación de carreteras en $\left(€ / \mathrm{m}^{2}\right)$.

$C_{W}$ Coste total del agua en $€ / \mathrm{m}^{3}$.

$C_{1}$ Procedencia de la energía (indicador de contexto).

$C_{11}\left(t_{r}\right)$ Coste de la tubería en obra $(€ / \mathrm{m})$.

$C_{12}\left(t_{r}\right)$ Coste de instalación de la tubería $(€ / m)$.

$C_{2}$ Exigencia energética de la red (indicador de contexto).

$C_{2}\left(t_{r}\right)$ Coste de reparación y mantenimiento ( $€ / \mathrm{m}$ rotura).

$C_{31}\left(t_{r}\right)$ Coste total asociado a la pérdida de agua fugada.

$C_{32}\left(t_{r}\right)$ Coste asociado a las pérdidas de energía $(€)$.

$C_{40}$ Otros costes sociales.

$C_{41}\left(t_{r}\right)$ Coste social asociado a la perturbación por obras $(€ / m)$.

$C_{41 A}^{\prime}$ Coste asociado a la interrupción del tráfico rodado $(€ / \mathrm{m})$.

$C_{42}\left(t_{r}\right)$ Coste social asociado a la pérdida de estándares de servicio $(€ / \mathrm{m})$.

$C_{5}\left(t_{r}\right)$ Coste de oportunidad $(€ / \mathrm{m})$.

e Energía por unidad de masa. 
$E_{C_{i}}\left(t_{1}\right)$ Energía de compensación de los depósitos en el instante inicial del cálculo

$E_{C_{i}}\left(t_{p}\right)$ Energía de compensación de los depósitos en el instante final del cálculo

$E_{F}\left(t_{p}\right)$ Energía invertida en vencer el rozamiento durante el periodo de simulación.

$E_{F}^{\prime}\left(t_{p}\right)$ Energía disipada por fricción en una red sin fugas.

$E_{\text {Dissipated }}\left(t_{p}\right)$ Energía disipada por fricción. Incluye las pérdidas en tuberías y en válvulas. En ausencia de éstas ultimas $E_{\text {Dissipated }}\left(t_{p}\right)=E_{F}\left(t_{p}\right)$.

$E_{\text {Input }}\left(t_{p}\right)$ Energía entrante o invertida en el sistema.

$E_{L}\left(t_{p}\right)$ Energía asociada a las fugas.

$E_{\min , u s e f u l}$ Energía minima teórica requerida en una red sin fricción y sin fugas en la que se entrega el agua a los usuarios a la presión mínima umbral.

$E_{\min , \text { flat }}$ Energía minima teórica requerida en una red completamente plana, sin fricción y sin fugas en la que se entrega el agua a los usuarios a la presión mínima umbral.

$E_{N}\left(t_{p}\right)$ Energía natural en el periodo de simulación aportada por un embalse o depósito situado en cabecera de red.

$E_{\text {Output }}\left(t_{p}\right)$ Energía saliente o consumida por el sistema en el periodo de simulación.

$E_{P}\left(t_{p}\right)$ Energía proporcionada por el equipo de bombeo en el periodo de simulación.

$E_{U}\left(t_{p}\right)$ Energía útil que se entrega en los nudos en el periodo de simulación.

$h_{\text {dia }}$ Número medio de horas de trabajo al día de los operarios encargados de la renovación.

$H_{i}\left(t_{k}\right)$ Altura piezométrica del nudo i en el instante $t_{k}$.

$\left(h_{\text {Min }}\right)_{i}$ Altura piezométrica mínima necesaria en el nudo i.

$H_{N i}\left(t_{k}\right)$ Altura piezométrica en el embalse i en el instante de tiempo $t_{k}$.

$H_{P i}\left(t_{k}\right)$ Altura $(\mathrm{m})$ de bombeo del equipo i en el instante $t_{k}$.

$H_{N i}$ Altura piezométrica del embalse, $H_{N i}=H_{N i}\left(t_{k}\right)$.

$I_{1}$ - Exceso de energía suministrada (indicador de gestión).

$I_{2}$ - Eficiencia de la red (indicador de gestión).

$I_{3}$ - Energía de fricción (indicador de gestión).

$I_{4}$ - Energía total asociada a las fugas (indicador de gestión).

$I_{5}$ - Suficiencia en el cumplimiento de estándares (indicador de gestión).

$I_{j}$ Término de inversión $(€ / m)$ para la técnica de renovación j.

$k$ Energía de bombeo adicional generado por fugas.

$I_{z}$ Longitud de la zanja.

$M$ Término de mantenimiento, ( $€ / \mathrm{m}$ rotura). 
n Número de nudos de la red.

$n_{C}$ Número de tanques de compensación de la red.

$n_{i}$ Número de intervalos de tiempo. $\left(t_{p}=n_{i} \cdot \Delta t\right)$.

$n_{L} \quad$ Número de tuberías de la red.

$n_{N}$ Número de embalses de cabecera.

$n_{P}$ Número de bombas.

$N(t)$ Número de roturas en el año t y unidad de longitud.

$N\left(t_{0}\right)$ Número de roturas en el año to.

$P_{C}$ Potencia de compensación.

$P_{F}$ Potencia disipada por fricción.

$P_{L}$ Potencia asociada a las fugas.

$P_{N}$ Potencia natural aportada por el embalse.

$P_{0}$ Potencia de entrada total.

$P_{P}$ Potencia aportada por las bombas.

$P_{U}$ Potencia útil que se entrega en los nudos.

$\frac{P_{u i}\left(t_{k}\right)}{\gamma}$ Presión en el nudo i en el instante $t_{k}$.

$\frac{P_{M i n}}{\gamma}$ Presión minima de servicio en todos los nudos de la red

$\frac{p_{s}}{\gamma}$ Presión media a la que se produce la fuga.

$q_{f}$ Caudal medio unitario por fuga ( $\mathrm{m}^{3} /$ rotura día).

$q_{j}\left(t_{k}\right)$ Caudal circulante por la línea j en el instante $t_{k}$.

$q_{l i}\left(t_{k}\right)$ Caudal fugado $\left(\mathrm{m}^{3} / \mathrm{s}\right)$ en las tuberías adyacentes al nudo i en el instante $t_{k}$.

$q_{l j}\left(t_{k}\right)$ Caudal circulante $\left(\mathrm{m}^{3} / \mathrm{s}\right)$ por la línea j que posteriormente se pierde en fugas.

$q_{u i}\left(t_{k}\right)$ Caudal $\left(\mathrm{m}^{3} / \mathrm{s}\right)$ consumido por el nudo i en el instante $t_{k}$

$q_{u j}\left(t_{k}\right)$ Caudal circulante $\left(\mathrm{m}^{3} / \mathrm{s}\right)$ por la línea j que es posteriormente consumido

Q Calor total que se aporta, o cede, al sistema.

$Q_{N i}\left(t_{k}\right)$ Caudal aportado por el embalse I en el instante $t_{k}$.

$Q_{P i}\left(t_{k}\right)$ Caudal aportado por el equipo de bombeo I en el instante $t_{k}$.

$r$ Tasa continua de actualización equivalente.

$R_{v u}$ Reducción de la vida útil de la carretera por efecto de la renovación /rehabilitación.

$t_{c}$ Año en que se produce la oportunidad.

$t_{d u r}$ Tiempo de duración de la renovación de una tubería. 
$t_{k}$ Intervalo de tiempo de la simulación.

$t_{0}$ Año inicial del análisis.

$t_{p}$ Tiempo total de la simulación (corto o largo).

$t_{p, T}$ Tiempo frontera entre el corto y el largo plazo (días).

$t_{p}$.Año actual.

$t_{\text {perd }}$ Tiempo perdido medio (h) para el conjunto de trabajadores por cada día que se tarda en realizar la renovación.

$t_{s}$ Año en el que se incumplen estándares de servicio.

$T_{t_{j}}^{* *}$ Tiempo óptimo que minimiza el coste total de todas las renovaciones excepto la primera desde el año $t_{r}$ hasta el infinito.

$t_{r_{j}}^{*}$ Tiempo que minimiza el coste de la primera renovación o duración óptima que minimiza el coste total de todas las renovaciones.

u Energía interna por unidad de masa.

$\forall_{L}\left(t_{p}\right)$ Volumen total fugado en el periodo de simulación.

$\forall_{N}\left(t_{p}\right)$ Volumen total inyectado en el periodo de simulación.

$\forall_{U}\left(t_{p}\right)$ Volumen total consumido por los usuarios.

$\forall_{u, i}\left(t_{p}\right)$ Volumen total demandado por el nudo i en el periodo de simulación $t_{p}$.

w Trabajo total que se realiza por, o sobre, el sistema

$x_{t o}$ Coeficiente de ponderación de otros costes sociales.

$x_{t 41}$ Coeficiente de tecnología asociado a la interrupción del tráfico rodado.

$x_{t 43}$ Coeficiente de tecnología asociado a la pérdida de productividad debido al ruido y vibraciones.

$x_{t 44}$ Coeficiente de tecnología asociado a las pérdidas en los negocios cercanos a la realización de obras.

$x_{5}$ Coeficiente de tecnología para el coste de oportunidad.

$z_{i}$ Cota del nudo i

$z_{i}\left(t_{1}\right)$ Nivel $(m)$ de la superficie libre de agua en el instante inicial del cálculo.

$z_{i}\left(t_{p}\right)$ Nivel $(\mathrm{m})$ de la superficie libre de agua en el instante final del cálculo

$\alpha$ Exponente de emisor.

$\alpha_{\text {est }}$ Coeficiente de estacionalidad asociado a la interrupción del tráfico rodado.

$\beta_{c 5}$ Coeficiente de acuerdo entre compañías.

$\Delta E_{C}\left(t_{p}\right)$ Variación total (desde $t_{1}$ hasta $t_{p}$ ) de la energía de compensación de los depósitos durante el periodo de simulación. 
$\Delta E_{C \max }$ Energía máxima almacenada en el depósito de compensación.

$\Delta h_{j}\left(t_{k}\right)$ Pérdida de carga $(\mathrm{m})$ de la línea j en el instante $t_{k}$.

$\Delta p_{\min }$ Exceso mínimo de presión (para todos los nudos en la simulación) calculado como la diferencia mínima entre la presión real y el umbral mínimo de presiones.

$\Delta t$ Intervalo de tiempo de integración $\left(\Delta t=t_{k+1}-t_{k}\right)$

$\Delta t_{a}$ Tiempo medio de actividad de la fuga (días).

$\Delta \forall_{T}\left(t_{p}\right)$ Volumen almacenado en el tanque de compensación en el periodo de simulación.

$\rho$ Densidad del agua $=1000 \mathrm{Kg} / \mathrm{m}^{3}$

$\rho_{g}$ Densidad media de personas afectadas por cada metro lineal de tubería renovada.

$\rho_{n}$ Densidad media de negocios afectados por la obra por metro lineal de tubería instalada.

$\varphi_{5}$ Coeficiente ponderación del coste de oportunidad.

$\gamma$ Peso específico del agua $=9810 \mathrm{~N} / \mathrm{m}^{3}$.

$\eta$ Rendimiento en tanto por uno de los grupos de bombeo. 


\section{REFERENCIAS}

ADF (2002) "Sénat: La qualité de l'eau et assainissement en France, quoting: Evaluation IFEN - Les données de l'environnement - décembre 2001 - Étude de I'Association des départements de France (ADF) ". http://www.senat.fr/rap/l02-215-2/l02-215-262.html

AEAS (2000), “El suministro de agua potable en España". Madrid, 2000.

AEAS (2006), "Suministro de Agua potable y Saneamiento en España. X encuesta nacional". www.aeas.es

AICV (2008), "Anuario Estadístico de la Ciudad de Valencia". ISSN: 1989-2594. http://www.valencia.es/estadistica

Alegre, H., Baptista, J.M., Cabrera Jr., E., Cubillo, F., Duarte, P., Hirner, W., Merkel, W. y Parena, R. (2006). "Performance Indicators for Water supply Services". Second Edition manual of Best Practices. London IWA. ISBN: 1843390515.

Allouche, D., y Freure, P. (2002). "Management and maintenance practices of storm and sanitary sewers in Canadian Municipalities". ICLR Research Paper Series, No. 18.

Almandoz, J.; Cabrera E., Gil, J. y Pellejero, I. (2003). "Evaluation of Leakage by means of night flow measurements and analytical discrimination. A comparative study". Proc. Of the IWA-IAHR International Conference PEDS 2003. Balkema publishers, pp 327-342.

Almandoz, J., Parra, J., Cabrera, E. (2004). "Renovación de redes mediante sistemas de soporte de toma de decisiones multicriterio". Análisis, diseño, operación y gestión de redes de agua con EPAnet. Tomo II. Instituto tecnológico del Agua. ISBN 8460963845.

Almandoz, J., Cabrera E., Arregui, F., Cabrera Jr. E. y Cobacho, R. (2005). "Leakage Assessment through Water Distribution Network Simulation". Journal of Water resources Planning and Management, 131(6), 458-466.

Arregui, F., Cabrera, E. y Cobacho, R. (2007). “Gestión integral de contadores de agua". Instituto Tecnológico del Agua- Universidad Politécnica de Valencia. ISBN: 84-608-0539-5 
ASCE (2009). "Report card for American infrastructure"

http://www.asce.org/reportcard

AWWA (1999). "Water audits and leak detection". Ed. American Water Works Association. Denver. Colorado. USA.

AWWA (2003). "Applying wordwide BMPs in water loss control". AWWA Water Loss Control Committee. Journal of the American Water Works Association. August 2003, pp 65-79.

AWWA, (2004). "Water Stats 2002 Distribution Survey". American Water Works Association, Denver, CO.

AWWA, (2004). "Water Stats 2002 Distribution Survey". American Water Works Association, Denver, CO.

BGW (2008). "Profile of the German Water Industry" (2008). Association of Drinking Water from Reservoirs (ATT), German Association of Energy and Water Industries (BDEW), German Alliance of Water Management Associations (DBVW), German Technical and Scientific Association for Gas and Water (DVGW), German Association for Water, Wastewater and Waste (DWA) y Association of Local Utilities (VKU). www.bgw.de

Boyce, G. M., y Bried, E. M. (1994). "Estimating the social cost savings of trenchless technique". No-dig Engineering, 1(2):12-14.

BOPV (2004). "Boletín Oficial de la Provincia de Valencia. Martes 14 de Septiembre de 2004". Edita: Diputación provincial de Valencia, № 219.

Budris, A.R. (2008). "Parallel pumps: Reduce Energy Cost without breaking the budget" American Water Works Association, 34 (2), 22-25.

Buendía, J. (2009). "Water and Energy: answers for the $21^{\text {st }}$ Century. Self sufficiency 2015". Water and Energy 2009- mitigation in the water sector \& potential synergies with the energy sector. 29 y 30 de Octubre 2009. Copenhague.

Bush, G., y Simonson, J. (2001). "Rehabilitation of underground water and Sewers lines... The costs beyond the bid". University of Houston.

Cabrera, E., Almandoz, J., Arregui, F. y García-Serra, J. (1999). “Auditoría de Redes de Distribución de Agua". Ingeniería del Agua. Vol 6. № 4. Dic. 1999. 
Cabrera, E., Pardo M. A., Cobacho, R. y Cabrera E. Jr., (2010). “Energy Audit of a water Distribution network". Journal of Water Resources Planning and Management American Society of Civil Engineering. (Pendiente de publicación).

Cabrera, E., Pardo, M. A., Cobacho, R., Arregui, F. J. y Cabrera, E. Jr.(2009). "Evaluation of Carbon Credits Saved by Water Losses Reduction in Water Networks".Waterloss 2009. ISBN 978-1-920017-38-5. Páginas 90-97.

CBO (2002). "Future Investment in Drinking Water and Wastewater Infrastructure," Congressional Budget Office.

CEC (California Energy Commission), (2005). "California's Water-Energy Relationship report". California

CEC (California Energy Comisión), 2006. "Refining Estimates of Water- Related Energy Use in California". CEC 500 - 2006 - 118. California Energy Comission. State of California. Diciembre 2006.

CEDEX (2006), "Guía Técnica sobre tuberías para el transporte de agua a presión". $3^{\text {a }}$ Edición, Ministerio de Fomento, Ministerio de Medio Ambiente. I.S.B.N. 847790-431-6.

Chatfield E., Dillon M. (1979) "A national study for asbestos fibres in Canadian drinking water supplies". Ottawa, Canada, Department of National Health and Welfare, 1979. Environmental Health Directorate Report 79-EHD-34.

Clark, R.M., Sivaganesan, M. Selvakulmar,A. y Sethi, V. (2002). "Cost Models for Water Supply Distribution Systems". Journal of Water Resources Planning and Management, 128(5), 312-321.

Cobacho R (2000) "La Gestión de la Demanda en el contexto de una nueva política integral del Agua. Su aplicación al suministro urbano" Tesis Doctoral. (En Español).

Cobacho R., Cabrera E., Cabrera Jr. E.; Arregui, F., y Dubois, M. (2003). "The repair and maintenance cost curve: Ways to calculate it from a medium size utility". Proc., PEDS 2003. Swets and Zeitlinger, Lisse. ISBN 9058095606.

Cobacho R. y Cabrera, E. (2009). “Determinación del nivel de fugas óptimo económico" Rehabilitación y Renovación de tuberías de Agua. Instituto Tecnológico del Agua. Universidad Politécnica de Valencia. (En Español). 
Colombo, A. F. y Karney, B. W. (2002). "Energy Cost of Leaky Pipes: Toward Comprenhensive Picture". Journal of water Resources Planning and management, 128(6); 441-450, November 1, 2002.

Colombo A. F. y Karney B. W. (2005). "Impacts of leaks on Energy Consumption in Pumped Systems with storage". Journal of water resources, planning and management, 131(2). 146-155.

Conroy, P.J., Hughes, D.M., y Wilson, I. (1995). “Demonstration of an innovative water main rehabilitation technique: In situ epoxy lining" American Water Works Association Research Foundation, Denver.

Construction innovation (1999). "IRC researchers investigate cast-iron pipe failure". Volume 4, Number 3, Spring/Summer 1999.

http://irc.nrc-cnrc.gc.ca/pubs/ci/v4no3/v4no3_13_e.html

Cromwell, J. y Speranza, L. (2007). "Asset management, too complicated? Just think about your car". Journal AWWA, January 2007. 46-51.

Deb, A. K., Snyder, J. K., Chelius,J. J.,y O'Day, D. K. (1990). "Assessment of existing and developing water main rehabilitation practices". American Water Works Association Research Foundation, Denver.

Deb, A. K., Snyder, J. K., Hammell, J. y Grablutz, F. (2009). “G.V. Loganathan 's Legacy on Water Distribution system Asset Managemet". Journal of Water Resources Planning and Management, 135(4), 216-226.

Deneen, M. y Gross,A.C. (2004). "The global market for Water Treatment Products". Bussiness Economics January 2005.

Di Federico, V., Cintoli, S., Pacchioli, M., Vispi, P., Di Federico, I., Mazzacane, S. y Volta, M. (2002). "A conceptual model for rehabilitation of water distribution Networks". VI simpósio Ítalo Brasileiro de engeharia Sanitária e Ambiental.

http://www.bvsde.paho.org/bvsacd/sibesa6/cxcviii.pdf

Diaz, C.A., Karney, B.W. y Colombo, A.F. (2005) "Saving energy while managing demand in water delivery systems". Proc., CCWI $20058^{\text {th }}$ Int. Conference on Computing and Control in the Water Industry., Research Studies Press, Hertfordshire,U.K. 
DOE (2006). "Energy Demands on Water Resource. Report to Congress on the Interdependency of Water and Energy". US Department of Energy. Washington DC. USA.

EA (2008). "Greenhouse gas emissions of water supply and demand management options". Science Report - SC070010, Julio 2008. EA. Bristol. UK.

EPA (1973). "EPA's Position on the Health Implications of Airborne Lead". EPA Journal November 1973.

EPA (1999) "Drinking water Infrastructure Needs survey. Modeling the Cost of Infraestructure".

EPA (1999). "Collection systems O\&M Fact Sheet. Trenchless Sewer Rehabilitation". Office of Water, Washington, D.C. EPA 832-F-99-032 www.epa.gov/safewater

EPA (2002). "Clean Water and Drinking Water Infrastructure Gap Analysis".

EPA (2003). "Drinking water Infrastructure Needs survey and Assessment Third report to Congress".

EPA (2008). "Summary of EPA Water and Energy Efficiency meeting". Chicago. United States Environmental Protection Agency Office of Water

EPA (2009). "Drinking water Infrastructure needs Survey and Assessment. Fourth report to Congress". Office of Water (4606M) EPA 816-R-09-001 www.epa.gov/safewater

EPA (2009). "Rehabilitation of wastewater Collection and water distribution Systems". EPA/600/R-09/048 | May 2009 | www.epa.gov/nrmrl

EU (2000). “Directiva 2000/60/CE del parlamento europeo y del consejo por la que se establece un marco comunitario de actuación en el ámbito de la política de aguas".

Farley, M. y Trow, S. (2003). "Losses in Water Distribution Networks". IWA publishing, Alliance House, 12 Caxton St, London SW1H 0QS, UK. ISBN: 1900222116.

Filion, Y., MacLean, H.L. y Karney B.W. (2004). "Life cycle Energy Analysis of a Water Distribution System". Journal of Infrastructure Systems, 10 (3), 120-130. 
IEA (International Energy Agency), (2008). "Energy Technology Perspectives. Scenarios \& Strategies to 2050".

Filion, Y. (2008). "Impact of urban Form on Energy Use in Water Distribution Systems". Journal of Infrastructure Systems, 14(4). 337-346.

García, V.F., Cabrera, E., y Cabrera, E. Jr (2007) Water saving evaluation applying a pressure management strategy. Proceedings of the Lessam 2007, Lisbon, Portugal. October 17-19.

Ghimire, S.R. y Barkdoll B.D.(2007), "Issues in energy consumption by municipal drinking water distribution systems" World Environmental and Water Resources Congress 2007.

Greenpeace (2001). "PVC-Free Future: A Review of Restrictions and PVC free Policies Worldwide". Greenpeace International, $8^{\text {th }}$ edition, August 2001.

http://archive.greenpeace.org/toxics/reports/restrictions.pdf

Gregg, T. y Dewees, A. "Water Accountability moves forward in Austin, Texas". Proc. Of the $4^{\text {th }}$ IWA specialist Conference on Efficient Use and Management of urban Water Supply. Efficient 2007.Pp 763- 768

Hightower M., (2005). "Energy-Water Research and Development Roadmap". Sandia National Laboratories. Albuquerque. New Mexico. USA.

Hirner, W. (1997a). "Technical, operational and economic performance indicators of water utilities". Actas del IWSA workshop on Performance indicators and distribution systems. LNEC. Lisboa. 5-7 Mayo 1997.

Hirner, W. (1997b). "Maintenance and rehabilitation policies for urban water systems". Water management international.

Hirner (2001). "Regulation of Urban Water supply: Standards of quality and control". International seminar, Valencia, June26-28, 2001: The urban Water supply debate."

Hoffman, H. W. (2005). "Energy \& Water Relationships, Working together to promote water conservation" California Energy Commission. November 2005 CEC-700-2005-011-SF

Hong, H. P., Allouche, E.N. y Trivedi, M. (2006) 
"Optimal Scheduling of Replacement and Rehabilitation of Water Distribution Systems."

Journal of Infraestructure systems, 12(3): 184-191. September 2006.

Hu,Y., y Hubble, D.W. (2007). "Factors contributing to the failure of asbestos cement water mains". NRC Research Press Web site. 15 th June 2007. Can.J. Civ. Eng. 34:608-621 (2007).

INE (2006). "Distribución por grandes grupos de usuarios y comunidad autónoma".

http://www.ine.es/jaxi/tabla.do?path =/t26/p067/p01/a2006/l0/\&file =01004.px\&type = pcaxis\&L =0

IWA (2000). "Losses from Water Supply Systems: Standard Terminology and Recommended Performance Measures". IWA, International Water AssociationTask Force on Water Losses, London, August 2000.

Jeyapalan, J. (2003). "Future Outlook for pipelines material, methods and maintenance" Pipelines 2003 ASCE Conference, Baltimore, Maryland, July 2003.

Jonkergouw, P. M. (2007). "Simulating chlorine decay in water distribution systems". Thesis. Exeter University.

Jowitt, P.W. y Xu, C. (1990) "Optimal Valve Control in Water Distribution Networks". Journal of Water Resources Planning and Management, 116 (4), 455472

Kleiner, Y. y Rajani, B. (2002). "Forecasting variations and trends in water-main breaks" Journal of Infrastructure Systems, v. 8, no. 4, Dec. 2002, pp. 122-131.

Kleiner, Y, Adams, B. J. y Rogers, J.S. (2001). "Water Distribution network renewal planning". Journal of Computing in Civil engineering, Vol. 15, No 1, January, 2001.

Lambert, A.O. (1994). "Accounting for Losses: the bursts and background concept (BABE)". IWEM Journal, April, 8(2), 205-14.

Lambert, A., Myers, S. y Trow,S. (1998). "Managing Water Leakage, Economic and technical issues". Financial Times energy, Tottenham Court Road, London W1P 9LL. ISBN: 1840830115.

Liemberger, R. (2005). "Real Losses and Apparent Losses and the new W392 Guidelines from Germany". Paper presented at the international Water Association Specialist Workshop, Radisson Ressort. 
Lingireddy, S. y Wood, J. (1998) "Improved operation of water distribution systems using variable-speed pumps". Journal of Energy Engineering, 124 (3), 90-103.

Lindley, T. R. y Buchberger, S. G. (2002) "Assessing intrusion susceptibility in distribution systems". J. Am. Water Works Assoc. 2002, 94 (6),66-79. (21)

Logathan, G. V., Park, S. y H. D. Sherali (2002) "Threshold Brake Rate for Pipelines Replacement in Water Distributions Systems". Journal of Water Resources Planning and Management, 128(4): 271-279. July/August 2002.

Luong, H. T. y Fujiwara, O. (2002). "Fund allocation model for pipe repair maintenance in water distribution networks". European Journal of Operational Research 136 (2002) 403-421.

MacKellar, S. y Pearson, S. (2003). "Nationally Agreed Failure Data and Analysis Methodology for Water Mains Volume 1: Overview and Findings". Report Ref. No. 03/RG/05/7, UK Water. Industry Research, London, UK.

Male, J. W., T.M. Walski, y A. H. Slutski, (1990). "Analyzing Water Main Replacement Policies", Journal of Water Resources Planning and Management, ASCE, 116, 363-374.

May, J. (1994). "Pressure dependent leakage." World Water and Environmental Engineering, October 1994.

McKenzie (2001). "Presmac, Pressure Management Program". WRC Report No TT 152/01 .http://www.wrc.org.za/downloads/report\%20lists/web\%20files/presmac/Presmac\%20Rpt\%20TT\%20152-01.PDF

McKenzie, R.S., Seago, S. y Liemberger, R. (2007). "Benchmarking of losses from potable water reticulation systems - Results from IWA task team". Waterloss 2007. http://waterloss2007.com/pdf_vortraege/Montag/B2-2.pdf

McKim, R.A. (1997). "Bidding strategies for conventional and Trenchless Technologies considering social Costs", Canadian Journal of Civil engineering, Vol 24, pp. 819-827.

McMahon, J. E., Whitehead, C.D. y Biermayer, P. (2006). "Saving Water Saves Energy". Lawrence Berkeley National Laboratory. University of California.

Millette JR et al. (1983) "Asbestos in water supplies of the United States". Environmental Health Perspectives, 53:45-48. 
Milly P., Betancourt J., Falkenmark M., Hirsch R., Kundzewicz W., Lettenmaier D. y Stouffer R., 2008. "Stationarity Is Dead: Whither Water Management?". Science Vol 319 February 2008 pp $573-574$

MIMAM (2000). "Libro Blanco del Agua en España". Ministerio de Medio Ambiente. Madrid.

MITYC (2007). "La energía en España". , Ministerio de Industria, Turismo y Comercio, I.S.B.N.-13: 978-84-96275-52-2. (En Español).

MMA (1998). "Libro blanco del agua".

http://www.mma.es/secciones/acm/fondo_docu_descargas/libro_blanco/pdf/sintesis.pdf

MMA (2008). "Inventario de Gases de Efecto Invernadero en España. Edición 2008".http://www.mma.es/secciones/calidad_contaminacion/atmosfera/emisiones/pd//Sumario_inventario_GEI_Espania_ ed_2008_serie_1990-2006.pdf

Murgui, M., Cabrera, E., Pardo, M. A. y Cabrera R., E. (2009) "Estimación del consumo de energía ligado al uso del agua en la ciudad de valencia". Jornadas de Ingeniería del Agua, JIA 2009.

Najafi, M. y Gokhale, S. (2004). "Trenchless Technology, Pipeline and Utility Design, Construction, and Renewal". Ed. Mc Graw-Hill Companies Inc. ISBN 0-07142266-8.

Newport, R. (1981). "Factors influencing the occurrence of bursts in iron water mains. Severn Trent Water Authority, Great Britain". Journal Aqua, No 3, 1981 274-288.

NRC (1993). "Water Mains Break Data on Different Pipe Materials for 1992 and 1993". National Research Council. Ottawa. Canadá.

http://www.ipexinc.com/Content/en_ca/4_0_Thermo_Today/4_3_Economie/Water_Mains_Break.pdf

NRC. (2008) "Desalination. A national perspective". The national academies press, Washington, USA.

Ochoa, L. y Bourguett, O.V. (1998)."Reducción integral de pérdidas de Agua potable". Instituto méxicano de Tecnología del Agua. ISBN 968-7417-23-4. Juitepec. México.

OFWAT (2001). "Leakage and the Efficient use of Water". Birmingham. England. ISBN 1874234809 
OFWAT (2002)." Financial performance and expenditure of the water companies in England and Wales 2007-08. Ofwat - Protecting consumers, promoting value and safeguarding the future". ISBN1-904655-45-9

OMS (1985). "Guías para la calidad del agua potable". Washington, D.C. (US), OPS, 1985. (OPS - publicación científica, Nº 481)

Pardo, M. y Cabrera, E. (2006). "Técnicas modernas de rehabilitación y renovación de tuberías. Análisis de Costes". Control de Pérdidas de agua en Redes Urbanas, Análisis de su incidencia en periodos secos. Instituto Tecnológico del Agua. Universidad politécnica de Valencia. (En Español).

Pardo, M. A. (2007) "Periodo óptimo de renovación de tuberías, incluyendo costes variables del agua, sociales y de oportunidad". Diploma de Estudios Avanzados. Universidad Politécnica de Valencia.

Parra, J. C. (2006). "Renovación de redes mediante sistemas soporte a la toma de decisiones multicriterio". Diploma de estudios avanzados. Universidad Politécnica de Valencia.

PEAASA (2006).

http://www.portugal.gov.pt/NR/rdonlyres/2E4F1B13-B462-4EE7-927C-

ODOF41BF129B/O/PEAASARII.pdf

Peters, D.C. (1984). "The social costs of sewer rehabilitation" International Conference on the planning, Construction, Maintenance and Operation of Sewerage Systems, Reading, England, B3, pp. 79-91.

Pelli, T. y Hitz, H. U. (2000). "Energy Indicators and savings in water supply". Journal American Water Works Association, Vol92 (6), June 2000.55-62.

Rajani, B. (2009). "Inspección y rehabilitación de tuberías de grandes diámetros". Rehabilitación y Renovación de tuberías de Agua. Instituto Tecnológico del Agua. Universidad Politécnica de Valencia. (En Español).

Rajani, B. (2009a). "Comportamiento de las redes de agua desde una perspectiva histórica". Rehabilitación y Renovación de tuberías de Agua. Instituto Tecnológico del Agua. Universidad Politécnica de Valencia. (En Español). 
Rajani, B. (2009b). "Tuberías de fundición dúctil". Rehabilitación y Renovación de tuberías de Agua. 9,10 y 11 de Junio 2009. ITA. Universidad Politécnica de Valencia. (En Español)

Rajani, B. (2009c). "tuberías de Polietileno y PVC". Rehabilitación y Renovación de tuberías de Agua. Instituto Tecnológico del Agua. Universidad Politécnica de Valencia. (En Español).

Rajani, B. (2009d). "Funcionamiento de tuberías de materiales en desuso (fundición gris y fibrocemento)". Rehabilitación y Renovación de tuberías de Agua. Instituto Tecnológico del Agua. Universidad Politécnica de Valencia. (En Español).

Rajani, B. (2009e). "Criterios para decidir si renovar o rehabilitar". Rehabilitación y Renovación de tuberías de Agua. Instituto Tecnológico del Agua. Universidad Politécnica de Valencia. (En Español).

Rajani, B., Kleiner, Y. (2003). "Protection of ductil iron water mains against external corrosion: review of methods and case stories". National Research Council Canada. http://irc.nrc-cnrc.gc.ca/ircpubs

Rao, Z., Wicks, J. y West, S. (2006) "Encoms - an energy cost minimisation system for real-time, operational control of water distribution networks". Water Management 160. Issue WM2. Optimising water supply and distribution operations. 95-101

RASARP (2004). Volume 3.

http://www.irar.pt/PresentationLayer/ResourcesUser/docum/rasarp/vol3/RASARP\% 20-

$\% 20$ vol3_4.pdf

Reis, L. F. R., Porto, R. M., Chaudhry, F. H. (1997) "Optimal Location of Control Valves in Pipe networks by Genetic Algorithm". Journal of Water Resources Planning and Management, 123 (6), 317-326

Rossman, L. A. (2000). "EPANET 2: User's manual". U.S. Environmental Protection Agency, Cincinnati.

Runge, J. y Mann, J. (2008) "State of the industry report, 2008". Journal American Water Works Association, 100 (10), 61-74.

Sala, L. "Balances energéticos del ciclo del agua y experiencias de reutilización planificada en municipios de la Costa Brava". Seminario Internacional Agua, Energía y cambio climático. Valencia, 29 - 31 Octubre 2007 
Skaarda, B. C. (1997). "The Swiss experience with performance indicador ad special viewpoints on water Networks". IWSA Workshop on performance indicators and distribution Systems. LNEC. Lisboa. May 1997.

Selvakulmar, A., Clark, R. M., y Sivaganesan (2002). "Cost Models for Water Supply Distribution Systems Rehabilitation". Journal of Water Resources Planning and Management, 128(4), 303-307.

Shamir, U., y Howard, C. D. D. (1979). "Analitical approach to scheduling pipe replacement." J. AWWA, 71(5), 248-258

Spero, M. I. (1999). "Trenchless 101- For industrial applications." Proc., Underground Construction Technology, Int. Conf. and Exhibition, Houston.

Sterling, M. y Bargiela, A. (1984). "Leakage reduction by optimised control of valves in water networks". Trans. Inst. Meas. Control, 6, 293-298.

Thornton, J. (2003), “Managing Leakage by managing pressure: a practical approach". Water 21. October 2003, pp. 43-44.

Thornton, C. I., Robeson, M. D., Girard L. G., y Smith (2005). "Culvert Pipe Liner Guide and Specifications". Publication No. FHWA-CFL/TD-05-003. http://www.cflhd.gov.

Thornton y Lambert (2005), "Progress in practical prediction of pressure: leakage pressure:burst frequency and pressure: consumption relationships". Proceedings of the Leakage 2005, Halifax, Canada. The world Bank Institute.

Tigue, S., Lee, T., McKim y Haas, R. (1999). "Traffic delay costs savings associated with trenchless technology". ASCE. Journal of Infraestructure Systems, 5(2):45-51.

Tigue, S., Knight, M., Papoutsis, D., Rodriguez, V. y Walker, C. (2002). “User Cost savings in eliminating pavement excavations using trenchless technology". Can. J. Civ. Eng. 29: 751-761.

Tiret (2008). "Fédération Professionnelle des Entreprises de I'Eau". 2e Rencontres des Maires- Symposium de Cannes. (en francés).

http://cms.sictiam.com/cms/30_adm06/upload/Gestion\%20de\%20leau.pdf

Todini E., (2000). "Looped water distribution networks design using a resilience index based heuristic apprach". Urban Water 2 (2000) pp 115-122. 
Tsiflisi, S., y Kanakoudis, V. (2008). "Performance indicators implemented in the city of Larissa water distribution network". COST C18. Performance Assessment of Urban Infrastructure Services. ISBN: 1843391910. pp 497-508.

Tuhovcak, L. y Kucera, T. (2008). "WaBe project- performance indicators of Water utilities in Czech Republic". COST C18. Performance Assessment of Urban Infrastructure Services. ISBN: 1843391910. pp367-376.

Tyco (2000). "Ductile Iron Pipelines Systems. Design manual". $4^{\text {th }}$ Edition. ABN 75 087415745 / ACN 087415 745. http://www.tycoflowcontrol-pc.com/getlit.asp?lit=ld/TWDIPS_00.pdf

USDE (2006). "Energy Demands on Water Resources. Report to congress on the interpendency of energy and Water".

Vewin (2007). "Water Supply stadistics". Association of Duch Water Companies, Available at:

www.vewin.nl/SiteCollectionDocuments/Publicaties/Overige\%20Vewinuitgaven/2007/Water\%20Supply\%20Statistics\%202006.pdf

Water UK (2009)." Water UK position paper on the revision of Council Directive 98/83/EC on the quality of water intended for human consumption (Drinking Water Directive)". http://www.water.org.uk/home/policy/positions/legislation/council-directive98-83-ec/wuk-position-paper-on-the-revision-of-the-drinking-water-directive-march-2008.doc

Walski, T. M., y A. Pellicia, (1982). "Economic Analysis of Water Main Breaks". J. American Water Works Association, 74(3), 140-147.

Watson, C. (198). "Rehabilitation of potable water main- The changing policy of Northumbrian water". Proc., Int. Conf. on rehabilitation Technology for the Water Industry, Lille, France.

White, F.M. (1974) "Viscous fluid flow". B.J. Clark and Michael Gardner eds, McGraw-Hill, New York. Chapter 3. Solutions of the Newtonian viscous-flow equations.

WICS (2008a) "Cost and Performance Report 2007 - 08". Ochil House, Spreinkerse Business Park, Stirling FK7 7XE. Report available at http://www.watercommission.co.uk/UserFiles/Documents/WICS\%20Costs\&Performance\%20FINAL .pdf 
WICS (2008b). "Investment Report 2007 - 08". Ochil House, Spreinkerse Business Park, Stirling FK7 7XE. Report available at http://www.watercommission.co.uk/UserFiles/Documents/Investment $\% 20$ report $\% 200708 \%$ 20FINA L.pdf

WEF (2009). "Energy Vision Update 2009. Thirsty Energy: Water and Energy in the $21^{\text {st }}$ century". Report available at www.weforum.org.

Webber, J., Covey, J., King, M. (1989) "Asbestos in drinking water supplied through grossly deteriorated A-C pipe". Journal of the American Water Works Association, 18:80.

Wegelin, W. y McKenzie, R. (2002). "Leakage reduction through Pressure Management in South Africa". Water research commission, TT 186/02. ISBN 1868458784.

White, F.M. (1974) "Viscous fluid flow". B.J. Clark and Michael Gardner eds, McGraw-Hill, New York. Chapter 3. Solutions of the Newtonian viscous-flow equations.

White, F.M. (2003) "Fluid Mechanics" $5^{\text {th }}$ Ed. Mc Graw-Hilleds., New York. Chapter 3. Integral relations for a control volume.

WIN (2000), "Clean and Safe Water for the 21st Century - A Renewed National Commitment to Water and Wastewater Infrastructure," p. 3-1. Water Infrastructure Network.

Wolff, G. Sanjay, G. y Winslow, M. (2004). "User Manual for the Pacific Institute Water to Air Models". October 2004. www.pacinst.org

WSAAfacts (2001). "The Australian urban water Industry". Published by Water Services Association of Australia Inc., 469 La Trobe St, Melbourne, Victoria Australia,3000. ISSN 1328- 2751.

Zhao, J.Q., y Rajani, B. (2002). "Construction and Rehabilitation Costs for Buried Pipe with a Focus on Trenchless Technologies". Institute for Research in construction. National Research Council Canadá. Ottawa.http://www.irc.nrc-cnrc.gc.ca/ircpubs.

Zhao, J.Q., McDonald, S. E., y Rajani, B. (2001). "Guidelines for condition assessment and rehabilitation of large sewers". Institute for Research in construction. National Research Council Canadá. Ottawa. 